
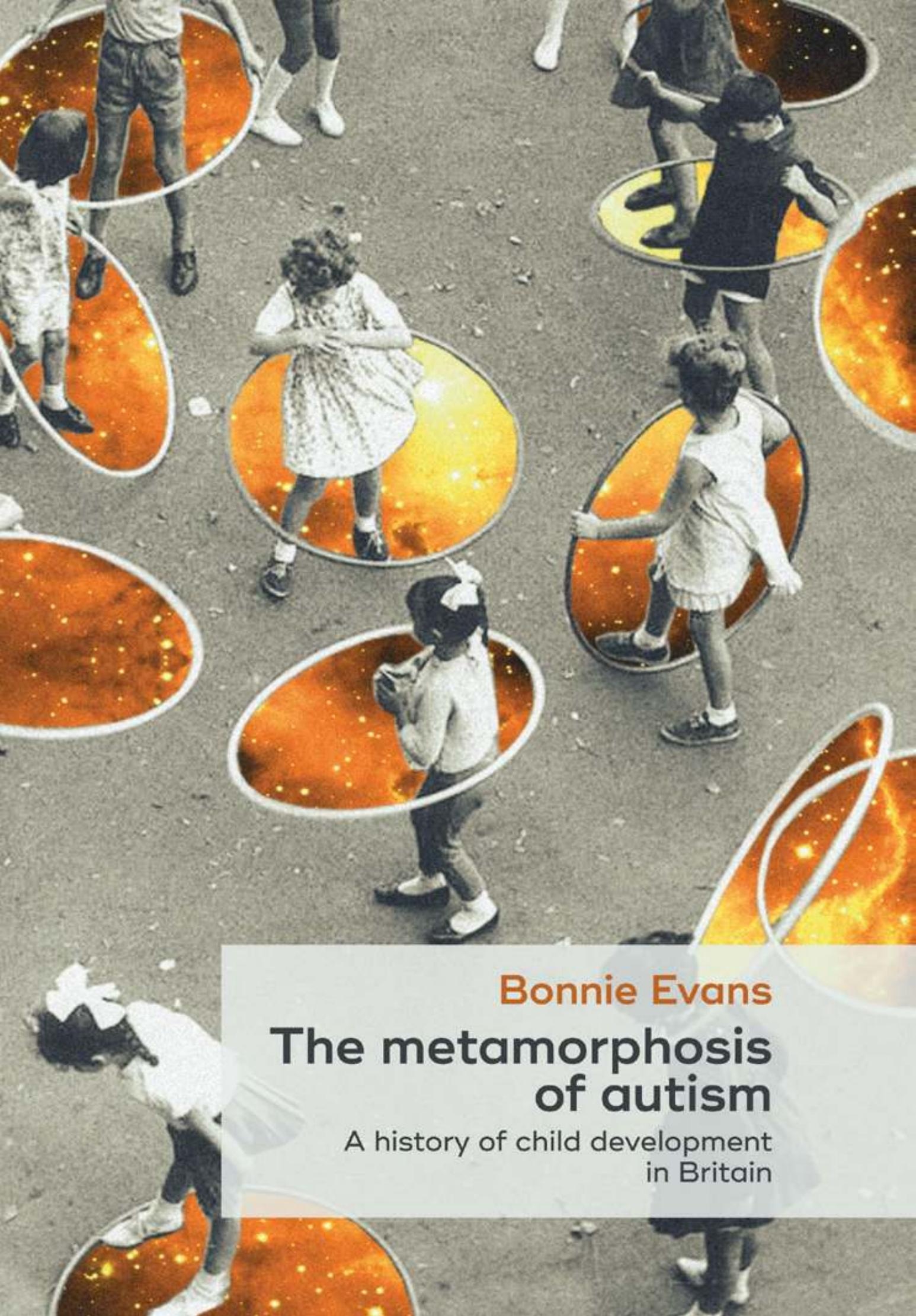


\section{The metamorphosis of autism}

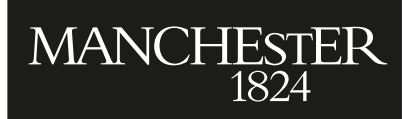

Manchester University Press 


\section{SSH}

\section{SOCIAL HISTORIES OF MEDICINE}

Series editors: David Cantor and Keir Waddington

Social Histories of Medicine is concerned with all aspects of health, illness and medicine, from prehistory to the present, in every part of the world. The series covers the circumstances that promote health or illness, the ways in which people experience and explain such conditions, and what, practically, they do about them. Practitioners of all approaches to health and healing come within its scope, as do their ideas, beliefs, and practices, and the social, economic and cultural contexts in which they operate. Methodologically, the series welcomes relevant studies in social, economic, cultural, and intellectual history, as well as approaches derived from other disciplines in the arts, sciences, social sciences and humanities. The series is a collaboration between Manchester University Press and the Society for the Social History of Medicine. 


\title{
The metamorphosis of autism
}

\section{A history of child development in Britain}

\author{
Bonnie Evans
}

Manchester University Press 
Copyright (C) Bonnie Evans 2017

The right of Bonnie Evans to be identified as the author of this work has been asserted by her in accordance with the Copyright, Designs and Patents Act 1988.

Published by Manchester University Press

Altrincham Street, Manchester M1 7JA

www.manchesteruniversitypress.co.uk

British Library Cataloguing-in-Publication Data

A catalogue record for this book is available from the British Library

Library of Congress Cataloging-in-Publication Data applied for

ISBN 9780719095924 hardback

ISBN 9781526110015 open access

First published 2017

An electronic version of this book is also available under a Creative Commons (CC-BY-NC-ND) license, thanks to the support of the Wellcome Trust. DOI: http://dx.doi.org/10.9760/ MUPOA/9781526110015

The publisher has no responsibility for the persistence or accuracy of URLs for any external or third-party internet websites referred to in this book, and does not guarantee that any content on such websites is, or will remain, accurate or appropriate.

Typeset by Out of House Publishing 
This book is dedicated to my father, Robin Evans (1944-93). 



\section{Contents}

List of figures viii

Acknowledgements $\quad \mathrm{x}$

Introduction: Perceiving, describing and modelling child

development

Part I The first autism: The observation and description of child development before 1959

1 The first autism

2 The first autism controversies 92

3 Inside the Maudsley Child Psychotic Clinic in the 1950s 135

$\begin{array}{ll}\text { Part II How autism became autism } & 187\end{array}$

4 The transformation of social life and the transformation of autism in the 1960s

5 How do you measure a social impairment? 248

6 Epidemiology, epidemics and autism as a global health crisis 339

Conclusion

Abbreviations for Archives and Government Acts 435

Bibliography 437

Index 486 


\section{Figures}

1 Facsimile of the first page of 'Condition on Admission' form used to collect information from children in the psychotic clinic in the 1950s (MHCP/A)

2 Chart, 'The psychotic ego with its defects and defences', from Elwyn James Anthony, 'Group therapeutic techniques for residential units', Case Conference 4, no. 6 (1957)

3 'A ward for imbeciles in a mental deficiency hospital', c.1956, from Leslie Hilliard and Brian Kirman, Mental Deficiency (London: Churchill, 1957)

4 Table, 'Mean percentage scores on 24 behaviour items', from Victor Lotter, 'Epidemiology of autistic conditions in young children', Social Psychiatry 1, no. 3 (1966)

5 Graph comparing verbal coding ability in 'normal' and 'autistic' children, from Brian Hermelin and Neil O'Connor, Psychological Experiments with Autistic Children (Oxford: Pergamon, 1970)

6 Uta Frith's early jigsaw tests for pattern detection, from Uta Frith and Brian Hermelin, 'The role of visual and motor cues for normal, subnormal and autistic children', Journal of Child Psychology and Psychiatry 10, no. 3 (1969)

7 Section from table of items used in discriminant functions analyses, from Lawrence Bartak, Michael Rutter and Anthony Cox. 'A comparative study of infantile autism and specific developmental receptive language disorders: III - Discriminant function analysis', Journal of Autism and Developmental Disorders 7, no. 4 (1977) 
8 Table comparing behaviour during babyhood in different groups of children, from Lorna Wing, 'Perceptual and language development in autistic children: A comparative study', in Infantile Autism: Concepts, Characteristics and Treatment, edited by Michael Rutter (London: Churchill Livingstone, 1971)

9 Table distinguishing 'socially impaired' and 'sociable severely retarded' children, from Lorna Wing and Judith Gould, 'Severe impairments of social interaction and associated abnormalities in children: Epidemiology and classification', Journal of Autism and Developmental Disorders 9, no. 1 (1979)

10 Table subgrouping socially impaired children, from Lorna Wing and Judith Gould, 'Severe impairments of social interaction and associated abnormalities in children: Epidemiology and classification', Journal of Autism and Developmental Disorders 9, no. 1 (1979) 


\section{Acknowledgements}

First and foremost, I would like to thank the Wellcome Trust for generously funding my research on the history of autism, and for enabling this book to exist. I would also like to thank all of the people who have supported the development of my work on child psychology and autism. This book emerged out of ideas that first came to my mind whilst conducting my $\mathrm{PhD}$ research on the history of child psychiatry at Cambridge. Professor John Forrester (1949-2015) was a wonderful $\mathrm{PhD}$ supervisor and a constant champion of, and inspiration for, my work. His encyclopaedic knowledge of the history and philosophy of science helped me to frame my own historical approach and encouraged me to enquire deeper into conceptual history than I had previously planned. Dr Rhodri Hayward, likewise, has been a fantastic mentor who has enabled me to develop a profound understanding of psychological concepts in history whilst simultaneously encouraging me to develop a strong historical grounding to my work. His comments on the first draft were tremendously helpful and without them, the book would have been a much lesser entity. I would also like to thank Professor Nikolas Rose for examining my $\mathrm{PhD}$, and for his support, comments and advice since then. Thanks also to all the people who have read and engaged with the ideas in the book at various stages and offered advice, in particular Professor German Berrios, Dr Deborah Thom, Professor Edgar Jones, Dr Rob Kirk, Professor Stuart Murray, Dr Stephen Casper, Dr Signe Nipper-Nielson, Dr Iris Montero, and the anonymous reviewers of the manuscript.

I would also like to give a special thanks to all those who agreed to be interviewed and those who assisted with enabling access to archival material. In particular, I am grateful to Professor Sir Michael Rutter, 
Professor Patrick Bolton and all the staff at the Social, Genetic and Developmental Psychiatry Centre, as well as to Uta Frith for her interview and for donating her archive. My thanks also to the staff of the UK National Archives, King's College London Archives, Bethlem Museum of the Mind, Wellcome Trust Archives, the National Autistic Society and the Royal Society Archives.

I would also like to thank everyone else who has supported and encouraged me in this project, particularly Janet Evans, Dr Chitra Sebastianpillai, Joanna Whitehouse, Barbara Chu and Professor David Grahame Shane. Finally, I express my deepest gratitude to Rajiv Pillai, and our son, Ashan Evans, for inspiring me every day that I wrote this book. 



\section{Introduction}

\section{Perceiving, describing and modelling child development}

Autism is an essential concept used in the description of child development and its variances. Yet the phenomenal success of autism diagnoses is relatively recent. Today, autistic spectrum disorder is regarded as a developmental condition with genetic and biochemical correlates that often persists into adulthood. In 2009, the Autism Act became the first ever 'disability-specific' legislation to be passed in the UK, demonstrating the significance of the autism diagnosis to reframing approaches to mental health care, social welfare provision and individual rights in the UK. In 2013, EU Aims, a major initiative to develop new treatments for autism, received the largest grant for any mental health problem in the whole of Europe, revealing the cultural capital and potential for revenue generation held by the diagnosis. All major works in developmental psychology, educational psychology, child psychiatry, and now adult mental health, discuss autism and its implications. Teachers, social workers, health visitors, general practitioners and other front-line service providers receive training on the signs and management of autism. Parent groups, self-advocates and others campaign, publish, blog and broadcast on their experiences of autism and make sure that autism awareness is raised and remains so. The literary world has also woken up to the significance of autism, with, for example, Mark Haddon's Curious Incident of the Dog in the Night-Time (2003) part of a growing genre of autism fiction in the English language. Other media and artistic representations of autism also flourish in Britain and abroad. ${ }^{1}$ This is perhaps not surprising given the increasing number of children and adults who receive the diagnosis, or indeed who self-identify with it. A 2009 study by Simon Baron-Cohen and colleagues claimed the UK 
child prevalence rate of autistic spectrum disorder could be as high as 157 per 10,000 , or 1 in every 64 children. $^{2}$

Yet it was not always like this. Just forty years ago, hardly anyone had heard of autism. The condition of autism was thought to affect just 4-5 per 10,000 people and was thus considered extremely rare. There were some psychological specialists who wrote on the subject of autism in the 1960s, but they largely regarded 'autism' as a normal developmental stage in the formation of human relationships, characterised by hallucinatory and imaginary thinking, which they thought some children were never able to overcome. This is not the 'autism', or autistic spectrum, that we know today. In fact, an important part of this book covers the major transition, indeed complete reversal, in the meaning of autism that occurred in the late 1960s and 1970s, and was fully embraced by the 1990s. In this book, I argue that it was this reversal in the meaning of autism that enabled the expansion of the category; the growth in diagnoses; the expansion of health, educational and social services for individuals diagnosed with autism; and the general cultural phenomenon that autism has become today.

Since the late 1990s, there has been a growing interest in why autism has become so prevalent in the UK and elsewhere in the world. The sociologist Gil Eyal has written convincingly of the impact of major changes in the institutional care of children diagnosed with 'mental retardation' that took place in the 1960s in many parts of the USA and Europe. He has argued that deinstitutionalisation provoked new questions about children's psychological development and enabled the formation of new networks of expertise uniting psychologists, psychiatrists, therapists and parents, thereby expanding the territory where autism could be discussed and increasing its prevalence. ${ }^{3}$ In 2006, the autism researcher Paul Shattuck used data on the enrolment of children in special education programmes across the USA from 1994 to 2003, demonstrating that whilst more were diagnosed with autism, fewer were diagnosed with 'mental retardation' and 'learning disability'. In fact, the category of 'developmental delay' had also increased somewhat during that period, yet no one had thought to interrogate the 'epidemic' of 'developmental delay.' Autism researchers whose working lives have overseen these transitions, such as Michael Rutter, have also argued that changes in the way that children have been assessed and treated for developmental abnormalities of all kinds have led to increases in 
the application of the autism diagnosis. ${ }^{5}$ Lorna Wing, whose work was critical in establishing the idea of the 'autistic spectrum' in the late 1970s, has always maintained that she did, indeed, expand the category of 'autism' so that it included more cases. ${ }^{6}$

Controversies surrounding the MMR vaccine, and the use of mercury in vaccines, have only sparked further speculation about what, exactly, has been fuelling the ever-growing diagnosis of autism. The debate was particularly vitriolic in the late 1990 s and 2000s. ${ }^{7}$ Yet the discussion on the changing kinds of categorisation of autism has led us to a point where only the staunchest anti-vaccine campaigners would argue that changes in the way that children and adults have been assessed and diagnosed have not been responsible for most of the reported increase in prevalence. There may be other factors, but understanding conceptual change is arguably just as important as researching those factors. Today, 'autism', 'the autistic spectrum' and its conceptual cousins encompass so many different presentations that to say that anything 'causes' autism necessarily warrants a considerable amount of clarification. The Metamorphosis of Autism seeks to explain why this is the case.

If diagnostic changes have occurred over time, the historical reasons for these changes and their relation to wider theories of child development are still little understood. Sociologists, journalists, philosophers, literary critics and others have offered different explanations as to why more people are now diagnosed with autism than in the past. Madjia Nadesan's Constructing Autism (2005) was the first book that tackled the 'construction' of autism, arguing that the current framework for understanding autism has largely been formed through the auspices of cognitive science. The philosopher Ian Hacking has written on the way in which autism has become a dominant trope in online communications and pointed out that non-interactive autistic ways of being are in fact supported by the new Internet computer technologies so common in the contemporary world. Stuart Murray has illuminated the ways in which autism has been represented in literature, the media and the arts, and how these diverse fields have directed wider understanding of autism in the public domain. Chloe Silverman has shown how parent groups have been critical in determining research agendas for autism. Journalist, Steve Silberman's eloquent popular book Neurotribes builds on the idea of neurodiversity to explain how the recent increased visibility of autism is related to the past. ${ }^{8}$ Other authors have stressed the external factors that influence how autism has been 
described and thought about by researchers, parents, autistic people and others. ${ }^{9}$ All of this work has highlighted the fact that autism is not, by any stretch of the imagination, a simple disease category. This fact has, in some ways, been echoed in scientific literature that now refers to 'the autisms' as a diverse group of psychological conditions with different causes. ${ }^{10}$

Although several scholars have examined the increasing prevalence of autism, no one has explained why autism, in particular, as opposed to any other descriptive concept in psychology, has grown in such immense proportions and gone on to achieve such a celebrity status within popular culture. Furthermore, no one has explored how changes in the description and understanding of child development have helped to fuel reported increases in prevalence and have influenced the definition of autism now dominant internationally. This book argues that increased rates of autism are, in large part, a product of a major transition in the way that general child development has been thought about, reflected upon, conceptualised and perceived. This major transition in the psychological description of childhood began to take place in the 1960s in Britain and was fully established by the 1990s. The British context is particularly important in the story that is told in this book. A unique political, cultural and legal climate in Britain in the 1970s and 1980s, along with the development of new sociological and epidemiological techniques of enquiry, supported the ever-increasing dominance of the autism category to describe developmental atypicalities in children up to the 1990s. It was in this cultural climate, in which researchers were preoccupied with developing a purely 'scientific' and 'acultural' version of child psychiatry, that the transformation of autism into a global category was made possible.

However, the roots of our current understanding of autism can be traced further back into the early twentieth century and to the vast psychological expertise established in Britain in this period. The fact that we now tend to perceive problems of child development in relation to autism is a by-product of many historical factors that I will explore in this book. It was by no means inevitable that the current autism concept would be the one that superseded all other categories governing mental atypicalities in infancy and throughout child development. Other terms such as 'childhood psychosis', 'childhood schizophrenia', 'autoerotism,' 'primary narcissism,' 'subnormality' or 'mental deficiency' 
have all, at times, shared meanings with autism, and could have easily taken centre stage if historical factors had been any different. This book argues that several factors converged in the 1960s that meant that prior meanings of autism began to be refashioned, resulting in the 'autism' and 'autistic spectrum' that we know today. In the 1960s, psychiatric epidemiology was regarded as a new tool with which to challenge theories of the unconscious in child development. By the 1990s, psychological theories on the significance of unconscious instinctual drives to the development of pathological forms of infantile thought were virtually obsolete. They had been superseded and subsumed within new neuroscientific models for understanding genetics and psychiatry. This wider background in the history of psychological theory is fundamental to understanding the phenomenal growth of the autism category. One of the main arguments made in this book is that the meaning of autism was, and still is, inherently tied up with the construction of children's rights. By exploring different models of children's access to education, financial support, welfare and social work assistance, it is easy to see how children's rights to be valued as social subjects have been tallied with different understandings of their subjective development.

The growth of the autism category was associated with the development of new models through which to identify, articulate, measure and understand infantile and child thought. The new models were deliberately pinned against the first wave of theories of the infantile unconscious that had been framed around Freudian psychoanalysis. If one were to simplify this, one could say that this is a story about how psychoanalysts were proved wrong. But the story is far more complicated, as the new epidemiological autism psychologists did not prove psychoanalysts wrong but instead did something far more insidious - they appropriated their concepts. This book is about how English psychologists in the 1960s appropriated models of the unconscious infantile mind and then rebuilt them. In particular, it is about how they appropriated the concept of autism, which was, and has always remained, the kernel of all descriptions of the development of modern subjectivity and self-identity.

The growth of the autism diagnosis is unlike the growth in any other psychiatric diagnosis in the post-war period. Several medical historians have drawn attention to increases in the diagnosis of psychiatric conditions such as anxiety, depression or attention deficit hyperactivity 
disorder (ADHD), for example. ${ }^{11}$ However, all of these conditions can be directly associated with increased drug prescriptions that have encouraged diagnosis amongst medical professionals, the key drugs in the aforementioned conditions being Valium, Prozac and Ritalin, respectively. It is easy in these instances to look to large pharmaceutical companies in order to consider the reasons for the growth of psychiatric disorders in which there are clear drug treatments. Autism is different. There has been no wonder drug associated with autism. The diagnosis has grown for reasons that are far more complex and far more interesting. Autism is unique because it has come to infuse all language used to describe the making of the modern self since the 1990s. The Metamorphosis of Autism explores how this has happened. This involves a total suspension of our current models for thinking about child development and the development of the self, and a journey back to a time when infancy, childhood and identity are almost unrecognisable.

\section{Methodology and the importance of historical enquiry}

The methodological approach to the subject of autism in this book is primarily historical in that archival and primary sources have been placed at the centre of my analysis. I explore not just changes in the conceptual history of autism, but also the legal and institutional networks in which those changes occurred. There is no particular critical approach that I have applied wholesale to this history. I have not 'thought with' a single theory, but I have drawn significantly from methods developed in the history and philosophy of science as well as the sociology of scientific knowledge. The work of Nikolas Rose, Ian Hacking and John Forrester, in particular, has been critical in guiding my approach to the way that different sciences or 'styles of reasoning' come into being, and, more importantly, how those 'styles of reasoning' have influenced the law, the government and political approaches towards individuals. ${ }^{12}$ In analysing the history of child development, I am thus also analysing how particular scientific approaches to children came into being and how they influenced the law and approaches to children's welfare, education and care via governmental and other agencies. The broad goal is to explore the way that scientific knowledge and legal and institutional change have impacted on perceptions of self-identity in children. 
Autism is a by-product of this history that has become increasingly important in the recent past.

As well as being about autism, this book is about the way that children's lives have been managed and governed by psychological experts via legal and political changes. It engages with Nikolas Rose's work on the links between political power and psychological expertise in Britain. It does not follow the theory of 'governmentality' wholesale, but instead draws attention to both professionals and non-professionals who challenged dominant theories of 'self governance', presented new ways to think about the development of individuality in children and also pushed for changes in the law to reflect this. The theory of autism was one of the central theoretical tools that they used in order to do this. In this sense, my book draws inspiration from Mathew Thomson's work, Psychological Subjects (2006), which has broken down many of Rose's claims on the importance of psychological theory to transforming the national psyche. However, instead of pointing out the places where psychological theory did not have an impact, The Metamorphosis of Autism argues that a parallel psychology was developed that presented different and more puzzling models of individuality, human relations and social development that contradicted psychological experts who claimed to have a theory of human relations based on wider political models of social interaction. The book explores these other models in depth and argues that they offered the potential for new types of political engagement.

One of the critical points concerning the history of the governance of everyday life in Britain, highlighted by Rose, is the fact that the idea of 'the social' is not a timeless entity but has its origins in the mid nineteenth century. It was only in the early twentieth century that the 'social sciences' began to achieve their most powerful form in political thought and in the government and management of individual lives via the definition of workers' rights and the provision of welfare, educational and other 'social' services. This model of society united individuals under moral obligations to provide, and be provided with, programmes of mass schooling, public housing and other mass social ventures. In roughly the last thirty years, there has been a weakening of this 'social' model and new and more diverse forms of identity have taken over in raising moral and political consciousness. ${ }^{13}$ These changes in how the 'social' is perceived are associated with wider political changes such as 
the growth of neoliberal economic models. This book tracks these significant changes in approaches to society, government and political and economic life, pointing out the importance of theories of child development to shaping ideas about social life and individuality. It looks in depth at how 'social development' in children has been described, formulated and understood, and how its antithesis has also been conceptualised. Again, autism plays a larger role in this longer and broader history than has previously been acknowledged.

Of course, many historians are more than savvy to the complex interweaving between psychological sciences, social theory and political and legal change, even if they do not allude to the theory of 'governmentality'. The work of Thomson, as well as Rhodri Hayward, Michal Shapira and others, has been central in opening out debates about the role of psychological theory in relation to political ideology and government policies in the UK. ${ }^{14}$ Furthermore, historians of social policy, public health and medicine have also raised important questions about the wider influence of scientific and sociological research on government policy concerning families, child welfare and education in the twentieth century. ${ }^{15}$ The history of the family and the establishment of health and social welfare policies have all had an impact on how society and social development is viewed. In this book, I seek to demonstrate that it is imperative to acknowledge this broader history of child health, education and welfare when writing the history of autism. Autism is not, and never has been, a minor esoteric subject, but one that has a significant bearing on how we think about social identity.

When exploring how scientific theories of autism have impacted health and education practices, and government policies, towards children, I have not only examined the impact of that scientific research, but have also reflected on what kind of theories and ideas about autism have been formulated at different periods of time. It is in this aspect of my work that I have drawn most strongly from the history and philosophy of science and Hacking's 'styles of reasoning', which he developed in his work on the rise of statistical thinking. ${ }^{16}$ Hacking's work illustrated the importance of statistical methods in the social and biological sciences as they enabled a new science of the state centred on probabilistic laws. In this work, he also articulated six 'styles of reasoning' within scientific thought, one being statistical analysis of regularities of populations. John Forrester later argued that one should also add 'thinking in 
cases' as another style of reasoning, in which individual cases served as exemplars with scientific and legal thought. ${ }^{17}$ Drawing from these arguments, in my analysis of the sciences of autism, I pay particular attention to the way that psychologists, psychoanalysts, epidemiologists and social scientists investigated autism and generated scientific knowledge about autism. In particular, in the second half of the book, I explore how statistical sciences prevailed over individual case histories in the expanding sciences of autism, and what this meant for the description of social development and individuality in children. ${ }^{18}$

The Metamorphosis of Autism thus fuses primary archival analysis of government reports, administrative records, scientific papers and individual case histories with theoretical reflections on the way that models of social development and individuality in children have been produced. It tells a history of autism that is framed by archival sources which reveal the individual, social and political consequences of autism as a concept, yet that also reflects in depth on the conceptual history of autism itself. It is thus not what one may call a classic conceptual history, as it seeks to engage firmly with the historical forces that have structured changes in the meaning of autism and that have enabled individuals to employ the concept in different settings. It explains how knowledge about child development has altered due to factors such as legal, political and economic changes, as well as wider international developments in the theory of child development or wider shifts in approaches to disability.

\section{How Britain stole the idea of autism}

The main thesis of this book is that the current global category of autism was forged from a refashioning of child development. A group of researchers based in Britain, and primarily in London, were responsible for this refashioning. The first international definitions of autism employed in the International Classification of Diseases and the Diagnostic and Statistical Manual were drawn almost exclusively from the work of two highly influential researchers in Britain: Lorna Wing and Michael Rutter. Wing, Rutter and their contemporaries used the modern metropolis of London as a base from which to restructure dominant tropes concerning the development of self-identity and 
to reformulate these as part of a new model of identity development. Autism was a central concept that had framed much critical thinking on the development of self-identity since the early twentieth century, and it is unsurprising that they turned to this concept in order to challenge psychological stagnation and to rethink the central tenets of child development.

The early twentieth century witnessed the first sustained attempts to scrutinise infantile thought as part of a wider project to understand the origins and development of mental illness in adults. Sigmund Freud was obviously the central figure who explored the infant's mind in an effort to explain how early traumas affected later psychological processes. ${ }^{19}$ However, other towering figures in descriptive psychopathology were also turning their attention to the infant mind at this time. The concept of autism was coined in 1911 by the German psychiatrist Eugen Bleuler to describe a symptom of the most severe cases of schizophrenia, a concept he had also created. According to Bleuler, autistic thinking was characterised by infantile wishes to avoid unsatisfying realities and replace them with fantasies and hallucinations. 'Autism' defined the subject's symbolic 'inner life' and was not readily accessible to observers. ${ }^{20}$ Psychologists, psychoanalysts and psychiatrists in Britain used the word autism with this meaning throughout the 1920s, up until the 1950s. Throughout this period, the words 'psychotic', 'schizophrenic' and 'autistic' held many similar meanings and were associated with adult schizophrenia, in particular Bleuler's description, and a lack of contact with reality. However, in the 1960s, many child psychologists in Britain challenged the contentions about infantile thought assumed by Bleuler and others and created new methods to validate child psychology as a science, in particular epidemiological studies. 'Autism' was then completely reformulated as a new descriptive category to serve the needs of this new model of child development.

From the mid-1960s onwards, child psychologists in Britain used the word 'autism' to describe the exact opposite of what it had meant up until that time. Whereas 'autism' in the 1950s referred to excessive hallucinations and fantasy in infants, 'autism' in the 1970s referred to a complete lack of an unconscious symbolic life. For example, Michael Rutter, a leading child psychiatric researcher from the UK's Maudsley Hospital who conducted the first ever genetic study of autism, claimed in 1972 that 'the autistic child has a deficiency of fantasy rather than an 
excess. $^{21}$ The meaning of the word autism was then radically reformulated from a description of someone who fantasised excessively to one who did not fantasise at all.

The Metamorphosis of Autism traces this radical transformation of the concept of autism in Britain, exploring the reasons behind the shift and the impact that it has had on psychological sciences relating to infants and children. It argues that the change in the meaning of autism was part of a more general shift in Anglo-American psychiatric reasoning that sought to understand psychological problems through epidemiological studies rather than individual cases. Epidemiological methods shifted and morphed central concepts in psychology, in particular the concept of autism. The diagnostic practices required of English psychiatric epidemiology in the 1960s continue to influence contemporary theories and descriptions of autism and to affect the way that government entities have managed and assessed child populations in relation to psychology.

This book locates changes in psychological theory in Britain in relation to larger shifts in the political and social organisation of schools, hospitals, families and childcare. Historical work on children and families has highlighted the importance of developing industrial economies to the establishment of welfare services for infants and children in the late nineteenth and early twentieth century. This research has been positioned within broader historical debates concerning the problem of national efficiency and the implementation of policies to improve the health of populations. The development of advanced systems for the protection of infant life improved methods for the collection of statistical data on the prevalence of infant mortality and childhood illnesses. Deborah Dwork's work on the infant welfare movement has highlighted the way that statistics on the crude birth rate at the end of the nineteenth century began to drive the establishment of policy measures to improve the survival chances of infants. ${ }^{22}$ Lara Marks has shown how debates that were raised over high levels of infant mortality in Poor Law institutions impacted upon the provision of maternity services and outdoor relief for expectant mothers following the 1907 Report to the Royal Commission on the Poor Laws. ${ }^{23}$ It was thus through the application and study of statistical evidence that arguments were first put forward to comprehensively alter institutional care for infants, children and mothers.

Harry Hendrick's work has explored how state surveillance and implementation of policies to improve both the material conditions of 
children, and their physical health, began to shift focus to the improvement of their mental health or minds with the rapid development of psychological sciences in the interwar period. ${ }^{24}$ It is true that psychological sciences became more dominant in descriptions of child development during the interwar period and that interrogating and understanding these sciences is critical to understanding both childhood and theories of self-governance in the twentieth century. However, most research on the history of twentieth-century psychology and education in Britain has focused on intelligence testing as the most significant practical tool that has influenced the development of psychological theory. ${ }^{25}$ Whilst it is correct that intelligence testing enabled a mammoth administrative and bureaucratic system that supported child psychological sciences, this book seeks to understand the lesser-known administrative and bureaucratic systems that shaped and produced new psychological theories and sciences to measure and quantify autism and 'social impairment' and which were just as influential in guiding government policy towards children, particularly in the second half of the twentieth century. Historical work on the concepts of 'feeblemindedness' and 'mental deficiency' and their management in children prior to the 1960s (when these categories became obsolete) has demonstrated that 'mental deficiency' and its offshoots were as much related to social exclusion as to educational and intellectual potential. ${ }^{26}$ It is particularly significant that from the 1960 s onwards, when new theories of psychological development and autism began to gain ground, the social exclusion of 'mentally deficient' children was falling into disrepute and institutions for 'mental defectives' were being closed down. There is a complicated history that follows these closures where children came to be integrated slowly into special educational services and later into mainstream classes. ${ }^{27}$ This history is intertwined with changes in the organisation of wider forms of residential care for children and, above all, major changes in the organisation of state-run social services. ${ }^{28}$ This book focuses specifically on Britain to understand how first the expansion, and then the closure, of institutions for 'mental deficiency' stimulated the development of new practical technologies to measure, classify and organise children who did not fit within the mainstream education system. It is by tracing the history of psychology in this context that the book explains shifts in the application and meaning of autism. 
Much research into autism at a critical period of its transformation in meaning - from the 1950s to the 1970s - took place at the Institute of Psychiatry in London, an institution established in 1948 as the largest teaching centre for psychiatry in Britain. The institute also housed the Occupational Psychiatry Research Unit, later renamed the Social Psychiatry Research Unit in 1958, which was funded by the Medical Research Council (MRC). It was there that researchers broke new ground in social-scientific and epidemiological work on psychological problems. This book argues that the intellectual climate created at this institution built on significant research agendas in British sociology and epidemiology in order to develop a unique concept of autism that has since become the international standard for research in autism via international classificatory systems. The MRC Developmental Psychology Unit, affiliated to University College London, was also important in expanding this model, as was the British Experimental Psychology Society. There are several significant individuals who played an important part in this transition in Britain, in particular Mildred Creak (1898-1993), Neil O’Connor (1917-97), Beate Hermelin (1919-2007), Jack Tizard (1919-79), John Newson (1925-2010), Lorna Wing (1928-2014), Elizabeth Newson (1929-2014), Michael Rutter (b. 1933), Uta Frith (b. 1941) and Simon Baron-Cohen (b. 1958).

Nevertheless, this book does not begin in the late 1960s when changes in the meaning of autism began to trickle through into psychological theory and make radical changes to our understanding of children's social, emotional and intellectual development. It is only by viewing these changes in context that one can fully appreciate the major alteration in descriptions of child development that occurred and their relevance to how differently we now think about children's thinking, development and play. So, this story is traced back to earlytwentieth-century Britain and to early attempts to describe and understand 'social development' in children. These are placed in the context of the Mental Deficiency Act 1913, and the appointment of Cyril Burt as the first 'official psychologist' in the world. This book traces early attempts to classify, organise and investigate the total child population using psychological methods. It positions this history as the background to understanding changes in the observation, assessment and management of child populations that enabled the contemporary concept of autism to be formulated. 
The argument of this book is that concepts of child development are intimately connected to the legal and social setting in which they are formulated. Contemporary concepts of autism are as strongly connected to our current techniques for modelling, mapping and understanding society as earlier concepts of 'mental deficiency' and 'childhood schizophrenia' were to mapping, modelling and conceptualising British society in the 1930s. This is not to say that autism is merely a 'social construct' without any bearing on the reality of psychological development and its atypicalities. As Ian Hacking has eloquently argued, the term 'social construct' has in some ways outgrown its usefulness for historians and others who want to think critically about the development of psychological ideas that interweave the biological and the social. ${ }^{29}$ Hacking introduced the idea of 'looping effects' to demonstrate the interrelation between ideas, on the one hand, and human development, on the other, as both biological and psychological facts. The Metamorphosis of Autism argues that understanding the broader background and setting in which autism developed provides us with a much more detailed and nuanced understanding of what, exactly, autism is and what it has become. This does not aim to invalidate the category. In fact, it confirms its significance and power, as well as the complexities of its meaning. This book should thus be useful to all those who critically reflect on the question of what autism is, whether they be scientists, clinicians, parents, historians, sociologists or anyone else. It argues that what autism is can only be fully understood when viewed in relation to a wider history of child development and education and welfare policy.

It is relevant to note here that there are only two concepts of child psychology that have ever been granted their own Act of Parliament in the UK. The first of these was 'Mental Deficiency' (1913) and the second was 'Autism' (2009). The reason for this is that both concepts have attracted public strategies for betterment and improvement, albeit in very different ways. What is more, both concepts have served as receptacles for new public strategies to intervene in the lives of children and adults. Whereas the 1913 Mental Deficiency Act did this via what was ultimately a project of social exclusion, the 2009 Autism Act does it in the spirit of children's rights to inclusion and acceptance within society. It is for this reason that the growth in diagnoses of autism cannot be regarded as an extension of psychiatric authority, but rather as part of a wider change that has ensured the legal rights of children to 
express their individuality and autonomy. This book explores the changes that this has effected in our understanding of child development. The growth of the autism category has been accompanied by a belief that there is a biochemical reality in differences in children's responses to parents and to the social world. Children are no longer just recipients of care; they have a say in this care too. The concept of autism gave such approaches psychological legitimacy and aimed to protect the rights of children so defined. However, it did not do so in the model of mental deficiency legislation, where children's autonomy became subsumed under the diktats of medical professionals. On the contrary, autism legislation seeks to protect the autonomy of children and adults with the diagnosis. It protects autistic autonomy in the eyes of the law. Autism thus became a statement of the authenticity of budding individuality in child development.

Think about it this way: the formation of the concept of intelligence and the development of intelligence tests at the start of the twentieth century did not simply bring to light a facet of human thought processes that had existed, yet never been exposed. The development of this concept and these tests completely transformed the way that society functioned. Intelligence tests enabled easier screening and separation of children based on intelligence levels, first justifying the assessment and complete social exclusion of children with IQs below 50, and later, in 1944, enabling the development of tests for eleven-year-olds and the establishment of the tripartite secondary school system covering grammar, secondary modern and technical schools. It also led to the establishment of an institutional empire built on measuring this newly discovered entity and added 'intelligence' to the tools of social-scientific researchers, who could correlate it with their other analytic categories - class, race, family size, etc. Researchers looked, and still look, for its genetic correlates, constantly searching for further confirmation that this psychological category has a basis in the brain. Biological correlates for intelligence may well exist, but the important point here is that society, law and public life were all transformed by the concept.

From a historical perspective, the concept of autism has many similarities to the concept of intelligence. The formation of this concept did not merely reveal an aspect of human thought that had lain dormant until that time. It completely transformed the ways in which we think about psychological development. Ever since psychological researchers 
developed tools to measure autism, these have been used to assess, categorise and sort children within the education system. Most importantly, the category was used to support the novel idea that children previously considered 'ineducable' could actually be educated.

Although it is usually considered that laws to ensure the rights of all children to be educated were enacted at the end of the nineteenth century, it was actually only in 1970 that all children in the UK were granted the right to be educated regardless of whether or not they had the supposedly correct levels of intelligence. It was the autism category that was fundamental in driving this transition in children's rights. The 1970 Education (Handicapped Children) Act paved the way for autism to be regarded as a unique impairment that required specialist education, leading to a transformation in the way that schools managed their intake and organised their classes via an expansion in the employment of educational psychologists, speech therapists and teaching assistants. The formation of autism as a measurable entity also encouraged epidemiological and social-scientific work that provided information about numbers of cases and offered political solutions for managing this new population. It also added a further analytic category to social-scientific and neuroscientific analysis and enabled an explosion of studies into environmental, biochemical, genetic and other sources of autism. Whether or not anyone was 'autistic' before diagnostic and measurement systems were developed is a moot point: people are now 'autistic' in a very different way than previously, and also in a very different social context than previously. If autism is a kind of 'social impairment', then surely this is significant.

Several scholars have interrogated, scrutinised and analysed the history of intelligence tests. ${ }^{30}$ Adrian Wooldridge, Gillian Sutherland and others have explored the history of intelligence tests in relation to schooling and access to education, describing the significance of these tests as a tool of modern British government and as the fulcrum on which psychological sciences fused with educational policy. ${ }^{31}$ Many have probed the life and works of Cyril Burt and accusations have flown as to whether his data was accurate or whether he had faked it in his desire to demonstrate the heritability of intelligence. ${ }^{32}$ There has been a fascination with the controversies and uses of intelligence tests throughout the twentieth and twenty-first centuries. However, no one has examined the importance of the development of new psychological 
tests that competed with intelligence testing and their impact on the education system, despite the fact that the impact of 'social impairment' and 'autism' tests has been phenomenal.

In the 1950s, researchers at the Maudsley Hospital and the Institute of Psychiatry found the intelligence test to be lacking in its ability to measure the capacities of one particular group of children deemed 'psychotic', 'schizophrenic' or 'autistic', following leads from the description of psychopathology in adults. This loss of confidence in intelligence testing was also associated with an international realisation, following the Second World War, that intellectual improvement and compulsory schooling did not necessarily make for a peaceful and happy social order. ${ }^{33}$ In the 1960s, new testing instruments and schedules were developed specifically for 'schizophrenic', 'psychotic' and 'autistic' children who did not fit into neat categories of intellectual ability. It was this that stimulated a new form of reasoning about mental development in children, which was accompanied by the foundation of a new system of social networks formed between mental deficiency institutions, the Maudsley Hospital, the Institute of Psychiatry, King's College Hospital, Rudolph Steiner Schools and other institutions for special education. It was through these networks that a new form of psychology came into being that began to undermine previous individual psychology based around intelligence tests. This generated a new 'style of reasoning' about child psychology. In the course of the book, I refer to this as 'spectrum-making' and argue that it has increasingly come to play a part in definitions of childhood and individualism in the late twentieth and early twenty-first century. This new technology of 'spectrum-making' directed and drove important practical and political considerations in British education concerning children's rights to schooling as well as their rights to be respected as autonomous individuals.

The Metamorphosis of Autism also explores how government entities have dealt with the psychological category of autism. It looks at how populations of children have been assessed and managed, and how psychological categories have changed in response to that management and government. It focuses on changes in the meaning of autism, but views this in relation to wider theories of child development and socialisation. Indeed, it points out that it was a necessary prerequisite for current theories of autism that educational, social and political systems already existed to observe and study children's psychological development, as 
without these the paraphernalia of contemporary autism measurement could not have been conceptualised or developed. In other words, child development could not have been redefined had it not already been defined in the first half of the twentieth century in relation to a prior era of social science guided by the science of intelligence testing and psychoanalysis. Sociological sciences of the late 1960s marked out new territory for assessing and analysing society. ${ }^{34}$ These were significant to the redefinition of child development and to the creation of autism as we understand it today.

\section{Early child psychology and its limitations}

The establishment of modern psychology was only made possible through the emergence of evolutionary sciences in the middle of the nineteenth century. ${ }^{35}$ With regard to child psychology, Susan Isaacs, who established the Department of Child Development at the Institute of Education, was critical in formulating an early theory of 'social development in young children' that was used to inform education policy and to educate the general public about the basic tenets of child psychology. Isaacs also propagated and developed the work of the Swiss psychologist Jean Piaget. Along with Melanie Klein and Margaret Lowenfeld in Britain, she established a way of thinking about children's play and socialisation that would remain steadfast until theories of autism came to replace it. This book looks in detail at theories of socialisation and instinctive motivation in children from the 1920s until the 1950s in Britain. It also looks at controversies over the description of social development and its absence in children, investigating early theories of autism. Most importantly, it examines why mental deficiency law, and theories of mental deficiency in infants and children, prevented psychologists from developing comprehensive models of autism and social development prior to the 1960s.

Of all the classic texts in developmental psychology written from the 1910 s to the 1950s, very few were concerned with the thought processes of children considered to have 'mental defect' or very low intelligence levels. Susan Isaacs' work focused on children in a typical nursery setting and considered the implications of early development to the education of typical children. Cyril Burt, even though he focused on social outliers such as 'backward' and 'delinquent' children, never attempted 
to describe the thought processes of those who were regarded as incapable of carrying out basic mental operations. In fact, Burt considered 'delinquents' as the true puzzles for psychological enquiry and the most significant psychological types who deviated from the norm. This was also the case for many involved in the Child Guidance Movement, such as William Moodie and Margaret Lowenfeld, because child guidance clinics did not accept children thought to have a 'mental defect' and were focused on the 'adjustment' of other children, of whom 'delinquents' then formed the most demanding group in terms of social adaptation. Sigmund Freud's daughter, Anna Freud and Melanie Klein, wrote about psychoanalysis and severe psychopathology, but even they were not attempting to treat children with major intellectual impairments. Even John Bowlby, who wrote widely on attachment theory as a facet of general psychology, never reflected on attachment behaviour observed in 'mental defectives'. For the most part, the study of 'mental defect' prior to the 1960s was left to medical specialists who had been unfortunate enough to be placed in what were then regarded as provincial backwater deficiency institutions, rather than cutting-edge centres of medical specialism. These were people such as Brian Kirman and Leslie Hilliard, whom barely anyone has heard of.

Even renowned international researchers in child development, such as Arnold Gesell in the USA and Jean Piaget in Switzerland, did not seek to delve into the thought processes of 'mental defectives' as they were too busy documenting the behaviour and thought processes of, previously undocumented, typical infants. In short, all these psychologists helped to create a myth of child psychology as an absolute science, relating to a total population group, which was not consistent with the actual range of possible childhood thoughts and emotional processes.

This all began to change in the 1960s, when psychological researchers shifted their attention to the actual total population of infants and children, rather than just those ones who were lucky enough to escape certification. This initially happened following pressure from medically trained psychiatrists who were working in cosmopolitan medical institutions such as the Maudsley Hospital in London. These professionals were the first to come across children who were living on the borderline of certification and who often displayed multiple medical and psychological atypicalities. Mildred Creak, Elwyn James Anthony and Kenneth Cameron from the Maudsley were amongst the first to challenge general theories of child development based on their observations 
of what they saw as severe psychopathology in infancy and childhood. In the USA, Leo Kanner and Lauretta Bender held similar positions and also sought to challenge convention. This book demonstrates how and why the approach in Britain was unique in its challenge to conventional psychological and sociological theory, and why it went on to dominate the scene of autism research from the 1960s.

Nikolas Rose's influential work on the psychological sciences in Britain in this period, Governing the Soul, placed a lot of emphasis on the work of the Tavistock Clinic and the Tavistock Institute of Human Relations as providing the dominant theoretical model that enabled the spread of psychological theory via government networks and health, education and social care agencies in Britain in the 1940s and 1950s. Key 'psy' professionals in this story include Melanie Klein, Anna Freud, John Bowlby and Donald Winnicott. They were all psychoanalytically oriented, although many presented a more palatable and user-friendly version of psychoanalytic theory. Their main interest was in human relationships and thus their theories were easily adaptable and transferable to industrial firms, management consultancies and government policy advisers. Rose's argument is that these professionals enabled, even compelled, individuals to govern themselves, and he also presents this as a success model for neoliberalism. ${ }^{36} \mathrm{He}$ is correct in identifying these professionals as critical in framing government policies in the immediate post-war period and up until the early 1990s. However, these were precisely the professionals that new psychologists interested in autism and 'social impairment' sought to overthrow from the 1960s onwards, finally succeeding in the 1990s. The psychology of autism 'spectrum-making' was a psychology that was based not on the study of human relationships but rather its obverse. By exploring the origins of the 'autistic spectrum', this book thus aims to reveal the undercurrent of psychological professionals who did not think that the soul could be governed and who campaigned and protested that the psychology of human relationships was not the answer to many of the pressing questions of human existence. The Metamorphosis of Autism thus throws contention and controversy into Rose's otherwise benign picture of psychological intervention. It also argues that the psychology of autistic spectrum-making has now largely replaced the psychology of human relationships, in particular in relation to child development.

In wider work on the history of psychiatry, German Berrios has argued that professional consensus on the nature of particular mental 
symptoms always has a major impact on clinical practice. ${ }^{37}$ Many have noted that the development of psychometric tests and statistical methodologies, driven by the demands of the Diagnostic and Statistical Manual, have transformed adult psychiatry. ${ }^{38}$ Several historians have examined the social and economic reasons for the growth in adult psychiatric categories such as depression, multiple personality disorder and post-traumatic stress disorder. ${ }^{39}$ There has been a fascination with neuroscientific approaches to psychiatric categories since the 1960s and the reasons why these changes took place. ${ }^{40}$ The history of child guidance, psychiatric theories of 'cultural deprivation' and the growth of the ADHD diagnosis have been explored in the USA.$^{41}$ However, British research on the history of child psychiatry and its interactions with government policy and education planning is distinctly lacking. This book demonstrates how the growth of the autism category in children in Britain has influenced wider understandings of psychiatric disorder and neurological dysfunction, in particular relating to concepts of schizophrenia, psychosis and delusion.

The history of child psychology in Britain has largely been compartmentalised into the history of child guidance, ${ }^{42}$ the history of intelligence testing, ${ }^{43}$ the history of special education ${ }^{44}$ and the history of psychoanalytic theory. ${ }^{45}$ There is very little work that has been done specifically on the history of child psychiatry in Britain, and this is important because it was via the discipline of child psychiatry that the psychology of autism spectrum-making began to gain a foothold and later entered more mainstream theories of children's psychological development. Several practitioners have provided important information on how this began to happen, although they have not explained the significance of these shifts in relation to general psychology and social organisation. ${ }^{46}$ Hendrick has demonstrated the degree to which much twentieth-century UK child law has been influenced by psychological theory, yet no one has examined the impact of the law on child psychiatry and autism research and thus the significance of autism to the organisation of contemporary British cultural and political institutions. ${ }^{47}$ Concepts of individuality in childhood were rewritten through changes in the meaning of autism, changes in the theory of child development and subsequent changes to the rights of people who were given, or who appropriated, the autism diagnosis. With this background, we should not be surprised to see the growth of the self-advocacy movement in relation to autism, as this is merely an affirmation of the social and 
legal changes that followed the development of autism spectrummaking and the redefinition of child development that began in the 1960s. In fact, the category of autism has been hugely influential in shaping contemporary health, education and welfare policy in the UK and in establishing autonomy and social rights for those who could be classed within the autistic spectrum.

The Metamorphosis of Autism seeks to clarify this through a detailed historical account of how legal, institutional and educational changes in the UK affected the diagnosis of autism. It shows how autism has been shaped through the business of British social administration. In addition to the Mental Deficiency Act, social and political changes stimulated by the 1959 Mental Health Act, the 1981 Education Act and the 1989 Children and Young Person's Act, for example, also pushed forward new approaches and ways of thinking about autism and child development. One important aspect of these changes was the construction of a unique model of children's rights in which the right to education, broadly defined, was secured for all children no matter what their intellectual level, followed by the right to have their identity respected.

I argue that this is a particularly important dimension to the global understanding of autism as it was primarily researchers in Britain, drawing from unique social-science research methods developed at the Institute of Psychiatry and related Medical Research Council units, who provided the first thorough methodological frameworks for identifying, measuring and calculating autism via their input to international classification and diagnostic tools. Their influence has become even more important in recent times. For example, the exemplary figurehead of this movement, Michael Rutter, worked internationally in the 1980s to establish the Autism Diagnostic Interview and the Autism Diagnostic Observation Schedule, now often publicised as the 'gold standard' for autism diagnosis worldwide. ${ }^{48}$ Researchers such as Michael Rutter, Lorna Wing, Uta Frith and Simon Baron-Cohen have generated unique models of children's social development and play that have had a wider impact on general theories of child development. By arguing that autistic children lack the capacity for imagination or 'mentalisation', Frith and Baron-Cohen extended Rutter and Wing's contention that such a construction of child thought should be applied for the purposes of epidemiological science. What was once, in the 1960s, a necessity for the critique of individualistically minded 
psychoanalytic theories, such as those of Melanie Klein and Susan Isaacs, has become a psychological model in and of itself. In fact, it is the seemingly atheoretical nature of current models of autism that have been the secret to their success. No one can criticise the concept because it is essentially based on an absence of information about child thought, into which various concepts of impairment, deficiency and lack have been placed. This book explores early theories of social and intellectual development in infants and children and looks at the connections established between psychological researchers and government administrators, It argues that these networks help to frame and understand changes in the meaning of autism.

The Metamorphosis of Autism argues that the concept of autism was crucial to the formation of child psychiatry as a discipline from the late 1920s to the 1950s, and that it was accorded a central role within wider psychological theory during this period. In the 1960s, a number of very specific and unique historical factors converged that enabled a radical reconceptualisation of the frameworks for understanding infantile thought and its 'pathologies'. The way in which 'autism' was defined began to characterise certain schools within child psychology. Child psychiatrists, hoping to carve out a field of 'developmental psychopathology' through the use of epidemiological studies used 'autism' as a means to quantitatively capture what was then regarded as an elusive and unconscious stage of thought. In doing so, psychologists of the 1960 s and 1970s rewrote the theory of social development, socialisation and the significance of play in infants and children. They were able to do this because they harnessed the explanatory capacity afforded to them by including total populations of children, in particular those who had previously been written off as 'mentally defective' and placed in institutional care. The category of autism took on a significant new role for those involved in implementing changes for the education of children previously regarded as 'mentally deficient' or 'subnormal'. It is only within this historical context that we can begin to understand why this thing called 'autism' has been perceived at different times as a psychiatric disorder, an illness, a disability, a neurodiversity label, a childhood developmental stage and a normal mental state.

This book is divided into two parts. The first half of the book, 'The first autism: the observation and description of child development before 1959', explores theories of social development in children from 
the 1920s to the 1950s in Britain. Chapter 1 explains how legal and institutional networks, framed around the concept of intelligence, affected children's rights to education and welfare support. It explains why children regarded as 'deficient' in thought were both physically and philosophically removed from the institution of child psychology in the early twentieth century, and why 'the first autism' therefore rested on quite a shaky legal and institutional support base.

Chapter 2 examines a series of major debates and controversies that erupted in the 1940s about the way children's thought could be investigated and explored. The outbreak of the Second World War had forced psychologists, psychiatrists, social scientists, anthropologists and others to challenge theories of human instincts in child development and to clarify the nature of socialisation in children. The theory of autism was critical to the reconstruction of instinct theory in the light of war and this led to many disagreements and debates. These controversies were silenced when the war drew to a close and psychologists shifted their attention to buttressing and reinforcing the aims of the welfare state in its provisions for children. John Bowlby's theories of the importance of 'maternal love' and the dangers of 'maternal deprivation' were the archetype of this post-war marriage of political and psychological aims, which quelled much anxiety about the precision of theories of ego development in an effort to re-establish supposedly 'traditional' family roles in support of child development. Although controversies about autism were then brushed under the carpet, they had not disappeared and would later re-emerge in new forms.

Chapter 3 looks in detail at a unique children's 'psychotic clinic' set up in London at the Maudsley Hospital in the 1950s. It argues that this clinic was unique in its critical outlook and patient population and bucked the trend of uniting political and psychological aims when thinking about children's social development. The clinic had sympathies with radical critiques of the adult asylum system and of the unhealthy tie that existed between the law and psychiatry, which were then causing a stir within critical thought and public policy. However, its scope was limited in the 1950s due to the continuation of restrictive laws on 'mental deficiency'.

The second half of the book, 'How autism became autism', looks at the dramatic change in the meaning of autism that occurred in the 1960s. It was not until deficiency institutions began to be closed down, 
following the 1959 Mental Health Act, that psychologists started to develop new models of autism. Chapter 4 explores the crisis of government that developed regarding the number of 'psychotic' children who were entering the public domain when large long-stay institutions closed. The Institute of Psychiatry's Social Psychiatry Research Unit in London became a dominant force in calculating the number of children with psychological problems and presenting these to government departments that acted accordingly in structuring social services to cater for these groups. The first ever epidemiological study of autism was conducted in Britain, primarily for administrative purposes, and set the scene for a new model of child psychology that united psychological and political aims, yet did so in a way that was far less overt and overbearing than the pre-1959 model symbolised by Bowlby's theories and articulated in Rose's theory of 'governmentality'. This new, reformulated, statistical, measurable, epidemiological model of autism transformed the meaning of autism and opened up original models of political engagement and new ideas about children's rights that had previously been unthinkable.

Chapter 5 looks at how changes in the organisation of education and social services for all children in 1970 gave further support to the concept of autism that was being developed in London's Social Psychiatry Research Unit. For example, the Local Authority Social Service Act 1970 led to the establishment of 'social service' departments within local authorities separate localities designed to facilitate social functioning for all. These united previously disparate services. It was in this climate that the description of autism as a kind of 'social impairment' was solidified and that the concept began to attract important legal significance in attributing rights to individuals diagnosed with the condition. The 1981 Education Act (enacted in 1983) and the 1989 Children's Act continued to bestow legal significance on the concept of autism and encouraged increases in its application within administrative circles. This also supported a broader definition of autism as a 'spectrum' and the development of increasing numbers of schedules and tests for measuring autism and 'social impairment'. The legal changes of the 1970s and 1980s thus supported the efforts of the new autism psychologists and enabled them to establish the psychology of the autism spectrum as the dominant model for understanding child development and its variations. 
The final chapter argues that epidemiological research on autism in the 1960s and 1970s pioneered at London's Institute of Psychiatry has come to define global attempts to analyse and understand what, exactly, autism is. This has happened primarily via the engines of the Diagnostic and Statistical Manual and the International Classification of Diseases. Autism is currently a global phenomenon, yet has very specific conceptual roots. Many of the most popular global diagnostic instruments for autism were developed by researchers trained at the Institute of Psychiatry and related institutions in Britain, hence the importance of understanding the historical context described in this book. With these instruments, many epidemiological studies have been conducted worldwide, building on the original UK study. Reported increases in diagnoses since the 1990s have stimulated a huge interest in autism as a phenomenon and supported the psychology of the 'autistic spectrum' as a way to understand social development. The emergence of the Internet in the early 1990s has also driven international collaborations between research groups, as well as parent groups and self-advocacy groups. This chapter explores how these changes have been associated with wider global changes relating to the definition and construction of children's rights. It argues that studies of autism have almost become status symbols, and demonstrations of advanced approaches to child rights, within the developing world.

The main premise of this book is that autism is not, and has never been, a concept or an idea that is easy to pin down, and that it is only possible to understand the phenomenon of autism if it is explored in relation to a wider history of childcare and education and a wider history of theories of child development and child psychology. It thus seeks to rethink the meaning of autism through its historical past. The definition, diagnosis and meaning of autism are important topics that affect the people diagnosed and their families; the structure of health, education and social care services; and neuroscientific research agendas and the money that is spent on them. The rise of autism is partly a story of how psychologists have employed testing methods in order to manipulate the organisation of educational, health and welfare services for children. By placing the concept of autism back into a wider history of psychology, I demonstrate how longer disciplinary and professional concerns, etiological hypotheses, psychological doctrines and socio-economic conditions have enabled the concept to take root 
and flourish. The Metamorphosis of Autism argues that it was a unique social, cultural and political climate in Britain in the 1960s and 1970s that sparked a radical transformation in the autism concept and which is critical to understanding today's neuroscientific research into autism, as well as today's global interest in autism as a phenomenon.

\section{Notes}

1 Murray, Representing Autism.

2 Baron-Cohen et al., 'Prevalence of autism-spectrum conditions'.

3 Eyal et al., The Autism Matrix; Eyal, 'For a sociology of expertise'.

4 Shattuck, 'Diagnostic substitution and changing autism prevalence'.

5 Rutter, 'Incidence of autism spectrum disorders'.

6 L. Wing, The Autistic Spectrum, pp. 20-21.

7 An excellent discussion of this controversy can be found in Murray, Autism.

8 Nadesan, Constructing Autism; Hacking, 'Autism fiction'; Murray, Representing Autism; Silverman, Understanding Autism; Silberman, Neurotribes.

9 E.g. Hollin, 'Constructing a social subject'; Verhoeff, 'What is this thing called autism?'; Feinstein, A History of Autism; Waltz, Autism. Singh, J Multiple Autisms.

10 Coleman and Gillberg, The Autisms.

11 Healy, The Anti-depressant Era; M. Smith, Hyperactive; Horwitz, Creating Mental Illness.

12 Forrester, 'If $\mathrm{p}$, then what? Thinking in cases'; Rose, Governing the Soul; Rose, Politics of Life Itself; Hacking, The Taming of Chance; Hacking, The Social Construction of What?; Miller and Rose, 'The Tavistock Programme'.

13 Rose, 'The death of the social?'.

14 Hayward, The Transformation of the Psyche; Hayward, 'Sadness in Camberwell'; Shapira, The War Inside.

15 E.g. Harris, The Health of the Schoolchild; Smith, Nutrition in Britain; Welshman, From Transmitted Deprivation to Social Exclusion; Hendrick, Child Welfare: England 1872-1989; Lewis, 'Anxieties about the family'; Thomson, Lost Freedom.

16 Hacking, The Taming of Chance.

17 Forrester, 'If $\mathrm{p}$, then what?'.

18 Ian Hacking did, in fact, later develop an interest in autism as a topic of enquiry, although he has focused on autism and narrative and has not addressed broader questions of autism sciences in relation to statistical 
and case sciences and the organisation of social, educational and medical services for children as I do in this book. See Hacking, 'Autism fiction'; Hacking, 'Autistic autobiography'; Hacking, 'How we have been learning to talk about autism'; Hacking, 'Humans, aliens \& autism'.

19 E.g. 'Three essays on the theory of sexuality', in Freud, Standard Edition, vol. VII.

20 Bleuler, Dementia Praecox or the Group of Schizophrenias, p. 63.

21 Rutter, 'Childhood schizophrenia reconsidered', p. 327.

22 Dwork, War Is Good for Babies and Other Young Children.

23 Marks, 'Medical care for pauper mothers and their infants'.

24 Hendrick, Child Welfare: England 1872-1989.

25 Sutherland and Sharp, Ability, Merit and Measurement; Wooldridge, Measuring the Mind.

26 Wright and Digby, eds, From Idiocy to Mental Deficiency; Thomson, The Problem of Mental Deficiency; M. Jackson, The Borderland of Imbecility.

27 Wright, Down's: The History of a Disability; Borsay, 'Disability and education in historical perspective'; Cole, Apart or a Part?; Ford et al., Special Education and Social Control.

28 E.g. Fink, 'Inside a hall of mirrors'.

29 Hacking, The Social Construction of What?

30 Steven J. Gould's classic text, The Mismeasure of Man, was perhaps the most widely quoted, well-known and controversial academic text on the subject. Gould used historical examples to demonstrate the prejudices behind intelligence testing.

31 Simon, Education and the Social Order; Wooldridge, Measuring the Mind; Sutherland and Sharp, Ability, Merit and Measurement.

32 Mackintosh, Cyril Burt; Joynson, The Burt Affair.

33 Vicedo, The Nature and Nurture of Love. Shapira, The War Inside.

34 Savage, Identities and Social Change in Britain since 1940.

35 Spencer, The Principles of Psychology; Young, Mind, Brain and Adaptation in the Nineteenth Century; Foucault, Folie et déraison. Rose, The psychological complex.

36 Miller and Rose, 'The Tavistock Programme'; Rose, Governing the Soul; Rose, The Psychological Complex.

37 Berrios, The History of Mental Symptoms.

38 Shorter, A History of Psychiatry.

39 Healy, The Anti-depressant Era; Hacking, Rewriting the Soul; A. Young, The Harmony of Illusions. 
40 Rose and Abi-Rached, Neuro; Casper, The Neurologists.

41 K.Jones, Taming the Troublesome Child; M. Smith, Hyperactive; Raz, What's Wrong with the Poor?.

42 E.g. Thom, 'Wishes, anxieties, play, and gestures'; Stewart, Child Guidance in Britain, 1918-1955; Levene, 'Family breakdown and the "welfare child".

43 E.g. Wooldridge, Measuring the Mind; Sutherland and Sharp, Ability, Merit and Measurement.

44 E.g. Cole, Apart or a Part?; Borsay, 'Disability and education in historical perspective.'

45 Van der Horst, John Bowlby; Riley, War in the Nursery.

46 Cameron, 'Past and present trends in child psychiatry'; Warren, 'You can never plan the future by the past'; Hersov, 'Child psychiatry in Britain'; Wardle, 'Twentieth-century influences'; Rutter et al., Research and Innovation on the Road to Modern Child Psychiatry; Neve and Turner, 'History of child and adolescent psychiatry'.

47 Hendrick, Child Welfare: England 1872-1989.

48 E.g. Lubetsky et al., Autism Spectrum Disorder, p. 30. 



\section{Part I \\ The first autism}

The observation and description of child development before 1959 



\section{1 \\ The first autism}

The first autism can only be understood in the context of the legal and institutional networks that enabled the spread of psychological theory as applied to infants and children in Britain in the early twentieth century. This chapter examines the integration of the concept of autism into psychological theory in Britain and the significance of the concept of autism in altering theories of social development in children. Early twentieth century evolutionary models of society generated a unique version of child development that was authenticated via social science, anthropology and political rhetoric. Theories of the 'social instinct' in infants and children developed alongside theories of intellectual development. Although this psychological model of child development was presented as comprehensive and harmonious, it was, in fact, glossing over a number of contentious and problematic issues concerning child rights. Wider child health and education legislation was seriously affecting the direction that any psychological research could take. The concept of 'mental deficiency' served as a convenient throwaway label for all infants and children who both psychologists and policy-makers thought were beyond help and not worthy of investigation. The effects of institutional care and the organisation of special schools affected the development of psychological theory by successfully excluding a large section of the total child population, and this influenced theories of social development, the social instinct and 'autism' in this period. In other words, those infants and children regarded as 'deficient' in thought were both physically and philosophically removed from the institution of child psychology in early-twentieth-century Britain. By the end of the 1930s, child psychological sciences, and the theory of autism, had achieved stability. However, this had only 
occurred in the context of major interventions in child rights that had taken place in the name of psychology.

The political landscape for the study of 'social development'

The first autism, prior to its metamorphosis in the 1960s, was an important organising concept within early theories of child development. The definition of this first autism was shaped by major political and legal developments that also created the settings for its dissemination. Prior to the late nineteenth century, the close observation of infants and children and the description of the way that they formed relationships with other people, and developed conceptual awareness of other people, held little scientific or political appeal. It was only after political reformers began to build the basic infrastructure for a framework of children's rights, and to implement a policy of compulsory education, that anyone became interested in the social development of children as a population group.

Late-nineteenth-century Britain witnessed a number of important legal and institutional changes to assist all children to achieve a basic level of shelter, food, clothing and protection against cruelty and violence from adults. These legal changes stemmed from a wider philanthropic movement to protect children from the demands of working life and to sequester them as a group that was particularly vulnerable to the vagaries of industrialisation and capitalist development. This was, in some ways, a development of Romantic ideals of childhood formed in the eighteenth century, but the late nineteenth century saw children's rights to unique legal protection established in both the law and in the theory of political economy. The creation of School Boards in England in 1870 to educate poor communities, and the introduction of compulsory education in 1880, formed the background to these changes by establishing comprehensive local authority networks to observe the total child population and to ensure that they were receiving some kind of education. The 1889 Prevention of Cruelty to, and Protection of, Children Act and the 1908 Children Act both encouraged a deeper monitoring and observation of family life and legislation for intervention by government agencies. These agencies included Children's Care Committees, Infant and Maternal Welfare Centres and Councils of 
Social Welfare. ${ }^{1}$ The early twentieth century also saw the passing of several Acts empowering local authorities to feed, clothe and medically inspect children under their jurisdiction. ${ }^{2}$ All these major legislative changes enabled local authorities and central government to provide services directly to children. They encouraged a more philanthropic approach to children generally, improved the home conditions of many, prevented many cases of cruelty and took away many aspects of parental rights to child ownership. This chapter explores how the establishment of this unprecedented legal and political climate for children in Britain encouraged the first applications of the concept of autism, and describes how it structured the meaning of autism in relation to children's rights to education and social welfare protections.

As more children came to the attention of government departments, it became evident that some children did not slot neatly into the national programme of industrial development and modernisation. ${ }^{3}$ The critical concept of psychological development, autism, was first employed to identify children who did not easily adopt their role within the new social networks that were being established in Britain at the time. Legislation limiting the availability of state education to groups considered 'ineducable' focused interest on identifying and sorting child types. Hence the early twentieth century witnessed a growth of research into the social and medical causes of what was then termed 'idiocy', 'feeble-mindedness' and 'mental deficiency' in children, as well as attempts to correlate it in statistical studies with undesirable behaviour such as criminality and delinquency. ${ }^{4}$ This was associated with a growing interest in eugenics, the political project of improving the quality of the human 'stock' or population through the implementation of scientific principles using the logic of social Darwinism.

Although descriptions of 'idiocy' can be traced back to the early modern period, ${ }^{6}$ it was the development of neurology in the early nineteenth century that encouraged further research into why this differed from 'insanity' or other afflictions of the mind. ${ }^{7}$ By the mid nineteenth century, medical specialists, such as John Langdon Down of the Earlswood Asylum, began to construct early taxonomies of 'idiocy' specifically in children, often drawing from racial and ethnic typologies, defining 'cretinism' and 'mongolism.' In 1868, Down set up a private establishment for the reception and training of 'imbeciles', which came to serve as a model for later homes. The creation of School Boards in 
1870 and the move towards compulsory education encouraged further classifications of children's mental states, and attempts were then made to create a complete science of mental pathology in childhood drawing from adult models. In 1874, John Thompson Dickson of Guy's Hospital wrote on 'infantile dementia', in which 'various deteriorations and defects in the nervous organisation' of the infant led to an arrest or regression in the development of the mind, yet how this differed from 'idiocy' was not clear. ' In 1886, the Idiots Act brought larger numbers of 'idiot' children into institutional care and further encouraged attempts to classify child psychological types and to study the medical causes of 'idiocy.' ${ }^{10}$ However, as German Berrios has demonstrated, it was only when quantitative methods were developed to measure intellect in the early twentieth century that more detailed descriptions of the distinction between mental defect and mental illness were made. ${ }^{11}$ As this happened, 'idiocy' was increasingly defined as a psychological concept and was integrated into a larger project to describe the early development of conceptual awareness in infants and children.

When the concept of autism was introduced in the early twentieth century, it was critical to early theories of child development that focused on social and emotional development as opposed to purely intellectual development. It was thus part of a major new movement in child psychology that was established in this period and which would become increasingly dominant. As Nikolas Rose has argued, by the early twentieth century, psychological sciences were becoming established as legitimate forms of knowledge via links with educational and social services. ${ }^{12}$ Evolutionary sciences in the middle of the nineteenth century had provided the foundations for the development of psychological sciences in Britain. Herbert Spencer's amalgamation of sensorymotor physiology, phrenology, philosophical associationism and evolutionary theory in The Principles of Psychology (1855) constitutes a significant moment in the history of this discipline. The late nineteenth and early twentieth centuries then saw the expansion of the psychological sciences in Britain, as well as across Europe and America. ${ }^{13}$ It was during this period that journals specific to psychology were established and psychological laboratories, institutes and departments were also founded. In England, James Sully, Professor of Mind and Logic at University College London (UCL), founded the first English laboratory for psychology in 1897. In the same year, W. H. R. Rivers began 
to teach experimental psychology at Cambridge University. The British Psychological Society was founded in 1901 under the leadership of Charles Myers and others. In 1904, the British Journal of Psychology was also established and was edited by Myers for the next twenty years. ${ }^{14}$ All of these developments ensured that psychological sciences were taken seriously as legitimate subjects of enquiry. This set the scene for the introduction of the concept of autism as a critical concept for thinking about child development.

Interest in 'social development' in infants and children emerged out of a wider concern with society at large as well as the development of the social sciences. Early-twentieth-century models of social development were created at a time when marked social hierarchies were assumed to be the norm, and an air of superiority prevailed amongst intellectuals who deemed themselves eligible to determine this hierarchy, often drawing from evolutionary sciences to do so. As Geoffrey Searle and others have argued, a British obsession with 'national efficiency' framed a number of arguments about the state of the British race and encouraged new statistical investigations into 'society' and its economic and racial hierarchies within the science of eugenics. ${ }^{15}$ At the same time, as William Wooldridge has pointed out, it led the bourgeoisie to develop a deep interest in inherited traits, sometimes as a means to challenge social divides and conventions. ${ }^{16}$ It is within this context that interest in social development in children emerged.

In 1908, William McDougall, an Oxford-based researcher with a part-time readership in psychology at UCL, published an Introduction to Social Psychology in which he argued that psychological theory should form 'the basis of all social sciences' and that this should be acknowledged and developed through the application of a 'hormic' model of behaviour based on a theory of instinctive drives in humans. McDougall sought to bind psychological and social sciences using this model, and his work was foundational for child psychological research in Britain. ${ }^{17}$ In fact, all child psychological sciences in Britain up until the 1960s were strongly directed by instinct theory, and descriptions of children's behaviour was regularly explained in terms of human instinct.

McDougall's early work described the social instinct as part of a general model of 'higher' and 'lower' instinctive drives, supporting a biased hierarchical model of society that was typical of the period. 'Civilised' man was compared to the 'savage' and 'stone age' man because he had 
learned to adapt his instincts through imitation of others and this had enabled social progress. McDougall understood this social progress as the gradual engagement of instinctive drives, by means of which individuals developed a capacity for higher social thought and action. $\mathrm{He}$ argued that energy could be transferred to different parts of the nervous system via a fluid called 'neurin' that was secreted in response to outside stimuli. Cortical synapses housed the seat of all psychophysical processes. Neurin could be canalised into particular channels, moving from places of high potential to places of low potential and eventually draining into the muscles where it produced a contraction. If, however, an individual had developed sophisticated 'synaptic resistance' to such processes, then the 'neurin' would not drain into lower channels but would instead remain available for intellectual processes. ${ }^{18}$

Although several child psychologists in the final years of the nineteenth century had described 'social' development in children, this was usually within the context of broad moral and political ideals and involved questioning children about their friendships and civic values. ${ }^{19}$ It was only following $\mathrm{McDougall}$ that psychologists began to study, observe and meticulously document the 'social' as it emerged in children from birth through the emergence of play activities and language. This was one aspect of what Nikolas Rose has described as a science of the 'social', which emerged in the mid nineteenth century, as an entity that could be mapped, tracked, quantified, analysed and studied using statistical methods and which achieved a naturalistic quality. ${ }^{20}$

The early twentieth century saw the establishment of statistical methodologies in the university system, and psychologists were keen to have their science recognised as being on a par with other sciences such as 'biometry', a field established by Francis Galton, president of the Anthropometric section of the British Association for the Advancement of Science, together with Karl Pearson and Walter Frank Weldon. When Galton died in 1911, Pearson took up a Galton Eugenics Professorship there with money bequeathed by Galton, and he turned the department into the focus of English statistics, drawing researchers from across Europe and the USA. Taking a strong hereditarian position, Pearson was convinced that abilities were inherited and maintained that social stratification was merely a by-product of natural capacities. The topic of social mobility was extremely contentious and many statisticians and social surveyors sought to offer scientific arguments one way 
or another. In 1906, David Heron, one of Pearson's students, argued that the lower classes were reproducing at a phenomenal rate, leading to a deterioration of the race, a familiar cry amongst eugenicists. The study was part of a series of seminars on the biology of social stratification that aimed to develop the theory of eugenics. ${ }^{21}$ It is within this context that psychological sciences to assess and measure children were developing, and it is perhaps unsurprising therefore that they developed in a restricted and inflexible manner.

At a broad political and moral level, the period saw reformers such as Charles Booth and Seebohm Rowntree use the new technique of 'social surveys' in order to analyse the relationship between 'inefficient' unfit populations and economic adversity, using evolutionary theory to argue for social reforms that would both curb the unfit and boost the economy. ${ }^{22}$ It was the statistical analysis of populations that enabled the first discussions between politicians, social reformers, medical men and pioneers of the statistical method such as Galton and Pearson on how to manage society as a population group..$^{23}$ Prior to the statistical mapping of problems such as illness, crime and pauperism, there was no scientific enquiry into the 'social'. Darwinian analyses of the population as an organic entity helped to naturalise this conception of the social order and to legitimate the social sciences as genuine scientific methods. ${ }^{24}$ William McDougall's concept of the 'social instinct' was an overt attempt to fuse these levels of understanding and to argue for a psychological model of social development that could be utilised by social scientists. As he put it: 'Among students of the social sciences there has always been a certain number who have recognised the fact that some knowledge of the human mind and of its modes of operation is an essential part of their equipment.' He went on to argue that many eminent contemporary social scientists, such as Emil Durkheim, refused to accept the centrality of psychology but argued that his work would encourage all to take account of its importance. ${ }^{25}$

McDougall first encouraged his students to develop mass methods to measure children's psychological capacities, after Galton, organised a wholesale survey of the British population in $1903 .^{26}$ Cyril Burt, then one of McDougall's students, translated and adapted intelligence tests developed by Alfred Binet of the Laboratory of Physiological Psychology at the Sorbonne, France, and his colleague Théodore Simon, adapting them so that they could be applied across 
large school populations in Britain. ${ }^{27}$ This first series of intelligence tests attempted to measure vocabulary, spatial perception, memory, reasoning and judgement in individuals. They were used primarily as a means to accurately identify 'mentally defective' individuals, but they came to adopt a new dimension within the expanding education system as a method of segregating and streaming the child population according to intelligence levels.

When studies of early psychological development began in Britain, they adopted a wider model of instinct theory and evolutionary sciences to justify their models of social development. Studies of infant and child development presented their theories of 'the social' as if it were wholly removed from the wider political, economic and social Darwinian concerns and aspirations that were so prevalent in earlytwentieth-century Britain. Child psychologists then began to create a highly idealised, stereotyped and somewhat clichéd version of what constituted 'social' relationships. Nevertheless, the hierarchical 'social' model on which this was based still guided the model. Psychological testing methods would increasingly be integrated into governmental and legal measures to control, organise and manage the population in the twentieth century via the education and social welfare systems. ${ }^{28}$ This was increasingly the case as Cyril Burt's influence grew following his appointment as a government official; given his other work as scientific researcher and adviser, teacher trainer and popular journalist, his influence thus spread far beyond administrative and academic circles. $^{29}$

Nevertheless, these early studies of intellectual and social development constructed by McDougall and Burt were limited by the fact that, despite their feigned abstraction, they were clearly tied in with rather restricted and presumptuous models of intellectual development, superiority and social development. Child psychology was being investigated under the blunt assumption that children's thought was merely an undeveloped form of adult thought. Although children's 'social' development was being integrated into the theory of instincts in an original way, and the discipline of child psychology was developing apace, the tools and means to understand how 'lower' instincts fed into 'higher' intellectual abilities, via social interactions and engagements, left a lot to be desired. This 
would only change after the introduction of the first autism into the theory of child psychology.

\section{Autism: the original}

The introduction of the specific term 'autism' into the language of Britain child psychological professionals occurred primarily via the work of Jean Piaget, a Swiss psychologist who had studied philosophy and psychology at the University of Zurich. The spread and uptake of the concept in Britain also occurred in an indirect way via the promotion and development of the work of Sigmund Freud by those interested in child development, such as Melanie Klein, Margaret Lowenfeld and Susan Isaacs. Many inaccurately attribute the origins of the concept to the American child psychiatrist Leo Kanner in 1943; however, autism had, in fact, been fundamental to shaping all theories and understanding of children's psychological development from the early decades of the twentieth century. The networks through which Piaget's model of autism first entered the country are important because it was in Britain, and even more specifically in London, that the most influential research on autism would be conducted from the 1960s.

Piaget had begun his training at the University of Zurich in 1918 where he attended many lectures by the psychiatrist Eugen Bleuler, who directed the Burghölzi, the psychiatric hospital attached to the university. Shortly after his training, Piaget was invited by Theodore Simon to standardise Cyril Burt's intelligence tests for schoolchildren in Paris. It was after this that Piaget began to focus on the development of children's reasoning abilities and established himself as an important thinker in the theory of child psychology. ${ }^{30}$ It was at the University of Zurich that Piaget was introduced to the concept of autism via Bleuler. As discussed in the Introduction, Bleuler had coined the concept of autism in 1911 to describe a symptom of the most severe cases of schizophrenia, a concept that he had also created. Bleuler argued that autistic thinking was characterised by infantile wishes to avoid unsatisfying realities and replace them with fantasies and hallucinations. 'Autism' defined the subject's symbolic inner life and was not readily accessible to observers. ${ }^{31}$ 
When Bleuler coined the term 'autism' in 1911, he attributed its etymology to Freud, and ultimately Havelock Ellis, through the term 'autoerotism'. ${ }^{32}$ Freud had used this word in 1905 to describe hallucinatory thinking in conjunction with self-soothing in a stage of thinking that preceded the infant's engagement with external reality. ${ }^{33} \mathrm{He}$ also used the concept to assist his explanation of the trajectory of the sexual instinct both ontogenetically, within the individual, and phylogenetically, with regard to the evolution of the human species. ${ }^{34}$ Bleuler also argued that the concept of autism was a refinement of what the French alienist Pierre Janet called perte de la fonction du réel (loss of the sense of reality). In 1903, Janet had explained the function of reality as a synthesis of all psychological functions ranging from automatic functions at the level of the nervous system up to complex thoughts and actions. If the nervous system was weak, psychological tension would drop and an individual would lose the ability to synthesise these complex functions and also lose the sense of reality. ${ }^{35}$ They would then revert to a form of thinking that preceded the individual's ability to conceptualise their sense of self.

Although Bleuler's description of schizophrenia covered more than just autism, and included disturbances of attention, the will and the intellect, the concept was crucial to his description of the schizophrenic's lack of contact with reality. According to Bleuler, when schizophrenics tried to conduct logical operations in thought, they were unable to draw upon all appropriate associations in the mind, thus leading to an unsatisfactory sense of reality. They therefore substituted this unsatisfactory reality with fantasies that more readily satisfied their affective needs. By blocking off the perceptive-sensory stimulations of the outside world, autistic thinking then came to obey its own special laws, which were no longer bound by the rules of logic. ${ }^{36}$ It was thinking that took place in symbols, in analogies, in fragmentary concepts, in accidental connections', and it was the source of both delusion and 'crude offenses against logic and propriety. ${ }^{\prime 3}$ Although autism was considered pathological within schizophrenia, Bleuler always regarded it as merely 'an exaggeration of a physiological phenomenon' that was present in all humans, and which manifested itself in normal fantasies and wishes. ${ }^{38}$ Bleuler argued that the sense of reality was lost in schizophrenics only in relation to matters that threatened to contradict their complexes, a concept that had originally been developed by Jung, who had claimed 
that it was analogous to what Janet called idée fixe subconsciente (fixed subconscious ideas). ${ }^{39}$

Although it described an early stage of infantile thought, the concept of autism was also critical to the developing field of descriptive psychopathology in adults. As German Berrios has argued, the most important mental symptom to be ascertained and diagnosed as part of adult descriptive psychopathology was hallucination. ${ }^{40}$ Both Freud and Bleuler sought to locate the origins of adult hallucinations and delusions in infantile thought that later influenced the adult unconscious mind. The concept of autism was critical in Bleuler's description of this process. After Bleuler had developed his own concept of autism to describe schizophrenic thought patterns, Freud went on to challenge Bleuler's description of autism by expanding psychoanalytic concepts to describe different types of early infantile thinking, thereby developing the concept of primary narcissism. Freud himself acknowledged that the concept of 'primary narcissism' was developed as a direct response to Bleuler's work on schizophrenia and autism. As he put it, 'A pressing motive for occupying ourselves with the conception of a primary and normal narcissism arose when the attempt was made to subsume what we know of dementia praecox (Kraepelin) or schizophrenia (Bleuler) under the hypothesis of the libido theory. ${ }^{41}$ Corresponding with Jung in 1908, Freud pointed out that he had had protracted discussions with Bleuler about his theories of infantile hallucination and what language should be used to describe the early stages of infantile thinking. Whereas Freud was intent on making sure that early infantile thought was conceptualised in relation to the libido and drive theory of instinct, Bleuler preferred to discuss early infantile thinking as simply not yet in contact with reality, and he was already using the term 'autism' to try to convince Freud to do the same. ${ }^{42}$ Nevertheless, they were both describing a similar thing, namely early infantile thought and its relationship to pathological thinking processes in schizophrenia. Bleuler, Freud and Janet's interest in the symptoms of autism and autoerotism in adults was shared by many other French alienists who had referred to aspects of autism as 'autophilia, egocentricity, ego-hypertrophy, and augmentation $d u$ sens de la personnalitié. ${ }^{43}$ Some French writers, such as Henri Claude of the Hôpital Sainte-Anne in Paris, criticised Bleuler's direct association between autistic thought and the loss of the sense of reality. ${ }^{44}$ However, child psychology researchers, such as Piaget and Isaacs, followed Freud 
and Bleuler in linking autistic or 'autoerotic' thought with hallucinatory thinking and an inability to conceptualise the external world. ${ }^{45}$ In the 1920 s, many professionals working with children began to use the concept of hallucination readily in the description of children's thought.

In 1922, Piaget gave a paper at the International Conference on Psychoanalysis in Berlin, entitled 'La pensée symbolique et la pensée de l'enfant' (symbolic thought and children's thought), where he put forward his theories on the way that infants and children developed a relationship to reality via their everyday interactions with people and objects. ${ }^{46}$ Drawing from the towering figures in descriptive psychopathology at the time - Eugen Bleuler and Sigmund Freud - he claimed that the pre-verbal stages of children's thought could be described as 'autistic' or 'symbolic'. During this stage of thinking, children could not follow logical rules and did not think conceptually, and there was a predominance of visual imagery in their minds. ${ }^{47}$ These thought processes subsided as the infant became more aware of the concrete objects and reality surrounding him or her. Piaget drew direct analogies between infantile thinking and unconscious symbolism as described in psychoanalytic theory ${ }^{48} \mathrm{He}$ claimed that 'autistic' and 'symbolic' thought were both characterised by three distinctive features, namely, 'absence de suite logique, predominance de l'image sur le concept, et inconscience des connexions qui relient les images successive entre elles' (an absence of logic, a predominance of visual imagery over conceptual thought and no awareness of the connections that can be made between visual perceptions). ${ }^{49}$ By demonstrating the relationship between the Freudian unconscious and Bleuler's concept of autism, Piaget linked the concept of autism directly to the child's progressive attempts to engage with reality. ${ }^{50} \mathrm{He}$ suggested that these attempts to engage with reality could be investigated using psychological tests that measured children's perception and self-awareness. Piaget was strongly influenced by Henri Bergson's metaphysics, in particular Bergson's Creative Evolution, which claimed that the theory of knowledge and the theory of life were inseparable. In 1929, he reported the results of tests in which he had questioned children on their beliefs about the physical world and argued that their thought developed from primitive magical imagination through to logical reasoning. ${ }^{51}$ Drawing attention to work by Freud on mental economy, he argued that when adults thought symbolically, they 'condensed' 
concepts and 'displaced' one image or concept onto another because they experienced a reversion to primary autistic thinking in which no distinction was made between the various external stimuli that bombarded the infant in his daily life. ${ }^{52}$

Unlike McDougall and Burt's theories of social development in children, Bleuler, Freud and Piaget's work offered a new model for describing early infantile thought that did not just present it as an unsophisticated, lower or more primitive version of adult thinking. These ideas employed instinct theory in a way that considered early thought as a vital, significant and creative force that remained significant into adult life. Furthermore, it tied the theory of child psychological development into a theory of self-awareness or ego development. Although Freud and Bleuler's readiness to match pathological thought in adults with normal infantile thought may appear strange, it was, of course, part of a bold new project to think of the origins of mental illness and to frame this in relation to a model of the unconscious understood through the logic of instinctive drives.

\section{The adoption of the first autism in Britain}

When child psychologists in Britain began to integrate theories of autism and Autoerotism into their models of an infant's ability to conceptualise the external world, they did so in the context of major anxieties about the subject of social development. As many historians have argued, the aftermath of the Boer War had drawn attention to the supposed 'deterioration' of the British race as well as the instabilities of the British Empire. ${ }^{53}$ This also sparked anxiety about the best way to manage supposedly undesirable aspects of society, in particular how to manage people who had low intelligence, an entity that could now be neatly measured using psychological tests. In 1908, the Royal Commission on the Care and Control of the Feeble-Minded produced a report arguing that 'mental defect' was primarily an inherited condition that would not respond to environmental improvements and should therefore be controlled through legislation that enforced certification and custodial care. The Board of Education strongly opposed the legislation and argued instead that the special school system should be expanded under a newly developed School Medical Service. ${ }^{54}$ However, both 
the Majority and Minority Reports of the Royal Commission on the Poor Law in 1909 supported the proposed legislation, and after lobbying by the Eugenics Society, they finally became law in 1913 under the first Mental Deficiency Act. ${ }^{55}$ This was the same year that Burt was appointed as the Official Psychologist to the London County Council (LCC) and tasked largely with identifying defectives so they could be referred to the Board of Control.

The Mental Deficiency Act thrust Burt and other early child psychologists in Britain into a major government programme of assessment and intervention as part of a national programme of certification and control. This was not made easier by the fact that the legal definition of 'mental defect' was far from clear, and major contradictions existed in the legislation. Section 1 (b) of the Mental Deficiency Act 1913 had defined 'imbecile', 'feeble-minded', 'idiots' and 'moral defectives' as incapable of learning in different ways and thus deemed them the responsibility of the Board of Control. However, Sections 2 and 21 of the Act had made the local education authority responsible for all children capable of benefiting from instruction in 'special schools', a term left undefined in the legislation. It was clear that these definitions were not mutually exclusive and led to much jostling between authorities that often used psychological definitions to their own economic advantage. ${ }^{56}$

In 1913, the President of the Board of Education, J. A. Pease, stated that 48,000 British schoolchildren required special care and education externally to the general schooling system, but that only one-third of them would be classifiable under the Mental Deficiency Act. ${ }^{57}$ The Elementary Education (Defective and Epileptic Children) Act 1914 compelled local education authorities to provide special education for 'defective' children, attempting to allay concerns from the Board of Education over the educational rights of 'defective' children. This Act did not cover the whole of the UK, in particular Scotland, where 'defective; children were the responsibility of the parish councils, and, in practice, different local authorities provided different levels of service across the UK. ${ }^{58}$ to enforce the schooling of some children, even if some psychological professionals considered them to be 'educable', and some local authorities thus pushed for certification. By 1915 there were 14,626 'defective' children in residential institutions for defectives or special schools in England and Wales, and by 1927 there were 17,337. ${ }^{59}$ 
The First World War and the following economic depression, however, heightened the problem of provision. There were simply not enough funds to educate some children who may in fact have been classed as 'educable'. In 1923-24 the estimated expenditure on special schools was $£ 1,260,383$, whereas the estimated required budget was over $£ 4,000,000 \cdot{ }^{60}$ Little additional funding was found during the 1920 s, and a further economic crisis of 1927 only exacerbated the situation. Even if attending 'special schools', 'defective' children were often removed from their families, who knew little about what they were being taught. In any case, the problem of the growing exclusion of 'ineducable' children in the interests of an exclusionary model of social organisation would fundamentally shape and define theories of child development, socialisation and intelligence over the following decades.

Although the Mental Deficiency Act provided an impromptu boon for psychological sciences, it simultaneously excluded, segregated and isolated a large section of the child population who would otherwise have had the opportunity to be integrated into psychological studies. Hence, although the Mental Deficiency Act stimulated a flood of studies aimed at measuring the psychological capacities of the total child population and their abnormalities or discrepancies, it also led to a fundamental lack of interest in child 'mental defectives' after they had been classified and institutionalised. Burt became obsessed with classifying the difference between children who were simply 'backward' and those who 'defective,, ${ }^{61}$ constantly seeking 'statistical evidence for the existence of a distinct species of pathological "defectives," unobtainable by normal variation. ${ }^{62} \mathrm{He}$ also became very interested in supporting a hereditary theory of general intelligence, as many have pointed out. ${ }^{63}$ This unprecedented attempt to employ psychological sciences in the service of government and local authority administration focused government psychologists on tests for 'educability'. The branch of child psychology that focused on intelligence testing quickly formed its own niche market in relation to the schooling and mental deficiency sectors. What this meant in practice was that statistical psychology was tied to a particular model of government service and, ultimately, social exclusion. Perhaps unsurprisingly, this left little time for governmentemployed psychologists to pontificate on the finer details of an infant's development of self-identity and its relation to unconscious life and creativity. 
Because most psychologists employed by the government were focused on intelligence testing based around a uniquely politicised model of social exclusion and progression, this left little room to think critically about how social development in infants could be abstracted from these ideologies. Statistical psychologists such as Burt were blinkered by their fixation with intelligence as a pure measure of mental ability, and models of 'social development' within this did not move far beyond McDougall's idealised characterisation of 'higher' and 'lower' channels for instinct and their potential to affect the mind. What this meant was that the integration of European studies of autism, autoerotism and primary narcissism into theories of child development fell more squarely on the shoulders of a new professional group of childcare workers who were assigned to deal more specifically with issues of child welfare. Many of these early psychologists, such as Susan Isaacs and Melanie Klein, were also those who were much more likely to think in terms of individual cases and individual children, rather than statistical methodologies.

Whereas the Boer War had focused attention on the problem of 'degeneration', the First World War, and the devastating experiences of trench warfare, led many to focus to the fragility of life. ${ }^{64}$ Moves that had been made during the late nineteenth and early twentieth centuries to protect child life and to provide children with basic provisions and shelter were reinforced following the war, even though at the same time the provision for 'special schools' to educate 'backward' children was failing to meet demand. This discrepancy was the result of an overvalued notion of 'normal' childhood and an incredibly undervalued and exclusionary view of any children who were not classed as such. It was also down to further external funding from North American philanthropic organisations such as the Rockefeller Foundation and the Commonwealth Fund, which provided additional funds to cater for the basic needs of the majority population of children rather than minority groups. For example, measures to support the lives of children led to an increase in the number of maternity, child and welfare centres in England, from 650 in 1914 to 1,278 in $1918 .{ }^{65}$ By 1935 , there were 3,113 centres and 1,417 ante-natal clinics. ${ }^{66}$ These clinics focused their attention on measuring means, norms and averages within childhood development stages and intervening to support those norms. 
One important development with regard to the uptake of the autism concept was the establishment of clinics in Britain specifically catering for those with psychological illness. The 1920s saw the establishment of two of the most important institutions involved in the propagation of new forms of psychological therapy in Britain, again stimulated by the war due to the growing problem of 'shell shock' in soldiers. The Tavistock Clinic, established in 1920, and the Maudsley Hospital, established in 1923, set the scene for the in-depth study and analysis of severe forms of mental illness in civilian populations. ${ }^{67}$ The theoretical orientation of the Tavistock Clinic was aligned with the theories and principles of dynamic psychology, broadly defined, seeking to develop and promote the work of Sigmund Freud. ${ }^{68}$ The broader ethos of the clinic sought to teach psychological methods and methodologies to a wider public, as emphasised in the director Hugh Crichton Miller's publication, The New Psychology and the Parent (1922). As Nikolas Rose has argued, the Tavistock constituted a vital force that impelled the uptake of psychological theories and self-governance in Britain. The Maudsley Hospital was more interested in developing a unique speciality of psychiatric medicine, yet it also had wider social goals. ${ }^{69}$

Both the Tavistock and the Maudsley Hospital sought to distance themselves from older forms of asylum care for adults and to develop new treatments for adults. Nevertheless, the clinics were soon inundated with child referrals. By 1935, the Maudsley was treating around 839 child cases per year, almost ten times its initial 1924 caseload. $^{70}$ In 1938, the Tavistock clinic was receiving around 341 new child cases per year. The referral of children to mental health institutions increased dramatically after the Local Government Act 1929 transferred responsibility for the care of around 90,000 children in poverty from Poor Law authorities to education and health departments. These children had to be re-categorised and new justifications had to be given for administering to their needs. In the late 1920s, the Commonwealth Fund began to provide funds for the purpose of improving 'child guidance' services in Britain, in which physicians, psychologists and social workers teamed up to assist the development of 'difficult' and 'troublesome' children. ${ }^{71}$ By 1938 , there were over sixty child guidance clinics in Britain. ${ }^{72}$ The London-based Child Guidance Council always remained adamant that mental deficiency should not be included as part of their remit of treatment and that 'mental defectives' should be dealt with via other 
channels. There was some opposition from one member, Evelyn Fox, a pioneer in the formation of the Central Association for the Mentally Defective, which later became the National Association of Mental Health. However, Fox's opposition was overturned and she was later effectively removed from the council. ${ }^{73}$ The omission or removal of 'defective' children from child guidance clinics, and from all clinics interested in child mental health, continued up until the end of the 1950s and provides an important context for the way in which theories of autism were integrated into British psychology.

When the theories of autism, autoerotism, ego development and primary narcissism entered the field of child psychology, they did not do so via institutions dealing with mental deficiency and backwardness. Instead, they entered via the new clinics and mental health institutions that were concerned with developing new concepts of psychopathology and breaking away from traditional notions of mental illness. These aims also differed significantly from those of psychological professionals based within the mainstream education system, and a very real and important divide would form between these two fields of practice. Many psychologists who worked in the medical sector were members of the British Psychoanalytical Society, established by Ernest Jones in London in 1913. Many of its members went on to develop psychological sciences in relation to children. For example, Melanie Klein, a Viennese émigré and child analyst who had joined the society in 1926, was extremely influential in the development of child psychotherapy in Britain. ${ }^{74}$ Susan Isaacs, a philosophy graduate from Manchester who became an associate member of the society in 1921, was also highly influential in developing the ideas and principles of dynamic psychology in children through observation and description. She later became head of the Department for Child Development at the Institute of Education and hugely influential on British childcare policy. ${ }^{75}$ Donald Winnicott took up a post in paediatrics at Paddington Green Hospital in 1923 and at the same time began to develop links with the British Psychoanalytical Society. Paddington Green thus became another important staging ground for the development of dynamic psychology and theories of the formation of self-identity and social awareness in children. ${ }^{76}$ Another important thinker in developing this perspective was Margaret Lowenfeld, paediatrician and founder of the first Children's Clinic for the Treatment and Study of Nervous and Difficult Children 
in 1928, which later became the Institute of Child Psychology. These people ensured that psychological theories of social development in children were developed thoroughly in Britain, in particular in London. One important point to mention here, especially given the overall low employment for women throughout the 1920s (less than 30 per cent of the total workforce and predominantly unmarried), ${ }^{77}$ is the fact that most of them were professional women seeking to develop new fields of professional activity and new domains of knowledge in which to thrive. Child psychology was one important area in which they could do so.

The parallels between the thought of adults with mental illness and the thought of normal infants, drawn so starkly by Bleuler and Freud, found their best reception amongst professionals working with children in institutions that also catered for adults, such as the Maudsley and the Tavistock. This is perhaps unsurprising, given the institutional context that also housed adults with mental illness. However, they also found an outlet in child guidance clinics and in institutions that bucked general trends in state education and worked for 'progressive' or 'permissive' educational settings, such as Alexander Sutherland Neill's Summerhill School, founded in 1921, and Susan Isaacs' Malting House School, founded in 1924, which shunned traditional practices of education and encouraged young children to learn through curiosity and creativity. ${ }^{78}$ These were very specific institutional contexts that shied away from the general trend that perceived and applied child psychology as merely a tool for measuring intelligence. Even more importantly, these were institutions where the children who attended were not regarded as extremely atypical according to the intelligence scales then available. Children who had received a classification of 'mental deficiency' were nowhere to be seen within these institutions. Such children would have been rapidly transferred to either the Board of Control or a 'Special School', if they were lucky, and would not have had recourse to institutions or facilities like the Tavistock, the Maudsley, child guidance clinics or permissive schools.

Thus, when critical concepts to conceptualise early social development in children were integrated into British psychology, they were integrated only into institutional contexts that were unique in that they both harboured a liberal, advanced and progressive view towards the treatment of childhood mental illness, yet simultaneously excluded a major section of the child population who were arguably most in need 
of understanding, care and treatment. This strange situation, the result of major anxieties and fears about deterioration and child protection in the context of the Boer War and the First World War, meant that theories of social development in children developed in a very bizarre way during the interwar period.

The introduction of the autism concept into the theory of child psychology occurred at the same time as the introduction of Bleuler's term 'schizophrenia', along with Freud's theories of hallucination and fantasy in early thought and its role in adult mental illness. It was not possible to draw clear distinctions between these concepts in early theories of child psychology, as we shall see. All of these concepts were used to describe children who were thought not to be engaged with reality due to their hallucinatory thinking, rather than their lack of intelligence. When such theories started to be touted, the concept of 'psychosis' was also sometimes employed to describe the same thing, psychosis being an older term introduced in the mid nineteenth century as an alternative to 'insanity' by the Austrian doctor Ernst von Feuchtersleben. ${ }^{79}$ By the 1920 s, with the expansion of child psychological sciences to mental health and child guidance institutions, 'psychosis' came to be used synonymously with 'autism' and 'schizophrenia' by child psychologists to designate early infantile thought presumed to be infused with hallucinations and symbolism. Piaget appropriated the concept of autism to enable a detailed description of infantile thought that moved beyond the concepts of intelligence. In fact, in The Language and Thought of the Child (1923), he developed a new concept of 'ego-centric' thought, which he claimed bridged the gap between the autistic thinking of early infancy and the intelligent thought of later childhood. ${ }^{80}$ At the same time, because Freud's work was developing the descriptive capacity to detail early infant thought experiences, the autism concept was becoming particularly popular amongst the burgeoning group of professional child psychologists, psychoanalysts and psychiatrists who were aiming to develop their profession, as well as promote the significance of their work. In other words, autism was a fundamental concept for psychological professionals interested in developing theories of child development that paralleled, but were distinct from, intellectual development.

In Britain, child psychological professionals introduced these theories in the 1920s and 1930s. Many English psychologists were familiar 
with Piaget's The Language and Thought of the Child, which elaborated his theories of autistic thinking. ${ }^{81}$ Isaacs had similar interests concerning the formation of children's thought processes, but there was one significant area where Isaacs and Piaget differed. In Judgement and Reasoning in the Child (1928), Piaget had argued that children's behaviour was only fully social from the age of eight when they emerged from their primarily 'egocentric' interests and began to take the perspective of other individuals. ${ }^{82}$ However, Isaacs and her contemporaries, such as Melanie Klein and Margaret Lowenfeld, saw the origins of social relations even in newborn infants. As far as they were concerned, there was no age too young for children to start to experience emotions concerning relationships with others that were the kernels of true social feelings and interactions. The actions, expressions and feelings of infants were described in immense detail and work was then used to form the basis of new theories on the significance of these early stages to later social abilities. In particular, they were also all fascinated by the play of children and its role in enabling those children to become social beings. It was in this way that psychological professionals in Britain began to develop a unique language to describe the thoughts of infants regarding their relations to other people, which became particularly formidable in the work of Klein and Isaacs. These theorists united ideas of hallucination and lack of contact with reality with theories about the early development of human relationships. The link between these ideas would fundamentally shape the first concept of autism as it developed in the English language. Hallucinatory thoughts about other people were regarded as the origins of unconscious thought prior to its repression during the processes of socialisation. Just as Isaacs took issue with Piaget's claim that social behaviour began at the age of eight, Klein took issue with Freud's idea that the 'Oedipus complex' occurred at the age of three when a child became aware of external moral and social restrictions to his instinctive and egotistical desires in the form of the superego. Klein argued that children had a social awareness from an earlier age. At first, she claimed this was in the second year of life, but she later claimed it came even earlier, at birth. ${ }^{83}$

The primary place in which early child dynamic psychologists looked to discover the link between hallucination and social thought in the 1920s was in children's play. Klein would describe the hallucinations associated with relationships as 'phantasies', taken from the English 
translation of Freud. ${ }^{84}$ She described the importance of play observation to the British Psychological Society in 1927:

When from our psycho-analytic point of view we watch the child at play and use special technical measures to diminish its inhibition, we can bring out these phantasies and theories, find out the experiences the child has had, and see all the child's impulses and its reacting criticizing faculties both at work ... Tiny dolls, men, women, animals, cars, trains and so on, enable the child to represent various persons, mother, father, brothers and sisters, and by means of the toys to act all its most repressed unconscious material. ${ }^{85}$

Klein, Lowenfeld and Isaacs assumed that all of the play engaged in by a child was associated with phantasies about relationships, and argued that these phantasies stemmed from early infancy when that child was in a state of thought characterised by free, unbound and unsocialised instincts towards other people or other objects. The Kleinian version of this very early stage of thinking was characterised by conflict and aggression. Building on Freud's discussions with Bleuler on autism, Klein claimed that an infant's relations to all other people and other objects was purely 'narcissistic', yet, unlike Freud, she argued that it was still during these early narcissistic stages of thinking that the infant also began to establish a relation to reality. She argued that they became aware of reality through their feelings of absence or lack of pleasuregiving objects. As she described it, 'children become acquainted with reality via the deprivations which it imposes on them. ${ }^{86}$ She frequently came to describe this in relation to the infant's early feelings and thoughts about the mother's breast.

In 1929, Klein published a paper on personification in the play of children in which she argued that if instinctual wish-fulfilment dominated over a child's recognition of reality, then the child could be described as experiencing a type of 'psychosis' where phantasies and wishfulfilment dominated over reality. ${ }^{87}$ She thereby developed Bleuler and Freud's theories that fused early infantile and schizophrenic thinking processes. However, Klein did this by claiming that that kind of early thought was already characterised by very complex relationships to objects and other people, rather than being completely un-relational, as in Bleuler's autism and Freud's primary narcissism. In 1930, she argued that schizophrenia and psychosis should be diagnosed more often in 
children, as this would help child psychologists to understand infantile thought and its extreme pathologies. ${ }^{88}$

Klein argued that child psychiatrists often misdiagnosed schizophrenia and psychosis as 'arrested development', 'mental deficiency', 'psychopathic condition' or 'asocial tendency.' ${ }^{89}$ For her, psychoanalytic descriptions of narcissistic and autoerotic thought provided the key to explaining the mental state of psychosis, and she argued that 'fully developed schizophrenia' and 'schizophrenic traits' were far more common in childhood than was previously supposed. Her reasoning was based on her treatment of several cases in which she had observed children with extreme versions of what were otherwise common traits in infancy and childhood, namely 'marked severance from reality, a lack of emotional rapport, an incapacity to concentrate on any occupation, silly behaviour and talking nonsense', as well as an 'excess of activity and stereotyped movements' and 'automatic obedience. ${ }^{90}$

In her early work, Klein tended to use the terms 'schizophrenia', 'psychosis' and 'dementia praecox' interchangeably. Employing her own scaled-down version of Freudian theory, Klein thought that schizophrenia in children was caused by excessive sadistic phantasies during the phase of primary narcissism that meant that the infant was unable to establish a 'right relation to reality'. As she understood it, the ego created an 'exaggerated and premature defence' against this early sadism, meaning that any further exploration of the mother's body and the external world were brought to a standstill. This led to a 'suspension of the symbolic relation to things and to reality. ${ }^{91}$ For Klein, failure in the development of phantasy relations could explain why infants and children later failed to establish relations to objects and to people in the real world, which also explained failures in the development of language. Klein also argued that, in schizophrenia, 'the capacity for personification and for transference fails'; in other words, the child found it hard to develop relationships because s/he had not developed a satisfactory relationship to the primary object of the mother. ${ }^{92}$ However, for Klein, this mother was a phantastical object, and ultimately a theoretical device, used to describe psychological development in infancy. The mother herself, and her actions, were irrelevant to the discussion. The mother was important only because she was the first object of the infant's phantasies. 
Klein's understanding of both normal and schizophrenic thought in infancy was popularised by Susan Isaacs and many other psychologists in Britain. In 1933, Isaacs claimed that childhood schizophrenia was an extreme version of the 'flight to phantasy' that followed the infant's anxiety over its early 'aggressive impulses', causing the child to 'withdraw from contact with real people and real situations. ${ }^{93}$ This description of childhood schizophrenia was formed from a fusion of British instinct theory, psychoanalytic theory, observations on the play of typical children and observations of child psychoanalytic patients. Klein was absolutely clear on the significance of phantasy to the construction of reality. As she put it, 'for all children in the beginning external reality is simply a mirror of the child's own instinctual life. ${ }^{94}$ It was out of this early 'primitive' reality that psychotic thinking processes were created. Klein sought to understand psychotic thinking processes because her aim was to treat them with psychotherapy, employing play techniques, discussion and suggestion. In 1931, Klein argued that the sadism of early infancy could also lead to 'intellectual inhibition' in children. ${ }^{95}$ Isaacs later expanded on this in her theories of anxiety in the first year of life. ${ }^{96}$

Many analysts working in Britain adopted a similar approach to the centrality of infancy in the development of psychotic thought processes, although they did not adopt Klein's theories wholesale. In 1932, Edward Glover argued that a psychoanalytic 'functional approach' to the classification of mental disorders was very productive. He claimed that schizophrenia was characterised by 'deep and extensive regressive features' to early stages of infancy and that these could be explained by interrogating the infants' early libidinal relationship to the external world ${ }^{97}$ Susan Isaacs, Margaret Lowenfeld and many other psychological professionals in the 1920s and 1930s supported Klein's ideas about the importance of describing hallucinations and fantasies about the mother and other 'objects' within infantile thought. The term 'objects' was coming to be used to describe any conceptual object that the child related to, including people, or parts of people, such as the mother's breast. Many also adopted Piaget's theories on child development to create a new model for understanding and describing the origins of social development and social awareness in children.

Child psychologists, psychoanalysts and psychiatrists in Britain employed the concepts of autism and primary narcissism to describe early infantile hallucinatory thinking. From the 1920s up until the 
1950s, they developed a unique perspective on this early stage of infantile thought that they regarded as infused with phantasies about people and 'objects', a perspective that would develop into the 'object relations' school of British psychoanalysis. In fact, English child psychologists in Britain became dominant in the field for their descriptions of the hallucinatory and fantastical thoughts of infants and children, and their relation to early relationships and social thinking, as observed through their play activities. This meant that they developed a unique perspective on child development during this period.

\section{Intelligence and social development}

The development of intelligence tests by Binet, Simon, Burt and Piaget in the early twentieth century was accompanied by a growing field of 'social development' measurement scales that mimicked and echoed intelligence tests and schedules in their structure, attempting to mark out the origins of early relationships. In the USA, the increased use of intelligence tests had sparked the creation of these 'social development' scales, which paralleled intelligence tests in their specificity and detail, whilst also allowing for very early testing of children's abilities. In 1911, Arnold Gesell established the Clinic of Child Development at Yale University and later adopted duties similar to Burt's in assessing and identifying 'retarded' children for the State Board of Education for Connecticut. In the early 1920s he began amassing a huge photograph library depicting various stages of children's normal development. ${ }^{98}$ His aim was to fuse the itemisation of intellectual abilities and social abilities in his developmental scales. In The Mental Growth of the Preschool Child (1925) and Infancy and Human Growth (1928), he detailed a total of 195 items that could be used to evaluate a child's development between three and sixty months concerning their 'motor', 'adaptive', 'language' and 'personal-social' abilities, and these items were presented as developmental schedules that represented typical behaviour at particular ages. ${ }^{99}$ At the Vineland Training School for Feeble-Minded Children in New Jersey, Henry H. Goddard pioneered new research into testing for abnormalities in children's psychological development, supporting Stanley Porteus and his non-verbal maze test, as well as Edgar A. Doll's research on birth injuries and later his definitive Vineland Social Maturity Test. ${ }^{100}$ 
In the USA, a wider genre of popular literature on child development had also developed, such as William Stern's Psychology of Early Childhood (1924), Jessie Fenton's Practical Psychology of Babyhood (1925) and Winifred Rand's Growth and Development of the Young Child (1931), which helped to popularise psychological theories of infant and child development. ${ }^{101}$ These books were also publicised in Britain. ${ }^{102}$ Gesell and Doll's 'social development' scales were praised by many international psychologists, such as Charlotte Bühler at the University of Vienna and Katherine Bridges at McGill University in Canada. ${ }^{103}$ They were part of a wider international movement within psychology to think about mental processes in infants and children, such as the work of Kurt Koffka, who had studied psychology under Carl Stumpf at the University of Berlin and was in 1927 appointed Professor of Psychology at Smith University, USA. However, few of these works integrated the concepts of autism, primary narcissism, schizophrenia and psychosis in their understanding of child development and were thus regarded as inadequate by the growing generation of dynamic child psychologists in Britain and elsewhere.

Many English dynamic psychologists in Britain in the 1920s and 1930s criticised and raised concerns about the applicability of standardised tests for social functioning, such as the work of Gesell. Isaacs pointed out that the Gesell scales normalised certain 'social' behaviours that were ultimately taught by parents and which therefore could not be indicative of genetic or biological endowments. She argued that all rating scales usually had 'an educational or moral bias' and that it would therefore be premature and 'quite sterile' to use them to devise social policies or to create interventionist treatments. ${ }^{104}$ Drawing from work by Charles Valentine, Professor of Education at the University of Birmingham and first editor of the British Journal of Educational Psychology, Isaacs pointed out that children's responses to all situations differed depending on variations in environment, for example, the presence or absence of the mother, or if the child was in the school or home environment. ${ }^{105}$ Isaacs was very critical of rating scales and experimental methods when it came to understanding social development in children. She argued that 'Those investigators who are attempting to build up rating scales and schedules for social and emotional development do not always seem to me to provide sufficiently against the risk of oversimplification. ${ }^{, 06}$ Isaacs wished to advance, and indeed complicate, the way 
that psychologists perceived social development, and she employed the work of Klein and other theorists on early infantile thought in order to do this. Her aim was to delve as deeply as possible into the biological processes behind children's thought, as well as the texture and character of that thought. As with most psychologists in Britain in this period, she was interested in instincts but she specifically focused on early infantile instinctive drives and on the way that social development emerged in minute stages.

Other, primarily female professionals also sought to promote new ideas about social development in children. Beatrice Edgell, the first British woman to obtain a doctorate in psychology and the first female president of the British Psychological Society (1929-32), was central in promoting all of these new theories in the UK, sharing with Piaget an interest in both philosophy and psychology. ${ }^{107}$ Writing in the second edition of the British Journal of Educational Psychology in 1931, her colleague Victoria Hazlitt, from the Department of Psychology, Bedford College, London, argued that traditional British faculty psychology was rapidly being superseded by detailed studies of children's thinking by Isaacs and Piaget. These studies, she argued, demonstrated that 'rigid' faculty models of the mind were useless and that the dynamic study of instinctive drives revealed this. ${ }^{108}$

At the same time, Jean Piaget was further developing his ideas about autism as an early stage of infantile thought. Then working at the Institut Jean-Jacques Rousseau in Geneva, he became increasingly interested in elucidating the working mechanisms of thought based on the study of logic in a typical sample of infants and children. ${ }^{109} \mathrm{His}$ prolific publication of books and articles on all aspects of children's reasoning processes sought to shed light on the way that infants and children formed concepts and conducted intellectual operations in their minds. After his 1923 study of children's language and thought, Piaget later published books on the child's understanding of causality; their conceptualisation of the external world; the origins of moral judgement and intelligence; imitation, play and dreams in children; and how children constructed reality, amongst other things. ${ }^{110}$ Unlike Gesell, Piaget's aim was not to explore the progressive stages of cognitive development in infants and children. Instead, he sought to explain why children thought how they did, rather than simply how children thought. He often questioned children about their reasoning 
in order to do this, claiming that this was the only way to generate the knowledge that he wanted. Isaacs and others argued that this method was 'suggestive' and could potentially influence responses in a way that direct observation did not. ${ }^{111}$ However, Isaacs and other dynamic child psychologists in Britain took a similar approach in that they attempted to unearth the motivations for children's thought, yet they focused much more on unconscious rather than descriptive thought.

It was by building particularly on the work of Isaacs that child psychologists in Britain sought to formulate a unique theory of child development that explained the origins of socialisation, but did so in a way that integrated theories of the unconscious mind with detailed observations of children's daily interactions. Furthermore, these new psychologists sought to clarify the ways in which infants and children developed a relationship to reality via their interactions with the social world. It was through thinking about social development, and the cases in which this development went wrong, that child psychologists in Britain began to develop the concept of autism and unite it with theories of social development and the development of relational thinking.

By the 1930s, Isaacs had become a formidable figure in British psychology. She had taught advanced psychology students at UCL and lectured widely on psychology and psychoanalysis. ${ }^{12}$ She also served on the editorial board of the British Journal of Educational Psychology and the British Journal of Medical Psychology. ${ }^{113}$ In 1933, Isaacs established the first Department of Child Development in Britain at the University of London's Institute of Education (IoE). She was also becoming influential in guiding government policy on childcare and education, giving evidence to the Hadow Committee on Infant and Nursery Schools in 1933 and later the Home Office Care of Children Committee in 1945. ${ }^{114}$ In 1948, she was appointed CBE for her services to education.

In 1933, the same year that the Department of Child Development opened, Isaacs published her authoritative treatise on The Social Development of Children, which was well received by Ernest Jones, Mildred Creak and others with a strong interest in developing child psychology via theories of the unconscious. ${ }^{115}$ Isaacs described what she regarded as the powerful emotions and feelings that infants experienced as they emerged from the 'egocentrism' of early infancy characterised by 'primitive libidinal wishes' and then developed an awareness of the family, nursery group and wider society around them. For Isaacs, early infancy 
was a time of intense emotion, when 'the instinctual longings of the child for food and love' were 'enormously strong', causing a 'stress of urgent unsatisfiable need' if food or love were found wanting. ${ }^{116}$ After these passionate experiences of early infancy, the child only slowly developed into a social being via daily interactions with parents, siblings and playmates where internal needs, wants and desires were 'projected' onto those other people in an attempt to make sense of the outside world and the way it functioned. It was only when individual desires were thwarted that children began to realise the need for social organisation, as they had to step outside their own egotistical wishes and consider the needs of other people. Activities such as play with toys and other objects enabled the child to improve their understanding of the external world and sowed the seeds of social interaction. Isaacs argued that in her work, she 'tried to unravel the pattern of the young child's behaviour so as to show the threads by which his pre-social feelings and phantasies are carried forward into the social relations of later life'. She was also interested in 'the development of social responsibility, and the forms which the individual's conscience in relation to his fellows first assumes. ${ }^{117}$ Isaacs' detailed study of social development epitomised new dynamic psychology approaches to child development in Britain at the time. Because it integrated theories of the 'egocentrism' of early infancy within a wider theory of general social development in children, it opened up new markets for theories of infant and child unconscious thought processes and their impact on their development of relationships. These new theories opened up new markets and new opportunities for the spread of the theory of infant and childhood 'autism', 'autoerotism' and 'primary narcissism' as a state of mind that structured children's later thinking but was unrelated to intelligence.

By the 1930s, there was a growing interest in treating children's problems via psychoanalytic theory. In the late 1920s, Edward Glover had been successful in ensuring that psychoanalysis was recognised as a legitimate branch of medical science in Britain at the British Medical Association (1926-29). ${ }^{118}$ In 1932, he founded the Institute for the Scientific Study and Treatment of Delinquency (ISSTD) that sought to treat criminal tendencies rather than to mete out punishment through the penal system, and the Howard League for Penal Reform supported this work. ${ }^{119}$ Glover's work at the ISSTD sought to discover the roots of crime in infantile impulses and drives and his work helped to promote 
theories of the unconscious to new domains within the criminal justice system. ${ }^{120}$ Psychoanalytic theory was also popularised in books such as Miller's edited volume, The Growing Child and its Problems (1937).

At the same time, Isaacs' theories of social development were also being promoted widely via the British education system. The work of the consultative committee to the Board of Education under Henry Hadow from 1920 to 1934, and later William Spens, was highly influential in the formation of British educational policy in the interwar period and beyond. The committee published a series of influential reports covering the emotional and intellectual development of children from birth to adolescence, in which evidence from Burt and Isaacs played a crucial role. Burt and Isaacs' evidence to the Hadow committee helped promote Isaacs' new theories of social development in children, yet it was the introduction of testing methods to identify intellectual ability and deficiency that stole the show for most government officials in the interwar period. ${ }^{121}$ Although central government adopted the idea of 'mental deficiency' wholeheartedly, the uptake of psychological theories within educational establishments in the interwar period occurred sporadically and was never absolute. Teachers were likely to encounter the psychological ideas of McDougall, Freud, Burt and Isaacs, but few teachers in state-funded mainstream schools were initially able to put any of these ideas into practice. Psychological theory was best received amongst young teachers who thought that such ideas could help them in their relations to students. ${ }^{122}$ Even then, ideas about autism, autoerotism, primary narcissism - all highly individualised concepts - retained a relatively small audience, although they were beginning to trickle down into mainstream theory.

\section{Instincts, phantasies and the social instinct}

All theories of developmental psychology in the 1920s and 1930s were framed by instinct theory. This held as much for traditional psychologists, such as Cyril Burt and C. W. Valentine, as it did for Susan Isaacs and psychoanalytically influenced child psychologists who were becoming interested in unconscious motivations that could be traced to early infancy. The late 1920s and early 1930s thus saw increased emphasis on how strong feelings in infancy impacted on social abilities and provided the kernel for all later difficulties in the functioning of society. 
However, many English child psychologists' understandings of socialisation were often straitjacketed by older versions of faculty psychology or even by anthropological sciences when it came to theories of socialisation. For example, Valentine approached the question of the origins of thought through the study of early reflexes, the 'transition from reflex to voluntary movement'. Building on the work of McDougall, he pointed out that voluntary movement presupposed consciousness so early voluntary movement could demonstrate the origins of consciousness and thinking. Rather than engaging with the child's individualistic perception of the world, he instead focused on the 'innate' basis of emotions such as anger, fear and disgust, as well as the innate capacity to learn, remember and speak. ${ }^{123}$ Valentine's interpretation of human instinct was thus limited in its scope as it could not encompass the questions of the infant's perception of the world in the development of social consciousness. Other child psychology professionals employed their own limited interpretation of instinct theory and the unconscious that did not encompass the complex problem of early infant perception in the development of relationships. For example, writing in the British Journal of Educational Psychology in 1931, George Augustus Auden, a School Medical Officer and the father of poet W. H. Auden, relied upon the anthropologist, doctor and psychologist W. H. Rivers' Instinct and the Unconscious (1920) and Freud's Introductory Lectures on Psychoanalysis in order to explain the means by which children developed conflicts between unbridled instinctive drives of 'the pleasure principle' and reality that led them to develop psychological problems in their attempts to accept social limitations. ${ }^{124}$

The anthropologist Margaret Mead was influential on many child psychologists in the period, but her model of socialisation in children did not allow for detailed inspection of early perception and thought. In 1931, Mead argued that 'every primitive society thus presents a laboratory to the social psychologist, in which he must test out whether certain aspects of behaviour are, or are not, socially determined. ${ }^{125}$ She encouraged psychologists to head to 'primitive' cultures in order to understand the differences between instinctive behaviour and socialised behaviour. Many psychologists in Britain identified their work closely with instinct theory, which was driving theories in anthropology and the social sciences, and many referenced Mead in their claims about 'primitive' early thought in infants. 
However, child psychologists, in particular those with a psychoanalytic orientation, focused on infant and child perception to develop a unique autonomy in their imposition of concepts onto the infant mind, particularly those concerning the social world. By the 1930s, Isaacs, Lowenfeld and the new generation of female dynamic psychologists were bringing a new dimension to the understanding of human development, buoyed significantly by the fact that this model of psychological science was no longer straitjacketed by wider sciences of human behaviour such as sociology and anthropology. At the same time, the exclusion of mentally defective children from the remit of deep psychological study was generating a huge amount of creative freedom in the description of the early unconscious mind. The popularity of the theories of Klein and Isaacs on pre-social thought must be understood in this context. Klein and Isaacs frequently contextualised their observations of infant behaviour with claims that it reflected infantile phantasies about their bodily experiences and their thoughts about other people, and strongly asserted the significance of bodily desires in the construction of the self. It was primarily via work such as that of Isaacs, Lowenfeld and Klein that explicit descriptions of phantasy life, as attached to infantile instincts, were nonchalantly accepted as part of the general discourse on normal child psychological development. This was also how the first model of autism came to be established in psychological theory.

Throughout the 1930s, Isaacs, Lowenfeld and other psychologists in Britain developed Klein's ideas about infantile phantasy in relation to socialisation. This deep reflection on, and study of, the phantasies of children was an entirely new intellectual project for psychologists. Isaacs, Klein, Lowenfeld and others placed an immense importance on the significance of phantasy life for understanding later social development. In general, these psychologists regarded phantasy as a concept through which to think about children's uncontrolled or unrestricted thought. Writing in 1935, Lowenfeld described the concept in these words:

Phantasy, as it is generally understood, is the name given to that kind of mental functioning which earlier was called day-dreaming or reverie, and which stands in opposition to imagination and controlled thought. Imagination is a creative activity with a definite relationship to reality; phantasy rules in a world of imagery, controlled entirely by the 
individual's desires. Phantasy is 'the stuff that dreams are made of', and the material out of which, in the early childhood of men and races, many conceptions of the outside world are forged. ${ }^{126}$

Lowenfeld regarded children's phantasy life as an important part of their development. She regarded children's play as the ultimate expression of their phantasies and encouraged and cultivated it in order to help children establish a satisfactory relationship to reality. At the Institute of Child Psychology, she provided 'phantasy material' to children to encourage them to explore their thoughts, such as water, earth, sand, dough, clay, plasticine, wood shapes and blocks, as well as cups, pots, kettles and other vessels into which materials could be placed. She argued that if children could express their phantasies, this could also aid their social development. ${ }^{127}$ If children did not engage effectively with others, then they were encouraged to do so through engagement with their phantasy. Within the general theory of child development, autism, autoerotism and primary narcissism served as important concepts that encouraged child psychologists to focus on children's play and on their imagination in order to engage with them and to help them develop relationships.

In general, psychoanalytically influenced thinkers, such as Klein, focused on the detailed observation of a few cases. However, Isaacs and Lowenfeld engaged in more systematic observation of children's play in developing their theories, monitoring all behaviour and any words spoken by a child, as well as detailed description of the precise context in which this behaviour or language emerged. This claim to objectivity was raised in order to place these social studies on a parallel with quantitative studies in intellectual development, such as those designed by Burt. Isaacs argued that children's play provided countless examples of egocentrism, hostility, aggression and power struggles, whilst also demonstrating friendliness and compassion - the true seeds of civilised social interaction. In order to understand the seeds of civilisation, one thus needed to delve deeply into the varied complex play activities of children and to document them. Isaacs argued that they revealed a 'pre-social matrix of individual feeling and phantasy out of which social relations are differentiated'. She also described this 'pre-social matrix' as 'those disruptive forces that have to be transformed before positive social relations can be transformed.' ${ }^{128}$ 
Phantasies about the body, and the instincts contained within it, dominated all these descriptions by early child psychologists of children's play, and enabled a new discourse to develop about the significance of such thoughts. Lowenfeld's observations of children's play took children's descriptions seriously. For example, This extract concerns a young child's interest in babies, birth and creation:

'GP Girl aged 2 1 1 2 She pretended a brick was a head and grated it through the mincer onto the floor. Then she cut it up. She asked if worker wanted a baby, and, if so, worker should take it out of the cupboard. Worker did so, and then she started to feed worker's doll with pieces she cut from the head.'129

Children were interested in their own bodily functions and instincts, and, whilst Valentine and other more conservative male researchers sidelined these discussions to focus on the core instincts of fear, aggression, etc., Isaacs and other female psychology researchers in Britain delved into these detailed descriptions of infants' and children's interests in their bodies and their instinctive drives and motivations. Piaget's detailed observations of children's reasoning fitted in with these theories far more than the older generation of faculty psychologists. As Isaacs put it, she was interested in 'love and hate in action', and this involved more detailed attention to the thoughts attached to early play and its relationship to bodily functions.

As the English early dynamic child psychologists began to describe it, phantasies about the body created the social world that emerged in childhood and afterwards. Phantasies were the driver for social relationships, and the means by which human relationships and social interactions could be understood. In infancy, instincts and phantasies dominated the individual's ability to develop a self-identity and to interact with others. For example, writing on infant emotion in 1932, Nina Searle argued that 'the libidinal life of the young child is very strong; his ego, that part of him which links to external reality, is very weak. ${ }^{130}$ Most importantly, these psychologists and psychoanalysts began to conceptualise the infant's relationship to its mother as fundamentally a social relationship and, more than that, the most significant relationship upon which other relationships are built. As Isaacs put it, 'The child's relation with his mother can be called social from a very early age, in the sense that there is a mutual action and reaction of feeling and behaviour. ${ }^{131}$ This simplified 
early social relationships to include any kind of interaction with another person, the most common of which concerned the mother. It was only through the process of taming the instincts via consistent social interaction that McDougall's 'social instinct' could be formed. They argued that it was impossible that something as complex as a social instinct, or human drives to social interaction, could be pre-formed. It was by complicating this model of a pre-formed 'social instinct' that the first descriptions of infant psychology in Britain were made.

This was an obvious critique of faculty psychology and any simplified explanation of human instincts and it relied heavily on Isaacs' description of the phantasy and unconscious life of infants and children. In fact, the description of unconscious and fantasy life was absolutely fundamental to the construction of early child psychology, in particular the ways in which child psychology formulated a model of the social world that infants and children could recreate through their pattern of growth. Isaacs, Klein and other female psychologists sought to bring the intensity of bodily experiences into the theory of psychology and to revolutionise the way that child development was conceptualised.

These psychologists were trying to answer the rather complex question of how early infant and child psychological experiences were mediated in the development of a social instinct and a relation to reality. Often, they fused the theory of social development with the theory of reality formation in their attempt to develop a comprehensive explanation for all infant and child psychological experience. The infant's early relationships were seen as the seeds of their ability to conceptualise other people, other objects and the entire world around them. If a child's development went according to plan, their later relationships and social interactions would be satisfactory and they would be considered well-adjusted, but if, for whatever reason, the infant failed to adapt their instinctual drives to the demands of society and reality then they would be prone to psychological disorder. These were early attempts to describe and understand early infant psychology and its role in the causation of later mental illness. It was perhaps because of this that there was immense enthusiasm to explain absolutely everything within this one theoretical model. Society, they argued, was created through bodily desires, instincts and drives. Psychologists knew nothing about socialisation if they could not explain how the child's body became a social body. 
As theories of schizophrenia, autism and primary narcissism began to be introduced into the language of child psychologists and to increase their repertoire for description, theories of how social development went wrong in infants started to proliferate. What is significant here is that early work on childhood autism, schizophrenia and psychosis was being produced at exactly the same time that child psychologists were constructing and developing their first scripts on the actions and words of developing infants and children. Hence, from the start, the theory of social development and the theory of autism were inseparable from each other. Similarly, whilst autism was being defined as an aspect of schizophrenic thought, and whilst autism, autoerotism and primary narcissism were being used to explain extreme pathologies in adult mental processes, they were also being articulated in infantile cases as part of descriptions of early socialisation. Although this may appear unusual, it was a reflection of the trajectories of instinct theory. It was also due to the fact that the investigation of the nature of 'mental deficiency' in children was a no-go area, forcing child psychologists to associate with professionals interested in psychopathology in adults.

\section{Child psychiatry and autism}

Whilst dynamic child psychologists developed their theories of phantasy and popularised them via child guidance clinics and the health and education system in Britain, the discipline of child psychiatry was slowly defining itself as a distinct sub-speciality that drew strongly from adult mental sciences. Although child psychoanalysts and developmental psychologists developed theories of early infantile thought, autism, autoerotism and primary narcissism based around theories of the unconscious, child psychiatrists developed their own models of these concepts. Child psychiatrists were influenced by their close alignment to other professionals in the field of adult psychiatry. Even more importantly, in their clinical work, they could not as easily disregard the thought of 'mental defectives' because they were often referred very difficult cases of children who displayed symptoms that placed them on the boundaries of mental deficiency and mental illness.

In Britain, the Maudsley Hospital served as an important hub for the development of British psychiatry. As Rhodri Hayward has argued, Frederick Mott's plans for the hospital had been modelled on the 
German university psychiatric clinics of Berlin, Munich, Halle and Heidelberg, where the discipline of psychiatry was framed as a medical speciality focused on observation of the incipient and later stages of mental illness and supported by university research in neurology. ${ }^{132}$ Emil Kraepelin's clinic in Heidelberg represented the epitome of this approach, and Kraepelin's work on the classification of discrete disease entities, in particular dementia praecox, was internationally renowned. When the Maudsley was established, it had close links with the London County Council Central Pathological Laboratory that received pathological samples from asylums across Britain for investigation, ensuring that biomedical research influenced the observation and treatment of patients. ${ }^{133}$ This created a unique environment for the study of mental illness and enabled the psychiatric specialism to thrive in Britain. The relations between medicine, psychology, neurology and psychoanalysis were somewhat fluid during the 1910s and 1920s, as exemplified in Charles Myers and William Rivers' establishment of a medical section of the British Psychological Society in 1919, and Ernest Jones' campaigns to have psychoanalysis recognised as a branch of medicine. ${ }^{134}$ However, the establishment of psychiatry in Britain encouraged a unique approach to the classification of mental illness, in particular its most severe forms described as dementia praecox, schizophrenia and psychosis.

Laboratory research on the organic causes of schizophrenia was also developing rapidly. In Britain, Frederick Mott and others investigated the disturbed endocrine systems of men and women who had died following severe episodes of mental illness in asylums. ${ }^{135}$ At Henri Claude's laboratory in Paris, H. H. De Jong injected the alkaloid bulbocapnine into cats to induce catatonia, a symptom that Bleuler had classed under 'schizophrenia', in an attempt to demonstrate that it could originate from an organic cause. ${ }^{136}$

Although concerned with younger developing minds, the establishment of child psychiatry in Britain quickly came to be framed around the concepts of dementia praecox and schizophrenia. Elsewhere in Europe, child psychiatry developed differently. For example, In 1925, Georges Heuyer, a doctor working in the Paris hospital system, was appointed to head a 'neuropsychiatric' clinic for children at the Salpêtrière. Heuyer appointed the psychoanalyst Sophie Morgenstern to work with him, encouraging close links between psychoanalytic and medical practice in 
France. ${ }^{137}$ In the same year, in Italy, the experimental psychologist and psychiatrist Sante de Sanctis published Neuropsichiatria Infantile, a book that popularised his concept of 'dementia precocissima', a condition that he named drawing upon terminology used by Kraepelin to define very early dementia. ${ }^{138}$ De Sanctis organised the fifth International Conference on Psychology where he presented on the testing of children with low intelligence, along with Binet and Simon, and he maintained a strong interest in dream analysis as well as child development. ${ }^{139}$

However, in the field of child psychiatry as it developed in the AngloAmerican world from the 1920s, the 'dementia praecox' and 'schizophrenia' concepts were adopted almost wholesale from Kraepelin and Bleuler and then applied to children, often without considering the new sciences of developmental psychology. Furthermore, the concept of psychosis in psychiatry and neurology, which had a history dating to the nineteenth century, had been increasingly divided into 'functional' and 'organic' types during the First World War in response to growing reports of 'shell shock. ${ }^{140}$ Child psychiatrists also adopted these distinctions in their conceptualisation of child disorders, again often not taking into account the theory of 'psychosis' as it was being described in developmental psychology and psychoanalysis.

In the USA and Britain in the late 1920s and early 1930s, specialist child psychiatrists thus drew strongly from Kraepelin and Bleuler in their concepts of severe psychopathology in infancy and childhood, in particular Leo Kanner at Johns Hopkins University, Moses Kaufman and Jacob Kasanin from the Boston Psychopathic Hospital and Mildred Creak in the UK. ${ }^{141}$ In 1935, Leo Kanner published the first ever English-language textbook of child psychiatry, hoping to establish child psychiatry as a unique profession, distinct from child psychology and child psychoanalysis. ${ }^{142}$ As the 1930s developed, child psychiatrists became distinct from psychologists and others because they trained within hospital settings with medical facilities and focused on severe psychopathology. In the USA and Britain, the affirmation of the distinctiveness of this profession was very important in the shaping of concepts in all the psychological sciences.

The Maudsley Hospital served as the heart of child psychiatric research in Britain from the 1930s onwards and was the primary location for child psychiatry training. Mildred Creak was a key figure in these developments. She joined the Maudsley Children's Department 
in 1928 and was appointed head of that department in 1931, having previously trained in medicine at University College Hospital. ${ }^{143}$ Creak became interested in the topic of childhood psychosis and schizophrenia for two reasons. First, because she was aligning herself with the professional field of adult psychiatry, and second, because she was professionally responsible for deciding the fate of children who sat on the borderline of mental deficiency. Her role was very different from that of a psychoanalyst such as Klein, who dealt primarily with private patients, or an academic psychologist such as Isaacs, who was focused on developing psychological theory and teaching.

Since opening, the Maudsley had received a caseload of very complex cases, in particular children whom other agencies could not manage, and who were sometimes simply diagnosed as 'unmanageable'. In the early years the Maudsley was an important referral ground for children with encephalitis lethargica, or sleeping sickness, an expertise it had acquired as the outcome of a major epidemic between 1918 and 1927. Dr F. C. Shrubsall, Honorary Lecturer on Mental Deficiency at the Maudsley Hospital and the Senior Medical Officer to the LCC, argued in 1925 that post-encephalitic children were remarkable for their 'state of irritability, lack of inhibition, and consequent impulsiveness. ${ }^{144}$ Dr Philip Cloake, conducting research into the illness for the Medical Research Council, argued that this was caused by a toxic state that depressed 'the highest psychic functions', allowing 'the freer play of partially uncontrolled instinctive activity' and leading to brain damage and the destruction of pituitary gland that regulated the endocrine system. ${ }^{145}$ Many post-encephalitic cases referred to the Maudsley were found to be difficult to treat. ${ }^{146}$ Nevertheless, the department developed a reputation in the LCC for accepting their most difficult cases, and care committees and other child welfare agencies readily exploited this. The Local Government Act 1929, which led to the final closure of all Poor Law institutions, put increasing pressure on these agencies to classify the precise problems of individual children so that they could receive welfare provision or institutional care. By the mid-1930s, the Maudsley was receiving over 800 new child cases per year. Of cases admitted in 1935 , over one-third were diagnosed using a combination of descriptors such as 'behaviour disorder', 'behaviour problem', 'unmanageable' and 'stealing. This level was maintained up until the start of the Second World War. ${ }^{147}$ 
Even other high-profile child psychologists and doctors referred their most difficult cases to the Maudsley. For example, in 1934 Emanuel Miller, of the East London Child Guidance Clinic, sent a difficult child who was possibly 'mentally defective', but for whom his clinic could do nothing. In 1935, Margaret Lowenfeld of the Institute of Child Psychology for the Treatment and Study of Nervous and Difficult Children referred a 12-year-old boy to the Maudsley, stating that 'his general attitude reveals an early paranoid of so outstanding a type that we are referring him to you for consideration'. Cases were also referred from Moodie's London Child Guidance Clinic, the Tavistock Clinic for Functional Nerve Cases, and many others. ${ }^{148}$

Whilst Creak was heading the Children's Department in the 1930s, she had to make very difficult decisions about onward referrals. At the same time, her professional interest in developing theories of severe psychopathology, in particular the classifications of dementia praecox and schizophrenia, almost compelled her to apply these concepts to children. She encouraged the development of research into autism, as a concomitant of schizophrenia, in infants and children from an angle that became distinct from its use in theories of developmental psychology. In child psychiatry, the concept was not employed within a theory of early child development prior to socialisation, but rather as a means to identify and name severe psychopathology in infants and children. This led to clashes and controversies between professionals working in different disciplines and dealing with different aspects of child development within their professional lives.

From the perspective of child psychiatrists, and for Creak in particular, devising clear-cut diagnostic categories for schizophrenia meant potentially reclaiming children who would otherwise have been forgotten about in defective colonies. In 1937, Creak claimed that a 'no-man's land ... exists between the clear-cut picture of amentia and psychosis' in children. In other words, it was not easy to tell whether a child did not have a mind at all or whether he had a mind that he had then lost. She argued that the study of psychosis and schizophrenia in children offered a 'tremendous field ... for observation and research' that could help to clarify the type of psychiatric help which any individual child may require. ${ }^{149}$ For Creak, it was problematic that writers such as Klein were employing the terms 'schizophrenia' and 'psychosis' to describe all forms of early infantile thought. Creak argued that although Piaget 
had shown that 'normal thought processes, at an early age, recapitulate those primitive and archaic forms so often seen in schizophrenics', childhood schizophrenia should be conceptualised as a 'reaction' that disturbed the normal development of infantile thought leading to problems in the formation of intellect and motor co-ordination. She claimed that in schizophrenic children, one could observe a 'tendency to fragmentation and interruption in the thinking processes' as well as 'dereistic thinking', which Bleuler used as a synonym for autistic thinking. ${ }^{150}$ Quoting from Charles Macfie Campbell, an Edinburgh-trained doctor who was then Professor of Psychiatry at Harvard Medical School, Creak claimed that a 'schizophrenic reaction' in children was characterised by diminished interest in the 'workaday world' and increased interest in 'subjective creations and fantasies. ${ }^{151}$ There was also a frequent occurrence of hallucinations as well as 'odd and fragmentary behaviour' and 'utterances of little adaptive value to the present situation. ${ }^{152}$ Creak defined childhood schizophrenia as:

the tendency to fragmentation and interruption in the thinking processes, dereistic thinking, which presumably lies behind the odd utterances and behaviour, the tendency to stereotypy of thought, action and expression, the poverty of output compared with capacity, the emotional lability, with inappropriate responses and poverty of affect, apathy and negativism, and tendency to regression to simpler, more archaic levels, and not least the disordered metabolism. ${ }^{153}$

She claimed that in similar cases that she had observed, there was evidence of organic factors such as acute tonsillitis, middle-ear disease and acute nephritis that led to this kind of 'dementing illness. ${ }^{\text {' }}{ }^{154}$

Creak's description of psychosis and autistic or 'dereistic' thinking clearly differed significantly from the one developing within psychoanalytic theory and developmental psychology. It was focused on severe pathology, not on social development. Nevertheless, because the concepts of schizophrenia and autism were associated with infantile thinking, and because these concepts were entering the description of children at different levels, disagreements clearly arose over what, exactly, autism was. Creak thought that early-onset schizophrenia was not a unique childhood illness, but merely a very early example of the kind of reaction and regression seen in all forms of schizophrenia in adults. The reason that speech was lost first, she argued, was because 
it was 'the most recently acquired and least stabilized achievement.' ${ }^{155}$ Motor co-ordination was retained longest because it was the most stable accomplishment.

Other researchers and psychiatrists in Britain in the late 1930s had attempted to clarify the problem of differentiating child and adult schizophrenia by focusing on the age at which a 'regression' occurred and how this could be identified. For example, in 1938, R. A. Q. Lay, a research fellow at Guy's Hospital, argued that in particular cases of early regression of 'the dementia infantilis type', there would be a 'rapid onset of the degenerative process on speech and the emotional sphere', although motor development and play may be unaffected. He argued that in these children 'behaviour is very markedly autistic. ${ }^{156}$ Employing both Bleulerian and psychoanalytic understandings of autism, he added:

Many symptoms may be described in terms of the autism which is such a marked feature. Hallucinations are difficult to demonstrate conclusively in young children, but may occasionally be presumed to exist from the behaviour ... The child schizophrenic, being preoccupied with phantasy, no longer pays attention to impressions from the environment. This lack of attention leads to the onset of mutism and failure to understand the speech of others. Commands are not obeyed - interruption of their thought leading on occasion to violent reactions, the children thus becoming difficult of management. ${ }^{157}$

It is clear that the reflection and study of autism in children, and its role in helping to ascertain disease categories of early childhood, was already in full swing in Britain by the late 1930s. Furthermore, there was a critical application to children of concepts and observations from studies of psychiatric disturbance in adults. These were reflections on the age at which 'dementia' occurred in children causing hallucinatory disturbance, rather than assumptions about hallucinatory mechanisms in early infancy as in theories of developmental psychology. However, Creak and her psychiatric colleagues were not developmental psychologists or psychoanalysts and had very little to say about child development and instinct theory generally. The question of whether autistic and schizophrenic thought was a normal stage in the development of infantile thought, or whether it was always pathological or regressive in presentation, is one that would grow in importance in the following decade. 
The fallacy of mental defect: limiting the landscape of child psychology

As mental deficiency law became increasingly entrenched, so too did attempts to integrate the thought of this supposedly distinct species of pathological defectives into the study of general psychology. In 1929, a report was published by the Interdepartmental Committee on Mental Deficiency (the Wood Report) that further stoked anxiety and fear about the 'mentally defective' population. It argued that 'mental defectives' posed a social threat, were usually irresponsible, promiscuous and likely to spread disease, and were also likely to become paupers, criminals or members of the unemployed. Although the report pointed out that different areas have different rates of 'deficiency' - it being more common in poorer areas - the authors argued that institutionalisation was the only way to protect society as a whole. It thus provided a primarily social definition of mental deficiency, arguing that 'defectives' usually needed to be removed from society in order to protect society as a whole. It played strongly on eugenicist fears and instituted the most oppressive legislation towards those labelled with mental deficiency that Britain would ever see.

The Wood Report encouraged Medical Officers of Health, responsible for giving assessments, to employ the concept of 'social inefficiency', i.e. those thought unable to contribute to society, as a criterion of this kind of classifiable low-grade 'mental deficiency.' ${ }^{158}$ In the same year, a Mental Deficiency Committee clarified some of the subtleties that had previously existed around mental deficiency legislation and children, removing the possibility of 'educable' 'mental defectives' and marking out a new group of 'low-grade' 'defective' children classed as 'feeble-minded', 'imbeciles' and 'idiots', who would now all be the responsibility of the Board of Control. By the 1930s, most defectives were therefore housed in large comprehensive institutions or 'colonies', some containing more than 2,000 patients, such as Leavesden, St Lawrence's, Caterham and Darenth Park. ${ }^{159}$ In any case, 'low-grade' child defectives were increasingly ostracised and not considered to be full subjects of individualised industrial societies. These legal and social restrictions became so entrenched that by the 1930s, classifiable 'mental defectives' were rarely used as subjects for detailed psychological studies. Mental 
deficiency legislation defined much of the work that early educational psychologists engaged in, and the possibility that any 'defective' thought processes could be measured on a par with that of 'normals' was absolutely unthinkable. From the 1930s to the 1950s, 'mental defectives', housed in defective institutions, were rarely used as subjects for psychological studies.

The role of phantasies within pre- social life and The concepts of autism and its conceptual cousins, primary narcissism, autoerotism, became established as part of child psychology doctrine through Susan Isaacs' theories of social development. This also broadened the scope of their reception by introducing them to educators and the general public. However, the institutional network that supported the promulgation of these ideas also acted as a limiting, regulating and restrictive factor in their development because the spread of intelligence testing, and the theory of mental defect, was influencing policy on the organisation and education of the total child population. Whilst at first this organisation was slightly haphazard, by the 1930s, the institutionalisation of people with 'mental defect' was becoming increasingly common, largely in response to the Wood Report of 1929. Ironically, it was just as the 'mentally defective' were excluded from society that theories of autism, child socialisation and the formation of early relationships were entering the new networks for the spread of psychology such as child guidance clinics, child hospitals and the juvenile criminal justice system. Indeed, it was just as 'mental defect' was completely excluded from psychological study that the study of childhood autism began to thrive.

One of the few psychologists who had conducted investigations on the psychological development of children classed as 'defective' in the 1920s, prior to the publication of the Wood Report, was Lucy Fildes, a psychologist who had studied with many senior professionals in the field of psychology at the time, as well as neurologist Henry Head of the National Hospital, Queen's Square. ${ }^{160}$ Evelyn Fox, Honorary Secretary for the Central Association of Mental Welfare, Frederic Bartlett, Director of the Cambridge University Psychological Laboratory, and Charles Myers all lauded Fildes' work in the 1920s, and she was granted a Board of Control scholarship to study the psychological problems of 'defectives' at the Psychological Laboratory, Cambridge. ${ }^{161}$ Fildes argued that although Cyril Burt, and increasing numbers of psychologists involved 
in ascertaining mental defectives, regarded low intelligence as the main criterion of 'mental deficiency', there was still little understanding of what intelligence actually was. Fildes urged psychologists interested in intelligence to avoid studying higher functions such as reasoning power and the formation of judgements, and instead to be more concerned with 'motor and perceptual functions. ${ }^{162}$ She devised experimental tests to ascertain why 'defective' children had problems learning to speak, testing them on things such as hearing ability, acuity of hearing, sound discrimination, visual discrimination and associations between words and objects or actions. ${ }^{163}$

A child's inability to discriminate sounds, she argued, 'cannot be regarded as a defect of intelligence - even specific; it more closely resembles defect in the peripheral end of the sensory apparatus, ${ }^{164}$ thereby aligning it more closely with other 'sensory defects' such as blindness, which did not require institutionalisation by law and did not render a child 'ineducable'. Although McDougall, Burt and others had regarded sensory defects as contributors to mental defect, they had not explored how or why this was the case in relation to thinking processes. Summarising her findings, Fildes argued that:

Experimental work with mentally defective individuals on many different aspects of cognitive ability suggests that their main difficulty throughout is to be found in inadequate synthesis or integration. Experiences remain comparatively isolated, they are not related to each other in a normal manner and so the whole fabric of mental life is weakened. Strands are left hanging loose, or are but incompletely joined together. Holes and thin places appear and the created material is of little practical service. $^{165}$

This led her to conclude that 'mental defect' did not result from any specific impairment in reasoning and that 'the results of the experimental work certainly give no support to the theory that any failure affecting language alone exists.' ${ }^{166}$ She claimed that 'defectives' learned in similar ways to 'normal' children, but because of their sensory defects, they lacked in their ability to think critically, to form associations and to work under new conditions. ${ }^{167}$

Fildes' work on mental defect had the promise of generating new models of psychological development that focused on sense perceptions in order to understand the processes of learning - both intellectual and 
social. It was supported by work on hearing impairment, such as that of Irene and Alexander Ewing from the Manchester Department of Audiology, who developed hearing tests for babies and toddlers and oral and speech therapies to assist with language development. ${ }^{168}$ Alexander Ewing was also working on the problem of 'high-frequency deafness', in which speech sounds were distorted, and aphasia, where children could apparently hear but could not understand or employ language. ${ }^{169}$ However, mental deficiency law, particularly after the Wood Report, restricted this kind of psychological research and prevented the development of a comprehensive theory of psychological development. The integration of studies of mental defect into the broader field of developmental psychology never occurred.

The growth of the child guidance movement also meant that all professionals interested in child psychology started to focus their attention on the broad range of 'difficult' children, rather than those with severe 'mental defect' or severe mental pathology. Fildes herself joined the staff of Moodie's Child Guidance Clinic in Islington in 1928, and did not study 'defective' children after that point. ${ }^{170}$ Very few child psychological professionals ventured into the territory of major defective colonies or studied the thought of children inside them during the 1930s and 1940s. This led to an unusual situation in which the sciences of developmental psychology and social development, which had emerged rapidly in response to the growth of child guidance in this period, were established without any sustained interest into this hugely significant section of the total child population.

In the 1930s, most research carried out on residents of mental deficiency institutions did not usually concern the treatment of those residents themselves, but instead simply exploited them as passive populations for research on diseases such as dysentery and syphilis. ${ }^{171}$ Most serious studies of mental deficiency in the 1930s concerned the heritability of 'mental defect', such as the work of Lionel Penrose and Eliot Slater. ${ }^{172}$ If the topic of 'mental deficiency' reached a general audience, it did so in the context of a broad social problem, rather than one concerning detailed individual development. For example, in 1931, Richard Berry and R. G. Gordon published Mental Deficiency: A Problem in Social Inefficiency in order to instruct the public on the reasons for social policy, wholly advocating the establishment of 'defective' colonies, although remaining ambivalent on the issue of sterilisation, which had 
been advocated by some members of the Eugenics Society. ${ }^{173}$ Following the Wood Report, statistical studies of 'mental defect' often aligned the condition with social threats. These surveys found, as Burt bluntly summarised it, that 'stupidity ... is not the inevitable result of poverty, though poverty seems its commonest concomitant', and that psychological measures of low intelligence could also be correlated with other social threats such as "poor, overcrowded, insanitary households. ${ }^{174}$ Burt was later accused of faking his data to prove the heritability of intelligence, although this was never proved definitively. ${ }^{175}$

Although the theory of general intelligence, $g$, was challenged within academic psychology, it was still employed in the practical work of identifying defectives. For example, a 1930 manual by Henry Herd, Certifying Officer to the Lancashire Mental Deficiency Authority, claimed that the measurement of $g$ was critical in identifying 'defectives. ${ }^{176}$ In 1933, Penrose, Research Officer at the Royal Eastern Counties Institution in Colchester, argued that the best way to ascertain a 'mental defective' was to ascertain his or her 'ability to learn', referencing Charles Spearman as the authority on this 'most important element of intelligence. ${ }^{177}$ Tests to identify a lack of general intelligence thrived in the 1930s. The young anthropologist Meyer Fortes, then based at UCL, writing his $\mathrm{PhD}$ under Spearman, devised a popular perceptual test. ${ }^{178}$ Other non-verbal tests in use by the 1930s and recommended for use by Henry Herd included the Porteus Maze test, the Cube Imitation Test, Henry Goddard's Adaptation Board Test, the Manikin Test, the Seguin Form-Board Test, the Diagonal Test and the Healy Puzzle. ${ }^{179}$ 'Defective' individuals were investigated as to the extent of their 'delay' and then placed within 'percentile ranks' and 'rating scales'. Their 'mental age', 'mental ratio' and 'achievement ratio' were also calculated. ${ }^{180}$

Burt's model of statistical psychology, which tied the language of drives, desires and instincts to the analysis of populations, was a dominant mode of description used by intelligence testers in this period. Burt regarded the constitution of an individual as a sum of instinctive forces that could be classified and then measured as to their intensity. Burt's work was ultimately influenced by Helmholtz's physiological principles via the work of Bain, Spencer, and James Sully. Bain had first employed the language of physiology to describe the psychological processes of energy, discharge and conservation. ${ }^{181}$ However, the exclusion of defectives meant that this model of statistical psychology developed in a 
unique and highly artificial social climate. Because statistical psychologists, and government departments, sought to relegate 'defectives' to the margins of social organisation, their thinking processes were barely considered during the early years of educational and developmental psychology.

Medical Officers of Health who certified defective children largely served as government officials, and had many other duties, so they were not generally inclined to theorise about the complicated distinctions between 'ineducable defectives' and other children. Cyril Burt, Phillip Vernon and C. W. Valentine were concerned with this problem from the perspective of intelligence testing, but other child psychologists tended to shy away from the issue. All psychological measurements and tests from the 1920s and 1930s, even those devised by Piaget, were concerned with the measurement of normal intelligence and normal developmental stages. Any children who did not come up to the listed standards were simply regarded as 'backward', merely a less developed version of a normal child, and their psychological processes were not thought to have any intrinsic value in and of themselves. The creators of these mainstream tests were not interested in integrating children who suffered from any form of abnormality, and the 'social' world constructed in these tests was therefore one without any 'defects'.

Furthermore, medical officers appointed to deal with the problem of 'mental deficiency' tended to work entirely independently of those interested in general child psychology. This led to the compartmentalisation of particular problems and the general neglect of children diagnosed with 'mental deficiency'. Several superintendents of mental deficiency institutions, such as Edward Birchall Sherlock of Darenth Park and Frank Douglas Turner of the Royal Eastern Counties Institution, wrote on the practical problems of deficiency administration, but very few had a specific interest in child psychology. For example, Sherlock's The Feeble-Minded (1911) and Minds in Arrear (1932) were both highly specialist practical guides concerning the care of 'defectives' with little theorisation of the developmental problems of these subjects. Furthermore, these books did not exactly fly off the shelves and did not enter into a wider popular discourse in psychology. Work in mental deficiency institutions was generally regarded as a backwater science with an extremely low status within the wider medical and psychological professions. ${ }^{182}$ 
Because 'mental deficiency' required institutionalisation by law, by the 1930s, its conceptualisation and administration was largely caught up in a bureaucratic system of administration, rather than deep analysis. Even as Burt oversaw the implementation of mental deficiency law, he rarely reflected on the accuracy of the psychological category, preferring to focus on the supposed social problems that 'defectives' engendered and the means to measure and account for this. Medical Officers of Health, involved in the practice of certification, were not specifically trained or interested in psychology and served a primarily administrative role. Because child guidance clinics did not accept 'defectives', this meant that, in practical terms, most child psychologists in Britain in the 1930 s were rarely faced with the serious question of whether an infant or child referred to them was 'defective', and even if they did they swiftly referred them on to Medical Officers of Health, rather than explore the depths of their psyche, because of legal requirements to institutionalise them. Very few psychologists therefore considered in any detail the thought of this hugely significant section of the population.

C. J. Earl, an Irish-born physician who obtained his DPM at London University in 1930 and worked at Caterham Asylum for child and adult 'mental defectives', was frustrated by this fact. Earl also held an appointment as Consultant Psychiatrist under the Birmingham Regional Hospital Board and as Lecturer in Mental Testing at the Maudsley Hospital. ${ }^{183}$ In 1933, he presented a paper to the British Psychological Society in which he pointed out that 'such studies as have been made on idiots have been concerned almost wholly with their cognitive ability. Their dynamic and emotional psychology has been very little explored. ${ }^{184} \mathrm{He}$ argued that because there was a general lack of interest in the treatment of this section of the population, dynamic psychology and the concepts used within it were flawed and inconsistent because they did not include defective populations. As he put it:

'The dynamic psychologists ... have concerned themselves almost entirely with the intelligent; even, it may be said, with the intelligentsia. Discussion of the emotional aspect of the psychosis, therefore, is handicapped by lack of emotional standards which may be considered "normal" for idiocy. ${ }^{185}$

Earl claimed that one visitor to see the wards at Caterham was so stunned by this fact that he offensively exclaimed: 'these boys simply 
reek of schizophrenia. ${ }^{186}$ Earl argued that there were many similarities in the behaviour of 'schizophrenics' and 'mental defectives'. These included the adoption of unusual gaits, such as the 'typical posture of schizophrenic stupor, with bent head and semiflexed knees - hands hanging idly by the sides', as well as 'muscular catatonia' and unusual 'hyperkinetic' monotypies such as rapidly rotating the body or moving the arms. Furthermore, both types were reported to commonly display 'the causeless laughter and weeping, the solitary habit, the impulsiveness, and the anomalous responses to stimuli. Earl himself claimed that in one particular group of patients, 'autism is seen in all the cases', as they were 'not interested in their surroundings; and are often solitary, sometimes morose, refuse to mix with others and tend to conceal themselves under tables or in corners. ${ }^{187}$ However, as the 1930 s progressed, dynamic psychology became increasingly distanced from the study of mental defect and the concepts developed within it therefore took on an increasingly bizarre hue. Earl's appeals to consider this group within dynamic psychology fell on deaf ears, particularly as mental deficiency law became increasingly exclusionary following the recommendations of the 1929 Wood Report to refer all children with IQs below 50 directly to the Board of Control. A 1934 memorandum advised all School Inspectors to do just that, meaning that these children never entered the domain of psychological study as it was being developed in schools and child guidance clinics.

Because 'defective' thought was not considered within studies of developmental psychology and social development, the concept of autism, as it was defined in these fields until the 1950s, was wholly inadequate and incomplete, to say the least. The child population investigated and treated by the first generation of professional child psychologists interested in social development and its antitheses was characterised by a gaping hole where 'ineducable' and 'mentally defective' children should have stood, and where they would indeed go on to stand in the post-1960s constructions of child psychology. This gaping hole defined the kind of research that was conducted on social development in children in this period. The first model of child psychology was determined to apply the logic of evolutionary theory and instinct theory to explain the place of the infant or child in the society that he or she inhabited. This representation of psychology would later rely heavily on naturalistic models, drawing from ethology and animal studies 
to support this view of child psychology. ${ }^{188}$ However, practically every study in child psychology conducted in this vein failed to represent the section of children regarded as 'ineducable'. Qualitative studies, such as those conducted by Susan Isaacs and Melanie Klein, were always focused on a section of the population that, however troubled, was nevertheless believed to be 'educable'. Furthermore, all studies in statistical psychology using factor-analytic techniques only examined the child population who were able to pass tests that demonstrated that they had an acceptable intelligence ratio of over 70 . Studies examining the 'mentally defective' child were not only few and far between but were also regarded as part of a backwater science with very little relevance to general psychology. Mental deficiency instead existed as a conceptual dustbin, an area of psychological experience that psychologists need not consider. Despite the administrative problems of properly defining it, mental deficiency simply was not an issue that psychologists were interested in. Ultimately, when it came to 'defective' cases, even specialist psychological and psychiatric clinics such as the Maudsley, the Tavistock and child guidance clinics served as little more than dumping grounds for cases that were just too difficult to cope with. ${ }^{189}$ The development of the psychological sciences up until the 1950s would be constantly overshadowed by the absence of this highly significant section of the population.

In psychological theories developed in the 1930s, autism, autoerotism and primary narcissism defined the pre-social or non-social aspects of infant and child thought. However, these concepts were often employed in a way that was abstracted, idealised and unrealistic because they were associated with a concept of the 'social' world that was based on the segregation and marginalisation of a major section of the child population. Furthermore, they were formulated when the idea of 'social development' was fundamentally tied up with the social Darwinian idea that intelligent, civilised, developed populations represented higher forms within the stages of evolutionary development, as evidenced in the work of McDougall. These major limitations to psychological theory in the early twentieth century were manifested in the inadequacy of children's rights to education. They were also a function of the prejudice with which ideas of 'lower' and 'higher' forms of social development were constructed using the logic of evolutionary sciences. 
Even though psychological sciences were advancing rapidly in the 1920 s and 1930s, theories of social development within them were strongly limited by these factors. Thus, when autism first entered the language of child psychological professionals, it entered an extraordinary and unrealistic descriptive domain. Here, professionals were attempting to describe social development and its obverse, whilst simultaneously being circumscribed in their conceptualisation of what constituted child thought. Mental deficiency law made certain forms of thinking uninteresting and irrelevant, whilst also putting pressure on average or typical infants to produce thought that could revolutionise and develop the psychological sciences.

Although the 1920s and 1930s saw a huge increase in the production of data and information on child development, 'mentally defective' children were neglected in these studies. Psychologists, such as Burt, were so interested in developing statistical techniques and methodologies that they failed to appreciate the significance of the population that they were continually excluding via the technology of the intelligence test. Likewise, Isaacs and others tried so hard to develop a coherent and comprehensive description of social development that they failed to appreciate that this did not apply to the 'mental defectives' who were excluded from the social system that their own work supported. The concrete and conceptual exclusion of mental defectives from society meant that those who were attempting to construct theories of social development, binding statistical sciences with instinct theory, were continually being duped by the fact that their statistical models never actually assessed total populations, but only idealised versions of psychological 'normality'. What is more, child psychiatrists who studied complex cases were too enthralled with adult mental sciences to really engage with psychological development in children with low intelligence. It is for this reason that the first autism was always destined for failure as part of a complete theory of social development in children.

\section{Notes}

1 Hendrick, Child Welfare: England 1872-1989, pp. 54-56; Jennings, The Private Citizen in Public Social Work.

2 Harris, The Health of the Schoolchild; Hendrick, 'Child labour'. 
3 Sutherland and Sharp, Ability, Merit and Measurement.

4 Thomson, The Problem of Mental Deficiency, pp. 17-19; Wiener, Reconstructing the Criminal.

5 E.g. Jones, Social Darwinism and English Thought.

6 Goodey, A History of Intelligence and 'Intellectual Disability'.

7 Berrios, The History of Mental Symptoms, p. 160.

8 Sutherland and Sharp, Ability, Merit and Measurement, p. 29; Wright, Down's: The History of a Disability.

9 Dickson, The Science and Practice of Medicine in Relation to Mind, pp. 322326.

10 Sutherland and Sharp, Ability, Merit and Measurement, p. 16.

11 Berrios, 'Retard mental et psychiatrie'.

12 Rose, The Psychological Complex.

13 Rose, The Psychological Complex; Young, Mind, Brain and Adaptation in the Nineteenth Century; Wooldridge, Measuring the Mind.

14 Forrester, '1919: Psychology and psychoanalysis', 38-39; Rose, The Psychological Complex, pp. 4, 115.

15 Searle, The Quest for National Efficiency.

16 Wooldridge, Measuring the Mind.

17 McDougall, An Introduction to Social Psychology.

18 Hearnshaw, A Short History of British Psychology 1840-1940, p. 187.

19 E.g. Monroe, 'Discussion and reports', 68-70.

20 Rose, Powers of Freedom, pp. 112-119.

21 Wooldridge, Measuring the Mind, p. 78.

22 G. Jones, Social Darwinism and English Thought; Searle, The Quest for National Efficiency.

23 Soloway, Demography and Degeneration; Peel, ed., Essays in the History of Eugenics; Thomson, The Problem of Mental Deficiency.

24 Rose, Powers of Freedom, pp. 112-119.

25 McDougall, Social Psychology, 1st edn, p. 13.

26 Wooldridge, Measuring the Mind, p. 77; Hearnshaw, A Short History of British Psychology 1840-1940, p. 202.

27 Burt, Mental and Scholastic Tests; Burt, 'The measurement of intelligence by the Binet tests'.

28 Rose, The Psychological Complex; Wooldridge, Measuring the Mind; Sutherland and Sharp, Ability, Merit and Measurement.

29 Sutherland and Sharp, Ability, Merit and Measurement, p. 55.

30 Vidal, Piaget before Piaget. 
31 Bleuler, Dementia praecox oder gruppe der schizophrenien, pp. 52-56.

32 Bleuler, Dementia praecox oder gruppe der schizophrenien, p. 52.

33 Freud, Standard Edition, vol. VII, pp. 130-243.

34 Freud, Standard Edition, vol. VII, pp. 181-183.

35 Janet and Raymond, Les obsessions et la psychasthenie, pp. 61-137.

36 Bleuler, Dementia Praecox or the Group of Schizophrenias, p. 373.

37 Bleuler, Dementia Praecox or the Group of Schizophrenias, pp. 66-67.

38 Bleuler, Dementia Praecox or the Group of Schizophrenias, p. 374.

39 Ellenberger, The Discovery of the Unconscious, p. 149; Moskowitz, 'Pierre Janet's influence on Bleuler's concept of schizophrenia'.

40 Berrios, The History of Mental Symptoms.

41 Freud, Standard Edition, vol. XIV, p. 74.

42 Freud, The Freud-Jung Letters, pp. 172-173, 178-179.

43 Bleuler, Dementia Praecox or the Group of Schizophrenias, p. 373.

44 Claude et al., 'Démence précoce, schizopmanie at schizophrénie'.

45 Harris, 'Piaget in Paris'.

46 Chapman, Constructive Evolution, p. 121.

47 Piaget, 'La pensée symbolique et la pensée de l'enfant', 290-293, 303-304.

48 Vidal, Piaget before Piaget, pp. 209-210.

49 Piaget, 'La pensée symbolique et la pensée de l'enfant', 290-293, 303-304.

50 Vidal, Piaget before Piaget, pp. 209-210.

51 Chapman, Constructive Evolution, pp. 48-50.

52 Piaget, 'La pensée symbolique et la pensée de l'enfant', 290-293, 303-304.

53 E.g. Searle, Eugenics and Politics in Britain, 1900-1914, p. 32.

54 Thomson, The Problem of Mental Deficiency, p. 33.

55 Sutherland and Sharp, Ability, Merit and Measurement, pp. 40-41.

56 Sutherland and Sharp, Ability, Merit and Measurement, p. 61; Mental Deficiency Act 1913, quoted in K. Jones, A History of the Mental Health Services, pp. 204-205. In Scotland, the 1913 Mental Deficiency and Lunacy (Scotland) Act initiated similar changes.

57 K. Jones, A History of the Mental Health Services, p. 209; Sutherland and Sharp, Ability, Merit and Measurement, pp. 46-47.

58 Sutherland and Sharp, Ability, Merit and Measurement, p. 48; Thomson, The Problem of Mental Deficiency, p. 232.

59 Sutherland and Sharp, Ability, Merit and Measurement, p. 297.

60 Sutherland and Sharp, Ability, Merit and Measurement, p. 60.

61 Wooldridge, Measuring the Mind, p. 87.

62 Burt, Distribution and Relations of Educational Abilities, p. 35. 
63 Many debates have raged over whether or not Burt faked his data in order to do this. See Mackintosh, Cyril Burt.

64 Shephard, $A$ War of Nerves.

65 Dwork, War Is Good for Babies and Other Young Children, p. 211.

66 Hendrick, Child Welfare: England 1872-1989, p. 144.

67 Rose, The Psychological Complex, p. 162; Dicks, 50 Years of the Tavistock Clinic; Miller and Rose, 'The Tavistock Programme'.

68 Dicks, 50 Years of the Tavistock Clinic, p. 29.

69 Rose, N. 'The Tavistock'.

70 Evans et al., 'Managing the "unmanageable".

71 Stewart, 'U.S. influences on the development of child guidance and psychiatric social work'.

72 Stewart, Child Guidance in Britain, 1918-1955, p. 5.

73 Thom, 'Wishes, anxieties, play, and gestures', p. 208.

74 Steiner, 'Background to the scientific controversies'.

75 Sayers, 'British psychology and psychoanalysis', pp. 215-216, 219.

76 Gerson, 'Individuality, deliberation and welfare in Donald Winnicott'.

77 Holloway, Women and Work in Britain since 1840.

78 Selleck, English Primary Education and the Progressives, 1914-1939, p. 40; Wooldridge, Measuring the Mind, pp. 117-119.

79 Berrios, 'Historical aspects of psychoses', 489.

80 Piaget, Le langage et la pensee chez l'enfant, p. 62.

81 Piaget, Le langage et la pensee chez l'enfant.

82 Piaget, Judgment and Reasoning in the Child, p. 209.

83 Likierman, Melanie Klein.

84 Appignanesi and Forrester, Freud's Women.

85 Klein, 'Criminal tendencies in normal children', p. 174.

86 Klein, 'The psychological principles of infant analysis', 25.

87 Klein, 'Personification in the play of children', 195.

88 Klein, 'The importance of symbol-formation in the development of the ego', 36-37.

89 Klein, 'The importance of symbol-formation in the development of the ego', 36-37.

90 Klein, 'The importance of symbol-formation in the development of the ego', 36-37.

91 Klein, 'The importance of symbol-formation in the development of the ego', 38-39.

92 Klein, 'Personification in the play of children'

93 Isaacs, Social Development in Young Children, p. 312. 
94 Klein, 'The psychotherapy of the psychoses (IV)', 242.

95 Klein, 'A contribution to the theory of intellectual inhibition'.

96 Isaacs, 'Anxiety in the first year of life'; Klein, 'A contribution to the psychogenesis of manic-depressive states'.

97 Glover, 'A psycho-analytic approach to the classification of mental disorders', 823.

98 Reisman, A History of Clinical Psychology.

99 Gesell, The Mental Growth of the Pre-school Child. Gesell, Infancy and Human Growth.

100 Doll, Mental Deficiency Due to Birth Injuries; Sutherland and Sharp, Ability, Merit and Measurement, pp. 126-127; Richards, Putting Psychology in Its Place, pp. 253, 285.

101 Baldwin and Stecher, The Psychology of the Preschool Child; Stern, Psychology of Early Childhood up to the Sixth Year of Age; Fenton, A Practical Psychology of Babyhood; Alpert, The Solving of Problem-Situations by Preschool Children; Rand et al., Growth and Development of the Young Child.

102 Hazlitt, 'Modern trends in infant psychology'.

103 Bridges, The Social and Emotional Development of the Pre-school Child; Bühler, 'The social behaviour of children'; Pickren et al., Portraits of Pioneers in Developmental Psychology.

104 Isaacs, Intellectual Growth in Young Children, pp. 5-6.

105 Isaacs, Social Development in Young Children, pp. 7-8.

106 Isaacs, Social Development in Young Children, p. 8.

107 E. Valentine, 'Women in early twentieth century psychology'; Anon., 'Beatrice Edgell, 1871-1948'.

108 Hazlitt, 'Modern trends in infant psychology'.

109 Bond and Tryphon, 'Piaget and method', p. 173.

110 Piaget, Le langage et la pensee chez l'enfant; Piaget, La representation du monde chez l'enfant; Piaget, Le jugement moral chez l'enfant; Piaget, La naissance de l'intelligence chez l'enfant; Piaget, La formation du symbole chez l'enfant; Piaget, La causalite physique chez l'enfant.

111 Bond and Tryphon, 'Piaget and method', p. 174.

112 Sutherland and Sharp, Ability, Merit and Measurement, p. 55.

113 Sayers, 'British psychology and psychoanalysis', pp. 215-216.

114 Sayers, 'British psychology and psychoanalysis', p. 219; Wooldridge, Measuring the Mind, pp. 133-134.

115 Graham, Susan Isaacs, p. 235. 
116 Isaacs, Social Development in Young Children, pp. 288-289.

117 Isaacs, Social Development in Young Children, p. 12.

118 King, 'Background and development of the Freud-Klein controversies'; Pines, 'Glover, Edward George'; Kubie, 'Edward Glover'.

119 Valier, ed., Psychoanalysis and Crime in Britain during the Inter-war Years.

120 Glover, The Diagnosis and Treatment of Delinquency.

121 Wooldridge, Measuring the Mind.

122 Thomson, Psychological Subjects, pp. 131-132.

123 C. Valentine, 'Reflexes in early childhood'.

124 Auden, 'The maladjusted child'.

125 Mead, 'The primitive child', p. 670.

126 Lowenfeld, Play in Childhood, p. 105.

127 Lowenfeld, Play in Childhood.

128 Isaacs, Social Development in Young Children, p. 11.

129 Lowenfeld, Play in Childhood, p. 129.

130 Searle, 'Some contrasted aspects of psycho-analysis and education', British Journal of Educational Psychology 2 (1932), quoted in Isaacs, Social Development in Young Children, pp. 285-286.

131 Isaacs, Social Development in Young Children, p. 11.

132 Hayward, 'Germany and the "making” of English psychiatry'; Engstrom, 'Organising psychiatric research in Munich'.

133 Evans and Jones, 'Organ extracts and the development of psychiatry'.

134 Forrester, '1919: Psychology and psychoanalysis'.

135 Evans and Jones, 'Organ extracts and the development of psychiatry'

136 De Jong and Baruk, La catatonie expérimentale par la bulbocapnine; Berrios, The History of Mental Symptoms.

137 Duché, Histoire de la psychiatrie de l'enfant, p. 337.

138 Kanner, Child Psychiatry, pp. 493-494; Parry-Jones, 'Childhood psychosis and schizophrenia', p. 4.

139 Lombardo and Foschi, 'Escape from the dark forest', 48.

140 Berrios, 'Historical aspects of psychoses'.

141 Kanner, Child Psychiatry; Kasanin and Kaufmann, 'A study of the functional psychoses in childhood'; Creak, 'Psychoses in children'.

142 Kanner, Child Psychiatry.

143 Graham, 'Creak, (Eleanor) Mildred (1898-1993)'.

144 Cole et al., 'Discussion on the mental sequelae of encephalitis lethargica', 22.

145 Cole et al., 'Discussion on the mental sequelae of encephalitis lethargica', 27. 
146 E.g. Bethlem Museum of the Mind Archives. Maudsley Case Notes 1923-1938 (BMMAMCN): S11.CFM: CFM003.585; CFM014.059.

147 BMMAMCN.S11.CFM: Child admission sheets 1928, 1931, 1935 and 1937/8; BMMAMCN: Maudsley Hospital Reports 1927-1931; 1932-1935.

148 BMMAMCN.S11.CFM: CFM017.200; CFM159.521; CFM163.650; CFM024.738.

149 Creak, 'Psychoses in children', 528.

150 Creak, 'Psychoses in children', 520-521; On Bleuler's use of the terms 'autistic' and 'dereistic', see Shorter, A Historical Dictionary of Psychiatry, pp. 34-35.

151 G. Richards, 'Campbell, Charles Macfie (1876-1943)'.

152 Campbell, quoted in Creak, 'Psychoses in children'.

153 Creak, 'Psychoses in children', 521.

154 Creak, 'Psychoses in children', 522.

155 Creak, 'Psychoses in children', 522.

156 Lay, 'Schizophrenia-like psychoses in young children', 119.

157 Lay, 'Schizophrenia-like psychoses in young children', 126-127.

158 Quoted in O'Connor and Tizard, The Social Problem of Mental Deficiency, p. 34.

159 Hilliard and Kirman, Mental Deficiency, p. 8.

160 Wellcome Trust Archives (WTA): WT/PSY/KEN/4/1: Correspondence between Lucy Fildes and Henry Head (1924).

161 WTA: WT/PSY/KEN/4/1: Reference letters for Lucy Fildes from Evelyn Fox (1928), F. B. Bartlett (1928) and C. S. Myers (1924).

162 WTA: WT/PSY/KEN/4/1: L. Fildes, 'Word deafness: A psychological contribution to the study of mental defect', thesis approved by the University of Cambridge Psychological Laboratory 1928, p. 112.

163 WTA: WT/PSY/KEN/4/1: Fildes, 'Word Deafness', p. 97.

164 WTA: WT/PSY/KEN/4/1: Fildes, 'Word Deafness', p. 116.

165 WTA: WT/PSY/KEN/4/1: Fildes, 'Word Deafness', p. 105.

166 WTA: WT/PSY/KEN/4/1: Fildes, 'Word Deafness'.

167 Fildes, 'Some memory experiments with high-grade defectives'

168 I. R. Ewing, The Handicap of Deafness; Pritchard, Education and the Handicapped, 1760-1960.

169 A. W. G. Ewing, Aphasia in Children.

170 Collins, 'England', p. 199.

171 Thomson, The Problem of Mental Deficiency, p. 142. 
172 Slater, 'The inheritance of manic-depressive insanity'; Turner and Penrose, 'An investigation into the position in family of mental defectives'; Penrose, A Clinical and Genetic Study of 1280 Cases of Mental Defect.

173 Thomson, The Problem of Mental Deficiency.

174 Burt, The Backward Child, p. 105.

175 Mackintosh, Cyril Burt.

176 Herd, The Diagnosis of Mental Deficiency, pp. 40, 74.

177 Penrose, Mental Defect, p. 49.

178 Fortes, 'Perceptual tests of general intelligence for inter-racial use'.

179 Herd, The Diagnosis of Mental Deficiency, pp. 135-151.

180 Terms employed by Burt in The Backward Child.

181 Hearnshaw, A Short History of British Psychology 1840-1940, p. 12.

182 Thomson, The Problem of Mental Deficiency, p. 127.

183 Anon., 'Obituary: C. J. C. Earl'; Malster, St Lawrence's.

184 Earl, 'The primitive catatonic psychosis of idiocy', 230.

185 Earl, 'The primitive catatonic psychosis of idiocy', 248.

186 Earl, 'The primitive catatonic psychosis of idiocy', 244.

187 Earl, 'The primitive catatonic psychosis of idiocy', 233-234, 244.

188 Vicedo, The Nature and Nurture of Love.

189 Evans et al., 'Managing the "unmanageable"'. 


\section{2 \\ The first autism controversies}

The disruption of harmony

Most people are aware of many controversies surrounding autism today, as well as those that abounded in the 1960s asserting the fault of mothers in causing the condition. Other major controversies have centred on the MMR vaccine and the use of mercury in vaccines. More recently, debates have exploded over whether autism can truly be defined as an illness or medical condition, or whether it is in fact merely a variation in the normal human condition. Thus, when the history of the concept of autism is fully explored and examined, one should not be surprised at the level of controversy and the impassioned arguments that have been, and still are, made about it. Autism, and its association with a wider model of social development in children, has always lent itself to controversy and intense debate about what those who purport to advance any theory of it are actually arguing. It has been open to such debate because it defines such an important and vital part of the theory of psychological development. It has always been a conduit for wider social anxieties because of the presumptions made about its potential to describe the origins of social development. To take on so much theoretical baggage could never have been easy.

The first major controversies over the theory of autism and social development in children emerged in the midst of war. By the mid-1930s, political posturing over which European nation was the strongest had intensified as Britain and other countries jostled to display their imperial power and national prowess. Children were often used as examples of the thriving British race, as in the 1937 Festival of Youth in which the king and queen, along with 60,000 others, watched a 10,000-strong 
display of British youth at Wembley Arena. ${ }^{1}$ With the outbreak of the Second World War in 1939, displays of prowess turned to outright military conflict. In Britain, the Chamberlain government shifted its focus to external pressures. This had a major impact on how children's welfare services were run. It also had an impact on who was available to run those services, and it heightened theoretical tensions over the best way to conceptualise and treat psychological problems in children. It led to a number of major scientific controversies about the way to collect and employ scientific data when making claims about children's early development.

As discussed in Chapter 1, the first autism was adopted into psychological theory in Britain primarily via major mental health institutions, child guidance clinics and progressive and permissive schools. It was not integrated via the mainstream education system, nor via the Board of Control authorities who preferred to work with more political ideas of social development and the presumed inability of certain groups to achieve this. One important consequence of this was that the children to whom the autism concept was first applied were always those who came within a normal range of intelligence and who had not been singled out as a supposed threat to society and placed in institutional care. As part of a growing concern with children's rights, psychological clinics collaborated with social workers in order to help gather knowledge of family life, as part of a growing network of social investigators. Although 'deficient' children were disregarded, other children's home lives were coming under intense scrutiny.

Shortly before the Second World War broke out, the Child Guidance Council and the National Committee for Mental Hygiene were consulted for a report on voluntary mental health services. The Feversham Report planned to extend child guidance services and child mental health services as part of a wider programme of preventing child 'maladjustment', a broad term used to define a child whose instincts were not adjusted to their environment. However, these plans were all put on hold as the pressures of war increased. ${ }^{2}$ Whilst the war led to the closure of many child guidance clinics as many of the staff were drafted into the armed forces, ${ }^{3}$ the conflict also stimulated the development of some forms of child observation and psychotherapeutic techniques by enabling an unfortunate testing ground for theories on the psychological impact of family breakdown, as many children were separated 
from their families during the mass evacuations from London during the Blitz. ${ }^{4}$ In just the first phase of evacuation in 1939, 750,000 schoolchildren and 542,000 mothers with small children were removed to the countryside. ${ }^{5}$ In London, according to official figures, half the entire school population was evacuated. ${ }^{6}$ Susan Isaacs, Lucy Fildes and John Bowlby, a young medically trained psychologist who had studied with most major figures in English psychology and psychoanalysis at the time, including Melanie Klein and Cyril Burt, were amongst a growing group of psychologists and psychoanalysts who studied the responses of children to these difficult circumstances and the impact on their mental health, culminating in the Cambridge Evacuation Survey of $1941 .^{7}$

During the war, huge controversies and vitriolic arguments raged about how psychologists gathered evidence to make claims about early child development. Whereas the interwar period had witnessed a rather blasé attitude towards the integration of intelligence tests and other scientific evidence as the basis for changes in government policy towards children with 'mental defect', the Second World War brought new suspicions about science, and in particular mistrust of claims made by eugenicists. In the interwar period, ingrained prejudice manifested itself in the belief that certain national and racial groups were superior to others, a belief that often found its way into language about the scourge of 'mental defectives', and which by the Second World War had become increasingly disconcerting. Furthermore, the idea that psychological health necessarily led to a healthy society seemed at odds with the mass violence that was spreading across Europe. The war ushered in a deeper awareness of the way that political and military powers could adopt theories regarding hereditary transmission and exploit them for their own ends. The seamless rhetoric that had united psychological and social theory was then placed on increasingly shaky ground.

\section{Instincts, science and proof}

Because the first theory of autism was so bound up with a theory of human instincts and drives, any threats to a science of human instinct were necessarily also a threat to the idea of autism as an early form of thought characterised by hallucinatory wishes. Although most child psychological sciences were based on instinct theory, some psychologists 
had not been impressed with it. Conwy Lloyd Morgan (1852-1936), a British experimental psychologist, had rejected the concept of instinctive 'drives' and the 'hormic' theory of action, which had been advanced by psychologists such as McDougall. Morgan thought that instinctive acts should not be conceived as the result of impulsive forces or powers because these forces were metaphysical entities. He claimed that the concept of 'behaviour' should be used to describe the actions of both humans and animals because it was more scientific and devoid of any metaphysical claims. ${ }^{8}$

Although Morgan had little support amongst child development specialists in Britain, in the USA, 'behaviourism', as the support of behavioural concepts came to be known, was advanced enthusiastically by John Broadus Watson at Johns Hopkins University and used to develop a theory of child learning. ${ }^{9}$ Behaviourism gained many followers in the USA, such as Robert Yerkes, a psychologist and primatologist who was president of the American Psychological Association. These psychologists used experimental studies of learning expounded by E. L. Thorndike from the Teachers College at Columbia University and also adopted the work of the Russian physiologist, I. Pavlov, which generated a terminology for describing the processes whereby children learned based on stimulus, response and reinforcement, which came to be known as 'conditioning. The early behaviourists prided themselves on basing their theories only on overt, visible, measurable phenomena. ${ }^{10}$ They shunned the study of subjectivity and selfhood in psychology.

Isaacs and other British child psychologists criticised the enthusiasm for behaviourism that was emanating from the USA, as they had criticised social development scales. As Isaacs and others pointed out, because of the approach that they took, behaviourists cleverly dodged the central problems plaguing those involved in developmental psychology, namely, the way that an infant developed a relationship to reality and a relationship to society. The description and conceptualisation of autism, primary narcissism and autoerotism, and their relation to childhood schizophrenia and psychosis, was at the heart of these problems, which behaviourists happily bypassed in their focus on behaviour management.

The 1930s had seen increasing support for instinct theory in Britain, and an increasing body of literature that described the 'conflicts' that emerged when animal instincts were confronted with social 
norms. In the twenty-third edition of An Introduction to Social Psychology, published in 1936, McDougall continued to defend his theory of instincts, stating that after the sale of 62,000 copies of his book in the English language, with more in translation, 'I am ever more convinced that these principles are valid. ${ }^{11}$ Furthermore, in 1938, Freud and his family moved from Vienna to London in order to escape persecution. Freud's psychological take on instincts, society and individualism was becoming increasingly well known in Britain, in particular his work on Civilisation and Its Discontents (1930), which used the theory of unconscious instinctive drives to explain the psychological conflict that civilised societies inflicted on individuals driven by animal desire. ${ }^{12}$ McDougall's Psychoanalysis and Social Psychology (1936) developed a similar argument, ensuring that instinct theory was recognised as paramount to understanding individual behaviour and its conflicts with law and social norms.

Following the outbreak of war, English psychologists became increasingly defensive of their model of human instincts and its potential for making political statements about the need for psychological support to assist humans to adapt to the civilised world. At the same time, behaviourists were forcing instinct theorists to generate more substantive evidence for the claims they made about human nature as all psychologists felt intimidated by the prospect that their theories on society and social development may fall on deaf ears after the war. In the early 1940s, a number of arguments and controversies arose amongst psychologists, psychoanalysts, educationalists and other professional groups working with children in Britain that all centred on the innate properties - 'impulses', 'instincts' and 'drives' - that were thought to structure the thoughts of children. The theory of autism, autoerotism, primary narcissism and related concepts was at the heart of these debates that interrogated the evidential base for a theory of instinctive drives in children and their impact on early thought.

In November 1941, Cyril Burt made the first contribution to a major symposium on Instincts that involved many major British psychologists such as T. H. Pear, Professor of Psychology at the University of Manchester, James Drever, Professor of Psychology at the University of Edinburgh, and the founder of the British Psychological Society, C. S. Myers, which was being published in the British Journal of Educational Psychology. ${ }^{13}$ Elsewhere, at the British Psychoanalytic Society, 
concerns surrounding the scientific description of instincts in psychology were also raised. In February 1942, just three months after the debate on instincts erupted in the British Journal of Educational Psychology, a major crisis about evidence and instincts also exploded within the British Psychoanalytic Society between Melanie Klein and Anna Freud. The story of the 'controversial discussions' has often been told against a background of personal infighting following the death of Freud, sparked by disagreements between the established group of psychoanalysts in Britain and the Viennese émigrés whom Ernest Jones, the president of the Society, had invited to Britain following the Nazi occupation of Vienna. ${ }^{14}$ However, the passionate debates that took place between members of the British Psychoanalytical Society were strikingly similar to the debates that were also taking place between educational psychologists and teachers sparked by the introduction of behaviourist and social work methods from the USA. All of these discussions centred on the problem of how to produce convincing scientific evidence for the existence of instinctive drives in infants and children. This necessarily encompassed a defence of all the psychological concepts that spun off from instinct theory, including the theory of autism, autoerotism and primary narcissism as the most primary, and developmentally significant, states of mind.

Burt was the most vociferous supporter of instinct theory and argued strongly that statistical psychology, based on Galtonian principles, should be employed in conjunction with instinct theory in order to gain evidence about child development. He claimed the human organism purposefully strove towards particular aims and this gave human behaviour its essential characteristics. Instincts provided the force that lay behind this determination, giving these aims 'energy'. Burt's description of instinctive drives drew from earlier models of the transfer of energy that he regarded as the best working model for the science of instincts. He also adopted Freudian terminology and concepts, claiming that instinctive 'unconscious motives' were biologically the most important drives in man. He argued that the body contained 'reserves of extra energy' that were 'automatically released at times of special crisis' to support instinctive motivations and aims. ${ }^{15} \mathrm{He}$ thought that behaviourists disregarded these fundamental neurological facts. Although the science of psychology needed development, he claimed that behaviourist models did not solve any problematic issues 
but merely shelved them. Instead of abandoning the foundations of psychology, Burt argued that psychologists and psychiatrists needed to conduct further factor-analytic studies that could then be used to generate a list of the fundamental human instincts that structured character traits in individuals.

Burt set out a very clear method for the collection and analysis of data to ensure that the existence of unconscious drives could be verified. He argued that infants displayed a wide range of behaviours in the first two or three years of life that could be easily predicted and recorded: 'Even when he [the baby] seems to be simply wriggling, his hand is more likely to move to his mouth than to any other part; his thumb more frequently approaches his first finger than any of the other three; his vocal organs give vent to certain melodic patterns and to certain articulate syllables more often than others. ${ }^{16}$ Older children will also produce certain types of behaviour that can be predicted such as 'running away, hiding, keeping perfectly still, crying out in a particular way, producing a particular expression on the face', etc. If data regarding these reactions, as well as their stimuli, were collected from large populations and then categorised into specific behavioural and emotional reactions, then, Burt claimed, one would find complete support for instinct theory and unconscious motivation. This would also lead to the identification of children who appeared to lack certain fundamental human instincts. Second, if one then tried to find correlations between the reactions of particular individuals and their parents, one could show that patterns of instincts were inherited across generations. His method was a 'double factorial analysis' that studied correlations in individuals and then correlations between individuals of the 'same family or species.' For Burt this factor-analytic approach would directly challenge all of the behaviourists' claims and reassert instinct theory in psychology. Although environmental and learned behaviours should be taken into consideration, the aim of psychologists would be to search for individual types with a particular biological make-up that made them susceptible to particular types of behaviour. Psychologists should then be able to predict the likely outcome for every child. ${ }^{17}$ It was with this model in mind that he attempted to prove the existence of unconscious instinctive forces in the child's body that defined the child's identity. In Burt's view, an individual's unconscious could be 
quantified and analysed. He was convinced that statistical methods would make this possible.

Burt claimed that he wanted to replace all behaviourists' claims to science with his own branch of psychology: 'In the present state of our knowledge I hold that there is room and need for a separate branch of psychology which I would call "psycho-dynamics," having much the same relation to "neuro-dynamics" as the classical dynamics of masses has to the atomic physics of quantum theory. Like the former, it would be essentially statistical. ${ }^{18}$ This new psychological science was needed because the measurement of intelligence was not enough to determine the mental functions and the potential social role of infants and children. For Burt, an instinct was a 'complex inherited tendency' that impelled an individual 'to perceive and pay attention to certain objects or situations' and to 'become pleasurably or unpleasurably excited about those objects whenever they are perceived'. These tendencies, which were 'cognitive, affective and conative', influenced the development of individual subjectivity and character. ${ }^{19}$ Any lack or deficiency in particular instinctive drives would affect the development of the child's individuality. Burt's aspiration to use statistical sciences in conjunction with instinct theory in order to generate the basic facts of child development was supported by E. L. Thorndike. ${ }^{20}$ However, James Drever thought that Burt was being 'unduly optimistic' about the potential uses of factor analysis in supporting instinct theory. ${ }^{21}$ Phillip Vernon, a pioneer in intelligence testing and psychological research adviser to the War Office during the Second World War, pointed out the danger of generating scientific proofs about children's characters that could then be used to legitimise apathy regarding social reform. Any administrative system would thus apply false labels to children that would not be helpful for their development. Factorial methods of analysis, he claimed, could only be used to measure objective phenomena and dabbling in them to explain the unconscious and its role in social development was not only dangerous but also bad science. This was somewhat ironic given the marked social apathy that existed around 'mentally defective' children; however, Vernon's point was that instinctive drives, the basis of unconscious thought, could not be measured in the same way as intelligence.

Although Gesell's social development scales and Isaacs' theory of social development were creating new models of psychological 
development in infancy and childhood and the formation of subjectivity and subjective awareness, no one had attempted to validate the claims made within them using statistical psychology in the same way that they had used statistical psychology to validate the theory of intelligence. Although Burt's work on education was accepted within government departments at the time, his view that the doctrine of instincts could be used in the construction of a comprehensive 'insurance' system for all children reflected these interests. By quantifying the exact proportion of children who had particular tendencies, one could draw up plans to administer and manage those children in the education and health care systems, as well as in the growing system of educational psychology that would sit uneasily between these two. In Burt's view, the collection of databanks of information for generating proofs about unconscious forces that were otherwise invisible and unknowable was essential to progress. Theories derived from them could then be used in order to structure future psychological and educational services for these children in Britain.

One thing was clear, in the heart of national and political crisis, psychologists were in desperate need of new forms of evidence that could justify their existence and support their work in a post-war administration. Behaviouristic theories were not enough to explain the development of children's self-identity and their contact with reality. There was a critical need for a new science of child development and its pathological manifestations that could form the basis for political reform.

Infants, the unconscious, autism, autoerotism and primary narcissism

At the British Psychoanalytic Society, other controversial discussions ensued over how to describe the development of subjectivity in infants and children. Although the precise concept of 'autism' was rarely mentioned, the descriptive concepts of 'autoerotism' and 'primary narcissism', a term that had been developed by Sigmund Freud as a response to Bleuler's concept of autism, were discussed frequently. These discussions of whether, and at what age, one could attribute desires and thoughts to infants were never concluded. Yet they continued to exist as important conceptual problems in child psychology because they concerned the origins of relational thought. 
Susan Isaacs supported a method for the scientific defence of instinct theory that was based not on statistics but on detailed observations of the play of individual infants. Isaacs, and the Kleinian group of analysts whom she supported, thought that their scientific observations provided evidence of subjective responses to instincts in infants. These presupposed the existence of complex mental mechanisms that could control, redirect and repress unconscious instinctual urges from the very first moments of life. For example, a phenomenon that they frequently drew attention to was that of feeding difficulties in very young infants. How could these be explained, they asked, were it not for the infant's subjective thoughts that led him to restrain his instincts to consume? Paula Heimann, a loyal Kleinian, claimed that the infant prohibited his desires and impulses in these very early stages of life because he felt himself to be overly greedy and 'cannibalistic' and had the capacity to recognise this fact and correct it unconsciously. ${ }^{22}$

Early in 1943, Isaacs described in detail her thesis that children experienced 'phantasies' in relation to their early experiences that led them to repress or divert internal forces and drives, which could manifest problems in later life. Isaacs claimed that from the moment an infant experienced an instinctual urge, he also had the capacity to think about that urge and to imagine the direction it may take. If an instinctual drive was frustrated, then the infant would also attach a meaning to this experience of frustration through his phantasies. As Isaacs put it: 'Phantasy is the mental corollary, the psychic representative of instinct ... Every impulse, every feeling, every mode of defence is expressed and experienced in such a specific phantasy, which gives it mental life and shows its specific direction and purpose. ${ }^{\prime 23}$ Isaacs then gave examples of the types of phantasies that infants may have in the first few months of life. These were not only libidinal instincts or drives but also destructive instincts and impulses. For example, if the child was feeling 'desires towards his mother', he would experience these, in Isaac's words, as: 'I want to suck the nipple, to stroke her face, to eat her up, to keep her inside me, to bite the breast, to tear her to bits, to drown and burn her, to throw her out of me.24 If these phantasies and desires then stirred up anxiety in the child because he thought that by doing this he may in some way destroy or provoke the mother with his aggression, he could then use other phantasies as defences against these anxieties or as a way of controlling instinctual urges. As Isaacs put it: 'When he feels anxiety, 
stirred up by an aggressive wish, he feels, "I shall be bitten or cut up by my mother". When he feels loss and grief, he experiences (as Freud taught us) "my mother has gone forever". When he wants to restore his mother, he feels "I want to make her better, to feed her, to put the bits together again" and so on. ${ }^{25}$ Although Isaacs was not claiming that the child experienced these phantasies in words, it is clear that she was claiming that the child, through these psychic experiences, actually felt and imagined that he was engaging in these activities. The infant thus felt this in an omnipotent way, as if every wish that he or she had actually came true.

In 1943, Isaacs published a paper on 'An Acute Psychotic Anxiety Occurring in a Boy of Four Years.' Her understanding of 'psychosis' did not relate to the boy's symptoms, which she described as 'periodic and severe attacks of rage when he is frustrated. ${ }^{26}$ Rather, it referred to his internal state of mind, which she claimed to have uncovered through observation of the boy's play. Isaacs thought that his play during analytic sessions showed 'psychotic anxieties':

In terms of the primary instincts, he was showing in these actions and threats his need to deflect outward the destructive impulses (the death instinct); in terms of emotional experience, he was urgently trying to get these frightening objects and events outside himself, because of his overwhelming anxiety about internal dangers. He felt, when in the grip of these phantasies, that all he could do with external objects was to destroy them. ${ }^{27}$

This description of a 'psychotic' state was premised on the idea that similar thought processes occurred in the early stages of life, before the infant developed relationships to other people. As in the work of Klein, the concept of psychosis was fused with all early thought processes, so that even pre-social or pre-relational thinking was characterised by a complex phantasy life. ${ }^{28}$

Taking a term from Ferenczi, and highlighting the fact that the first desires that an infant has are oral, Isaacs and the Kleinians claimed that the infant used his early experiences and phantasies as the basis to build up a 'rudimentary ego' or sense of self. The infant would 'introject' good experiences that came to form a part of the self, and 'project' painful experiences that were not associated with this ego. Along with this rudimentary ego, the child would also develop a rudimentary 
'super-ego', which could invoke feelings of anxiety and guilt and censure the instinctive desires of the child. The Kleinians claimed that these psychic mechanisms developed after the child first experienced a feeling of loss and unconsciously attributed this loss to his own actions. These were termed 'depressive' feelings. The group were never entirely clear about when exactly these feelings first took place, though in a paper given in March 1944, Klein stated that 'the assumption seems justified, that the seeds of depressive feelings, in so far as birth gives rise to feelings of loss, are there from the beginning of life. ${ }^{29}$ As Freud's daughter, Anna, and others would often point out, the Kleinians were essentially positing an early stage of development that structured the mind, and restricted instinctual drives, in a similar way to the Oedipus complex, but which occurred in the very early stages of life. ${ }^{30}$ In other words, it was a model of how laws and social forces impacted on thinking, occurring from the first moments of birth; infants were always social beings.

The critics of the Klein group argued that they were attributing advanced psychical processes to the infant without giving thorough evidence and explanation for these claims. Kate Friedlander, a colleague of Anna Freud who had also studied juvenile delinquency in children, claimed that Kleinian theory was incompatible with brain anatomy because 'the myelinisation of the white matter of the brain and the formation of the cortex are by no means finished even at the end of the first year of life'. She claimed that 'the formation of conceptions and abstract thinking as well as the faculties which we ascribe to the function of the superego' was dependent upon a fully grown cortex and it was ludicrous to suggest that infants could engage in such advanced thought. As Friedlander put it, 'we would not say that the child does not start to walk in the first weeks of life because it is prevented from doing so by some mental process, but on account of the fact that the motor tracts are not fully developed yet'. If Klein's mental functions were translated into motor functions, 'it would mean that the child starts to walk within the first weeks of life, before it has been sitting up and crawling. ${ }^{31}$

One of the most vociferous opponents to Kleinian ideas about children's mental development was Edward Glover. Glover was highly respected in medical circles and served on the Psychological Committee of the British Medical Association in the planning of a national psychiatry service during the early $1940 \mathrm{~s}^{32}$ Glover accused Isaacs and the Kleinian group of misunderstanding the first stages of life that formed 
the basis for the infant's comprehension of reality and for all scientific thinking. He argued that they were 'addicted to a sort of psychic anthropomorphism' that led them to confuse concepts of the psychic apparatus with actual psychic mechanisms, and then to claim that both were 'phantasy. ${ }^{33}$ In Glover's view, the infant built up the means for reality testing before he started to phantasise about the possible directions that his instincts might take. If this was not fully taken into account then there was a danger that psychoanalytic theories would revert to, and support, pre-scientific models of thinking. Glover argued that in the early stages of life, the child builds up 'memory traces' in the mind that are associated with either pleasurable or painful experiences. The function of these images is that of adaptation, and the image associations develop a reality value. When the child is frustrated, it seeks out images associated with pleasurable experiences and avoids those associated with pain. It is when these images become associated with actual objects that the child is able to prove the existence of reality, and to correlate the subject, the aim, and the object of any instinct that arises in him or her. These early memory traces cannot be associated with phantasies as it is only when the child has an awareness of the subject, aim, and object that he is able to phantasise about these things. To claim that the child phantasised from the beginning of life denied the stages of basic reality testing in infancy. ${ }^{34}$

Anna Freud argued that after an infant was born there was a period of roughly six months when the child was inherently 'narcissistic and autoerotic'. During this phase, the aim of an instinct was fundamental but the object of that instinct was 'only dimly taken into account'. In this state, 'satisfaction counts for everything and objects count for nothing'. The child had no awareness of the effects of his actions on others, had no sense of guilt or anxiety over his actions and no sense of loss. ${ }^{35}$ In 1936, Anna Freud had produced a classic text, The Ego and the Mechanisms of Defence, translated into English the following year, which described the developmental stages of the ego's formation in a clear and lucid way and which served as the model for understanding the ego's defence mechanisms of repression, projection and sublimation. She always maintained that infants could not relate to others in any way in these early stages and therefore these early stages of thinking could not be related to later emotional disturbances. She thus supported a pure psychic state before the onset of phantasy concerning other objects and other people. 
Unperturbed by such criticisms, the Kleinians claimed that they could observe the unconscious thought processes of small infants by observing their behaviour. Isaacs, for example, gave several illustrations of the way that children's behaviour was supposedly indicative of early phantasies. These came in the form of general observations about an infant's behaviour such as their ability to recognise and react to their mother's voice at around one month old and their interest in watching bodies in the room and reacting with happiness or distress to particular people. 'In these observations as to the infant's active concern with his mother's body - both loving and aggressive - we have full confirmation of Melanie Klein's theories', she claimed. In addition, in the observation of their later play activities, such as 'putting one thing inside another, e.g. poking the finger into a hole of a bead, digging nails into soap, putting finger or hand into a can ... pounding, tearing, throwing, opening boxes', after around six months old, Isaacs claimed that one could find 'evidence' of children acting out instinctive phantasies of getting inside and attacking objects, which they developed in early infancy.

The analysis of children would be conducted in relation to these behaviours, which Kleinians associated directly with 'free association' in adults. This technique was based on interpreting the child's 'transference' relation, i.e. 'the feelings, phantasies, and sexual desires' towards the therapist, which she assumed were re-enactments of the child's relation to objects in very early infancy, in particular the mother. Klein claimed that 'the transference situation permeates the whole actual life of the child during analysis'; thus any material that the child brought to analysis was immediately interpreted in relation to this transference relationship, i.e. the child's relationship to the analyst as a person. ${ }^{36}$ Glover and others claimed that both the observation and analysis of children using the Kleinian technique was self-perpetuating and prejudiced. Using this method, anything could be offered up as 'clinical evidence' that Kleinian theories were correct. ${ }^{37}$ Marjorie Brierley argued that the Kleinians were guilty of taking analogies literally, which put limitations on 'understanding the subjective meaning of our unconscious preconceptions about mental processes and to equate these with the processes themselves. ${ }^{\prime 3}$ Many accused the Kleinians of developing religious doctrines and then pretending they were science. Anna Freud went further, arguing that if heretical psychoanalytic techniques and theories were adopted without question, then one could end up with 
a psychotherapeutic institute such as that set up in Berlin under the express wishes of the Nazi regime. ${ }^{39}$

Although the infighting sometimes clouded the clarity of the debate, in all of these discussions it was clear that very important questions were being raised about how scientific evidence could be generated in order to explain psychological development and the formation of relationships in, and also to justify psychological work with, infants and children. The Kleinians did develop quite sophisticated theories to explain forces of energy as they travelled through the body and were then repressed and redirected. In 1943, Susan Isaacs and Paula Heimann wrote an influential paper on the nature of 'regression', in which they outlined their understanding of the way that instinctual drives were frustrated or blocked and then regressed to earlier stages of development. Sigmund Freud's theories on infant sexuality had taught that during child development, the life instinct attached itself to different parts of the body. At first it was attached to the oral zone during suckling, then the anal zone during potty training, and then the phallic, or genital, zone, during the Oedipus complex. In regressive states the force of this instinct, the libido, could revert to one of the earlier 'fixation points' on the body, or to a similar acute phase of attachment towards a particular 'object'. ${ }^{40}$ This occurred to some degree in all mental pathologies. Freud would often discuss the libido in terms of dynamic flows, as he also discussed the movement of mental energy. Isaacs and Heimann used these ideas as the basis for their new metapsychology, but instead of focusing purely on the libido, they also began to theorise the 'death instinct' as if it were also an active force that manifested itself as aggression. They claimed that when there was an excess of aggressive impulses, the libido would get 'dammed up' and then both instincts would 'defuse', causing a backward flow of the instincts towards earlier fixation points. The libido could only overcome such regressive forces by its attempts to 'drain the sources of destructive impulses' and to master, or control, them. In particular, the libido would have to master the early destructive oral impulses from the first stage of life that were felt to be particularly strong. ${ }^{41}$ This detailed explanation of regression via bodily processes offered a concrete explanation of what was otherwise a very problematic concept, yet one that was often vital in the diagnosis of schizophrenia and psychosis in childhood. 
Through these descriptions of energy 'draining' from one source to another, Isaacs and Heimann's theories appeared to support the existence of some kind of primordial substance such as McDougall's neurin. In their view the drainage and transmission of energy took place between the instinctual forces of life and death. In addition, although they described regression of genital impulses back towards the anal and the oral stages, it was clear that they considered the destructive oral impulses as primary. As Glover pointed out, this implied that there was a primary independent core to the unconscious through which all instincts had to pass. ${ }^{42}$ It was clear that the Kleinian theory of instincts envisaged the human being as something like a hydraulic system with a central control device. Instincts were channelled through the body after being adapted by a central unconscious gauge that could determine 'good' and 'bad' forces and deal with them appropriately. The Kleinians' tendencies to simplify the vicissitudes of both instincts and mental energy lay behind Glover and Freidlander's claims that Klein and her adherents were not true adherents of 'dynamic' psychology because their description of instinctive drives was too 'primitive. ${ }^{43}$ Klein's theory was controversial because it attempted to explain the origins of all subjective thinking processes. In any case, it was the Kleinians who developed the most comprehensive theory of the role of thinking processes in the very earliest stages of socialisation and this is why their work received so much attention and interest. It was a comprehensive theory of how infants developed relationships with others in the earliest stages of life via a theory of instinctive motivation.

Nevertheless, as demonstrated in Chapter 1, although Klein, Isaacs and other child psychologists went into the depths of psychological theory to develop a complete theory of human relationships, they were still blinkered by the fact that they did not include the mentally defective populations. Their 'style of reasoning' would thus always be limited when it came to postulating comprehensive theories of the development of all children as a collective mass. Even Burt's arguments that factor analysis was the only way to prove that subjective development occurred in a similar fashion across populations did not intend to encompass defective populations. It was thus restricted in its approach. Defences for instinct theory and the concepts of developing subjectivity that it supported, including autism, autoerotism and primary narcissism, were thus all put forward without any consideration for a major 
section of the population and their psychological experiences. It was particularly important to include this section of the population when these psychological theories were going on to influence the management of child populations at policy and government level.

The Second World War was fuelling anxieties about what would become of the child population. When the debate on instincts and the development of infant subjectivity erupted in Britain, the administration of social welfare was under reconstruction. In 1942, the Beveridge Report on Social Insurance and Allied Services was published, which alerted everyone to potential drastic changes to social insurance. In particular, the Beveridge Report laid out plans for the establishment of the National Health Service (NHS). The report set in motion discussions between medical doctors and government departments over the way in which a national health service should function once it was established. It was because of this that in July 1943, John Bowlby sought to suspend the controversial discussions to insist that the Psychoanalytic Society set aside their disagreements and immediately establish a 'Medical Committee' and a 'Child Welfare Committee' in order to consult with government departments over the future of state services. ${ }^{44}$ Theories of child development that had been forged in the throes of war, and without any regard for children with low levels of measured intelligence, then began to form the basis for post-war government policy towards children. These practicalities of management meant that the passionate arguments died down, but the fundamental problems inherent in the description of developing subjectivity in infants and children had not gone away.

\section{Experimentation and childhood schizophrenia in the USA}

Whilst debates raged in Britain over the development of subjective awareness in infancy, in the USA, several clinicians working in the field of child psychiatry thought through similar issues but employed different methods. Lauretta Bender from the Bellevue Hospital in New York was an early supporter of Kleinian theory. She was married to Paul Schilder, who had been a member of the Viennese Psychoanalytic Society and an associate of Freud..$^{45}$ Schilder was also important in developing the neurologist Henry Head's work on the 'body schema', which 
he called a 'surface schema' in which vision and cutaneous experience enable one to develop a model of the self. ${ }^{46}$ Bender had always been interested in psychoanalytic theory, as evidenced clearly in the title of one of her early papers: 'The Anal Component in Persecutory Delusions'. In 1938, Bender developed a method for testing the 'perceptual problems of schizophrenic children', in which she gave children gestalt figures to draw. ${ }^{47}$ From the late 1930s, she began to test the responses of 'schizophrenic' children, arguing that their responses showed an 'accelerated impulse to motion, action, whirling, dancing, and aggression' and an inability to understand the physical 'boundaries and peripheries' of the body. These children would sometimes draw extra heads and limbs. Bender argued that these images revealed 'a motor compliance and cohesiveness between the boundaries of two objects' that reflected the child's 'fluid ego boundary. ${ }^{48}$ Bender also developed a 'whirling' test in the late 1930s in which a doctor would ask a child to stand in front of him with his arms stretched out and eyes closed and would then turn the head of the child on the neck. According to Bender, normal children responded by turning their bodies to move in line with the head, whereas 'the schizophrenic child responds with a graceful fluid whirling which he quickly accepts as a new pattern of activity'. Such 'rotating and whirling play in motor activity' was thought to reflect the child schizophrenic's 'relationship to the reality of the outer world' ${ }^{49}$

Bender drew substantially from the work of Melanie Klein because it described the early stages of infantile thought as a bodily experience in immense depth, and it linked this directly to schizophrenic or 'psychotic' thinking. Later she also drew from the work of Gesell and Amatruda, who were interested in documenting normal developmental stages drawing on biological concepts. In their classic text The Embryology of Behavior (1945), they maintained that children's behaviour evolved in a foetal infant through stages from homeostasis of vasovegetative control; respiratory patterns; sleep and wakefulness; tissue tonus; and motor activity patterned on a primitive tonic neck reflex behaviour. Bender defined childhood schizophrenia as a 'pathology in behaviour at every level and in every area of integration or patterning within the functioning of the central nervous system, be it vegetative, motor, perceptual, intellectual, emotional or social. ${ }^{50}$ She claimed that childhood schizophrenia struck 'at the substratum of integrative functioning or biologically patterned behaviour', and that it could present as 
a 'dramatic emergence' of 'artistic, philosophic or linguistic preoccupations' rather than a simple loss of mental functions. ${ }^{51}$ She drew from Klein to argue that child schizophrenics became fixated on the stage of infancy characterised by 'internalised objects. ${ }^{52}$ She also claimed that they were particularly driven by infantile aggression. This caused 'condensation or the superimposing of many levels of thinking and psychological problems. ${ }^{53}$ Whereas in normal children symbolism became abstract and appeared only in dreams, fantasies and fairy tales, the symbolic thought of schizophrenic children remained concrete and structured their entire thought disorder. ${ }^{54}$ Bender later used Kleinian theory to argue that 'psychotic' children retained 'primitive homeostatic control' and 'primitive patterns of sleep and wakefulness with waning states of consciousness'.

Other child psychiatrists in the USA interested in the problem of childhood schizophrenia in the early 1940s included Frances Cottington, also from Bellevue, Louise Despert from Cornell University Medical College and Charles Bradley from the Emma Pendleton Bradley Home, Rhode Island. ${ }^{56}$ In the USA, several medically trained psychiatrists readily adopted psychoanalytic theory in their understanding of childhood schizophrenia and saw no problem in integrating it into a model of severe psychopathology. Margaret Mahler, a doctor based at Columbia University and the New York Psychoanalytic Institute, wrote widely on her therapeutic work to encourage psychotic children to engage with 'outer reality', as she described it. ${ }^{57}$ She developed a concept of 'symbiotic infantile psychosis' that she said occurred between the ages of two and five when, she claimed, children developed symptoms in order to avert the 'catastrophic anxiety' of separation. ${ }^{58}$ She argued that Klein's concepts of 'introjection' and 'projection' were advanced psychical mechanisms and followed Anna Freud in her descriptions of ego development in children and its failure in child psychosis. ${ }^{59}$ Many US researchers regarded childhood psychosis as a problem of the formation of the concept of selfhood. ${ }^{60} \mathrm{~J}$. Cotter Hirschberg, director of the Department of Child Psychiatry at the Menninger Foundation in Topeka, Kansas, argued that schizophrenic children demonstrated severe forms of 'emotional disturbance' that could be treated using directed education based on 'ego development' as understood by Anna Freud. ${ }^{61}$ Unlike Creak, many US child psychiatrists saw little problem with employing Kleinian concepts of psychosis, schizophrenia and 
child psychoanalysis and fusing these with the idea that childhood schizophrenia was a form of extreme psychopathology with biochemical correlates. This also encouraged a much more experimental treatment culture in relation to children than was seen in Britain.

As Edward Shorter and David Healy have argued, the Second World War stalled much European research and experimentation using insulin coma, and the focus then shifted to the USA..$^{62}$ In Britain, a drive towards modernisation had brought insulin treatments to the Maudsley Hospital, where William Sargant and Russell Fraser pioneered them in the late 1930s with adults. ${ }^{63}$ Prior to this, Maudsley doctors, such as Emslie Hutton, had experimented with thyroid shock treatment, but this was a much less dramatic treatment and was not intended to induce coma. ${ }^{64}$ As Jack Pressman has argued, North American psychiatrists in the 1930s and 1940s sought desperately to dissociate themselves from the tarnished image of state-managed asylums that served primarily as dumping grounds for the insane, in which treatment was minimal and neglect was common. ${ }^{65}$ These psychiatrists jumped at the prospect of presenting themselves as enlightened medical scientists engaging in cutting-edge research rather than merely asylum footmen. It was in this context that it is possible to understand the rapid growth of psychosurgery and other dramatic physical interventions in the treatment of mental illness in the 1940s, such as electroconvulsive therapy and insulin shock treatment.

The use of amphetamine for children had been trialled by Charles Bradley at the Emma Pendleton Bradley Home, Rhode Island in the late 1930s, and Bender also employed it directly for childhood schizophrenia. In fact, the late 1930s and 1940s saw much experimentation with different kinds of shock therapy for mental illness in the USA, and children were subjected to very invasive treatments during this period. ${ }^{66}$ Walter Freeman, head of neurology at George Washington University, who was well known for conducting lobotomy in adult patients, also conducted several experimental lobotomies on children diagnosed with 'schizophrenia' in the 1940s, some as young as four years old. ${ }^{67}$ Frances Cottington at Bellevue, New York, had also started 'treating' childhood schizophrenia with Metrazol shock therapy by 1941 and these experiments were continued by Lauretta Bender. ${ }^{68}$ Bender also engaged in a mass programme at Bellevue to administer electric shock therapy to one hundred 'schizophrenic' children aged four to twelve. ${ }^{69}$ 
It was only later that children suffering from the after-effects of Bender's experiments convinced other doctors to strongly warn against its use. There were reports that the children later described the experiences as horrific, one recounting that he was 'scared to death' and 'felt like a bunch of rocks were going around in my head'. ${ }^{70}$ Nevertheless, these invasive treatments for children unlucky enough to have been diagnosed with schizophrenia were sadly quite common in the 1940s.

It is in the context of increasing controversy over the description of subjective development and the formation of relationships in infants and children, as well as a strong North American focus on invasive treatments, that the publication of Leo Kanner's 1943 article on 'Autistic Disturbances of Affective Contact' in 1943 must be viewed. Kanner claimed that he had identified a "unique "syndrome" not heretofore reported', which was 'inborn' and characterised by 'extreme autism, obsessiveness, stereotypy, and echolalia' in children. He claimed that these symptoms brought 'the total picture into relationship with some of the basic schizophrenic phenomena'. Kanner initially distinguished his own group of eleven cases from those of 'dementia infantilis' by claiming that his group of children had not experienced any period of normal development but had 'all shown their extreme aloneness from the very beginning of life. ${ }^{71}$ However, he later revised this theory, claiming that 'autistic' children were not always 'autistic' from birth. ${ }^{72}$

What was unique about Kanner's 1943 article was precisely the fact that it did not employ any particular psychoanalytic, psychological or psychiatric framework, nor make any claims about treatment efficacy. Instead, he simply described a group of cases in which he had observed similar symptomatology. Kanner had conducted very close observations of these children and his writing style reflected this. A typical description went as follows:

There was a marked limitation of spontaneous activity. He wandered about smiling, making stereotyped movements with his fingers, crossing them about in the air. He shook his head from side to side, whispering or humming the same three note tune. He spun with great pleasure anything that he could seize upon to spin. He kept throwing things on the floor, seeming to delight in the sounds they made. ${ }^{73}$

When Kanner employed the concept of autism in his article, he made no claims about the symbolic phantasy life of the children he was 
describing. He noted that this group of children tended to use language in a very literal fashion and that they failed to relate to other people physically. However, he also pointed out that if they were not 'dumped in a school for the feeble-minded', they were able to progress and develop in a way that 'refute[d] the earlier impression of extreme limitation in the child's ideational content.' ${ }^{74}$

Kanner's description of 'autistic disturbances of affective contact' followed descriptions of autism as both an early stage of thinking and as a unique clinical 'syndrome' that was a subgroup of schizophrenia, so there was very little that was new in either of those ideas. What was new was his ability to capture these ideas in a circumscribed group of child cases. Kanner's legitimacy as a writer stemmed from his pivotal place in the newly developing field of child psychiatry, as writer of the first English-language textbook on the subject. Kanner's 1943 work has received much attention within popular understanding of the history of autism research. ${ }^{75}$ However, his work was not widely accepted at the time and many other child psychological professionals in both Britain and the USA continued to employ the concepts of autism in conjunction with autoerotism, primary narcissism and symbolic thinking to understand infantile psychopathology and problems with developing relationships. Bender, for example, always maintained that Kanner's 'autism' was simply a description of amentia or 'mental defect. ${ }^{76}$ Of course, C. J. C. Earl had pointed out long before that 'mental defectives' were all 'autistic'. Kanner's definitions of autism would also be frequently challenged in Britain using these older theories of autism as part of social development and its antithesis. ${ }^{77}$

It is true that Kanner highlighted the 'affective' aspects of the condition, arguing that the primary problem was one concerned with emotions and affects rather than just intellectual defect. However, as discussed earlier, the relationship between intellectual development and social and emotional development was only just beginning to be mapped out in individual and statistical studies of child development. Kanner's work presented the topic of atypical or abnormal emotional development as something that could precede intellectual development, but in fact this had been an interest of researchers in defective institutions for a long time, and interest into this had been stimulated precisely by Bleuler's concepts of schizophrenia and autism and Freud's concept of primary narcissism. They had been inspired by an interest 
in the early stages of development and their impact on later thought through the work of Piaget. What Kanner did was present very clear and concise case histories that ostensibly carried very little theoretical baggage.

English theories of normal social development and its relation to autism, autoerotism and primary narcissism in children existed alongside the idea that Kanner's autism was an inborn condition. This coexistence kept alive the idea that autism was a normal stage of early thinking that preceded socialisation and that some children simply could not move beyond this stage. The idea that childhood psychosis, and autism within it, was always a pathological manifestation and a shift away from normal development was promoted in some psychiatric circles, for example, by practitioners such as Creak, but the focus on the autistic aspects of childhood schizophrenia tended to shift attention away from the study of disease and pathology. The inherent contradiction between Bleuler and Piaget's claim that autism was a normal stage of all child development, versus the claim that autism was 'inborn' in a select group of children, would continue to lead to many clashes and confrontations between different disciplinary groups and theoretical advocates in the post-war period. At the same time, the fact that 'mental defectives' were still being shunned as subjects for in-depth psychological research did not help matters.

\section{Bowlbyism and its discontents}

As the war drew to a close in Britain, fear, anxiety and uncertainty turned to optimism as new institutions for social reform were established. Beveridge's plans were enacted in a range of new policies, including the Family Allowances Act 1945, the National Insurance Act 1946 and the Children's Act 1948, which led to the introduction of family allowances, comprehensive welfare assistance and the establishment of local authority children's departments in every locality, which had the right to receive children 'in need of care and protection'. New administrative centres were set up to cater for the basic problems of malnutrition, childcare and family management. ${ }^{78}$ The National Health Service Act 1945 placed responsibility for all children's medical treatment on regional hospital boards rather than local authorities. 
These changes helped to develop medical and psychological specialities by shifting responsibility away from specialist institutions such as the Maudsley, which had previously had to deal with the needs of children suffering from malnutrition, neglect or other indications of poverty, as well as serving as an evaluation centre for schools. Both the Maudsley Hospital and the Tavistock Clinic then began to achieve a higher level of autonomy in the research they conducted and the cases they received. In 1946, John Bowlby was appointed to head the Child Department of the Tavistock, the same year that the institution came under the auspices of the NHS and expanded its training and services. $^{79}$

When considering the impact of child psychologists on British childcare policy, it is hard to underestimate the significance of John Bowlby. His work was so influential that historians have since referred to the phenomenon of 'Bowlbyism' as a wide-ranging social tendency to support the place of mothers in the home environment. One wellknown aspect of 'Bowlbyism' was a tendency to blame mothers for any complications with their child's development. It is important to point out that this applied not only to the development of 'autism' in children but also to every kind of psychological 'problem' that a child may have developed or displayed. Nevertheless, as many historians have argued, Bowlbyism was not simply a ploy to blame mothers for everything. It was part of a much wider movement in the development of child welfare, and a far more complex story about the development of children's rights, than is often acknowledged by those who characterise it as merely a dark period in the history of autism.

Denise Riley pointed out long ago that although Bowlby's theories were clearly influential, they were in many ways simply a reassertion of wider policies of post-war pro-natalism in which women were encouraged to resume their roles in the home environment following the huge increase in female employment during the war. ${ }^{80}$ Bowlby had collaborated with important political figures, such as the Labour politician Evan Durbin. In their joint publication, Personal Aggressiveness and War (1939), a watered-down version of Kleinian theory was employed to emphasise the importance of mothers to the 'emotional education' of their children. ${ }^{81}$ As Harry Hendrick has argued, reformers of the 1940s extended the need for emotional love and stability to 
their model of the welfare state, which they viewed as an organic whole that could stave off rampant individualism. ${ }^{82}$ As the Second World War came to a close, it became almost a cliché in many official documents to claim that motherhood and housework was 'essential work' and that the government should recognise this by 'enabling' women to return to the home. Fabian socialists were the strongest supporters of a model society in which women stayed at home to look after their children whilst they were young. Their ideals were supported in official policy when state nurseries that incentivised female factory work during the war were closed. ${ }^{83}$

As Mathew Thomson has recently argued, however, Bowlby's interest in demonstrating the ill effects of maternal deprivation was part of a wider critique of state institutional care for children, and also a critique of the rather tactless way in which the state often intervened in removing children from their homes. ${ }^{84}$ By the end of the war, the separation of children from their families in the interests of the nation had reached considerable proportions. When the Curtis Committee reported the number of UK children resident in institutional or foster care away from their families in 1946, they gave a figure of $124,900 .^{85}$ The removal of children from the home had become almost a staple of British life, and was even extended in the case of mass child migrations to new care homes in Canada, Australia and elsewhere. ${ }^{86}$ This is a very important point because there were then few people making arguments against child institutional care or removal from the home. Bowlby's work played a major role in the post-war construction of welfare services for children. For example, the Children Act 1948 affirmed the importance of stable family environments for children and established a centralised structure to childcare. Local authority children's officers oversaw children's psychological development and sought to intervene where they saw necessary, replacing the more haphazard model of child removal that had preceded this ${ }^{87}$ However, 'defective' children were not integrated in this new-found model of child freedom that prevailed after the war. The idea of 'mental defect' still had so much stigma attached to it that any children classified as such were not given the same rights as other children under the 1948 Act. This cultural anomaly existed up until the end of the 1950s, and overshadowed most attempts to construct comprehensive theories of social, emotional and psychological development in children. 
Bowlby had a unique way of gathering evidence for his theories of maternal deprivation and its impact on the young child's developing mind. He did not rely on scientific models of 'instinct theory', as Isaacs, Klein and Anna Freud had done, but instead drew very squarely from statistical and social scientific studies documenting children's behaviour following deprivations, in particular from studies conducted in the USA ${ }^{88}$ The use of this kind of evidence was anathema to a significant majority of the psychoanalytic community, who accused him of misunderstanding the unconscious. He also provoked controversy when he drew from animal studies of behaviour, in particular the work of Konrad Lorenz and Harry Harlow, to demonstrate the effects of maternal deprivation. These animal studies gave Bowlby's work scientific legitimacy from the biological sciences and helped him create a model of mother love as 'natural', likening the need for maternal love to the need for vitamins. ${ }^{89}$ They were his response to the growing criticism of instinct theory as a model for understanding child development in and of itself.

Bowlby wanted clear evidence for his claims that would be accepted in the wider scientific and social scientific community. After joining the Tavistock Clinic, he appointed Esther Bick to organise the training of child psychotherapists and she instituted methods of infant and child direct observation that were later replicated internationally. ${ }^{90}$ After the war, professionals based at the Tavistock became dominant in the development of the 'human relations' and 'object relations' school of psychoanalysis in Britain through training programmes that they ran, along with associated courses at the London School of Economics (LSE). ${ }^{91}$ The term 'object relations' began to be used increasingly in Britain from the 1950s in psychoanalytic writing as a shorthand to describe early thought processes prior to the development of the ego. Klein's work was important in generating a language with which to describe such early mental states, and later psychoanalytic writers, such as W. D. Fairbairn, highlighted that early infantile instinctive drives were oriented towards 'objects', rather than merely towards pleasure-seeking. ${ }^{92}$ The Tavistock Clinic became an important institutional outlet for 'object relations' theory. The Tavistock was involved in the national post-war training of psychiatric social workers and other professionals specialising in social work. During the war, Susan Isaacs' involvement with the Mental Health course for social workers at the LSE had led to Kleinian 
approaches being integrated into the training. This trend would continue and in 1950 the Advanced Course in Social Case Work was established at the LSE, led by Bowlby's department at the Tavistock Clinic.

In the 1940s and 1950s, Bowlby achieved something like celebrity status through his engagement with the media at a time when media outlets were rare. He came to define a particular approach to child development that quelled the controversies over the finer points of instinct theory and the early stages of ego development by presenting a plain and lucid explanation for the cause of most childhood psychological problems. In his celebrated 1951 report for the World Health Organization, Bowlby largely referenced studies on the direct observation of mother/child separations that focused on children in institutions with little one-to-one contact. ${ }^{93}$ Gesell, for example, found that these children demonstrated marked developmental lags such as 'diminished interest and reactivity', 'excessive preoccupation with strange persons' and 'channelization and stereotypies of sensorimotor behaviour. ${ }^{94}$ These findings supported those reported by other researchers, such as Rene Spitz from the University of Colorado School of Medicine, who had studied hospitalised children, ${ }^{95}$ as well as Anna Freud and Dorothy Burlingham's studies of children displaced during wartime and the Cambridge evacuation surveys. Donald Winnicott, a paediatrician from Paddington Green Children's Hospital who developed a strong interest in psychoanalysis following an analysis with James Strachey, had also drawn attention to the plight of institutionalised infants who were denied the attention and love of a mother. ${ }^{96}$ Bowlby claimed that every researcher in the field, 'with monotonous regularity, each put their finger on the child's inability to make relationships as being the central feature from which all other disturbances sprang.9. ${ }^{97}$ Bowlby did not claim that institutional deprivation caused autism per se, although he did discuss 'autistic' states as a developmental stage as Piaget had done, drawing directly from a 1929 study by Marguerite Loosli-Usteri, who was then based at the Institut Jean-Jacques Rousseau with Piaget. ${ }^{98}$ What Bowlby did claim was that institutionalisation caused problems for children in forming relationships. In 1951, particularly in Britain, this was not yet synonymous with the term 'autism', although it would later become so. 


\section{Winnicott and the psychoanalytic theory of autism}

Bowlby was not the only psychoanalyst to become a towering figure in the popularisation of child psychoanalysis. Winnicott also took on this role with aplomb, appearing on numerous radio shows for the $\mathrm{BBC}$, which were broadcast across the UK from the mid-1940s. For example, in 1949, the BBC producer Isa Benzie commissioned a series of radio programmes by Winnicott on 'The Ordinary Devoted Mother', which propelled his theories and parenting advice into the public arena. ${ }^{99}$ As Michal Shapira has argued, Winnicott's radio work was pivotal in the popularisation of psychoanalysis and in the promotion of the centrality of the mother-child bond to the development of emotional stability in infants and children. ${ }^{100}$

In the early 1950s, Winnicott began to develop the specific language of 'autistic states' in infants as states in which an infant or child was 'in defence against the terrible anxieties of the paranoid state. The 'autistic state', he argued, had been given various names, but it was essentially a psychological state of 'defensive pathological introversion' in which 'the infant lives permanently in his or her inner world which is not, however, firmly organised.101 By the early 1950s, object relations theorists had thus developed quite a sophisticated language with which to describe early emotional attachments to internal objects that they claimed resembled adult psychopathology, and they used the term 'autism' to explain this. As Winnicott argued, 'emotional development in its primitive or earliest stages concerns exactly the same phenomena that appear in the study of adult schizophrenia', and can also be seen in 'organized defences against confusion and un-integration. ${ }^{102}$ Winnicott, in particular, used the term autism, as opposed to 'primary narcissism' or 'autoerotism', in his description of these states, and he was very clear on how to prevent them developing. As he put it: 'I realise that much that I shall say is controversial. Nevertheless, it is necessary to explore the possibility that mental health in terms of lessened ability to develop schizoid states and to schizophrenia is laid down in the very earliest stages, when the infant is being introduced gradually to external reality. ${ }^{103}$ Winnicott argued that if one could intervene in infancy, one could therefore prevent schizophrenia in adulthood. This was a new departure for psychoanalysts who had previously been more interested in developing the language to describe internal mental states in great 
detail. Winnicott began to use the term 'good enough mother' in the early 1950s as a response to Klein's discussions of the 'good' and 'bad' mother, which she used in the abstract to discuss an infant's 'internal objects', rather than the actual mother herself. Winnicott used the term 'good enough mother' to discuss real women, bringing the descriptive terminology of psychoanalysis into the domain of parenting advice. ${ }^{104}$

Similarly, Edward Glover argued that 'the most difficult and responsible task with which the child psychiatrist is confronted is the recognition of psychotic reactions in childhood. ${ }^{105}$ Similarly to Winnicott, Glover asserted that concepts from adult psychiatry were useless because what the psychoanalyst was searching for was more like a 'psychotic predisposition' or a 'pre-psychotic formation' in infancy that could later develop into a multitude of symptom formations including 'psycho-somatic disorders, psychopathic reactions, sexual perversions' and 'psychoneurotic types of mechanisms'. He was interested in reality testing more than anything else because 'the main criterion of all psychoses, whether childhood or of adult life, lies in the degree of maldevelopment of or injury to the sense of reality-proving', so he wanted to know if, when and how that mal-development took place. He argued that even in the first eighteen months of life, a child's 'incapacity to endure stress' suggested a 'constitutional predisposition' to psychosis. For him, this was what to look out for: 'Persistent disturbances of sleep, excessive anxiety reactions of a primary type, constant disturbances of body function, especially of oral and gastro-intestinal processes, marked skin sensitiveness, violent muscular crises of the tantrum type or persistent inertia are also significant. ${ }^{106}$ Furthermore, if the child had major 'outbursts of violence' following delay in gratification or 'rapid diminution of an existing capacity for emotional enjoyment', this suggested inadequacy in the 'development of object relations'. For Glover, problems with object relations were most problematic if they were expressed as incapacity to stand the strain of object-contact during periods of gratification', 'incapacity to sustain a state of object recognition in the intervals between gratification' and 'incapacity or delay in making a distinction between the "self" and the "non-self" combined to form "what is generally called an "autistic" reaction. ${ }^{107}$

With regard to the difficult question of hallucination, phantasy and its relation to schizophrenia in childhood, Glover argued that 'the existence of phantasy products is not in itself pathognomonic' and that 'the 
content and bearing of the phantasies on object relations is the essential point to determine. ${ }^{108}$ Of course, all children phantasised, but one had to be particularly wary of 'those persistent negative transferences that generally accompany the psychoses. ${ }^{109}$ Drawing from both ego psychology and Kleinian theory, he argued that the analysis and treatment of all children was possible depending 'on the degree of synthesis of the originally fragmented ego." ${ }^{110}$

Some other specialist child psychiatrists in Britain readily adopted Kleinian perspectives. For example, Louise Eickhoff, Senior Lecturer in Child Psychiatry at the University of Leeds, drew from Bender and Klein to argue that schizophrenic children demonstrated 'emotional fixation at the infant to toddler level', in which they fixated on the 'oral to anal level of eroticism', the 'practice of bodily movements' or the 'flights in fantasy' of these early stages, often employing bodily comfort mechanisms like nursery children. Eickhoff was referred a child via the local education authorities who was 'backward, maladjusted and showed abnormal sexual advances'. Eickhoff claimed the girl was schizophrenic because she showed 'bizarre behaviour' and 'difficulty with abstract thought'. Furthermore, 'She frequently demonstrated this inability to appreciate the realities of her environment, pointing [sic] Melanie Klein's statement of schizophrenic children in general that the ego has ceased to form a relationship to reality. ${ }^{111}$ Eickhoff argued that schizophrenic children showed 'a delay in the formation of the body image' and 'delay in general image formation' leading to 'retardation or arrest in development of abstract thinking. This meant that the 'formation of the body image is at an intuitive rather than a perceptual level' and does not respond to sensations registered by nerve endings in the muscles and the skin. Instead, she claimed, it 'travels to the higher centres via the posterior columns and the thalamus', leading to inadequate perceptions of the external world. She argued that it was possible that 'an overactive mother might affect adversely the neurological "finish" of her child' through her impact on foetal development. ${ }^{112}$ The cure, she claimed, was as follows: 'On this hypothesis I can conceive a scheme of treatment which would be on the lines of remedial sensation development, involving mild massage, almost fondling, of the whole body daily, gymnastics, dancing, play in water, graduated from the passive to the active. ${ }^{113}$ She claimed to have treated three children using this method in the early 1950s, in collaboration with a physiotherapy department at 
Birmingham Hospital, a complete child guidance clinic team, the head teacher and staff of a school and the 'devoted mothers' of the children in question. Eickhoff claimed that it is possible to undo the schizophrenic process in children." ${ }^{\text {114 }}$

Many other psychologists in Britain employed Kleinian theory to try to explain psychosis as a form of severe maladjustment. In 1948, Elizabeth Norman, a child psychologist at Guy's Hospital, London, published a series of pictures drawn by a 'psychotic' child who had attended Emanuel Miller's clinic in East London, arguing that these pictures reflected the child's 'lack of reality determination in the manner of play', his 'lack of unity and coherence in play objects' and his 'composite or mutilated objects, symbols, inappropriate to the reality theme of the play. ${ }^{115}$ She became especially interested in the play of 'psychotic' children and was later referred more cases by Dr König from the Camphill Rudolf Steiner schools and Dr Howells from the Department of Child Psychiatry at Ipswich. As with many English thinkers, Norman saw 'early infantile autism' as an early form of schizophrenia. Drawing from the work of Klein and Bender, she thought that the infant's suckling stage, and the inner changes relating to it, enabled the infant to 'form a unity that precedes to integration of his own individuality as a unitary of experience, action and body-boundary'. ${ }^{116}$ She argued that 'failure in development of such integration' and an 'impoverishment of the ego' led to the development of 'a relationship to objects' that was dominated by 'projective identification'. Building on Winnicott's work on primitive emotional development, she claimed that 'psychotic' children were thus not able to integrate internal affective experiences with bodily experiences. ${ }^{117}$ Norman pointed out the general consensus was that 'schizophrenic children are mute because they are self sufficient in a world of fantasy', although it was also true that some tried to communicate. Shifting from the intra-psychic world to the problem in relationships, as was typical at the time, she argued that 'Crucial to the withdrawal and the disturbance in social behaviour was the failure of the children to respond emotionally to the emotional behaviour of others, the failure in empathy or sympathetically induced emotion. ${ }^{118}$ Norman took the last phrase from McDougall. All in all, Norman's arguments were largely negative expressions of the stages that normal infants were supposed to go through in early development as outlined by Klein 
and Winnicott. As she understood it, if children failed to go through these normal psychological developmental stages then they would become psychotic. This is why the 'schizophrenic' child was an object of such intense scrutiny and interrogation. 'Schizophrenic' and 'psychotic' children represented the failure of all human development. They had a lot to answer for.

Glover, Winnicott and Bowlby were all considered part of the 'independent' group when it came to the disagreements between Anna Freud and Melanie Klein, but they developed their own unique arguments that explained all children's psychological problems as problems of emotional attachment. They all had wider areas in which they wanted to cast their nets. Glover was interested in juvenile justice and Bowlby and Winnicott sought to turn psychoanalysis into a theory of general child development in order to guide parents and to direct public policy. Although they did not take sides on psychoanalytic controversies, they all remained committed to a theory of childhood psychosis, schizophrenia and autism that was structured around a theory of ego development that psychoanalysts could engage with therapeutically and potentially alter. As Winnicott described it, he was putting forward the contention that 'disturbances which can be recognized and labelled as psychotic have their origin in distortions in emotional development arising before the child has clearly become a whole person capable of total relationships with whole persons.' ${ }^{119}$ This was tied in with a general treatise on the best family situations that infants should experience in order to develop well. Psychosis and autism were thereby drawn firmly into a general theory of child development in a way that was unique to the post-war era. For Winnicott, the development of the child's relationship to reality was the development of the child's relationship to other people. ${ }^{120}$ This fitted well with the school of human relations in which he worked and also with the modelling of psychoanalysis as a total human science akin to anthropology. Perhaps most importantly, it supported his belief that English paediatricians should be involved in promoting general mental health. He thought they were a significant group involved in national health and were responsible for preventing psychosis within the nation. As he put it, 'prophylaxis against psychosis is therefore the responsibility of the paediatricians, did they not know it. ${ }^{121}$ 
At the same time, the post-war period in Britain also saw the wider conceptualisation of schizophrenia as a problem caused by culture or society. The flurry of interest in childhood schizophrenia in the early 1950s was part of a much wider interest in schizophrenia and development in the fields of psychiatry, psychoanalysis, psychology, anthropology and other human sciences of the period. Many child psychologists in Britain, including Margaret Lowenfeld, Susan Isaacs and Lydia Jackson, quoted the North American anthropologist Margaret Mead in their work on child development. In fact, in the early 1950s, Mead communicated directly with Lowenfeld over her concept of a 'primary system' that referred to the infant's primary drive towards patterning, grouping, synthesising and reproducing experiences. Mead argued that the concept of a 'primary system' would lead to confusion with Sigmund Freud's 'primary processes', which described early imagistic thinking that could tolerate contradiction and was not oriented to reality, and so Lowenfeld renamed it a 'protosystem.' ${ }^{122}$ Mead, as with many anthropologists of the period, was well versed in psychoanalysis and other 'psy' subjects. Child psychologists, psychiatrists and anthropologists claimed they could uncover the 'primitive' stages of human thought as a form of psychosis. ${ }^{123}$

The post-war period also saw the development of therapeutic psychiatry that played a large role in framing understandings of mental illness generally and schizophrenia in particular. During the war, Joshua Bierer began group treatments at Runwell Hospital, near London, and later Maxwell Jones developed 'therapeutic communities' at Mill Hill, leading to an expansion of the project in the post-war era. These unsurprisingly encouraged social and cultural explanations for the development of schizophrenia. From the late 1940s, a growing number of psychiatrists, social scientists and anthropologists in both Britain and North America explained mental illness as the result of social sickness. ${ }^{124}$ Many of these expanded on Sigmund Freud's Civilisation and Its Discontents. After collaborating with Margaret Mead, his first wife, on the schizophrenic nature of Balinese culture, the Cambridge-educated all-round human scientist, Gregory Bateson, published on 'The Social Matrix of Psychiatry', proclaiming that the psychiatric study of individuals was irrelevant because individuals were part of a wider social matrix in which changes in communication technology were transforming human behaviour and selfhood. ${ }^{125}$ 
These ideas were taken up directly by child psychologists interested in childhood psychosis. For example, Lydia Jackson, an Oxfordtrained psychologist who had published a best-selling book on play therapy, argued that whether classed with 'childhood schizophrenia, infantile autism or pre-psychotic state', all of these children did not speak and were 'characterized by severe regression, and regression means retreat before a danger or an obstacle. ${ }^{126}$ She claimed that the psychopathology they presented represented a primitive response to danger observed in other animals, namely, fight, flight or feign death. As she put it, 'silence and the absence of relationships with others are, after all, a kind of death, non existence as a social being. ${ }^{127}$ She also thought this was supported by anthropological work by Mead that demonstrated similar responses in Balinese children, following early frustration and teasing within the culture as a whole. She therefore encouraged 'permissive' techniques in enabling the child to play and explore, in a mode similar to that adopted by Isaacs and Lowenfeld. Techniques such as Lowenfeld's sand tray were employed. Later, the therapist works to form a relationship to the child so that child views them 'as a person', and finally by helping the child to broaden his or her circle of relationships by encouraging group activity and learning. ${ }^{128}$ Jackson employed the term 'emotional and behaviour disorders' to encompass everything that could possibly go wrong in a child's psychological development and included conditions labelled as autistic, psychotic and schizophrenic. ${ }^{129}$

This wider cultural shift to understand 'schizophrenia' as a social sickness and to relate it to particular social contexts helps to explain its rather liberal use not only in relation to infants and children but also in wider contexts. It also helps to explain how the doctrine of maternal deprivation rose so rapidly as an explanation for all forms of mental illness. In fact, it was largely historical chance that linked a lack of maternal care to all forms of psychological instability, of which childhood schizophrenia was touted as the pinnacle.

Whereas Bleuler, Piaget and Klein used the terms schizophrenia, psychosis and autism to describe internal psychic processes only, when 'psychosis' and 'autism' entered the dialogue of everyday childcare and mothering, they were used as tools to criticise parenting and the institutional practices of childcare; that is, they were used politically. Although employed for the purposes of guiding a newborn, needy, 
flailing welfare state, the concepts therefore became increasingly controversial, not only amongst infighting psychoanalysts, or mental defect specialists, but also amongst the wider public. At the same time, the use of such concepts, and the presumed judgements associated with their use, became increasingly common and pervasive.

In the late 1940s, child psychiatrists such as Mildred Creak, working largely out of the public eye, continued to focus on 'schizophrenia' and 'psychosis' as a psychiatric and medical diagnostic category, whilst child psychoanalysts seeking to devise comprehensive theories of social development, and to popularise such ideas, instead focused on 'schizophrenia' and 'psychosis' as a normal stage of child development. It was entirely problematic that both were using the same terms of psychosis, schizophrenia and autism to describe both normal and atypical development. That psychologists such as Klein, Bowlby, Winnicott and others appeared to be unaware of this can only be explained by the fact that their work occupied a unique cultural zone in which the social development of a large section of the child population was not regarded as significant to the development of policies for those children thought to be in the 'normal' range.

Other post-war institutes did begin to develop new ways to measure and monitor subjective development using statistical methods, in a manner similar to that which Burt had proposed during the controversial discussions. In 1949, Alan Moncrieff, director of the Institute of Child Health, and Dorothy Gardner, head of the Department of Child Development at the Institute of Education, established a Child Study Research Project with the aim of conducting longitudinal studies of child development that tracked a group of individuals from infancy to adulthood, and that attempted to integrate knowledge on the physical, intellectual and emotional aspects of personality'. The Child Study Research Project also intended to compare results on the development of 'normal' children with the development of 'abnormal' children, both physically and mentally, and the researchers were in contact with Creak and others based at Great Ormond Street Hospital, where Creak had moved after the war. ${ }^{130}$ Furthermore, they aimed to draw international comparisons with similar institutions in France, Switzerland, Sweden and the USA. With regard to psychological development, their aim was 'at various age levels to assess, so far as is possible, the child's developmental level, including cognitive 
abilities and, more particularly, certain personality characteristics. ${ }^{131}$ Moncrieff, Gardner and the wider research team decided that, in comparison to Gesell and Amatruda, who had focused on cognitive development, they would focus instead on 'the orectic side of the personality'; in other words, 'the emotional characteristics, social behaviour and personal relationships' that differentiated children 'in another dimension'. Developmental scales were used only as yardsticks with which to measure this other 'less well charted dimension'. The development of speech, manipulation and other characteristics were dependent on 'strength of drive and attitude' and 'opportunity for learning', and 'personality development' was dependent on 'the relationship the child makes with his parents and siblings in a particular social context.'132

This use of statistical models to track child development built on Cyril Burt's dream to use statistics to explain all social development in children. However, this project was obviously hampered by the fact that the models for analysing, describing and detailing child development had still not effectively integrated mental models that could describe the experiences of those classed with 'mental defect'. Even though the absence of this group was creating major rifts and disagreements amongst psychologists, problematic theories were re-hashed, allegiances were formed and no one seemed to realise that if childhood psychosis, schizophrenia, autism and mental defect were all the obverse of normal social development, then 'normal social development' must be a pretty problematic concept in itself.

Nevertheless, in the 1940s and early 1950s, largely due to the popularisation of psychoanalysis, it was widely accepted that during the early stages of social development, infants experienced mental states that resembled schizophrenia and psychosis in adulthood. These mental states were characterised by phantasies and hallucinations concerning people, or parts of other people such as 'the breast', and were often terrifying. They were associated with a complete lack of contact with any form of reality and also existed before the onset of any kind of relational or social thinking. These states were described widely as 'autistic', 'schizophrenic' and 'psychotic'.

At the Tavistock Clinic, the Children's Department was renamed the Department of Children and Parents in 1953, and psychotherapists aimed to integrate whole families into the treatment process. 
Klein's theories of infantile phantasy and Winnicott's work on 'transitional objects' helped to establish British 'object relations' theory as a dominant discourse within both psychological and political circles and helped to establish the 'Tavi' model of child psychotherapy, in which clinicians employed play therapy and transference models to elicit and expel pathological memories. ${ }^{133}$ All of this helped to support the work of Bowlby, Winnicott and Glover on the importance of early mothering to stable mental health. Nikolas Rose has argued that this model of 'human relations' psychology was part of a wider political project to promote individual freedom, whilst simultaneously ensuring that this model of individuality mapped neatly onto the goals of British postwar objectives to establish social stability within a welfare state. Public officials would therefore use psychology to ensure that industrial workers remained contented, that women adopted their roles as Winnicott's 'good enough mothers' and that social workers remained convinced that adapting and interfering in the structure and organisation of family life was a necessary task. Whilst this is largely true, it is imperative to acknowledge that this Tavistock-inspired model of psychology constructed a unique model of the development of subjectivity and individuality that was structured around the idea that early infancy was characterised by complex thinking patterns and affective bonds that pre-existed the establishment of human relationships and social relationships. This model of early infantile thought was necessary to justify the social interventions that sought to relieve and help to stabilise it.

By the early 1950s, the Tavistock model of child psychology presented a model of relationship formation that was structured on theories of pre-social unconscious object relations and pre-ego development that did not include mental deficiency, yet which privileged models of adult mental illness, in particular schizophrenia, which had at its core ideas about persecutory delusional states. However, this model of child development and human relations would come to be increasingly challenged as the social model that excluded 'mental deficiency', and other atypical forms of infantile thought began to be acknowledged as legitimate parts of a comprehensive social model. In fact, the controversies that existed around the description of infantile thought in the 1940s and 1950s were always constrained by the fact that 'defective' thought was off the table for discussion. The fact that 
these discussions were so exclusive only helped to fuel the disputes over who could present a complete model of children's psychological development that was comprehensive. Unfortunately, few people were able to acknowledge the glaring omissions that had made that project impossible in the 1940s.

\section{Notes}

1 Zweiniger-Bargielowska, 'Building a British superman'.

2 Hendrick, Child Welfare: England 1872-1989, pp. 109-110.

3 This was particularly the case for medically trained staff. Mildred Creak, for example, joined the Women's Army Corps.

4 Rose, Governing the Soul, pp. 163-167.

5 Isaacs et al., The Cambridge Evacuation Survey, p. 1; Rose, Governing the Soul, p. 165.

6 White, London in the Twentieth Century, p. 43.

7 Isaacs et al., The Cambridge Evacuation Survey; Rose, Governing the Soul; Shapira, The War Inside.

8 Hearnshaw, A Short History of British Psychology 1840-1940, pp. 96-100; Young, Mind, Brain and Adaptation in the Nineteenth Century, pp. 192-193.

9 Richards, Putting Psychology in Its Place, pp. 62-67; Watson, 'Psychology as the behaviourist views it'.

10 Richards, Putting psychology in its place.

11 McDougall, Introduction to Social Psychology, 23rd edn, p. xxii.

12 Freud, Standard Edition, vol. XXI.

13 Burt, 'The case for human instincts'; Thorndike, 'Is the doctrine of instincts dead? III: Human instincts and doctrines about them'; Drever, 'Is the doctrine of instincts dead? IV: Instinct as impulse'; Pear, 'Is the doctrine of instincts dead? V: Not dead, but obsolescent'; Myers, 'Is the doctrine of instincts dead? VI: Retrospect and prospect'; Burt, 'Is the doctrine of instincts dead? VII: Conclusion'.

14 Steiner, 'Background to the scientific controversies'; Roazen, Oedipus in Britain.

15 Hearnshaw, A Short History of British Psychology 1840-1940, p. 190.

16 Burt, 'The case for human instincts', 168.

17 Burt, 'The case for human instincts', 169-170.

18 Burt, 'The case for human instincts', 162 (footnote 161). 
19 Burt, 'The case for human instincts', 158.

20 Pear, 'Not dead, but obsolescent', 146-147; Thorndike, 'Human instincts and doctrines about them', 87.

21 Drever, 'Instinct as impulse', 95-96.

22 Heimann, 'Some aspects of the role of introjection and projection', p. 1510.

23 Isaacs, 'The nature and function of phantasy', pp. 1277-1278. Isaacs spelt fantasy with a 'ph' to emphasise the fact that phantasies were unconscious and distinguishable from conscious fantasies. This spelling also became popular in England because James Strachey and others always used the 'ph' spelling in their translations of Freud.

24 Isaacs, 'The nature and function of phantasy', p. 1277.

25 Isaacs, 'The nature and function of phantasy', p. 1277.

26 Isaacs, 'An acute psychotic anxiety occurring in a boy of 4 years'.

27 Isaacs, 'An acute psychotic anxiety occurring in a boy of 4 years', 21-22.

28 Isaacs, 'An acute psychotic anxiety occurring in a boy of 4 years'.

29 Klein, 'The emotional life and ego development of the infant', p. 1265.

30 A. Freud, 7/4/43, in King and Steiner, eds, The Freud-Klein Controversies, p. 424.

31 Friedlander, 17/3/43, in King and Steiner, eds, The Freud-Klein Controversies, p. 408.

32 Glover, 21/7/43, in King and Steiner, eds, The Freud-Klein Controversies, p. 488.

33 Glover, 17/3/43, in King and Steiner, eds, The Freud-Klein Controversies, pp. 325-327, pp. 395-400.

34 Glover, 'First series, third discussion', in King and Steiner, eds, The FreudKlein Controversies, pp. 325-327, pp. 395-400.

35 A. Freud, 7/4/43, pp. 418-421.

36 Klein, 'Memorandum on her technique by Melanie Klein', in King and Steiner, eds, The Freud-Klein Controversies, pp. 635-638.

37 Glover, 'First series, sixth discussion', in King and Steiner, eds, The FreudKlein Controversies, p. 562.

38 Brierley, 'First series, sixth discussion', p. 538.

39 A. Freud, 'Memorandum', in King and Steiner, eds, The Freud-Klein Controversies, pp. 629-634.

40 'Three essays on the theory of sexuality' (1905), in Freud, Standard Edition, vol. VII.

41 Isaacs and Heimann, 'Regression', in King and Steiner, eds, The FreudKlein Controversies, pp. 687-709, esp. p. 707. 
42 Glover, 'Second series, discussion on regression', in King and Steiner, eds, The Freud-Klein Controversies, p. 719.

43 Friedlander, 'First series, first discussion', p. 346; Glover, 'Resignation letter', in King and Steiner, eds, The Freud-Klein Controversies, p. 853.

44 AGM 21/7/43, in King and Steiner, eds, The Freud-Klein Controversies, pp. 476-500, pp. 867-869.

45 Cook, 'Obituary: Lauretta Bender'.

46 Head, Studies in Neurology; Schilder, Introduction to a Psychoanalytic Psychiatry.

47 Bender, A Visual Motor Gestalt Test and Its Clinical Use.

48 Bender, 'Clinical study of one hundred schizophrenic children', 47.

49 Bender, 'Clinical study of one hundred schizophrenic children', 43; Bender, 'Childhood schizophrenia' (1941).

50 Bender, 'Clinical study of one hundred schizophrenic children', 40.

51 Bender, 'Clinical study of one hundred schizophrenic children', 40.

52 Bender, 'Clinical study of one hundred schizophrenic children', 51.

53 Bender, 'Clinical study of one hundred schizophrenic children', 674-675.

54 Bender, 'Genesis of hostility in children'.

55 Bender, 'Childhood schizophrenia' (1953), 674-675; Bender et al., 'Schizophrenia in childhood', 67.

56 Bradley, Schizophrenia in childhood; Cottington, 'The treatment of childhood schizophrenia'.

57 Mahler, 'Remarks on psychoanalysis with psychotic children'.

58 Mahler, 'On child psychosis and schizophrenia', 289.

59 Mahler et al., 'Clinical studies in benign and malignant cases of childhood psychosis', 298.

60 E.g. Gardner, 'The pseudo-psychotic nucleus in the behavior disorders'; Gurevitz, 'The total point of view in psychotherapy of schizophrenic children'.

61 Hirschberg, 'The role of education in the treatment of emotionally disturbed children'; Schulman, 'Concept formation in the schizophrenic child', 15.

62 Shorter and Healy, Shock Therapy, p. 54.

63 Shorter and Healy, Shock Therapy, p. 53.

64 Evans and Jones, 'Organ extracts and the development of psychiatry'.

65 Pressman, Last Resort.

66 M. Smith, Hyperactive. 
67 Freeman and Watts, 'Schizophrenia in childhood'.

68 Bender, 'Childhood schizophrenia' (1953); Cottington, 'The treatment of childhood schizophrenia'.

69 Bender, 'One hundred cases of childhood schizophrenia treated with electric shock'.

70 Clardy and Rumpf, 'The effect of electric shock treatment', 621.

71 Kanner, 'Autistic disturbances of affective contact', 248.

72 Kanner and Eisenberg, 'Early infantile autism'.

73 Kanner, 'Autistic disturbances of affective contact', 219.

74 Kanner, 'Autistic disturbances of affective contact', 249.

75 E.g. Feinstein, A History of Autism; Verhoeff, 'Autism in flux'.

76 Bender, 'Autism in children with mental deficiency'.

77 E.g. Creak, 'Schizophrenic syndrome in childhood'; Anthony, 'An aetiological approach to the diagnosis of psychosis in childhood.

78 Evans et al., 'Managing the "unmanageable".

79 Rose, Governing the Soul, p. 172.

80 Riley, War in the Nursery.

81 Thomson, Psychological Subjects, p. 221; Durbin and Bowlby, Personal Aggressiveness and War.

82 Hendrick, 'Optimism and hope versus anxiety and narcissism'.

83 Riley, War in the Nursery.

84 Thomson, Lost Freedom.

85 Report of the Care of Children Committee, Cmd. 6922 (London, 1946).

86 Welshman, Churchill's Children; Dunae, 'Gender, generations and social class'.

87 Hendrick, Child Welfare: England 1872-1989, pp. 138-139.

88 See Bowlby, Maternal Care and Mental Health, p. 12.

89 Vicedo, The Nature and Nurture of Love, p. 40.

90 Harris et al., The Tavistock Model.

91 Rose, Governing the Soul, pp. 155-181.

92 Fairbairn, 'The repression and the return of bad objects'.

93 Gesell and Amatruda, Developmental Diagnosis; Spitz, 'Hospitalism'; Roudinesco and Appell, 'Les répercussions de la stabulation hospitalière'; Goldfarb, 'Effects of psychological deprivation in infancy and subsequent stimulation'; Brodbeck and Irwin, 'The speech behaviour of infants without families'; Gindl et al., 'Inadequacy of institutions as life space of infants'.

94 Gesell and Amatruda, Developmental Diagnosis. 
95 Spitz, 'Hospitalism'.

96 Winnicott, The Ordinary Devoted Mother and Her Baby.

97 Bowlby, Maternal Care and Mental Health, p. 34.

98 Loosli-Usteri, 'Le test de Rorschach appliqué à différents groupes d'enfants de $10-13$ ans'.

99 Winnicott, The Ordinary Devoted Mother and Her Baby.

100 Shapira, The War Inside.

101 Winnicott, 'Psychoses and child care', 73.

102 Winnicott, 'Psychoses and child care', 70.

103 Winnicott, 'Psychoses and child care', 69.

104 Abram and Karnac, The Language of Winnicott, p. 221.

105 Glover, Psycho-analysis and Child Psychiatry, p. 23.

106 Glover, Psycho-analysis and Child Psychiatry, p. 25.

107 Glover, Psycho-analysis and Child Psychiatry, pp. 25-26.

108 Glover, Psycho-analysis and Child Psychiatry, p. 30.

109 Glover, Psycho-analysis and Child Psychiatry, p. 30.

110 Glover, Psycho-analysis and Child Psychiatry, p. 33.

111 Eickhoff, 'The aetiology of schizophrenia in childhood', 230.

112 Eickhoff, 'The aetiology of schizophrenia in childhood', 233.

113 Eickhoff, 'The aetiology of schizophrenia in childhood', 234.

114 Eickhoff, 'Treatment of childhood schizophrenia', 402.

115 Norman, 'The play of a psychotic child', 170.

116 Norman, 'Reality relationships of schizophrenic children', 10.

117 Norman, 'Reality relationships of schizophrenic children'; Winnicott, 'Primitive emotional development'.

118 Norman, 'Affect and withdrawal in schizophrenic children', 11.

119 Winnicott, 'Psychoses and child care', 69.

120 Winnicott, 'Primitive emotional development'.

121 Winnicott, 'Psychoses and child care', 74.

122 Lowenfeld et al., Child Psychotherapy, War and the Normal Child.

123 E.g. Carothers, The African Mind in Health and Disease.

124 On North America, see Staub, Madness Is Civilization.

125 Ruesch and Bateson, Communication.

126 L. Jackson, Child Treatment and the Therapy of Play.

127 L. Jackson, “"Non-speaking” children', 7.

128 L. Jackson, " "Non-speaking” children'.

129 L. Jackson, “"Non-speaking” children', 99. 
130 Moore et al., A Longitudinal Research in Child Development, vol. II.

131 Moore et al., A Longitudinal Research in Child Development, p. 1133.

132 Moore et al., A Longitudinal Research in Child Development, p. 1136.

133 Rose, Governing the Soul. 


\section{3 \\ Inside the Maudsley Child Psychotic Clinic in the 1950s}

\section{Radicals and establishments}

The 1950s were turbulent, dramatic and provocative times for people interested in social change and its impact on child psychology. The Butler Education Act 1944 had created a revamped education system in which compulsory free education was expanded to secondary level until the age of fifteen; this was in full swing by the 1950s, enabling a revolution in social mobility. ${ }^{1}$ These widespread internal changes were coupled with major shifts at an international level: Britain's imperial strength was being vigorously contested, for example, by the Suez Crisis in 1956, and the global stage was set for the growth of new superpowers, in particular the USA. In many arenas, conservatism and attempts to hold on to old power and traditional forms of knowledge were confronted by radical overhauls of such authority and supremacy.

The 1950s was an important decade for psychological research that took 'society' and social causes within its remit. A new generation of social researchers was beginning to emerge, although they remained partly shackled by the reaffirmation of 'traditional' family values and ideologies after the war. Just as the post-war period had seen a reassertion of women's role in the home and the affirmation of associated cultural dogmas, it also witnessed a reassertion of what Mike Savage has called a 'gentlemanly' form of sociological research, in which uppermiddle-class assumptions were made about normal behaviour and the 'social' was understood within an evolutionary progressive model. Most sociologists working in the late 1940s and 1950s were still privately educated and convinced by a broad modernist agenda. However, in the 1950s a new breed of intellectuals, supported by the grammar 
school system, were beginning to develop radically new ways of thinking about society that took dogmatically assumed cultural and social 'truths' and exposed them for what they were. It was the beginning of an approach to social life that analysed social life itself. ${ }^{2}$

There were many reasons for these rumblings of discontent, most notably the fact that a new generation of motivated young researchers saw opportunities to challenge social norms and create new models of social engagement. One arena in which this was particularly evident was the field of mental health. Inside the walls of long-stay mental health institutions, optimism was growing over the possibility of new treatments for schizophrenia and psychosis in adults, following the widescale implementation of electroconvulsive therapy and the first trials of drugs such as chlorpromazine. This promised revolutions in the asylum approach to mental illness that had prevailed since the nineteenth century in Britain, Europe and the USA. Several other compounds, such as iproniazid and reserpine, were trialled in the rapidly developing new science of psychopharmacology. ${ }^{3}$ At the same time, there was a growing humanitarian challenge to the asylum system, given impetus following the 1953 publication of the report by the Third Expert Committee on Mental Health of the World Health Organization (WHO), which suggested that the 'classical' closed asylum system needed to be replaced with a more liberal model in which treatment was offered in hospitals and outpatient treatment centres and that the freedom and rights of individuals needed to respected. ${ }^{4}$ This led to a growth in the discipline of psychiatric social work as more professionals were employed to cater to people with mental health problems living in the community. ${ }^{5}$

In Britain, new networks were established at the London mental health institutions, the Tavistock Clinic and the Maudsley Hospital, to explore the social causes of mental ill health. At the Tavistock Clinic, psychoanalysts built on ideas proposed by McDougall and Freud, yet they provided far more complex systems, techniques, organisation and procedures with which to explore and investigate these issues. Within these networks, some therapists, especially those based at the Tavistock Clinic, became interested in the social context of psychosis in order to try to make psychotic thinking comprehensible. R. D. Laing, the father of anti-psychiatry, joined the Tavistock Clinic in 1956 after working with serious schizophrenics in long-stay institutions. He would go on to argue, in his first book, The Divided Self, that psychosis was an intense 
version of the 'divisions of the self' that echoed the fragmentation of modern society. Although Bowlby had many reservations about the book, and eight publishers rejected it, it sold 380,000 copies in the UK and Laing quickly became an international celebrity. ${ }^{6}$ It was thus a fascinating, yet problematic, period for the study of severe psychopathology more generally. Laing worked with child analysts Klein, Isaacs and Winnicott, although he focused on adults. Nevertheless, there was clear dialogue taking place between adult and child mental health practitioners about the relation between early development and adult mental illness. Winnicott's ideas about the 'true' and 'false' self, in which a child could build up a 'false' sense of their identity, was developed at the same time, building on his theories of autism in children. The roots laid down by Bleuler and Freud, linking infantile mental life to adult mental illness, found new avenues and roads on which to travel in the expanding interest of society and extreme psychopathology in the 1950s.

The impact of Bowlbyism and general pro-natalism after the war reasserted women's roles as housewives and mothers. Political parties were largely united in the view that married women should not work and there was a general lack of interest in developing provisions for state childcare under Attlee's Labour government, or Churchill or Eden's Conservative governments that followed. ${ }^{7}$ The impact of the Children Act 1948 and the increased sanction given to psychiatric social workers to explore and investigate family life placed mothers in an unusual situation where they were dominant in their home, yet also faced increasing interruption and intervention by Children's Officers, psychiatric social workers and others parties interested in their children's development. Armed with an overarching framework for intervention in child development issues, taken wholesale from the recommendations of the Curtis Committee, state interference into family life grew substantially in the 1950s.

The decade also witnessed growing rifts between approaches taken by different institutions, in particular between those who adopted Bowlby's approach and those who did not. At the Tavistock, no one strayed far from an overarching Freudian model of instinct theory. Even the Tavistock Institute of Human Relations, established in 1947 with funding from the Rockefeller Foundation, drew from Freudian theories of the unconscious in their efforts to explain wider social 'human relations' issues in the field of industrial psychology. ${ }^{8}$ The Tavistock 
sought to develop new ways to think about the subjective aspects of social life and new ways to manage these passively via therapeutic measures rather than full-scale political intervention. In fact, the Tavistock model provided the first prototype institution for Nikolas Rose's now celebrated theory of 'governmentality.' Their goal was to find ways to employ psychological knowledge to enable more sophisticated forms of social governance.

At the Maudsley Hospital, similar moves were made to develop a sophisticated programme to study and intervene in social life, but this never took wider instinct theory, or the unconscious mind, for granted. In the summer of 1948, the Medical Research Council (MRC) provided finances to create a separate unit to investigate psychiatric problems in industry. ${ }^{10}$ The approach was always more process-driven, rather than aimed at exploring the depths of desire and the moral codes created in relation to it. As the director, Aubrey Lewis, described it, they aimed to measure the 'mental and emotional characteristics' of workers in relation to their productivity and social capacity. ${ }^{11}$ Unlike the Tavistock School, which used the psychology of the individual to understand group productivity, the Maudsley School used the psychology of populations in order to understand individual productivity. This distinction was crucial in determining the theories of mind and individual development that researchers at the Institute of Psychiatry then began to produce. Tavistock theorists already had an overarching framework for understanding subjective development drawn from Freud's theories of the unconscious. The Maudsley did not have this in the 1950s, although, as this chapter will demonstrate, there were some who were seeking to develop it.

Hans Eysenck, head of the Psychology Department at the Maudsley, was a critical thinker in the development of supposedly objective tests to measure 'personality', as opposed to intelligence, in Britain. As Maarten Derkson has pointed out, one of his main goals was to draw a distinction between what had previously been termed 'educational psychology' and what he referred to as 'clinical psychology. ${ }^{12} \mathrm{He}$ wanted to develop an objective science of psychology based on direct observation that was primarily experimental in nature, yet which also got to the heart of subjectivity and self-hood. ${ }^{13}$ In this way, his work had parallels with Cyril Burt's dream to develop tests to understand subjective development, although Eysenck was not really interested in child 
development. He was very critical of all psychoanalytic concepts of the unconscious, and he also challenged the efficiency of psychotherapy as a curative technique. ${ }^{14}$

Eysenck considered the human personality to be quantifiable in terms of 'introverted' and 'extraverted' reflexes. He worked on developing tests measuring performance and productivity presented as objective measures of personality, often drawing from the work of Neil O'Connor, an experimental psychologist with a strong interest in Soviet psychology. These tests measured performance and productivity but were presented as measures of personality. ${ }^{15}$ Although Eysenck discussed the terms 'introvert' and 'extravert' purely in terms of measurable bodily reflexes, he had in fact taken them from Freud's former colleague Carl Jung, who had claimed that these personality types developed as the result of an individual's unconscious instinctive urges. Jung had modelled these types on Pierre Janet's differentiation between hysterical and psychasthenic characters, though he had broadened these out to include non-pathological character formations. ${ }^{16}$

Eysenck's tests were employed regularly at the Unit for Research in Occupational Adaptation, an adjunct to the Maudsley Hospital funded by the MRC, and also headed by Aubrey Lewis. However, the use of experimental psychology to measure personality types was a long way from psychoanalysis as a comprehensive model of the development of subjectivity and human relationships that was applicable across multiple domains. These psychological tests of 'personality' and subjective awareness slowly trickled down into studies of child development at the Maudsley in the 1950s, but the Tavistock theorists always had the upper hand when it came to understanding the development of human subjectivity because they could easily draw from British instinct theory and theories of the unconscious, without feeling the need to employ methods from experimental psychology. This is why the Tavistock became a dominant force in promoting and publishing theories of child development in the 1950s. Nevertheless, there were moves at the Maudsley to develop new theories of subjective development. However, without the strength and charisma of $\mathrm{BBC}$ personalities such as Bowlby and Winnicott, these theories took some time to get off the ground. This chapter looks at the origins of these theories and the reasons why they were developed. 


\section{The strange case of 'psychotic' children}

By the early 1950s, children classed with 'psychosis', 'schizophrenia' and 'autism' stood at the heart of controversies over the social and emotional development of children, as well as the role of parents, educators, social workers and other agencies in the socialisation of those children. Childhood psychosis was, therefore, an incredibly controversial and poignant topic, touching on all aspects of child development, as addressed by different groups ranging from psychologists and psychoanalysts to parents and government officials. Of course, different professional groups took different approaches to the problem, and this only added to the controversy surrounding the category. Amongst professional child psychiatrists, there was definitely no consensus over the aetiology and prognosis of autism or childhood schizophrenia, and the same was clearly true for psychoanalysts and psychologists who were also grappling with these concepts of early mental development. Health care workers more generally and those engaged with the law concerning child education and welfare thus had very little to work with when it came to legislating for this group of children. Clearly, this did not help in the creation of any solid medical or legal categories to secure services and help for these children, and this group ended up occupying a rather absurd social, political and cultural space.

Although theories of psychosis, schizophrenia, autism, autoerotism and primary narcissism continued to be promulgated within models of normal child development and employed widely in the theories of Susan Isaacs, Melanie Klein, Donald Winnicott and John Bowlby, there were some major ironies that existed for children who actually received a diagnosis of 'schizophrenia' or 'psychosis'. Although welfare measures were put in place to help children who may have been 'deprived of a normal home life, ${ }_{17}^{17}$ and interventions and psychological therapies developed to help children via child guidance services, in fact any child who actually received a diagnosis of very severe psychopathology in the form of 'schizophrenia', 'psychosis' or 'autism' effectively fell through the cracks of any kind of social policy aimed at social and emotional education.

The Education Act 1944, although revolutionary in its claims to expand secondary education for all, made no provisions for such children. Neither did it make any such provision for children with 'mental 
defect'. Although it was not much consolation, 'defective' children were still catered for under the Mental Deficiency Act, even if only with the provision of large-scale institutions. Children diagnosed with 'schizophrenia,' 'psychosis' and 'autism' were thus not recognised under any English law and therefore received no special welfare entitlements or provisions. In 1945, the Handicapped Pupils and School Health Regulations that supported the 1944 Education Act legally obliged local authorities to provide special education to all children who could be classed under the following eleven labels: i) blind; ii) partially sighted; iii) deaf; iv) partially hearing; v) delicate; vi) diabetic; vii) educationally subnormal; viii) epileptic; ix) maladjusted; $\mathrm{x}$ ) physically handicapped; xi) those suffering from speech defects. ${ }^{18}$ 'Psychotic', 'schizophrenic' or 'autistic' children were not included. Although these conditions were sometimes smuggled in under the category of 'maladjustment', problems could occur if the child's condition was regarded as a form of severe psychopathology. Services for 'maladjusted' children were not set up to deal with such children and, in practice, most children diagnosed with 'schizophrenia' or 'psychosis' were usually referred swiftly on to the Board of Control as cases of 'mental defect'.

In 1948, the Ministry of Education issued a circular that directly implicated medically trained psychiatrists in the diagnosis and treatment of 'maladjusted' children. This prompted the employment of child psychiatrists in all child guidance clinics across the country, leading to both a growth and a dispersal of the profession. Hospital boards paid the salaries of psychiatrists whilst local authorities continued to pay for the clinic grounds and other staff. ${ }^{19}$ This move did not encourage the treatment of 'childhood schizophrenia' and 'psychosis' because the child guidance clinics were still obliged to refer severe cases on to mental defective institutions. However, it did mean that some child psychiatric departments were able to specialise. It also linked the discipline of child psychiatry more definitively to adult psychiatric sciences. In 1946, Aubrey Lewis required that all psychiatric trainees spend six months in the children's department to ensure that they received a comprehensive education in all psychiatric problems. ${ }^{20}$ In January 1948, the Maudsley Medical School was renamed the Institute of Psychiatry. The Medical School had already functioned as a specialist psychiatric teaching centre, but in the post-war period the Institute of Psychiatry became the major psychiatric teaching centre in the UK, forming one 
limb of the British Postgraduate Medical School, which had established central institutes for all medical specialities across the UK. ${ }^{21}$ When, in July 1948, the Maudsley Hospital was granted National Health Service (NHS) funding, its position as the primary British training centre in psychiatry was confirmed. Yet, the role of child psychiatrists in popularising theories of child development remained very limited and was incomparable to the work of child psychologists and psychoanalysts in generating a popular model of child development. In this respect, the human relations school of psychology remained dominant throughout the 1940s and 1950s. Nevertheless, some child psychiatrists, now dealing with a more specialist clientele, were able to focus on conceptual problems in psychology and education rather than the practical administration of child welfare. 'Mentally defective' children were not technically part of their remit, although the absurdity of this legal archaism was slowly coming to the fore.

Because 'psychotic' children were not mentioned in the 1945 Handicapped Pupils and School Health Regulations, local education authorities did not have to provide special education for them. However, child psychiatrists were incredibly keen to diagnose 'psychosis' in particular, because they thought it would not only help them to develop the science of child psychiatry, but also give them an advantage in developing the finer points of human relations psychology. This led to a peculiar situation where increasing numbers of children were being diagnosed as 'psychotic', yet there was no legal framework to cater for their needs. The early 1950s saw the establishment of several centres for the reception of 'psychotic' children across Britain. In 1953, Dr Elwyn James Anthony and Dr Kenneth Cameron founded a 'psychotic clinic' for the intensive observation and study of children suffering from major psychosis or schizophrenia at the Maudsley Hospital. Cameron had been appointed as head of the Maudsley Children's Department in 1946, after returning from war service in the navy. He had initially joined the Maudsley in 1939 after working with Leo Kanner and Adolf Meyer on a Rockefeller fellowship in Baltimore. Cameron had previously studied medicine in Edinburgh and specialised at the Royal Edinburgh Hospital for Nervous Disorders under David Henderson, whose name, along with that of William Gillespie, was becoming synonymous with British psychiatry through the constant republication of their classic Textbook of Psychiatry. ${ }^{22}$ 
The children who were observed at the clinic during the 1950s were usually aged between three and nine years and were referred from schools, hospitals and child guidance clinics across Britain. All of the children were admitted as inpatients for 'two weeks [of] observation and investigation' as part of the 'psychotic survey programme' and were then referred elsewhere for residential placements. ${ }^{23}$ Many were kept on for treatment as outpatients. Other similar clinics were established in the 1950s, such as Alan Cashmore's clinic at Booth Hall Hospital in Manchester. ${ }^{24}$ In June 1955, Mildred Creak noted that there were 'five centres up and down the country where psychotic children are accepted, mostly on a regional basis. ${ }^{25}$ Anthony and Cameron's clinic was unique because the staff focused on generating observations for the purposes of research. Because of this, 'child psychotics' from other reception centres were often referred to the Maudsley for intense observation. For instance, Cashmore sent virtually all of his Manchester patients to the Maudsley for this purpose. ${ }^{26}$ The foundation of the psychotic clinic strengthened the reputation of the Maudsley as a reception centre for the most severe cases of childhood psychiatric disorder, and as a place where the finer points of psychological theory could be interrogated in depth.

Because the Mental Deficiency, Education and National Health Service Acts made no mention of the concepts of childhood psychosis or schizophrenia, the children diagnosed with these conditions had no legal rights to long-term treatment or education. The Maudsley psychotic clinic was founded partly in order to get 'childhood psychosis' recognised as a legal category and also to reinforce the role of medically trained child psychiatrists in determining the treatment that 'psychotic' children received. On the other hand, because these children were neither theorised nor classified under law, Maudsley doctors were left with a considerable amount of creative freedom in their work, freedom that they would not have had in the treatment of children diagnosed with conditions listed in the 1945 Handicapped Pupils and School Health Regulations.

Although child psychiatry was rapidly developing following the establishment of the discipline at the Maudsley, and as a result of the 1948 Ministry of Education circular that implicated child psychiatrists in the diagnosis and treatment of 'maladjusted' children, there was still a lot of debate over the use of different theoretical models in 
the definition of childhood mental illness. Child psychiatrists began to think more systematically about the definition of childhood schizophrenia as a clinical or medical category, and this was part of a wider shift of interest in the collection of statistics on mental ill health. In 1952, the first Diagnostic and Statistical Manual of Mental Disorders (DSM) was published in the USA with the aim of standardising diagnostic practices in the field of mental illness. It was the first statistical manual to focus on mental disorders. In 1948, the WHO had also taken control of international attempts to standardise all disease categories developed in the International Classification of Diseases (ICD) and had listed a large number of conditions under the heading of 'psychoses', hence the general interest in this particular classification in Europe. However, psychiatrists in the USA were deeply critical of the ICD classifications, and so they developed the DSM. In Britain, clinicians began to draw from both the ICD and the DSM in formulating diagnostic categories in mental illness. For child psychiatrists, the 1952 DSM was more relevant because it attempted to define 'childhood schizophrenia' as a unique condition under the broader heading of psychoses.

In the first DSM, childhood schizophrenia was listed as 'schizophrenic reaction: childhood type'. This classification was subsumed within a wider definition of 'psychotic reactions' in which 'the personality, in its struggle for adjustment to internal and external stresses, utilizes severe affective disturbance, profound autism and withdrawal from reality, and/or formation of delusions or hallucinations.'27 At the same time, it was noted that 'the clinical picture may differ from schizophrenic reactions occurring in other age periods because of the immaturity and plasticity of the patient at the time of onset of the reaction. Psychotic reactions in children, manifesting primarily autism, will be classified here. ${ }^{28}$ This definition drew substantially from the work of Adolf Meyer and was not particularly helpful in establishing a divide between the use of autism as a developmental stage and as a psychopathological category. Nevertheless, it did provoke discussion about definitions and encouraged further exploration of how, precisely, childhood schizophrenia was an extreme form of 'maladjustment', stimulating debate about the particular mental life of children with schizophrenia and how far this could be associated with 'maladjustment'. 
In 1950, the Underwood committee had been appointed to investigate the treatment and prevention of 'maladjustment' in children in Britain and their 1955 report focused on the importance of keeping families together. 'Maladjustment' was used as a broad term to describe a child's inability to control his instincts according to social requirements. The Underwood report was highly influential on the organisation of welfare services for children, in particular on professionals associated with the Kleinian or Tavistock school. ${ }^{29}$ However, it was not well received amongst Maudsley-trained child psychiatrists. This was because it effectively sought to determine their work using the concept of 'maladjustment' as a guide. ${ }^{30}$ In 1955, Kenneth Cameron criticised the entire concept of 'maladjustment' as a working term. He argued that it was simply 'a neutral word utilised to cover a group for whom special provision is required' and was concerned that the concept was becoming reified as a clinical entity in a similar way to the legal term 'insanity' and the social term 'delinquency'. He found these developments disturbing and regarded them as a misunderstanding of both instinct theory and medical science. ${ }^{31}$

Cameron's criticisms sought to silence human relations and Tavistock psychologists who were beginning to attribute all childhood mental illness to insufficiencies in family life and their effect on children's social development. He was infuriated that this model of child development was getting such a good reception at the level of government, when in fact the medical evidence was not there to support it. He argued that the pronouncements of psychology's popularisers were often quite vague when explored in any detail. A few years earlier, Cameron had publicly criticised a speech by Winnicott at the Royal Society of Medicine in which Winnicott had highlighted the normality of 'psychosis' as part of normal developmental stages. Cameron took issue with Winnicott's statement that 'the young child lives in a mad world and only gradually learns to relate himself to reality' and that 'the child analyst has to be able to enter a mad world where reality is dealt with by means of magical thinking. ${ }^{32}$ Cameron was one of the first people to argue that discussing normal phases of development as 'psychotic' and as forms of 'madness' was apt 'to cause alarm and misapprehension' amongst parents and lay people. ${ }^{33}$

Unlike Tavistock 'object relations' theorists who dominated the political application of psychology in the 1950s, child psychiatrists, with 
much less political clout, were beginning to think in more depth about the relationship between mental deficiency and mental illness. This link was being encouraged by work conducted at the Unit for Occupational Adaptation. In the 1950s, a small number of psychologists in Britain had begun to argue that 'mentally defective' children did not need to be consigned to isolated deficiency institutions. After the NHS Act was passed in 1948, mental deficiency institutions became the responsibility of regional hospital boards under the Ministry of Health $(\mathrm{MoH})$. The practices of care used within them were suddenly opened up to new scrutiny by institutions supported by the MRC, in particular the Unit for Research in Occupational Adaptation. In the early 1950s, Neil O'Connor and Jack Tizard used Eysenck's tests to determine whether it was possible to measure 'instability' objectively amongst a defective population. ${ }^{34}$ They argued that the motor skills, performance, intelligence and personality of defectives could be improved so that they might be capable of even employment and life outside an institution, thereby challenging the view that institutional care was the only option.

Shortly afterwards, in 1953, the unit expanded its area of interest to schizophrenic and psychotic populations. This was contemporaneous with the foundation of Anthony and Cameron's psychotic clinic for children. Peter Venables, the chief researcher on schizophrenia at the unit, claimed that schizophrenics constituted 'a population of patients, with in some sense a defined disease, whose magnitude was such as to form a problem of social significance. ${ }^{35}$ Venables, along with O'Connor and others, tested schizophrenic populations using similar measures to those used on defective populations. In particular they measured their reaction times, perception, motor responses and ability to conduct tasks. In one experiment, for example, 'chronic schizophrenics' were given tasks that measured their reaction times to visual stimuli. Venables found that the performances of schizophrenics were slower than 'normal' controls. He reasoned that schizophrenics reacted to stimuli with fatigue or boredom and this inhibited their ability to perform during the task. He then developed tests to prevent these subjects' introversion by distracting them with additional stimuli, such as white noise, during the tasks. This was thought to raise the arousal level via sensory input to the reticular activating system and then by non-specific pathways to the cortex. Venables found that this 'performance' task split the group into 'withdrawn' types, who were less aroused than optimal and 
responded to distraction positively, and 'non-withdrawn' types, who were more aroused than optimal and thus unable to work in the presence of multiple stimuli. ${ }^{36}$

Although the categories of 'schizophrenia' and 'mental defect' remained both legally and socially distinct, the transfer of defective institutions to the management of regional hospital boards under the NHS increased their visibility and raised questions about what the real distinction was. Many psychiatrists thus came to be employed in mental deficiency institutions and many began to assert that deficiency was not an isolated entity and that it could be associated with childhood schizophrenia. For example, in 1952, Gerald O'Gorman, consultant psychiatrist at Borocourt Hospital, Reading, for children and adults classed with mental deficiency, argued that the diagnosis of 'mental defective' was not inaccurate for individuals who had developed schizophrenia in early childhood because 'schizophrenia interrupting normal development ... may so retard a child's progress that he does in fact become a mental defective.' O'Gorman claimed that 10 per cent of adolescents and adults with mental defect had developed this as a result of early schizophrenia. ${ }^{37}$ Mildred Creak also began to argue that the onset of a 'psychosis' in children prevented them from developing normally intellectually and the child therefore developed 'mental defect' as a secondary symptom. ${ }^{38}$

In 1950, Middlesex Mental Defective Colony was renamed Harperbury Hospital and B. W. Richards sent a paper to the Journal of Mental Science highlighting the relationship between mental deficiency and schizophrenia, attempting to figure out whether some of the patients in his institution had, in fact, suffered from a very early psychosis that had been misdiagnosed as a mental defect. 'At this institution', he remarked, 'there are more cases of childhood and pubertal schizophrenia without any fundamental intelligence defect than there are of propfschizophrenia, a term developed by Emil Kraepelin to describe 'dementia praecox' in conjunction with 'mental retardation'. However, Richards would not go as far as Neustadt in dismissing propfschizophrenia entirely. What was clear was that many were beginning to wonder whether institutionalised cases were, in fact, cases of early mental illness, and whether child psychiatrists could in fact assist in preventing the development of such problems. Richards claimed that the early onset of the illness meant that 'schizophrenic' symptoms were unique 
in young children and focused on psychomotor or simple verbal symptoms, such as echolalia, rather than advanced ideational problems such as delusions and obsessive ruminations.

The age of onset continues to act as a limiting factor right into adult life, for the result of the characteristic affective change beginning in childhood is a narrowing of the circle of social contacts. The personality of the patient, never having extended object attachments deeply into the affairs of society with its complex goals, competitive spirit and clash of personalities, gains but a slender hold on the fabric of reality. The clinical picture and psychopathology in adult life are correspondingly threadbare. ${ }^{39}$

By stripping the problem of mental deficiency and childhood schizophrenia down to a problem of early or late onset of mental illness, Richards bypassed the problem of describing early psychological and developmental stages that authors such as Piaget and Isaacs were addressing. However, he did engage with the problem of distinguishing defect and psychopathology, which was not always high on the agenda of psychologists who studied development.

In the USA, several clinicians who regularly came into contact with children classed with 'mental retardation' made similar points. For instance, in 1951, Clemens Benda, Director of Research and Clinical Psychiatry at the Walter E. Fernald State School in Massachusetts for mental retardation, argued that the distinction between mental defect and mental illness in children was artificial and merely a useless application of legal categories from adult psychiatry..$^{40}$ In the same year, M. Bergman from the Newark State School assessed over 300 children who seemed to be both 'defective' and 'schizophrenic' and tried to find out what came first. ${ }^{41}$ Leo Kanner argued that emotional problems could 'interfere' with intellectual functioning in the development of infantile autism. ${ }^{42}$ In short, in the 1950s, childhood schizophrenia was an important issue in the USA and Britain and child psychiatrists were finally beginning to think in more depth about its relationship to 'mental defect. ${ }^{43}$ They knew that it was central to developing theories of social and emotional development in children, and researchers were beginning to communicate internationally about their theories and approaches. ${ }^{44}$ Louise Eickhoff pointed out that there were transnational differences in the diagnosis of cases and that childhood schizophrenia seemed 
to be less common in Britain than in the USA, although she didn't know why. ${ }^{45}$

By the early 1950s, it was clear that 'psychotic' and 'schizophrenic' children were being used as objects with which to settle controversial discussions on the nature of child development. Many in the USA regarded the study of childhood schizophrenia as a way to challenge behaviourist theories. As George Gardner, from the Judge Baker Guidance Center in Boston, put it, 'no learning experiment, however exquisitely designed', will be able to match clinical observations of childhood schizophrenia in advancing an understanding of the human mind. ${ }^{46}$ In 1953, a major discussion was held on the subject of childhood schizophrenia in the USA. The discussion was remarkably similar to that which had ensued in Britain in the 1940s and rehearsed the problem of behaviourism versus instinct theory and the problem of ego development and the initiation of the Oedipus complex in full. ${ }^{47}$ Everyone thought that the answer now lay in 'schizophrenic children', the new jewels in the crown of psychological theory.

Although Cameron rejected some aspects of 'object relations' theory, in particular the recent fusion of theories of subjective development and ego development in relation to the mother's ability to create a stable emotional setting for child development, he did not reject the project of using childhood schizophrenia as a springboard from which to understand wider problems in child development. The psychotic clinic was largely established in order to clear up confusions and controversies about the category that were rife in the early 1950s.

\section{Inside the first psychotic clinic for children}

My special purpose is the reinstatement of the psychotic within the theoretical framework of our normal practice ... Too often and for far too long we have stood outside and regarded him with increasing theoretical bewilderment as his behaviour continued to transgress the laws of orthodox psychopathology ... Getting inside the psychotic child is by no means an impossible phenomenological undertaking. (Elwyn James Anthony, 1957) ${ }^{48}$

Elwyn James Anthony was born in India and then moved to Britain for medical training just before the Second World War. As a citizen of 
the Empire, he was drafted into the British Army to serve as a doctor where he was 'put into a tent' with John Rickman, a British psychoanalyst who had trained with Melanie Klein and had just started working at the Tavistock Clinic when war broke out. Anthony was then recruited into an army battalion before being placed again with Rickman at Northfields, the legendary military hospital where Rickman, together with Wilfred Bion and Siegmund Heinrich Foulkes, all prominent members of the British Psychoanalytic Society, began a major experiment in the use of group therapy to treat soldiers suffering from 'military neurosis. ${ }^{49}$ As if such diverse experience were not enough, Anthony then trained under Aubrey Lewis at the Maudsley in the late 1940s before being granted a Nuffield travelling fellowship to study with Jean Piaget at the Institut Jean-Jacques Rousseau in Geneva in $1951 .{ }^{50}$ On his return, a new post was created for him as Senior Lecturer in Child Psychiatry, which he took up in February 1952. ${ }^{51}$ This was the first academic post in child psychiatry to be established at the Maudsley. ${ }^{52}$ By the mid-1950s, Anthony was also lecturing at the London School of Economics and presenting frequent papers to the British Psychological Society. He also gave addresses to the London County Council Child Welfare Officers and the Association for Workers of Maladjusted Children. ${ }^{53}$ In 1959, he emigrated to America to join the Washington University School of Medicine in St Louis and in 1960 he joined the Chicago Psychoanalytic Association, where he trained as a psychoanalyst. ${ }^{54}$

In the 1950s, however, he was not psychoanalytically trained and was far more interested in developing the work of Piaget who was, he claimed, like Freud, a 'system maker. ${ }^{55} \mathrm{He}$ was interested in bridging gaps between psychoanalytic theory and the theory of developmental psychology, yet he developed this in a slightly different direction than Isaacs, Klein, Winnicott and Bowlby, who had focused on the majority population and on Freudian models in order to develop theories of the mother and child relationship. Instead, Anthony focused on very complex cases that sat at the border of mental deficiency, and then used them as a model for understanding regular developmental psychology in a Piagetian model that employed tests for subjectivity in order to build up an understanding of the development of individual conceptual awareness.

Anthony's work supported Cameron's more practical approach to the assessment and treatment of cases. Cameron's primary interest 
was to classify disease entities in child psychiatry. ${ }^{56}$ When Cameron took charge of the Children's Department, he was finally able to put to use buildings that had been constructed at the end of the 1930s. This architecture enabled the close observation of children from virtually every standpoint and provided the perfect setting for the psychotic clinic. Children could be placed under constant observation by nurses in a centralised ward. Others could be placed in one of the four glassfronted rooms. During play times, all of the children were easily observable in the two bright and spacious recreation rooms.

Although Anthony and Cameron provided the theoretical impetus for the psychotic clinic, nurses conducted the majority of the observational work. This fact is significant as these nurses were largely unhampered by the debates that had been raging over child development and schizophrenia, having been trained principally as domestic attendants who would serve the treatment regimes of doctors. ${ }^{57}$ Nevertheless, they were given a unique role as observers and reporters. In the psychotic clinic, this enabled the creation of vast swathes of material on the behaviour of children who received a diagnosis of 'psychosis', material that could never have been collected by Creak or earlier psychiatrists, who were far too stretched dealing with huge multifarious populations to be able to focus on such detail. Every nurse who reported for duty at the psychotic clinic was given the brief to closely observe the children whom she was also employed to care for. Doctors encouraged them to describe each child's use of language in detail and to illustrate their awareness of other people and objects. As one registrar put it, he was 'interested in observations of [the child's] autistic behaviour when absorbed in his play - arm movements, expressions, verbalisations. ${ }^{58}$

Nurses produced their observational reports in standardised notepads and these reports were read by Anthony, Cameron and other registrars, who would then correct the descriptions. For example, when one nurse began her observations in 1954, she would initially portray her six-year-old male patient using language similar to that of the social workers. Her descriptions were infused with assumptions about the way that children should relate to one another. ${ }^{59}$ However, after further instruction and requests by the doctors to focus on the boy's 'autistic behaviour', she began to produce detailed accounts of the child's individual behaviour and speech. Each action that the child carried out and everything he said were recorded. In particular, the nurse would 
describe all behaviour that appeared to have some bearing on the child's perceptual awareness and his ability to understand concepts. For example, one account read:

When he does play by himself, he walks up and down very precisely with small steps holding his arms out bent at the elbow as if he was wavering on something ... At night when he is in bed he talks to himself a good deal often going over events ... He dresses himself but is very slow needing constant verbal encouragement, 'is this the vest?' he asks, 'is this the right way up?', etc. with every garment. He understands 'upside down' and 'the wrong way up' but is puzzled by 'inside out. ${ }^{\text {'60 }}$

The above observation is typical of those recorded in the 1950s because of the training the nurses received. The aim of collecting these observations was to catalogue the particular conceptual problems that each child was experiencing. From these descriptions, the child's conceptual schema, and their self-awareness, could be ascertained and compared with that of the other children. There was no attempt to use statistical methods to confirm these findings, although the observation of similar behaviour in multiple cases was taken as confirmation.

Central to all of these accounts were detailed descriptions of the child's vocalisations. If children were unable to speak then emphasis would be placed on the noises that they made and whether or not these were imitative. It was thought that these accounts could demonstrate the child's contact with reality by showing his ability to respond to external stimuli. For example, one patient was unable to speak but could mimic 'the noises of things - trains, clocks, things that go "bang". The nurses recorded all the noises that he did make, pointing out that 'he seems to make happy little noises' and that he was able to imitate musical sounds, an indication that he could sense external sounds and respond to them. ${ }^{61}$ Another patient was described as having a 'refusal to speak', although it was noted that he 'whistles beautifully' and 'hums anything from a continuous monotone to ... meaningless monosyllables. He could also 'yelp and scream almost like a puppy'. ${ }^{62}$

If the children were capable of using language then the nurses would record their words in full, in particular noting any set phrases that they used. Many of the children repeated set idioms and phrases and many also exhibited echolalia. Others presented with more unusual speech abnormalities. For example, one patient was reported to 'add the word 
"after" wherever possible and doesn't respond to correction'. This child also had unusual mannerisms in the intonation of his speech. The nurses noted that 'he likes to coin some words in sheer ecstasy especially "it is lunch time" or "I will be last to dinner", etc.' ${ }^{63}$

Nurses would also pay attention to the children's use of personal pronouns that could indicate their capacity to distinguish themselves from others - the fundamental milestone in the psychoanalytic and Piagetian model of child development. Many of the children in the psychotic clinic referred to themselves in the third person or would confuse themselves with other people. For instance, one patient would never speak in the first person and would always refer to herself using her proper name or the name of 'her latest friend. Whenever she misbehaved, she would always deny that she had committed any mischievous acts and would then always adopt the persona of another. ${ }^{64}$ Although not all of the children adopted other personalities, most of them habitually spoke in the third person. In fact Cameron considered that, in terms of diagnosis, any 'inability to distinguish between first and third person ... suggests psychosis. ${ }^{65}$

All of the children's relations were observed and described in language that was dispassionate, detached and devoid of emotion. In 1955, one nurse was able to give an account of a child's aggressive behaviour without making any mention of his feelings. Instead, she used detailed descriptions of his movements and actions to convey his possible thoughts:

Today Arthur was very aggressive towards the staff ... His aggression takes the form of butting with his head, kicking and slapping with the palm of his hand. Arthur makes no attempt to play with the other children but is stimulated by them e.g. Kevin went up and hit Arthur ... on the back for five seconds. There was no response and then Arthur turned round, saw who it was and went up and hit Kevin back, on the head. ${ }^{66}$

In many ways, these accounts were behaviouristic because they focused on stimulus and response and did not attribute any motivations or feelings to the children. However, because the nurses were focusing on 'autistic' behaviour, this would be integrated into a wider theory of autism and subjective development, especially through the work of Anthony.

In the nurses' descriptions of each child's individual behaviour, the child's subjective thoughts were considered to become evident. A description of one child, for example, reported that he 'often stands 
somewhere near the window for long periods twisting curtains around ... [and] sings a lot to himself or sucks some object which gives him great pleasure. When alone, this child 'appeared to be happy most of the time, [though] he often had spells of sudden screaming and biting his arm. ${ }^{67}$ Another was reported to 'kneel on the floor and bang his head once or twice' on a regular basis. ${ }^{68}$ Yet another would engage in other rituals. For example, it was reported that once he 'sat on his bed and screamed for no apparent reason at all ... he then proceeded to hop on his left leg, around the table in the ward. After encircling the table three times he discontinued this. ${ }^{\prime 69}$ All of the nurses' notes are littered with such descriptions of individual behaviour that appeared to have emotional significance only to the child concerned.

For the doctors, the most treasured depiction of a child's individual thoughts and phantasies came in the form of detailed accounts of that child's speech when they were engrossed in thought. Nurses would record every single word and phrase that the child spoke when they observed these situations. The following account quotes in some detail the speech of an eight-year-old girl. Similar accounts cover scores of pages. They represent occasions where the children described their own desires and emotions and were thus viewed as the only legitimate documentation of these phenomena:

The child speaks to herself continually. Her conversation:

She wants to go out to tea, do you want to go out to tea, Friday, you ought to go. Your handies cold warm them up (puts them on radiator) dicky birds, little baby ones, do you want to sit on that (potty) sit on the potty, put her there. Little monkey get out of the way. See her handy pandies are freezing (waves hands about). Do your business in the potty, sick in the potty (she was sick this morning). See the bunny. You're not well, you've got a nasty chill you don't want to come, we'll see these bunnies after dinner. Have you been a good girl today, not well, bunnies asleep, see bunnies presently. (Giggles to herself and runs hands over the radiator). Don't keep on asking me questions. You get the key get him out of my way, let him out of the hutch, not well enough 72 days 'til Christmas when you get a bigger girl you will be quiet (holds hands over her ears) there'll be trouble. Get a good hiding don't sick on the floor. There's a potty here. (Gets the potty and puts it on the window sill) ${ }^{70}$ 
These words were thought to be a window onto psychotic states of mind. For Anthony and Cameron, who oversaw the production of this discourse, it could reveal the thinking processes that later led to adult schizophrenia.

Although the impetus for these descriptions came from Anthony and Cameron, it is clear that these nurses' reports began to guide the direction that psychosis research took. This is essentially because the nurses began to develop a general discourse for describing psychotic children and their activities. This was the beginning of a new language of autism. In 1957, Anthony argued that one could only truly understand the psychotic mind if one developed a language that could describe both the inner and the outer perceptions of the psychotic individual. Using poetic terms, Anthony once described the child psychotic's mental state as 'the world of the very young infant set in the twilight of consciousness'. This world

will sometimes be overwhelming in its sensation, sometimes wild and frightening, sometimes flat and uninteresting; time will be reduced to the 'here and now' and space to the subjective needs of the moment; objects will sometimes be permanent and sometimes impermanent, sometimes meaningful and sometimes meaningless. ${ }^{71}$

Anyone attempting to observe this phenomenon must be prepared to enter into this world and to understand the way psychotic children conceptualised both phantasy and reality. Children who could use language to describe their conceptual 'worlds' were prized objects at the psychotic clinic because they provided the most direct access to this inner reality. The experiences of child 'psychotics' that Maudsley nurses began to document were unique because they described children's thought independently of their relationships to others. All thought that was considered to be 'psychotic' was defined by these discursive rules and boundaries.

The observational method developed by Anthony and his work on childhood psychosis was extremely influential and was quoted by many authors of the 1950s and 1960s, including Michael Rutter, who based his first classifications of psychosis and autism on the work of Anthony and, by proxy, the nurses at the psychotic clinic. ${ }^{72}$ 


\section{Testing, testing, testing}

All of the children in the psychotic clinic were given a battery of tests on arrival in order to determine their physiological functions and their levels of intellectual and social development. These included X-rays, brain scans and tests on the nervous system conducted by doctors, as well as a large number of standardised psychological tests conducted by psychologists. Every child was tested using electroencephalography in order to measure the electrical charges in their brain. This built on Piaget's work on electroencephalography and child development and the theories of alpha, beta and gamma rays in developing brains he had presented at a major WHO conference on the psychobiological development of the child. ${ }^{73}$ X-rays would be taken of the child's wrists to measure the age and structure of their bones. If it was thought that there may be any damage to the child's head, then X-rays were also taken of their skull. Wasserman and Kahn tests for syphilis were given, as were cardio-lipine tests for thrombosis. Some of the children were also photographed or filmed. Anthony produced a short film on childhood psychosis using footage from the clinic that he presented at the Second International Congress in Psychiatry in Zurich in $1957 .^{7}$

A standardised form covering aspects of the child's nervous system, circulatory system, respiratory system, alimentary system and urinary system would be completed in full. The form was based on a tradition of nerve and reflex testing that drew strongly from the neurological sciences. The child's weight, height and complexion would be recorded, as well as any 'deformities or stigmata'. In measuring the child's nervous system, 'involuntary movements', 'tremors' and 'tics' would be noted, as well as 'deep reflexes', 'superficial reflexes' and every twitch, reflex or expression that would indicate the functioning of the cranial nerves (Figure 1). This information was collected in order to assist Anthony and Cameron in their measurement of biological functioning at the sensory-motor level and its influence on the child's psychological state.

Standardised psychological tests were applied by psychologists employed solely to test the children. H. Gwynne Jones, M. Newell, Patricia Audley and A. D. E. Schonfield all worked at the clinic as staff psychologists in the 1950s, along with trainee clinical psychologists. The most common form of intelligence test used on psychotic children at the Maudsley in the 1950s was the Wechsler Intelligence Scale for Children (WISC). 


\section{CONDITION ON ADMISSION}

An entry, positive or negative, to be made if possible against each heading. This may be in the briefest form which is complete and intelligible. If space does not permit adequate entry refer to separate note. Statements of patients to be distinguished by inverted commas.

Height Weight Tpr. P. R. Nutrition

General bodily health Relation of appearance to age

General development and build

Complexion Colour of irides Cornea, Conjunctiva

Skin eruptions, etc.

Hair on cranium; $\quad$ on Face;

Any anomaly of Cranium, Face, Ears, Palate, etc. Bones and joints

Deformities and stigmata

Signs of old or recent injury

Signs of sinus infection

Thyroid

Lymphatic Glands

\section{NERVOUS SYSTEM}

Symptoms

Sleep

TRUNK AND LIMBS Trophic State of Skin etc.

Any wasting of muscles

Pareisis

Muscular tone

Involuntary movements, tremors, tics, etc.

$\begin{array}{lllll}\begin{array}{l}\text { Deep reflexes K.J. } \\ \begin{array}{l}\text { Superficial reflexes } \\ \text { Coordination }\end{array}\end{array} & \text { B.J. } & \text { T.J. } & \text { S.J. } \\ \text { Station }\end{array}$

Cutaneous and deep sensation

Pain and paraesthesiae

$\begin{array}{llll}\text { CRANIAL NERVES } & \text { I. Smell } & \text { II. Vision } & \text { Fundi } \\ \text { III, IV, VI Exopthalmus } & & \text { Ptosis } & \text { Strabimus Diplopia } \\ \text { Movement of eyes } & \text { Nystagmus }\end{array}$

Pupils. Outline R. L. Consensually R.

Jaw muscles Sensation of face

II Voluntary facial movement

L. To accommodation R. L.

Prevalent expression

III Hearing Tinnitus Vertigo

Reflexes corneal, conjunctival

IX, X, XI, XII Movements of Palate Tongue

Swallowing Articulation and Phonation

\section{CIRCULATORY SYSTEM}

Symptoms Oedema Cyanosis Anaemia

Flushing Dilated Capillaries Varicose Veins

Condition of arteries

BP

Pulse Circulation in Extremities Sweating

Figure 1 Facsimile of the first page of 'Condition on Admission' form used to collect information from children in the psychotic clinic in the 1950s (MHCP/A) 
David Wechsler had studied under Charles Spearman at University College London and went on to serve as chief psychologist at the Bellevue Hospital in New York from 1932 to 1967. In 1939, he published the Wechsler-Bellevue intelligence test and followed up with several revisions that increasingly divided Spearman's concept of ' $g$ ', or general intelligence, into different parts. ${ }^{75}$ In 1949, Wechsler published the Wechsler Intelligence Scale for Children, a testing schedule that divided a child's IQ level into two different fields. If a child was able to complete certain 'performance' tasks, such as the arrangement of pieces to form a model of a car, or the coding of geometrical shapes, then he could receive a high IQ score in that area, even if he was unable to score highly on the 'verbal' tests. This meant that even mute children could be rated with very high intelligence scores in non-verbal areas. Wechsler's tests also allowed for interruption or spoiling so that if a child refused to finish the tests or spoilt his paper in some way then the IQ values could still be calculated. ${ }^{76}$ In the psychotic clinic, there were frequent cases of 'spoiling' and many of the test papers were left uncompleted. Up until the 1950 s, children with such test papers would have been written off as 'defective'.

Other tests used in the Maudsley psychotic clinic measured specific aspects of each child's motor development and perceptual functions. These included the Vineland Social Maturity Test, the Rorschach test, the Goodenough 'draw a man' test, the Romberg test and the 'whirling' test. The Vineland Social Maturity Test was developed by Edgar A. Doll, who was based at the Vineland Training School for FeebleMinded Children in New Jersey. The test was published in 1935 when Doll was head of the psychological laboratory. He succeeded Henry H. Goddard and S. D. Porteus in this post, both of whom had been very influential in the fields of intelligence testing and eugenics. Goddard translated Binet's tests into English between 1905 and 1908 and publicised them in the USA, just as Burt publicised them in Britain. ${ }^{77}$ Doll's test was designed to measure not only the child's conceptual awareness but also his competence in usefully applying this conceptual knowledge in the management of his life. For children between the ages of one and eleven, it would rate such things as whether or not, when prompted, the child 'walks about room unattended', 'transfers objects', 'gives up baby carriage', 'discriminates edible substances' or 'walks upstairs unassisted'. The more tasks that the child could complete, the higher his social age 
was rated. This was then calculated with his actual age to produce a 'social quotient', or SQ, that was unrelated to his IQ.

The Rorschach or 'inkblot' test was first published in $1921 .{ }^{78}$ Its creator, Hermann Rorschach, had trained in Zurich and Neuchâtel, graduating in 1906. He had studied with Bleuler and was greatly influenced by the work of Jung. In 1912, he published his doctoral work, 'On Reflex Hallucinations and Kindred Manifestations'. This addressed the question of how hallucinatory experiences could exist when they related to states of being that were physiologically impossible. This work was written in the frame of Bleuler's model of associationism in psychology. ${ }^{79}$ Rorschach's interest in hallucinations was coupled with a growing fascination with the way in which patients free-associated to images. His inkblot tests were aimed at standardising visual material to which patients could respond with associations. Rorschach's tests were not generally well received in Britain, ${ }^{80}$ but they were employed in the Maudsley psychotic clinic. Children's responses were thought to reflect their phantasies and thus indicate whether they inhabited a psychotic mind-state. If they took a long time to respond, or made 'bizarre' suggestions, it was thought that their phantasy life was unusually active and this was taken as indicative of developing or existing schizophrenia.

Some tests employed by Anthony and Cameron were specific to the identification of schizophrenia in children. In 1952, the 'whirling' test was evaluated by Yale Kramer and other doctors from the Department of Pediatrics at Bellevue, who 'whirled' 700 children in order to see whether the test could be used alone as a diagnostic tool. They argued that it was useful, though not decisive, in identifying schizophrenia. ${ }^{81}$ At the Maudsley, the test was employed as a measure of the child's motor co-ordination and his sensory-motor functions. It was similar to the Romberg test in which children were blindfolded and tested as to their spatial awareness. All of these tests could help to build a picture of the child's internal conceptual framework and his sensory-motor functions, and his efficacy in determining external reality.

The 1950s saw the first systematic application of tests to schizophrenic children in order to ascertain what their problem really was. ${ }^{82}$ Play techniques and the discussion of projective mechanisms by psychologists, such as Lowenfeld, encouraged the observation and analysis of drawings by schizophrenic children in order to ascertain the perceptual problems that may accompany the condition. ${ }^{83}$ Lowenfeld argued 
that her 'world technique' was a tool of particular value for the study of schizophrenic children. Children were presented with trays of sand and miniature toys representing their everyday life and experience, and through this they were expected to express their emotions and inner worlds. ${ }^{84}$ Other North American writers were interested in the drawings of child schizophrenics as representative of their 'perceptual problems', such as J. Allison Montague from Columbia University. ${ }^{85}$ In order to test the children's bodily boundaries, at the Maudsley children were asked to 'draw a man' and the picture was then analysed. Some of the psychotic children at the psychotic clinic were unable to complete the task at all, which was thought to signify a complete inability to recognise others or an inability to represent reality. Others included disturbing features or omitted vital features such as the body or the eyes. ${ }^{86}$

Anthony and Cameron developed their own unique logic regarding which tests to apply to which particular children at the clinic. For example, in 1952 one six-year-old child was described by M. Pines, a registrar in the psychotic clinic, as 'a very seriously disturbed child presenting signs of autism and speech disturbance involving reversal of pronouns, obsessional traits, marked anxiety and phobias. ${ }^{87}$ On admission the boy was given the WISC verbal and performance tests, the Goodenough test and the Rorschach test. Unlike many other psychotic children, his verbal and performance test scores were similar, though they were both in the low range. These results were not thought to be wholly reliable as the child 'did not really make an effort' and was 'dreamy and slow to respond'. However, even when making an effort he did not appear to understand the questions concerning comprehension and gave many unusual responses. For example, when asked 'what should you do if you cut your finger', he replied, 'I take the blood out'. In the Goodenough test he scored very highly, though he gave the man unusual features such as 'a penis, navel and breasts, and on one foot he drew skates'. In the Rorschach tests he refused to co-operate and 'finally nearly got into a white rage so that the test was discontinued. The psychologist reported him as 'certainly not defective', and noted that he shows 'emotional responsiveness and is not completely withdrawn socially'. However, she also pointed out that 'some of his drawings have bizarre features' that may indicate 'schizophrenic signs', even though this could not be verified in the Rorschach test. ${ }^{88}$ According to Anthony, test results such as these indicated that the child's 'educational backwardness is secondary 
to his mental disturbance which corresponds to an autistic type of childhood psychosis. ${ }^{89}$ In other words, the child's lack of subjective awareness led to educational problems.

Anthony and Cameron used their arsenal of testing methods to identify the primary problem that they thought led to a child's psychosis. For example, in 1958 one eight-year-old girl was referred to the clinic and given a preliminary diagnosis of 'childhood schizophrenia'. Her inpatient summary stated that she was hostile to her younger siblings, had a 'speech defect', could not write and had been excluded from school 'after three weeks because she took no notice of anybody. ${ }^{90}$ On the reflex tests, she was found to have limited movements of expression in her face and possibly no sensation. Her 'prevalent expression' was recorded as 'perplexed. The psychologists tested her using a battery of tests that did not require any verbal responses. These included the Goodenough test and the WISC performance scale, as well as 'picture vocabulary' and 'progressive matrices' tests. Although she scored well on the Goodenough test and was rated with an IQ of 86 , she scored very badly on the WISC performance scale. Her low scores were thought to reflect her problems 'involving abstraction of ideas e.g. number and classes of objects'. In several tests, she appeared unable to understand what was being asked of her and would merely repeat the instruction and move the test materials around randomly. Though given no formal spoken or written tests, her speech was recorded on tape for a period of forty minutes, during which she was given small toys and pictures to look at. It was noted that 16 per cent of her speech was echolalic and that she had huge difficulty in pronouncing consonants. In cases such as this, Anthony and Cameron would consult other doctors, in particular, neurologists, over the speech problems of 'psychotic' children. This girl was referred to Dr Hulbert at the West End Hospital for Neurology and Neurosurgery with an accompanying question: 'Does she have a specific neurological speech defect in addition to the speech disorder associated with her psychosis?" ${ }^{91}$ Hulbert responded that she had 'a mild dyslalia with defect of intonation', but that 'speech therapy was unlikely to help until her level of cooperation [had] been improved from the psychiatric angle'. $\mathrm{He}$ thought that 'psychiatric' treatment would help her to understand 'the mechanics involved' in the pronunciation of words. ${ }^{92}$ Cameron and Dr Kreitman, his registrar, acknowledged that distinguishing between the girl's speech defect and her psychosis was an 'extremely difficult 
and perhaps insoluble problem. ${ }^{93}$ However, they all agreed that speech therapy should be attempted as this may lead to improvements in her psychotic condition. The conclusion in this case was that the girl's problems were the result of her inability to speak and think conceptually, rather than her phantastical and psychotic state of mind being the cause of her speech problems. ${ }^{94}$ Cameron would refer to this and similar conditions as 'primary backwardness with a psychotic overlay. ${ }^{95}$ In cases such as these, the child's phantasy life was not of primary interest.

Psychological tests could help to distinguish between different forms of child psychosis that were observed at the psychotic clinic. The use of standard psychological tests alongside reflex and medical tests meant that a child's conceptual development could be tallied with their functional abilities. The results formed the backbone to new theories of psychotic phenomena in children that divided 'psychotic' children into types in an attempt to ascertain causes. In a 1957 article, Anthony described the results of tests he had been conducting on psychotic children that aimed to test their reactions to stimulus in order to rate their degree of 'egocentricity' and their ability to distinguish themselves from others. The majority of these experiments drew from tests devised by Piaget. For example, in 'the test of three mountains', psychotic children were shown a series of toy mountains. A toy child then climbed each of these mountains and took a picture at the top. The children were then asked to identify the position from which each photograph was taken. In order to complete the test successfully, the child must be able to see things from the point of view of the toy child. ${ }^{96}$ It was predicted that all psychotic children would score highly on this perceptual test for 'egocentricity' and the test results confirmed this prediction. Given that Piaget was the first person to develop the theory of autism in relation to children, it is entirely appropriate that he was also the first person to develop a test for 'egocentricity' or subjective awareness for children, which was then followed up by Anthony.

Prior to the establishment of the psychotic clinic, and Anthony's appointment as Senior Lecturer in Child Psychiatry, children who were referred to the Maudsley in the late 1940s and early 1950s and diagnosed with schizophrenia or psychosis were often given very intensive and invasive treatments. These ranged from insulin shock and drug therapies to intensive psychoanalytic treatment. For example, in 1955, Cameron reported the case of one psychotic girl who had begun 
to deteriorate at the age of three and who was treated at the age of eight 'by insulin comas without benefit and during the course of treatment died from subarachnoid haemorrhage. ${ }^{97}$ A nine-year-old boy admitted in 1950 was given insulin shock treatment over a period of twenty-six weeks. ${ }^{98}$ After four weeks of treatment, the patient was seen by Cameron, who is reported to have commented that 'where before insulin treatment he was a thin miserable, mute child, he is now a fat happy mute child.99 Other than this development the treatment did not alter the child's condition, and Cameron later admitted that 'insulin treatment has been disappointing in pre-pubertal cases. ${ }^{100}$ This bleak episode in the treatment of 'psychotic' children in Britain was a reflection of the parallels drawn between adult and infantile 'psychotic' thought. However, the close parallels and extreme experimentation were still not on a par with the aggressive approaches that had thrived in the USA. There is no evidence that any children were treated with insulin shock after the late 1950s at the Maudsley. This change was influenced by the work of Anthony, which viewed autism, psychosis and schizophrenia as often closely aligned to other forms of 'normal' or typical development.

In the late 1940s and early 1950s, some 'psychotic' children were given intensive psychotherapy at the Maudsley, usually under the supervision of Clifford Scott. ${ }^{101}$ Scott was a medical doctor who had studied at the University of Toronto and Johns Hopkins University in Baltimore. In 1931, he moved to London where he joined the British Psychoanalytic Society and was assigned to Melanie Klein for analysis. By the late 1940s, he was director of the London Clinic of Psycho-analysis and a senior psychotherapist at the Maudsley, where he worked psychoanalytically with both adults and children. In 1948, he had a paper accepted in the prestigious British Medical Journal that defended Klein's theories on the origins of depression. As he put it, depression

often occurs early in the first six months of life. It must also be remembered that the tests of reality which can be made at such a period are of an infantile type. The intensity and explosiveness of the infantile satisfactions and rages interfere with perception of reality, both inner and outer. The way each satisfaction and each rage is shown colours the outer world and the inner world by rapidly acting and by complicated types of introjection and projection. ${ }^{102}$ 
Other therapists were also employed at the Maudsley child clinic and many used Kleinian theory and technique. For example, one boy was given 'psychoanalytic treatment' for four months by Dagny Oftedal in the early 1950s. Oftedal described her technique as follows:

It was felt to be important to deal as much with the patient's behaviour and his relationship with the therapist as with content of phantasies. His evidence of emotional contact, his fear of showing any affect, and after the affect was obvious, his reluctance to admit that he was angry with the therapist, or fond of her, was constantly interpreted to him. ${ }^{103}$

Although such therapies were reported to have some efficacy by the therapists themselves, Anthony and Cameron thought that they were often followed by relapse. After the opening of the psychotic clinic, children who presented with psychotic symptomatology were very rarely treated with psychoanalytic therapies.

In place of insulin shock therapy and intensive psychoanalytic therapy, the establishment of the psychotic clinic saw the introduction of more sedate therapeutic measures, in particular 'occupational therapy' or 'school therapy'. 'Occupational therapy' was usually conducted by nurses. ${ }^{104}$ 'Instructions' were given by doctors who stated that the desired outcome of the treatment was 'socialisation'. In contrast to the 'socialisation' encouraged by psychiatric social workers, the 'socialisation' practised by nurses was focused on preventing bad behaviour rather than analysing and interpreting the child's relationship to others. For example, Anthony described one child admitted in 1953 as 'functioning at a very early social level and his contact with people is intermittent'. Occupational therapy reports pointed out that

He plays OK with the sand - letting it run through his fingers or watching it drop on the floor, and also eats it, but makes no attempt to play constructively with it. This and shutting himself in the small cupboards both activities which the psychotic children indulge in more consistently than any other, is what he prefers to do and has any drive to do. He spends a lot of time wandering around the room throwing things on the floor, usually things that the other children are absorbed in. This is done in a rather vague unpredicted and yet compulsive way. ${ }^{105}$

Therapy focused on upgrading his social level. Nurses were instructed to 'encourage him to be independent in dressing, eating, etc'. The aim was to enable the child to live without institutional support rather than 
to engage with his fantasy life and improve his relationships. This kind of 'occupational therapy', also referred to as 'training', was thought suitable for children with low IQs who made up the majority of the psychotic clinic's population.

Almost all of the children who were admitted to the psychotic clinic in the 1950s were referred to 'special schools', 'training' or 'defective' institutions when they left. The doctors and clinic staff considered the question of where to put each child as one of 'disposal'. This word was used on the standardised admission and discharge form and was often quoted in letters to County Medical Officers. The following extract is from a 1958 letter written by Cameron to a consultant paediatrician in Lancaster concerning a six-year-old child who was under consideration for disposal in a defective institution:

By now it is clear that this boy developed a psychotic illness at the very end of 1955, of which you must have seen the initial phase of withdrawal, muteness, loss of toilet habits, etc. At present he is active and lively, does not speak except a few words but whistles tunefully, and is improved in his habits: but he does not relate in any ordinary way to his surroundings, performing odd little mannerisms which are presumably related to his inner fantasies. The prognosis is not good and he may have to be dealt with ultimately under the mental deficiency acts. ${ }^{106}$

It was this kind of reasoning that led Cameron and others to refer psychotic children with potential 'inner fantasies' to institutions designed to deal with 'defectives'. However, most of these children were still kept on the books of the Maudsley, thereby generating a population of children who were living in defective institutions and residential special schools, yet were also registered at the Maudsley. Cameron, Anthony and others kept in contact with many of these institutions and formed very strong institutional, intellectual and administrative bonds with many of them.

Many 'psychotic' children who were thought to have the potential to develop through education and speech therapy would be sent to one of several Rudolph Steiner schools across Britain. The 'Camphill Rudolph Steiner Schools' had their headquarters in Harley Street, London, where their superintendent, Karl König, worked in conjunction with the Medical Officer, Neil McArthur Lees. ${ }^{107}$ König, who had trained in medicine in Vienna, acted as consultant for cases at the Larfield Hall School in Kent, the Salmon's Cross School in Surrey and the Murtle 
House School in Aberdeen, where former patients of the psychotic clinic were sent. Staff at the Steiner schools wanted to know the kind of information that Maudsley doctors were interested in. For example, the principal of Salmon's Cross School wrote to Cameron in 1955, including reports of a case, adding that 'there is of course much more that can be said about him and I shall be very glad to do so if you think the enclosed reports are not quite sufficient. ${ }^{108}$ Cameron and König also corresponded on the diagnosis of certain cases. ${ }^{109}$ In the majority of cases, the placements were successful, although in some cases they were not. For example, one child was referred to a Steiner school but was later referred back to the Maudsley because 'he shows a typical schizophrenic grin, he shouts, often repeating in an obsessional way some indecent word. He quite obviously has hallucinations of some sort and he cannot be kept in class with other children. ${ }^{110}$ This child was later admitted to an institution for mental defectives.

After the foundation of the psychotic clinic, Maudsley doctors ceased to maintain close contact with child guidance clinics or training schools that analysed and treated children using psychoanalytically influenced therapeutic methods. Although Anthony and Cameron were sympathetic to psychoanalytic theory, they were suspicious of many forms of psychoanalytic therapy for children. For example, they did not support methods based primarily upon developing a child's relationships rather than their intellect. They also supported parents who sought to remove their children from institutions where these forms of therapy were practised. For example, one child had been diagnosed with 'general backwardness' and had been treated by a play therapist at Ilford child guidance clinic. He was removed by his parents because they found his condition to be deteriorating instead of improving. He was then sent to the psychological medicine department of a major UK hospital, where the clinician deemed that 'this type of child cannot learn from experience.' It was on this assertion that the parents referred him to the Maudsley for a different opinion, and he was later accepted as a patient in the psychotic clinic. ${ }^{111}$

In cases where a psychotic child was deemed to be mentally defective, there was often an appeal against the decision by the parents. Correspondence and discussions pending the appeal could take place over months or even years as the parents sought to postpone decisions, and these would continue if the appeal was upheld. Maudsley 
doctors corresponded with County Medical Officers and representatives of local education authorities. For example, in 1954, the Principal School Medical Officer of West Sussex County Council, J. S. Bradshaw, claimed that one child who was attending Anthony's psychotic clinic was, in the words of the Education Act 1944, 'suffering from a disability of mind of such a nature or to such an extent as to make him incapable of receiving education at school. The child's parents were unhappy with this ruling and claimed that their child should be sent to a special school rather than a defective institution where he would be 'doomed for life'. Anthony wrote to Bradshaw, claiming that it is difficult to explain to parents that there is nothing wrong with the child's brain and yet the child is not normal'. Nevertheless, Anthony engaged in discussions with the parents until they accepted the ruling. ${ }^{112}$

By the 1950s, some mental defective institutions for children were beginning to market themselves as pleasant places of residence in order to avoid such resistance by parents and to align themselves with the special schooling system rather than the asylum system. Prospectuses put a positive gloss on the treatment that children received: for example, St Agnes' Home School prospectus stated that the school was located in beautiful 'country surroundings' and that 'the life of the children is a very happy one.' Children would be given 'care and training combined with a happy and healthy home life [with] the utmost importance ... attached to training in personal hygiene and good habits.' ${ }^{113}$ If a 'psychotic' child did reach the end of the line in the 1950s, then they were lucky if they reached an institution such as this an institution such as this.

It has become commonplace to claim that the closure of asylums at the end of the 1950s was a consequence of improved drug treatments that enabled patients to be treated in the community. ${ }^{114}$ However, there were other highly significant factors that led to the new policies assumed by asylums and mental defective institutions after 1959. The move towards discretionary admission of defective children first arose following the National Health Service Act in 1948 when some mental defective institutions began to invoke Section 3 of the Mental Deficiency Act to admit child patients at the behest of their parents without a magistrate's order. Before 1948, this section of the Act had only been used to admit patients into private hospitals. However, the changed status of mental deficiency institutions after 1948 left the issue 
of informal admissions ambiguous. According to L. T. Hilliard, consultant psychiatrist and physician superintendent of the Fountain Mental Deficiency Hospital, Tooting, there was initially some uncertainty over the legality of Section 3 admissions, but their increase put pressure on the Ministry of Health to reconsider their stance on the requirement for certification. ${ }^{15}$ On 21 January 1952, Ministry of Health Circular $5 / 52$ was issued, which enabled mental deficiency hospitals to admit uncertified patients on a short-stay basis not exceeding two months. By 1955 , nearly 2,000 uncertified cases had been admitted to mental defective institutions on a short-stay basis. ${ }^{116}$ After the closure of deficiency institutions following the 1959 Mental Health Act, Section 5/ 52 was still retained but was reformulated as a clause to allow for the short-term admittance of patients to hospital for 'social' reasons. Many hospitals then began to admit children for weekends or short breaks if it was felt that their families needed respite. ${ }^{117}$ These changes were largely driven by the establishment of short-stay admissions for children with psychosis.

The conceptualisation of the 'psychotic' child

In 1958, the European Journal of Child and Adolescent Psychiatry published an article by Anthony entitled 'An Aetiological Approach to the Diagnosis of Psychosis in Childhood'. The article was very well received and was later quoted by most Maudsley researchers on autism such as Lorna Wing and Michael Rutter. ${ }^{118}$ In the article, Anthony presented 'the concept of psychosis ... [in] relationship with other psychiatric disorders of childhood. ${ }^{119}$ It was an attempt to merge psychoanalytic theory and Piagetian theory with the sciences of infant observation, symptomatology and natural history in the Kraepelinian sense of tracking the development of an illness over time.

Anthony argued that within all cases of childhood psychosis and autism, there were 'components of three basic conditions of malfunctioning. These were, first, an inability to form a coherent and stable sense of self; second, an inability to 'cathect' internal experiences accurately, leading to 'difficulties in interpersonal relationships and displacement of affect onto things'; and, third, 'a confusion of self and non-self and disturbances in the perception of the self.' ${ }^{120}$ Anthony named this 
last problem 'a-dualism', borrowing the term from Piaget. ${ }^{121}$ This triad of 'malfunctions' was an original way of perceiving problems of selfidentity and would later form an important basis for all psychosis and autism research at the Maudsley, in particular the work of Lorna Wing and Michael Rutter.

Anthony thought that although all autistic and psychotic children displayed abnormalities in ego development, these disturbances followed different trajectories and so could not all be classed under a general term. He identified three different developmental stages during which childhood psychosis could strike, drawing from a similar claim by Lauretta Bender based on her understanding of Klein. ${ }^{122}$ These different ages of onset did not designate different conditions but merely different outcomes that were dependent upon the child's psychological maturity. In the first age group, which Anthony thought corresponded most closely with Kanner's description of infantile autism, 'the psychotic process fuses with earliest infancy' and the child is unable to respond normally to external bodily contact. Such children were often misdiagnosed as defective or deaf. In the second age group, in which onset occurred between the ages of three and five, the child suffered 'a massive regression to an autistic level'. This caused a 'turbulent' phase that was then followed by 'a diminution in anxiety and activity as the child sinks into a mute, manneristic and unoccupied state'. If the condition arose at this age, it was often mistaken for an organic dementia. Finally, psychosis could onset in the middle or late years of childhood, in which case the regression was minimal but 'the behaviour is compulsive and "odd" and there is a preoccupation with natural phenomena'. This condition could be mistaken for 'severe obsessional states', but Anthony regarded it as most definitely a manifestation of psychosis. When describing these different phases, it is clear that Anthony's understanding of autism drew directly from Bleuler and Piaget and not from Kanner. ${ }^{123}$

Anthony argued that the age at which a child developed autism or psychosis affected the particular form that the disorder took. His distinction between different ages of onset was framed by the conviction that 'every infant begins its psychological life in an autistic state.' Using a concept borrowed from Freud's Beyond the Pleasure Principle, Anthony employed a 'barrier hypothesis' to explain the development of different types of autism in children. The concept of an 'autistic barrier' had 
entered literature on adult schizophrenia and it was thought that psychotherapy could 'break through' that barrier. ${ }^{124}$ As Anthony described it, during normal development, the constitutional barrier that protects the infant is supplemented by a maternal barrier, which eventually gives way to an 'autonomous ego barrier'. This barrier enables the child to focus and not to be distracted by every passing stimulus. In the case of primary autism in the 'first age' group, the infant's constitutional barrier is 'abnormally thick' and the infant then goes on to develop 'an unselective psychotic barrier with the result that he fails to emerge from his primary autism'. In cases of secondary autism, or the second and third age group, the constitutional barrier is 'abnormally thin', allowing an excessive amount of stimulation to affect the psychotic child's ego. In this situation, he 'withdraws behind a thick, unselective psychotic barrier which blankets the stimulation' (Figure 2). ${ }^{125}$

Anthony maintained that the causes of childhood psychosis were numerous and often took place simultaneously. He therefore postulated an amalgam of forces that include 'constitutional, organic, genetic and psychogenic determinants and possibly some still unknown factor. ${ }^{126}$ Anthony strongly urged against any 'monocausal' view of the condition, especially that which placed excessive emphasis on 'schizophregenic' or 'psychotogenic' parents. The role of disturbed parents in the aetiology of the condition had been raised by Kanner as well as several other American doctors, such as William Goldfarb from the Henry Ittleson Center, whose evidence Bowlby had relied upon heavily in his WHO report. ${ }^{127}$ Goldfarb had described the mothers of autistic children as 'wooden', and argued that these mothers added to the confusion of their children by lacking any form of direction. ${ }^{128}$ Anthony took issue with both of these accounts as they seemed to suggest that bad parenting could be the sole cause of childhood psychosis. As he put it, in an attempt at clarification: "Not all "psychotogenic" mothers produce psychotic children; nor are all the children of "psychotogenic" mothers psychotic or the mothers of psychotic children "psychotogenic." ${ }^{129}$ On the other hand, he also criticised doctors and researchers who placed too much emphasis on 'organic' or 'constitutional' factors in causation. He admitted that there were always cases in which organic factors may have played a part. For example, Bender had identified neurological damage and evidence of encephalitis and encephalopathy in some of her cases of childhood schizophrenia. However, Anthony warned 


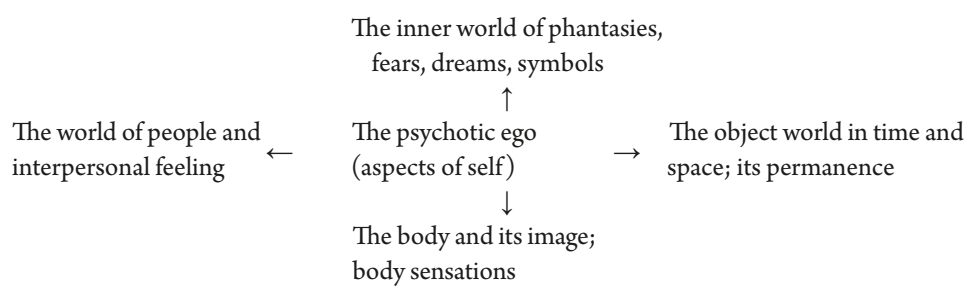

The failure to relate:

The defects

1. The ego to the inner self (asymbolia, absence of dreams, confusion of inner phantasy with outer reality).

2. The ego to itself (lack of self-recognition, self-consciousness, ego boundaries, selfidentity; dysidentity)

3. The ego to objects (no object concept, impermanence of objects, no conservation or constancy; $a$-dualism).

4. The ego to people (constriction and diminution of feeling, inability to give or reciprocate; $a$-cathexis).
5. The ego to its body (inadequate body image, poor localization of sensation and pain, poor co-ordination; poor representation).

\section{The defences}

1. Perseveration, rigidity;' just-so' behaviour, stereotypy, repetition, circular behaviour, replacement activity.

2. Withdrawal, pseudo-deafness, visual evasion, raised sensory thresholds, going under cover.

3. Transitional relationships to inanimate objects.

4. Projection, introjection, denial.

Figure 2 Chart, 'The psychotic ego with its defects and defences', from Elwyn James Anthony, 'Group therapeutic techniques for residential units', Case Conference 4, no. 6 (1957)

against making direct correlations between cause and effect in childhood psychosis. Taking the 'multicausal' view, he drew up a 'diagnostic schema' listing five different continua on which all cases of childhood psychosis could be placed. They could be placed on either a 'normal', 'deficiency', 'organic', 'neurotic' or 'psychopathic' continuum. Once identified on one of these continua, the severity of the child's disturbance could also be measured 'in terms of withdrawal, regression, rigidity, [and] the presence or absence of organic involvement. ${ }^{130}$

Anthony's aim was to (re)integrate psychoanalytic theory into the Piagetian scheme of subjective development to enable the detailed description of both normal and abnormal infantile thought. ${ }^{131}$ In the developmental model that he put forward, the initial stages of a child's life were said to be characterised by primary narcissism or egocentrism in which 'the self and the environment are one and there are no permanent 
external objects. ${ }^{\prime 132}$ The emergence of self-awareness occurred after the child, as organism, ceased to function through pure reflex action and came to use 'inventive action' to grasp and direct objects in space. This emergent intellectual ability was paralleled with a new emotional ability to relate to objects. As Anthony described it, 'the child was only able to proceed to a full emotional relationship with objects after he had rendered them permanent and substantial. ${ }^{133}$ After the child recognised the existence of other objects in the world, he began to adapt to his environment through the psychological processes of 'assimilation' and 'accommodation'. Assimilation consisted of the mental incorporation of objects in the environment that fulfilled the organism's, or the child's, individual needs. Accumulated incorporated objects in the mind formed elementary structures called schemata. Accommodation was the process whereby the child adapted these internal schemata to fit with the external environment and then directed his interactions with real external objects. Anthony considered Piaget's assimilation-accommodation mechanisms to be largely analogous to the projection-introjection mechanisms of psychoanalytic theory. In the assimilation-accommodation mechanism, however, there was a feedback system that created the 'logical machine' of the child's mind. By contrast, the projection-introjection processes led to the formation of the child's sense of self. Anthony speculated that perhaps, if one considered the result of these processes together, 'the logical machine might almost be described as the ego-ideal of the Piagetian intellectual system.' ${ }^{134}$

'Psychotic' children were children in whom normal identification processes had failed. Anthony claimed that the 'psychotic ego' failed to draw a distinction between inner phantasy and outer reality, resulting in an 'asymbolic' state of mind. The 'psychotic ego' was also unable to establish a relation to external objects, leaving it without a sense of object permanence and constancy. In addition, it could not relate to people and neither could it relate to its body or its self. This inability to relate to definable objects and identities left it in a state of defence that resulted in stereotyped behaviour and a withdrawal from sensory experiences. The psychotic child then formed 'transitional relationships to inanimate objects' and engaged in 'projection, introjection' and 'denial.' ${ }^{135}$

Anthony argued that psychotic children exhibited 'curious disturbances of object and space-time development' that could shed light on normal perceptual development in infants and children. His eventual 
aim was to use observations from the psychotic clinic in order to develop new theories of psychological development in children. His 'style of reasoning' about childhood psychosis was an individualistic, case-based style of thinking that drew from wider scientific theories on children's 'normal' psychological development and the 'organic' factors that could affect it.

Nevertheless, the work that Anthony was able to conduct at the Maudsley was limited by the Mental Deficiency Act 1913 and the Education Act 1944. Because these Acts enforced statutory care for children who were considered to be 'ineducable', children who supposedly had the most active phantasy lives, whose cases were regarded as exemplars of the autistic mind, were in practice those children most likely to be sent to defective institutions and thus taken furthest away from the Maudsley psychological and observational gaze. This was clearly not the wish of doctors such as Anthony and Cameron, who wanted to build conceptual frameworks for psychology around such cases. It was not until these Acts were overturned that new psychological theories could be constructed around the autistic mind. However, by this time, other political and legal changes meant that the study of 'psychosis' and 'autism' within a wider theory of individual child development was no longer viable. Anthony moved to the USA to become Ittleson Chair of Child Psychiatry at Washington University Medical School, St Louis. His ideas about autism would be fundamentally reshaped by later Maudsley researchers interested in childhood psychosis who came to focus on the importance of statistical reasoning in framing the concept.

Although psychological models were built around them, the children who attended the first psychotic clinic in Britain would actually grow in significance post-1959. This is because it was from this clinic that the first cases of 'autism' were selected for statistical studies that would sow the seeds for autism spectrum-making within child psychology.

\section{Statistics, schizophrenia and the growing significance of the Institute of Psychiatry}

Statistical approaches to the measurement of unconscious instinctive drives in children, such as those sought to be developed by Burt, hit a brick wall in the 1950s due to the major controversies concerning the 
description of infantile thought. In 1950, Glover founded the British Journal of Delinquency and it was primarily via this outlet, as well as the ISTD, that medically trained child psychiatrists employed statistical research on the criminal tendencies of children. Several Maudsley doctors, such as T. C. N. Gibbens and Wilfred Warren, published in the journal in the 1950s. This work used statistical methodologies in innovative ways, fusing psychoanalytic and case-based 'styles of reasoning' with statistical analyses. Although some people, such as Glover, continued to think about the role of instincts in the development of delinquency and criminality, on the model of child guidance, their statistical studies of atypical development were based on simple outcome measures of criminal behaviour. ${ }^{136}$ The possibility of integrating atypical versions of child development into a comprehensive theory of psychological development, objectively measured, was only possible if psychologists were able to measure, using psychological tools, the emergence of selfidentity in infants and children. Until that was possible, there could be no proof for theories in developmental psychology regarding the role of instinctive drives in structuring the personality.

Aubrey Lewis had supported research into mental deficiency at the Unit for Research in Occupational Adaptation not only because it could lead to better training and productive potential, but also because defectives provided 'a rewarding field for systematic enquiry' since their problems were 'less diverse and elusive, and lend themselves rather more readily to measurement, than those of most other branches of psychiatry.137 However, actual research into mental deficiency proved the fallacy of such ideas. In 1956, Jack Tizard and Neil O'Connor claimed that 'the categories of mental disorder and mental deficiency are frequently confused and probably interrelated.' ${ }^{138}$ This similarity had been adduced through the study of defectives' behaviour. As O'Connor and Tizard put it, 'In the general behaviour of defectives, psychiatrists have frequently detected features similar to those seen in psychosis. "Psychotic" cases are to be found among imbeciles, and patients may, because of psychosis, score on some tests at the performance level of imbeciles. ${ }^{139}$ Because Maudsley researchers were using objective measures for personality, they could not see the theoretical distinctions that had previously been drawn between defective and schizophrenic populations. Their amalgamation of the defective and schizophrenic categories was an artefact of their testing methods. ${ }^{140}$ 
Similarities between the two categories were also made in the USA during the 1950s, where comparable changes in the organisation of welfare provision had brought defective populations to the attention of sociologists and psychologists. ${ }^{141}$ By the late 1950s, Clemens E. Benda, who had assisted Binswanger at the Bellevue Hospital in Switzerland in the early 1920s and was then working as medical director of the Walter Fernald School for 'mentally retarded' children in Massachusetts, ${ }^{142}$ argued that when 'applying psychiatric standards to behavioural patterns, the idiot is almost, by definition, an "autistic" child." ${ }^{143}$ By the end of the decade, mentally defective populations had been drawn into the general study of psychiatry. When applying statistical methodologies, the behaviour and performance problems of 'defectives' were directly analogous to those observed in 'schizophrenics'.

The application of simplified tests of personality thus blurred the boundaries of mental defect and schizophrenia, to such an extent that this began to further challenge the divisions inherent in psychological theory and again to highlight the fallacy of 'mental defect' as a concept. The challenge to this concept came in the form of not only schizophrenia research but also further analysis into the validity of the claim that 'mental defect' was a clearly definable and heritable condition. In conjunction with Anthony and Cameron's work, researchers at the MRC Unit challenged the laws that were preventing 'psychotic' children from developing to their full potential. By maintaining contact with Steiner schools and others, they began to argue that with the correct education and treatment, 'psychotic' children could develop beyond their psychotic state. They called for more research to enable a greater understanding of the psychological development of children found to perform badly in standard intelligence tests.

In 1957, Brian Kirman and L. T. Hilliard from the Fountain Hospital drew attention to the fact that the psychological term 'mental deficiency' encompassed a number of different psychological and physical states. In their attempts to integrate this category into general psychology, Kirman and Hilliard were interested in genetic transmission and deficiencies or aberrations during gestation that affected the development of the brain. In 1938, Lionel Penrose, a medical doctor based at the Royal Eastern Counties Institution in Colchester, had conducted a Clinical and Genetic Study of 1280 Cases of Mental Defect in which he had argued that 'mental deficiency' was hereditary. ${ }^{144}$ Penrose had drawn 
distinctions between different forms of mental deficiency, arguing that phenylketonuria, amaurotic idiocy, microencephaly and some types of cretinism, deaf mutism and congenital diplegia were transmitted genetically in a recessive manner. However, Kirman criticised Penrose's distinctions, arguing that some of these conditions, microencephaly for example, were not disease entities and thus atypical forms of the condition could be generated by other factors, such as deficiencies or aberrations during gestation. Of these, viral infections, bacterial and protozoal infections, irradiation, chemical imbalances and hormonal imbalances could all contribute to the production of birth deformities. ${ }^{145}$ In making these claims, Kirman drew evidence from a growing number of animal studies conducted during the 1950s into congenital malformation, such as Eayrs' study of thyroid function in gestating rats and Hicks' work on the irradiation of pregnant animals by X-ray. ${ }^{146}$ Kirman pointed out that the exact cause of mental deficiency was still only ascertained in very few cases, despite the growing research into the topic. In a study conducted at the Fountain Hospital in 1955, the pathological cause of defect was confirmed in only 17 out of 154 cases, despite the fact that countless tests had been conducted at leading London hospitals. ${ }^{147}$ However, Kirman and Hilliard highlighted that it was important to bring knowledge of these conditions into the wider domain of general psychology, however unusual they may be. They described cases of microcephaly, hydrocephalus and acrophalosyndactyly, a disorder in which the limb buds do not develop properly and the head grows disproportionately in height. ${ }^{148}$ All of these conditions were associated with the psychological state 'mental deficiency', but they were all unique conditions and this problematised the use of the general concept in psychological theory.

In the case of less obvious abnormalities, Kirman and Hilliard collected information from patients at the Fountain concerning their general medical and social history. The purpose of this was to identify both the social factors that may cause mental deficiency as well as the social problems that may result from it. Kirman argued that these two groups of problems were 'difficult to disentangle' and that they clearly 'interact with each other'. He overtly criticised the previous standard textbook on Mental Deficiency by Alfred Frank Tredgold from University College Hospital. Tredgold had maintained that defectives were produced in families in which there was a large amount of 'mental abnormality' forming what he called a 'psychopathic diathesis'. 
Kirman countered that 'It is possible on such a hypothesis to list all forms of deviation from an approved mean of social behaviour in the family of a mental defective as evidence of a "psychopathic diathesis." 'Kirman and Hilliard instead sought to offer a new model of mental deficiency in which either the physical abnormalities of the body and brain were clearly identified, or the causes were opened out into the realm of more sophisticated sociological research. ${ }^{149}$

In 1955, Beate Hermelin and A. D. B. Clarke published an article on the 'abilities and trainability' of 'adult imbeciles'. They argued that the problem of training imbeciles was becoming increasingly important because the post-war decline in infant mortality and the advent of new drugs had 'prolonged their life-span and hence [increased] their numbers. ${ }^{150}$ Up until the 1950s, British writers on mental deficiency had always regarded the problem as a failure of normal development, hence the epithet 'deficiency'. Hillard and Kirman considered that their problems may be the result of physical 'disorders of gestation' causing 'somatic as well as neural' abnormalities. They also considered the importance of birth injury and post-natal infections or 'chemical, nutritional and endocrine causes' that affected the development of the brain and body. This brought a new dimension to the approaches that could be taken to 'mental deficiency' as a psychological problem. ${ }^{151}$

Because neither intelligence measures nor behaviourist observations could be used to track all psychological development in children, the detailed observation and study of 'mental defectives' and 'childhood schizophrenics' promised to bring a new dimension to the understanding of the way that biological abnormalities and instinctive drives impacted upon the development of self-identity and enabled socialisation in children.

Nevertheless, it was Bowlby and Winnicott's work on child psychology that was widely known in the public domain, not the Maudsley work. This skewed public understanding of autism and stoked further controversy. It is notable that even Kanner argued that the description of autism was being overused in the 1950s and that the USA 'seemed to be populated by a multitude of autistic children' whose condition appeared to be caused by faulty 'maternal emotional determinants. ${ }^{152}$ Although it was clearly a problem that parents were being unduly criticised, the more general engagement with parents occurring in this period, in which families were brought into a wider nexus of educational and psychological 
services to support child development, was a positive move. Childhood schizophrenia and autism became caught up in a wider trend for governmental agencies to observe and adapt parental behaviour. The 1950s were a problematic decade for child psychologists and for children who were observed under this rubric. Whereas, on the one hand, child psychologists such as Bowlby fought for their descriptions of instinctive drives and attachments in children to be taken seriously and to frame new political approaches to social interaction, on the other hand social reformers and psychologists like Jack Tizard sought to improve the integration of 'mentally defective' and 'mentally ill' children and adults, failing to appreciate the radical challenge that this would pose to theories of normal psychological development. Bowlby's argument that 'maternal deprivation' was just like nutritional deprivation in the marked effects that it had on an infant's brain development and precious psychological structures rang loud. Nevertheless, whilst this was represented as laudable advocacy of an infant's right to care in some cases, it did not make sense to extend the theory to all children with 'mental deficiency' or sensory defects of sight or hearing. It was not just psychiatrists and mental deficiency specialists who criticised the logic of mother blaming. For example, by the mid-1950s, Anna Freud had begun to take issue with Bowlby's interpretation of her observational evidence from the Hampstead nurseries. She claimed that he was paying too much attention to external circumstances, the actual mother-child relationship, whereas the aim of psychoanalysis was always to look at mental representations of instinctive drives and external relationships, not to look at the relationships themselves. ${ }^{153}$ However, because of the social and cultural capital of Bowlby's theories, it would only be after 'mental defectives' were fully integrated into models of society that they could be fully integrated into models of psychology.

\section{The problem with the 1950s}

Although Anthony was beginning to rethink the relationship between mental defect and mental illness, he was still drawing from psychological and psychoanalytic models of social development and the formation of relationships that were based only on homogenised population groups. Because psychological theories of child development and relationship 
formation discounted the most interesting and significant section of the population when it came to child development, it was unusual that psychiatrists describing very atypical children would employ them. And yet, there was really nothing else for them to draw upon without causing a crisis of confidence not only in psychological theory, but also in the institutions that were based upon it, in particular institutions for 'mental defectives', as well as in the structure of the school system. Concepts of intelligence and instinct theory had become ingrained in English and North American culture by the mid-1950s and it was virtually impossible to challenge them. Theories of relationship formation, even those as radical as those put forward by Melanie Klein, were all basically formed around that model and it was impossible to think about child development without thinking about instinctive drives towards relations and social interactions, and measurements of intelligence.

Instead of challenging the monoliths of instinct theory and the theory of intelligence, some researchers tried to surreptitiously integrate very atypical children into models of normal psychology. In Britain, most clinicians were not particularly concerned with Kanner's work in the 1940s and early 1950s but were instead desperate to present wholesale theories of social development. They regarded psychosis, schizophrenia and autism as handy concepts to throw into this description. The significant legal changes witnessed at the end of the 1940s in Britain ensured that children diagnosed with schizophrenia or psychotic disorders became increasingly important subjects for psychological investigation. Children diagnosed with these disorders promised to answer the pressing conceptual issues in psychology, psychoanalysis and psychiatry and a flurry of research built up around them. In Britain, Maudsley doctors Elwyn James Anthony and Kenneth Cameron experimented with physical and behavioural methods to alter the development of schizophrenic psychopathology and attempted to place schizophrenic children on a spectrum with other psychological states. Melanie Klein, Susan Isaacs and Anna Freud continued to research the significance of primary narcissism to understanding both normal and pathological development.

In general, there was a disciplinary and institutional gap between those working on general child development and socialisation, such as Isaacs and Lowenfeld, and those working on severe psychopathology such as Creak and Anthony, the latter based in hospitals whilst the 
former worked in nurseries, child guidance clinics and university psychology departments. When their theories collided, they did so in a way that was slightly haphazard. Although psychiatrists such as Anthony and Cameron were treating children with very severe psychopathology, they were importing their models of normal or general psychological and social development from researchers such as Isaacs and Piaget, who had quite different objectives in their descriptions of 'autism'. The result was a fusion of models drawn from the observation of severe psychopathology in adults with those drawn from the observation and study of typical behaviour and development in infants and children.

Whereas North American writers tended to turn to Gesell for a description of normal development, Anthony turned to Piaget. This was significant because Piaget was obviously more interested in the development of children's thought as a system of advancing logic, and interpreted this from a philosophical standpoint. In Britain, it was unlikely that Anthony would have followed any other direction given the significance of Isaacs' theories and her reliance on Piaget. What this meant in practice was that British descriptions of childhood schizophrenia, psychosis and autism were framed within a very particular theory of social development, conceptual awareness and the construction of logic in a child's mind. Furthermore, Gesell was more interested in describing typical developmental behaviours forming from the foetal infant onwards, whereas Piaget was not interested in behaviour per se, but was focused on the description of children's logical thinking. To put it another way, an infant who learned about the social world through his bodily behaviour, and one who learned about it through his ability to think logically, constituted very different beings. These differences would become more marked with the creation of the psychology of autism spectrum-making in the 1960s. In the 1950s, there were still too many obstacles to research in atypical child development and it would take a revolution before this problem would be overcome.

\section{Notes}

1 In Scotland, the 1945 Education (Scotland) Act initiated this process.

2 Savage, Identities and Social Change in Britain since 1940.

3 Healy, The Anti-Depressant Era.

4 K. Jones, A History of the Mental Health Services, p. 293. 
5 Shorter, A History of Psychiatry; Grob, From Asylum to Community; Healy, The Creation of Psychopharmacology.

6 Showalter, The Female Malady.

7 Riley, War in the Nursery.

8 Dicks, 50 Years of the Tavistock Clinic, p. 207.

9 Miller and Rose, 'The Tavistock Programme'.

10 Institute of Psychiatry Archives, Annual Report, 1950-1951, p. 3.

11 O'Connor, 'The origins of the Medical Research Council Social Psychiatry Unit'.

12 Derksen, 'Science in the clinic', pp. 271-274.

13 Derksen, 'Science in the clinic'.

14 Meaning psychoanalytic psychotherapy. Eysenck, Rebel with a Cause, pp. 127-129.

15 Eysenck, Dimensions of Personality.

16 Eysenck, Rebel with a Cause, pp. 96-97; Jung, Psychological Types, p. 413.

17 Report of the Care of Children Committee, Cmd. 6922 (London, 1946).

18 Handicapped Pupils and School Health Regulations, 1945, quoted in Phtiaka, Special Kids for Special Treatment?, p. 9.

19 Kahn, 'The local authority child guidance clinic'; Warren, 'You can never plan the future by the past', 244-245; Wardle, 'Twentieth-century influences', 58; Kier, 'A history of child guidance', 5-6.

20 Hersov, 'Child psychiatry in Britain', 784.

21 Institute of Psychiatry, Annual Report, 1950-1951, pp. 1-3.

22 Henderson and Gillespie, A Text-book of Psychiatry for Students and Practitioners.

23 Maudsley Hospital Childhood Psychosis/Autism Archive (all case numbers have been anonymised) MHCP/A: 448773: Letter - Cameron to Frederic De Havas, Salmon's Cross School, 21/7/54; MHCP/ A: 979317: Letter from L. Wilson (Maudsley Registrar), 20/6/55.

24 MHCP/A: 573500: Letter - Cameron to Cashmore, 28/10/58.

25 MHCP/A: 926185: Letter - Creak to Dr Elliot, County Medical Officer, County Hall, Maidstone, 24/6/55.

26 MHCP/A: 573500: Letter - Cashmore to Anthony, 30/10/57.

27 American Psychiatric Association [APA], Diagnostic and Statistical Manual (First edition, 1952), p. 12.

28 APA, Diagnostic and Statistical Manual, p. 28.

29 Rose, Governing the Soul, pp. 176-177. 
30 Hersov, 'Child psychiatry in Britain', 785.

31 Cameron, 'Diagnostic categories in child psychiatry', 67.

32 O'Gorman et al., 'Psychoses in childhood', 603.

33 O'Gorman et al., 'Psychoses in childhood', 603.

34 E.g. O'Connor, 'Neuroticism and emotional instability'; O'Connor and Tizard, The Social Problem of Mental Deficiency.

35 Venables, 'Experimental psychological studies of chronic schizophrenia', p. 83.

36 Venables, 'Factors in the motor behaviour of functional psychotics'; Venables, 'Experimental psychological studies of chronic schizophrenia'.

37 O'Gorman, 'Psychoses in childhood', 602.

38 Creak, 'Psychoses in childhood' (1951).

39 B. W. Richards, 'Childhood schizophrenia and mental deficiency', 303.

40 Benda et al., 'The inadequacy of present-day concepts in mental deficiency'.

41 Bergman et al., 'Schizophrenic reactions during childhood in mental defectives'.

42 Kanner, 'Emotional interference with intellectual functioning'; Kanner, 'The conception of wholes and parts in early infantile autism'.

43 E.g. Le Vann, 'A concept of schizophrenia in the lower grade mental defective'; Kugelmass, Management of Mental Deficiency in Children.

44 Harms, 'Essential problems regarding our present knowledge'; Bakwin, 'Etiology of behavior disorders'; Bakwin, 'Early infantile autism'; Ackerman, 'Psychiatric disorders in children'; Kestenberg, 'The history of an autistic child'; Kestenberg, 'Pseudo-schizophrenia in childhood and adolescence'; Clardy, 'A study of the development and course of schizophrenia in children'.

45 Eickhoff, 'The aetiology of schizophrenia in childhood', 230.

46 Gardner, 'Childhood schizophrenia', 520-521.

47 Freedman, 'Childhood schizophrenia', 487-488.

48 Anthony, 'An experimental approach: Autism', 211-212.

49 Flapan, 'The ongoing journey of an extraordinary man'.

50 Institute of Psychiatry, Annual Report, 1950-1951, p. 13; Shepherd, Conceptual Issues in Psychological Medicine, p. 134.

51 Institute of Psychiatry, Annual Report, 1951-1952, p. 15.

52 Hersov, 'Child psychiatry in Britain', 793.

53 Anthony, 'An experimental approach: Encopresis', 146; Anthony, 'Group therapeutic techniques for residential units'; Anthony, 'Other people's 
children'; Anthony, 'The system makers'; Anthony, 'The significance of Jean Piaget for child psychiatry'.

54 American Psychoanalytic Association, 'Annual meetings of the APA 1960', pp. 724-741.

55 Anthony, 'The system makers', 255-269.

56 Anon., 'Kenneth Cameron: Obituary'; Cameron, 'A psychiatric inpatient department for children'; Cameron, 'Symptom classification in child psychiatry'; Cameron, 'Diagnostic categories in child psychiatry'.

57 Nolan, A History of Mental Health Nursing.

$58 \mathrm{MHCP} / \mathrm{A}$ : 874753: 'Record for nursing staff: Instructions from doctor', $26 / 10 / 1954$.

59 MHCP/A: 874753: Nurses' notes, 19/10/54-26/10/54.

$60 \mathrm{MHCP} / \mathrm{A}:$ 874753: Nurses' notes, 30/10/54.

$61 \mathrm{MHCP} / \mathrm{A}: 338427$ : Nurses' notes, 20/3/55.

$62 \mathrm{MHCP} / \mathrm{A}: 573500:$ Nurses' notes, 9/10/58.

63 MHCP/A: 772931: Nurses' notes, 27/2/58.

$64 \mathrm{MHCP} / \mathrm{A}: 636380$ : Inpatient summary, 1958.

65 MHCP/A: 874753: Case summary, c. 1954.

$66 \mathrm{MHCP} / \mathrm{A}: 386165$ : Nurses' notes, 23/10/55.

$67 \mathrm{MHCP} / \mathrm{A}: 207036:$ Nurses' notes, 15/5/57.

$68 \mathrm{MHCP} / \mathrm{A}: 338427$ : Nurses' notes, 26/3/55.

69 MHCP/A: 436751: Nurses' notes, 18/11/53.

70 MHCP/A: 893951: Nurses' notes, 29/10/53.

71 Anthony, 'An experimental approach: Autism', 212.

72 Rutter, 'Behavioural and cognitive characteristics', pp. 53-55.

73 WHO, Proceedings of the First Meeting.

74 Anthony, Clinical Aspects of Childhood Psychosis [film].

75 Tulsky et al., 'Historical overview of intelligence and memory', pp. 23-28.

76 Lickorish, 'Psychological tests in child psychiatry'; Weschler, Weschler Intelligence Test for Children.

77 Gould, The Mismeasure of Man, pp. 188-189; Sutherland and Sharp, Ability, Merit and Measurement, pp. 126-127; Richards, Putting Psychology in Its Place, pp. 253, 285.

78 Galison, 'Image of self'.

79 Galison, 'Image of self', p. 267.

80 Richards, Putting Psychology in Its Place, p. 146.

81 Kramer et al., 'Whirling as a clinical test in childhood schizophrenia'. 
82 Helen Mehr, 'The application of psychological tests and methods', 90; Anderson and Zahm, 'Obituary: Helen Margulies Mehr (1916-1992)'; Mosse, 'The Duess test', 230-236.

83 Montague, 'Spontaneous drawings of the human form in childhood schizophrenia'.

84 WTA: PP/LOW/C/19. Lowenfeld, 'A combined approach to the study and treatment of disturbed children'.

85 Montague, 'Spontaneous drawings of the human form in childhood schizophrenia'.

$86 \mathrm{MHCP} / \mathrm{A}:$ 'Draw a man' pictures, 1950s.

87 MHCP/A: 436751: Report by Pines, 9/9/52.

$88 \mathrm{MHCP} / \mathrm{A}$ : 436751: Reports by Margaret Newell, Staff Psychologist, November 1955.

$89 \mathrm{MHCP} / \mathrm{A}:$ 436751: Letter from Anthony, 7/5/56.

$90 \mathrm{MHCP} / \mathrm{A}$ : 636380: Formulation and inpatient summary by Cameron and Kreitman.

$91 \mathrm{MHCP} / \mathrm{A}$ : 636380: Letter - Kreitman to Hulbert, 14/7/58.

$92 \mathrm{MHCP} / \mathrm{A}:$ 636380: Letter - Hulbert to Kreitman, 14/7/58.

$93 \mathrm{MHCP} / \mathrm{A}:$ 636380: Letter - Kreitman to Hulbert, 14/7/58.

94 MHCP/A: 636380: Psychological tests, 'Analysis of speech', 20/8/58.

95 E.g. MHCP/A: 772931: Letter from Cameron, 7/11/58.

96 Anthony, 'An experimental approach: Autism', 223-224.

97 Cameron, 'Psychoses in infancy and early childhood', 280.

$98 \mathrm{MHCP} / \mathrm{A}:$ 887704: Insulin treatment chart, 3/8/1950-11/01/1951.

$99 \mathrm{MHCP} / \mathrm{A}:$ 887704: Inpatient medical notes, 14/11/50.

100 Cameron, 'Psychoses in infancy and early childhood', 283.

101 E.g. MHCP/A: 563119: BMMA Case Summaries 1948/S BMF/5 (Author's code: 869086).

102 Scott and Clifford, 'Psycho-analytic concept of depression', p. 540.

$103 \mathrm{MHCP} / \mathrm{A}: 470968$ : Oftedal's notes, 1952-1953.

104 E.g. $\mathrm{MHCP} / \mathrm{A}: 338427$ : OT report, 20/12/54.

$105 \mathrm{MHCP} / \mathrm{A}: 681884$ : OT report, 12/12/53.

$106 \mathrm{MHCP} / \mathrm{A}:$ 573500: Letter, 29/10/58.

107 MHCP/A: 948758: Letter - König to Cameron, 19/6/52.

$108 \mathrm{MHCP} / \mathrm{A}$ : 532153: Letter - De Havas to Cameron, 12/12/55.

$109 \mathrm{MHCP} / \mathrm{A}:$ 948758: Letter - König to Cameron, 19/6/52.

$110 \mathrm{MHCP} / \mathrm{A}:$ 772931: Letter - De Havas to Cameron, 22/10/57.

$111 \mathrm{MHCP} / \mathrm{A}:$ 563119: Report of case, 15/10/52. 
$112 \mathrm{MHCP} / \mathrm{A}:$ 874753: Letter - Anthony to Bradshaw, 22/9/54.

113 MHCP/A: 772931: Prospectus - St Agnes' School, 1958.

114 E.g. Shorter, A History of Psychiatry.

115 Hilliard, '(b) Mental deficiency aspects'.

116 Spencer, 'The revision of the Mental Health Act, 1959'.

117 Spencer, 'The revision of the Mental Health Act, 1959', 84.

118 J. K. Wing, 'Diagnosis, epidemiology, aetiology'; Rutter, 'Behavioural and cognitive characteristics', pp. 16, 55.

119 Anthony, 'An aetiological approach to the diagnosis of psychosis in childhood', 94.

120 Anthony, 'An aetiological approach to the diagnosis of psychosis in childhood', 91.

121 Anthony, 'An experimental approach: Autism', 216.

122 Bender, 'Clinical study of one hundred schizophrenic children', 53.

123 Anthony, 'An aetiological approach to the diagnosis of psychosis in childhood'; 91-92.

124 Betz, 'A study of tactics for resolving the autistic barrier'.

125 Anthony, 'An experimental approach: Autism', 218.

126 Anthony, 'An aetiological approach to the diagnosis of psychosis in childhood', 93.

127 Meyers, 'Obituary: William Goldfarb’, 391-392.

128 Goldfarb, quoted in Anthony, 'An aetiological approach to the diagnosis of psychosis in childhood', 92.

129 Anthony, 'An aetiological approach to the diagnosis of psychosis in childhood', 92.

130 Anthony, 'An aetiological approach to the diagnosis of psychosis in childhood', 95.

131 Anthony, 'The system makers'.

132 Anthony, 'The system makers', 262.

133 Anthony, 'The system makers', 258.

134 Anthony, 'The significance of Jean Piaget for child psychiatry', 22.

135 Anthony, 'An experimental approach: Autism', 212.

136 Shaw, 'ISTD Summer School, 1950', 150-151; Glover, The Diagnosis and Treatment of Delinquency, p. 15; Warren, 'Conduct disorders in children aged five to fifteen years', pp. 164-186.

137 Lewis in O'Connor and Tizard, The Social Problem of Mental Deficiency, p. vi.

138 O'Connor and Tizard, The Social Problem of Mental Deficiency, p. 60. 
139 O'Connor and Tizard, The Social Problem of Mental Deficiency, p. 52.

140 Tizard and Venables, 'Reaction time responses by schizophrenics, mental defectives and normal adults'.

141 E.g., Franz Kallmann et al., 'The role of mental deficiency in the incidence of schizophrenia'; Sarason, Psychological Problems in Mental Deficiency.

142 Freud et al., The Sigmund Freud-Ludwig Binswanger Correspondence, 1908-1938, p. 172. Benda's name has more recently been associated with radiation experiments conducted on children at the Walter Fernald School; Moreno, Undue Risk.

143 Benda, Developmental Disorders of Mentation and Cerebral Palsies, quoted in Bender, 'Autism in children with mental deficiency'.

144 Penrose, A Clinical and Genetic Study of 1280 Cases of Mental Defect.

145 Penrose quoted in Hilliard and Kirman, Mental Deficiency, pp. 53-56.

146 Hilliard and Kirman, Mental Deficiency, pp. 61-62.

147 Hilliard and Kirman, Mental Deficiency, p. 53.

148 Hilliard and Kirman, Mental Deficiency, pp. 355-367.

149 Hilliard and Kirman, Mental Deficiency, p. 33.

150 Clarke and Hermelin, 'Adult imbeciles', 337.

151 Hilliard and Kirman, Mental Deficiency, pp. 61, 66, 68.

152 Kanner, 'Infantile autism and the schizophrenias', 413.

153 Vicedo, The Nature and Nurture of Love, pp. 132-137. 


\section{Part II}

How autism became autism 



\section{The transformation of social life and the transformation of autism in the 1960s}

The change in meaning

The establishment of child psychology in the early twentieth century enabled a stable theory of the development of children's subjectivity to settle by the 1950s. This model can be characterised as one in which early infantile hallucinatory wishes, dreams and thoughts slowly come to be replaced by reality, and realistic representations in the mind, via the infant's everyday experience and interaction with objects. It was only behaviourists that challenged this theory, but as they had no replacement model for the development of subjectivity, all they could offer were criticisms rather than an alternative. However, by the 1960s, shifts began to take place that encouraged the development of new theories of the development of subjectivity in infants and children. These new models built on Cyril Burt's idea to use statistical analyses of populations in order to generate scientific proof for the development of conceptual awareness in children. Just as in all earlier theories of child development, these new theories of subjective development had the concept of autism at their core.

One important occurrence in the search for scientific proof for autism was the deconstruction of the concept; it was interrogated, probed and criticised to its limits so that by the end of the 1960s, the initial meaning of the word 'autism' was completely annihilated. In fact, the new 'autism' that was developed during the 1960s had the exact opposite meaning of that which had prevailed until the end of the 1950s. Whereas autism and its conceptual cousins - primary narcissism, autoerotism, etc. - had previously always referred to hallucinatory 
dreamlike imaginary thought that preceded the establishment of realistic thinking, 'autism' from the 1960s was used to refer to a lack of imagination, a lack of hallucinatory thought, a lack of creativity and a lack of dreams. It was a concept that was predicated on the absence of imagination. 'Autism' of the 1960s thus became the kernel for describing the development of subjectivity in infants and children, yet it also referred to a state of mind that completely lacked any content or any meaning of its own and which gained its meaning only via the instruments used to measure it. This chapter examines this radical transformation in the meaning of autism. It examines why the shift in meaning occurred by placing it into the context of legal and political changes in Britain concerning the rights of children, and the impact of these changes on the construction of scientific studies of children.

\section{The transformation of social life}

In order to effect a major shift in the meaning of autism, there also had to be a major shift in the organisation of social life. Such a transformation began in 1959. This was the year in which the Mental Health Act was passed, which led to the closure of long-stay institutions for children. It was the Mental Health Act 1959 that set the scene for the gradual establishment of a framework for children's rights that was not exclusionary but in fact encompassed rights to education and social care for all children, regardless of their mental state. This generated new ideas about who could be accepted and incorporated into a new model of society.

The 1960s was also a decade in which increased liberalism about social norms finally began to permeate everyday life and expression. A growing generation of grammar-school-educated critical thinkers was finally able to challenge the authority of traditional models of social progress and evolutionary development espoused by authorities such as Cyril Burt. On the international stage, the British Empire was in its death throes. Harold Macmillan's 'Winds of Change' speech to the parliament of South Africa in 1960 signalled full independence for former colonies and encouraged critical reflection on the wider ideologies of social and evolutionary progress that had sustained British imperialism. ${ }^{1}$ A larger, educated reading public encouraged the publication of 
new journals and critical reflections on public life, creating a broader counter-culture movement. At the same time, increased availability of television and radio media enabled a surge in alternative forms of 'pop' culture. New visions and versions of 'society' and new ways to investigate, explore and understand it were feeding into the university system via the growth and expansion of the social sciences as a rational, neutral form of social exploration, unshackled by the dogmas and prejudices of Darwinian models of social progress. ${ }^{2}$

In the domain of family life, women were slowly gaining the right to make decisions about their own fertility and reproduction. In the early 1960s, the contraceptive pill was introduced as a licensed drug and made available on the National Health Service (NHS). By 1969, around one-and-a-half million women in the UK were on the pill. ${ }^{3}$ In addition to this, the legalisation of abortion in 1967 gave new rights for women who had experienced rape or unwanted pregnancies. Whereas the 1950s offered women Bowlbyism, pro-natalism and the drudgery of housework, the 1960s gradually began to offer them new models of social engagement. This led to some easing of the extreme moralising that had surrounded women's lifestyle choices and which had led to such injustices as forced adoptions for unmarried mothers. ${ }^{4}$ Some of this moralising had occurred under the auspices of the Children Act 1948, much of which had to be reorganised and rebuilt as the rights of women to make their own choices were ratified.

It is in this context that we must view the radical changes taking place in the area of children's rights. As Mathew Thomson has argued, postwar models of child subjectivity had propagated a model of children as simply inactive victims or welfare beneficiaries rather than active agents. Critiques of this model of children as passive welfare recipients of health, education and family life at the behest of the government would be increasingly challenged in the 1960s via radical movements that presented new models of individual and social development. ${ }^{5}$ The Mental Health Act 1959 was so significant in this field because it led to major changes in the organisation of care, welfare and education services for children. Once 'mentally defective' children, who had previously been excluded from all discourse and discussions concerning children's rights and entitlements to psychological health under the Children Act 1948, began to be regarded as legitimate psychological citizens, there were huge repercussions for the organisation of both child and family life. 
Child laws that were focused on supporting family life and providing children with a right to normal social adjustment, as typified in the Children's Act 1948, were based on Tavistock models of child development. These had been dominant in the post-war era, helping to propagate a model of human relations that could be quickly adopted within models for welfare policy aimed at stabilising family and social relationships. Bowlby and Winnicott had disregarded the detailed problems of describing the origins of subjective awareness that had been raised in the Controversial Discussions and focused instead on the practicalities of mothering, influencing welfare policy and popular understandings of childcare. Up until the late 1950s, the concept of 'maladjustment' had framed policy discussions over the organisation and management of children's social welfare services to enable the most favoured outcomes. However, in the 1960s, a new psychology of autism was used to challenge the social ideology of intervening in, and supposedly rectifying, child 'maladjustment'. The sciences of instinct theory and ethology could no longer support the entire edifice of child psychology. New models to measure 'autism' were developed in the fields of both experimental psychology and psychiatric epidemiology.

\section{The unmaking of mental deficiency law and} the making of autism law

The concept of autism was first raised in parliament in May 1960 by the Conservative MP William Compton Carr. ${ }^{6}$ Carr was also vicepresident of branches of the National Society for the Prevention of Cruelty to Children and the Society for Mentally Handicapped Children. ${ }^{7}$ He questioned the parliamentary secretary to the Ministry of Health, Edith Pitt, on why responsibility for 'mentally handicapped' children was not borne by the Ministry of Education. The prospect of improving the mental capacity of such children, or 'upgrading' them, was steadily growing and he argued that the government should ensure that research in this area be supported:

The most exciting thing, which is still a frontier to be crossed, is the work on causes and treatment of so-called autistic - sometimes called schizoid, sometimes psychotic - children, which is almost unknown territory. These children are apparently schizoids who live in a dream 
world. They seem intelligent, but it is impossible to touch them even with treatment that is nowadays giving success in 75 per cent of normal adult schizoids. We must pay attention to that factor. ${ }^{8}$

This was an important moment for all children defined with psychosis, schizophrenia and autism. Prior to this point, the developing subjectivity of these children was of interest to few people other than psychological professionals who worked with cases of borderline mental deficiency, such as Anthony, Cameron and Creak. However, in the 1960s, children with childhood psychosis became an issue that was relevant to everyone involved in the NHS and local authority administration. The catalyst for this change was the Mental Health Act 1959.

In 1954, the British government had established a Royal Commission on the Law relating to Mental Illness and Mental Deficiency. ${ }^{9}$ This was a response to growing dissent concerning the civil liberties of the mentally ill following the publication of the 1953 World Health Organization (WHO) report. ${ }^{10}$ Important members of the committee included Sir Russell Brain, a distinguished neurologist with an interest in perception and speech disorders in children, and Mrs Bessie Braddock, a Labour MP concerned with problems of urban poverty. ${ }^{11}$ The Percy Report argued that any individuals with 'mental' or 'personality' problems and illnesses should be treated under the law 'with no more restriction of liberty or legal formality than is applied to people who need care because of other types of illness, disability or social or economic difficulty.' ${ }^{12}$ It discredited most legal powers that had been employed to compel the mentally defective and insane to institutional treatment. ${ }^{13}$ However, the rights and liberties of children diagnosed with 'psychosis', 'schizophrenia' and 'autism' were not clear in the resulting legislation.

Numbers of patients registered at hospitals for mental defectives had risen steadily throughout the late 1940s and 1950s. The director of 'subnormality' research for the Wessex Hospital Board, Albert Kushlik, argued that these rises reflected the fact that minatory agencies such as the police or social workers sometimes used the law to abandon difficult children who presented challenges to society, yet who were not necessarily 'defective. ${ }^{14}$ This followed the spirit of the Wood Report in including 'social inefficiency' in the classification, but the notion that people, especially children, could be labelled in such a way was 
unacceptable to the new generation of social investigators, social scientists and psychologists. Statistics obtained from the Board of Control for 1955 revealed a total of 141,164 'defectives' certified under the Mental Deficiency Act. ${ }^{15}$ Although only 12.33 per cent of cases were under the age of sixteen, the majority of all defective cases were certified during childhood. For example, of the total 6,386 'defectives' ascertained in 1954, 73 per cent had been referred by local education authorities. ${ }^{16}$ Many who worked in deficiency institutions pointed out the difficulties of supervising large groups of child 'defectives' in institutions, as illustrated in Figure $3 .{ }^{17}$

The Mental Health Act 1959 brought the recommendations of the Percy Report into force in England and Wales, kickstarting a new approach to mental health across Britain. ${ }^{18}$ As a result of this, the terms 'defective', 'idiot', 'imbecile' and 'feeble-minded' were all abandoned as legal terms and replaced with the terms 'subnormal', 'severely subnormal' and 'psychopathic disorder.' ${ }^{19}$ The Percy Report argued that the term 'psychopathic' should replace 'feeble-minded' and 'moral defective', and other 'pathologically mentally abnormal' persons who would not previously have been classed as 'mentally defective. ${ }^{20}$ A number of debates then ensued in parliament regarding this definition of 'psychopath', which many regarded as too broad. ${ }^{21}$ In the 1959 Act, 'subnormality' was defined in relation to intelligence levels, and 'psychopathy' in relation to conduct, and both conditions had to be 'susceptible to medical treatment or other special care and training of the patient.'.2 In both cases, a type of child was created in law who was 'mentally disordered' yet susceptible to treatment, and this type of child entirely replaced the 'defective' child who was legally incapable of social transformation. However, what was to be done with this new social being was not clear.

It was still the duty of the medical officer to determine whether or not a child was educable. However, now the legal status of children who were 'ineducable' included both children who would have previously been termed 'defective' and those who were increasingly coming to be called 'psychotic'. These conditions were thus conflated in the eyes of the law. Most importantly, Section 8 of the Children Act 1948, and subsection (6) of Section 5 of the Matrimonial Proceedings (Children) Act 1958, which had given powers to medical officers to remove children from the care of local authorities and place them in hospitals and defective institutions, then ceased to have any effect. ${ }^{23}$ Local authority 


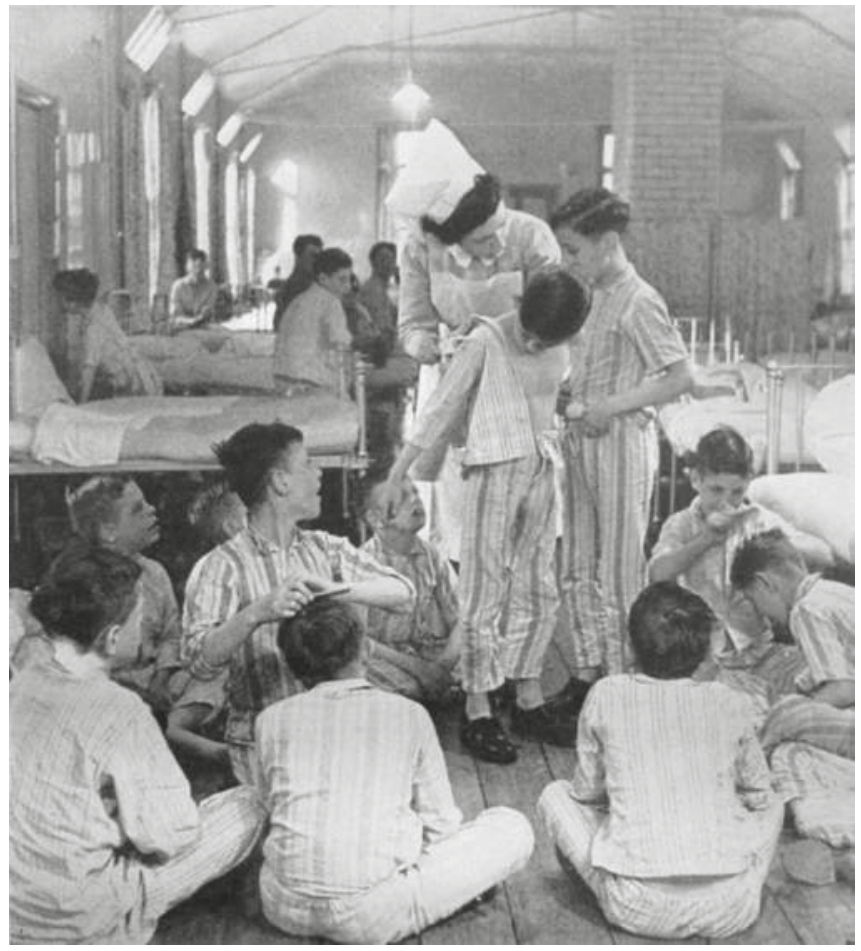

Figure 3 'A ward for imbeciles in a mental deficiency hospital', c.1956, from Leslie Hilliard and Brian Kirman, Mental Deficiency

(London: Churchill, 1957)

children's departments then assumed responsibility for all children, whether educable or not, unless they were thought to require specific short-term observation or hospital treatment for 'psychopathy' or 'subnormality. ${ }^{24}$ Children's departments also became responsible for all decisions over the long-term institutionalisation, education, adoption and care of children. This placed a huge pressure on children's departments that they had not previously experienced. It also opened their eyes to a generation of children who had been neglected within social and public policy. 
There were many inconsistencies in the implementation of the Mental Health Act. After it was passed, all registered 'defectives' were reclassified and responsibility for their care was transferred from hospital authorities under the NHS to local authorities. However, this handover was not accompanied by the transfer of hospital authorityrun institutions back to the management of local authorities. Local authorities were left with the task of building up a reserve of residential accommodation for such patients, yet had no infrastructure on which to assemble it. ${ }^{25}$ In practice, this meant that the buildings of 'defective' colonies and institutions acquired a new administrative role as hospitals for the 'mentally disordered' whilst still providing informal noncompulsory residential care for those now termed 'subnormal', under the guise of 'hospital treatment. ${ }^{26}$ Because individuals could no longer be committed under law purely on account of their 'subnormality', all child admissions into hospital or residential care took place via a negotiation between NHS hospitals and parents or local health care authorities. Doctors could only issue short-term enforced observation orders for children with 'psychopathy' or 'subnormality' for twenty-eight days. ${ }^{27}$ The Mental Health Act thus gave parents new powers to make decisions regarding the care and treatment of their children. Provided that a child had not been taken into local authority care under Section 1 of the Children Act 1948, all long-term admissions to hospital were voluntary and parents were at liberty to take their children home if they wanted to. ${ }^{28}$ After the Mental Health Act was passed, a child's long-term committal into institutional care could only occur at the behest of the parents or via the juvenile justice system. In Scotland, the 1960 Mental Health Act issued similar changes across Scotland.

This all created a major overhaul of the government systems designed to manage children's care. Just as a new generation of liberated women were finding their feet in the labour market and being granted improved rights to control their reproductive lives, the Mental Health Act also saw a huge change in the rights of women to keep their children at home, no matter what their intelligence level was. The new generation of social scientists also confirmed to the government that women welcomed this change. One major study conducted by Jack Tizard in the early 1960 s Mental Health surveyed 250 families of children who had previously been classified as 'imbeciles' or 'idiots' under the Mental Deficiency Act. He found that parents almost always reported that they wanted to 
keep their children at home, even if this compromised them in terms of their finances and social contacts. ${ }^{29}$ Although subnormality hospitals, managed by regional hospital boards under the Ministry of Health, were supposed to replace mental deficiency institutions in catering for children with 'subnormality', they had no legal right to detain such children and had to gain support from parents in doing so, and that was not happening. This put further pressure on the government to find new ways to support families and new ways to think about child development. Bowlby's notion that mothers were at the core of all problems of psychological development had thrived in a social welfare system that excluded 'mental defectives' and 'social inefficients', but it began to look quite ridiculous in a social welfare system that encompassed individuals with the full range of human mental capacity. New models for thinking about healthy child development, and for developing social welfare models to support it, were urgently required.

The bureaucratic problem: how many children are 'psychotic'?

The closure of mental deficiency institutions led to complete chaos in the administration of child welfare provisions for all children previously labelled as 'defective'. Local education authorities had adapted to dealing with the Board of Control when encountering difficult child cases and simply referred them on to this agency. Local authority children's departments had no expertise whatsoever in administering and catering to this group of children and referring them for placements. Children's departments also had to think very differently about what it meant to be a child 'in need of care.' This legal epithet thereafter no longer referred only to children who needed care because of parental harm or neglect, but also included children who were in need of care due to their own inherent mental 'subnormality'. This transition instituted a new way of thinking about children's psychological problems because it brought all of these problems to the attention of social work agencies, schools and local doctors. This initiated new ideas about what constituted a 'problem' child for state-managed agencies.

One important administrative problem that was quickly identified was that no one was entirely sure who should be responsible for 'psychotic' and 'severely maladjusted' children who would previously have 
been sent to the Board of Control because they were just too difficult for any other agency to deal with. After the passing of the Mental Health Act, it was unclear whether care for this group should be the responsibility of the local education authority or the local health authority. One major issue associated with this was the rather pressing one of how many children were actually 'psychotic', because the government needed numbers before they could begin to organise social services, education and other provisions for such children.

In 1961, the Ministry of Health began to collect information on 'the nature and extent of the hospital inpatient accommodation which is needed for mentally ill and maladjusted children and adolescents'. All existing children's units, including that based at the Maudsley, were asked how many beds they had for children under the age of twelve classed as either suffering from 'behaviour problems requiring shortterm treatment' or as 'psychotic and others requiring long-term treatment. ${ }^{30}$ There were sixteen inpatient units (containing a total of 340 beds), each specialising in particular types of case. For example, the inpatient unit at Belmont specialised in 'deaf psychotic' children; Pewsy Hospital in Wiltshire and Smith Hospital in Henley on Thames specialised in children with mental illness combined with 'subnormality'; The Park at Oxford specialised in what they termed 'neuropsychiatric' cases; and Whipps Cross in London took less severe cases as they were housed in a paediatrics department. The draft paper for the Standing Mental Health Advisory Committee (SMHAC) stated that provision was immediately required for children who needed long-term hospital treatment and that the Maudsley Hospital had stated this case most strongly. The committee suggested that twenty beds per million were required for children for short-term treatment and around twenty-five beds per region were required for long-term treatment for childhood psychosis. ${ }^{31}$

However, the committee was still unclear as to how many children actually had 'psychosis' or 'severe maladjustment' and thus would require special treatment. ${ }^{32}$ This was frustrating for both the Ministry of Education and the Ministry of Health because they could not plan services accordingly. Taking a standard view of national health requirements, the consensus amongst both ministries was that probably one unit for 'psychotic children' should be provided in each regional hospital board. However, Miss H. E. Clinkard of the Ministry of Education 
dryly pointed out that, in fact, 'neither Department had any real knowledge of what the total need amounted to in terms of places required. ${ }^{33}$ If it were not for the seriousness of the issue, the situation could appear somewhat farcical.

The fact that no department knew how many children were 'psychotic' added to legal issues emerging over the education of 'psychotic' children. Following the 1959 Mental Health Act, increasing numbers of parents began to use Section 57 of the Education Act 1944 to appeal against decisions that their child was 'ineducable'. In March 1962, Clinkard argued that 'psychotic' children in particular were making the decisions of local education authorities extremely difficult. She claimed that in reality there was little logic or justification to the decisions made about each child's ability to be educated. It did not help that local education authorities had no idea how to educate children who were 'psychotic. ${ }^{34}$ Faced with this complex conceptual problem about how to define and categorise a child's developing subjectivity and their ability to engage with the external world, the Education Department took a dim view. In March 1962, a major gathering was held regarding the issue of what to do in cases where parents claimed that their child was educable and 'psychotic'. Senior officials of the Ministry of Education, including Kingsley Whitmore, the Senior Medical Officer for the Department of Education and Science, argued that 'psychotic children' should be provided with 'hospital provision on a regional basis' because of the 'poor prognosis' of such cases and the 'inability of special schools to provide suitable conditions. They wished to shift responsibility for the problem onto the Ministry of Health, which they thought should provide services for 'autistic psychotics and extremely disturbed children', whom they combined under the same label. In the meantime, all cases of 'psychotic children' whose parents were appealing the classification of 'ineducable' would be sent directly to Kingsley Whitmore for a personal assessment. ${ }^{35}$ As a senior adviser, it was thought he would wield some clout when telling parents that their child was probably 'ineducable.' This was the line taken by the Ministry of Education in the early 1960s.

The Ministry of Health was generally prepared to take on the challenge of catering to 'psychotic' children, although only if they were 'in educable', an absurd tautology that was becoming increasingly difficult to bear. Nevertheless, the Health Department was still unclear as to how to establish hospital accommodation for 'psychotic' children 
because they were still not sure how many of them there were. In September 1962, one Ministry of Health official, P. Benner, argued that it was impossible to determine how many children had psychosis, claiming that

there is no real prospect of it being possible to make enquiries now which would yield information about future needs of sufficient reliability to be used for planning purposes. I am sure that the main need is to get the boards moving; and it might well be a positive disadvantage if at this stage we saddled ourselves with an estimated figure which turned out to be incorrect. ${ }^{36}$

However, because of the great uncertainty regarding the definition of children's psychological problems, they found it hard to reach even a ballpark figure and this was becoming increasingly problematic. This wrangling between central government departments was almost comical in the way that responsibility was endlessly shifted from one department to another as officials made wild guesses about the level of psychosis in the child population. Amidst all this debate, it was blatantly obvious that no one actually knew what childhood psychosis was.

In 1961, inspired by the complex dilemmas of those working in central government, Mildred Creak and Kenneth Cameron got together with several others to draw up a definitive list of diagnostic points that could be used to identify psychotic children with accuracy. This list would provide the basis for the first ever global epidemiological study of 'autism', so it was an important endeavour. However, it was not born out of methodical scientific enquiry, but rather the administrative nightmare in which the UK was engulfed. Other members of the committee who drew up the list included Miss Sylvia Ini, a psychiatric social worker who worked with 'psychotic' children at Great Ormond Street; Dr Guy Mitchell from the Tavistock Clinic Department for Children and Parents; Dr Ronald MacKeith, a paediatrician from Guy's Hospital; and Frank Orford Esq., a clinical psychologist who had previously worked at the Fountain Hospital for 'Mental Defectives'. There was no clear consensus on the terminology that should be used to describe the problem identified by the committee. Whilst some members wanted to call the phenomenon 'psychosis in childhood', others preferred the 'more specific' term 'childhood schizophrenia'. In the end, the committee reached a compromise with the awkward term 'schizophrenic 
syndrome in childhood', a classification that would never catch on. ${ }^{37}$ The committee agreed on nine diagnostic points that they claimed were crucial to a diagnosis. These were:

1. Gross and sustained impairment of emotional relationships with people;

2. Apparent unawareness of his own personal identity;

3. Pathological preoccupation with particular objects;

4. Sustained resistance to change in the environment;

5. Abnormal perceptual experience;

6. Acute, excessive and seemingly illogical anxiety;

7. Speech may have been lost or never acquired;

8. Distortion in motility patterns;

9. A background of serious retardation in which islets of normal, near normal, or exceptional intellectual function or skill may appear. ${ }^{38}$

Creak argued that if all psychiatrists could agree on the same diagnostic features then this 'would clear the way towards a common understanding and recognition of the phenomenological composition of the syndrome' and towards better treatment options. These nine diagnostic points came to be well known by all those interested in the field of childhood psychosis and autism research in Britain. They formed the basis of the 'second' autism, the autism that depicted absence of imaginative thinking and fantasy. This new 'style of reasoning' about autism was formulated as a direct response to government pressures and demands for numerical and statistical knowledge about the child population.

\section{The Society for Autistic Children and the pressure for educational rights}

For parents, Creak's definition of the 'schizophrenic syndrome in childhood' provided the ideal ammunition for confronting government departments and demanding action. This was because it gave a clear set of diagnostic points for a 'syndrome' that was not 'subnormality', hence not linked to intelligence levels, and therefore meant that children so diagnosed were 'educable'. In January 1962, the Autistic Children's Aid Society of North London was established by a group of parents who were frustrated with government inaction and took it upon themselves 
to provide long-term residential care 'for the treatment and education of autistic or psychotic children. ${ }^{39}$ It was parents who latched onto the diagnosis of 'autism', which they much preferred to 'psychosis' and 'schizophrenia' because of the social stigma attached to those labels. By 1963, the North London Society had already established themselves as a national body, the Society for Autistic Children (SAC), with additional goals to improve scientific research and public understanding of the condition. Two years later, Bernard Rimland and other parents formed a similar society in the USA.

As Chloe Silverman has pointed out in relation to the USA, parent groups were significant as they advocated strongly for children diagnosed with 'autism. ${ }^{40}$ Parent groups in Britain were also important in providing political clout and encouraging treatment and research. SAC campaigned directly to the Ministries of Health and Education and helped to push through reforms to ensure that children diagnosed with these conditions received education. However, in Britain, these changes were only possible after the 1959 Mental Health Act, as it was this Act that passed powers of institutional committal onto parents and also highlighted the predicament of 'psychotic' children who did not fit into prior classification systems.

In 1963, the term 'autistic' was beginning to be used frequently in administrative literature, following the lead of parent campaigners. In 1963, the Standing Health Advisory Committee was sent a memorandum from SAC written by John and Lorna Wing of the Social Psychiatry Research Unit at the Institute of Psychiatry. The Wings were also parents of a child with autism and this had led to their association with SAC. They had both trained in medicine at University College Hospital and then went into the field of psychiatry. Mildred Creak had introduced them to the topic of childhood schizophrenia and autism. ${ }^{41}$ The Wings would form the backbone to all changes in the administration and definition of autism in Britain. As parents, advocates, researchers and professionals at the Institute of Psychiatry, they had all perspectives on the topic covered. Their memorandum was intended to clarify the unique problems of autistic children, as opposed to any other type of child, and the educational and hospital services that they would require. It would become a historic document in redefining the rights of children labelled as 'autistic', yet it was also a historic document in redefining the rights of all children to an education, no matter what 
their supposed limitations were. The Wings were thus important political campaigners for all children's rights.

The Wings argued that it is now accepted that the processes underlying normal child development may go wrong in various ways', and that wholesale terms, such as 'mental subnormality', were not specific enough to plan 'detailed measures of treatment or education'. They further argued that if officials could recognise the 'specific handicap' of a child, then it was always much easier to manage their 'problem behaviour'. Clarifying their understanding of autism, they argued that "The term "autism" is a convenient label for a behavioural syndrome with a first onset in early childhood, in which the most obvious symptom is a difficulty in forming social relationships. ${ }^{\prime 2}$ Although 'childhood schizophrenia' had previously been used as a label, they thought that "autism" is preferable because of its neutrality and lack of implications about aetiology and prognosis. ${ }^{43}$ One of their claims was that if a child 'cannot make sense of what he sees or hears (who cannot recognise a lamp-post let alone a parent)', then they 'will clearly be autistic. ${ }^{44}$ However, they also argued that the condition was not necessarily associated with intelligence. In a review of seventy-four cases seen by Anthony and Cameron at the psychotic clinic (cases the Wings now classed as autistic), they found that 37 per cent had a 'nuclear' form that did not affect their intelligence at all. ${ }^{45}$ They argued that the discovery of 'autism' in a child 'gives rise to problems of treatment, education and management different to those found in other psychiatric disorders of childhood: ${ }^{46}$ They added that some 'dysphasias, agnosias and dyspraxias' should be included under the 'autism' label because children with these conditions often demonstrated 'several features of the autistic syndrome without social withdrawal, ${ }^{47}$ For these children, treatment should be based on a 'practical assessment of disabilities' followed by 'special educational methods'. In short, they argued that 'subnormality' was a useless label and that intelligence testing could not identify each child's specific problem well enough. Although ostensibly discussing 'autism', the Wings' memorandum was just as much a manifesto for special education as it was for autism per se. It was part of the wider movement within child psychology that aimed to identify autism in order to challenge a paternalistic model of welfare state provision for children with individual difference. In psychological language, the portrayal of 
individual difference was now increasingly being framed in terms of autism rather than maladjustment.

The Wings were unequivocal in their condemnation of long-stay institutional care. However, unlike Bowlby, who criticised institutional care for the mainstream population because it separated them from their mothers, the Wings criticised institutional care for all children of all intellectual levels. They did so primarily on the grounds that it was not stimulating enough. They argued that autistic children, in particular, needed even more individual attention than other children. As they put it, 'Certain kinds of environment are known to be harmful even to normal children - particularly the depriving and understimulating conditions of institutions and centres where staff cannot give individual attention to each child. Autistic children, because of their tendency to social withdrawal, are particularly vulnerable to such conditions.' ${ }^{48}$ They highlighted the 'evils of large institutions' and pointed out that the best environment for autistic children was the family. ${ }^{49}$ This criticism of institutional care was becoming increasingly widespread by the early 1960s. In the late 1950s, Jack Tizard had gathered together several children from the Fountain Hospital for Mental Defectives and transferred them to a beautiful house in Surrey with a much higher staff ratio, aided by a grant from the Mental Health Research Fund. ${ }^{50}$ When tested, these children had increased their verbal age significantly compared to those left in hospital. They were also 'healthy, sun-tanned and alert' and played more co-operatively than those in hospital. Thus, Tizard and other Maudsley psychiatrists argued that all children, whatever their mental states, benefited from small care homes with a good allocation of adult staff, and this advice was echoed by the British Psychological Society. ${ }^{51}$ Tizard's 'Brooklands Experiment' later became a model of a treatment centre for children classed as 'subnormal. ${ }^{52}$ The BPS report claimed that 'children who show autistic or psychotic symptoms - at least 10 percent of the admissions in the present survey - tend to become even more withdrawn if left to their own devices. ${ }^{53}$ Unlike Bowlby and Winnicott's pronouncements on the necessity of maternal love, Tizard and the new autism psychologists regarded the problem of institutional care as primarily economic. These children needed greater financial assistance from government before they needed maternal love. They argued for smaller units or family care for children of all mental states. 
This work would lead to Tizard being appointed as a consultant adviser in mental subnormality to the Department of Health and Social Security from 1965 to 1975 . He later became a member of its Chief Scientists' Research Committee in 1973 and Consultant to the Home Office Research Unit in 1975. In a research capacity, Tizard was also Professor of Child Development at the Institute of Education from 1964 to 1971; chairman of the educational research board of the Social Science Research Council between 1969 and 1971; and president of the BPS from 1975 to 1976 . His portfolio of work as a psychologist and adviser instituted major changes with regard to the study and education of 'subnormal' populations. ${ }^{54}$

In 1963, SAC submitted a memorandum to the Ministers of Health and Education putting additional pressure on them to standardise their approach to 'autistic or psychotic' children. They argued that parents had to 'fight administrative confusion' as local education authorities often disagreed with local health authorities. They cited the case of one boy whose local education authority had claimed was 'maladjusted' and had asked the parents to select their own school whilst the local Medical Officer of Health put pressure on the parents to place him in a health authority-maintained 'Junior Training Centre' for 'subnormals'. SAC claimed that such inconsistencies in approach were appalling, and ultimately stated clearly that 'We are of the opinion that all children, however handicapped, should be the responsibility of the education authorities and that there should be legislation accordingly. ${ }^{55}$ This was a bold statement, impacting not only children deemed 'autistic' but all children regarded as 'ineducable'. SAC was therefore pushing for reforms that would inevitably affect all children whose care came under the health authorities. SAC criticised intelligence tests, not because of their economic bias or even their validity per se, but rather because they simply did not give 'autistic' children the time and space to express their full potential. They argued for early diagnosis, whilst simultaneously admitting their underlying motive was that 'early diagnosis will quickly reveal the lack' of facilities. ${ }^{56}$

Statutory machinery already existed for special classes to be run at established ESN schools, schools for the maladjusted and Home Tuition Units, and for classes to be established at a school. Section 56 of the Education Act 1944 had enabled local education authorities to establish 'home situation groups', which, if approved by the local 
education officer, could receive financial support from the government. SAC initially applied for government funding via these channels and then slowly began to expand their work. In July 1962, SAC had devised a model day and residential treatment/education centre for autistic children in London. They also argued for the establishment of family-style homes for children outside London, as well as specialist centres for adolescents. SAC was noncommittal on the efficacy of psychoanalytic psychotherapy in the early 1960s, arguing that it should be available on the NHS for autistic children because 'some children can be helped in this way', even if 'some members of the medical profession are not in favour of this treatment. ${ }^{57}$ Providing all of this help and medical support for autistic children was not cheap. In fact, one of the reasons why British research in the 1960s became so influential is that it was specifically devised to engage with government departments and to make arguments about why this particular group of children needed specialist support. It thus became quite flawless in execution.

When submitting costs to the Ministry of Education in the early 1960 s, SAC stated that 'it is recognised that having 2 teachers to 5 children is enough to appal any self respecting financial officer', but tried to bring all on their side by arguing that it provided individual attention which is so necessary to engender confidence in these children'. ${ }^{58}$ SAC pointed out that 'No specific courses for teaching autistic or psychotic children exist', but they recommended other training channels for the new teachers who would be required to educate this new group. The Wings had already begun to give guidance on particular teaching methods, such as the need to teach through action, pointing out that for one child, "Words (such as "Draw a circle") only became meaningful after the motor acts had been acquired', and that 'Such simple principles can be worked out for most autistic children and obviously help to accelerate their development.' SAC recommended courses for the training of teachers of ESN and maladjusted pupils, such as a one-year full-time course at the Institute of Education and the Department of Child Development, London, and similar courses run at the LCC and Reading University. Finally, Maria Grey College in Twickenham ran a training course for teaching 'backward children', which SAC also endorsed. ${ }^{59}$ This built on the methods of Stanley Segal, who had founded the Guild of Teachers of Backward Children and publishing Forward Trends in the Treatment of Backward Children between 1957 and $1966 .{ }^{60}$ In the 
mid-1960s, the guild had approached the Ministry of Health and the Department of Education and Science proposing an enquiry into special education and the needs of all children, including those then excluded from the school system. SAC also supported the Montessori and Steiner methods. Furthermore, they recommended that prospective staff could also adapt methods for teaching blind and deaf children. This appeal to enlist teachers from other fields was important because it helped to form a wider network of teachers and parents who were challenging the 'ineducability' of any child. They argued that their children were not really any different from 'deaf' or 'blind' children, whom the government had always recognised as legitimate subjects for education. These parallels would crystallize as theories of 'sensory impairment' and autism were developed. SAC also argued that the government must give grants to teach autistic children in independent schools if local authority schools could not provide proper education for them. ${ }^{61}$

New methods specifically designed for educating autistic children were often highlighted by SAC as important models from which to learn. At the Maudsley, some behaviourist experiments with language learning were trialled amongst children with the autism diagnosis, derived from the work of one of Skinner's colleagues, Charles Ferster, who claimed he had designed a way to teach language to children diagnosed with autism using an experimental room containing a range of bizarre devices including a pastry-vending machine, a pigeon contained within a transparent wall unit, a pin-ball machine, an eight-column sweet vendor modelled on a cigarette vending machine, a spinning colour wheel, an organ and a phonograph that played music. ${ }^{62}$ This work, the forerunner of Applied Behavioural Analysis, built on a body of research conducted in the late 1950s on the use of operant conditioning to teach speech to animals, children and mute schizophrenic adults, such as that carried out by Catherine Hayes, $\mathrm{H}$. Rheingold and W. Isaacs. ${ }^{63}$ These operant conditioning methods were trialled at the Maudsley and the British Autistic Society Schools from the mid-1960s, although they were quickly integrated into a uniquely British model for testing and responding to 'autistic' children based on sensory awareness. ${ }^{64}$

In the USA, behaviourist methods for treating autism became very popular. In Britain, these methods were viewed more skeptically, within a wider context of educational theory. There was concern about 
the fact that in the USA, purely 'behaviouristic' approaches were being applied directly to children when coupled with shock therapy. For example, I. O. Lovaas, one of the pioneers of behavioural therapy for 'schizophrenic' children at the Neuropsychiatric Institute of the University of California, Los Angeles (UCLA), argued that behaviouristic speech-training therapies avoided all attempts 'to respond to, or otherwise "understand", the child on the basis of his psychotic verbal or non-verbal communications. ${ }^{65}$ Lovaas later wrote on 'building social behaviour in autistic children by the use of electric shock', a rather incongruous idea, but he had a lot of support for his work ${ }^{66}$ In the USA, the 1960s also saw a flood of experiments with LSD (d-lysergic acid diethylamide) in the 'treatment' of autism in children. Lauretta Bender conducted LSD experiments on children from the ages of four to fifteen years and argued that the drug improved children's 'verbalisations' and 'reality testing', whilst reducing their 'anxiety' and 'bizarre ideation'. Bender and her colleagues, by their own admission, had already experimented in treating autistic children with 'metrazol, electric convulsions, subshock insulin, many psychopharmaceutical agents, the milder antihistamines (Benabdryl), amphetamines, phenothiazines, reserpines, antidepressants, tranquilisers, etc.. ${ }^{67}$ This aggressive treatment culture would begin to wane by the late 1970s, but during the 1960s such experiments were trialled by researchers across the USA: for example, at the Mount Sinai Hospital New York Medical College and UCLA. ${ }^{68}$ British researchers were reluctant to adopt medical approaches and focused instead on educational methods that had a longer tradition in British special education.

Through their work with schools and universities, SAC sought to educate all educational and health professionals to see autism, to identify it and to diagnose it. As they put it: 'Through letters and articles in the medical press and through the distribution of diagnostic information, it [the Society] means to educate General Practitioners, Medical Officers, and Health Visitors to consider autism as a possible diagnosis for children whose intellectual processes fail to develop along normal lines. ${ }^{69}$ In January 1963, the society published a survey of 140 children whose parents regarded them as 'autistic' (105 boys and 35 girls), finding that over 50 per cent were still in Subnormality Hospitals and Training Centres or being cared for at home with no educational provision, a situation that was hugely unsatisfactory for their parents. ${ }^{70}$ They 
championed parents to become social activists and to use the diagnosis of autism in order to do so.

William Compton Carr, MP, was an important associate of SAC. After introducing the Houses of Parliament to the word 'autism' in the 1960s, he continued to emphasise the need for more research into child autism and psychosis. In a speech to the House of Commons in March 1963, Compton Carr argued for 'more and earlier diagnosis and more surveys to assess the need for services', 'more flexible educational special and medical services', 'a more open mind to unorthodox techniques', 'more residential care for all ages in schools and hospitals', 'more help for the family', 'more research and experimentation', 'more public understanding' and, last but not least, 'more money.71

By late 1963, a sea change was beginning to occur. The Special Education Sub-Committee at the Department of Education produced a report stating that:

Autistic is the name now given to severely disturbed psychotic children suffering from a form of childhood schizophrenia. They are unresponsive, withdrawn, non-communicating children who live in a dream world and are unable to form or sustain relationships with people, and are without sensory or other physical or mental defects that would account for this disability. ${ }^{72}$

This showed an acceptance that 'autistic' children differed from those with subnormality, although it maintained the first definition of autism as 'children who live in a dream world'. Nevertheless, it was the beginning of a shift in acknowledging education rights, although such rights still depended on the government knowing how many 'autistic' children there were, or how many 'psychotic' children there were. In the upper echelons of parliament, the Parliamentary Secretary to the Ministry of Education, Christopher Chataway, confirmed that there were now twenty-one hospital units located in England and Wales 'for severely maladjusted and psychotic children', based on figures from the Health Department, and that parental demands were beginning to be met. Although there was still a lot to be desired in terms of definition, this was an acknowledgement that the government was beginning to think differently about the rights of all children to be educated. Chataway claimed that he no longer thought of education purely in terms of economic return and pointed out that the Report by the Ministry's Chief 
Medical Officer on the Health of the Schoolchild had emphasised that no children should be excluded from the educational system without a prolonged trial of psychiatric and educational treatment. There was a minor caveat for those whose impairment of mental function was too gross for response to therapy ${ }^{73}$ However, the existence of this elusive 'ineducable' group would become increasingly difficult to prove. Most importantly, Chataway praised the work of researchers from the Institute of Psychiatry, highlighting the enthusiasm and general rhetoric of the period, adding: 'Whatever else can be said about the age in which we live, it is one in which we are learning to avoid the waste and grim frustration in human talent which has hitherto prevailed..$^{74}$ In July 1964, a meeting was held between members of the Department of Education and Science, the Ministry of Health and SAC to discuss state provision for autistic children. Baron argued that although Section 33 of the Education Act purported to provide for such a group, in fact, 'few were receiving specialist help to overcome their difficulty in communicating. Lorna Wing argued that 'the only way to assess the suitability of a child for education was to attempt to educate him', dismissing the expertise of Medical Officers of Health as the adjudicators of educational justice. Jack Tizard pointed out that his work with children at the Maudsley Unit had shown that children with IQs below 50 could be educated, arguing that 'I.Q. rating should not be regarded as the touchstone for educability' but should rather 'be employed constructively to identify a child's skills on which future progress could be based. There could not have been a more damning critique of the Department of Education and Science's stance on 'ineducability'. Although the discussion was focused on 'autistic' and 'psychotic' children, it was clear this was developing into a wider critique of policy on all 'ineducable' children and the government were finally beginning to listen. ${ }^{75}$

Throughout all of these discussions, there was no clear figure on the exact number of autistic children, no clear definition of what 'autism' was and why it made a child 'educable'. Chataway had actually drawn attention to the effort being made by the London County Council to collect figures on the numbers of children with 'psychosis', as it was paramount to any government progression on provision. ${ }^{76}$ However, none of these attempts provided quite enough ammunition to fully challenge the government's stance on 'ineducability'. It would take the first epidemiological study of autism to do this. 


\section{The quantification of autism}

The first statistical study of 'autism' began in 1963 under the supervision of John Wing and Neil O'Connor. This attempt to make a previously immeasurable concept concerning the early stages of infantile development, autism, into an entity that was identifiable and measurable across populations would mark a radical shift in the conceptualisation of child development. As Rhodri Hayward has argued, the formation of what he refers to as 'the statistical psyche' can be traced to the late 1950s, when the association between historical truth and individual cure was broken down as claims made for the efficacy of psychoanalytic psychotherapy were confronted with new drug cures that worked without the need for a historical narrative. At the same time, new statistical instruments were rapidly being developed in the field of clinical psychology, such as Hans Eysenck's Maudsley Personality Inventory (1959) that enabled character to be assessed via aggregated scores rather than individual interviews. The tests of clinical psychologists were used for a major project in the quantification of the psyche that enabled tests for therapeutic efficacy and planning of clinical trials, right through to the planning of national mental health services. The creation of the randomised control trials in Wales in 1950 and publication of the first Diagnostic and Statistical Manual in the USA in 1952 provided new methods with which to measure the psyche in figures and statistics, and these methods became increasingly sophisticated. ${ }^{77}$ As Ian Hacking, Theodore Porter and others have explained, these instruments are part of wider historical trends that followed the rise of statistical thinking. ${ }^{78}$

Victor Lotter's attempt to develop a method to quantify autism in the early 1960s must, therefore, be viewed within this wider context. However, this particular project was unique as it did not just attempt to measure 'behaviour', 'character' or other broad traits of the human personality, it actually attempted to measure the central component of unconscious thought in the early stages of infancy. It attempted to measure the very core of subjectivity, the essence of individual thought as it developed from the early stages of life. The measurement of 'autism' within a total population was an exceptional undertaking, and thus it received much attention and went on to form the basis of a global definition. 
In fact, other Maudsley researchers were already starting to dabble in the use of statistical and epidemiological studies in order to identify psychological states in childhood. In 1958, following the publication of the Percy Report, the Unit for Research in Occupational Adaptation at the Institute of Psychiatry was renamed the Social Psychiatry Research Unit. The idea of 'social psychiatry' was based loosely on McDougall's 1908 model of 'social psychology', although it also drew from a growing interest in therapeutic communities and the use of 'society' to treat mental health problems, as discussed in the work of Maxwell Jones, in the wake of the 1959 Mental Health Act. ${ }^{79}$ The Social Psychiatry Research Unit came to serve as the bureaucratic hub for psychological population studies. Some of the first studies carried out at the unit were conducted on children who would have previously been institutionalised. In 1960, Jack Tizard conducted two comprehensive surveys on the prevalence of 'mental subnormality' in children in the London and Middlesex areas, although these were primarily administrative surveys and were not presented as 'epidemiological studies'. As Tizard put it, 'we know the size of the administrative problem. ${ }^{80}$ The child population of Middlesex was then 213,945 and the number of children classified as 'idiots' and 'imbeciles' or 'severely subnormal' was 738 . This gave a prevalence rate of 3.45 per $1,000 .^{81}$ This prevalence rate was almost identical to the figure obtained by the Ministry of Health in their count of all patients in psychiatric beds following the Percy Report. The Minister of Health, Enoch Powell, reported this in 1961 as 3.4 per $1,000 .^{82}$

In the early 1960s, several child psychiatrists at the Maudsley were becoming interested in the idea of conducting large-scale total population studies, for administrative as well as epidemiological purposes. One person who was particularly interested in this model of research in the 1960s was Michael Rutter. Rutter had studied under both Aubrey Lewis and Hans Eysenck at the Maudsley and also under Ben Pasamanick in New York. ${ }^{83}$ Pasamanick was a psychiatric epidemiologist who was interested in using epidemiological methods to determine causation and Rutter sought to expand this methodological approach to the field of child psychiatry ${ }^{84}$ In May 1965 Rutter was appointed as Senior Lecturer in Child Psychiatry, filling the post that had been left vacant since Anthony's departure in $1958 .{ }^{85}$ He would later publish a manifesto arguing for the classification of all childhood 
psychiatric disorders, ${ }^{86}$ and also worked closely with the WHO in developing a multi-axial system of psychiatric diagnoses. ${ }^{87}$

In 1964, an Epidemiology of Mental Disorders Committee was established under the Medical Research Council (MRC). Jack Tizard and Michael Rutter served on the subcommittee exploring the need for child psychiatry services. They were scathing in their criticisms of the Underwood Report, which had claimed that it was 'impossible to forecast' the services required for 'maladjusted' children. ${ }^{88}$ Rutter, Tizard and the new psychological epidemiologists at the Institute of Psychiatry argued that this was a ludicrous claim because psychiatric epidemiology could measure rates very precisely. They claimed that 'within a year or two it should be possible to give a much more accurate picture of the prevalence of neuroses and psychoses in children, and of the medical, educational and social services required to deal with them ... epidemiological work in this field is today perfectly feasible. ${ }^{89}$ In Camberwell, a register of psychiatric morbidity had been established through a major collaboration between the Maudsley's Social Psychiatry Research Unit, the Ministry of Health and the local health authority, and this was providing the basis for a revolution in the measurement of psychological conditions. ${ }^{90}$ They argued that efficient screening techniques can be devised' and that 'diagnosis - by type of disorder and by severity - can be made reliable', and claimed that if investigators 'follow the standard procedures of epidemiological study' then 'the results are very satisfactory. ${ }^{91}$ Most importantly, they argued that an epidemiological study of autism was under way that was going to revolutionise service planning.

In fact, in the early 1960s, Rutter had conducted a small-scale study on the rate of 'autism' and other rare psychiatric conditions with a colleague in Aberdeen. However, Rutter was not at that point wholly convinced that autism could be measured, given the imprecision of the term, and he even placed 'autism' in inverted commas in his publication of the data. ${ }^{92}$ However, the debates on psychiatric epidemiology inspired him and Tizard to take on an even larger project in the measurement of the total child psyche. Thus, in 1964, he embarked on a major survey of all 'medical, behavioural, educational and other handicaps' in a total population of children living on the Isle of Wight, in collaboration with Kingsley Whitmore, the Senior Medical Officer of the Department of Education and Science. With this study, Rutter and Tizard sought to radically rethink the provision of special educational 
services in the whole of the UK, and they managed to persuade Whitmore to collaborate with them in doing so. By the mid-1960s, confidence was growing amongst government officials and research bodies, such as the MRC, that psychiatric epidemiology was a viable tool that could be used to plan services for exceptional groups who required unique forms of specialist help.

It was in this spirit of general optimism over the precise measurement of psychiatric conditions that the first full epidemiological study of autism, as a clearly definable, measureable entity, was conducted. There was nothing naive about this new approach to child development. One of Lotter's supervisors, Neil O'Connor, had studied philosophy and experimental psychology at Oxford, later moving to the Institute of Psychiatry to study the educational capacity and employability of 'defectives' with Tizard. He was a self-proclaimed communist and was committed to developing new approaches to social inclusion. ${ }^{93}$ Under O'Connor and John Wing's supervision, the young researcher, Lotter, was confident and steadfast in his approach to defining and measuring 'autism', and forged ahead with his study with remarkable determination, conviction and persuasion.

Dismissing the entire history of psychiatry and the description of infantile thought, Lotter proclaimed that 'autism' was entirely knowable and entirely measureable. Creak's committee had claimed that it was 'impossible' to use purely behavioural criteria 'if we were to convey what we all felt to be the heart of the matter - namely the presence of an impaired capacity for human relationships. ${ }^{94}$ However, Lotter argued that clear-cut, purely behaviouristic criteria were paramount to the development of reliable research on 'autism', regardless of the fact that the psychological state that was being described concerned the capacity to relate to others. Lotter drew his definition from Creak's, but discarded the category of 'apparent unawareness of his own personal identity' and subsumed it within other behavioural measures. $\mathrm{He}$ also replaced the presence of 'islets of ability' with objective test scores (Figure 4). Lotter surveyed all children in the Middlesex area aged between eight and ten years in order to generate a percentage figure for the rate of 'autism' in the general population of Britain and eventually to lead to new hypotheses on causation. ${ }^{95} \mathrm{He}$ developed a list of statements that were used to identify children with autistic conditions. This form was issued to teachers of 76,388 children between the ages of eight 


\begin{tabular}{|c|c|c|c|}
\hline \multirow[b]{3}{*}{ Item Behaviour range } & \multicolumn{3}{|c|}{$\begin{array}{c}\text { Mean percentage numbers and } \\
\text { types of children }\end{array}$} \\
\hline & \multicolumn{2}{|c|}{ Autistic } & \multirow{2}{*}{$\begin{array}{c}\text { Non-autistic } \\
\text { Group C } \\
(\mathrm{N}=22)\end{array}$} \\
\hline & $\begin{array}{l}\text { Group A } \\
(\mathrm{N}=15)\end{array}$ & $\begin{array}{l}\text { Group B } \\
(\mathrm{N}=17)\end{array}$ & \\
\hline All speech items* & 54 & 38 & 12 \\
\hline $\begin{array}{l}\text { 1. Speech not used } \\
\text { for communication }\end{array}$ & 63 & 33 & 0 \\
\hline 2. Reversal of pronouns & 21 & 12 & 8 \\
\hline 3. Echolalia & 67 & 46 & 25 \\
\hline 4. Repetition of phrases & 67 & 53 & 13 \\
\hline All social behaviour items & 72 & 53 & 14 \\
\hline 5. Visual avoidance & 53 & 58 & 2 \\
\hline 6. Solitary & 97 & 70 & 18 \\
\hline 7. Ignores children & 87 & 79 & 15 \\
\hline 8. Aloof and distant & 97 & 70 & 18 \\
\hline $\begin{array}{l}\text { 9. Walks/looks through } \\
\text { people }\end{array}$ & 30 & 6 & 0 \\
\hline All movement peculiarity items & 40 & 38 & 8 \\
\hline 10. Self-spinning & 47 & 14 & 0 \\
\hline 11. Jumping & 43 & 11 & 14 \\
\hline 12. Flapping & 33 & 14 & 14 \\
\hline 13. Toe walking & 13 & 18 & 9 \\
\hline $\begin{array}{l}\text { 14. Other marked } \\
\text { mannerisms }\end{array}$ & 63 & 47 & 5 \\
\hline All 'auditory' items & 45 & 34 & 10 \\
\hline 15. Behaves as if deaf & 67 & 50 & 5 \\
\hline 16. Covers ears & 17 & 26 & 11 \\
\hline 17. Distress at noise & 23 & 26 & 14 \\
\hline All repetitive/ritualistic items & 49 & 16 & 7 \\
\hline 18. Elaborate food fads & 27 & 6 & 2 \\
\hline
\end{tabular}

Figure 4 Table, 'Mean percentage scores on 24 behaviour items', from Victor Lotter, 'Epidemiology of autistic conditions in young children', Social Psychiatry 1, no. 3 (1966) 


\begin{tabular}{|c|c|c|c|}
\hline \multirow[b]{3}{*}{ Item Behaviour range } & \multicolumn{3}{|c|}{$\begin{array}{c}\text { Mean percentage numbers and } \\
\text { types of children }\end{array}$} \\
\hline & \multicolumn{2}{|c|}{ Autistic } & \multirow{2}{*}{$\begin{array}{c}\text { Non-autistic } \\
\text { Group C } \\
(\mathrm{N}=22)\end{array}$} \\
\hline & $\begin{array}{l}\text { Group A } \\
(\mathrm{N}=15)\end{array}$ & $\begin{array}{l}\text { Group B } \\
(\mathrm{N}=17)\end{array}$ & \\
\hline $\begin{array}{l}\text { 19. Lines and patterns with } \\
\text { objects }\end{array}$ & 43 & 9 & 0 \\
\hline 20. Spinning objects & 17 & 9 & 5 \\
\hline 21. Other elaborate ritual play & 83 & 35 & 11 \\
\hline $\begin{array}{l}\text { 22. Carrying, banging, twirl- } \\
\text { ing etc. objects }\end{array}$ & 37 & 38 & 9 \\
\hline $\begin{array}{l}\text { 23. Insistence on } \\
\text { sameness (objects) }\end{array}$ & 53 & 9 & 15 \\
\hline $\begin{array}{l}\text { 24. Insistence on } \\
\text { sameness (events) }\end{array}$ & 80 & 12 & 9 \\
\hline
\end{tabular}

Figure 4 (cont.)

and ten attending schools in the Middlesex area. Children identified by teachers were then further assessed to confirm their autism. Lotter reported the prevalence rate to be 4.5 per 10,000 of the population. ${ }^{96}$

Lotter claimed that he had developed 'adequate behavioural descriptions' for the condition of autism. These descriptions would encapsulate the symptom of autism, which he understood as a behavioural parameter and not a disease entity. As he put it:

the adjective 'autistic' was used in this study as a convenient descriptive label. It is important to note that the term was not intended to refer only to Kanner's syndrome of 'infantile autism', and in what follows is used without qualification to refer to all children who met the behaviouristic criteria used to select cases. References to 'autistic behaviour' are to be similarly interpreted..$^{97}$

Lotter's study was hence a quantification of the description of 'the autistic' within a total population. The requirement for 'precise behavioural criteria', which epidemiological studies demanded, encouraged 
new perspectives and descriptions of autism. The original 'autism' that had developed as the backdrop to theories on the role of instinctive drives in the formation of relationships, and which had been dominant in developmental psychology and psychoanalytic writings up until the 1950s, was anathema to psychiatric epidemiology. And yet, psychiatric epidemiologists were desperate to measure and quantify 'autism' because it was the only way that they could present a legitimate model to the government to champion the rights of 'autistic' children to be educated. Lotter's study, which bypassed the depth of conceptual problems associated with this, was gold dust to every parent or special educator who needed proof that an individual child had a right to be accepted, acknowledged and educated. It thus became fundamental to the construction of a new model of children's rights that incorporated all children, no matter what behaviour they displayed.

In developing ways to quantify and to measure autism, Lotter and the new autism psychologists necessarily redefined the concept of autism. Instead of measuring child development and its anomalies via theoretical models of an individual child's successive attempts to engage with reality through their relationships with people and objects, as in the Kleinian and Piagetian model, these studies measured child development and its anomalies as behavioural variables within a total population that represented the norm. The study of human relationships was not written out of this model because human relationships could still be observed as phenomena. However, questions about how, why or when relationships became pathological, particularly those concerning the child's capacity to imagine, hallucinate or fantasise about others, were absent from this new theoretical model.

When Lotter's study was finally published, it quelled the growing frustration amongst government officials about how to manage psychological disorders in children by providing a figure for the government to work with. Once this figure was available, the possibility of treating and educating these children became a reality. ${ }^{98}$ Lotter's epidemiological study offered new possibilities for the analysis of children's developmental and psychological problems using socialpsychiatric methods. Drawing from childhood psychosis research, it established autism, the major symptom of childhood psychosis, as a label that could be used in the rapidly changing landscape of mental 
health care for children. This label has stuck precisely because it provided security and certainty to parents, bureaucrats, psychiatrists, social scientists and others who witnessed the changes brought about by the Mental Health Act 1959.

Following publicity campaigns by SAC, Lotter's epidemiological study was reported in ten national newspapers, which increased public awareness of the condition..$^{99}$ In light of the media airtime granted to psychoanalytic popularisers, such as Winnicott and Bowlby, this kind of coverage was crucial to reformulating ideas of autism and children's rights. At a Department of Education and Science meeting in 1966, it was proposed that around 300-400 teachers would be required to teach autistic children. Courses at the Institute of Education and Birmingham University could be adapted 'to cater for the needs of psychotic children.' ${ }^{100}$ Tizard was to be consulted on this. Even though it was still sometimes called 'childhood psychosis', autism was finally achieving recognition at government level. Although, in 1968, the newly formed Department for Education and Science still refused to recognise autism as a specific handicap, they suggested that small educational units and parental guidance should be provided to all children with 'severe learning and developmental problems. ${ }^{\text {'01 }}$ Lotter had not fully convinced the government to adopt this label, but he had set in motion huge changes in the construction of children's rights as increasing numbers of people began to use the autism diagnosis as a way to prove that a child was not 'subnormal' or 'ineducable' and that they should be granted legal rights and entitlements to education, welfare and social support just like any other child.

\section{What is 'intelligence' anyway?}

As described in the first half of this book, the construction of psychology, and the social model it supported up until the end of the 1950s, was strongly associated with models for the measurement of 'intelligence' and 'intellectual ability'. As Wooldridge, Sutherland and others have pointed out, intelligence was the cornerstone of the development of psychology from the early twentieth century, and it was especially important in the field of experimental psychology and the development of tests for mental capacity. ${ }^{102}$ In fact, it was so dominant that, 
until the 1950s, there was no theory of mental capacity other than that of intelligence. However, the first attempts to quantify autism in the 1960s saw the first attempts to develop systematic tests for the measurement of other kinds of mental capacity that challenged and critiqued the supreme dominance of the intelligence test. These tests supported the new model of autism that was being assembled in the 1960s and were critical to its ascendency as it worked to challenge theories of children's inability to be educated.

Early psychological tests for autism focused on the measurement of sense perception, that is, the ability to 'sense' the environment and to perceive the external world. These differed from intelligence tests in that they focused on the finer points of sense perception and the way that these perceptions enabled individuals to form different models of the external world that were not necessarily related to their intellectual capacity. In fact, these tests were often pitted against IQ tests in order to show that some children could 'sense' the world around them, yet still could not develop concepts in relation to those perceptions. On the other hand, some children could not 'sense' the external world in the first place and this was why they could not develop concepts and the capacity to think. The latter were those considered to be 'psychotic' and 'autistic'. In other words, these tests explored the finer points of distinguishing between children who had previously been labelled 'mentally defective', 'subnormal' and 'psychotic'. They also provided the basis of a new model for testing subjectivity. Unlike mere behavioural criteria, these tests also enabled the formulation of new psychological theories on child development.

The application of tests to specifically identify 'autistic' children in Britain began in the 1960s with Beate Hermelin and Neil O'Connor's tests for pattern detection. Beate Hermelin was a German-born artist who studied psychology as a mature student at the University of Reading, before working on her $\mathrm{PhD}$ with Neil O'Connor on 'Concept Learning and Verbalisation in Imbeciles' in $1958 .{ }^{103}$ They were both part of the new generation of epidemiological and experimental psychologists, largely inspired by Tizard, who thought seriously about the psychology of 'defective' children, broadly defined. Instead of focusing on AngloAmerican models of child development, Hermelin and O'Connor cast their nets wider to encompass theories drawn from experimental psychologists internationally. In the early 1960s, O'Connor edited a 
volume on Recent Soviet Psychology, introducing British researchers to articles from the journal Voprosy psikhologii (Issues Relevant to Psychology), which had been established in 1955 and featured work by A. V. Zaporozhets, amongst others. Zaporozhets was a student of the controversial Soviet psychologist Lev Vygotsky and was interested in the development of conscious control of movements in infants and children. ${ }^{104}$ Hermelin and O'Connor were interested in his work on tracking the development of sensory functions. Herb Birch had written on the way the visual sense became established in children and how it influenced the child's ability to recognise words. These writers seemed more relevant to those interested in 'defective' children as they offered explanations for psychological abnormalities based on defective senses rather than psychogenic causes. Anthony had argued that childhood 'psychosis' was characterised by an infant's inability to process sensory information. Similar theories had also been put forward by William Goldfarb, who claimed schizophrenic children had a 'receptor dominance' for 'proximal' over 'distance' stimuli, resulting in a preference to touch, smell or lick, rather than look and listen. ${ }^{105}$ However, the details and causes of this inability had not been probed through the application of psychological testing materials and the quantification of the issue.

Hermelin and O'Connor's work did not primarily seek to challenge psychoanalytic models of autism, but rather sought to challenge theories of intellectual development that did not pay enough attention to the role that sense perception played in the formation of cognitive structures. In fact, Hermelin and O'Connor's work on subnormality had already tried to problematise and expand discussions on what human 'intelligence' really was by demonstrating that, if the specific sensory capacities of an individual's nervous system and the specific cognitive structure of their mind were understood, then special educational measures could be put in place to enable them to learn. The extent to which Hermelin and O'Connor's work was challenging general theories of intelligence was pointed out by one North American reviewer who suggested that their 1963 book, Speech and Thought in Severe Subnormality, should be renamed 'IQ isn't all' or 'intelligence isn't everything' because it demonstrated the many ways through which speech and thought could develop. ${ }^{106}$ It was this interest in the processes of learning that inspired them to develop a range of testing methods and materials. These included experiments for visual-motor reaction time, 
tactile and visual discrimination, auditory discrimination, transfer of training skills, generalisation of information and the psychological 'coding' of information using different modes or senses. They employed techniques such as galvanic skin conductance, electroencephalogram (EEG) recordings, heart-rate measures and systematic observation and recording methods in order to test for these. ${ }^{107}$

One key contributor who was instrumental in developing these tests was a psychologist named Peter Venables. He had studied skin resistance changes in industrial workers for his $\mathrm{PhD}$ thesis at the Social Psychiatry Research Unit, using an amplifier he had designed himself based on his knowledge of wartime radar. There was a growing interest in methods for measuring psychological activity using the techniques of biochemistry, physical chemistry and electronics in this period, leading to the establishment of the Society for Psychophysiological Research in $1960 .{ }^{108}$ Venables was a pioneer in the field, with his work on standardisation of method and nomenclature being adopted internationally. ${ }^{109} \mathrm{He}$ often collaborated with Hermelin and O'Connor in developing these techniques.

When Hermelin and O'Connor began to develop psychological tests to identify autistic children, they were interested in understanding the infant's ability to grasp reality, not in an abstract way that concerned their ability to form an ego and to understand their relationships to other people, but rather through the development of the infant's sensory systems and modes of perception. The 1959 Mental Health Act had expanded the testable child population, in particular enabling comparisons between 'subnormal' and 'autistic' groups. In the early 1960s, Hermelin and O'Connor worked with staff at Botley's Park Hospital in Chertsey and St Lawrence's Hospital in Caterham to select 'ten autistic and ten undisturbed, severely subnormal' children. In the same year, they collaborated with Brian Kirman from the Fountain Hospital, and would later collaborate with Sybil Elgar and others running the first schools specifically for autistic children. ${ }^{110}$

In their first 'sensory input' study, all children were matched for IQ levels using non-verbal tests such as the Seguin Form Boards, in which children had to place geometric shapes into their corresponding recesses. 'Autism' was then identified by child psychiatrists and was distinguished from simple 'subnormality' by the presence of at least three of Creak's nine points for 'autism'. In the test, children were rewarded if 
they gave correct responses to tactile, auditory and visual stimulation. They argued that 'autistic' children were more likely to respond to tactile and visual stimulation than auditory stimulation, although they could be taught to respond to sound if they were rewarded. ${ }^{111}$ In grasping for a larger theoretical framework through which to understand this phenomenon, Hermelin and O'Connor suggested that the developmental process in all infants was driven by a 'hierarchical structure of sensory systems'. At first, an infant responded to 'interoceptive and visceral sensations' and these were later superseded by a dominance of tactile and kinaesthetic sensations. Finally, the auditory and visual sensory systems became dominant. These developments were paralleled by the integration of different sensory information' in order that 'stimuli to one sense can be readily recognised and interpreted in another'. It was argued that 'autistic' children did not find it hard to learn new response patterns to auditory and visual stimulation, but rather found it difficult to inhibit earlier, more primitive responses. Hermelin and O'Connor argued that autistic children developed a spontaneous preference for tactile and visual stimuli and found it difficult to renounce this preference when presented with auditory stimulation. This distinguished them from their subnormal controls who did not have any sensory preferences, though they still found it difficult to learn. ${ }^{112}$ These tests appeared to provide psychological proof that 'autistic' children remained stuck in early stages of development in a way that was unique and not related to intelligence.

Hermelin and O'Connor later began to focus on the precise processes that children engaged in when learning from tactile, acoustic and visual stimuli. In their study of visual stimuli, they studied the eye movements of 'autistic' children when presented with images of different coloured cards or a human face that they viewed inside a small box. Sliding between the concepts of autism and psychosis, a typical phenomenon of the time, they argued that 'psychotic' children showed a 'longer time in undirected gazing' than 'subnormals' or 'normals', speculating that perhaps 'central fixation on a visual stimulus yields less information to psychotic children than to others. ${ }^{113}$ O'Connor suggested that it was the 'short visual inspection time' of autistic children that 'handicapped' them in their daily life and their ability to learn. ${ }^{114}$ When it came to measuring auditory perception, they explored the 'psychotic' or 'autistic' child's ability to recall sequences of words. These tests determined that 'psychotic' children found it just as easy to remember a random 


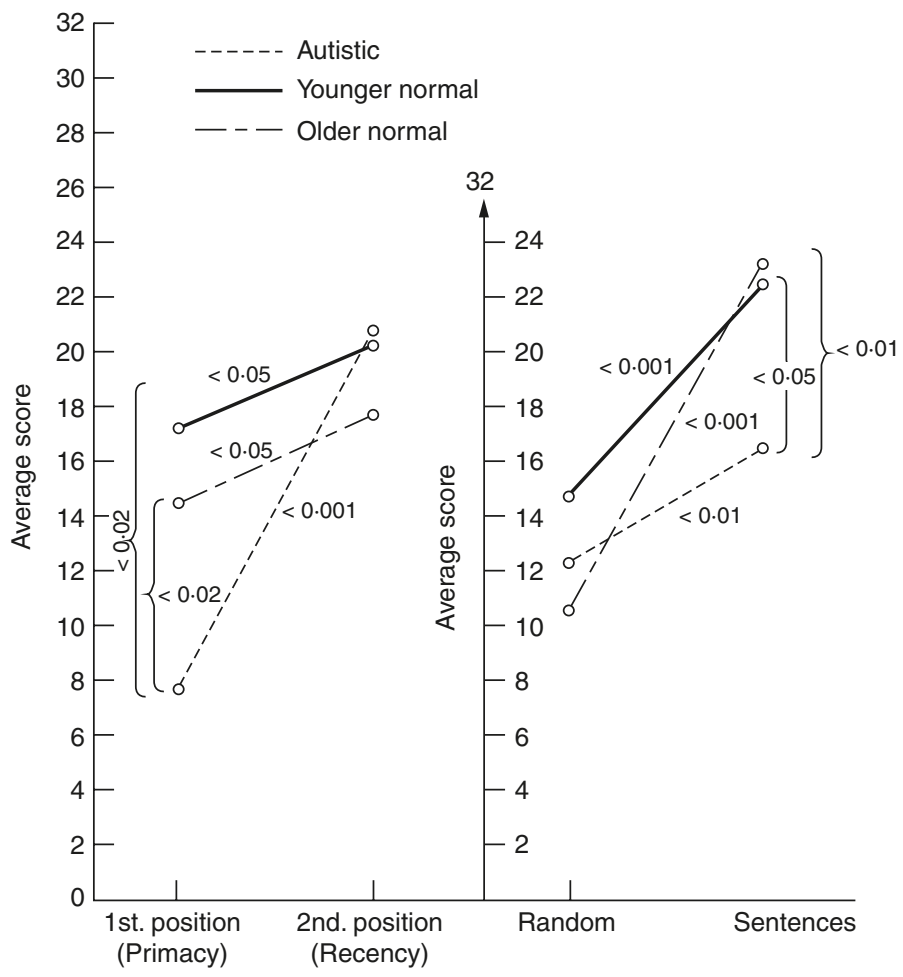

Figure 5 Graph comparing verbal coding ability in 'normal' and 'autistic' children, from B. Hermelin and N. O'Connor, Psychological Experiments with Autistic Children (Oxford: Pergamon, 1970)

sequence of words, such as 'glass hand cow pot cup meat spoon place', as they did a grammatical sentence. This differed from 'subnormal' and 'normal' children, who were more likely to remember grammatical sentences by sequential probability or to group random words according to concept. ${ }^{115}$ Placing this into a developmental theory based on language progression in 'normal' versus 'autistic' children, Hermelin suggested that this was because 'autistic children tend to "read back" words more exclusively from an immediate memory store than do the normals'. Autistic children showed particular 'deficits in verbal coding and patterning' that were unique to this group (Figure 5). ${ }^{116}$ 
Although much of Hermelin and O'Connor's work focused on sensory impairments in order to understand how autistic children developed intellectual capacity, they also conducted experiments to try to understand how sensory impairments may impact on a child's development of relationships and emotional attachments. One experiment, for example, sought to emulate experiments conducted by Harry Harlow. Harlow's famous experiments to test Bowlby's theory of attachment using rhesus monkeys had constructed cloth and wire 'mother' statues as substitutes for real monkey mothers in order to test the importance of the mother and child bond to later attachments. Without soft cloth, Harlow's infant monkeys often died, and even when raised with cloth and wire doll 'mothers', they later developed into disturbed adult monkeys. ${ }^{117}$ Hermelin and O'Connor tried to compete with attachment theorists and replicate this powerful cultural fable in order to generate a different story about autistic children. In one experiment, their aim was to measure different children's responses to isolated stimuli, such as rocking, softness, hardness and human contact. As these were human experiments, they thankfully did not emulate the extreme deprivation that Harlow's monkeys were subjected to and instead tested their 'autistic' and 'subnormal' children for five-minute bursts over the course of a day. What they found was that, after a long day of experiments, autistic children were just as likely to respond to real-life adults as 'subnormal' children, and that all the children treated a soft cloth (designed to represent the comfort of softness) and rocking platform (designed to represent the comfort of movement) in the same way as they did a box. There was very little that they could infer from such results, other than the fact that 'autistic children of this [low] intelligence level respond positively to an adult', which appeared to contradict the theory that autistic children shunned human contact. They realised their limitations, pointing out that the autistic children had in fact been more rational than they had been when the experiments were being planned. ${ }^{118}$ Nevertheless, they hypothesised that perhaps autism was not defined by a 'lack of interest in human or social contacts', but rather by 'more marked and extensive central nervous system anomalies' in a similar way to subnormality. It only developed as a problem with human relationships over time. ${ }^{119}$

By the mid-1960s, Hermelin, O'Connor and the new autism psychologists consistently presented the view that autism was a kind of 
sensory impairment that prevented the infant or child from developing emotional attachments. Writing on 'diagnosis, epidemiology, aetiology' in 1966, John Wing argued that the autistic child's problems were similar to those of deaf and blind children. As he put it: 'Autistic children are not totally deprived ... but their basic disability may be analogous to the deaf/blind child in that they are unable, at first, to make meaningful patterns out of sensory stimuli, whether auditory or visual. ${ }^{\prime 20}$ The child may shun social contact in the form of 'visual avoidance' because he or she 'often tries to avoid complex visual patterns (the most complicated of which is a human being).'121 They may also engage in 'auditory avoidance' because of their 'difficulty in making use of auditory information'. This, in turn, led to speech disorders or lack of speech. The 'behavioural abnormalities' and 'affective disturbance' were all symptoms of this primary impairment and could vary widely amongst children depending on 'the severity of the perceptual and speech disorders' and the 'suitability of the environment.' ${ }^{122}$ Taking the analogy further, John Wing pointed out that the epidemiological figures for autistic children were broadly analogous with those for blind and deaf children. Using Lotter's survey as a benchmark, he calculated 1,400 'autistic' children in England and Wales, an identical figure to the 1,400 blind children listed by the Department of Education and Science in $1962 .{ }^{123}$ It was clear that the new autism psychologists wanted the autistic impairment to be recognised on a par with other perceptual impairments.

Hermelin and O'Connor's tests were readily being employed to generate a considerable critique of general intelligence tests as the true measure of psychology. Writing in 1966, Peter Mittler, a lecturer in Developmental Psychology at Birkbeck, London, denounced the fact that general intelligence tests remained 'an important feature of the educational machinery in this country' even though they were wholly inadequate for testing all 'handicapped' children. He appreciated the development of the Merrill Palmer Scale because it could be flexibly applied in subsections and included non-verbal elements. ${ }^{124}$ Nevertheless, it still measured 'intelligence'. The Unit for Research in Occupational Adaptation had already challenged the idea of intelligence as a useful tool in social planning, demonstrating instead that all individuals had the potential to become social subjects, they just had varying levels of skills and capacity. The reincarnation of the unit as the Social Psychiatry Research Unit in 1958 only re-emphasised that all population 
groups could be measured, accounted for and enabled using new learning tools and techniques. The new autism psychologists were part of a new movement that was wholly against an elitist version of social mobility, as put forward by Cyril Burt and others, that linked intelligence to financial and social rewards. They were engendering a new model of society and social responsibility that did not rely on discriminatory models of intelligence and hierarchy. Instead they championed a model of society in which all individuals could contribute. They also championed the creation of new policies on education, employment rights, etc. to enable individuals to contribute, whatever their capability. As well as asserting total productivity, this model also asserted autonomy for all individuals regardless of their abilities, an aim that was strengthened via the 1959 Mental Health Act. The development of tests to identify 'autism' was one way to facilitate a new model of society.

The race was then on to develop accurate tests to measure the unique sensory impairments experienced by autistic children. The growth of the 'cognitive' movement in psychology meant that these sensory deficits were often explained in relation to the cognitive impairments that they engendered. ${ }^{125}$ One thing was clear, the new autism psychologists were united in the view that the condition was not caused by internal hallucinatory mechanisms associated with instinctive drives that affected emotional reactions, but was instead characterised by a sensory deficit that affected the child's ability to discriminate external images and sounds. Theories about dominant mothers were replaced with theories of 'sensory dominance' and the language of maternal deprivation was replaced with the language of sensory deficiencies and impairments. In this model, problems or difficulties in emotional development were regarded as a consequence of an infant's inability to " "make sense" of the world'.126

\section{The primacy of sense perceptions}

The 1960s witnessed a revived interest in questions highlighted by earlier developmental psychologists concerning the primacy of sense perceptions in the development of early thought. ${ }^{127}$ Progressive educators such as Maria Montessori had noted how frequently young children employed their tactual senses in order to explore 
objects. ${ }^{128}$ Furthermore, Piaget's work on the development of thought in children had highlighted the sensori-motor stage, in which infants grasped and manipulated objects in their attempts to conceptualise them. ${ }^{129}$ Experiments conducted by the North American psychologist Samuel Renshaw in the 1930s, as well as experiments at Zaporozhets' laboratory at the Moscow Institute of Psychology in the 1950s, had appeared to demonstrate the superiority of tactual-kinaesthetic over visual sensations in young children, and these were all well known in the 1960 s. ${ }^{130}$

However, in the mid-1960s, Hermelin and O'Connor and other developmental psychologists in both Britain and the USA began to challenge the idea that tactual-kinaesthetic senses were superior to visual perception in the development of early thought. This research had been stimulated by the integration of new 'defective' populations into the field of developmental psychology as well as a revived interest in William James' ideas of brain plasticity in the processes of learning. ${ }^{131}$ Herbert Pick and others from the University of Minnesota planned experiments of visual versus tactual shape sorting and matching to see which could be carried out prior to the other, arguing that visual perception was, in fact, important to infants from a very early age and that it preceded tactual discrimination in cognitive development. ${ }^{132}$ Richard Held at MIT sought to demonstrate that both tactualkinaesthetic and visual perceptions were completely dependent on each other when it came to the development of integrated behaviour in animals and humans. He devised a series of experiments with both humans and kittens in order to test 'plasticity in sensory-motor systems'. The most creative of these experiments involved the placement of two kittens inside a gondola with visual pattering on the inside. The exact spatial movements of one kitten were transmitted to a second kitten, which thus saw an identical visual display; however, the second kitten was not able to move its limbs freely and thus to correlate visual and motor information. As suspected, the second 'passive' kitten did not show normal physical responses to balls and other objects when leaving the gondola, whereas kitten number one readily held out its forepaws and avoided potential hazards. Held claimed that these experiments confirmed 'the sensory feedback accompanying movement-reafference plays a vital role in perceptual adaptation', and that motor movement assisted sensory awareness. ${ }^{133}$ These experiments also purported to 
show that visual cues and motor cues for behaviour were independent of one another.

In 1967, the MRC established a Developmental Psychology Unit under the directorship of Neil O'Connor. It was a small institution occupying the lower ground floor of a building on Euston Road in central London, and included 'a small laboratory with an electronic workshop bench' and a room with a 'two way screen' for child observation. None of the staff was medically qualified but all had a strong commitment to the principles of experimental psychology. At the MRC unit, the experimental study of autistic children became central to understanding wider problems within the science of developmental psychology. The unit brought together O'Connor, Hermelin, Venables and Uta Frith, who had conducted her PhD under O'Connor and Hermelin at the Institute of Psychiatry, focusing on visual pattern detection in autistic children. Venables' $\mathrm{PhD}$ students also worked there, along with a technical officer who provided transducers for recording signals, EEGs and skin resistance. The unit also had a strong connection to the Department of Psychology at University College London. ${ }^{134}$ The exploration of sense perception in the development of thought was central to many of the experimental methods developed there, in particular visual and aural senses. For example, one of Venables' PhD students, R. A. Hayes, conducted investigations into middle-ear function in autistic children to see whether problems in middle-ear muscles affected the ability to discriminate sounds and thus to understand speech. They hypothesised that this could also explain why autistic children showed heightened EEG-measured 'arousal' when subjected to continuous noise. ${ }^{135}$

Developing Hermelin and O'Connor's hypotheses, Frith argued that 'emotional disorders (withdrawal for instance) might be secondary to the severe difficulties in perceiving, thinking, understanding, and speaking. ${ }^{136}$ Frith would increasingly explain this in the language of cognitive sciences; for example, arguing that autistic children lacked 'complex perceptual tasks that depend on efficient information processing. Writing in 1969, Hermelin and Frith argued that 'The impairment might consist of a failure to make use of complex information from any one sense, or of a failure to integrate information coming from different sensory channels. ${ }^{137}$ One of their classic experiments employed a series of jigsaw puzzles, which relied more or less heavily on visual or tactual cues for fitting the pieces together (Figure 6). Frith and Hermelin argued 


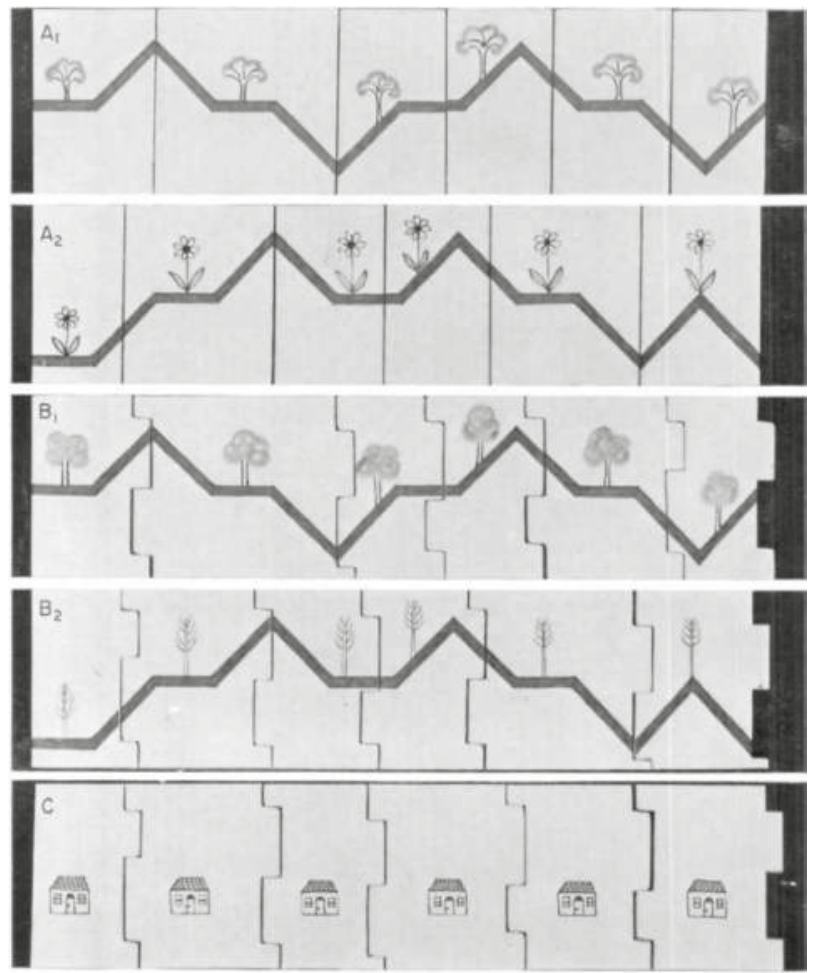

Figure 6 Uta Frith's early jigsaw tests for pattern detection, from U. Frith and B. Hermelin, 'The role of visual and motor cues for normal, subnormal and autistic children', J Child Psychol Psychiatry 10, no. 3 (1969)

that autistic children of low intelligence performed worst on the experiments that relied most heavily on visual cues, concluding that autistic children 'made relatively less efficient use of visual cues and relatively more of motor feedback than did other groups. ${ }^{138}$

Shifting their interest to language development, they asked, 'Can autistic children make sense of what they see and hear?', and employed different types of word 'recall' tests to see whether autistic children did not understand grammar, or whether it was the rules and patterns associated with grammar that they did not understand. Children in 
the autistic group failed to make use of either grammatical structures or other structures such as the use of repetitions or alterations in a sequence of words. They did not seem to apply logical rules in their reconstruction of language or in their reconstruction of patterned visual series of green, yellow and other coloured counters. Frith and Hermelin concluded that autistic children often reproduced patterns that were 'highly repetitive, predictable and rigidly structured', rather than extracting features from what they had heard or seen and then responding appropriately. ${ }^{139}$ Frith and Hermelin argued further that this inability to extract information and to respond appropriately extended even to the autistic child's behaviour. As they put it:

The stereotyped, rigid, ritualistic phenomena in the behaviour of autistic children might be regarded as an exaggerated form of pattern imposition. On the other hand, the unpredictable, often inappropriate, and seemingly random responses to environmental stimuli typical of autistic children may indicate an impairment in the feature-extracting process. ${ }^{140}$

Frith later developed more tests using xylophone sounds and rubber stamps to argue that autistic children did not increasingly adhere to rules as other 'normal' and 'subnormal' children did. Because early language acquisition is based on flexibility of rule application, autistic children had problems because they excessively followed simple rules and were unable to be flexible and abandon old rules when the situation required. ${ }^{141}$ All of these new ideas about autism were framed around the central claim that it was a kind of 'sensory impairment' similar to that seen in children with visual and hearing impairments.

\section{The central 'cognitive disorder' of autism}

In an international study group on infantile autism in 1970, a number of researchers put forward proposals for the central 'cognitive disorder' from which infantile autism developed. Drawing from Hermelin and O'Connor, J. A. M. Martin argued that the primary problem in autism was a failure of 'sensory organisation'. Martin had been testing the hearing responses of children diagnosed with autism and had found that they were unable to identify and recognise complex sounds. Although it was clear that such children could hear, it appeared that 
they were unable to bring this sense in accordance with other senses, thus suggesting 'imperfect multi-sensory integration. ${ }^{142}$ A similar view was put forward by Edward Ornitz of UCLA, although he expanded this, suggesting that 'the underlying disturbance may be a failure of the normal homeostatic balance between excitatory and inhibitory influences within the central nervous system', adding that 'this disturbance appears as a faulty modulation of motor output and sensory input. ${ }^{143}$

Lorna Wing conducted a comparison of the abilities of children with 'receptive or executive aphasia' and 'partial blindness' or 'deafness'. Her test results showed that the language and perceptual problems of autistic children resembled that of aphasic and partially blind/deaf children respectively. She argued that the existence of such 'specific handicaps' in autistic children meant that neurological and sensory handicaps must be causative of the condition and that therefore 'the "emotional withdrawal" hypothesis is completely untenable.. 144 Throughout the late 1960s, Lorna Wing promoted herself and her approach, helping to popularise her views. In 1969, she produced a leaflet for the Society for Autistic Children Children Apart: Autistic Children and Their Families, which was later published in the USA and also distributed internationally. Wing also published widely in women's magazines and public information leaflets, such as an article in Maternal and Child Care in 1967 stating that 'autistic children behave and respond to psychological tests, as if they cannot make a coherent pattern of the information which comes to them through their eyes and ears. ${ }^{145}$ Although these theorists took different standpoints on the exact form of the central sensory disorder that caused autism, they were all united in the view that the condition was not caused by emotional reactions or phantasies about relationships, but was instead characterised by a fixed deficit in certain aspects of thought. All of these theories had the potential to influence the mainstream education and treatment of autistic children at the start of the 1970s. Whoever could pinpoint and explain the precise cognitive problem, and develop tests for it, had the key to diagnosing autism.

At the biochemical level, many clinicians and researchers sought to identify the precise disturbances in metabolism that affected brain activity with a view to discovering genetic causes. By the mid-1960s, hospitals such as the Maudsley and Great Ormond Street would regularly send children for a series of biochemical tests. Children could be referred for full blood counts, insulin tolerance tests, urinary amino 
acid tests, X-rays of the wrist to detect bone age, X-rays of the skull, heart and lungs, and adrenocorticotropic (ACTH) stimulation to measure the response of the adrenal glands to stress. ${ }^{146}$ The child's head circumference, weight and height were also measured and EEG tests were carried out to measure electrical charges in his brain. ${ }^{147}$ In 1968, Brian Kirman, then consultant physician at the Maudsley and lecturer at the Institute of Psychiatry, published an article in the British Medical Journal urging all doctors to give full diagnostic assessments to mentally atypical children, including 'a biochemical screening for metabolic errors, examination of the urine for mucopolysaccharides, of the lymphocytes for inclusions or vacuoles, [and] possibly an EEG. ${ }^{148}$ The aim was to distinguish different problems within this large group of children and eventually to develop new treatments. Kirman had published work on 5-hydroxytryptamine (serotonin) levels in children with phenylketonuria and had a general interest in building on previous studies that had associated metabolic abnormalities with mental deficiency, such as Fagge's association between cretinism and absence of thyroid production. ${ }^{149} \mathrm{He}$ regarded autism as a form of retardation with probable organic cause. ${ }^{150}$ Reviewing the growing literature on autism in 1967, Kirman argued that autism was a form of mental retardation in which only certain intellectual functions could advance: 'It is probable that most patients who would have previously been described as "idiot savant" would now be classed as autistic."151 Although none of this research provided any evidence that there was a unique biochemical disturbance that could be related directly to autism, it did help to support the idea that there may be a biochemical reason why 'autistic' children lacked abilities in sensory perception.

In the midst of whirlwind change concerning the conceptualisation of child development and with a lack of evidence regarding biochemical causation, psychological researchers in Britain began to focus wholeheartedly on the details of definition. It should be no surprise that the most vehement and passionate debates between psychologists should take place over the concept of autism. Because of its importance within a general theory of child development, autism had become a genuine battleground for the soul. The Maudsley group of autism psychologists, distinguished themselves within this fracas by focusing in precise detail on the development of psychological tests to identify autism; the use of epidemiology to rationalise and validate those tests; and ultimately the 
development of a genetic theory of autism. Their idea of what constituted scientific evidence was strongly secured in statistical techniques developed in the Galtonian tradition. They drew impressively upon this tradition in the construction of their arguments and this is why they ultimately received so much support. It is because of this that definitions of autism developed in Britain were widely dominant in the international literature.

By the early 1970s, the argument that autism was a problem in sense perception that led to cognitive impairments, which in turn led to emotional withdrawal, in precisely that order, was vying with psychoanalytic models that still relied heavily on descriptions of early phantasies involved in the formation of emotional attachments, and the potential role of mothers in disturbing these early fragile bonds. Discussions of sensory impairment then vied with descriptions of maternal deprivation in establishing a logic for the creation of autistic symptoms. The new autism psychologists argued that visual and aural sense perceptions were impaired in autistic children and this restricted their normal development. This highlighted the significance of these systems in all children's development, as well as helping to develop a new language for the description of autism that did not engage with psychoanalytic descriptions of infantile phantasies and the early development of unconscious mental life, nor with the role of mothers in affecting this. These approaches would become increasingly distanced in the 1970s, so that work such as that conducted by Anthony that fused psychoanalysis, developmental psychology and psychiatry was harder to sustain. From the psychoanalytic side, Winnicott, in particular, firmly drew the line between these approaches, claiming that a problem with the infant-mother bond could lead to an 'adaptive failure' in the child, causing autism. In 1966, he gave a paper to the Society for Autistic Children in Leicester in which he discussed his approach to some children he had treated and claimed that this validated his concern about maternal care and autism. ${ }^{152}$

In 1972, Frances Tustin, a child psychotherapist who was trained at the Tavistock Centre under Esther Bick, published her first book Autism and Childhood Psychosis, in which she put forward her theory of 'normal primary autism' where 'the infant is the stream of sensations from which constructs emerge as nameless entities. ${ }^{153}$ This, she claimed, was akin to what E. J. Anthony had called 'normal neo-natal solipsism', which 
was part of normal child development. Tustin was a critical voice in developing the original concept of autism in relation to infantile phantasy, but she was encountering growing obstacles placed by the new generation of autism psychologists. Tustin's theory of 'encapsulated' or 'regressive' secondary autism also developed Anthony's work, depicting a child with either 'hypersensitive responses to sensory stimuli' in 'encapsulated' autism or 'intolerance of bodily separateness' in the 'encapsulated' form. ${ }^{154}$ With regard to the issue of sensory impairment, she argued that although sensory impairments could stunt a child's development, thus leaving them in a state of autism, it was the psychological state of autism, associated with infantile phantasy, that was primary. She argued that it was to be expected that 'the sensory impediment of deafness is sometimes to be associated with autistic features', as was 'mental-defect and brain-damage', because 'impediments to taking in the outside world can mean that sensations in the child's own body remain of undue significance.' However, she maintained that the state of autism existed before sensory impairments and that autism should be understood as an internal emotional state associated with 'phantasies' and 'hallucination' that later became the mainstay of unconscious life. ${ }^{155}$ This came to the crux of what distinguished the approach of Tavistock human relations psychologists and the new autism psychologists. Even though the new autism psychologists were discussing the formation of atypical human relationships in autism, they were doing so in a way that did not engage with psychoanalytic models of phantasy and early unconscious life. Their new 'style of reasoning', based on measuring 'the autistic' within a population group, meant they began to forge new meanings for the concept. Their commitment to defining what was initially a description of subjective early unconscious life using objective measures from psychiatric epidemiology and experimental psychology led to a complete transformation in the meaning of autism.

Goodbye phantasies: the disappearance of hallucinations

By the early 1970s, epidemiological and experimental studies of autism by the new autism psychologists were pushing the limits of a human relations approach to developmental psychology. This highlighted the issue of whether or not autism was in fact associated with schizophrenic 
thinking, which had been a cornerstone of the original concept of autism and its theoretical application. The increasing establishment of child psychiatry as a unique discipline was also adding momentum to this question. In 1965, Wilfred Warren from the Maudsley served as Consultant Advisor in Child Psychiatry to the Ministry of Health, helping to plan child psychiatric services across England and Wales. ${ }^{156}$ $\mathrm{He}$ argued that children admitted as psychiatric inpatients should not be kept on the general paediatric wards, and that child psychiatrists should be managed under the health rather than the education authorities. ${ }^{157}$ The 1965-68 Royal Commission on Medical Education endorsed Maudsley principles and concluded that training in child psychiatry should constitute an essential part of any training in general psychiatry. In a paper presented to the Association for the Study of Medico-Education conference in the late 1960s, Rutter pointed out that advances made in child psychiatry in the fields of 'mental subnormality', 'cerebral palsy' and 'epilepsy' meant that child psychiatry could no longer be regarded as the poor cousin of adult psychiatry and that the discipline needed to open up to the reality that many adults with psychiatric disorders had developmental histories. ${ }^{158}$

In the late 1960s, Rutter and several colleagues at the Institute of Psychiatry decided to address the relationship between autism and adult schizophrenia by conducting a follow-up study of sixty-three children who had been seen at the Maudsley psychotic clinic in the 1950s and tracking their development. They compared their outcomes to those of sixty-three children who had not presented with any concerns in childhood and sought to discover how many of them went on to develop schizophrenia or hallucinatory experiences. Concerning the problem of hallucinatory phenomena, they ascertained that although 'several adolescent children continued to have childish fantasies' in followup, they 'all distinguished between reality and make-believe'. In addition, although a few of the children 'behaved in an odd manner which gave rise to the suspicion that they were having hallucinatory experiences ... in none was there convincing evidence of hallucinations, and no child with speech described sensations or happenings which were hallucinatory.' ${ }^{159}$

The possibility of hallucinations and phantasies in non-speaking autistic children was a moot point in the late 1960s following Lotter's work. Whilst on the one hand, Lotter could claim to have turned autism 
into a purely behavioural category, Creak and others still insisted that its relation to subjective development meant that it could never be a purely behavioural category. However, approaches in epidemiology and experimental psychology became increasingly standardised, and Hermelin, O'Connor and Frith's work challenged the idea that any mental processes could pre-exist sense perceptions, which, they argued, were primary in the development of infantile thought patterns. All this work was shifting the new autism psychologists away from the idea that autism was a subjective state characterised by a complex and creative fantasy life.

However, the most significant study that was conducted within these significant shifts was one developed in 1971 by Israel Kolvin, from the Nuffield Child Psychiatry Unit in Newcastle. This study initially sought to test Anthony's hypothesis that 'psychotic disorders in childhood are dependent on the age at which the process begins'. In order to do this, Kolvin separated childhood psychotics into groups relating to age of onset and then divided up the 'phenomenology' of the condition according to these different groups. What was significant in the planning of this exercise was the implementation of 'rigorous criteria' to ensure that the children could be compared with one another equally. As with other epidemiological models of autism, the rigorous quality of the data depended on its ability to be examined and then replicated by numerous researchers.

Kolvin argued that researchers should never attribute phantasies to children who did not have the words to describe these themselves. He explained his approach as follows: 'Both groups of psychotics were examined for hallucinatory phenomena ... Gazing round in a distracted manner or looking as if they were hearing voices were insufficient. In addition, at some time the child must have given an account of hallucinatory phenomena. ${ }^{160}$ These criteria were exceptionally rigorous - to the extent that they were narrowly conceived - when concerning infants and children who could not talk or had very limited language abilities. Nevertheless, they were regarded as essential to the progression of statistical methods in child psychiatry. Given the study design, it is perhaps unsurprising that Kolvin found that children with late-onset psychosis 'commonly hallucinated', whereas those with early-onset psychosis, in the first three years of life, were more likely to suffer from 'severe speech delay and many speech anomalies' as well as 'stereotyped movements' 
and 'poor relationships' rather than hallucinations. ${ }^{161}$ Kolvin's study excluded the possibility that autism in infants and young children was accompanied by hallucinatory thinking in any form. His description of autism was the direct opposite of that which had first been put forward by Bleuler and which had been supported by Creak, Klein and Anthony from the late 1920s to the 1960s. However, it is this model of 'earlyonset psychosis' that later became dominant in descriptions of the concept of 'autism. This is ironic because 'autism'. had originally been used precisely to describe ordinary early infantile thought.

In 1972, Kolvin argued that 'the subject of childhood hallucinations requires clarification' and that any account of a hallucinatory experience in childhood would have to include, at the very least, an account of its 'sensory modality', a description as to its intermittent or continuous type, an account of whether the child can appreciate its pathological nature, whether there is 'imagery' or 'pseudo hallucinations', the child's state of consciousness, and their psychological meaning. ${ }^{162}$ This developed work on sense perception by seeking to clarify the precise senses that infants were using to conceptualise objects and other people to make emotional connections. Again, clearly, it was not possible to give details on the sense modalities of hallucinations in infants and children without speech, and this poured more cold water on the concept of childhood schizophrenia and on theories of the visualisation of instinctive drives generally that had been dominant in psychoanalytic descriptions. In fact, Kleinian theory in particular had not clarified the sense modalities of early infantile hallucinatory thought, but had presented it as almost a whole body experience, and Bender and others had also followed such a model.

Kolvin's 1971 study was extremely influential and all researchers who followed his study design reached similar conclusions. ${ }^{163}$ In the 1970s, these researchers focused more and more on the study of language and increasingly regarded autism as a 'communication' disorder rather than a psychotic disorder. A 1972 quotation from Rutter summarises the uncertainty and, indeed, irony, surrounding the reversal in the meaning of autism that followed the introduction of statistical and epidemiological methods:

Autism means a withdrawal into fantasy but this is not what happens in the syndrome of autism. The schizophrenic may retreat from reality into 
fantasy, but the autistic child does not retreat, rather he fails to develop social relationships - a crucial distinction. Furthermore, so far as one can tell, the young autistic child has a deficiency of fantasy rather than an excess. ${ }^{164}$

Of course, what constituted 'convincing evidence' of the existence of hallucinations in children differed widely amongst practitioners. Whereas psychoanalytically influenced psychologists inferred hallucination from children's actions, Kolvin, Rutter and related researchers thought that this kind of inference should be eliminated from all research inquiries. This was not because they were averse to the idea of hallucinations in infants and children, but rather because such claims would have disrupted the accuracy of epidemiological and observational studies. In general, researchers would follow Kolvin and Rutter in claiming that unless a child described hallucinatory thoughts using speech, they could not be assumed to experience hallucinations. Whereas this contention would not eliminate the concept of hallucination in adult psychiatry, because linguistic descriptions of hallucination still counted as a form of behaviour, it completely transformed child psychiatry where infants and young children had no words to describe such events.

Highlighting the changes occasioned by the introduction of statistical and epidemiological methods, Rutter had argued in 1972 that 'the autistic child has a deficiency of fantasy rather than an excess', and in a 1978 article, he lamented the fact that 'childhood schizophrenia' had suggested a 'rich fantasy life', when in fact autism was characterised by a 'lack of imagination. ${ }^{165} \mathrm{He}$ was also frustrated by the fact that many child psychiatrists 'use childhood schizophrenia, autism, and child psychosis as interchangeable diagnoses', because this had further confused matters. ${ }^{166}$ Although his work had successfully cast off the ties of childhood hallucination theories, he had not been able to build an alternative foundation theory of the origins of human relationships as he focused on building statistical and social scientific methodologies.

As discussed in Part one, the 1940s and 1950s saw, human relations psychology, and the theories of childhood psychosis, schizophrenia, autoerotism, primary narcissism and autism within it, enter into a general discourse of child development and subjectivity that was popularised in relation to wider theories of maladjustment. Needless to say, the neglect of children with 'mental deficiency' or 'subnormality' within 
theories of the development of emotional stability and the formation of relationships was an obvious problem in the models of welfare provision that prevailed in the post-war period. However, the rumblings of discontent amongst parents who disagreed with the logic of professional psychologists, psychiatrists and social workers of the human relations school became louder and louder in the 1960s. The 1960s thus witnessed growing criticism of the expertise supposedly held by human relations and object-relations psychologists. This further sanctified the divide between professionals trained within the Tavistock and those trained in what was increasingly becoming a distinctive school of experimental psychology focused on the central issue of autism, dominated by psychologists based at the Maudsley and the Institute of Psychiatry. This led to a radical critique and overhaul of Tavistock human relations models of child development. In this overhaul, the core of all theories of psychological development - autism - was systematically pulled apart and reinvented.

What is important to remember, however, is that Rutter, Kolvin, Hermelin, O'Connor, Lotter, Frith and the Wings did not adopt a total behaviourist stance that disregarded the possibility of unconscious or preconscious mental processes. In the 1960s and 1970s, such an idea would have been untestable within the growing cognitive movement. ${ }^{167}$ Instead, they always promised the eventual revelation of the mental processes that lay behind the phenomenon of 'autism', the ultimate exposé of the hidden thinking processes that meant that some children did not develop language and relationships in the same way as others. The Wings and Lotter claimed that by calculating 'the autistic' in a population, it would eventually lead to a better definition and deeper understanding of the category; Hermelin, O'Connor and Frith argued that experimental psychology would reveal the specifics of sense perception in autistic children and the unique way that they developed conceptual maps that influenced their emotional life; Rutter and Kolvin thought that limiting the application of the concept of hallucination would clarify its form and validity within theories of developmental psychology. This promise of an eventual revelation supported further research and exploration using a model of autism that was stripped of its original meaning. This was a new version of 'autism' in which there was no phantasy, no hallucination, no unconscious, but merely the absence of thought and meaning where an entire edifice had once been built. In 
general, this strengthened all theories of childhood psychological disorder that were focused on a cognitive deficit or impairment model. It also strengthened all epidemiological and sociological work that promised to offer some details and explanations about these thinking processes, and to finally develop some psychological theories to replace those that had been based on instinctive drives and hallucinatory thinking. The 1970s and 1980s saw the first attempts to revivify the meaning of autism using new tools, ideas, methods and ideologies.

It was via the creation of these new models for measuring and managing autism that the meaning of the term 'autism' would undergo a radical transformation. By the 1970s, there was a complete reversal in the meaning of the word. From the 1920s to the 1960s, the term had been used by child psychiatrists and psychoanalysts in Britain and the USA to describe excessive hallucinations and phantasy in infants and children and was regarded as a subcategory of childhood schizophrenia. However, the new generation of epidemiological and experimental autism psychologists in Britain in the 1960s and 1970s transformed that meaning. Instead of employing the term to describe excessive hallucinations and a complex fantasy life, they began to use it consistently to describe a lack or deficiency of fantasy life. This transformation in the meaning of the term 'autism' was paralleled in Britain by further shifts in the institutional care and education of children considered to have mental abnormalities. This chapter has argued that after institutions for 'mentally defective' children were closed, many people thought it was no longer acceptable for child psychiatrists to speculate about the fantasy life and hallucinations of children and to view their problems as models for the psychiatric problems of adults. This was the start of a new discourse that emerged to describe the 'impairments' of autistic children. This previously highly-influential descriptive model for representing children's thoughts was disregarded in preference for statistical and experimental accuracy.

Notes

1 Schofield, Enoch Powell and the Making of Postcolonial Britain; Ward, British Culture and the End of Empire.

2 Savage, Identities and Social Change in Britain since 1940.

3 Marks, Sexual Chemistry. 
4 Thane and Evans, Sinners? Scroungers? Saints?.

5 Thomson, Lost Freedom.

6 Hansard, William Compton Carr, 18 May 1960.

7 Robert Holt and John Turner, Political Parties in Action.

8 Hansard, William Compton Carr, 18 May 1960.

9 K. Jones, A History of the Mental Health Services, p. 306.

10 K. Jones, A History of the Mental Health Services, p. 293.

11 K. Jones, A History of the Mental Health Services, p. 304.

12 Percy Report, 1957, paras 17-19, in Watkin, Documents on Health and Social Services 1834 to the Present Day, p. 387.

13 Percy Report, 1957, paras 17-19, in Watkin, Documents on Health and Social Services 1834 to the Present Day, p. 387.

14 Kushlik, 'Social problems of mental subnormality', p. 396.

15 Hilliard and Kirman, Mental Deficiency, p. 8.

16 Hilliard and Kirman, Mental Deficiency, p. 24; O'Connor and Tizard, The Social Problem of Mental Deficiency, pp. 33-34.

17 Hilliard and Kirman, Mental Deficiency.

18 Watkin, Documents on Health and Social Services 1834 to the Present Day, pp. 392-393.

19 Wilkin, Caring for the Mentally Handicapped Child.

20 Percy Report, 1957, paras 17-19, in Watkin, Documents on Health and Social Services 1834 to the Present Day, p. 389.

21 E.g. Hansard, HC Deb 6 May 1959 vol 605 cc 403-483.

22 MHA1959: Part 1, Section 4, p. 3; Section 3, p. 3.

23 MHA1959: Part 2, Section 10, p. 6.

24 MHA1959: Part 4, Sections 25 and 26, pp. 15-16.

25 Watkin, Documents on Health and Social Services 1834 to the Present Day, p. 393.

26 Kushlik, 'Social problems of mental subnormality'.

27 K. Jones, A History of the Mental Health Services, p. 316.

28 Bowtell, 'The historical background'.

29 Tizard and Grad, The Mentally Handicapped and Their Families.

30 National Archives (NA) NA/ED50/994: Special Educational Treatment Psychotic Autistic Children 1961-1965. Letter from P. Benner (MoH) to H. E. Clinkard (MoE), 27 August 1961.

31 NA/ED50/994: Special Educational Treatment Psychotic Autistic Children 1961-1965. Letter from P. Benner (MoH) to H. E. Clinkard (MoE), 27 August 1961. 
32 NA/ED50/994: Draft report of the SMHAC sent from Benner to Clinkard 6 September 1962.

33 NA/M.603(1)/61 (ED 50/789-792): Letter from H. E. Clinkard (MoE) to P. Benner (MoH), 21 June 1962.

34 NA/M.603(1)/61 (ED 50/789-792): Minutes of Meeting, 2 March 1962.

35 NA/M.603(1)/61 (ED 50/789-792): Minutes of Meeting, 16 March 1962.

36 NA/ED50/994: Special Educational Treatment Psychotic Autistic Children 1961-1965. Letter from P. Benner (MoH) to H. E. Clinkard (MoE), 6 September 1962.

37 Creak, 'Schizophrenic syndrome in childhood', 889.

38 Creak, 'Schizophrenic syndrome in childhood', 889-890.

39 Allison, 'Perspectives on a puzzle piece.'

40 Silverman, Understanding Autism.

41 Brugha et al., 'Contribution and legacy of John Wing, 1923-2010'.

42 NA/ED50/994: Wing Memorandum, p. 2.

43 NA/ED50/994: Wing Memorandum, p. 3.

44 NA/ED50/994: Wing Memorandum, p. 2.

45 NA/ED50/994: Wing Memorandum, p. 8.

46 NA/ED50/994: Wing Memorandum, p. 2.

47 NA/ED50/994: Wing Memorandum, pp. 2-3.

48 NA/ED50/994: Wing Memorandum, p. 10.

49 NA/ED50/994: Wing Memorandum, p. 10.

50 Tizard, 'Social psychiatry and mental subnormality', p. 59.

51 Tizard, 'Community services for the mentally subnormal', p. 133-134; Tizard, 'Results and summary of the Brooklands experiment'.

52 NA/BD 18/1438: Appendices to Letter from M. J. Craft to Dr P. Alwyn Smith, 18 January 1965.

53 NA/ ED50/ 994: Draft BPS report 1966.

54 Neil O’Connor, 'Tizard, Jack (1919-1979)' Oxford Dictionary of National Biography. http://dx.doi.org/10.1093/ref:odnb/31764 Accessed 25th October 2016.

55 NA/ED50/969: Special Services: General Files, Society for Autistic Children 1964-1968, 'A memorandum to the Ministers of Health and Education on the diagnosis, education and treatment of autistic children' from the SAC, October 1963, p. 3.

56 NA/ED50/969: 'A memorandum to the Ministers of Health and Education on the diagnosis, education and treatment of autistic children' from the SAC, October 1963, p. 3. 
57 NA/ED50/969: 'A memorandum to the Ministers of Health and Education on the diagnosis, education and treatment of autistic children' from the SAC, October 1963, p. 4.

58 NA/ED50/969: 'Costs of running a day school for five autistic children'.

59 NA/ED50/969: SAC Memorandum on the Training of Teachers.

60 Mittler. 'Obituary: Stanley Segal' The Independent Saturday, 9th July (1994).

61 NA/ED50/969: SAC Memorandum on the Training of Teachers.

62 E.g. Ferster and DeMyer, 'The development of performances in autistic children'.

63 Isaacs et al., 'Application of operant conditioning to reinstate verbal behavior in mute psychotics'; Hayes, The Ape in Our House; Rheingold et al., 'Social conditioning of vocalisations in the infant'.

64 MHCP/A: 640995: Report, 14/12/65.

65 Lovaas, 'A program for the establishment of speech in psychotic children', p. 143.

66 Lovaas et al., 'Acquisition of imitative speech by schizophrenic children'; Lovaas et al., 'Building social behaviour in autistic children by use of electric shock'.

67 Bender et al., 'Treatment of autistic schizophrenic children with LSD-25 and UML-491'; Bender et al., 'The treatment of childhood schizophrenia with LSD and UML'.

68 Bender et al., 'Treatment of autistic schizophrenic children with LSD-25 and UML-491', 170; Abramson, 'The use of LSD (d-lysergic acid diethylamide) in the therapy of children'; Freedman et al., 'Autistic schizophrenic children'; Simmons et al., 'Modification of autistic behavior with LSD-25'.

69 NA/ED50/969: 'A Memorandum to the Ministers of Health and Education on the Diagnosis, Education and Treatment of Autistic Children' from the SAC, October 1963, p. 5.

70 NA/ED50/969: 'A Memorandum to the Ministers of Health and Education on the Diagnosis, Education and Treatment of Autistic Children' from the SAC, October 1963, p. 6.

71 Hansard, HC Deb 22 March 1963 vol 674 cc 912-922. William Compton Carr Autistic Children (Education and Training).

72 NA/ED50/969: Special Education Sub-committee Report, 28 January 1963, p. 1.

73 Hansard, Christopher Chataway: 'Autistic Children (Education and Training)', HC 22 March 1963; Report by the Ministry's Chief Medical Officer on the Health of the Schoolchild for 1960 and 1961. 
74 Hansard, Christopher Chataway, 'Autistic Children (Education and Training)', HC 22 March 1963.

75 NA/ED50/969: 'Meeting to discuss the provision for autistic children with representatives from the Society for Autistic Children, 23rd July, 1964'.

76 The findings were reported in Wilson, Administrative and Social Aspects.

77 Hayward, 'Medicine and the mind'.

78 Porter, The Rise of Statistical Thinking, 1820-1900; Hacking, The Taming of Chance.

79 McDougall, An Introduction to Social Psychology. On Wundt, see Hearnshaw, The Shaping of Modern Psychology, pp. 136-137; Shorter, A History of Psychiatry, pp. 229-238; M. Jones, Social Psychiatry; Bell and Spiegel, 'Social psychiatry', 337-338; Lunbeck, The Psychiatric Persuasion.

80 Tizard, 'Community services for the mentally subnormal'.

81 Tizard, 'Community services for the mentally subnormal'. Note, this study was conducted before the administrative integration of Middlesex into the Borough of London.

82 K. Jones, A History of the Mental Health Services, p. 339.

83 Rutter, 'The emergence of developmental psychopathology'.

84 Rutter, 'The emergence of developmental psychopathology'.

85 Institute of Psychiatry, Annual Report, 1964-1965.

86 Rutter, 'Classification and categorisation in child psychiatry', 71-73; Shaffer, 'Classification and categorisation revisited', pp. 108-110.

$87 \mathrm{MHCP} / \mathrm{A}$ : Item sheets.

88 Report of the Committee on Maladjusted Children (The Underwood Report), 1955.

89 MHCP/A: Rutter Files: Autism Research: MRC Epidemiology of Mental Disorders Committee: Sub-Committee on InPatient Accommodation for Mentally Ill and Seriously Maladjusted Children and Adolescents, c.1964, p. 5.

90 Hayward, 'Sadness in Camberwell'.

91 MHCP/A: Rutter Files: Autism Research: MRC Epidemiology of Mental Disorders Committee: Sub-Committee on InPatient Accommodation for Mentally Ill and Seriously Maladjusted Children and Adolescents, c.1964, p. 5.

92 Rutter, 'Schooling and the "autistic" child'.

93 Interview with Uta Frith, conducted by Bonnie Evans, 17 December 2014.

94 Creak, 'Schizophrenic syndrome in childhood', 889-890. 
95 J. K. Wing, 'Social treatments of mental illness', p. 27.

96 Lotter, 'Epidemiology of autistic conditions in young children'.

97 Lotter, 'Epidemiology of autistic conditions in young children', 125.

98 NA/ED50/994: Branch meeting with HM inspectors, 30 March 1966.

99 NA/ED50/969: Newsletter, SAC, March 1965.

100 NA/ED50/994: Branch meeting with HM inspectors, 30 March 1966.

101 NA/ED50/969: Minute Sheet concerning SAC, 1968.

102 Wooldridge, Measuring the Mind; Sutherland and Sharp, Ability, Merit and Measurement.

103 Hermelin, Concept Learning and Verbalisation in Imbeciles.

104 Holovinskyi, Psychology in Ukraine.

105 Goldfarb, 'Receptor preferences in schizophrenic children'.

106 Spradlin, 'Review of Speech and Thought in Severe Subnormality', 110.

107 O'Connor and Hermelin, Speech and Thought in Severe Subnormality.

108 Royal Society Archives (RSA) Uta Frith, personal archive (Box 1): 'Developments in British psychophysiology from the 1950s', by Peter Venables.

109 Lykken and Venables, 'Direct measurement of skin conductance'; Venables, 'Psychophysiology of abnormal behaviour'.

110 Hermelin and O'Connor, 'The response and self-generated behaviour of severely disturbed children'.

111 Hermelin and O'Connor, 'The response and self-generated behaviour of severely disturbed children'.

112 Hermelin and O'Connor, 'Effects of sensory input and sensory dominance'.

113 Hermelin and O'Connor, 'The selective visual attention of psychotic children'.

114 O'Connor, 'Visual input and social response in autistic children'.

115 Hermelin and O'Connor, 'Remembering of words by psychotic and subnormal children'.

116 Hermelin and O'Connor, Psychological Experiments with Autistic Children; Hermelin, 'Coding and immediate recall in autistic children', 564.

117 Vicedo, The Nature and Nurture of Love; Blum, Love at Goon Park.

118 Hermelin and O'Connor, 'Measures of distance and motility', 33.

119 Hermelin and O'Connor, 'Measures of distance and motility', 29, 33.

120 J. K. Wing, 'Diagnosis, epidemiology, aetiology', p. 6.

121 J. K. Wing, 'Diagnosis, epidemiology, aetiology', p. 7.

122 J. K. Wing, 'Diagnosis, epidemiology, aetiology', p. 11.

123 J. K. Wing, 'Diagnosis, epidemiology, aetiology'. 
124 Mittler, 'Psychological assessment', p. 147.

125 J. K. Wing, 'Diagnosis, epidemiology, aetiology'.

126 Hermelin and O'Connor, Psychological Experiments with Autistic Children.

127 Pick et al., 'Perceptual integration in children'.

128 Smith and Montessori, The Montessori System of Education.

129 Chapman, Constructive Evolution, p. 77; Piaget, La naissance de l'intelligence chez l'enfant.

130 Renshaw, 'The errors of cutaneous localization'; Pick et al., 'Perceptual integration in children'.

131 Berlucchi and Buchtel, 'Neuronal plasticity'.

132 Pick et al., 'Perceptual integration in children'.

133 Held, 'Plasticity in sensory-motor systems'.

134 NA/FD9/901: MRC Developmental Psychology Unit: Physiological Study with Autistic Children.

135 NA/FD9/901: MRC Developmental Psychology Unit: Physiological Study with Autistic Children.

136 Uta Frith Archive: Uta Frith, Notes for a talk at St Lawrence's Hospital, June 1968, p. 2.

137 Frith and Hermelin, 'The role of visual and motor cues', 153.

138 Frith and Hermelin, 'The role of visual and motor cues', 163.

139 Hermelin and Frith, 'Psychological studies of childhood autism', 115.

140 Hermelin and Frith, 'Psychological studies of childhood autism', 115.

141 Frith, 'Cognitive mechanisms in autism.

142 Martin, 'Sensory disorder in the autistic child', p. 295.

143 Ornitz, 'Childhood autism', p. 66.

144 L. Wing, 'Perceptual and language development in autistic children', pp. 173-195.

145 L. Wing, 'The handicaps of autistic children', 521.

146 MHCP/A: 644128: Report 20/5/65.

147 Institute of Psychiatry, Annual Report, 1964-1965, p. 14.

148 Kirman, 'Mentally handicapped persons', 688-689.

149 Kirman and Pare, 'Amine-oxidase inhibitors as possible treatment for phenylketonuria'.

150 Kirman, Mental Retardation; Kirman, Mental Handicap; Kirman, The Mentally Handicapped Child; Kirman, Science and Psychiatry.

151 Kirman, 'Autistic children', 727.

152 Wellcome Trust Archive PP/DWW/A/A/106: Winnicott paper to the Society for Autistic Children 1966. 
153 Tustin, Autism and Childhood Psychosis, p. 56.

154 Tustin, Autism and Childhood Psychosis, p. 74.

155 Tustin, Autism and Childhood Psychosis, pp. 29, 78.

$156 \mathrm{NA} / \mathrm{BD} 18 / 1438$.

157 NA/BD18/1438: Letter or note ref: PAS/PD From Dr Alwyn Smith (Senior Administrative MO) to Dr M. L. Cattell (Assistant senior admin MO), 26 February 1965.

$158 \mathrm{MHCP} / \mathrm{A}$ : Rutter's files: 'Working paper on the place of child psychiatry in post-graduate training in general psychiatry', c.1968.

159 Rutter et al., 'A five to fifteen year follow up study of infantile psychosis', 1190.

160 Kolvin, 'Psychoses in childhood', p. 22.

161 Kolvin, 'Psychoses in childhood'.

162 Egdell and Kolvin, 'Childhood hallucinations', 279.

163 Rapoport et al., 'Autism spectrum disorders and childhood-onset schizophrenia'.

164 Rutter, 'Childhood schizophrenia reconsidered', 327; emphasis added.

165 Rutter, 'Childhood schizophrenia reconsidered', 327; Rutter, 'Diagnosis and Definition', 139.

166 Rutter, 'Childhood schizophrenia reconsidered'.

167 Kihlstrom, 'The cognitive unconscious'. 


\section{5 \\ How do you measure a social impairment?}

Disrupting the welfare state's 'bonds of love'

If the Children Act 1948 and the publication in 1955 of the Underwood Report of the Committee on Maladjusted Children were significant moments in the formation of government policy towards children based on the Tavistock Model of Human Relationships, then the Mental Health Act 1959, the 1970 Local Authority Social Service Act, and the Education (Handicapped Children) Act 1970 were the key pieces of legislation that would begin to topple the Tavistock hegemony. These Acts helped to build new models for understanding children's rights to relationships and new models of social welfare that challenged the ideology of organising child welfare services with the aim of preventing child 'maladjustment'. New models of child development built around the new autism concept would increasingly be used to present alternatives to this social model and to develop a new model of child development and the formation of relationships in children that supported new government policies aimed at correcting individual impairments rather than imposing an idealistic model of family life that would prevent the frustration of instincts and the resulting 'maladjustment' of children.

The closure of deficiency institutions and asylums following the Mental Health Act 1959 was putting increasing pressure on the government to develop welfare and social work provisions that would enable the care of these individuals in new residences other than in large-scale institutions. In the mid-1960s, the need for robust structures to support social work services was highlighted after various committees of enquiry had put the needs of unique social groups under the spotlight, in particular the 'mentally handicapped'. These committees drew attention to 
the fact that social services within a welfare state required advocates and mediators who would work in the interests of their patrons, rather than imposing a top-down system of welfare. In 1965, the well-known social researcher, Richard Titmuss, pointed out that many people with mental health problems or other isolating conditions would not be able to rely on a 'family department' to cater to their problems, and argued that social services should be organised around the facilities to be offered, rather than around fragmented categories of those in need. ${ }^{1}$ In the same year, the Seebohm Committee was established to review the organisation of social services in order to ascertain what changes were needed to ensure an effective family service now that large-scale institutional care no longer served a purpose in maintaining social stability. ${ }^{2}$

When the Seebohm Committee reported on Local Authority and Allied Services in 1968, they recommended that local authority social services departments be established and that appointed Directors of Social Services should manage these departments. Within these plans, it was argued that children with mental health problems should be managed via these departments rather than health departments. ${ }^{3}$ This new managerial framework would replace specialist services, such as psychiatric social work, and create a new overarching general framework. In Scotland, comprehensive changes were already being implemented via the Social Work (Scotland) Act 1968. On 29 November 1969, the Association of Psychiatric Social Workers and the Association of Mental Welfare Officers were both officially terminated. The Seebohm Committee had deliberated at length on the question of whether or not mental health services should become the responsibility of health departments or whether they should be integrated into the new social services departments. In the end, they opted for the latter, arguing that failure to acknowledge mental health as a social problem 'would mean further segregation of the mentally disordered when in fact the community is becoming ready for their integration.' The Conservative government implemented the Local Authority Social Service Act 1970 soon after they came to power under Edward Heath, following Seebohm's proposals. Social service departments were established in all local authorities in Britain and the Central Council for Education and Training in Social Work (CCETSW) was established, launching the generic Certificate of Qualification in Social Work in 1972. Seebohm had proposed the 
creation of local social service departments with an optimism about the way these would work to 'enable the greatest number of individuals to act reciprocally'. The belief was that these would provide a 'community based and family oriented service' that intervened early at a local level. He had argued that field-level social workers should be skilled in dealing with a range of needs, rather than in any specialist area. The reforms forged a sense of 'society' that social workers were trained to alter and manipulate at a local level. Social work agencies thereafter took over much decision-making and service organisation for children who would have previously been dealt with by health authorities. This moved the study and diagnosis of children's psychological states into a much wider nexus of application.

One area in which social workers cam to directly impact children's lives was via the 'care order'. After 1969, there were only two ways in which a child could be committed into care of the state. Either they could be received into care under Section 1 of the Children Act 1948, or they could be taken into care under the Children and Young Persons Act 1969, a central piece of legislation in relation to juvenile justice that aimed to shift responsibility for young offenders from the police, magistrates and prisons onto local authorities, social workers and the Department of Health. ${ }^{5}$ Unless criminality was involved, the care order became the central bureaucratic tool employed to take children out of the care of their parents. ${ }^{6}$ Local authority social workers were the typical agency to issue care proceedings, in which they had to prove that the 'child's proper development is being avoidably prevented or neglected or his health is being avoidably neglected or he is being ill treated', or that he was exposed to 'moral danger', 'beyond the control of his parents', guilty of an offence or not receiving education suitable to his 'age, ability and aptitude'. This increased the power of social workers and educational authorities in the classification and psychological assessment of all children. More importantly, it shifted the nexus of power for the committal of children fully away from the assessment of their intelligence or social inefficiency and towards a more detailed assessment of their psychological and physical development. This placed a large amount of power in the hands of social workers, power that would come to be increasingly challenged over the following decades. 
It is not a coincidence that it was in this climate of radical change in the organisation of social services that autism was first officially recognised in British law. It was the Chronically Sick and Disabled Persons Act 1970 that first enshrined the category of autism in law by listing it as a disability that assured special education, along with 'other forms of early childhood psychosis.' ${ }^{8}$ This was a direct response to the evidence submitted by John and Lorna Wing on behalf of SAC and a clear indication that the government was beginning to rethink the education and long-term social integration of previously excluded groups. The Act guaranteed that professional organisations paid attention to children categorised with autism and psychosis and ensured that their families were informed about their rights to education, child welfare provisions and other social work services. It also entitled them to forms of financial assistance for people registered with disabilities. The National Insurance Act 1970 saw the introduction of an attendance allowance to be paid when a severely mentally or physically ill person was being cared for within the home. ${ }^{9}$ The National Insurance Act 1971 and the Social Security Act 1975 introduced invalidity benefits and the noncontributory invalidity pension respectively. ${ }^{10}$ In 1976 , the Department of Health and Social Security (DHSS) also introduced mobility allowances. ${ }^{11}$ Individuals with autism could potentially claim all of these benefits if their carers could demonstrate that they were sufficiently impaired to require them. Such benefits provided additional support for the care of these children whose full-time institutional care was no longer supported through the hospital system.

Psychological research by Tizard, O'Connor, Rutter and other new autism psychologists was demonstrating the specific problems with sense perception and conceptualisation that autistic and 'subnormal' children were thought to suffer from, thereby increasing the possibility that teaching techniques could be developed to compensate for these impairments. This encouraged not only SAC, but also other charitable groups to campaign for the government to rethink their policy on keeping 'subnormal' children in hospitals rather than schools. This put pressure on the government to rethink the education of all children, no matter what their problems or impairments, as it was becoming increasingly difficult to argue that certain subsections of the population were completely 'ineducable' and needed to be retained in hospital for the sake of wider social needs. One month 
after the Chronically Sick and Disabled Persons Act was passed, Lawrence Pavitt, MP for Willesden West, tabled a motion in the House of Commons for changes to the Education Act 1944, requesting that 'autistic' children be included in the eleven categories previously listed as requiring special education. Drawing attention to new diagnostic testing methods, he pointed out that, although the issue of autism was 'comparatively small, in proportion' to all mental handicap, it was 'indicative of a wider problem relating to new and sophisticated diagnostic techniques. ${ }^{12}$ Highlighting the work of the new autism psychologists, he argued that the study and treatment of autism was the first step towards the study and treatment of all forms of 'mental handicap', and that the government needed to take a stronger stance on the education of autistic children, as well as their integration into the wider community once they turned sixteen. ${ }^{13}$

These sentiments slotted neatly into the reshuffles that followed Seebohm's proposals and that would transform the social welfare system to make it more integrated and to enable growing sections of society to access it. In 1965, the first independent school solely for 'autistic' children was founded by the Society for Autistic Children, shortly followed by two more schools. By the late 1960s, there were also many schools specifically for children with 'severe language disorders. ${ }^{14}$ In 1968, the Association for All Speech Impaired Children (AFASIC) was established in London, a reflection of these changes. ${ }^{15}$ Pressure was also coming from groups founded to represent all 'ineducable' children. The growth in specialist schools for 'autistic' and 'language impaired' children put even more pressure on the government to revise their position concerning the 'ineducability' of 'subnormal' children. The creation of 'social services' had a huge impact on many children's lives July 1970, the government announced that it intended to transfer responsibility for the education of all 'severely subnormal' children from the Department of Health to the Department of Education and Science (DES). At the same time, special educational services would have to expand to manage these new groups. This new administrative plan was written into the Education (Handicapped Children) Bill, which received Royal Assent in July 1970, just one month after the Conservative government came to power.

The transfer of functions from the Ministry of Health to the DES directly affected 32,837 children. Of these, 7,711 were registered as 
subnormal and were resident in hospital, whilst the other 25,126 were attending Junior Training Centres or Special Care Units. An additional 1,340 children were attending independent establishments such as the Autistic Society schools. ${ }^{16}$ Because the Education Act 1944 compelled local education authorities (LEAs) to ascertain which 'educable' children required specialist education, the DES had collected figures on the exact numbers of children ascertained under each category defined in the Act. Between 1960 and 1970, there had been a steady rise in the number of children defined as both 'maladjusted' and 'educationally subnormal' attending specialist schools as a direct result of the Mental Health Act 1959. In 1960, 1,742 children were classified as 'maladjusted' and 32,815 were classed as 'educationally subnormal'. In 1970, this figure had risen to 6,293 and 51,768 respectively. ${ }^{17}$ Over the same period, the numbers of adults and children in hospital for 'subnormality' had reduced by $33,875 .{ }^{18}$ However, after 1970 , many of these children would begin to be reclassified.

After 1970, the five categories of children whose numbers rose significantly were the 'maladjusted', the 'physically handicapped', 'epileptics', those with a 'speech defect' and the 'educationally subnormal'. Between 1970 and 1975, the number of 'maladjusted' children registered at the DES increased from 6,293 to 13,527, the number of physically handicapped pupils increased from 8,830 to a total of 12,224 , the number of epileptic children rose from 1,015 to 2,205 and the number of children with a 'speech defect' increased almost tenfold from 828 to 6,893 . The number of 'educationally subnormal' children shot up from 51,768 to 72,636 , of whom 19,892 were assigned the new category of 'severely educationally subnormal'. In addition, 542 children were registered under the new category 'autistic.' ${ }^{19}$ In total, this showed an increase of 39,293 newly categorised children, a number comparable with the 34,177 who were transferred from the health authority to the DES and then integrated into the education system through various classificatory routes after 1970 . The small discrepancy in figures can be accounted for by population increases, the growth of specialist education services generally and the elimination of the category 'delicate', which had previously classified 1,729 children. ${ }^{20}$ It is clear from these figures that when 'subnormal' or 'defective' children were integrated into the general education system, they entered along many different routes and in doing so assumed many different classifications, such as 
'speech disorder', 'maladjusted' and 'autistic'. There were many increases in numbers of children with particular diagnoses. However, at this time, the 'autistic' label was still only applied to a minority of children.

After 1970, there was also an increase in the number of children with 'psychosis' and 'autism' diagnoses attending special schools and special classes that had not traditionally been created for 'autistic' children. The reason for this was the final closure of schools for all children with subnormality that led to the need for additional specialist schooling facilities. Many children diagnosed with 'autism', 'schizophrenia' and 'psychosis' diagnoses were sent to language units, such as that attached to the Forest Oak special school in Solihull, ${ }^{21}$ or the Charles Burns Unit for children with language and communication problems in Warwickshire. ${ }^{22}$ Other children were sent to mixed special schools such as Court Meadow special school in Sussex, ${ }^{23}$ the Dysart Special School in Surrey $^{24}$ or the J. F. Kennedy Special School in Newham. ${ }^{25}$ Some children were sent to Steiner schools, as in the 1950s, and many of these reclassified themselves as schools for children with 'severe learning difficulties', such as Sunfield School in Worcestershire. ${ }^{26}$ Each of these schools had its own approach to the education of children and each claimed to specialise in a particular type of child. Following their lead, some special schools, such as Doucecroft School in Essex, were classified as schools specifically 'for autistic children. ${ }^{27}$ In the late 1960 s, Rutter and Lawrence Bartak had conducted studies of the best kind of educational setting for children diagnosed with autism using funding from the DES and the Gulbenkian foundation. ${ }^{28}$ They drew attention to the fact that although psychoanalysts and behaviourists presented radically different theories, educational approaches were often quite similar in practice. Most importantly, they all encouraged social engagement. They argued that the most effective approach was when the 'perceptual, motor and cognitive handicaps of the children were seen as primary and around which education was to proceed. ${ }^{29}$ Organising structured activities for an autistic child was thus the best way to increase his behavioural repertoire' and to facilitate more successful adaption to his environment. As Rutter described it, 'as social demands were increased, so was the likelihood that the child would make some kind of social response; as the task-related features increased, so did the rates of productive behaviour. ${ }^{30}$ Because the definition of 'autism' had been given support via epidemiological studies, the justification for treatment 
approaches based on a new model of 'socialisation' and training followed, but these recommendations did not tend to be particularly specific, focusing on general social engagement. This is perhaps understandable given that more children were being integrated into society.

Although the category of autism was used to classify only a few children in 1970, its appeal would gradually expand as children's psychiatric needs were increasingly recognised in an educational setting. In the mid-1970s, SAC urged parents to get early diagnoses for their children if they suspected they had autism. This was encouraged for children 'as a way of triggering a whole range of activities on their behalf from advice to parents in the management of their children to directing them towards appropriate specialised care and education. ${ }^{31}$ A diagnosis of 'autism' ensured that a child received greater attention and also had the weight of the Society for Autistic Children behind it. By the 1970s, it was therefore becoming a somewhat desirable label, and definitely preferable to 'subnormal.'.

It is within this new social and legal climate that psychiatric epidemiology would thrive as a social scientific methodology that could be used by government departments in order to plan the management of social service departments. Bowlby and Winnicott's work on the need for family security and mother love was gradually pushed aside to make room for new models of psychological development that did not overlook the needs of 'subnormal' populations and which recognised that social services had to cater to populations with very distinct individual needs. The work of Lotter, Tizard, Rutter and many of the new generation of psychiatric epidemiologists and statistical researchers was important in guiding discussions regarding the future of hospital and social services because it claimed to provide an accurate measure for all social needs. As Albert Kushlik put it, 'the epidemiological approach lends itself to the development of a service which can both anticipate and deal with problems which are known to be present a long time before they come to the notice of existing services. ${ }^{33}$

The rest of this chapter explores how new techniques were developed to measure 'social impairment' in children in light of the Seebohm reforms of 1968 and other legal changes of the early 1970s. These led to major changes in the organisation of educational and social services. For example, the Local Authority Social Service Act 1970 led to the establishment of social service departments in each locality. Whereas 
previously, different welfare departments had been managed separately, the 1970 Act led to the foundation of 'social services', designed to facilitate social functioning for all. This helped to consolidate the idea that autism was a measurable and quantifiable entity, and that it was a kind of 'social impairment'. Attempts to investigate and understand autism then came from diverse fields of research. The social sciences, in particular, offered innovative kinds of analysis and conceptualisation of autism, helping to enliven the concept and form it into its current incarnation.

The development of educational psychology and the Summerfield Report

In order to cope with the huge impact that the integration of mental defectives was having on the schools system, and to plan a psychological strategy, in 1968, at the request of the Secretary of State for Education and Science, the president of the British Psychological Society (BPS), Arthur Summerfield, published a report on the number of educational psychologists that should be employed in British schools. The Summerfield Committee argued that education authorities were the most appropriate bodies to appoint psychologists to work with children and that psychological work should be organised in the field of education 'on a much larger scale than at present', as this 'would be conducive to a high standard of service, to efficiency, and to economy of manpower. ${ }^{34}$ The report recommended that one educational psychologist per 10,000 schoolchildren should be employed and that new training should be implemented. ${ }^{35}$ A BPS committee was quickly established to draft a syllabus for a BPS Diploma in Educational and Child Psychology and consultations began with the Division of Educational and Child Psychology and the Association of Education Psychologists. ${ }^{36} \mathrm{It}$ was agreed that the syllabus would teach candidates 'a critical knowledge of biological, neurological, sociological factors affecting development', including 'the significance of early learning' and 'critical and sensitive periods of development'. As well as theories on intelligence, students would study theories of cognitive development, including the work of Piaget, and 'the major theories of personality development including psychoanalysis, ethology and learning theory’. With regard 
to experimental and statistical psychology, candidates would examine the 'assessment of sensory, motor and perceptual handicaps' as well as 'survey methods and epidemiological studies'. Candidates also had to develop a good knowledge of 'exceptional children', including 'handicapped children'. In addition to the eleven labels of 'handicap' drawn up in 1945, the BPS now included 'children with specific learning disabilities' and 'psychotic children., ${ }^{37}$

It was via the development of training courses for educational psychologists following the Summerfield Report that the study of 'psychotic' children became part of everyday practice. The BPS committee argued that trainee developmental and educational psychologists should make direct contact with 'a wide range of children and adolescents', including the 'psychotic' and 'those with intellectual, sensory and physical handicaps'. It was no longer possible for psychological professionals to sideline children who demonstrated such differences. ${ }^{38}$ Although autism and psychosis did not yet occupy a central platform in theories of developmental psychology, the subjects were firmly placed on the curriculum for all new trainees in educational psychology.

In 1971, the BPS held a meeting on the implications of the Summerfield Report in which it was noted that the closure of subnormality hospitals had meant that many new responsibilities were falling on the shoulders of educational psychologists that had not been envisaged in that report. In particular, educational psychologists were being asked to oversee the transfer of responsibility for children previously designated 'severely subnormal' and 'mentally defective' from local health authorities to LEAs. They were also being asked by local authorities to assume responsibility for children under care orders and those who had previously been at approved schools, and also for reorganising children's departments into social service departments with a wider responsibility for child welfare. Finally, they were being asked to establish local authority and other assessment units for 'handicapped' children. The committee conceded that the Summerfield recommendations of working towards one educational psychologist per 10,000 schoolchildren had not gone far enough and that more money was desperately needed to enable the training of many more candidates. All of this information was to be conveyed to the Secretary of State for Education. ${ }^{39}$ These changes stimulated the movement sparked by the new 
autism psychologists to assess and attend to children's psychological problems from a new perspective.

In March 1975, the DES issued circular no. 2/75, 'The Discovery of Children Requiring Special Education and the Assessment of Their Needs.' This circular removed power from members of the medical profession to determine to which schools children who required special education should be sent. The power to decide on a placement was instead given directly to educational psychologists, who were thereafter required to relay all information to the educational authorities. This placed a major demand on their time and limited the services that they could offer to children. These became increasingly concerned with assessment and placement rather than treatment. ${ }^{40}$ This transition also led to the establishment of new centres, such as the Educational Guidance Centre in Brixton, London, directed by R. A. Porteous, which provided 'a diagnostic service and informal education for children unable to maintain attendance at an ordinary school because of acute behavioural difficulties. ${ }^{41}$ These centres provided stop-gaps for children between educational placements and created a new landscape of children with no fixed schooling placement. For example, at one child guidance clinic in Brixton in the mid-1970s, staff began to observe a growing number of referrals of schoolchildren who had been excluded from school and were waiting to be given new placements. ${ }^{42}$ Increasing delays were also noted with regard to the placement of children as a consequence of the administrative changes following circular $2 / 75$. In 1979, staff at the Brixton clinic noticed 'a continuing severe pressure on the Unit's work [of] referrals of children whose educational placement has already completely broken down, whether in ordinary or special schools. ${ }^{\prime 3}$ These referrals could not be managed at the rate at which they were being referred, and families were reported to experience many frustrations due to such delays. In large part, this was due to the fact that children could not be suitably classified and placed with the support of the multiple agencies that were required to co-operate in such classificatory procedures.

After the DES had issued circular 2/75 in 1975, educational psychologists started to play a significant role in ascertaining autistic children as well as 'subnormal' children and arranging their placements. The number of educational psychologists increased steadily from the late 1960s following the publication of the Summerfield Report 
in 1968. In 1967, there were 375 full-time educational psychologists employed by local authorities, but by 1972 this number had risen to 638. ${ }^{44}$ In 1979 the figure had risen further to 935 and by 1983 it was over $1,000 .{ }^{45}$ In conjunction with teachers and parents, this new professional group began to appropriate the language of specific learning problems and autism that spread throughout the primary and secondary educational system.

In relation to this shift, the early 1970s also saw a major push to increase numbers of speech therapists employed by health authorities following the publication in 1972 of the Report of the Committee of Enquiry into Speech Therapy Services (Quirk Report). Following the Education (Handicapped Children) Act 1970, more speech therapy services for children were required because increasing numbers of children were entering the education system. In 1972, the Quirk committee reported that in England, Wales and Scotland, well over 300,000 individuals were in need of speech therapy services and that 270,000 of these were children. ${ }^{46}$ They urged schools of speech therapy to attain a target intake of 350 students per annum by 1982 at the latest. This target was reached in 1977. In 1972, 820 speech therapists were employed by health authorities across the UK, each taking on around 100 patients, making a total of 82,000 patients. In 1978 , this number had risen to 1,376 speech therapists serving a population of around $137,600 .{ }^{47}$ Ten years later, it would increase to 3,000 therapists serving 300,000 patients. ${ }^{48}$ This was a massive expansion of a service that had previously been offered to an exclusive few.

With growing numbers of children being assessed via social and educational services, and with the category of 'autism' listed in the Chronically Sick and Disabled Persons Act 1970, the diagnosis of autism became increasingly popular to designate a child who had specific needs that could not be summarised using any other diagnostic term. The diagnosis of 'maladjusted' did not help educational psychologists to generate a detailed understanding of a child's educational needs, whereas 'autism', in its new incarnation as a kind of sensory impairment, was useful in enabling educational psychologists and speech therapists to put together teaching plans and advice in the context of the education system. It was via this entry into the education system that the term autism would begin to appropriate new meanings associated with assorted types of 'impairments.' This new 'autism' would become 
increasingly important in the description of children's behaviour in multiple contexts as the term came to imitated and replicated across all professional groups working with children, in particular within the education system. The term would also become increasingly dissociated from professionals working in family services, as 'social work' became a generic category and more educational professionals began to appropriate the term and adapt its meaning.

\section{Epidemiology, schooling and 'social deprivation'}

The closure of mental deficiency institutions in the wake of the 1959 Mental Health Act, the Seebohm reforms and the slow integration of all children into the education system were transforming ideas about social work and what it meant to educate and integrate all members of a population into society. In 1970, Rutter, Tizard and Whitmore's study on the Isle of Wight was published, following an expansion of the remit to generate 'a comprehensive picture of "handicap" in a total population of children who lived in a defined geographical area'. The study had also sought to assess the need for social service provision for that population. Rutter et al. had defined 'handicaps' in three groups, namely: 'intellectual or educational retardation, emotional or behavioural problems and chronic or recurrent physical disorders (including neurological conditions). ${ }^{49}$ The study was published in book form with a simple title that bore witness to its grand social objectives: Education, Health and Behaviour. Rutter et al. considered their results to be translatable to populations across Britain, provided that other social factors were taken into account.

Using a combination of intelligence tests, medical tests, teacher questionnaires and parent and child interviews, they argued that from a total population of 2,199 children aged between nine and eleven, 354 suffered from 'some form of handicap' that caused a 'considerable interference with their ability to lead a normal life.' They then inferred from this finding that at least one in every six children within an average population would require some form of special educational provision. They argued that 3.4 children per 1,000 had severe intellectual retardation', but that 8 per cent of all children had 'intellectual and educational difficulties. ${ }^{50}$ Rates of children with physical handicap were reported 
to be 5.7 per cent. ${ }^{51}$ The proportion of children with 'psychiatric disorder' involving 'suffering in the shape of anxiety or unhappiness' or 'conflict between the society and the child, bringing trouble to both' was rated at 6.8 per cent. ${ }^{52}$ Although there were crossovers between some of these groups, the figures gave an estimation of the extent of social services that were required to cater for each unique problem. Rutter et al. also found that, whichever investigative method they used from teacher questionnaires to psychiatric interviews - 'emotional and behavioural disorders were considerably commoner among children with intellectual retardation or with specific reading retardation than among control children., ${ }^{53}$ Further studies confirmed relationships between children with specific and non-specific intellectual problems and what was regarded as 'abnormal' behaviour. ${ }^{54}$ Rutter later claimed that there was a relationship between 'low IQ' and 'psychiatric disabilities and a whole range of deviant behaviours. ${ }^{55}$ What is important to recognise here is that, in light of the major social reforms, classificatory systems used to label and categorise children were in flux, to such an extent that when working on social planning, psychologists disregarded clear distinctions and divisions between the mentally deficient and the mentally ill - distinctions that had focused researchers throughout the function of mental deficiency law and had structured the work of many human relations psychologists and child guidance workers. Psychiatric epidemiologists embraced the freedom that social reconstruction was engendering with an open mind about the new boundaries that would be set about the form and limitations of the developing mind.

In 1973, Margaret Thatcher, then Minister of Education, proposed a committee 'to review educational provision in England, Scotland and Wales for children and young people handicapped by disabilities of body or mind. ${ }^{56}$ Rutter had previously met with Thatcher and had discussed some of the findings of his research with her. ${ }^{57}$ Because the Isle of Wight study was so comprehensive and claimed to have measured the total need for psychiatric services within a geographic area, the resulting Warnock Committee based many of their plans for special educational provision directly on that report. In their 1978 Report, Mary Warnock and her colleagues referred to the Isle of Wight study as 'the most detailed study of the incidence of intellectual and educational retardation, psychiatric disorder and physical handicap' ever conducted..$^{58}$ 
The study sparked a number of later comparative surveys generating further statistics that could be compared and contrasted with this model population. Studies in London found higher rates of psychiatric disorder and reading retardation, pointing to the possible influence of urban living. ${ }^{59}$ These social surveys formed the basis for a new style of social psychiatry that aimed to study development across populations and to explain each child's individual psychiatric problem as a sum of data based on its intellectual and behavioural outcome. It was through this style of psychiatry that the 'social' was distanced from the child's creative development and reformulated as a collection of forces that impacted upon the child at different strengths and variations. Instead of examining the internal instinctive drives that impacted on the child's mental development in the model of McDougall or Burt, Rutter and the new generation of epidemiological and experimental psychologists conceptualised and measured the external social forces that were impacting upon each child's developing mind.

As John Welshman has argued, the late 1960s and 1970s witnessed a surge of interest in the social sciences on how 'social deprivation' was 'transmitted' across generations, thereby reproducing inequalities and preventing social mobility. ${ }^{60}$ Michael Rutter was a key contributor to these discussions and developed an important and inventive way in which to employ Bowlby's ideas of 'maternal deprivation' across a wider range of social circumstances. In the late 1960s, the concept of 'deprivation' was expanded within psychological sciences and disciplines to cover all forms of 'social deprivation', not just 'maternal deprivation', and this is how new epidemiological researchers such as Tizard and Rutter understood it. ${ }^{61}$ Writing in 1970, Michael Power from the Social Medicine Research Unit at the London School of Hygiene and Tropical Medicine argued that:

It is widely recognised that adverse family, school and neighbourhood circumstances impair a child's healthy development. A discussion of such deprivation must be concerned with the social inequalities that are to be found in the way that we arrange our society, with its market economy and class divisions; in particular the strong element of competitiveness and of unequal opportunity that bears heavily when certain groups of the population e.g. the poor, the chronic sick, the coloured immigrant. ${ }^{62}$ 
Power, along with those working for the MRC in the 1960s and 1970s, began to employ the concept of 'social deprivation' to describe the effects of economic, social and cultural failings on the developing minds of children. In fact, they employed the term in a similar way to Bowlby's concept of 'maternal deprivation' but included in it a range of other forms of poverty, scarcity or lack. The psychological outcomes of such deprivation were many and varied, they argued, but there was no doubt that psychological development could be thwarted or impacted by 'social deprivation. In the 1970s, this idea of 'social deprivation' differed from models of 'sensory deprivation' that were being put forward by Hermelin and O'Connor and others to explain the development of autism. However, the 1970s would witness the amalgamation of these ideas as more educational psychologists and child psychiatrists sought to understand and describe the causes of the phenomena that they were witnessing in the new population of schoolchildren. By this time, many were arguing that understanding autism was fundamental to understanding wider issues within social development and social deprivation. For example, John Wing argued that autism should be regarded as a 'paradigm for looking at the problems of social psychiatry and community care' as the 'handicaps' associated with it 'can be described in detail and methods for overcoming them or compensating for them are now beginning to be available. ${ }^{63}$

Speaking in 1970, Mary Wilson, Staff Inspector for Special Education, Inner London Education Authority (ILEA), pointed out that by 1970, the word 'deprived' was being employed in educational circles in four different ways. First, following the Curtis Committee, it was used to describe children who were 'deprived of a normal home life', this leading to 'educational backwardness' or 'emotional disturbance.' Second, to describe children in poverty who were 'deprived of good material things in life such as adequate food, good housing, [and] clothes'. Third, to describe 'cultural deprivation' leading to 'acquired intellectual handicap' and 'delay in the acquisition of language skills' because of 'insufficient variety of play materials and insufficient opportunity for sharing activities with interested adults'. Finally, it was used to describe 'emotional deprivation which is found in children who have been from an early age and for a long time deprived of normal parental care. ${ }^{64} \mathrm{Wilson}$ argued that many children including 'the brain injured, the psychotic, the delinquent, and the deprived', pointing out that most of them had 
suffered some deprivation, even though the outcome was heterogeneous. ${ }^{65}$ In other words in the 1970 s, psychologists such as Wilson began to believe that they could measure social deprivation as it impacted on individual problems in psychological development. ${ }^{66}$

Whereas Freud, Bleuler, Anthony and Cameron had shifted their attention onto the hallucinatory aspects of 'autoerotism' and 'autism' in attempting to understand the most significant stages of children's psychological development, researchers at the Social Psychiatry research unit studied 'autism' as an unknown category that had the promise to elucidate the most significant stages of socialisation and to explain the outcome of both social and sensory deprivation. Instead of focusing on individual cases, Maudsley researchers of the 1960s focused on the study of total populations of autistic individuals. Eysenck's research techniques, which had turned the study of unconscious drives into measurable behaviouristic reflexes, had enabled the study of autistic and psychotic phenomena using the model of statistical psychiatry. The impact of this on the conceptualisation of all psychological problems in childhood was significant and continued to generate effects.

\section{How British sociology met autism}

By the early 1970s, the thriving interest in autism and its causes amongst a new generation of epidemiological and experimental psychologists was coupled with a growing critique of approaches to child development based on the study of human relationships. The controversy over Bowlby's report on maternal deprivation had, in fact, become so widespread by the 1960s that the World Health Organization issued a public health paper that reassessed the debate. ${ }^{67}$ Epidemiologists and experimental psychologists had used new methodologies to challenge Bowlby's claims that mothers were the only people who could offer emotional security to children and also his belief that psychoanalysis was the only science that could explain early emotional development.

The impetus for these investigations came from a rapidly developing field of sociological research that was generating new methods to address and understand detailed aspects of family and social life. As Mike Savage has argued, British sociology came of age in 1962 when the journal New Society was founded to propagate the wisdom of the 
social sciences amongst policy-makers, educationalists and other professionals. This stimulated a new interest in the social sciences in Britain that saw their entry into the syllabi of many university departments as a critical challenge to arts and humanities education. Much British sociology of the 1960s was focused on the study of everyday life and interaction, the normal population rather than the deviant classes of the previous generation of sociological investigation. As Savage has pointed out, it represented a political movement in that it sought to present a new perspective on social interaction, a new vision of society. Post-1962, British sociology also anchored itself as a unique discipline, rather than following the earlier practice of merely gathering information with an overarching theme of society, progression and evolution. ${ }^{68}$ It enabled new theories of child development to be formulated that did not follow the quasi-evolutionary models of development and maladjustment that had been propagated by Cyril Burt and Bowlby.

By the 1960s, there were a plethora of studies that used new statistical methodologies in order to answer age-old problems concerning child development and the impact of parental and social determinants on psychological problems. Characterising this shift, Simon Yudkin, consultant paediatrician at the Whittington Hospital in London, worked with the Council of Social Welfare to persuade numerous university departments to conduct interview research with mothers who left their children in nurseries whilst they went out to work. Working Mothers and Their Children (1963) argued, against Bowlby, that working mothers could indeed produce psychologically healthy children, and that early psychological development was dependent on numerous factors. ${ }^{69}$ Yudkin's other work also drew further attention to the fact that poverty, a social determinant, was linked to poor nutrition in the mother's pregnancy and in early childhood, and that these factors were associated with perinatal mortality, growth and intellectual development. ${ }^{70}$

In the early 1960s, Rudolf Schaffer, a former colleague of Bowlby's, and Peggy Emerson had begun following a group of sixty mothers and their children in Glasgow in order to track their children's development using sociological techniques. They were interested in 'the development of social attachments in infancy' and how these were formed throughout the developmental process. They qualified Bowlby's category of 'attachment' to distinguish 'indiscriminate' and 'specific' attachments, and argued that infants did not develop 'specific' attachments 
until around four to six months and that these increased in intensity until around nine months, falling off slightly when the infant was learning to crawl and walk, before peaking again at eighteen months. Their argument, backed up with much quantitative data from numerous interviews with the mothers, was that infants developed indiscriminate' attachments before forming specific bonds, and that these indiscriminate attachments continued after specific bonds were formed. These 'pre-social' attachments were part of a learning process through which the infant began to discriminate important bonds and that this 'innate behaviour propensity' was 'in the beginning not a truly social activity' but only became so through 'contact with a particular kind of environment', meaning a stable familial bond. They also downplayed the significance of mothers as the only caregiver, arguing that many infants formed their strongest attachments with their fathers or other family members. ${ }^{71}$

These debates covered much of the ground that had been traversed in the controversial discussions between Anna Freud and Melanie Klein in the 1940s concerning the importance of the early stages of life to the development of psychological mechanisms that enabled ego development and the formation of relationships. However, instead of describing and elucidating the unconscious instinctive drives that structured social interaction, they highlighted the complexity of environmental factors that could impinge on the infant's capacity to form social bonds. For Schaffer and Emerson, describing social development was not so much about articulating the drives for human relations as it was about defining the ways that sometimes functioned and the subsequent impact of this on a child's mental stability. As they argued: 'Whom an infant chooses as his attachment object and how many objects he selects depend, we believe, primarily on the nature of the social setting in which he is reared and not on some intrinsic characteristic of the attachment function itself. ${ }^{\prime 2}$ They sought to understand attachment not as a problem of relationships but as a problem of 'social setting.'

Rutter also employed the arsenal of experimental methods and statistical techniques derived from sociological sciences to measure 'family activities and relationships', arguing that this could enable a clearer understating of how environment affected development. ${ }^{73} \mathrm{He}$ also questioned Bowlby's theories of maternal deprivation, arguing that it was not separation per se that caused psychological problems 
in children, but rather the circumstances surrounding that separation. Rutter's popular Penguin paperback, Maternal Deprivation Reassessed (1972), sought to topple Bowlby's monopoly on the topic of emotional development and the causes of psychiatric disorder in children. For example, using epidemiological evidence on children whose parents had divorced, he claimed that some children were 'invulnerable' to deprivation and that those from broken homes were more likely to be affected by the discord rather than the separation itself. He also drew from Shaffer and Emerson to argue that mothers were not always the most significant figures in the formation of children's early bonds, and that other figures also held a significant influence. ${ }^{74}$ Furthermore, he quoted Jack Tizard's wife, Barbara Tizard, who had conducted observational studies of children reared in institutions from birth to eight years and found that these children did not show any impairment in intellectual function if they received enough intellectual stimulation, hoping to prove that it was not 'maternal deprivation' that caused intellectual delays but other distinct factors. ${ }^{75}$ Steven Wolkind, of the Family Research Unit at London Hospital Medical College, studied 'affectionless psychopathy' in institutionalised children and he and Rutter conducted an epidemiological study of children who had been brought up in care, in order to understand the breadth and depth of their psychological problems. ${ }^{76}$ These were not only caused by 'maternal deprivation' but multiple kinds of social deprivation.

Throughout the 1970s until the early 1980s, Rutter then embarked on a series of other major survey studies that interrogated the social world as a producer of psychiatric disorder. Cycles of Disadvantage (1976) explored the impact of everything from wealth inequality, housing, occupational mobility, crime, racial discrimination and schooling to both psychological and social stability. Rutter argued that the deprivation that causes psychiatric disorder is not just maternal deprivation but social deprivation in all its forms. Social science could explain much more about the causes of psychological problems than any mother and baby study could on its own. Fifteen Thousand Hours (1979), the number of hours that an average child spends at school, the most important 'social institution' in industrialised societies. The book investigated the possible impact of all this time on the child's psychological stability. Changing Youth in a Changing Society (1979) used epidemiological and developmental studies to think about the nature 
of adolescent behaviour and the impact of social disadvantages such as poverty, overcrowding and lack of resources on this behaviour, thereby aiding policy advisers. Juvenile Delinquency: Trends and Perspectives (1983) used theories of psychological motivations, such as aggression, to understand delinquency across the lifespan and its relation to social inequalities. As with the Isle of Wight studies, many of these studies presented a complete picture or snapshot of children's lives and experiences and the multiple social forces that impacted that development. This picture was far more complex than a mother and baby portrait.

With specific regard to the theory of autism, it was actually two sociologists who would generate the most significant new methods for approaching autism within theories of child development in the 1970s. The work of John and Elizabeth Newson fitted neatly into the development of new sociological expertise, building a new model of how everyday normal British society functioned. They argued that when considering 'social development' in children, one should not limit oneself to development schedules, but rather think about the multiple influences that infants and children perceived when entering the social domain. In the late 1950s, the Newsons had established the Child Development Research Unit at the University of Nottingham through which they produced studies of infant care such as their classics Infant Care in an Urban Community (1964), Four Years Old in an Urban Community (1968) and Seven Years Old in the Home Environment (1976), which analysed interviews with over 700 mothers in Nottingham about their child-rearing practices and experiences with their children in the first, fourth and seventh year of life. More social surveys than psychological studies, the Newsons argued that parental attitudes had as much influence on a child's psychological development as parental behaviour did. Their studies brought the immediate social environment of the children into stark relief, discussing attitudes and behaviours from discipline, smacking and guilt to public approval, love, kissing and even watching television. Their aim was to show that child development was part of a wider cultural and social network, thus sharing much in common with Maudsley researchers such as Tizard and Rutter.

The Newsons were also interested in 'handicapped' children and their experiences, working on the day-to-day life of children with cerebral palsy in the homes. In 1969, they teamed up with the Nottingham and District Society for Autistic Children, which was establishing a 
school, a collaboration driven by their own parental needs. This enabled liaison with the local authority and the Newsons quickly established themselves as specialists in the field of autism and therefore saw most children with autism in Nottinghamshire, also receiving referrals from Leicestershire, Lincolnshire and Derbyshire. ${ }^{77}$ In the late 1970 s, in line with the growing significance of autism to understanding child development, they established a major study of the way that autistic children functioned in social contexts and they collaborated with the Department of Health in effecting policy changes.

These studies all came to similar conclusions, pointing out that everything from schooling and social change to genetic disorders and handicapping conditions had an impact on child development. To think that the only influential forces impacting psychological development were parents was thoroughly misguided and wholly outdated. There were so many factors that could influence a psychological outcome. However, there were still some conflicts to these approaches. For example, whilst Rutter was, on the one hand, dabbling in the new British sociology, he was, on the other hand, building up and clarifying classification methods in child psychiatry and affirming autism as a unique cognitive impairment. Child psychiatric diagnoses largely remained framed by the needs and categorical systems of adult psychiatry and were thus restricted in their scope and capacity to truly reconceptualise child development in relation to social change. However, this began to change in the 1970s as the 'autistic spectrum' expanded the limits of this crucial psychological term. This opened the floodgates for psychological researchers to re-orient their theories concerning social development in children.

Michael Rutter, language and autism

In 1970, the Journal of Autism and Childhood Schizophrenia was established under the editorship of Leo Kanner, and Michael Rutter was appointed as an Associate Editor representing Great Britain. The aim of the journal was to bring together researchers 'for the purpose of relieving the sufferings of psychotic children and their families'. It claimed to have no theoretical bias in approaching this task but simply the aspiration 'to promote scientifically ascertained observations and facts from every source which can widen our horizon. ${ }^{38}$ The editors stated that the 
journal was 'devoted to all psychoses and severe disorders of behaviour in childhood. ${ }^{79}$ This claim directly linked the category of psychosis to 'behaviour disorders'. The first edition of the journal in 1971 featured an article by Rutter and Lawrence Bartak on the 'Causes of Infantile Autism' that highlighted Rutter's proposition that a 'language and cognitive defect constitutes the primary handicap in autism. ${ }^{80}$ Their theory was that the autistic child has a 'central defect in the processing of any sort of coded, meaningful or temporarily-patterned stimuli' ${ }^{81}$

This proposition differed from that of Hermelin, O'Connor and Frith, which explored sensory impairments and their impact on cognitive processes. Rutter instead wanted to clarify the exact cognitive or thought processes that were associated with autism and which subsequently led to the symptoms of withdrawal. Therefore, instead of focusing on the way that sensory impairments could be tested, he focused on language as the key area where any cognitive defect would be evident. This focus on language impairment was also a function of the administrative and bureaucratic system in which the category of autism was born. Because 'language impaired' children were being integrated into the education system via the growth of speech therapy services, there was a burgeoning interest in language impairment.

At the same time, similar policy shifts in the USA meant that the growing cognitive psychology movement there was increasingly focusing on language development, further stimulated by the work of the emerging linguistic star, Noam Chomsky. Chomsky was one of a group of researchers based at the Massachusetts Institute of Technology and the universities of Stanford and Harvard who challenged a model of behaviour dependent on the stimulus-response paradigm and instead described behaviours in terms of a nesting and clustering of programmes of action that an individual organism ran through in order to reach its goals. In Britain, scientists such as W. Grey Walter, a key figure in the development of EEG studies, developed similar approaches. ${ }^{82}$ As Rhodri Hayward has argued, Grey Walter was also an advocate of using EEG recordings and computer modelling to explain desire and emotional attachments, although his views were never accepted in the mainstream. ${ }^{83}$ This 'cognitive' model drew primarily from computer technology and information processing rather than animal models of action. ${ }^{84}$ Chomsky's work aimed to use the theory of language as a model for psychology in general and he published a damning critique of Skinner's work on language as 
a form of behaviour. ${ }^{85}$ Chomsky maintained that it may eventually be possible to study the 'built-in structure of an information (hypothesisforming) system' that enabled subjects to form grammatical language, also suggesting that this system was innate. ${ }^{86}$ In his monograph, Syntactic Structures, he had also argued that syntactical relations could be used to construct a general theory of grammar. ${ }^{87}$ Chomsky's work was well known amongst child psychiatrists, developmental psychologists and speech therapists in the UK by the early 1970s; in particular it was quoted in relation to the use of behavioural techniques in the teaching of language skills to children who could not talk. ${ }^{88}$

These theories encouraged new work on language development in Britain, although they had not gained full acceptance by the new generation of epidemiological and experimental child psychologists in the 1960 s and 1970s, partly because they clashed with Piagetian models of development. Piaget's work had been highly influential on UK educational practice and training. For example, the 1967 Plowden Report for the Central Advisory Council in England stressed the importance of Piaget with regard to understanding intellectual, social and cognitive development and sensory integration in developing children. ${ }^{89}$

In October 1975, Piaget and Chomsky, together with a group of distinguished psychologists, linguists, epistemologists, neurobiologists and social scientists, held a conference to discuss the disparity between Piaget and Chomsky's respective views of language acquisition. Whereas behaviourists such as Skinner had ignored the question of language acquisition almost entirely, Piaget's theories of genetic epistemology presented a model of this process that conflicted with Chomsky's model of generative grammar. In his opening presentation, Piaget put forward his central view of cognitive development:

Knowledge does not result from a mere recording of observations without a structuring activity on the part of the subject. Nor do any a priori or innate cognitive structures exist in man; the functioning of intelligence alone is hereditary and creates structures only through an organisation of successive actions performed on objects. ${ }^{90}$

Piaget argued that Chomsky was incorrect in claiming that there was an 'innate fixed nucleus', an a priori cognitive structure for language acquisition. In his view, language was the outcome of an infant's biological and behavioural auto-regulations in its interaction with the external world. 
Because these interactions were limited by physical reality, both external and internal to the organism, each infant would necessarily develop the same systems for thinking that enabled both language acquisition and syntactical regulation. ${ }^{91}$ In other words, all logico-mathematical structures in the mind, including grammars, were formed through 'an exact and detailed adaption to reality' rather than pre-formed prior to that interaction. ${ }^{92}$ Chomsky, on the other hand, maintained that the capacity to develop grammatical language was innate.

Rutter and other new autism researchers were slightly in thrall to Chomsky's work emerging from the USA and they sought to emulate its significance in their own work. It was actually quite an unusual move for Rutter to want to develop a cognitive model of autism, given that the concept had been drawn entirely from models of subjectivity that were based on an infant's adaptation to reality via interactions with people and other objects, as in the work of Piaget, but also Isaacs and others. In developing a cognitive model of autism, Rutter was also, by default, developing a cognitive model of subjectivity and the origins of human relationships. Prior models of developing subjectivity had drawn from instinct theory and Piagetian models of mind-object interaction. The idea that the development of subjectivity and relationships could be studied cognitively was new.

Since the mid-1960s, Rutter had argued that 'speech disorders' and difficulty with language characterised children with 'psychosis' and 'autism. ${ }^{93}$ He later argued that autistic children usually scored well on block design tests and object assembly because these tests did not require the concepts of abstraction, symbolisation and logic that were associated with language. In contrast, they always scored badly on tests for picture arrangement or other things that did require those symbolic skills. ${ }^{94}$ In 1968, Rutter argued that the primary deficit in autism was a language problem and that this then gave rise to the other symptoms that were secondary. He quoted studies such as Hermelin and O'Connor's to argue that autistic children's difficulty in comprehending sentence structures showed that their memory of words was independent of the meaning of those words. Rutter claimed that autistic children suffered a 'cognitive and perceptual deficit' rather than a problem with emotional attachment. He acknowledged that it was 'difficult to differentiate between poor social perception and a general impairment in symbolic functioning or language comprehension'. Nevertheless, he 
argued that the study of 'speech disorders' provided the key to understanding child psychosis and autism. ${ }^{95}$

Instead of drawing from psychoanalytic models of child development, or those based on the model of instincts and emotions, Rutter turned to neurology and to neurological studies of language processing and aphasia. In 1975, Rutter, Lawrence Bartak and Anthony Cox published the first part of a major 'Comparative Study of Infantile Autism and Specific Developmental Receptive Language Disorders' in the British Journal of Psychiatry. ${ }^{96}$ These studies argued that, although there were similarities in these groups, comparisons showed that autistic children demonstrated particular 'deviant' forms of language such as echolalia, pronoun reversal, stereotyped utterances and metaphorical language. In the case of children who only had language disorders such 'deviant' speech was not prevalent, but this group was much more likely to have defects in articulation. The language 'deviance' and impaired usage of spoken language and gesture seen in autistic children was different from the problems seen in other language-disordered children. ${ }^{97}$ Figure 7 shows a section from a table of items used to discriminate between these two groups in 1977 and the discriminant function that had been calculated from the 1975 study. Discriminate function analysis demonstrated that autism was a reliable diagnosis within a wider spectrum of 'severe developmental disorders of receptive language' and further cluster analysis and statistical techniques could confirm this. ${ }^{98}$ Testing for these abnormalities of language offered a way for researchers to identify the core cognitive deficit of autism using large populations of children. The work was taken up enthusiastically internationally. For example, Giampiero Bartolucci, from the McMaster Psychiatric Unit, Ontario, argued that autistic children may be 'deficient in their ability to extract the components of structured auditory input' and that this was evidenced in their unique use of phonemic substitutions. ${ }^{99}$

It has frequently been pointed out by historians and cultural critics that the 1960s brought forth a 'linguistic turn' in multiple disciplines including anthropology, philosophy, psychoanalytic theory, literary criticism and psychology. ${ }^{100}$ The significance of this major transition for the field of child psychiatry has been little explored. However, it is clear that the study of language was becoming fundamental to all theories of autism in the late 1960s and 1970s, and that this new-found topic of interest was diverting attention away from instinct theory and 
D. Current language behavior

1. Pronominal reversal

$-0.434$

2. Use of stereotyped utterances

0.096

3. Repetition of own phrases over and over $\quad-0.001$

4. Immediate echolalia $\quad-0.022$

5. Utterance length $\quad 0.461$

6. Metaphorical language $\quad-0.227$

7. Abnormal articulation $\quad 0.347$

8. Odd intonation $\quad 0.039$

9. Use of gesture to communicate -0.037

10. Communication to ask to go somewhere $\quad 0.013$

11. Communication to comment on things happening 0.251

12. Communication to report on events spontaneously -0.431

13. Communication to to report on events in response to questions 0.143

14. Communication to to answer question 'What are you doing?' $\quad 0.046$

15. Communication to chat to adult $\quad-0.168$

16. Communication to ask if he can help with activity $\quad 0.129$

17. Talking to himself about his activity $\quad 0.156$

18. Displays sympathy to others $\quad 0.004$

19. Creative play -0.133

20. Imaginative play $\quad-0.096$

21. Cooperative imaginative play (test situation) $\quad-0.217$

Figure 7 Section from table of items used in discriminant functions analyses, from Lawrence Bartak, Michael Rutter and Anthony Cox. 'A comparative study of infantile autism and specific developmental receptive language disorders: III - Discriminant function analysis', Journal of Autism and Developmental Disorders 7, no. 4 (1977)

fantasy formation in the minds of developing infants. In Britain, the closure of mental deficiency institutions and the growth of speech therapy services provided the perfect administrative setting for research into language problems in children. The focus on autism as a cognitive disorder, and specifically one associated with language, was strongly associated with this political, social and cultural setting.

The closure of deficiency institutions had served as the impetus for the first large-scale studies of 'speech disorder' in children. ${ }^{101}$ The concept of a 'speech disorder' could be traced back to the work of the French physician Paul Broca and the German physician Carl Wernicke in the nineteenth century on areas of the brain responsible for language and how damage to these areas affected adult speech. ${ }^{102}$ The term 'disorder' began to be used frequently in British writings on speech problems 
at the start of the twentieth century. ${ }^{103}$ In the 1930s and 1940s, some neurologists such as Russell Brain began to use this approach to understand speech problems in childhood. ${ }^{104}$ In 1959, T. T. S. Ingram from the Department of Child Life and Health at the University of Edinburgh argued that 'speech disorders' were characterised by the 'retarded development of the ability to articulate speech sounds accurately', but which 'cannot be attributed to the presence of mental or emotional retardation or physical disease. ${ }^{\prime}{ }^{105}$ After 1959, the wider availability of child subjects who would have previously been classed with 'mental defect' meant that 'speech disorders' appeared to be more common and it became possible to undertake more complex studies into their form. A growing focus on the key cognitive deficit of autism in the early 1970s helped to fuse these models, and neurological models of brainspecific areas gave further support to the idea of a fixed, measurable malfunction in the brain that characterised 'autism'. These changes were contemporaneous with a wider interest in the 'communication' problems of children as opposed to their emotional problems. ${ }^{106}$

Prior to the 1970s, the term 'developmental disorders' was rarely used, and when it was used, it was employed primarily in relation to speech disorders. As Gil Eyal has shown, in the USA, the term 'developmental disabilities' was first used in 1970 by Congress as part of the legislation that began the process of deinstitutionalisation. ${ }^{107}$ In North America, 'developmental disorder' began to be used more freely in the early 1970s to include 'mental retardation, learning problems, communication disorders, and visual-perceptual and perceptual-motor problems. However, it was Rutter's work in Britain in the mid-1970s that fused the study of language disorders with the study of autism and presented both as a form of 'developmental disorder'. The introduction of the term 'pervasive developmental disorder' in DSM-III, with autism as a subcategory, sealed the description of autism as a problem concerning delays in development rather than a condition caused by emotional determinants.

This fusion was accompanied by a more general description of 'neurodevelopmental' problems in children. The concept of 'neurodevelopment' became established in British literature on child development in the early 1970s. In 1973, Kingsley Whitmore, along with Martin Bax from Guy's Hospital, published a paper in the Lancet arguing for the introduction of a short battery of 'neurodevelopmental' tests for 
children. ${ }^{108}$ The term 'neurodevelopmental' was clearly instituted as part of the demographic shift towards the inclusion of all children into the comprehensive education system. The idea of 'neurodevelopmental' disorders enlightened teachers about atypical behaviour and also justified integration, unlike prior terms such as 'handicapped' or 'defective. Although these unfortunate terms had not entirely died out in the 1970s, 'neurodevelopmental' at least had the potential to surpass them as a more sophisticated way to depict and describe the variations that could occur throughout children's development. Along with epidemiological sciences, 'neurodevelopment' opened up the study of child psychology to new scientific horizons and diminished terms such as 'mental defect' that were associated with social exclusion. In 1977, Cecil M. Drillien from the Department of Child Life and Health at the University of Edinburgh edited a volume titled Neurodevelopmental Problems in Early Childhood that argued for a radical rethink of the way that 'neurodevelopmental problems' were managed in childhood, arguing for better definition and responses that were proven to be effective. The authors were concerned with the 'commoner mental, neurological, sensory and behavioural disorders'. The 'neurodevelopmental' nature of these problems was becoming more widely recognised in families, schools and other social settings. And with this awareness came a burgeoning language to describe the various ways that the development of the brain and its functions could be affected. ${ }^{109}$ This new language increasingly replaced the language of instincts as the umbrella theory for understanding child development and its anomalies.

Even as early as 1972, the Times Educational Supplement had published a report by Lorna Wing that argued that autism was a 'condition of multiple neurological impairments involving language, perception, and organisation of movement' caused by many factors including genetics, infections and other problems affecting foetal development. She pointed out that although 'this formulation cannot justifiably be called a theory', it has 'the advantage of recognising the multiplicity of problems that have to be taken into account before any hypothesis as to the nature of childhood autism can be accepted.' ${ }^{110}$ Indeed, the proposal that 'neurodevelopmental disorders' better defined autism that emotional or imagination difficulties did help to expand the domains of research that could be included as part of a wider strategy to understand 'autism'. 
In the late 1960s and early 1970s, Michael Rutter managed a clinic for autistic children at the Maudsley Hospital where children were referred from all over the UK and even from the USA. ${ }^{111}$ He quickly became an 'acknowledged expert' in the field of autism study and was asked by SAC to act as the referring psychiatrist to their schools. ${ }^{112}$ Between the mid-1960s and early 1970s, the majority of suspected cases of autism in Britain were referred to Rutter's team. Rutter and colleagues corresponded widely with teachers, parents, educational psychologists and speech therapists across all major English counties from Essex and Kent to Devon and Durham. They also saw cases, and maintained contact, with many parents and professionals in Scotland, Wales and Northern Ireland. In much of this correspondence, case formulations or summaries highlighting the salient features of autism were used as a basis for descriptions of the child's problem to various professional and non-professional groups.

Children referred to the autism clinic at the Maudsley were tested using a selection of developmental indices and intelligence tests, which would take up to four hours, in which psychologists aimed to get a thorough understanding of the child's cognitive capacities. After the 1970 Acts that expanded education for all, children were no longer considered purely in terms of their 'intelligence', but their overall cognitive abilities were assessed as well. A number of tests were employed in this period to test capacities. As well as Hermelin and O'Connor's tests, these included standardised testing scales such as the Merrill Palmer scale of intelligence, the Vineland Social Maturity Test, the Reynell Developmental Language Scale and the Illinois Test of Psycholinguistic Ability. ${ }^{113}$ Many of these tests enabled comparisons of linguistic and non-linguistic abilities, hence the focus on this aspect of autistic children's cognition. A typical account of an 'autistic' child read 'probably of high ESN level on non-verbal material [but] ... he is grossly retarded in language both in comprehension and expression. ${ }^{114}$

As discussed earlier, the integration of growing numbers of children into the education system after 1970 meant that increasing numbers were labelled with speech disorders. Some of these children were referred to Rutter's clinic whilst others followed a different route via 
audiology and speech therapy departments within general hospitals and from there directly into special schools. In the late 1960s, J. A. M. Martin from the Nuffield Hearing and Speech Centre established a unit for the treatment of speech and language disorders at Ealing where children could be admitted with their mothers for short periods in order to train the mothers how best to treat and look after their children. ${ }^{15}$ Rutter and Martin corresponded frequently over particular cases and about general theories concerning language training in children with specific language problems and those who were autistic. Concerning the development of speech in one four-year-old boy, Martin wrote to Rutter arguing that:

It looks as though language is purely 'linguistic' responding to Brain's rather quaint idea that there are not only one word schemas but also sentence schemas, and that the child picks out an appropriate sentence which he has learnt ... He is entirely incapable of manipulating words as symbols and has to rely entirely on pre-arranged learnt structures. ${ }^{116}$

Children who presented with such unusual forms of speech became models on which debates about the development of symbolic forms of thinking were reframed. Some of these children demonstrated echolalia or other speech presentations that differed from other children their own age. Instead of using the linguistic utterances of autistic children to search for metaphoric meaning, as prior child psychologists such as Isaacs had done, Rutter and the new generation of epidemiological and experimental psychologists used these utterances to search for standard differences that would be repeated by children across the total autistic population.

Looking in detail at specific cases in Rutter's autism clinic, it is easier to see how this focus on language and measurable behaviour was coupled with a shift away from an interest in hallucinations, phantasy and instinctive drives. In the case reports of children who were observed and treated at the autism clinic during the 1970s, a descriptive mode arose that gave great details about repetitive and ritualistic actions and language and highlighted an absence of fantasy and creative play. A typical description of an autistic child from 1972 stated 'limited imaginative play' and 'inability to cope with abstract concepts. ${ }^{117}$ A typical summary of one autistic boy in 1974 listed a series of 'mannerisms': 'Collects bits of paper with drawings on them ( $\mathrm{TV}$ test card, car numbers etc.). Also [has a] treasured box of 50 diaries, collection of toy buses. Pulls lips 
twists hair when concentrating. When on swing will go into a "trance", spins slowly, peripheral gaze at books. ${ }^{118}$ Several of the children were noted to have abnormal obsessions with vacuum cleaners, lawnmowers or other unusual objects. ${ }^{119}$ Other children showed abnormal interest in particular sounds or tunes. One child, for example, was obsessed with the theme tune of News at Ten. ${ }^{120}$

Even if the child was able to describe phantasies or the contents of their thoughts, these were often relegated in a descriptive model that was searching primarily for repeatable instances of behaviour and language. It was via this continual search for repeatable behaviour and linguistic utterances that the method of epidemiological sciences actually came to structure the definition of autism in individual cases. For example, in the following summary of a 'typically autistic' child diagnosed with autism in 1975 at the age of eight, there is a marked emphasis on observation, classification and measurement that all quantitively outweigh the significance of descriptions of 'phantasies' or symbolic material.

Play: mainly collecting and classifying objects, sorting them out and manipulating them. Since 6 months ago has phantasy of a giant hook, a persecutory supreme being in animal form which he is able to draw and share with his younger brother. No phantasies about people. Mannerisms: A few remaining stereotypies such as handshaking, head nodding. Obsessed with flowers, insects, feathers, searching for them, counting them and sorting them. Collects plastic spoons in public places. Plaits great quantities of wool. Marked resistance to environmental change. ${ }^{121}$

Even though the new generation of epidemiological and experimental psychologists had not completely ruled out the possibility of hallucinations or imaginative thought in 'autistic' children, these became increasingly sidelined under the weight of measurable quantifiable behaviour and linguistic utterances.

For example, in the case of one child who was referred to the clinic in 1970 after causing violent episodes on a children's ward in a hospital, the referring doctor described him as follows:

This boy functions as a subnormal, although I believe, following a detailed examination, that the diagnosis is that of schizophrenia. I found him difficult to examine and rather restive, continually exhibiting echolalia. The boy looked vague and was very clumsy. He laughed aloud for 
no apparent reason and there were times during the examination when he adopted an attentive attitude as if he was listening to voices. I feel there is no question but that he is hallucinated. Emotionally, he was very flat, showing no warmth whatsoever ... He remains hallucinated and likes to be alone with the voices ... During all the time I have known him, he has not been aggressive to anyone, but there are times when he stamps his feet, kicks out and hits his head with his hands, probably this is a result of his hallucinations. ${ }^{122}$

Rutter responded, stating that the diagnosis was 'certainly that of infantile autism, and his subsequent course and progress has been consistent with this diagnosis'. Concerning the presence of hallucinations, Rutter pointed out that 'He certainly shows the odd behaviour that you describe in your letter but I would personally doubt whether in fact he was hallucinated. With a boy who cannot communicate it is, of course, practically impossible to tell one way or the other.' ${ }^{123}$

It was because of this that children's play began to take on very different meanings. The representation of children's play then also became focused on repetitive quantifiable actions rather than a reflection of instinctive drives. This turn away from the imagination and the fantasies of children, and the focus on their language and behaviour as repeatable items, characterised autism research in the 1970s and also characterised the definition of autism itself. The category of autism came to serve as a receptacle for children who did not think according to established models of subjective development. This new category of children presented a challenge to all other models of child development, and it was a challenge that was rapidly growing in size due to increasing diagnoses.

Rutter's tacit assumption here was that 'social relationships' were contemporaneous with the development of language, at least in the case of autistic children. Children's psychiatric case notes from the 1970s are filled with the phrases 'lack of fantasy or pretend play' or 'limited fantasy and creative play' as evidence that a child had autism. ${ }^{124}$ As studies of autistic children continued to multiply during the 1970s in the attempt to explain this central problem in child psychiatry, Kolvin's statistical studies and Rutter's speculations were transformed into claims that autistic children simply did not hallucinate or have fantasies at all. This characteristic was increasingly supported by studies emerging from the Social Psychiatry Research Unit and a consensus began to emerge there that knowledge about children's thought should work from the 'social' 
and statistical downwards to the individual case, rather than from the individual case upwards into the social world, as had been typical in psychoanalytic theory. It was just as this statistical model in child psychiatry was being established that interest in autism began to grow. This condition, which was part of a model of subjectivity, yet which denied the possibility of individualistic interpretations, was the perfect disorder through which to impose a statistical model that purported to measure the 'social' in its description of abnormal child development.

\section{'Autistic features' in context}

After Lotter's epidemiological study had defined autism according to behavioural criteria, Rutter cast the net wider in attempting to develop a behavioural definition of autism that was also distinguishable from similar psychological problems in children. Rutter argued that the 1961 working party definition of autism was too comprehensive because it included things such as over-activity and excessive anxiety, 'which do not serve to distinguish the autistic child from children with other psychiatric disorders. ${ }^{125}$ Hence, in 1968, Rutter replaced Creak's nine points with three key features that characterised autism. These were 'profound abnormalities of language development, a variety of ritualistic and compulsive phenomena ... [and] a particular variety of disturbance in interpersonal relationships. ${ }^{12}$ Rutter pointed out that these 'features' were specific to early childhood and that they would be modified and sometimes absent in older children with the condition.

In the case reports of every child that was referred to the Maudsley in the early 1970s, these 'features' were repeated regularly. For example, in a 1975 letter from Rutter's registrar Dr M. Weiselberg to Dr Philip Graham from the Department of Psychological Medicine at Great Ormond Street, one child was described as showing 'classical autistic features in that there is a severe disturbance of peer relationships, a developmental abnormality of language and numerous manneristic behaviours dating from birth'. ${ }^{127}$ These exact words were then repeated in letters to the Essex Special Services Education Department, the Helen Alison School for Autistic Children and the child's local GP surgery. ${ }^{128}$ Through letters such as these, the basic model or key features of 
autism were distributed and publicised throughout school and social work agencies across Britain. This demonstrates how a formulaic observation was used as a theory-promoting mechanism.

The idea that autism could be subdivided into separate 'features' increased the chances of a child being classed with the category. Disconnected autonomous autistic 'features' first began to be observed in children with specific language disorders, as well as those who were otherwise globally retarded and 'subnormal'. For example, in October 1970, the School Medical Officer from the Public Health Department of the Borough of Colchester, M. J. Brown, wrote to Rutter concerning a child whose parents considered him to be autistic and wanted him to be educated at an autistic school. Brown's own point of view was made clear in his claim that 'I do not believe this child to be autistic but severely retarded and the parents are quite unable to accept this'. On seeing the child, Rutter's response to Brown was that 'the clinical picture is that of a severe developmental disorder with some autistic features'. He then suggested that he be sent to an autistic school, 'although he is not strictly speaking autistic'. The boy was later accepted at an autistic school; however, it was found not to cater for all of his needs. In 1972, Rutter contacted Colchester Social Services Department requesting that a community social worker be appointed to the family to provide them with additional support in dealing with the boy, whom he described as 'a severely handicapped child with a profound global language disorder, autistic features and some intellectual retardation.' ${ }^{129}$

Concerning the diagnosis of autism in a seven-year-old child who was referred to the clinic in 1978, Lucy Ellis, School Medical Officer for Solihull Area Health Authority, wrote to Rutter asking whether the child should be referred to an autistic unit or a language unit for his education. She queried whether the boy was autistic because he did not exhibit visual avoidance or auditory non-recognition. Rutter's response explained his reasons as follows:

I agree with you that the boy does not show any auditory nonrecognition and that he shows little visual avoidance (although there was some indication of this at times when I saw him). As you say, he also makes some social approaches, is generally cheerful and makes some spontaneous remarks. These are all characteristics which would be most unusual for an autistic child below the age of 5 but it is not at all uncommon to see this in the milder autistic children at a slightly older age. ${ }^{130}$ 
Rutter therefore diagnosed the child with 'mild autism' but thought that a school for autistic children would not be appropriate because they tended to deal with children who were much more 'handicapped'. Rutter therefore recommended a school that took on children who were in the ESN (Mild) level of functioning. ${ }^{131}$

Autistic 'features' also came to be regarded as offshoots of primary problems in learning and development. For example, one four-yearold child whose parents had been referred to Rutter via the Society for Autistic Children in 1969 had test results that 'were well above the test ceiling' on non-verbal tasks, yet had failed most items testing speech. This discrepancy suggested autism, though the boy was not found to have any of the other symptoms associated with the condition. The senior School Medical Officer of his district had suggested that the boy be placed in a partial hearing unit, even though there was no evidence of deafness, because the emphasis there would be on teaching speech development. The child had also been referred for speech therapy at the local children's hospital but the speech therapist was uncertain as to whether what she regarded as his 'severe behavioural problems' were secondary to his 'developmental language disorder' or were causing it. After seeing the boy, Rutter thought him to be suffering from a 'profound developmental language disorder' associated with 'problems in tongue and lip co-ordination'. In later correspondence from the mid1970s, Rutter began to describe him as 'a boy of normal intelligence on non-verbal tests, who had a very specific language disorder associated with some autistic features.'. ${ }^{132}$

In the mid-1970s, educational psychologists and others working in the field of education also started to use the term 'autistic features'. Writing in 1975 about an eleven-year-old boy, who had been diagnosed with 'childhood psychosis' at the age of five, the Senior Educational Psychologist of Essex County Council described him as:

a severely subnormal boy, developing mentally at about one third the normal rate, whose behaviour shows some autistic features, but he does not in many respects fit the classic picture of the autistic child. It seemed to me that many of his 'autistic' behaviours were symptoms of either a) his developmental stage - it is normal for 3 yr olds to have violent temper tantrums, or b) his poor comprehension of instructions and of social situations or c) his inability to cope with unstructured teaching and caring situations. ${ }^{133}$ 
Descriptions such as this draw attention to the way in which 'autistic features' were becoming synonymous with infantile behaviour and early developmental stages generally.

There were several cases in which some professionals saw autism and autistic features whilst others saw none. For example, one child had been diagnosed with autism in 1976 at the age of four by an educational psychologist who said that all the 'criteria of childhood autism are present. He was also seen by a consultant child psychiatrist, Dr Ross, who thought that the boy was 'probably suffering from childhood autism. The parents then took the child to see Dr Hugh Jolly, consultant paediatrician at the Charing Cross Hospital, who did not think that the boy was autistic and 'the label of autism was thus removed by Dr Jolly'. Dr Mackay, consultant paediatrician at the Royal Manchester Children's Hospital, also thought that the boy 'did not show the classic features of autism. When the boy was later referred to the Maudsley at the age of eight, Rutter argued that he was 'suffering from childhood autism in a mild form.'. ${ }^{134}$

Although Rutter had restricted his three key features to early childhood, at Rutter's clinic the staff relied primarily on the reports of parents and teachers for descriptions of the child's behaviour in infancy. Most children suspected of autism were not observed directly in infancy. In these cases, children would be diagnosed with 'autistic features' rather than definite 'autism. The establishment of 'autistic features' as an idea helped to affirm the label of autism within the system of government administration and also enabled the cognitive model of psychology, developed by a new generation of epidemiological and experimental psychologists, to be used to challenge wider assumptions about emotional development that were then enshrined in government policy towards families following Bowlby and Winnicott.

Rutter became increasingly important in the international arena of autism research and the theories he formulated in his clinic went on to have global significance. In 1979, the Journal of Autism and Childhood Schizophrenia was renamed the Journal of Autism and Developmental Disorders. Writing in the editorial of that year, Rutter, who had also been promoted to European editor, along with Eric Schopler, who had replaced Kanner as chief editor in the mid-1970s, explained the transition as follows: 
In order to stimulate more flexible research strategies, the title and scope of the journal have been broadened to include a wider range of developmental disorders related to autism. This carefully circumscribed broadening is also intended to clarify the developmental factors that shape the autistic symptom picture. By focusing on all types of issues within a wide span of developmental problems it is hoped that there may be a greater clarification of both the similarities and the differences between the various disorders that delay or distort the developmental process. We hope, too, that it will lead to greater knowledge on the various connections between physical anomalies of development and their psychosocial and behavioral sequelae. ${ }^{135}$

Kanner's stipulation that the journal be devoted to 'all psychoses and severe disorders of behaviour in childhood' was rewritten and, in 1972, the editors claimed that the journal was 'devoted to all severe psychopathologies in childhood'. An advertisement in the Schizophrenia Bulletin in 1975 described the journal as 'a multidisciplinary forum for the rapid dissemination of information ... [which] deals with research, theory, and therapy in all severe behaviour disorders of childhood. ${ }^{136}$ It was clear that Rutter and Schopler had ambitions to build a new style of thinking about deviations in children's development and that they saw the categories of 'autism' as central to this conceptual revolution. This was an important moment for child psychology because autism was such a central concept. Once this concept had been appropriated and defined as a developmental problem associated with language, the concept of hallucination, which had been a key concept in all descriptive psychopathology since the nineteenth century, was written out of developmental psychopathology. As autism was associated further with developmental disorders, hallucination was increasingly eradicated from the concept. The concept of autism was thereafter increasingly defined and described according to the tools that had been used to measure it.

Social development as a cognitive achievement and the birth of 'social impairment'

'Neurodevelopment' was becoming increasingly common as an umbrella term to describe childhood psychological development and its anomalies. Although Rutter sought to locate it clearly in atypical language 
function in the case of autism, the Newsons and Lorna Wing would shift the study of autism in a different direction. This new direction was more closely aligned with the radical changes occurring in the social welfare system with its focus on generic 'social service' departments. In 1975, John and Elizabeth Newson published 'Intersubjectivity and the Transmission of Culture: On the Social Origins of Symbolic Functioning', a paper that grappled with Piaget's theories of psychological development and argued for a radical rethink. Rutter wrote a report supporting this research. ${ }^{137}$ In 1963, John Flavell, a US-based developmental psychologist, had published an easily accessible summary of Piaget's theories in English that helped to popularise and promote Piaget's ideas in the anglophone world. In the late 1960s, Piaget and Bärbel Inhelder's The Psychology of the Child was published in English (going on to many editions), which also provided a concise summary of Piaget's key theories. By the 1970s, Piaget's work was widely known and widely discussed in Britain. In the 1970s, several autism researchers in Britain began to challenge Piaget's theories of psychological development in order to present their new theory of child development modelled around autism. In The Psychology of the Child, Piaget and Inhelder emphasised the importance of symbolic functioning to the establishment of cognitive structures in the process of development, arguing that after the sensori-motor period, at around eighteen months, the child develops the capacity to think symbolically. As they described it, drawing from the famous Swiss linguist Ferdinand de Saussure: 'It consists in the ability to represent something (a signified something: object, event, conceptual scheme, etc.) by means of a "signifier" which is differentiated and which serves only a representative purpose: language, mental image, symbolic gesture and so on. ${ }^{\prime 38}$ The Newsons felt compelled to critique the view that sensori-motor interactions and knowledge were primary and that the ability to represent only arose at eighteen months. They argued that the infant's most important transactions were with other human beings and that therefore their cognitive development had to be reconsidered as including aspects of symbolic thinking in early life. As they put it: 'The chid only achieves a fully articulated knowledge of his world, in a cognitive sense, as he becomes involved in social transactions with other communicating human beings. ${ }^{139}$ This was clearly not a new discovery. Many child psychoanalysts and developmental psychologists from Susan Isaacs and Melanie Klein to Anna Freud and John Bowlby had 
discussed these stages of development in great detail since the 1930s. What was novel was that the Newsons presented social development as a form of cognitive development. They were not interested in the theoretical abstractions drawn from the study of instinctive drives and their impact on unconscious mental processes. Instead, they described social development as a cognitive achievement and verified it with experimental studies.

Instead of describing the ways in which instinctive drives compelled the desire for human interaction, the Newsons argued that 'the infant is somehow innately primed to participate in complicated social rituals. ${ }^{140}$ This claim that infants had innate cognitive social structures vied with Chomsky's claims that the language faculty was innate, and with Piaget's claims that intelligence was innate. The Newsons were aware of this and sought to generate a theory of innate mental capacity that had the absence of that innate capacity as its obverse. Just as children could have intellectual impairments or 'mental deficiency', or speech and language impairments, they could also have 'social impairments' that affected the development of their innate social capacity. The difference between these impairments was a function of the support for the intellectual, language or social cognitive faculties. In the mid-1970s, the claim that the social faculty, or social capacity, was a fully formed and complete innate unit was not concluded, although it would become so by the end of the decade. It took new work on 'intersubjectivity' to bridge the gap.

Lorna and John Wing supported and popularised the Newson's work, and developed it, drawing particularly from the work of Colwyn Trevarthen from the University of Edinburgh. ${ }^{141}$ Trevarthen followed the work of William Condon and Louis Sander from the Boston University School of Medicine. Condon and Sander were using close observation of infants to argue that they responded to human speech with an ongoing 'dance', suggesting the presence of a 'primary linguistic-kinesic interaction process' in which the infant provided very early cues to the social advances of others. ${ }^{142}$ Other well-known North American psychologists such as Peter $\mathrm{H}$. Woolf at Harvard explored the exact quality of babies' cries and parental responses to these. ${ }^{143}$ Trevarthen was interested in testing these theories in detail. One significant development in the 1970s was the increasing availability of relatively inexpensive yet sophisticated video equipment to university departments that enabled 
the recording, and slow replay, of infant movements and interactions. This enabled incredibly detailed observations of infant movement and pre-verbal 'speech'. Trevarthen's work was strongly influenced by this development and his theories were more widely respected due to the support of this steadfast visual evidence. Trevarthen and Penelope Hubley had used video evidence to show that eye movements of infants were co-ordinated with hand, arm, facial and mouthing movements, in such a way that this could be considered 'pre-speech'. Trevarthen developed these ideas in terms of a theory of 'intersubjectivity', a term that he had taken from the German sociologist and philosopher Jürgen Habermas. ${ }^{144}$

The term 'intersubjectivity' can be traced back to the French philosopher Edmund Husserl's works in phenomenology. Husserl had used it to describe the way that beliefs and meanings are formed through both empathy and a shared sense of egocentric perception. ${ }^{145}$ Maurice Merleau-Ponty had discussed 'intersubjectivity' in 1945 in relation to early infant interaction with the mother when describing the infant's ability to understand shared perception, but he had not dwelt on the topic. ${ }^{146}$ In the 1970s, Habermas significantly developed the concept in response to Chomsky's theory of innate linguistic competence. As well as 'monological' linguistic competence, Habermas proposed a theory of language based on 'intersubjectively valid rules' that make mutuality of understanding possible. ${ }^{147}$ Drawing from Habermas, Trevarthen argued that intersubjective interlacing of perspectives could be ascertained in infants' relationships to their mothers even at the age of two months where infants expect particular responses from their mother and respond to what she does. They termed this 'primary intersubjectivity'. Trevarthen further argued that by the end of the first year, infants are able to engage in deictic expressions that indicate, time, space, articles and demonstrative pronouns. This he termed 'secondary intersubjectivity. ${ }^{148}$ Crossing the boundaries between psychology, linguistics, philosophy and sociology, Trevarthen and Hubley were carving out a new theory of infant development. Their research was funded, remarkably, by the Social Science Research Council of the United Kingdom, further proof that epidemiological and sociological understandings were impinging on theories of child development in this period.

Trevarthen's video evidence of 'intersubjectivity' in infants gave a new dimension to autism research and to wider theories of infant 
psychological development. The Newsons saw this as evidence of 'the primacy of social responsiveness in human infants'. They argued that in their sociological interview samples, many mothers had talked of getting 'on the same wavelength' as their babies, and suggested that these constituted 'intersubjective' processes generating shared understandings that constitute human knowledge. In summary, the Newsons argued that in using the term 'intersubjectivity':

attention is being drawn to a fundamental proposition: that the origin of symbolic functioning should be sought, not in the child's activities with inanimate objects, but rather in those idiosyncratic but shared understandings which he first evolves during his earliest social encounters with familiar human beings who are themselves already steeped in human culture. ${ }^{149}$

Some have developed this theory. The theory of intersubjectivity would be taken up by Peter Hobson, Professor of Development Phychopathology at UCL in the 1980s. ${ }^{150}$ In the 1970s, it helped to promote a particular approach to 'symbolic' play that was distinguishable from psychoanalytic approaches focused on phantasy relations.

In 1975, Lorna Wing, then based at the Medical Research Council's Social Psychiatry Research Unit, argued that 'the central problem in early childhood autism is an impairment of complex symbolic function affecting all forms of communication'. In the majority of cases this was, she argued, 'associated with other impairments of the central nervous system.' ${ }^{151}$ It was the child's 'lack of symbolic play' that characterised this impairment, and from the mid-1970s Wing focused increasingly on symbolic play and its significance. A 1977 study of symbolic play in 'autistic' and 'severely mentally retarded' children attempted to delineate out the difference between the ways that children played. It had been conducted with the help of Lorna Brierley from the Medical Department of the Inner London Education Authority and Sybil Yates from the Health Department of the London Borough of Southwark over the preceding four years. For Wing, 'symbolic play' meant that, for example, a child 'made appropriate noises while pushing a toy car' or 'pretended to drive it into a garage to fill up with petrol'. If the child played with a doll, the play should involve 'at least holding them up if they were real babies and brushing their hair, or tucking them up in 
bed'. At a higher level, it involved 'active participation in pretend play with other children' as well as 'the invention of stories' and 'modelling or drawing pictures with imaginative themes'. Children without symbolic play dealt with objects in a very different way. This involved the 'repetitive manipulation of toys or other objects regardless of what they represented' such as spinning the wheels of a toy car without using it to represent a real car. Some children played in a 'stereotyped' way that straddled the two extremes. ${ }^{152}$

In trying to draw a distinction between the retarded and the autistic, she claimed that 'no child with symbolic play has the complete autistic syndrome', although children with 'severe retardation', in particular Down's syndrome, often played symbolically. ${ }^{153}$ Her purpose in drawing these distinctions was to offer guidance to educational establishments. Whereas Tizard's 'Brooklands' experiment had highlighted the value of play in improving the lives and educational capacity of 'retarded' children, Wing argued that this would not necessarily be the case for autistic children, a largely forgotten group, and that their education needed to be rethought in terms of operant conditioning and the reduction of behavioural disturbances.

If the 1960s saw a focus on diagnostic tests and experimental studies, symbolised by Creak's nine key features of autism in 1964 and Hermelin and O'Connor's tests of sensory impairment, the 1970s saw increased focus on the systematic study of how autistic children communicated and interacted with others through language, play and other symbolic systems and how this compared to other groups.

Writing in 1970, Wing described autism as characterised by 'perceptual disorders' and 'abnormalities of language', which caused 'secondary behaviour problems'. In 1978, Beate Hermelin argued that applying tests to autistic children in relation to 'normal' children was not a useful exercise because it is neither very illuminating nor profitable to come up repeatedly with the finding that children who are ill do less well than children who are not. ${ }^{154}$ Since their 1970 study, Hermelin and O'Connor had encouraged the use of control groups matched on mental and chronological ages drawn from other clinical subgroups, such as children with speech disorders. This method had been employed by Rutter and William Yule in the mid-1970s and led to their increasing conviction that autism was characterised by a problem of language development. ${ }^{155}$ This encouraged an increase in the number 
of studies that sought to discriminate ever-more minute details about the communication and social interaction of autistic children and how this compared to communication and social interaction in 'control groups' drawn either from other clinical samples or from the general child population.

This work did receive some criticism in the 1970s. Luke Y. Tsai and Jean M. Beisler from Iowa University criticised British researchers, namely Beate Hermelin, Neil O'Connor, Michael Rutter, Linda Lockyer, Lorna Wing and Judith Gould, to argue that more research needed to look into the way in which control groups were recruited, in particular when children were selected based on matched language abilities. Tsai and Beisler pointed out that autistic children tended to do better on the Peabody Picture Vocabulary Test (PPVT) than on the Test for Auditory Comprehension of Language (TACL). Furthermore, children with other psychological disorders did much better in the TACL than on the PPVT, in particular girls. Tsai and Beisler thus criticised Frith's 1970 study and Hermelin and O'Connor's 1967 study, which had used only PPVT to measure controls, claiming that the male 'controls' probably had much lower language ability than their autistic counterparts, and that the female controls actually had much higher language abilities. They were therefore not very good 'controls'. Such critiques placed further pressure on Maudsley psychologists to develop better testing schedules that measured specifically for autism, and that enabled greater capacity to match intelligence levels.

Attempting to address some of these issues, Wing developed questionnaires for parents that were used to track differences and similarities in the very early development of autism versus other developmental conditions. Relying on parental testimony, she argued that children with autism showed evidence of perceptual abnormalities early in their development. She also claimed that their early behaviour showed similarities with that of children with congenital receptive aphasia, congenital executive aphasia and congenital partial blindness and partial deafness, even though the total clinical picture was very different. ${ }^{156}$ The inference from that was that autism was a problem of sense perception, similar to all these others, because the speech and behaviour of autistic children was affected in similar ways, which she had pointed out in 1970 (Figure 8). Wing did not leave the analysis there but went on to argue that problems in social interaction experienced by autistic 
Behaviour during babyhood

A. Percentage of children showing abnormal behaviour in each group

\begin{tabular}{|c|c|c|c|c|c|c|c|}
\hline & \multicolumn{2}{|c|}{ Autistic } & \multicolumn{2}{|c|}{ Aphasic } & \multirow{2}{*}{$\begin{array}{c}\text { Part blind/ } \\
\text { part deaf } \\
(\mathrm{N}=15)\end{array}$} & \multirow{2}{*}{$\begin{array}{l}\text { Down's } \\
\text { syndrome } \\
(\mathrm{N}=15)\end{array}$} & \multirow[b]{2}{*}{$\begin{array}{l}\text { Normal } \\
(\mathrm{N}=25)\end{array}$} \\
\hline & $\begin{array}{l}\text { Speaking } \\
(\mathrm{N}=20)\end{array}$ & $\begin{array}{l}\text { Mute } \\
(\mathrm{N}=7)\end{array}$ & $\begin{array}{l}\text { Receptive } \\
(\mathrm{N}=11)\end{array}$ & $\begin{array}{c}\text { Executive } \\
(\mathrm{N}=10)\end{array}$ & & & \\
\hline \multicolumn{8}{|l|}{ A. General problems } \\
\hline (i) Poor sleep & 30 & 43 & 18 & 20 & 33 & 7 & 16 \\
\hline (ii) Feeding problems & 35 & 57 & 27 & 30 & $80^{* *}$ & 53 & 16 \\
\hline (iii) Frequent screaming & 30 & 29 & 9 & 20 & 27 & 7 & 20 \\
\hline \multicolumn{8}{|l|}{ B. Response to physical contact } \\
\hline (i) Lack of response to cuddling & 45 & 29 & 18 & 20 & 53 & $7^{*}$ & $4^{* *}$ \\
\hline (ii) Lack of response to tickling & 25 & 0 & 9 & 10 & $0^{*}$ & 33 & $0^{*}$ \\
\hline \multicolumn{8}{|l|}{ C. Anticipation of being picked up } \\
\hline (i) Lack of anticipation & 55 & 57 & 18 & 20 & $87^{*}$ & 47 & $4^{* * *}$ \\
\hline \multicolumn{8}{|l|}{ D. Response to social contact } \\
\hline (i) Lack of response to mother's voice & 40 & 1 & 27 & 10 & 67 & 13 & $0^{* * *}$ \\
\hline (ii) Lack of social response to own family & 35 & 14 & $0^{*}$ & 10 & 40 & 7 & $0^{* * *}$ \\
\hline (iii) Lack of social response to strangers & 55 & 29 & 56 & 20 & 53 & $20^{*}$ & $16^{* *}$ \\
\hline \multicolumn{8}{|l|}{ E. Interest in the environment } \\
\hline (i) Lack of interest & 75 & 86 & 45 & $20^{* *}$ & $100^{*}$ & 67 & $4^{* * *}$ \\
\hline (ii) Very quiet baby & 65 & 70 & 36 & 50 & 40 & 73 & $24^{* *}$ \\
\hline \multicolumn{8}{|l|}{ F. Self-stimulation } \\
\hline (i) Rocking etc. & 70 & 57 & 45 & 40 & 60 & $13^{* * *}$ & $12^{* * *}$ \\
\hline
\end{tabular}

Notes

Each value of $\mathrm{P}$ is the significance of the difference from the speaking autistic children's score. ${ }^{*} \mathrm{P}<0.05$; ${ }^{* *} \mathrm{P}<0.01$; ${ }^{* * *} \mathrm{P}<0.005$

Figure 8 Table comparing behaviour during babyhood in different groups of children, from Lorna Wing, 'Perceptual and language development in autistic children: A comparative study', in Infantile Autism: Concepts, Characteristics and Treatment, edited by Michael Rutter (London: Churchill Livingstone, 1971) 
children could be directly correlated with the number of cognitive handicaps that they had. As she put it: 'The number and severity of problems such as social withdrawal, attachment to objects and routines, abnormal emotional responses to situations, lack of appropriate play, and socially embarrassing behaviour, are related to the number and severity of the perceptual and language handicaps.' ${ }^{\text {. }} 57$

Wing's work was important because she developed a new theory of social development that held both political and scientific sway. This essentially held that social behaviour in infants and children was made possible by a fully functioning central nervous system and that it was thwarted by any impairments in that system. No doubt, this was a simplified model of social development and it bypassed many of the issues raised in the Newson's theories of 'intersubjectivity'. But it was the simplicity that gave Wing's work power, both in scientific circles and in political circles. This model of social development was politically important because, unlike the models of social development put forward by psychoanalytically oriented theorists such as Susan Isaacs, Wing studied 'social development' across an entire population group, covering individuals with all capacities and capabilities. The idea of social development was then no longer tied to a model of society in which certain members were excluded and hidden away. Wing's model of social development was an inclusive model. As a political ideal, this model of society was unsurpassable, hence its immediate uptake within government circles. Unlike earlier researchers such as Isaacs, Wing was not really interested in how 'normal' or typical children developed but rather how mentally 'handicapped' and psychologically impaired children failed to develop social awareness. This failure was then used as the basis on which to build a new theory of social development. As Wing considered it, if a sensory or perceptual impairment created an atypical social response then the obverse of that impairment, as manifested in a normal child, must be the cause of a normal social response. For Wing, if infants were not impaired then they would develop normal social responses, socially and that was that.

Unlike Susan Isaacs who regarded social development as a phenomenon that occurred in all infants and children through the force of their instinctive motivations, sustained by infantile hallucinations, Wing regarded social development as a phenomenon that occurred merely because perceptual, sensory and executive cognitive mechanisms 
were intact. This was a significant difference because it suggested that an infant's thought about other people was defined by their ability to grasp external perceptual experiences. Instead of forming the basis of the unconscious mind, early thought in normal infants was merely a fact of life. Nevertheless, Wing's model was definitely not the atheoretical behaviouristic vision of the mind put forward by writers such as J. B. Watson and Hans Eysenck. On the contrary, Wing and other Maudsley psychologists offered an alternative model in place of the passionate unbounded fervent desires that had been the mainstay of psychoanalytic and human relations-style psychology. They presented a new model of social development, but instead of framing it in terms of desire, they framed it in terms of a capacity for social interaction. Some infants had this capacity, some had less of it, but it could be measured. Most importantly, it was not just a kind of behaviour but an ability to be a social subject. The new theory of autism and the autistic spectrum provided new models for thinking about human social development that were just as detailed and complex as those presented by the psychoanalysts. No one could accuse the new autism psychologists of abandoning the concept of the mind, as had been the case with Watson and Eysenck. If you understood 'social impairment' in all its complex details through statistical mapping, then you would have a theory of psychology. Nothing more was needed. Wing effectively argued that there was no need to have a theory of normal social development because society was simply the benchmark for that normality. Psychoanalytic thinkers had failed in attempting to develop an acultural and unbiased model of human development. Wing and the Maudsley psychologists sought to replace this with their new model of social development, within which the new autism, the second autism, featured as the core concept.

Anthony, Piaget, Isaacs, Klein, Tustin and others had argued that the comprehension of pathological thought in 'psychotic' and 'autistic' thinking could structure general theories of psychological development, but they had regarded it as an early stage of thought in all children. Once autism was no longer conceptualised as a normal early stage of thinking associated with fantasy, it had no psychological clout or influence. Hermelin, O'Connor, Frith, Rutter and the behaviourists in the USA had struggled to give it any psychological meaning in the 1970s once its role as the kernel of psychological experience was rejected. However, Wing reaffirmed its significance by asserting its place within a 
general scale of social capacity. Instead of being an early psychic organiser, autism became a peripheral non-social experience, linked to other 'handicaps', which could be identified with tests and statistical tools and compared and contrasted with the otherwise rather boring standard results of the rest of the population. Autism no longer structured the psyche but it captured the imagination. It no longer channelled the social instincts but instead clarified them from above. The key feature of the shift in the meaning of autism in the 1970s and 1980s was the externalisation of developmental psychology. Meaning was suddenly shifted from internal theories to external testing schedules and mechanisms. Psychological knowledge about human relationships no longer had to be inferred from models of normal animal instincts but rather imposed from statistical knowledge about when it all went wrong. Developmental psychology organised and directed externally by the concept of autism, rather than merely employing the concept of autism as an infantile form of unconscious, hallucinatory, asocial mode of being. The concept of autism now began to drive psychology rather than vice versa.

Historically, there could have been no better time for such a shift. The population of children who would have previously been excluded from society on the grounds of their 'mental defect' were being fully acknowledged as social beings and fully integrated into the mainstream school system to develop along with all other children. It was no longer possible to conceptualise a model of society based on intellectual hierarchy where elite institutions housed the highest ranks and 'defective' institutions housed the lowest scorers of IQ tests. Psychologists trained at the Institute of Psychiatry were the first to conceptualise this new psychology because they helped to form the society in which it was created.

Between 1979 and 1981, Wing presented a critique of almost all previous classificatory systems and divisions drawn within child psychiatry and developmental psychopathology, including the work of Kanner, Heller, Mahler, de Sanctis and Van Krevelen. The classification of childhood disorders concerning social interaction was in 'a most unsatisfactory state', as she put it, because various 'syndromes' had been described without the full support of epidemiology or statistical methods. ${ }^{158}$ Wing then proposed to strip down descriptive psychopathology to its foundations in order to build it up again, brick by brick, around the concept of social impairment. Clearly, this was a wide 
and open goal because all conditions, issues, problem, etc. in children could arguably be regarded as forms of social impairment. Wing's work was thus, by proxy, a criticism of the whole field of child psychology and psychopathology. In fact, she argued that her theory concerning the 'triad of impairments' presented reasons to reconsider the psychological descriptions of 'schizoid personality', 'schizophrenia', 'other psychotic syndromes', 'obsessional neurosis' and 'affective conditions', thus appearing unconcerned, even nonchalant, about all other approaches to child and adult psychology that had preceded her own. ${ }^{159}$

Nevertheless, Wing was presenting an original argument, which was that all children's psychological conditions should be conceptualised in relation to their social capacities. It was not novel to suggest that children's social development was critical to understanding their psychological state; Susan Isaacs had argued as much. Nor was it novel to claim that children with 'impairments in social interaction' shared some similarities with children with intellectual impairments. What was new was that Wing and the new autism psychologists created new concepts and tools that could be used in the assessment of all children who were brought to the attention of social authorities. These concepts and tools were designed to replace theories of the unconscious. Not only did this satisfy the growing backlash against the kind of psychologists who blamed the mothers, but it also enabled a unifying of social scientific approaches to atypical or abnormal groups and naturalistic or genetic-based theories of such groups that had been widely criticised in the post-war era due to the taint of eugenics. Wing and the Maudsley psychologists created a way to overcome this because they placed psychological theory and social theory on a par. Wing's reason to focus on the problems of social interaction was that 'all the conditions in which the triad of language and social impairments occurs, whatever the level of severity, are accompanied by similar problems affecting social and intellectual skills. ${ }^{160}$ This was in many ways a tautology - of course impairments of social interaction affect social interaction - but it was a tautology that enabled a new science of psychology to develop. The metamorphosis of autism meant that tests for sensory impairment, perceptual problems and language disorder were reframed as problems of social interaction. A number of different kinds of impairment hence became 'social impairments'. The allure of this new science was due to the fact that it quantified domains of psychological knowledge 
that had previously been attributed to 'unconscious' mental processes that affected mental function. These were now reclassified as kinds of 'social impairment'. The new model of autism, the second autism, also provided a beautiful quantitative and statistical framework for everything that was unknown about children's thought about relationships. However, this did not obliterate the tautology. A social impairment is a social impairment.

In 1978, John Wing, Lorna Wing's husband, had published an edited volume showcasing Maudsley statistical and social scientific approaches to schizophrenia. ${ }^{161}$ Lorna Wing regarded these as a complement to her work as they highlighted the variability of schizophrenic symptoms across total population groups. Her own work sought to clarify this variability at a developmental level. Unlike Mildred Creak and other of her predecessors, Wing had freed herself from the chains of Piagetian developmental psychology.

In 1979, Wing and Gould published their study on the prevalence of what they termed 'Severe Impairment of Social Interaction and Associated Abnormalities' in children. They stated that the 'pattern of impairments and behaviour problems' that they were describing had previously been 'variously (and unfortunately) termed childhood psychosis, childhood autism, or childhood schizophrenia.' ${ }^{162}$ Wing and Gould essentially thought that these terms were unfortunate because they had divided the 'schizophrenic' child from the 'retarded' child. They argued that there were clear overlaps between autistic children and those who were administratively classed as 'subnormal', in particular those with IQs below 50. It was also noted that many children with 'abnormalities of social interaction and language development, and stereotyped behaviour' also performed as severely or mildly retarded on nonverbal tests. Wing and Gould therefore decided to scrap all previous definitions that had been made in relation to such children and to create their own classificatory system based on a prevalence study. The aim of Wing and Gould's 1979 study was to find: 'a) the prevalence and distribution of three types of abnormalities, and whether they tended to occur together, $b$ ) how the clinical pictures of which they formed a part could be subgrouped, and c) how they were related to mental retardation.' ${ }^{163}$ Some 35,000 children under the age of fifteen were selected for the sample, gathered from the Camberwell Register, which had been established by the Social Psychiatry Research Unit in $1964 .{ }^{164}$ Using 
this register, Wing and Gould identified all children who were known to the local health, education or social services 'for reasons of physical or mental handicap or behaviour disturbance'; 914 children were selected, including those known to be 'severely mentally retarded'. The rest were screened via interviews to identify 'absence or impairment of social interaction', 'absence or impairment of development of verbal or non-verbal language' or 'repetitive, stereotyped activities of any kind'. These were taken directly from Rutter's three key features of autism. Some 132 children were selected in total. ${ }^{165}$

These 132 children were then given further tests. Previous schedules that had been specifically designed for 'retarded' children were thought to be unsuitable for the study because they 'do not cover in sufficient detail the development of ... comprehension and use of both verbal and nonverbal communication'. Likewise, 'checklists' for autism and childhood schizophrenia were considered unhelpful because they were 'far too selective to be useful with retarded but nonpsychotic children. ${ }^{166}$ What Wing and Gould created in their place was the Children's Handicaps, Behaviour and Skills (HBS) structured interview schedule - a system of measurement that would amalgamate both 'psychotic' and 'retarded' children, whilst at the same time enabling distinctions to be made according to their social abilities. In particular, they argued, their schedule was useful for distinguishing between autism and 'the specific developmental receptive and expressive speech disorders'. The schedule was described as 'a framework for eliciting, systematically, clinical information to be used in conjunction with appropriate, standardised psychological tests for assessment and diagnosis. ${ }^{167}$

The schedule enabled new distinctions to be drawn in the differentiation of children's psychological problems. Instead of dividing children purely by intellectual level, one could now divide them up by social level as well, as demonstrated in Figure 9. Furthermore, new subgroups could be created and these could be analysed by variables such as language comprehension, gender and age. Figure 10 shows a chart depicting methods used to differentiate socially impaired children, demonstrating, for example, that socially 'aloof' children were most likely to have a low level of language comprehension. This suggested that divisions according to social impairment fared just as well as the autism diagnosis when it came to statistically significant 


\begin{tabular}{lcc}
\hline & Socially impaired & $\begin{array}{c}\text { Sociable severely } \\
\text { retarded }\end{array}$ \\
\hline $\begin{array}{l}\text { Number of children } \\
\text { Percentages showing following } \\
\text { abnormalities }\end{array}$ & 74 & 58 \\
$\quad$ History of typical autism & $100)$ & $(100)$ \\
$\quad$ Speech & 23 & $0^{\mathrm{b}}$ \\
$\quad$ None & 55 & $33^{\mathrm{b}}$ \\
$\quad$ Echolalia & 35 & 17 \\
Idiosyncratic speech and/or reversal of & 8 & 0 \\
pronouns (ever) & & \\
Symbolic activities & 55 & $10^{\mathrm{b}}$ \\
$\quad$ None & 42 & 14 \\
$\quad$ Repetitive & & $7^{\mathrm{b}}$ \\
Overall interest pattern & 72 & 31 \\
$\quad$ Repetitive only & 28 & $0^{\mathrm{b}}$ \\
$\quad$ Repetitive and constructive & 23 & \\
Elaborate repetitive routines & & \\
\hline
\end{tabular}

\section{Notes}

At time of interview unless otherwise specified

${ }^{\mathrm{b}} \mathrm{p}<.001$ (ch-square test)

Figure 9 Table distinguishing 'socially impaired' and 'sociable severely retarded' children, from Lorna Wing and Judith Gould, 'Severe impairments of social interaction and associated abnormalities in children:

Epidemiology and classification', Journal of Autism and Developmental Disorders 9, no. 1 (1979)

variables. The authors hypothesised that 'certain areas or functions of the brain are responsible for the development of social interaction and symbolic imaginative activities. ${ }^{\prime 68}$ They argued that some organic pathologies such as Down's syndrome left these functions intact but destroyed others. 'Social impairment' measures were the best way to conceptualise the mental problems of children because they were more closely related to known gross aetiology. In her radical critique of prior descriptions of autism, Wing argued that 'Mutism, echolalia, absence of or repetitive symbolic activities, and an interest pattern consisting entirely or partly of stereotyped activities did not differentiate those with and without a history of typical autism. On the other 
Comparison of methods of subgrouping socially impaired children: demographic, psychological and medical variables

\begin{tabular}{|c|c|c|c|c|c|}
\hline & \multicolumn{3}{|c|}{$\begin{array}{l}\text { Severity of social } \\
\text { impairment }\end{array}$} & \multicolumn{2}{|c|}{$\begin{array}{l}\text { History of typical } \\
\text { autism }\end{array}$} \\
\hline & $\begin{array}{c}1 \\
\text { Aloof }\end{array}$ & $\begin{array}{c}2 \\
\text { Passive }\end{array}$ & $\begin{array}{c}3 \\
\text { Odd }\end{array}$ & $\begin{array}{c}1 \\
\text { Present }\end{array}$ & $\begin{array}{c}2 \\
\text { Absent }\end{array}$ \\
\hline Number of children & 37 & 20 & 17 & 17 & 57 \\
\hline Rates per 10,000 aged $0-14$ years & 10.6 & 5.7 & 4.9 & 4.9 & 16.3 \\
\hline Percentages in each group & $(100)$ & $(100)$ & $(100)$ & $(100)$ & $(100)$ \\
\hline \multicolumn{6}{|l|}{ Chronological age at interview } \\
\hline$<10$ years & 46 & 30 & 53 & 64 & 54 \\
\hline $10+$ years & 54 & 70 & 47 & 36 & 46 \\
\hline \multicolumn{6}{|l|}{ Sex } \\
\hline Male & 70 & 80 & 71 & 94 & 67 \\
\hline Female & 30 & 20 & 29 & 6 & 33 \\
\hline \multicolumn{6}{|l|}{ Language comprehension age } \\
\hline$<20 \mathrm{~m}$ & 92 & 40 & $6^{\mathrm{a}}$ & 59 & 58 \\
\hline $20+\mathrm{m}$ & 8 & 60 & 94 & 41 & 42 \\
\hline \multicolumn{6}{|l|}{ Nonverbal IQ } \\
\hline $0-49$ & 78 & 40 & $53^{\mathrm{b}}$ & 35 & $70^{\mathrm{b}}$ \\
\hline $50-69$ & 17 & 25 & 35 & 35 & 19 \\
\hline $70+$ & 5 & 35 & 12 & 30 & 11 \\
\hline \multicolumn{6}{|l|}{ Reported age of onset } \\
\hline birth & 54 & 90 & $82^{c}$ & 47 & $77^{\mathrm{b}}$ \\
\hline$<3$ years & 41 & 10 & 12 & 47 & 19 \\
\hline $3-5$ years & 5 & 0 & 6 & 6 & 4 \\
\hline \multicolumn{6}{|l|}{$\begin{array}{l}\text { Associated organic conditions } \\
\text { (hierarchical order) }\end{array}$} \\
\hline $\begin{array}{l}\text { Reported to be associated with } \\
\text { social, language and behavioral } \\
\text { impairment }\end{array}$ & 61 & 25 & $12^{a}$ & 47 & 37 \\
\hline Down's syndrome & 3 & 0 & 0 & 0 & 2 \\
\hline Other identifiable conditions & 14 & 15 & 24 & 12 & 19 \\
\hline Dubious or none identified & 22 & 60 & 65 & 41 & 42 \\
\hline
\end{tabular}

\footnotetext{
Notes

${ }^{a} \mathrm{p}<.001$ (Chi-square test)

${ }^{\mathrm{b}} \mathrm{p}<.05$

$\mathrm{p}<.01$
}

Figure 10 Table subgrouping socially impaired children, from Lorna Wing and Judith Gould, 'Severe impairments of social interaction and associated abnormalities in children: Epidemiology and classification', Journal of Autism and Developmental Disorders 9, no. 1 (1979) 
hand, they were very significantly associated with the degree of social impairment. ${ }^{\prime 69}$ In 1981, Wing explained her reasoning for grouping together children with the 'triad of impairments', she argued that

The justification for regarding them as related is that all the conditions in which the triad of language and social impairments occurs, whatever the level of severity, are accompanied by similar problems affecting social and intellectual skills. Furthermore, individuals with the triad of symptoms all require the same kind of structured, organized educational approach, although the aims and achievements of education will vary from minimal self-care up to a university degree, depending. ${ }^{170}$

Wing and Gould recommended that future studies of the mental problems of all children base their divisions upon social impairment as measured by the HBS. Impairments of reciprocal social interaction were reported to occur in 21.2 of every 10,000 children in the area studied, of whom 4.9 presented with a history of 'typical autism'. In all cases the symptoms had first been noticed before the child was five years old. ${ }^{171}$

Wing and Gould's attempt to place 'autistic' children on a continuum with other similar children was similar to Anthony's attempts to place 'severely psychotic' children on a continuum with other partially 'psychotic' children and they flagged up this connection. ${ }^{172}$ Whereas Anthony's three criteria had been based on psychoanalytic and Piagetian 'styles of reasoning' describing an 'a-genesis', 'a-cathexis' and 'a-dualism' in the process of development, leading to an inability to create a stable ego, 'displacement of affect onto things' and 'disturbances in the perception of the self', Wing and Gould described the problem purely in behavioural terms, creating their own triad of observable symptoms. ${ }^{173}$ In doing so, they transformed the problem of ego development and engagement with reality into a problem of social impairment and social adaptation. They also transformed the problem of sensory impairment into a problem of 'social impairment'.

What was innovative about Wing and Gould's 1979 study was that it fused the new sociological category of 'social impairment' along with prior classifications for autism and mental handicap. In doing this they generated a new model for uniting mental handicap and autism that fused the two into an epidemiological entity. Whereas Rutter, Tizard and Whitmore had, in the 1960s and early 1970s, employed the concept of 'social impairment' as a sociological measure in relation to an ability to function in society, Wing turned it into a psychological entity. 
Much has been made of Wing's article on 'Asperger's syndrome' in 1981 as it had such major repercussions. ${ }^{174}$ In short, Wing decided to employ a 1944 paper by the Austrian paediatrician, Hans Asperger, in order to support her own theories of autism and 'social impairment'. Although this story is often told as though Wing unearthed the true definition of autism in the historical past, in fact the reality surrounding Wing's recovery of the Asperger's paper is far more complex. Asperger's paper used very similar definitions of 'autism' and 'psychopathy' to those circulating amongst his contemporaries. What distinguished Asperger's paper was very similar to what distinguished Kanner's paper, namely that it contained very clear and concise case histories that contained vivid descriptions of individual children. Wing's 1979 article using statistical methodologies lacked this kind of description so Asperger's article was a useful tool for her. Furthermore, the Asperger's article supported her aims to break down the concepts of autism and schizophrenia and redefine them according to statistical models of social interaction. This was because Asperger's work highlighted the inconsistencies of the autism concept and its relation to schizophrenia. Wing's 'rediscovery' of Asperger's case studies were useful because they helped her to topple Kanner's hegemony concerning the concept of autism in childhood. They also enabled her to bring autism back this into the field of schizophrenia research, only to divide it up on new lines, unrelated to the concepts of hallucinations and delusions. She claimed that:

The relationship to schizophrenia of Asperger syndrome, autism and similar impairments can be reconsidered. Although they are dissimilar in family history, childhood development and clinical pictures, both groups of conditions affect language, social interaction and imaginative activities. The time of onset and the nature of the disturbances are different, but there are similarities in the eventual chronic defect states that either may produce. It is not surprising that autism and schizophrenia have, in the past, been confused. Progress has been made in separating them and it is important to continue to improve precision in diagnosis, despite the many difficulties met in clinical practice. ${ }^{175}$

As the mother of a child with the autism diagnosis in an unforgiving social climate, Asperger's male authority was also useful. It was via the Asperger's paper that Wing was able to support work on autism and social impairment that she had already outlined in 1979. 
Whereas sensory impairment, as described in the theories of Hermelin and O'Connor and Uta Frith in the 1960s, was very specific in its definition concerning a child's inability to 'sense' the external world through internal capacities, 'social impairment' expanded the limits of what could be conceived as coming under that title. More importantly, it reclaimed the study of human relationships as a science for the new psychology of autism, rather than a science for the Tavistock Institute of Human Relations and the instinct theorists. An infant's engagement with reality thus became synonymous with his or her engagement with social reality because the individual's engagement with social reality could be measured using epidemiology coupled with other methods from experimental psychology. By linking cognitive tests for autism, whether for pattern-detection or language abnormality, under the framing concept of 'social impairment', Wing brought them into the field of human relations psychology and gave them a new legitimacy within wider psychological theory. What more could one want to frame the psyche than the concept of society itself? There was no longer a need for the unconscious when all perceptual and sensory capacities were quantified, qualified and thoroughly known via statistical mapping. The parallels with the generation of evidence for the concept of intelligence in the early twentieth century are marked. With statistics and genetics, Maudsley psychologists sought to establish their model of learning and social development at the heart of British society. This was the basis for a new 'style of reasoning' about autism as a statistical and epidemiological entity.

The dominance of Tavistock models would change dramatically in the 1980s following Wing and Gould's tools to measure 'impairments in social interaction. Wing and Gould's work on 'social impairment' turned Maudsley autism psychology into a theory of human relationships. They thought that because the theory of human relationships was grounded in the theory of autism, their statistical and epidemiological models of autism would, by proxy, lead to new statistical and epidemiological models of human relationships and social development that were truly revolutionary. This would then complete the Maudsley critique of Tavistock models of psychological development. Wing and Gould even developed tests and tools to measure social impairment or the inability to engage or become a fully functioning social subject. Even Bowlby, with his ethological examples, and Winnicott, with his 
poignant descriptions of human development, had not conceived of the possibility of employing tests for social engagement in order to construct a theory of human relationships. It was through the development of such tests that Maudsley psychologists were eventually able to outshine the Tavistock generation in terms of guiding government policy and advising government officials on childcare and education.

The Newsons, with their sociological expertise, were critical to this transition. In the 1970s and early 1980s, government officials were informed about autism almost entirely by the work of Elizabeth Newson and Lorna Wing. George Young and other members of the DHSS had read a 1979 paper by Elizabeth Newson on 'Making Sense of Autism' that highlighted the point that an 'important, pervasive and intractable characteristic of the social impairment of autism is a failure to develop social empathy. ${ }^{176}$ She also drew attention to the flood of research in the late 1970 s that had focused on mother-baby interactions, demonstrating that the infant was far from passive in these interactions and that most 'babies are biologically and innately social, and are ready without being taught to play an active role in social interaction. ${ }^{177}$ Elizabeth Newson argued that in cases of autism, individuals lacked 'social empathy'. An autistic infant was 'suffering from a primary brain dysfunction which interfered with his ability to code or make sense of messages in all usual modalities - spoken language, gesture, facial expression and other body-language. ${ }^{178}$ This failure would 'effectively and repeatedly sabotage his earliest experience of social interaction. ${ }^{179}$ In this construction, the entire 'social' world, the ability to be 'social', became an entirely internal construction. This internal construction of the complete concept of 'the social' echoed legal changes made in relation to the workings of 'social services' at an externalist level. In other words, it was only possible to conceptualise a mental faculty or cognitive structure for 'the social' when it was possible to conceptualise an administrative service to cater to 'the social' from a political perspective. The Seebohm reforms thus also acted as the final juggernaut that stopped the growth of psychoanalytically inspired 'human relations' models of infantile thought.

Before the development of Wing and Gould's tests for social impairment and the Newsons' claims that babies were biologically and innately social, Institute of Psychiatry-trained psychologists had been limited in their ability to test for 'autism' or lack of social engagement. 
Lotter had given epidemiological data that could apparently quantify the problem. Hermelin, O'Connor and Frith had measured children's ability to code and understand the world through language and visual stimuli, but they were limited in their ability to explain social interaction, writ large. Rutter had developed tests to measure the exact impairment in language acquisition and unusual speech of autistic children. But no one had developed a test for social impairment in all its forms. In fact, many Maudsley and other cognitive psychologists in the 1960s and 1970s deliberately avoided all theories of 'failure of interpersonal communication' because they were actively seeking to demonstrate that psychosis and autism were caused by a brain-based cognitive impairment relating to sensory perception. This was precisely how Hermelin and O'Connor regarded the problem, and their theory was echoed in the USA by writers, such as Bernard Rimland, who argued that autistic children were unable to integrate separate experiences and relied on memory for problem-solving, rather than abstract thinking. ${ }^{180}$ Nevertheless, it was the Maudsley group who developed the tests to measure the precise cognitive problems of autistic children and it was this emphasis on measuring senses, perception, memory, recall, etc. that directed attention away from problems of human relationships. The Maudsley group also always employed statistical methodologies when analysing their results, thus providing clear quantitative evidence for the claims they were making about autistic specificity.

Whereas the first psychologists interested in social interaction and play, such as Isaacs and Lowenfeld, had derided both US attempts to measure social scales and behaviourism as a psychological approach, psychiatric epidemiology was a different beast. Behaviourists had argued that there was no way to measure human instincts whatsoever, that it was simply impossible and that therefore psychologists had to abandon their aim to explore these in their theories of socialisation. Psychiatric epidemiologists, on the other hand, did not disregard the theory of human instincts in psychology, but rather argued that epidemiological sciences had the potential to quantify and articulate drives towards social interaction. Once identified within total populations, social instincts and their vicissitudes could be tracked, mapped and understood, as could 'social impairments' or inabilities to create relationships and to socialise. In fact, in its own way, psychiatric 
epidemiology gave structure and scientific credibility to theories of natural or instinctive drives towards human interaction.

Anyone who presented a definition of autism that did not draw from psychiatric epidemiology in the 1970s and 1980s was widely criticised. For example, in the early 1970s, the Nobel Laureate Nikolas Tinbergen teamed up with his wife to develop an ethological theory of autism, building on the work of Bowlby. Their book Autistic Children: New Hope for a Cure argued that autism was caused by environmental stresses within the family, speculating that stressful situations caused by 'modern life' such as long car drives, high-rise tower blocks and parental neglect due to work pressures could all be 'autismogenic. ${ }^{181}$ Even though the Tinbergens put the word 'autism' in quotation marks, they clearly threatened cognitive and epidemiological scientists who were working with a model of autism that focused on recognising the impairments and disabilities of autistic people, and therefore helping to develop better education and social services for them. For the new cognitive autism researchers, the Tinbergen's pronouncements on the causative factors of 'modern life' were a joke. In a scathing review of the Tinbergens' book by Uta Frith, she argued that the Tinbergens' claims that modern life was damaging humanity was 'in a different class from that normally found in scientific discussions', that the authors failed to take into account the latest models of autism and that 'this book presents no more than a veneer of science.' ${ }^{182}$ This criticism of the scientific credentials of a Nobel prize winner must be viewed in context of the fact that the Maudsley model of autism, epidemiological autism, was supporting a new model of child disability rights. Tinbergen's science had therefore become politically problematic.

\section{Rethinking autism and children's rights in the 1980s}

Wing's model of 'social impairment' and children's rights provided the backbone to the implementation of social policies that integrated all children into the education system and society at large in the 1980s. The full integration of all children into the education system was a slow process. Although the 1970 Acts had ensured that all children were the responsibility of the education department, they did not provide any 
binding contracts that ensured that children with special educational needs actually progressed in their learning and social integration. It would take the Education Act 1981 (1983) to obligate LEAs to work with parents with the aim of ensuring progression.

The Education Act 1981 (1983) was based on the recommendations of the Warnock Report and it took seriously Rutter's studies on the prevalence of general handicap, as well as Pringle et al's National Child Development Study. ${ }^{183}$ Warnock's report had marked a watershed for the classification, research and 'special education' of children who were thought to be 'handicapped' physically or mentally, or both. The report had made it very clear that epidemiological and prevalence-rate studies issuing from the Institute of Psychiatry were much more reliable than previous counts for general psychological problems in children that had presented radically varying results. In 1977, one London borough had ascertained as 'maladjusted' ten times as many children compared with another London borough, thereby drawing attention to the inadequacy of that category when searching for statistical and administrative accuracy. ${ }^{184}$ However, Rutter's studies led Warnock and her colleagues to agree that 'the planning of services for children and young people should be based on the assumption that one in six children at any time and up to one in five children at some time during their career will require some form of special educational provision. ${ }^{185}$ The plans under the Education Act 1981 (1983) were based on this measure.

Although the Warnock committee aimed to base service provision on prevalence-rate studies, they argued for specific individualised responses when addressing each particular child's problem. As they put it, 'the particular form presented by an individual child is not necessarily determined by the nature of any disability or disorder suffered by him. ${ }^{186}$ The committee then proposed that the term 'learning difficulties' should be applied to all children with any kind of special educational need and that all previous categories such as 'maladjusted' and 'educationally subnormal' should be abolished. The only thing that would now distinguish the groups from the perspective of education would be the 'specific' form of their problem, ${ }^{187}$ thus specific problems in learning became paramount to administrative definitions after 1983.

In the run-up to the 1981 Education Act (1983), the DHSS had raised questions about the identification of children with mental health problems prior to their entry into school. The Child Psychiatry Client 
Group of the Mental Health Advisory Committee then argued that 'screening for autism needed to be part of a wider screening system of pre-school surveillance with an emphasis on delayed language development' and that 'manpower planning for speech therapists should take account of the growing recognition of their value in the mental health field?. ${ }^{188}$ It was widely acknowledged that most child psychiatrists had very little understanding of the problem of autism, despite the fact that they were trained specialists in childhood mental health problems. This rather satirical situation was due to the fact that child psychiatrists had largely worked in child guidance clinics, which had not treated children with 'mental deficiency'. Professor Philip Graham, Consultant Advisor to the Chief Medical Officer, began discussions with the Institute of Psychiatry and the Institute of Child Health in the late 1970s concerning the establishment of relevant training in autism for child psychiatric professionals. ${ }^{189}$ The plan was that these institutions would lead others to take new approaches to autism in children, and challenge accounts that explored the play of these children within a framework of unconscious fantasy relations. ${ }^{190}$

The resulting report by the DHSS stated that the priorities of future health and social services for preschool children would be 'early identification and assessment', '[t] he development of home-based treatment plans' and 'the development, where appropriate, of specialised playgroup and day nursery facilities'. Using the language of Rutter and Wing, the report argued that 'autistic children, or children whose behaviour includes autistic features, need skilled help in a structured setting' to enable them 'to be helped to move away from the stereotyped "play" that may be inimical to their development. The DHSS gave a grant to 'Family Tree' to develop home-based treatment programmes for preschool children. ${ }^{191}$ For school-age children, they recommended specialist input into schools and assessment facilities and the possible establishment of regional centres of specialist expertise. They also argued for better after-school care, although focused on those who came under the remit of 'services for the mentally handicapped'. ${ }^{192}$

For charitable groups dealing with the most complex cases of need, in particular the Society for Autistic Children, the generalisation of 'social services' only encouraged and impassioned them to argue that 'autistic' people were those who required the most attention to enable them to become social subjects. The Seebohm reforms had been 
criticised for the growth of bureaucracy and administrative paperwork that they had created, but also for the growing professionalism of social workers who may become more interested in career development than in helping needy people. The radical social work movement, 'Case Con', went further in claiming that the Act shifted blame onto families for their shortcomings, rather than acknowledging the role of the state in generating inequalities. ${ }^{193}$

These concerns about the need for greater understanding amongst general social workers to enable social adjustment came to a head in 1979. The Society for Autistic Children had made a deputation to the parliamentary secretary and a meeting was held on 5 October that brought together Sybil Elgar, Lorna Wing and other members of the SAC together with Sir George Young, junior health minister, and other members of the DHSS. The society argued that 'because social services departments had little experience of providing for autistic people', there was a strong need for training as there was 'a serious lack of social workers with the knowledge and experience to understand the autistic person' and that 'there were signs that social services departments might be becoming more reluctant to pay the necessary fees' for the establishment of specialist care for autistic children to live outside of the home. The society asked for greater education amongst health and social service authorities to ensure that they understood that 'the needs of autistic people were fundamentally different from those of the mentally handicapped generally' and to encourage social service departments to 'support voluntary effort' and enable local autistic societies to make use of closed hospitals and other buildings that the Seebohm reforms had made defunct. ${ }^{194}$ The Newsons also argued that people 'with autistic features' were clients with special needs for social services unlike no other client group because of their social impairments, and their views were repeated in government documents. ${ }^{195}$

In 1980, Young wrote to the Society for Autistic Children to say that he supported collaborations between NSAC and other local authorities, but remained lukewarm on the subject of further training workers to deal specifically with the needs of autistic people. There were, he argued, 'other groups of mentally handicapped people who have special needs or who suffer from syndromes which are not yet widely understood', and he could not give extra priority to autistic children, 
even though he would speak to other ministers about the possibility of disseminating information on the topic. ${ }^{196}$ In September 1979, one adviser, Vivienne Simmons, had been prepared to accept Lotter's figure of 4.5 per 10,000 with autism, but questioned the legitimacy of Wing's claims that the number of children with 'autistic features' was '2-3 times as many' as that, arguing in a prejudiced way that 'possibly her small Camberwell Sample with its high ethnic mix is atypical.'197 Another adviser, Mr French, argued that Wing's sample was definitely atypical and that all attempts to measure prevalence were 'sheer guesswork. ${ }^{198}$ However, this resistance to the growing application of autism within health and social service departments was countered by the increased interest in the education sector and, ultimately, in the passing of the 1981 Education Act (1983).

The 1981 Education Act, which became law on 1 April 1983, stated that all LEAs must draw up 'statements' that were legally binding contracts between the authority and the child's parents. ${ }^{199}$ In 1983, the DES and the DHSS issued a joint statement to all LEAs stating that in any description of a child's 'special educational needs':

The main focus should be on the child himself rather than on his disability. The extent to which a learning difficulty hinders a child's development depends not only on the nature and severity of that difficulty but also on the personal resources and attributes of the child, and on the help and support he receives at home and at school. ${ }^{200}$

Although this approach was ostensibly individualised, guidelines on completing the bureaucratic paraphernalia associated with the creation of 'statements' continually reiterated the point that the problems of 'statemented' children should be understood as 'strengths and weaknesses' in terms of their 'functioning. ${ }^{201}$ Such an approach echoed models of autism that highlighted a child's unique individuality as a function of their level of 'social impairment.' The Warnock Committee's proposal that a 'named person' should be responsible for supporting and informing the parents was not always followed in practice, and this resulted in varied liaisons between a multitude of professional groups directed only by these descriptive guidelines. ${ }^{202}$ Because of their promotion following the 1975 DES circular 2/75, educational psychologists increasingly took on the role of the 'named person' who represented the needs 
of the child concerned. They thus developed a vested interest in ensuring that a child received a statement.

An FA2 form was a legally binding statement under the Education Act 1981 in which a psychiatric professional described the special educational needs of an individual child. A typical FA2 form concerning a child diagnosed with autism in the 1980s read:

she showed repetitive and limited language, her social behaviours were very disinhibited, and she showed a great deal of attention-seeking behaviour, her imaginative play was limited and there was also some evidence of obsessional behaviours ... a school for children with mixed developmental disorders was, therefore, felt to be appropriate at this stage although it was noted that the placement would be reviewed regularly. ${ }^{203}$

Part of the goal of the Education Act 1981 was to further integrate children with special educational needs into mainstream schools. This process had already been set in motion after the 1970s and many separate units had been established within mainstream schools for the purpose of integrating 'handicapped' children. The number of 'handicapped' children receiving education in such units was counted as 11,027 in 1973 and this rose to 21,245 in 1977. ${ }^{204}$ The Education Act 1981 sought to increase the number of 'handicapped' children integrated into ordinary schools and encourage integration within schools themselves and not just in units on the school grounds. The Warnock Committee had described this as 'social' and 'functional' integration as opposed to integration purely in terms of location. ${ }^{205}$ This meant integrating handicapped children at social events such as eating and playing at lunch times and eventually involving them in 'functional' lessons in the classroom.

The introduction of the statementing system in 1983 increased the power and discretion of educational psychologists to make decisions concerning placement of children with 'autistic features'. In addition, because of the emphasis that the Act placed on integrating all types of children into normal schools, many children with 'autistic features' began to be integrated into mainstream classes. ${ }^{206}$ The appointment of home tutors to assist children with 'autistic features' in normal schools was a practice that began in 1983 and enabled children to get additional help at home that enabled their integration into mainstream education. 
In 1974, just thirty-four children registered with autism were being taught in special classes attached to mainstream schools, but after the Education Act was passed, children with 'autism' and 'autistic features' regularly began to be integrated into mainstream schools. ${ }^{207}$

It was via the Education Act 1981 that large numbers of professional groups were introduced to the term autism and also began to use it widely in the work of classifying and allocating children with diverse forms of 'special educational need'. However, many of these professionals had not been trained to recognise the difference between a child who was hallucinating and one who was not, at least not through the traditional route of medical and psychiatric training, and this stirred the Royal College of Psychiatrists to try to claw back their exclusive rights to diagnose children. In fact, in 1988, the Royal College issued a statement to the DES and the DHSS criticising the implementation of the Education Act 1981 and claiming that the system was both slow and inexpedient. They then recommended that: 'Child and adolescent and where appropriate mental handicap psychiatrists should be involved with the placement of children whose special educational needs result from emotional or behavioural problems, including many children with intellectual and learning problems. ${ }^{208}$ Such children, they argued, constituted a 'high proportion of those who will be the subjects of statements of need' and that immediate steps be taken to consult psychiatrists directly concerning the placement of these children. However, this battle to regain psychiatric power over child classification was not won. Instead, through the operation of the statementing system, educational psychologists, parents, parent-led organisations, teachers, bureaucrats, administrators and psychiatrists had to work together to propagate and disseminate new categories. Autism had become the most salient of those categories because it referred to an individual state of mind that could be measured using psychiatric definitions and altered using educational means. The new autism psychologists' growing arsenal of testing equipment was used to outsmart psychoanalysts in their dominant discourse of human relations and interactions, and also to outwit IQ specialists and intelligence testers because it provided an alternative means to measure capacities and capabilities in children.

Although Tavistock models of human development had been very influential in policy relating to health and social welfare, an area in which human relations-style psychology did not gain a foothold in the 
post-war era was in the field of education. For the organisation of the schooling and education system, intelligence tests had provided far too strong and powerful a tool for political wrangling so that complex theories of social development and the unconscious in children took a back seat when it came to classroom planning. As Mathew Thomson has pointed out, older ideals and class divisions also guided government policies in this period. ${ }^{209}$ Education policy in the post-war period tended to focus on identifying and training or educating children according to a simply stratified vision of society. This changed radically following the Education Act 1981.

The strong support for the category of autism within the education system also had an effect on the organisation of wider social services, and encouraged parents to take a more active approach to their children's diagnoses. After the Education Act 1983, many parents began to request additional social service support specifically for the reason that their child had 'autism', claiming invalidity benefits and other forms of support such as mobility allowance and special allowances in the provision of housing. ${ }^{210}$ Again this introduced more professional groups working in social services to the subject of autism. This growing awareness of autism was coupled with increased attempts to identify it outside of educational circles.

In 1980, John and Elizabeth Newson launched a 'media search' for people with autism, requesting that journals and magazines help in getting in touch with the parents of 'autistic young people who may never have been diagnosed as such'. Newson specifically requested 'mildly autistic people', stating:

Some of your readers may have suspected that their child was autistic because from a very early age he was withdrawn, distant and aloof, and probably still remains 'cut off' socially in some ways. He is likely to have had certain obsessions and rituals, to have had odd difficulties in using and understanding language normally, and to use it now in a rather stilted and pedantic way. It will have been hard to have normal relaxed conversations with him because of this combination of social and language difficulties as well as obsessional preoccupations. ${ }^{211}$

The Newsons said that of autistic children of normal intelligence, it can be argued that these children suffer from the "purest" form of autism, in the sense that their handicap is not in terms of general 
mental retardation but in terms of the specific impairments that define autism. ${ }^{212}$ This interest in identifying and testing an expanding population of autistic individuals reflected the expansion of social services and educational services to cater to autistic groups.

Parents became acutely aware that the new autism psychologists could help them to gain the support that they wanted. For example, one mother wrote to the Newsons in the early 1980s in desperation after social workers had removed her child from her 'on grounds of her imputed neglect having "caused" the child's impairment. ${ }^{213}$ The Newsons brought in Lorna Wing to diagnose autism, and persuaded the director of social services for the local authority to return the child to her mother. For the Newsons, this only confirmed the need for further research on autism to prevent such injustices. Social workers needed better guidance when it came to making judgements about mothers and their capacities. This was no longer the era of the Tavistock theory of human relationships, the days were over of social workers making their own judgements about what caused children's problems. Parents began to reclaim their power to define what was or was not wrong with their children. They were coming to be increasingly supported under changes in childcare law.

Another important transition that took place in the 1980s was that the first generation of children given the autism diagnosis in the 1960s were now growing up and their needs were becoming increasingly apparent in legal discourse surrounding disability legislation. After the government acknowledged that all children had the right to an education, they also had to acknowledge that autistic adults also had to be integrated into the social fabric and supported. Responsibility for the social care needs of older individuals with autism had been debated since the 1970s. ${ }^{214}$ As autistic children grew into adulthood, many were referred on to government schemes introduced in 1975 and 1980 in order to improve their chances of living independently. ${ }^{215}$ In July 1983, G. P. Price, Project Development Officer for the Birmingham and District Society for Autistic Children, wrote a report on the special needs of autistic adults in the West Midlands that was forwarded to the then secretary of state, Mr Fowler. ${ }^{216}$ Price's report included an appendix by Lorna Wing explaining the triad of impairments. ${ }^{217}$ In 1984, Michael Rutter proposed to examine 'the specific socio-emotional deficits and abnormalities shown by autistic adults of normal non-verbal intelligence and a normal level of language expression and comprehension. ${ }^{218}$ 
In the early 1980s, John and Elizabeth Newson worked hard to highlight the fact that autistic children grew into autistic adults and that many of these adults developed new social needs. ${ }^{219}$ In 1984 , a seminar was organised in collaboration with the DHSS. Newson estimated that 'autistic people with overall near-normal intellectual ability represent from 10-25 percent of the total autistic population', pointing out that this could be an underestimate because of the 'reluctance and failure of some professionals to recognise that autistic children are not necessarily mentally retarded' and the 'lack of agreement and clarity as to the definition of autism. ${ }^{220}$ The conclusion of the report was that better diagnostic services needed to be implemented and linked directly to follow-on advice. LEAs needed to improve their staff training, especially concerning 'the more able' children and educational provision needed to be considered in a number of settings. Newson criticised the focus on behaviour-modification techniques for autism, because she considered that they were aimed at the less able group. Newson also recommended 'interpersonal social skills training', particularly at adolescence, to inculcate social awareness, and that this training should continue beyond sixteen and possibly even nineteen years of age. Better vocational training and opportunities for sheltered state-organised employment should be offered. In the spirit of inclusivity and the new sociology, the Newsons even argued in the 1980s that autistic people should become part of the debate about their own needs and services.

It is clear that diagnoses of autism increased after the condition was related to mental deficiency, thereby expanding the category to include individuals who would previously have been excluded. What was equally important to the expansion of the category was the fact that age of onset was increased to cover the whole of childhood. This meant that 'social impairment' could be identified in older children with varying levels of intelligence. 'Autistic' became a description that could be used in multiple contexts covering multiple age ranges. From the perspective of welfare and social justice, this aimed to ensure that no one who could have benefited from a diagnosis lost out; however, it also meant that more infants, children and adults were regarded as suffering from a delay that affected their social, linguistic and imaginative capacities.

In the 1980s, local authority social service departments had to grapple with the fact that the 'social' world they were trying to manipulate was not a concept that everyone understood. At the 
same time, a theory was constructed that babies created 'the social' through innate cognitive mechanisms and not by instinctive desires for sexual and bodily relationships that they unconsciously fantasised about. It was during this transition that the creative aspects of play were rewritten not as attempts to imaginatively act out relationships, but rather as structured attempts to represent social scenarios, events and interactions.

\section{A new 'theory of mind'}

The changes occasioned by the Education Act 1981 were paralleled by new developments in the conceptualisation of autism within a general theory of psychology. As would be expected, the intellectual milieu that had been forged at the Institute of Psychiatry and University College London (UCL) was critical in shaping these new intellectual models or 'styles of reasoning. These theories would later become dominant internationally in shaping a general theory of autism. In 1982, Neil O'Connor retired from the UCL Medical Research Council Developmental Psychology Unit and it was taken over by John Morton, a graduate of Reading University and a member of scientific staff at the MRC Applied Psychology Unit in Cambridge. Morton renamed the unit the MRC Cognitive Development Unit and sought to focus attention on using experimental psychology to generate wider theories of general cognition. This was not something that had particularly interested Neil O'Connor but it would increasingly come to define the work of the unit. Under this new direction, Frith began to work on the subject of autism again and also began to supervise $\mathrm{PhD}$ students, most notably Simon Baron-Cohen. Frith, Baron-Cohen and Alan Leslie, a recent $\mathrm{PhD}$ graduate from the University of Oxford, became particularly interested in the potential for theories of autism to explain wider questions in general psychology.

In July 1983, Uta Frith started writing notes on the basic definition of autism, affirming to herself that Rutter's three criteria for autism were just a working definition of autism and 'there is still a need to relate cognitive/language/social/stereotypic phenomena in a meaningful way in order to explain varieties of autistic behaviour. ${ }^{221}$ In essence, this was also what Wing was working towards in her description of Asperger's syndrome. The fact that there were many varieties of autistic behaviour 
encouraged a wider conceptual model for the diagnosis. Frith's important contribution was to pose the question: 'How far are social difficulties part of [the] cognitive deficit?"222 In her notebook from 1983, Frith hypothesised that the 'cognitive dysfunction' of autism was due to a 'raw in-out cycle of processing', or 'processing without representation', where perceptual stimuli remain " "raw", "unanalysed", "not encoded". This short-circuiting of input and output was also the reason why some autistic people demonstrated very good motor skills, rote memory and drawing skills. Building on Hermelin and O'Connor's work, Frith reasoned that autistic people experienced all stimuli as of equal value; there was a lack of ability to embed 'hierarchically salient features' leading to 'excessive segmentation. ${ }^{223}$ It was this reasoning that led her to the hypothesis that autistic people had 'no intentionality, no "theory of mind", no person awareness, no social faculty."224 This therefore explained their 'lack of pretend play', 'inability to form and utilise symbols' and 'inability to communicate linguistically on a sophisticated level'. It meant that from the age of nine months to a year and onwards, autistic infants displayed an 'inability to take another person's mental state' and an 'inability to know ones own mental state.225

When Simon Baron-Cohen, Alan Leslie and Uta Frith argued that autistic children lacked a 'theory of mind' in 1985, they built on the post-1960s conception of autism, describing it as 'a profound disorder in understanding and coping with the social environment', in which the main symptom is 'impairment in verbal and non-verbal communication. ${ }^{226}$ Frith, Baron-Cohen and Leslie took the term 'theory of mind' from the work of Premack and Woodruff who had employed it to describe their study of chimpanzees. Frith, Baron-Cohen and Leslie used it to describe the ability to attribute autonomous mental states to the self and others so as to predict and explain actions. Leslie had been conducting work on the abilities of normal two- year-olds to understand pretend play and argued that autistic children showed deficits in their capacity for imagination. Baron-Cohen et al. then put forward the hypothesis that autistic children suffered an impairment in the cognitive mechanism required for 'mentalising' or representing mental states. 'False belief' tasks, in which subjects were tested to see if they could predict the thoughts of others, were employed to test this theory. In many trials, these tests were used to compare children with autism to control children with low language abilities or 
low IQ levels. ${ }^{227}$ These study designs were very similar to those used by Hermelin and O'Connor. The description of autism as a 'theory of mind' deficit did not exclude subjects who might have good vocabulary, syntax, phonology and rote language. Their only failure related to their ability to think of the mental states of others.

This attribution of autism as a 'theory of mind' deficit was the complete opposite of the theory of autism as a state of mind characterised by visual hallucinations and bodily experiences of relating to other objects and other people. It built directly on Wing's model of autism as a 'social impairment'. This theory of autism was only made possible by the integration of all child populations into a general theory of psychology and the subsequent removal of theories of adult psychopathology within developmental psychology. This was also related to the shift away from theories of instinctive motivations and 'maladjustment' that had prevailed within earlier models of child psychology. Interestingly, however, what was put in its place in the 1980s was: nothing. The theory of autism developed in this period stemmed from the claim that there was a complete absence of knowledge about the nature of early infantile thought and that only the conduct of more experimental psychology and epidemiological studies could fill this gap. This is how the theory of autism came not only to challenge but also to replace theories of unconscious instinctive motivations: because it broke down the psychoanalytic theory of ego development to its core, offering the potential to replace it with new, standardised, reproducible tests. The question of whether such tests could really explain the development of subjectivity within the context of the formation of relationships was a moot point. The new autism psychologists wanted to develop a new theory of mind.

Baron-Cohen, Frith and Leslie drew from Piaget's tests of 'egocentricity' in their proposition that autistic children lacked a 'theory of mind', in particular the test of 'three mountains' in which a child was asked to describe what could be seen from another person's point of view on a mountain. However, building on the work of Peter Hobson, they argued that the three mountains test only identified 'visuo-spatial skills', whereas their test could identify whether or not a child was able to impute 'higher-order' mental states to others. Children were presented with a model of a room with Sally, Anne, a basket, a box and a 
ball. They were told that Sally puts her ball in the basket and leaves the room. Whilst she is out, Anne takes the ball from the basket and puts it in the box. The question was: where would Sally look for her ball? Frith, Baron-Cohen and Leslie argued that those who are able to impute mental states to others would say that she would still think it is in the basket, whereas 'autistic' children will assume that she knows it is in the box.

This reformation of Piaget's famous test for egocentricity was particularly telling, as it was Piaget who had introduced the concept of autism into developmental psychology. For Piaget, autism existed before egocentricity and was not determined by it, but Frith, Baron-Cohen and Leslie argued that the Sally-Anne test was able to delve deep into a child's mental ability to understand other people's thoughts and that this was the explanation for all their problems. In fact, 'theory of mind' tests were a way to describe an individual's relationship to other minds that completely bypassed the thought processes that may have mediated that relationship. This model or 'style' of reasoning about autism represented exactly what was required in that historical moment - an account of the development of thought in infants that concerned their ability to relate to others, yet that did not speculate at all on the thought processes, hallucinatory or otherwise, that may have structured those relationships.

Although Wing had argued that autistic children lack 'symbolic representation' in 1976, she had not developed cognitive models to explain why this was, hence Frith's work, when collaborating with Baron-Cohen and Leslie, was important in forging new concepts. Thinking about the problem in relation to wider theories of child development, they reasoned that even in early infancy, humans show species-specific social behaviour in terms of 'interest in people, faces, voices', 'imitation', 'social smiling', 'early pointing' and 'anticipation of pick-up', and that therefore deficits in primary social responses may be indicative of autism. ${ }^{228} \mathrm{How}$ ever, what they needed to explain was the primary deficit and how this related to the second-order impairments. In their search for the basic perceptual problem of autism, Alan Leslie argued that this should be regarded not as a failure of selective attention but rather as an 'unusual "awareness" of lower level perceptual products.229 This drew from Hermelin and O'Connor's work on sensory awareness but was now, of course, framed in the language of cognition and information-processing. 
Frith, Baron-Cohen and Leslie knew that this presented a challenge to psychoanalytic models of development because it argued that social capacities, and the ability to think creatively and imaginatively, were not necessarily given psychological faculties. Whereas Isaacs, Klein and Anna Freud had built their theories on an edifice of human fantasies as the drives towards human relationships, Frith and colleagues were arguing that human relationships depended on an individual being able to adopt the perspective of another. Instead of the sex drive, it was the ability to see another's perspective that was the glue that created the social world. This was not just about how individuals diagnosed with autism were perceived, it was also about how society perceived its non-functional subjects. Instead of a social model built on reproduction and the exclusion of non-productive elements, Frith and colleagues espoused a social model built on 'social abilities' and the will to support and encourage those abilities. The Journal of Autism and Developmental Disorders continued to serve as a conduit for this new research on autism.

By the mid-1980s, the MRC Developmental Psychology Unit had around 800 babies on its books, whose mothers would bring them regularly by taxi to engage in studies of normal development. Work on autism had spurred the study of normal infantile perception, in an effort to understand the subtle differences that could cause that development to take an atypical route. Leslie became interested in testing infantile perceptions of cause and effect, employing increasingly sensitive tests to identify perceptions from very early ages, such as the way in which an eighteen-month-old would reach for an object with an anticipation of its weight, or the way that a six-month-old's visual attention would shift when it repeatedly watched collision events. He used these studies to demonstrate that even six-month-old infants could perceive cause and effect and that cause and effect was therefore built into the visual apparatus that an infant was born with. As with 'theory of mind' tests, these studies also sought to overturn Piagetian models of children's perception by presenting a model of children's thinking that could be tested and measured using proto-behavioural measures.

This also presented a challenge to Piaget's descriptions of cognitive development by demonstrating that typical children could understand cause and effect from a very early age, and that inabilities to reflect on the logic of certain situations could be due to inabilities to perceive the 
thought processes of others, rather than simple logical errors. As Leslie described the findings to a Nursery World reporter in 1985:

It would never have been dreamed of 20 years ago that a six-monthold could perceive cause and effect. It was originally thought that they would have difficulty in perceiving colours and even shapes. To find something as abstract and as sophisticated and intellectual as cause and effect amazed us and changed our whole view on how the human mind develops. ${ }^{230}$

New 'theory of mind' tests, together with the large-scale psychological investigation of babies' perception of cause and effect, proved a useful support to the epidemiological category of autism. There were, however, some major legal and social changes that had to occur before these theories and 'styles of reasoning' about children's social development, and autism as its antithesis, were adopted within mainstream theories of infant development.

\section{Autism and the Children Act 1989}

After the late 1970s, child psychology became increasingly framed around the second concept of autism and the logic of Wing's 'social impairment' model. It progressively applied and integrated the new sciences of measurable 'social impairment' into its theories of child development. Two things enabled this autification; first, the standardisation of testing schedules for autism, and second, the increased application of the category within the education system. Psychiatric epidemiology had given credence to the new autism and educational establishments grasped at these new certainties in their efforts to integrate diverse populations. Significant changes in the construction of children's rights over the course of the 1980s encouraged child psychologists to adopt the theory of autism as part of a political project of social integration. By supporting its logic of child autonomy and independence. Major changes in the construction of children's rights in British law affected how education, health and social service departments described children's individual differences. These changes in child law increasingly structured social services around an individual child's specific needs, rather than implementing them according to pre-formed ideas about family life and the services needed to protect it. The growth of tests to assess and 
measure autism and 'social impairment' fitted neatly into this new model of service provision for individuals, specifically children, with specific social needs. Once these legal transformations had taken place, increases in rates of autism began to be reported in epidemiological studies. These increases were largely a reflection of the fact that there were simply new ways to measure autism and that these new models had come to be accepted within the education system and across social services.

It was thus the administrative framework that supported the production of a new model of autism in Britain. The standardisation of autism under the wide umbrella of 'autistic spectrum disorders' and the way that schools and educational services readily adopted new psychological tests for autism in their efforts to integrate all kinds of children into mainstream educational settings in the 1980s helped to propagate this model. Psychological tests for autism have thus become critical to the formation of social policy relating to child welfare, health and education. 'Social deficit' models of autism have led psychologists, psychiatrists and even psychoanalysts to rethink their understanding of what is regarded as 'normal' social development. They have become standard fare in psychological textbooks, and part of the standard set of instruments used by educational psychologists and child health professionals. By tracing the development of these tests in relation to the increased prevalence of autism, one can see how the theory of autism has altered perceptions of parent-child relationships and has also transformed the organisation of educational and social services in Britain.

The mid-1980s saw radical attempts to restructure childcare and family law. In 1984, the Parliamentary Select Committee (Social Services Committee) was established to rationalise and modernise the law relating to children and families. It was conceded that the construction of childcare and child welfare law up until that point had been largely ad hoc and had arisen at different times regarding unrelated concerns. ${ }^{231}$ The committee concluded that 'social services', as they had come to be known generically under that title, were failing to work in partnership with parents and were too prone to rely on compulsory orders. This was largely a result of the Seebohm reforms, which had created standardised 'social service' departments as anonymous entities that were criticised for supporting their own existence rather than the needs of families. ${ }^{232}$ At the same time, organisations such as Justice for Children began organising themselves around the issue of children's rights and 
this approach was followed by specialist charitable organisations such as SAC, which was renamed the National Autistic Society in 1982. A 1985 report by the Department of Health, Review of Child Care Law, and the resulting white paper, The Law on Child Care and Family Services, argued for a 'major overhaul' of childcare law that resulted in the Children Act 1989 (1991).

The 1989 Act stated that all children, wherever possible, should be brought up within their own families and that if children had any specific needs relating to their welfare, these should be provided by external agencies that worked as service providers to the family. Children 'in need', as defined in the Chronically Sick and Disabled Person's Act 1970 and related legislation, including children diagnosed with 'autism', should be assessed and provided for in such a way as to minimise the effects of their disability and to enable them to lead 'lives which are as normal as possible..233

The 1988 Children Bill, which led to the Act, was described by the Lord Chancellor, Lord Mackay of Clashfern, as 'the most comprehensive and far-reaching reform of child care law which has come before parliament in living memory.234 One of the most striking changes occasioned by the Act was the introduction of rights for children to have a say in their own care. Children were thus no longer presented as the mere recipients of state and/or parental care but had a right to that care. As part of this transition, the concept of 'parental responsibility' superseded previous legal terminology that had described the 'rights', 'duties' or 'authority' of parents over their children. This moved away from the perception of the child as an object for the parents to own. As Clashfern put it: 'The overwhelming purpose of parenthood is the responsibility for caring for and raising the child to be a properly developed adult both physically and morally. ${ }^{235}$ At the same time, the Act also ensured that welfare professionals were also responsible for ensuring that children's rights were upheld. In fact, one of the major changes occasioned by the Act was the increased monitoring and accountability of welfare professionals in upholding those rights.

Prior to the passing of the 1989 Act, much child law had been phrased under the notion that children were defenceless creatures who needed the protection of social workers and other welfare agents who acted benevolently in the interests of the state. The 1989 Act overturned these ideas and gave agency to children as subjects in their own right. Children were reconceived as people to whom duties were owed, and were 
not just the possessions of others. Within the family courtroom, the Act ensured that 'the ascertainable wishes and feelings of the child concerned' be taken into account when decisions were being made about their care. ${ }^{236}$ Provisions were established to enable the easier presentation of children's views to the court. Local authorities were also made more accountable for decisions concerning children in their care, and complaints procedures were made available regarding decisions made about children in care or 'in need. ${ }^{237}$ Furthermore, local authorities were required to open and maintain a register of all disabled children in their area and this 'may be kept by means of a computer. ${ }^{\text {'238 }}$ Children were given powers of refusal to submit to medical or psychiatric examinations as directed by the court if they were deemed to have 'sufficient understanding' to make a refusal. ${ }^{239}$ The Act thus dealt a heavy blow to psychiatric authority. It gave new weight to children's own opinions and empowered them as individual subjects. The Act was very important in ensuring that children's individuality was recognised in law.

As well as leading major changes in disability and education legislation, parent groups such as SAC were part of a growing movement representing parental power to challenge decisions made by local authorities. These included Justice for Children, National Children's Bureau, Advisory Centre for Education, National Council for One Parent Families, and Voice of the Child in Care. ${ }^{240}$ In 1974, the Family Rights Group had been established to assist families involved with local authority intervention concerning their children's care. In 1979, the National Association for Mental Health (MIND), together with the Cobden Trust, published In Whose Best Interests?: The Unjust Treatment of Children in Courts and Institutions, a radical critique of then current practice for state assessment and provision for the needs of all children. This argued that in many cases where children had been placed in boarding schools for the 'Educationally Subnormal' (ESN), for example, 'it is no exaggeration to describe them as having been socially crippled by well intentioned and ill considered care' that had not equipped them with 'basic social survival skills. ${ }^{241}$ In Whose Best Interests advocated for a better legal framework to protect such children. In 1981, the Children's Legal Centre was established to advocate for children's rights. These publications and institutions led to the changes occasioned by the Children Act 1989. After the Children Act came into force in 1991, this new legal framework gave an important expression to children's desires, wishes, needs and wants, 
which had previously not been written into child law. It was this legal shift towards child autonomy that truly enabled the concept of 'autism' to become established and to grow and multiply as a dominant way of thinking about children's development and mental states.

Unlike earlier models, the 1980s model of autism offered certainty and clarity to government officials interested in developing new models of education and society based on neoliberal models of intervention that privatised public services and encouraged free-market competition. Margaret Thatcher, who famously declared in 1987 that 'there is no such thing as society', was then promoting these new visions as the prime minister. The statement was part of Thatcher's well-known rhetoric regarding the great value of the 'family' and the way that it should be protected from unnecessary state intervention. ${ }^{242}$ Her period as prime minister coincided with wider criticisms of state intervention and 'social services' through the formation of groups such as PAIN (Parents Against INjustice), which challenged the authority of 'social work' professionals to remove children from their parents. PAIN enlisted lawyers, doctors and others to support their cause, building new professional and legal networks working to challenge local authority decisions. ${ }^{243}$ These moves away from a model of children's rights that relied on benevolent local authority decisions were coupled with the move towards a model that relied on legal definitions of children's rights and 'social entrepreneur' parents who worked hard to ensure that these rights were met. From the viewpoint of psychologists from the Social Psychiatry Research Unit, 'social impairment' measures provided a way to measure each individual's potential to understand what society was. For Maudsley psychologists, 'society' needed to be reduced not just down to men, women and families, as in Thatcher and Hayek's vision, but into even smaller discrete entities that took account of each individual's unique abilities to engage in the social fabric. This was, in some ways, a form of individualism, but it took individualism to an extreme in its attempt to measure the very core of what individuality and social capacity were.

The 1980s thus saw a set of major shifts in the construction of child law that destabilised further the earlier discourse surrounding children's needs and development that were framed largely in the model of the Tavistock school of human relations. Institute of Psychiatry and UCL psychology researchers were at the forefront of these shifts. Lorna Wing petitioned education, health and social service departments to 
conceptualise children within a total population and then think about the limits of social abilities. Rutter, Tizard and Whitmore encouraged education authorities to develop the 'statementing' system to ensure that the needs of individual children were being met. The goal of both was to standardise children's experiences of society, to enable them all to live lives that were as 'normal' as possible. This vision fed into a new discourse of children's rights that ostensibly placed children at the centre of legislation concerning their health, education and welfare and encouraged inclusive social practices. Instead of supporting social hierarchies and class divides, this new model of society aimed to enable all children to develop to their potential. This new discourse of children's rights and the inclusion of children with all forms of 'handicap' obviously encouraged different visions of what constituted society at the level of government. However, it was also stimulating a reconceptualisation of the ways that individual children learned to become social beings. In other words, in the 1980s, it was not just Lorna Wing and the Maudsley-trained researchers who became interested in how far children could engage socially with others, respond to 'social services' and develop a broader appreciation of 'society'. Such questions were also being triggered in government and social work discourse by the changes occasioned by the recognition that children with mental handicaps or impairments had the right not only to an education, but to an education that was tracked and measured via legally binding documents. The idea that autism, or indeed any form of marked mental difference in childhood, was a kind of 'social impairment' slotted neatly into this new model.

There were some inherent contradictions in these changes. The Children Act reduced the powers of the state to intervene in family life, in the sense that it increased the accountability of welfare agencies and disallowed arbitrary state interventions. However, it also highlighted the need for children's individual freedom to be defended under the law, and to make sure that if and when the state did intervene in a child's care, it did so with the full weight of the law behind it. Thus, although children's autonomy and freedom were to be respected, this necessarily had to happen in a legalistic framework where procedures were clearly defined under the law. Child autonomy was granted, but it depended on its quality being constructed by legal agencies. Because of this, interest in the definition of child autonomy began to grow. People wanted to understand more about its nature, class, type and kind. 
Autism became a critical concept in the significant reframing of child law that occurred in the late 1980s. With a burgeoning interest in child autonomy, a growing number of professionals and parents became interested in psychological theories of social engagement and its absence. Although autism was increasingly defined as a 'social impairment' characterised by lack of imagination and of the ability to play, to communicate and to interact socially, this same model of autism was also used to affirm absolutely the rights of autistic individuals to participate in social life and to have their rights acknowledged and appreciated on a par with those without such impairments. It is this contradiction that has given autism its appeal as a diagnosis and as a way to challenge established psychological theory. This is why it has always been an 'enigma' to Uta Frith and others: it represents both the freedom and limitation of children's social expression and capacity.

The implementation of the Children's Act 1989 was a very complex process because interests, 'wishes and feelings' of children were always being weighed up in court against judgements about the child's 'best interests'. This put children's wishes on a whole new platform. Children's individual 'wishes and feelings' could clearly no longer be determined or classified by childcare professionals such as Susan Isaacs, John Bowlby or Margaret Lowenfeld, who claimed to have the authority to know what these really were. Now children's 'wishes and feelings' were important legal objects that had to be taken seriously in court. These defined a child's autonomy and their ability to state their needs. It should not be surprising that statistical psychologists such as Wing, Rutter, Tizard and Frith held much more legitimacy in their descriptions of child development than anyone who had focused only on children's desires as the measure of their identity. The Children's Act signalled a new vision of children's identity and freedom to state their wishes, and those wishes had to be legally verifiable. No wonder people began to take a much more cautious approach to the study of their expression. The full acceptance of statistically defined autism as a means to describe the individual thought patterns of children was one way that this Act was played out in children's new experiences of their personality, individuality and selfhood.

As the rights of individuals with mental atypicalities and differences were further supported in legal definitions, the new generation of epidemiological and experimental psychologists felt increasingly selfassured in their ability to make pronouncements on the significance of 
the autism category for understanding child development in general. The passionate support for the rights of children with serious difficulties in social interaction, and the campaigning for their rights on every level, necessarily had to be supported by further scientific investigations. In the 1980s, the concept of autism was, on one level, a key legal concept in the assurance of children's rights and, on another level, a central concept in the reframing of childhood psychological sciences as epidemiological and experimental sciences. The concept became increasingly entrenched on both of these levels, with child rights supporters and cognitive psychologists supporting each other in affirming the significance of autism and assuring services for any children diagnosed with the condition. By the late 1980s, the new autism psychologists had become stronger and more persuasive in their affirmation of their model of the category and its role in assuring rights to social care, education and acceptance for all. British researchers also persuaded the international community to adopt this approach.

The strength of conviction espoused by the Wings and the other new autism psychologists in Britain in the 1980s was impressive. They were very successful in advocating educational rights for autistic children in the UK, and in ensuring that a new network of agencies was established to support this project. This move towards the provision of services to children as part of a new market for care, rather than a top-down social intervention programme, slotted neatly into new neoliberal models of social welfare provision. The growth of autism and the growth of economic citizenship and advanced free-market liberalism thus went hand in hand.

However, when Lorna Wing's work and the science of autism epidemiology were launched on the global stage, they took on a life of their own and generated new ideas, thoughts and fears about the new autism. It is these international ideas about 'social impairment' and the new autism to which we will now turn.

\section{Notes}

1 Titmuss, Commitment to Welfare.

2 Seebohm, Report of the Committee on Local Authority and Allied Personal Social Services, p. 11. 
3 CLAAPS1968, p. 25; K. Jones, A History of the Mental Health Services, p. 332.

4 CLAAPS1968, p. 25; Mittler, 'Obituary: Stanley Segal'.

5 Brearley, Admission to Residential Care, pp. 69-84; Hendrick, Child Welfare: England 1872-1989, pp. 231-235; R. Harris, 'The life and death of the care order (criminal)'.

6 Roshier and Teff, Law and Society in England, p. 135.

7 Brearley, Admission to Residential Care, pp. 69-84.

8 Hansard: HC Deb 10 February 1971 vol 811 c 203W; CSDPA1970(1971).

9 Watkin, Documents on Health and Social Services 1834 to the Present Day, p. 108.

10 Thomas et al., The Health and Social Needs of Young Adults with Physical Disabilities, p. 99.

11 Robson and Kjønstad, Poverty and the Law, p. 82.

12 Hansard, 16 July 1970, vol 803, no. 14, col. 1684.

13 Hansard, 16 July 1970, vol 803, no. 14, col. 1691.

14 Bartak and Rutter, 'Special educational treatment of autistic children', 161.

15 Allison, 'Perspectives on a puzzle piece'.

16 K. Jones, A History of the Mental Health Services, p. 332.

17 DES figures quoted in Kushlik, 'Social problems of mental subnormality', p. 399.

18 K. Jones, A History of the Mental Health Services, pp. 353-365.

19 DES figures quoted in Ford et al., Special Education and Social Control, p. 24.

20 Ford et al., Special Education and Social Control, p. 24.

21 MHCP/A: 514794: Letter - Director of Education, Solihull, to Dr Skuse, November 1978.

$22 \mathrm{MHCP} / \mathrm{A}: 514794$.

$23 \mathrm{MHCP} / \mathrm{A}: 901137$.

24 MHCP/A: 723269.

$25 \mathrm{MHCP} / \mathrm{A}: 281589$.

$26 \mathrm{MHCP} / \mathrm{A}: 761794$.

$27 \mathrm{MHCP} / \mathrm{A}: 307194$.

28 NA/ED50/994: Branch meeting with HM inspectors, 30 March 1966, pp. 7-8.

29 Barkak and Rutter, 'Special educational treatment of autistic children', 165.

30 Rutter and Clark, 'Autistic Children's Responses', 216.

31 Allison, 'Perspectives on a puzzle piece', 6-9. 
32 Hurt, Outside the Mainstream, 182.

33 Kushlik, 'Social problems of mental subnormality', p. 399.

34 Summerfield Report, quoted in B. Harris, The Health of the Schoolchild, p. 210.

35 Department of Education and Science and Summerfield, Psychologists in Education Services.

$36 \mathrm{WT} / \mathrm{PSY} / \mathrm{BPS} / 1 / 4 / 2$ : British Psychological Society, minutes of the Committee on the Implications of the Summerfield Report, 1969-1971.

37 WT/PSY/BPS/1/4/2: First draft of Diploma in Developmental and Educational Psychology 1969; British Psychological Society, minutes of the Committee on the Implications of the Summerfield Report, 1969-1971, pp. 1-2.

$38 \mathrm{WT} / \mathrm{PSY} / \mathrm{BPS} / 1 / 4 / 2$ : First draft of Diploma in Developmental and Educational Psychology 1969; British Psychological Society, minutes of the Committee on the Implications of the Summerfield Report, 19691971, p. 3.

39 WT/PSY/BPS/001/4/03: Fifteenth meeting, 16 February 1971, p. 2; British Psychological Society, minutes of the Committee on the Implications of the Summerfield Report, 1969-1971.

40 KCL/BCGC: Annual Reports, 1975 and 1976.

41 KCL/BCGC: Annual Report, 1976.

42 KCL/BCGC: Annual Report, 1976.

43 KCL/BCGC: Annual Report, 1979.

44 Harris, The Health of the Schoolchild, p. 182; Wooldridge, Measuring the Mind, p. 316.

45 Hansard, HC Deb 25 October 1983 vol. 47 c 132.

46 Lindsay, Screening for Children with Special Needs, pp. 88-89.

47 Hansard, HC Deb 13 November 1980 vol. 992 cc 421 w.

48 Hansard, HL Deb 28 July 1988 vol. 500 cc 386.

49 Rutter et al., Education, Health and Behaviour, p. 3. These types were modified when described from the child's perspective; pp. 348-351.

50 Rutter et al., Education, Health and Behaviour, p. 52.

51 Rutter et al., Education, Health and Behaviour, p. 292.

52 Rutter et al., Education, Health and Behaviour, p. 200.

53 Rutter et al., Education, Health and Behaviour, p. 108.

54 E.g. Berger et al., 'Attainment and adjustment in two geographical areas: II', 510. 
55 Rutter and Hersov, Child Psychiatry, p. 367.

56 WARNOCK1978, pp. 1-3.

57 Interview, Professor Sir Michael Rutter, conducted by Bonnie Evans, History and Philosophy of Science Dept, Cambridge, 7 December 2006.

58 WARNOCK1978, pp. 36-49.

59 Rutter et al., 'Attainment and adjustment in two geographical areas'; Berger et al., 'Attainment and adjustment in two geographical areas: II'.

60 Welshman, From Transmitted Deprivation to Social Exclusion.

61 Rutter et al., Education, Health and Behaviour.

62 WT/PP/ADD/E.5/2: Paper by Michael Power, MRC Social Medicine Research Unit, LSHTM, 26th Child Guidance Inter-clinic Conference.

63 J. K. Wing, 'Social treatments of mental illness', p. 27.

64 WT/PP/ADD/E.5/2: Paper by Mary Wilson, Staff Inspector for Special Education, ILEA, 26th Child Guidance Inter-clinic Conference.

65 WT/PP/ADD/E.5/2: Paper by Mary Wilson, Staff Inspector for Special Education, ILEA, 26th Child Guidance Inter-clinic Conference.

66 On the concept of 'deprivation' in the USA, see Raz, What's Wrong with the Poor?.

67 Ainsworth et al., Deprivation of Maternal Care.

68 Savage, Identities and Social Change in Britain since 1940.

69 Yudkin and Holme, Working Mothers and Their Children.

70 Yudkin and Yudkin, 'Poverty and child development'.

71 Schaffer and Emerson, 'The development of social attachments in infancy', 71.

72 Schaffer and Emerson, 'The development of social attachments in infancy', 71.

73 Brown and Rutter, 'The measurement of family activities and relationships'.

74 Rutter, Maternal Deprivation Reassessed.

75 Rutter, 'Maternal-deprivation, 1972-1978'.

76 Wolkind and Rutter, 'Children who have been "in care".

77 National Archives: MH166/1503: Research proposal by John and Elizabeth Newson in association with Peggie Everard (formerly Hon. Secretary NSAC), p. 1.

78 Kanner, 'Childhood psychosis', 2.

79 Kanner, 'Childhood psychosis', 19.

80 Rutter and Bartak, 'Causes of infantile autism', 29.

81 Rutter and Bartak, 'Causes of infantile autism', 27. 
82 Richards, Putting Psychology in Its Place, p. 91.

83 Hayward, 'The tortoise and the love-machine.'

84 Gardner, The Mind's New Science, pp. 32-33; G. Richards, Putting Psychology in Its Place, p. 94.

85 Gardner, The Mind's New Science, pp. 191-193; Chomsky, 'A review of B. F. Skinner's Verbal Behaviour', p. 563.

86 Chomsky, 'A review of B. F. Skinner's Verbal Behaviour', pp. 578, 563.

87 Chomsky, 'A transformational approach to syntax', pp. 182-191; Gardner, The Mind's New Science.

88 E.g. Mittler, 'Opening remarks', p. 142; Howling, 'The effectiveness of operant language training', 101.

89 Central Advisory Council for Education, Children and Their Primary Schools.

90 Piaget, 'The psychogenesis of knowledge', p. 23.

91 Piaget, 'The psychogenesis of knowledge', p. 31.

92 Piaget, 'The psychogenesis of knowledge', p. 59.

93 Rutter, 'Speech disorders in a series of autistic children', p. 45.

94 Rutter, 'Behavioural and cognitive characteristics'.

95 Rutter, 'Concepts of autism', 12.

96 Rutter et al., 'A comparative study of infantile autism: I', 127.

97 Rutter et al., 'A comparative study of infantile autism: I'; Bartak et al., 'A comparative study of infantile autism: III'.

98 Rutter et al., 'A comparative study of infantile autism: I'; Bartak et al., 'A comparative study of infantile autism: III'.

99 Bartolucci et al., 'Phonological investigation of verbal autistic and mentally retarded subjects', 303.

100 E.g. Rorty, The Linguistic Turn; Clark, History, Theory, Text.

101 Morley, The Development and Disorders of Speech in Childhood; Schofield, 'Morley, Muriel Elizabeth (1899-1993)'.

102 See Clarke and Jacyna, Nineteenth-Century Origins of Neuroscientific Concepts; Harrington, Medicine, Mind and the Double Brain; Young, Mind, Brain and Adaptation in the Nineteenth Century.

103 Head, Aphasia and Kindred Disorders of Speech.

104 Orton, Reading, Writing and Speech Problems in Children, p. 2; Brain, 'Speech and handedness'.

105 Ingram, 'Specific developmental disorders of speech in childhood', 450.

106 Franklin, Children with Communication Problems.

107 Eyal et al., The Autism Matrix, p. 197. 
$108 \mathrm{Bax}$ and Whitmore, 'Neurodevelopmental screening in the schoolentrant medical examination.

109 Drillien and Drummond, Neurodevelopmental Problems in Early Childhood.

110 L. Wing, 'A place in life'.

111 E.g. MHCP/A: 909969.

112 MHCP/A: 603491: Letter from Dr Michael Black, Consultant Psychiatrist Bedfordshire County Council CGC, 13/6/69; NA/ED50/ 969: Report on Ealing School, 1968.

113 McCarthy and Kirk, Illinois Test of Psycholinguistic Abilities; Danforth, The Incomplete Child.

114 MHCP/A: 200150: 'Assessment of intelligence in an autistic boy', 8/1/73.

115 MHCP/A: 533358: Letter - Martin to Rutter, November 1969.

116 MHCP/A: 533358: Letter - Martin to Rutter, November 1969.

117 MHCP/A: 726323: Report, October 1979.

118 MHCP/A: 275685: Summary, February 1974.

119 MHCP/A: 856229: Formulation, October 1982.

120 MHCP/A: 470433: School report, February 1978.

121 MHCP/A: 397168: Report, June 1975.

$122 \mathrm{MHCP} / \mathrm{A}: 143950$ : Letter to Rutter, 1970.

$123 \mathrm{MHCP} / \mathrm{A}:$ 143950: Letter from Rutter, 1970.

$124 \mathrm{MHCP} / \mathrm{A}: 1970$ s cases.

125 Rutter, 'Concepts of autism', 4.

126 Rutter, 'Concepts of autism', 4.

127 MHCP/A: 196002: Letter from Weiselberg, 31/6/75(1).

128 MHCP/A: 196002: Letters from Weiselberg, 31/6/75(2), 31/6/75(3), $8 / 7 / 75$.

$129 \mathrm{MHCP} / \mathrm{A}: 260422$.

130 MHCP/A: 430794: Letter from Rutter, 27/12/78.

131 MHCP/A: 430794: Letter from Rutter, 27/12/78.

132 E.g. MHCP/A: 982784. Letter from Rutter, 15/10/75.

$133 \mathrm{MHCP} / \mathrm{A}: 603491$.

$134 \mathrm{MHCP} / \mathrm{A}: 172559$.

135 Schopler et al., 'Editorial: Change of journal scope and title'.

136 Anon., 'Advertisement: Journal of Autism and Childhood Schizophrenia'.

137 National Archives: MH166/1503: Mental Illness Working Group RLG, 12 July 1978.

138 Piaget et al., The Psychology of the Child. 
139 Newson and Newson, 'Intersubjectivity and the transmission of culture', 438.

140 Newson and Newson, 'Intersubjectivity and the transmission of culture', 438 (emphasis added).

141 Trevarthen et al., 'Psychological actions in early infancy'.

142 Condon and Sander, 'Synchrony demonstrated between movements'; Condon and Sander, 'Neonate movement is synchronized with adult speech'. Woolf, 1969.

143 Trevarthen and Hubley, 'Sharing a task in infancy', 72.

144 Husserl, Cartesian Meditations, 5th Meditation.

145 Merleau-Ponty, Phénoménologie de la perception, p. 404.

146 Habermas, 'Towards a theory of communicative competence'.

147 Trevarthen, 'Communication and cooperation in early infancy'; Trevarthen and Hubley, 'Secondary intersubjectivity'.

148 Newson and Newson, 'Intersubjectivity and the transmission of culture', 445.

149 Hobson, 'Early-childhood autism and the question of egocentrism'.

150 Ricks and Wing, 'Language, communication, and use of symbols'.

151 L. Wing et al., 'Symbolic play in severely mentally-retarded and in autistic-children', 169.

152 L. Wing et al., 'Symbolic play in severely mentally-retarded and in autisticchildren', 173.

153 Hermelin, 'Images and language', p. 141.

154 Hermelin, 'Images and language.'

155 L. Wing, 'Perceptual and language development in autistic children'.

156 L. Wing, 'Perceptual and language development in autistic children', pp. 188-189.

157 Wing and Gould, 'Severe impairments', 12.

158 L. Wing, 'Asperger's syndrome', 121-122.

159 L. Wing, 'Asperger's syndrome', 124.

160 J. K. Wing, Schizophrenia.

161 Wing and Gould, 'Severe impairments', 11.

162 Wing and Gould, 'Severe impairments', 13.

163 Wing and Gould, 'Severe impairments'.

164 Wing and Hailey, Evaluating a Community Psychiatric Service.

165 Wing and Gould, 'Systematic recording of behaviours and skills', $80-81$. 
166 Wing and Gould, 'Severe impairments', 26.

167 Wing and Gould, 'Severe impairments', 22.

168 L. Wing, 'Asperger's syndrome', 124.

169 Wing and Gould, 'Severe impairments', 26.

170 Wing and Gould, 'Severe impairments', 26.

171 Wing and Gould, 'Severe impairments', 12.

172 Wing and Gould, 'Severe impairments',

173 L. Wing, 'Asperger's syndrome', 124.

174 NA/MH154/1521: 'Making Sense of Autism' by Elizabeth Newson, p. 8.

175 NA/MH154/1521: 'Making Sense of Autism' by Elizabeth Newson, p. 21 (emphasis in original).

176 NA/MH154/1521: 'Making Sense of Autism' by Elizabeth Newson, pp. 21-22.

177 NA/MH154/1521: 'Making Sense of Autism' by Elizabeth Newson, p. 22.

178 Silberman and Feinstein.

179 L. Wing et al., 'The prevalence of early childhood autism'; Wing and Gould, 'Severe impairments', 80.

180 Rimland, Infantile Autism.

181 Tinbergen and Tinbergen, Early Childhood Autism.

182 Frith, 'Review of Tinbergen, Autistic-children: New hope for cure', 461, 463.

183 Kellmer-Pringle, 11,000 Seven-Year Olds.

184 WARNOCK1978, para. 3.7.

185 WARNOCK1978, para. 3.17. One-in-six figure was taken from Rutter et al., Education, Health and Behaviour, p. 348.

186 WARNOCK1978, para. 3.21.

187 WARNOCK1978, para. 3.26.

188 NA/MH154/1521: Meeting to discuss policy on autism 23 August 1978, pp. 1-3.

189 NA/ MH154/1521: Draft 'Policy on Autism', 5 December 1979, p. 5.

190 NA/ MH154/1521: Brief for meeting between Parliamentary Secretary (HPSS) and NSAC, 5 October 1979.

191 NA/MH166/1504: 'Policy on Autism' report, December 1979.

192 NA/MH166/1504: 'Policy on Autism' report, December 1979.

193 Turbett, Doing Radical Social Work. 
194 NA/MH154/1521: Note of a meeting with the NSAC, 5 October 1979.

195 National Development Group for the Mentally Handicapped, Improving the Quality of Services for Mentally Handicapped People, p. 33, para 75.4.

196 NA/MH154/1521: Note from George Young to the Society for Autistic Children, 1980.

197 NA/MH154/1521: Dr Vivienne Simmons, Comments on meeting between PS and NSAC, 26 September 1979.

198 NA/MH154/1521: Note by Mr French.

199 KCL/BCGC: Annual Report 1983.

200 MHCP/A: 590494: DHSS/DES circular 1983, quoted in ILEA notes on Education Act 1983, Appendix 3.

201 MHCP/A: 590494: DHSS/DES circular, 1983.

202 KCL/BCGC: Annual Report, 1983.

203 MHCP/A: 590494: ILEA Special Educational Needs form FA2, March 1985.

204 WARNOCK1978, para 7.2.

205 WARNOCK1978, para 7.7-7.9.

$206 \mathrm{MHCP} / \mathrm{A}: 497583$.

207 Hansard, HC Deb 20 December 1974 vol. 883 cc 627W; e.g. MHCP/ A: 901137; Hansard, HC Deb 27 January 1988 vol. 126 c 233W.

208 Royal College of Psychiatrists, 'Statement to the DES and DHSS', 72.

209 Thomson, Lost Freedom.

210 E.g. MHCP/A 659400; 865920; 917644; 755419; 133378.

211 NA/MH166/1504: Letter from Elizabeth Newson to Dr Dastgir, Department of Health and Social Security, 30 September 1981. Attached note A.

212 NA/MH166/1503: Research proposal by John and Elizabeth Newson in association with Peggie Everard (formerly Hon. Secretary NSAC), p. 2.

213 NA/MH166/1504: Letter from Elizabeth Newson to Dr Dastgir, Department of Health and Social Security, 30 September 1981.

214 Letter from C. H. Benson to Mr Straubenzee 1971, National Archives: 'Extended Education for Autistic Children Beyond the Age of 16' (ED 269/62).

215 White Paper quoted in Malin, Services for the Mentally Handicapped in Britain, pp. 112-115; Fiddy, In Place of Work, pp. 1-2. 
216 NA/MH166/1504 DHSS: Letter from C. L. Souter, private secretary to Mr Fowler, to G. P. Price; NA/MH166/1504: Report by G. P. Price on the West Midlands, 1983.

217 NA/MH166/1504: Wing, 'The handicaps of autistic children', Appen$\operatorname{dix} 3$ to G. P. Price Report.

$218 \mathrm{MHCP} / \mathrm{A}$ : Rutter's files: 'Some notes on the naturalistic study of social interactions of intellectually able autistic adults', 26/6/84.

219 NA/MH166/1504: 'Note of client group to discuss seminar on autism'.

220 NA/MH166/1504: E. Newson et al., 'Summary of report to the DHSS', p. 1; E. Newson, 'Diagnosis and early problems of autistic children'.

221 RSA Uta Frith Archive: Uta Frith, Notebook: History of Ideas Autism, 1968, 1970, 1983-1984. 'Basic Diagnosis: 7.7.83', p. 1.

222 RSA Uta Frith Archive: Uta Frith, Notebook: History of Ideas Autism, 1968, 1970, 1983-1984. 'Basic Diagnosis: 7.7.83', p. 1.

223 RSA Uta Frith Archive: Uta Frith, Notebook: History of Ideas Autism, 1968, 1970, 1983-1984. 'Basic Diagnosis: 7.7.83', p. 7.

224 RSA Uta Frith Archive: Uta Frith, Notebook: History of Ideas Autism, 1968, 1970, 1983-1984. 'Basic Diagnosis: 7.7.83', p. 8.

225 RSA Uta Frith Archive: Uta Frith, Notebook: History of Ideas Autism, 1968, 1970, 1983-1984. 'Basic Diagnosis: cont. 15.10.84', p. 8.

226 Baron-Cohen et al., 'Does the autistic child have a "theory of mind”?'.

227 Leslie and Frith, 'Autistic children's understanding'; Perner et al., 'Exploration of the autistic child's theory of mind'.

228 RSA Uta Frith Archive: Uta Frith, Notebook: History of Ideas Autism, 1968, 1970, 1983-1984, 'Primary social responses versus higher order social responses 12.09.84-12.10.84', p. 21.

229 RSA Uta Frith Archive: Uta Frith, Notebook: History of Ideas Autism, 1968, 1970, 1983-1984. 'Primary social responses versus higher order social responses 15.10 .84 ’, p. 23.

230 Robinson, 'People talk with their eyes'.

231 Parton and Lyon, 'Children's rights and the Children Act 1989'.

232 Pilcher and Wagg, 'Keeping it in the family'.

233 Children Act 1989, Schedule 2, Part 1, para 6.

234 Hansard, HL Deb 6 December 1988 vol. 502 cc 488.

235 Hansard, HL Deb 6 December 1988 vol. 502 cc 490. 
236 CA1989 (1991), Sched. 2, Part 1, para 2.

237 CA1989 (1991), Part 1, Section 1(3)a.

238 CA1989 (1991), Sched. 2, Part 1, para 2.

239 Parton and Lyon, 'Children's rights and the Children Act 1989.

240 L. Taylor et al., In Whose Best Interests?, p. 94.

241 Taylor et al., In Whose Best Interests?, pp. 58-59.

242 Pilcher and Wagg, Thatcher's Children, p. 2.

243 Crane, 'Painful times'. 


\section{6 \\ Epidemiology, epidemics and autism as a global health crisis}

\section{Children's rights in global context}

The 1970s and 1980s had brought important changes to the structure of children's rights in Britain that had repercussions around the world. At the same time, Margaret Thatcher's model of economic policy that encouraged privatisation of public services and a reduction in public spending, together with tax cuts, was a prototype that was either emulated or scorned across the world. Together with US president Ronald Reagan (1981-89), Thatcher came to represent a model of social and economic policy that could dismantle social welfare systems whilst simultaneously building them up under new neoliberal models of engagement. As historian Ben Jackson has argued, her success was predicated on the development of an 'archipelago' of 'think-tanks' established in the post-war period in Britain and internationally with support by interested donors, who developed an international model of neoliberalism as a valid political philosophy. ${ }^{1}$ The 1980 s saw this political model thrive and it continued to hold weight in British politics and elsewhere in the 2000s through the creation of Tony Blair's 'third way' and beyond.

Nikolas Rose has questioned whether neoliberal policies of marketisation and privatisation have caused the 'death of the social', leading to a form of economic government in which active entrepreneurial citizens are encouraged to model their own lives through engaging in a market for welfare products such as educational advantage and health status. ${ }^{2}$ The introduction of neoliberal interventions into social welfare has definitely led to a radical restructuring of the conception of children's rights. The growth of a 'neoliberal' model of citizenship helped 
frame the Children Act 1989 through the idea that children were full individuals and not just appendages to their parents, and therefore involved in decision-making about their own welfare. ${ }^{3}$ However. the place of children within this new network of 'post-social' technologies is complicated by the fact that they still occupy a position where they may be 'in need of care and protection' by the state. Within earlier social welfare policies, tensions had always existed because children were subjects of the state yet also subjects of their parents. Harry Hendrick has argued that the 1980s saw these widespread tensions finally overcome, as the construction of true individualised approaches to childhood began to crystallise. ${ }^{4}$ One thing is clear, it is within these new models of children's rights that new prototypes of disability rights began to take shape. It is also within this new model that the concept of autism was adopted widely as a global category and an international model for thinking about individual children's atypical development.

In the same year that the Children's Act was passed in Britain, the United Nations issued a Convention on the Rights of the Child. The 1989 Convention was unanimously adopted by the UN General Assembly and initiated an international agreement on child rights that was the first of its kind, and which replaced all non-binding international declarations on child rights that had focused on children as passive recipients of care and charity. The creation of the 1989 Convention was the outcome of proliferating international agreements on human rights that had sprung from the UN's Universal Declaration of Human Rights in 1948. Many theoretical debates had blossomed in the 1960s and 1970s in Europe and the USA on whether or not children's rights included 'pupil power' to challenge teachers, or complete autonomy from parents, and whether this meant they were in opposition to those of adults. ${ }^{5}$ It took the growing threat of unrestrained neoliberal ideologies in the 1980s to push for an international treaty that would clarify what, exactly, child rights were, and to ensure that they were implemented.

It is in the context of these radical changes in the construction of child rights that the British model of autism came to be adopted across the world as part of a model legal and psychological framework model for recognising both disability rights and children's rights. This chapter explores how British epidemiological research on autism in the 1960s and 1970s came to define global attempts to analyse and understand 
what, exactly, autism is. It argues that these changes have been associated with wider global changes relating to the definition and construction of children's rights. Studies of autism have now almost become status symbols, and demonstrations of an advanced neoliberal approach to child rights, within the developing world.

\section{Victor Lotter's journey to Africa and the globalisation of the second autism}

After Lotter conducted the first epidemiological study of autism in 1966, he became increasingly interested in whether his definition of autism could be applied in a global context. Discussions and concerns over the international applicability of psychiatric concepts drove this fascination. In addition, cultural diversity was rapidly becoming a feature of post-colonial London in the 1960s and 1970s, as immigration from former colonies increased rapidly. By 1981, the London population of 6.6 million included more than one in six people born outside the UK, including 634,000 from Asia, Africa and the Caribbean. ${ }^{6}$ This growing international community was of interest to many child psychiatrists. Furthermore, increasing numbers of doctors from the New Commonwealth were also immigrating and this encouraged debate within the medical community itself. Aubrey Lewis's insistence that all psychiatric trainees spend six months training in child psychiatry encouraged this debate. By the 1980s, international doctors and social workers were regularly training and working at the Brixton Child Guidance Clinic and by 1984, fortnightly meetings were held on 'racism awareness and multi-ethnicity.7 Some researchers, including Rutter, attempted to tackle cultural differences head on in the 1970s. ${ }^{8}$ The field of 'cross-cultural' psychiatry became established internationally during this period. ${ }^{9}$ However, by and large, researchers in child psychiatry treated international diversity as a challenge to the robustness of their concepts.

In the 1970s, Victor Lotter, the pioneer of autism epidemiology, decided it was time to challenge the durability and stability of the new concept of autism by leaving the anonymous suburbs of Middlesex and heading to Africa, embarking on an extensive tour of several major cities to see if he could find cases of autism in Accra, Ghana; Lagos, Nigeria; 
Nairobi, Kenya; Lusaka, Zambia; Salisbury, Rhodesia; and Cape Town, South Africa. ${ }^{10}$ This was the first attempt to make autism a global category and to use epidemiology to raise questions about the cultural specificity of the condition. At the Third Pan-African Psychiatric Conference in 1972, two Nigerian doctors, C. I. Longe and T. Asuni, had described four cases of 'infantile autism' in Nigerian children, claiming the condition was more common in children from the upper-middle classes. Lotter thought that better social and epidemiological methods were required in order to test such a claim. His aim was to survey children already classed as 'mentally handicapped' in all the African regions he visited and to see how many of them were 'autistic' according to the new criteria. His overt goal was to test the claim that all autistic symptoms were universal in order to see how far the environment impacted on symptomatology. As he put it, because 'the psychological environment for children is maximally different (in unspecified ways) from that in technologically developed countries', a 'cross-cultural' study could reveal how far environmental factors were important. It could also silence the speculation that autism did not actually 'exist' in Africa, pointing out that his extensive studies proved that 'autistic children "undoubtably exist" there. ${ }^{11}$

During Lotter's major tour, he examined 1,300 children known to local authority services, most of whom were institutionalised, finding 'autistic-like behaviour' in only thirty of them. According to Lotter, only nine of them were found to be 'autistic according to Western criteria'. Based on his own observations and discussions with African doctors, he reported that in African institutional populations there were, apparently, far fewer children who engaged in 'elaborate ritualistic activities involving objects', and other repetitive movements such as flapping, rocking and headbanging, than was the case in Western institutional populations. This was significant if autism was to be diagnosed according to behavioural criteria only, as he had defined it in his 1966 study. Lotter acknowledged that this was not a full epidemiological survey, but he argued that the proportion of mentally handicapped children that fitted his behavioural criteria for autism was only 0.7 per cent in his African sample but between 5 and 8 per cent in his Middlesex sample. ${ }^{12}$ He speculated that this may be due to better rates of infant survival in Britain, but acknowledged that the findings were as yet inconclusive. ${ }^{13}$ Lotter's findings did not explore cultural difference in 
any detail, nor did they encompass the post-colonial reflections on self-identity, raised by scholars such as Frantz Fanon, that were reaching a wide audience by the $1960 \mathrm{~s} \cdot{ }^{14}$ An important part of the British epidemiological model was that it insisted on the universality of its concepts.

One thing that Lotter's study did reveal was that the level of provision for the treatment of childhood psychiatric and psychological problems was very limited. Scant administrative systems also meant that very little was known about the occurrence of all forms of 'mental handicap or behaviour disorders generally'. Furthermore, limited resources meant that priority was often given to what were 'quantitatively more pressing developmental problems such as malnutrition, infectious diseases, blindness and deafness. ${ }^{15}$ These were strong findings of health inequalities, and said a lot about the lack of disabled children's rights. Lotter's work therefore encouraged international epidemiological studies of autism, making the argument that such studies would provide the key to discovering the true nature of this elusive and complex psychological definition.

In fact, international epidemiological studies of autism in the aftermath of Lotter's first 1966 epidemiological study of autism in Middlesex had been remarkably scarce, and most had reported very low rates. Most of these were not full epidemiological surveys but merely based on clinic populations, such as the 1970 study by Danish researcher Birte Hoeg Brask, who posited a rate of 4.3 per 10,000 in Aarhus; a 1970 study by US doctor, Darold Treffert, who gave a rate of 2.5 per 10,000 in Wisconsin; and a series of studies in different districts in Japan in the early 1970 s that gave rates varying from 0.9 to 5.02 per $10,000 .{ }^{16}$ None of these studies used the concept of autism to try to reframe wider concepts of child development as Lorna Wing and Judith Gould's study had done. It was only after the publication of Wing and Gould's landmark epidemiological study in 1979 that international epidemiological studies of autism began to thrive. Furthermore, it was only after this that reported rates of autism began to increase. These increases were associated with a widespread change in the description of the condition that had only materialised in Wing and Gould's work. They were supported by the diagnostic engine of the DSM, which was encouraging critical reflection and discussion on the global applicability of psychiatric concepts. 


\section{International child psychiatry and psychology}

International agreements on child rights were paralleled by international agreements on the definition and description of psychological conditions in children. This is perhaps unsurprising given the correlation between individual child rights and psychological discourse in Britain that was mapped out in the previous chapters. Yet, now, the recognition of autistic spectrum conditions as fundamental to ensuring universal child rights has been adopted on a global stage. Since the 1960s, Michael Rutter had been active in trying to achieve an international consensus on the definition of psychological conditions in children. The psychiatric diagnoses first published in the sixth edition of the International Classification of Diseases (ICD) in 1949 had not been widely accepted. ${ }^{17}$ Within the subdiscipline of child psychiatry, there was even less consensus amongst practitioners, as many preferred to work with psychoanalytic concepts, and this persisted into the 1970s. Rutter's 'multi-axial' system helped to achieve some consensus as it acknowledged 'psychosocial' factors in its diagnostic coding system, thereby quelling the anxieties of child psychoanalysts and psychologists who wanted to resist purely neuroscientific models. ${ }^{18}$ The aim of Rutter's system was to encourage further research that used the statistical method in order to clarify phenomenological problems in psychiatry. His multi-axial model of diagnosis was included in the Diagnostic and Statistical Manual (DSM) in 1980. It was only after the publication of this manual that detailed international discussions, debates and agreements on the definition of 'psychiatric disorders' began to crystallise, thereby enabling diagnoses that could be employed in international studies. ${ }^{19}$ It was also the DSM that encouraged the wider use of the term 'disorder' when describing psychological or psychiatric conditions generally.

Historians, psychiatrists and many others have argued that the publication of the third edition of the DSM (DSM-III) in 1980 was a definitive moment in the history of psychiatry. This is primarily because Robert Spitzer of Columbia University, USA, and the 'task-force' who were employed to revise earlier versions of the manual claimed they had produced a radically new scientific textbook that defined symptoms objectively in the tradition of Kraepelin. Most importantly, the manual created a common language that could be used by various disciplinary groups ranging from psychiatrists, social workers and psychologists 
to researchers, insurance companies and pharmaceutical companies. This helped to generate its success in the USA where it was born, and then also elsewhere where such common agreement was required. ${ }^{20}$ The hype surrounding the publication helped to ensure its widespread reception and encouraged much critical debate. ${ }^{21}$

Rutter's work was also fundamental in shaping a lot of the child psychiatric definitions. The classification of 'infantile autism' employed in DSM-III was derived directly from a definition drawn up by Rutter in 1978, namely:

(1) an onset before the age of 30 months,

(2) impaired social development that has a number of special characteristics and is out of keeping with the child's intellectual level,

(3) delayed and deviant language development that also has certain defined features and is out of keeping with the child's intellectual level, and

(4) insistence on sameness, as shown by stereotyped play patterns, abnormal preoccupations, or resistance to change. ${ }^{22}$

It was via the DSM that British models of autism, developed in the legal, political and social context of 1970 s post-Seebohm Britain, would come to dominate international definitions of autism.

In particular, DSM-III helped to consolidate the new model of autism as an absence of hallucination, delusion, fantasy life and an inability to play, imagine and creatively represent objects in the mind. Although it had figured prominently in earlier versions of the text, the category of 'childhood schizophrenia' was completely written out of DSM-III (1980). Instead, DSM-III introduced the new category of 'pervasive developmental disorders', a diagnosis that included four subcategories: namely, 'infantile autism', 'childhood onset pervasive developmental disorder', 'residual autism' and an 'atypical form'. The idea that autism was one of a range of related conditions was thus set in stone. At the same time, the original concept of autism, which had previously played an important part in the diagnostic criteria for adult schizophrenia, was completely removed from the diagnostic criteria for schizophrenia in adults. Spitzer argued that this was due to its unreliability as an observable symptom. ${ }^{23}$ But this effectively meant that 'autism', although 'unreliable' as a key concept in the diagnosis of adult schizophrenia, was then implemented as a category within 'pervasive developmental disorders 
of childhood' because it was considered reliable when applied to children under a wide umbrella of other psychological disorders - now termed 'pervasive developmental disorders'. It was regarded as reliable because of the growing paraphernalia for testing autism in children and the fact that this new concept of autism, the 'second' autism, now had a completely differently meaning. The fact that the second autism assumed its position as part of a wider framework for thinking about atypicalities in child development was not new. What was new was that autism now meant the opposite of what it had meant before. Throughout the 1980s and 1990s, the second 'autism' would be the one that took centre stage across the globe. It did so via a web of epidemiological studies that simultaneously disseminated, reproduced and multiplied this model.

In the early 1980s, many clinicians criticised DSM-III criteria for 'infantile autism', based on Rutter's work, because they found it too restrictive. ${ }^{24}$ Many clinicians who had been diagnosing 'childhood schizophrenia', 'psychosis' and 'autism' for some time found that their cases no longer qualified. This included clinicians who were generally psychoanalytically inclined and who had employed the terms 'autism, 'childhood schizophrenia' and 'childhood psychosis' in a rather general way due to the influence of Klein, Bender and others. It is thus unsurprising that they found Rutter's criteria restrictive. In a formal evaluation of the criteria in the USA, many practising child psychiatrists found the criteria unworkable. ${ }^{25}$ For example, a meeting of autism researchers in 1984 expressed concerns about the classification of infantile autism and, in fact, all 'pervasive developmental disorders', and called for a more logical approach to classification. ${ }^{26}$ In the model of the DSM, no approach to the classification of childhood developmental conditions could be more logical than Wing's approach, which took a complete population of children and defined the total population using behavioural criteria. Wing's definition was coming to be acclaimed internationally. Her astute, yet subtle, creation of a comprehensive model of inclusive human relations was lapped up by behaviourists, government officials and others struggling to create some way of conceptualising social development in children now that psychoanalytic models were being widely challenged and neoliberal ideologies were stripping the 'social' of its association with welfare and national rights. 
Although the DSM was a US publication, British researchers were shipped over in order to settle the argument over autism. This should not be a surprise as these British researchers had been those who were most focused on developing robust statistical tools for measuring autism epidemiology since the 1960s. Michael Rutter had a major public debate with Lorna Wing at the committee meeting. This focused on the DSM-III requirement that autism could only be diagnosed if it started in the first thirty months of life. Rutter thought this was essential as it encouraged research into different clinical groups with different aetiologies and encouraged detailed developmental histories, but Wing did not agree. She argued that removing the age of onset would encourage research into aetiology because autism would be defined descriptively, rather than categorically, in a similar way to mental retardation, and this would encourage interest into its origins. Wing's argument that the definition needed to encourage research within new epidemiological and statistical sciences of mental disorder was the most compelling at a time when such sciences were in their infancy. The concept of autism offered so much promise for setting these sciences straight because it was still regarded by many as a core concept within theories of child development. Just as the first autism served as an organising concept within earlier models of infantile thought and its unconscious or unknown elements, the second autism promised to provide a baseline or reference model for the statistical sciences in psychiatry. It is for this reason that so much controversy existed around its entry into the DSM and for this reason that it has become such a popular diagnosis.

The publication of DSM-III had led to a lot of discussion about the new collection of 'pervasive developmental disorders' and many began to use that term as a synonym for 'neurodevelopmental disorders'. AS discussed earlier, 'Neurodevelopmental' was a term that had been in use since the 1970s to describe all kinds of research on the brain development of infants, although its use to describe a type of 'disorder' grew rapidly with the publication of DSM-III. ${ }^{27}$ There was a growth in the use of all these terms and an increasing lack of clarity about what they all meant. Autism was sometimes used interchangeably with 'pervasive developmental disorders', which increased confusion. In 1983, Martha Denckla from the US National Institute of Neurological and Communicative Disorders and Stroke organised a major conference on the 'diagnosis of autism and related disorders', bringing together 
child psychology professionals from across the USA, such as Marian K. DeMeyer from Indiana, Fred Volkmar from Yale and Eric Schopler from North Carolina, along with Lorna Wing from the UK. There was a consensus that the DSM-III definition of autism was not yet a sufficient classification, particularly for epidemiological studies, and that researchers were clearly interested in the much broader spectrum of 'pervasive developmental disorders. ${ }^{28}$ One major criticism of Rutter's narrow definition of autism was that it was not good for the development of psychiatric epidemiology that, in the spirit of the DSM, was now placing several other conditions such as 'depression' and 'bipolar disorder' on 'spectrums' or 'scales. ${ }^{29}$ In the process of denouncing the first autism, it was agreed that researchers should adopt an 'atheoretical' view but should describe 'social and non-verbal communicative skills', and possibly 'symbolic imaginative play skills too', when describing their chosen subjects. This would help to build up a new understanding of social engagement and imaginative play based on the mass observation and calculation of children's behaviour, rather than psychoanalytic ideas about infantile fantasy. ${ }^{30}$

DSM-III-R criteria for autism were drawn, almost word for word, from Wing's definition of the 'triad', namely: 'A. Qualitative impairment in reciprocal social interaction,' 'B. Qualitative impairment in verbal and nonverbal communication, and in imaginative activity' and 'C. Markedly restricted repertoire of activities and interests'. Each part of the triad was then elaborated with sixteen item descriptions and illustrations: for example, 'qualitative impairment in social interaction' could be manifested as 'marked lack of awareness of the existence of feelings of others (e.g. treats a person as if he or she were a piece of furniture; does not notice another person's distress; apparently has no concept of the need of others for privacy)'. Autism could be diagnosed if eight of the total sixteen items were present across the entire triad. ${ }^{31}$ There was some concession to Rutter as age of onset still had to be recorded for research purposes. ${ }^{32}$ The publication of DSM-III-R was a major turning point that enabled the spread of Wing and Gould's model of epidemiology and autism, and galvanised teams of researchers to investigate. The seeds were then fully sown for increased observations and diagnoses of autism, which was now a descriptive term once more. In 1989, ICD 10 followed the DSM in listing autism as one of several 'pervasive developmental disorders', drawing from Wing's definition. ICD 
10 also included Wing's category of 'Asperger's syndrome', which further propagated her conviction that stereotyped play signalled a lack of imaginative abilities and further expanded the cases in which the diagnosis could be applied.

The reason that psychologists from Britain were so dominant in directing international definitions of autism was because they had consistently drawn upon statistical and epidemiological models to define autism that had provided them with a set of criteria that were not defined by cultural or social specificities. The setting of post-colonial London, and Lotter's research in Africa, had strengthened this acultural, ahistorical and, ultimately, very open definition of autism that the global community went on to adopt with such enthusiasm. This second autism was an ideal concept upon which to build a new model of human relations, of sociality and relationships that could support new models of child rights within a neoliberal model of social entrepreneurialism. It provided it with statistical accuracy and mathematical precision, qualities much valued in an era of financial speculation and globalisation. Lorna Wing's 'style of reasoning' that viewed autism as an epidemiological entity defined by the absence of imagination and creativity, and the presence of scientific calculated precision, was the perfect acultural construction of childhood psychological development. Autism's success must be viewed within this context.

\section{International development and the first wave of epidemiological studies}

It was after Wing and Gould's 1979 epidemiological study that reported rates of autism began to increase. During the 1980s, Victor Lotter's attempts to instigate discussion about different rates of autism in different countries were beginning to bear fruit. In 1984, Victor Sanua from the Department of Psychology at St John's University, New York, had written to child psychiatrists across the world asking for their opinions on the question 'Is infantile autism a universal phenomenon?' The Chairman of the Department of Psychology of the University of Sao Paulo, Dr Lourencao Van Kolck, had replied: 'Really, autism is a rare disease in our country'. Dr Chakraborty, Professor of Psychiatry at the R. G. Kar Medical College of Calcutta had apparently concurred that 
cases were also rare in India, and Dr Mohammed Fakr el Islam, who practised widely in the Middle East, had argued that 'cases of infantile autism are very few in this part of the world'. There was no way of validating such claims, or even confirming that everyone was actually talking about the same thing. However, Sanua concluded that infantile autism appears to be an illness of Western Civilization, and appears in countries of high technology, where the nuclear family dominates. ${ }^{.33}$ Sanua had support for this in the theory of Nikolas Tinbergen, which had drawn upon a form of anthropological reflection on Western civilisation as the cause of autism, a theory that had quite a short shelf life given wider changes in the spread of neoliberalism and the critique of evolutionary models of social progress. The idea that autism was a disease of western civilisation looked increasingly shaky as parent groups started to form and demand that autism be investigated properly in their countries and that international children's rights be adhered to.

In the early 1970s, Peter Venables, the doyen of psychophysiological research who had moved from the Institute of Psychiatry to Birkbeck, London, had established a major longitudinal study of child health and development following a meeting with the World Health Organization (WHO) Scientific Group of Neurophysiological Methods. ${ }^{34}$ The WHO Scientific Group recommended that any longitudinal study should be conducted in a developing country and that it should investigate three-year-old children, establish nursery schools for these children and use psychophysiological research to identify their risk factors for later mental illness. Mauritius was chosen as the destination as it was a small island with low emigration. It was also a former British colony, granted independence in 1968. This study established by Venables became a model for health epidemiology in developing countries and a symbol of international collaboration. ${ }^{35}$ It later received funding from multiple health research bodies from Denmark, Britain and the USA. ${ }^{36}$ By the late 1970 s, the WHO study was providing reliable information on international child health and was frequently emulated as a model for international research. It defied theories of child development framed by unhelpful models of evolutionary progress and presented an exemplary approach to international research that was widely respected.

Building on Venables' successes in international collaboration, autism researchers began to develop new ways to research autism 
across national boundaries and to use this international research to develop new hypotheses about both the condition and the importance of its recognition in ensuring children's rights. For example, the Society for Autistic Children in Britain teamed up with parental organisations and research communities across the continent to form Autism Europe in 1976. The initial aim was to draw together the expertise of European researchers. However, their goals quickly evolved. In 1983, the International Association Autism Europe (IAAE) was established to create a forum that also valued parental opinion and to create a space where parents and professionals could 'meet and overcome the problems that differences of health, education, legal and social systems create. This enabled Europe-wide comparisons in social care and research approaches and the sharing of databanks and information, and also deliberately encouraged changes in the law to acknowledge the specific rights of people diagnosed with autism. ${ }^{37}$ After the formation of IAAE, the role of parents and autism self-advocates became part of most conferences.

In 1989 Autism Europe presented a charter of rights for autistic people based on the United Nations' Declaration on the Rights of Mentally Retarded Persons (1971) and the Rights of Handicapped Persons (1975). The charter was presented at the 1992 Autism Europe Conference. It included the right of people with autism to live independent and full lives to the limit of their potential', 'the right of people with autism to sexual and other relationships, including marriage, without exploitation or coercion' and 'the right of people with autism to freedom from fear or threat of unwarranted incarceration in psychiatric hospitals or any other restrictive institutions.' The declaration also stated that 'at least one million citizens within the EU are affected by autism which is a mental disability. ${ }^{38}$ This was an important document as it acknowledged that autistic children grew up into autistic adults and therefore expanded autism rights across a wider age range. The efforts of Autism Europe to bring together European professionals and parents was obviously facilitated by the growing social and economic links created across Europe in the 1980s, in particular the signing of the Single European Act in 1986, leading to the creation of the Single Market in 1993. The third Autism Europe Conference was held in Hamburg in 1988, with a strong focus on education programmes designed specifically for autistic children, including computer-assisted learning. ${ }^{39}$ 
In the same year, Autism Europe established LINK, a project to publish important international research, collaborative research and press reports three times yearly to keep all those in the international field up to date.

However, it was not just European countries that were becoming interested in this new measure of childhood disability and were attempting to use it to redefine conceptions of child rights and human rights. By the early 1990s, societies specifically for autistic children had been created in forty countries, among them countries as diverse as Australia, Brazil, Bulgaria, Germany, Iceland, India, Japan, Russia and Trinidad and Tobago. ${ }^{40}$ By the early 2000s, these organisations had spread to over eighty countries across the globe including Sri Lanka, Lithuania, Lebanon, Mexico and Nigeria. ${ }^{41}$ All of these organisations worked with international definitions ultimately derived from Wing's epidemiological study of social impairments. The late twentieth and early twenty-first centuries have also witnessed a major proliferation of research studies on autism diagnosis, epidemiology, genetics and more. These are conducted in research institutes across the world, as well as via collaborative international research.

Autism, as a globalised category, is important because it has provided unique rights to those diagnosed with it and has also enabled parents of children diagnosed with autism to become part of a wider network of global institutions interested in the treatment of developmental conditions in children generally, as well as in providing financial assistance and support. Unlike mere 'subnormality' or 'intellectual impairment', autism was a topic that literally 'captured the imagination' and encouraged international researchers and parents to come together and collaborate in order to generate new models of early infantile thought.

British epidemiological definitions of autism, developed by Maudsley-trained researchers, were becoming increasingly globalised and were being used in epidemiological studies across the world. Such studies became increasingly coveted as status symbols in the developing world. Without epidemiology, child psychiatrists and psychologists had limited influence as they could not engage in international debates and research. The first epidemiological studies following Wing's work were conducted primarily in Europe. In the 1980s, Christopher Gillberg began studies of mental retardation and autism in the 
total population of Gothenburg, Sweden. Whilst he found only 3.9 per 10,000 to have typical autism, he reported an identical rate to Wing and Gould's measure of the 'triad of impairments' in a total population at 21 per $10,000 .^{42}$ This helped to support Wing's methodology and the general idea of a wider 'spectrum' of neurodevelopmental disorders associated with autism.

As more international researchers became interested in autism, it became evident that unique national approaches were affecting reported results, even though Wing and Gould's work provided the working model. In Canada, for example, a 1987 study by Susan Bryson from Dalhouisie University, Nova Scotia, found a rate of 10 per 10,000 ostensibly using Wing and Gould's definition of autism. However, Bryson had not included 'asocial severely retarded' in her sample, as Wing and Gould had done. Bryson argued that her definition of autism was thus closer to the 'nuclear' form, for which a rate of 4-5 per 10,000 was usually found. She claimed her increased figures were due to the fact that children who would otherwise have been overlooked as being within a typical or normal range of development were now being included because they demonstrated the 'triad of impairments' to a very minor degree. ${ }^{43}$ This was a slightly different take on Wing and Gould's approach and obviously had an impact on the final reported data and how it could be interpreted.

In France, psychoanalytic definitions of autism remained stronger than elsewhere, thus a different interpretation emerged. ${ }^{44}$ In 1989 , P. Cialdella from the Hôpital Bellevue, Saint Etienne, and M. Mamelle from the Institut National de la Santé et de le Recherche Médicale conducted an epidemiological study that integrated psychoanalytic interpretations. Cialdella and Mamelle liked Wing's 'continuum hypothesis' within the framework of pervasive developmental disorders. Interestingly, however, and in a uniquely French fashion, they argued that it expanded the possibilities for diagnosing 'child psychosis' and schizophrenic symptomatology in children, arguing that pervasive developmental disorders were identical to 'what French psychiatrists call child psychosis'. In their epidemiological count of 10.8 per 10,000 , they included children with 'schizophrenic features' such as 'listening attitudes', thought to be 'related to hallucinations', as well as 'incongruent laughing or crying', apparently not heeding the reservations expressed by Lotter, Rutter and Wing on the problems of 
including symptoms of hallucination and delusion in children in an epidemiological survey. ${ }^{45}$

In Japan, Toshiro Sugiyama of Aichi Prefectural Colony and Tokuichiro Abe of Shizuoka Prefectural Hospital conducted an epidemiological study based on Wing and Gould's definitions, finding a rate of 13 per 10,000. However, they argued that it was not entirely clear what separated 'typical' autism from wider 'social impairment' in Wing's work, or what separated children with autism from those with 'autistic features' in Lotter's study. They also had several questions about what diagnosis a child should receive if they had 'autism' at age two and then lost it by age three, a question that Western researchers had not thought relevant. ${ }^{46}$ Diagnostic criteria did not always travel easily, but this merely encouraged more debate about how Wing and Gould's definitions could be refined.

By the late 1980s, it was becoming apparent that researchers in different countries, and even different regions, were giving very different figures on the prevalence of autism and different interpretations of what autism was. Gillberg's continued studies on the rate of autism in Sweden found regional variations as well as increases over time. A 1986 epidemiological study of 'autism and autism-like' conditions in children aged $2-11$ years in Gothenberg found a rate of 6.6 per 10,000, although Gillberg pointed out that this did not include children with 'autistic traits' and 'autistic spectrum disorders' or the 'triad of impairments' and that inclusion of such children would have raised the reported levels. ${ }^{47}$ However, Gillberg claimed he was finding different rates of autism in Sweden, pointing out in 1991 that in one area of Gothenberg, autism had increased in prevalence per 10,000 from 4.0 in 1980 to 7.5 in 1984 and 11.6 in 1988 . After building up such a comprehensive picture of rates of the new 'total population definition of autism', Gillberg felt confident enough to use these epidemiological studies to make hypotheses about causation, raising questions about maternal age and the higher diagnoses of autism in immigrant populations that, he argued could be due to lower levels of prenatal, perinatal and postnatal care for women who had given birth in developing countries, among other things. ${ }^{48}$ All of this was speculative, but then autism epidemiology inherently encouraged speculation. 
Measuring the second autism

As Rhodri Hayward has pointed out, the development of the post-war 'statistical psyche', compounded by the publication of DSM-III, encouraged application of numerous psychiatric scales to measure psychiatric conditions such as depression, anxiety, bipolar disorder etc. This has led to a proliferation of measuring scales, such as the Hamilton scales for anxiety (1959) and depression (1960) and Eysenck's scales for personality. ${ }^{49}$ This encouraged the expansion of psychiatric categories, or what psychiatrist Peter Kramer has termed 'diagnostic bracket creep', encouraging other minor variants of each condition to be lumped into one wider psychiatric label..$^{50}$ Psychiatric categories, which at first defined only a small group of individuals, could be expanded to include increasing numbers of people who had fewer and fewer symptoms of the original condition. In the case of major depression, Kramer argued that it was primarily the introduction of Prozac that stimulated increasing diagnoses. ${ }^{51}$ In fact, in most instances, this 'diagnostic bracket creep' has been associated with increased production of pharmaceuticals designed to target psychiatric conditions, as described astutely in David Healy's The Anti-depressant Era (1997) and The Creation of Psychopharmacology (2002). However, in the case of autism, the growth in diagnosis had absolutely nothing to do with pharmaceutical products. This was thus a unique kind of 'diagnostic bracket creep' that was associated with concerted attempts by clinical and educational psychologists to criticise apathy and ignorance regarding the presumed 'ineducability' of groups of children, as described in Chapter 5. It was also part of a concerted effort to develop new tools and measuring scales that could be used instead of intelligence tests and could therefore generate a more inclusive model of variations in human development and establish a new model of child rights and disability rights.

Whilst Hermelin and O'Connor, Frith and Baron-Cohen had begun to construct the basis of a way to define and measure social development as opposed to intellectual development in children, it was the ultimate social science and statistical entrepreneur, Rutter, who first designed an extremely successful international instrument for measuring autism. Following the changes that were made in DSM-III-R, Rutter quickly began to work on a new diagnostic instrument that 
could be used to identify cases, now acknowledging that the category had been expanded to include children who developed the complete picture of 'autism' after the age of thirty-six months. In an effort of international collaboration, Rutter and Ann Le Couteur from the Medical Research Council Child Psychiatry Department at the Institute of Psychiatry teamed up with Catherine Lord from the Department of Pediatrics at the University of Alberta, Canada, to develop the Autism Diagnostic Interview (ADI), 'a new standardised investigator-based tool for use in the differential diagnosis of pervasive developmental disorders. ${ }^{52}$ In his attempt to distinguish the ADI from intelligence tests, Rutter always emphasised the necessity of differentiating between immaturity associated with low mental age and what he termed the 'developmental deviance' that is part of autism. As Rutter and Eric Schopler described it, 'impaired language and socialisation is found in many disorders (especially general mental retardation), but the particular patter of deviance found in autism is distinctive to that syndrome. ${ }^{53}$ This was an important distinction because the ADI did not focus only on the ability to function socially, but rather on age deviations from normal social interaction. In fact, the ADI highlighted the separation of delay from deviance by paying a lot of attention to the 4-5 age period where this was easiest to isolate.

A number of observational scales for 'autism' had been designed in the late 1970s and early 1980s, most issuing from the USA, creating a panoply of abbreviations: BRIAAC, CARS, BOS, ABC (ASIEP). ${ }^{54}$ These had focused on distinguishing autistic children with low intelligence from children with other kinds of developmental delays, or from typical children. However, with the growing acceptance that 'autism' was a unique kind of sensory impairment that had its own internal mechanisms, and was not merely the antithesis of intelligence, led to new approaches.

The ADI and the Autism Diagnostic Observation Schedule (ADOS) drew from techniques employed by British sociological researchers and indeed the widespread sociological studies that Rutter had conducted in the 1960s and 1970s. The ADI was designed to numerically code behavioural descriptions, rather than to numerically code 'yes' or 'no' answers. The creation of a questionnaire that did not seek any 'yes' or 'no' answers could be traced right back to the Isle of Wight study, which constantly sought clarification in the interview technique in order to 
recreate the closest thing to actual observation as possible. In fact, this was a skill being developed by the new generation of British sociologists in the 1960s as well, to get as close as possible to the representation of reality through the use of interview techniques. It took much time and many resources but sociologists argued that it generated true snapshots of society, true images of the life of large groups. Interviewers had to be trained to encourage their informant to remember real events and to report these accurately so that the 'behaviour' was recaptured without the need for direct observation. When creating the ADI, Rutter and colleagues argued that creating a snapshot was more reliable as a diagnostic tool because it got closer to presenting the behaviour that a clinician may observe in practice. Furthermore, the ADI employed creative psychological techniques, such as reference to birthdays, family holidays, Christmas or other key events, in order to gain the correct age range from parents who were recalling earlier developmental stages. Family events would then be cross-referenced in order to ensure the reliability of reported behaviour. This method of measurement enabled the interviewer to collect, analyse and measure multiple 'scaled' behaviours in a way that was impossible with most rating schedules. The ADI was thus the pièce de résistance of developmental interviews that enabled such a detailed exploration into a child's development and behaviour that it was almost impossible to criticise its precision. Interviewers used parental recall to recreate an individual child's entire development. The form covered 101 pages, each probing into the life of the individual child.

The first publication of the ADI in 1987 began with the collection of general family information, such as number of children and any known health problems in family members, followed by a detailed summary of education and contact with special educational services. The parent or carer was then asked what were his/her main worries and concerns about the child and what symptoms they had noticed, at what age, and whether previous medical advice had been sought. Specific information was taken about developmental milestones such as when the child first walked and sat unaided. The interview then covered different aspects of the child's development starting with their language development and other methods of communication, and then explored 'social development', covering similar territory to the Gesell scales such as whether the child held a direct gaze, smiled or anticipated gestures and at what 
age they started to do this. ${ }^{55}$ The next section moved on to 'social intentionality', such as when the child tried to get attention and whether they could discriminate between adults. 'Imaginative play' explored the child's play with toys and the nature of that play, such as whether toys were used as whole objects or parts, and whether they were used as part of wider 'pretend play'. After early development had been ascertained, the interviewer focused on the child's behaviour in the last year, focusing on language in detail and exploring the child's use of metaphorical language, for example, as well as their articulation and vocal expression. The parent or carer was then asked about the child's responses to other people's feelings, and whether they had friends their own age. They were questioned even further about the child's recent 'imaginative or creative' activity, and then asked about whether they had any 'unusual preoccupations', 'compulsions' or 'rituals', or any abnormal responses to sensory stimuli. Finally, the interview turned to whether there were food fads, pica, overactivity, underactivity, stereotyped movement, tics, vocal tics, unusual gait, self-injury or loss of skills. ${ }^{56}$

This ultimate overview of every aspect of a child's development was not just a means for identifying a set of behaviours as in Lotter's model, or even a means to identify impairments and handicaps as in Wing and Gould's HBS Schedule, it was more of a means to observe social behaviour in childhood in all its complexity. It was as if Rutter was arguing that if DSM-III-R was expanding the category, then it must now take all of childhood social development into its observational remit. Rutter then made it very clear that Wing's 'style of reasoning' about autism was associated with a wider change in how social development in children was perceived.

Just in case informants were not reliable, the ADI was supported by the ADOS. Again, this was another way to create a snapshot of the child using the logic of sociological research, designed to recreate social situations as accurately as possible, without the child being aware that this was what was happening. It was also another example of psychologists creating the environments and social settings in which to house their newly formulated concept of autism. As it was described in 1989:

The general format of the schedule is to encourage an interaction that appears natural, during which preplanned 'occasions' for certain behaviors arise, with the imposed structure as invisible to the subject as possible. 
However, in reality, this structure has been carefully determined in terms of social tasks that are defined in detail by variations in cognitive demands, in the type of materials, and in the behavior of the interviewer. These standard situations thus provide comparable social stimuli for all subjects. ${ }^{57}$

This set-up fused clinical observation with experimental psychology where 'the examiner is considered a participant/observer or confederate in a social experiment', thereby multiplying the points at which psychologists could observe and record children's behaviour. These were no longer limited to the institutional settings of clinics, nurseries and schools, but now encompassed the newly created faux social environments of the ADOS, as well as multiple sites of memory that were gleaned through the $\mathrm{ADI}$ interview setting. It was via these multiple points of observation that the autism category would find increasing support for its validity and rationality. The consistency, frequency and abundance of these observational settings meant that the new meaning of autism was frequently reinforced and supported. There was no way that a theory of psychology grounded on unconscious instincts could compete with this new-found quantifiable, calculable and computable evidence for 'social impairment'. It was very hard to present any kind of argument about 'autism' that researchers could not systematically debunk, or at least fend off, using knowledge collected from the ADI and ADOS. The ADOS was also videotaped, therefore increasing its potential as a self-reinforcing instrument. The more that social situations were acted out, the more those particular interactions could be observed, memorised and re-enacted by future assessors. At the same time, the more that children were observed responding in a particular way in a 'social' scenario, or responding to mechanical objects in particular ways, the more this would be used as evidence that this behaviour was a variant of autistic behaviour. For example, training tapes for ADOS and ADI released in the early 1990s referred to a case of a boy with a strong interest in computers who was given a diagnosis of Asperger's syndrome. ${ }^{58}$ The increasing number of boys with an interest in computers in late 1980s and early 1990s was a cultural phenomenon, but the $\mathrm{ADI}$ and $\mathrm{ADOS}$ enabled the creation of scenarios in which such interests could be probed. It thus provided a framework in which a child's play with these objects could become a reason for a diagnosis. 
Although Lorna Wing had been critical in developing the description of the triad of impairments through epidemiological studies, she did not have the social scientific expertise that Rutter had developed through his prolific social surveys. This gave him the edge when it came to developing a complex diagnostic instrument based on interviewing techniques and working with international collaborators to formalise it. Wing's response was the creation of the Diagnostic Interview for Social and Communication Disorders (DISCO). Although it had a catchy acronym, it was an awkward testing instrument and never caught on in the same way that the ADI did. ${ }^{59}$ Hence the ADI and the ADOS became the 'gold standard' for autism testing. The building international consensus over testing instruments for autism enabled autism to become an important aspect of the growing 'statistical psyche' in which statistical and epidemiological instruments offered the promise of explaining and fully comprehending the mind. Just as intelligence was a measurable entity that could be applied across a total scale, so autism also became a similar measurable entity. The ADI and the ADOS helped to consolidate this entity and to expand its measurable dimensions.

The growth of testing instruments, such as the $\mathrm{ADI}$ and the ADOS, helped to popularise the idea that autism was part of a general scale of human development and that it was therefore a topic of interest to many people, not just the minority who were affected. As Stuart Murray has argued, in the 1980s and 1990s theories of autism were popularised through proliferating media channels that had international reach. ${ }^{60}$ The Hollywood movie, Rain Man (1988), spurred a series of articles on autism in the press that directly linked this film to current scientific theories of autism. Writing for New Scientist in 1989, John Morton argued that 'Rain Man has drawn the public's attention to this mysterious disorder', later clarifying what autism is: 'there is a cognitive deficit underlying autism which amounts to an inability to create certain kinds of representation, particularly of other people's mental states. ${ }^{61}$ In 1993, Uta Frith wrote an article for Scientific American that drew attention to Rain Man, whilst also popularising her work. She put her theories in a nutshell with formulations such as: 'The autistic child has a mind that is unlikely to develop self-consciousness. ${ }^{\text {' } 2}$ Ideas about autism were definitely reaching a wider audience, but at the same time they were also developing the potential to be abridged, simplified and somewhat altered in their meaning. Just as testing scales enabled the concept to be 
expanded as part of a wider model of statistical psychology, so did the representation of autism in the media. This led to new summaries and articulations about what, exactly, autism was, and ultimately led to shifts in the meaning of the concept. The work of the new autism researchers was fundamental in defining these new conceptions of autism.

In 1991, the British Psychological Society issued a media release about the work of Frith at the MRC Unit and the light it shed on all people with unusual interests including 'academics' and 'collectors. ${ }^{6} 3$ Frith would later speak to the press about trainspotters, walking encyclopaedias and trivia collectors. The autistic children of the 1960s had now grown up and such unusual adult behaviour was now a topic for psychological scrutiny. 'Train spotters "may suffer from autism", declared a headline in the Independent. 'Train spotting is fertile ground for people with Asperger's syndrome', Frith argued, and went on, 'not all train spotters have this syndrome, but I know one, for example, who is really interested in carriage light fittings. That is fairly specialist. ${ }^{34} \mathrm{By}$ the mid-1990s, autism was established as a topic of general journalism and this was encouraged by the publication of several literary works by individuals who had been diagnosed with autism as children such as Birger Sellin and Donna Williams. ${ }^{65}$ Furthermore, television programmes helped to exhibit the preoccupations and talents of people who had received the autism diagnosis. In 1987, the BBC documentary, The Foolish Wise Ones, featured Stephen Wiltshire, a boy from South London with an extraordinary talent for drawing. In addition, more popular books emerged on the subject such as Oliver Sacks' An Anthropologist on Mars (1995), which also featured Stephen Wiltshire as one of the cases. Wiltshire has since received an MBE for services to the art world and is now an internationally renowned artist. ${ }^{66}$ An article in the Guardian in 1995 described all these popular representations of autism, arguing that although the Institute of Psychiatry trained scientists appeared to have agreed on a definition, there was much work to do. As the journalist put it, rather wryly, 'After half a century of seeking an answer, the world's experts have barely worked out the question. ${ }^{67}$

There was something of a self-fulfilling prophecy here: just as measurement scales became increasingly definitive, the demarcation of autism was readily expanded through journalism and general discussion. 
Uta Frith's students, Simon Baron Cohen and Francesca Happé were the most passionate public writers on the new autism. Like Bowlby and Winnicott had done in the 1950s, they used available media formats in the 1980s and 1990s to ensure that the public understood the new science of autism sought to ensure that new theories of autism were popularised to a wider audience and that ideas about autism were clarified in the minds of the general public both in the UK and abroad. Simon Baron-Cohen and Patrick Bolton's Autism: The Facts (1993) sought to clarify new approaches to autism by Maudsley-trained psychiatrists and to support the view that 'modern medical evidence suggests clear biological causes for autism. ${ }^{68}$ Francesca Happés Autism: An Introduction to Psychological Theory (1994) stated confidently that 'Autism is not caused by refrigerator parenting'; 'Autism is not confined to childhood'; 'Autism is not always characterised by special or "savant" skills'; and 'Autism is not just a "shell" within which a "normal" child is waiting to get out.' Luckily, she also knew what the new autism was and argued that 'Autism is a biologically based disorder'; 'Autism is a developmental disorder which lasts throughout life'; 'Autism is found at all IQ levels, but is commonly accompanied by general learning difficulties (mental handicap)'; and 'Autism is a severe disorder of communication, socialisation and imagination. ${ }^{69}$ This was a passionate manifesto for the new autism, and it was incredibly persuasive. It helped to establish new 'styles of reasoning' about autism and social development that aimed to crush the Tavistock human relations model, and to establish a disability and rights-based model of autism.

\section{The big global increase}

The large rise in levels of autism across the globe began to be reported in the 1990s. This happened in line with the widespread adoption of Wing's model of an autism continuum or spectrum, as well as the growth in application of the $\mathrm{ADI}$ and $\mathrm{ADOS}$ in the process of diagnosis. These new concepts and tools were enabling a widespread statistically validated crushing criticism of the first autism and the creation of a new set of quantitative tools that promised to give meaning to the second autism in its new metamorphosis. As we saw in Chapter 5, these tools had been developed by a group of researchers in Britain who sought to 
challenge 'the Tavistock programme' and to provide new ways to think about psychological abnormalities within total populations. These new technologies were radically opposed to psychological models that did not integrate children with low intellectual levels. However, they were also radically opposed to hierarchical, planned social welfare models that imposed ideologies about the logic of care. The new autism was tailored to new liberal societies that sought to develop consumer-oriented models of care and to create models of child rights and disability rights that ensured these new models encompassed all members of society. By the early 1990s, everyone from children, parents, teachers and educational psychologists to lawyers, police officers and social workers had a clear set of criteria that could be used to make their own claims and inferences about child psychology and about the needs and rights of children.

By the mid-1990s, it became apparent that many more children were being diagnosed with autism in Britain than previously. Writing in the British Medical Journal in 1996, Wing summed this up as follows: 'Autism seems to be on the increase. This at least is the feeling of many professionals in the field of child development in Britain, who believe that in recent years they have been seeing more children with autistic spectrum disorders. ${ }^{70}$ Wing pointed out that it was not possible to compare pre-1979 epidemiological studies of autism with post-1979 studies, arguing correctly that her own epidemiological study in 1979 had linked autism to a 'range of developmental disorders' that had since become known as 'autistic spectrum disorders', thereby expanding the category from previous definitions. In 1996, Wing argued that there was 'no evidence for or against an increase in prevalence' of autism, espousing an ambivalent approach to the problem that was ultimately unsustainable. $^{71}$

Wing's ambivalence in 1996 is interesting given her significant role in championing the new model of autism. What is more, her promotion of the Asperger's category, which specifically included individuals with high intelligence levels, added new figures to the general field of autism epidemiology by adding an additional category to measure. In 1993, Gillberg and Stephan Ehlers published an epidemiological study based on diagnostic criteria for Asperger's taken from ICD 10 and also criteria devised by Gillberg himself that included 'Social impairment (extreme egocentricity)' with subcategories such as 'lack of appreciation of social 
cues' and 'lack of desire to interact with peers'. They found a prevalence rate of 0.71 per cent $(0.97$ per cent of all boys and 0.44 per cent of all girls), a figure that surpassed their expectations. Gillberg's study placed Asperger's well and truly on the map of population health epidemiology, ${ }^{72}$ whereas before his study, it had been viewed with some wariness and suspicion. The epidemiological engine that was driving the expansion of diagnoses was demonstrating that Asperger's definitely existed. Of course it did; it had an epidemiological study to back it up.

When DSM-IV was published in 1994 it retained the 'triad of impairments' for 'autistic disorder' but it also included 'Asperger's Disorder' as a distinct category and a subtype of what were termed, 'pervasive developmental disorders'. The criteria for Asperger's diagnosis were similar to those for 'autistic disorder' but Asperger's did not contain the 'qualitative impairments in communication' feature of the triad. In fact, the criteria specifically stated that in cases of Asperger's, 'there is no clinically significant general delay in language' and 'no clinically significant delay in cognitive development', thereby encouraging the diagnosis in children who only presented with 'qualitative impairment in social interaction' and 'restricted repetitive and stereotyped patterns of behaviour, interests or activities. ${ }^{73}$ If a child met only three behavioural criteria, such as 'failure to develop peer relationships appropriate to developmental level', 'lack of social or emotional reciprocity' and 'persistent preoccupation with parts of objects', then they would meet the criteria for an Asperger's diagnosis.

In Britain, many researchers with links to the Institute of Psychiatry began to challenge the category of Pervasive Developmental Disorder, in particular the prefix 'pervasive', which had emerged in DSM-III as a catch-all category that included autism. In 1991, Gillian Baird, Uta Frith, Lorna Wing, Simon Baron-Cohen, Christopher Gillberg, Patricia Howlin and others has written an open letter to Developmental Medicine and Child Neurology arguing that although it was a good thing that autism had been recognised as a developmental disorder, and thus associated with mental retardation and other developmental problems rather than emotional problems, this had been overshadowed by the fact that it was classed as a 'pervasive' developmental disorder. Clinicians increasingly challenged the contention that autism was pervasive at all as it was possible to have the condition in a minor form, yet the idea of a 'mild pervasive developmental disorder' was an oxymoron. In Britain, 
autism was regarded as anything but 'pervasive'. Gillberg later added that the 'Pervasive Developmental Disorder' diagnosis often meant that those diagnosed under the broader label, yet not classed as 'autistic', were not getting the help they would be legally entitled to were they classed 'autistic.' ${ }^{74}$ 'Pervasive Developmental Disorder' was the ultimate misnomer, yet it was a step on the way to creating a broader definition of autism. As it happened, DSM-IV quelled many of these concerns by adding Asperger's to the list, thereby making it very clear that Pervasive Developmental Disorders were not always 'pervasive'.

The addition of Asperger's and the debates over Pervasive Developmental Disorders led to many slippages and indiscretions in the language surrounding autism, the 'autistic spectrum', Asperger's and pervasive developmental disorders generally. Autism was increasingly associated with the concept of 'neurodevelopmental disorders' to the extent that 'neurodevelopmental disorder' became used often as a synonym for 'autistic spectrum disorder. ${ }^{75}$ At the same time, the term 'neurodevelopmental' was growing in its application to describe all childhood psychological disorders that were thought to have any kind of correlate in brain chemical development, including dyslexia, dysgraphia and 'clumsiness. ${ }^{76}$ Just as diagnoses of autism and autism-related conditions grew, the psychology of 'neurodevelopment', along with a wealth of neuroscientific studies, became focused on broad problems of social interaction and 'social impairment'. This burgeoning scientific field of genetic and neurochemical research into 'social impairment' supported Frith, Baron-Cohen and Leslie's 'Theory of Mind' hypothesis. ${ }^{77}$ It has also increasingly meant that attempts have been made to identify 'social phenotypes' within neurodevelopmental disorders both in Britain and internationally. ${ }^{78}$ Autism has served as a central concept through which to approach such studies.

International studies of autism began to thrive in the 1990s, with some pointing out that changing diagnoses seemed to be leading to more reported cases. Drawing directly from Gilberg's epidemiological approach, a 1996 study by $\mathrm{H}$. Honda on rates of autism in Japan, gave a rate of 21.1 per 10,000 using ICD 10 criteria. Half of that figure concerned 'high-functioning cases. Without attending to philosophical and scientific inconsistencies, Honda argued that this 'proves the existence of more high-functioning cases. ${ }^{79}$ An Icelandic study by Magnusson and Sæmundsen then showed very different rates for children classed under ICD 9 and ICD 10 criteria in the 1990s, and the authors conceded that changing diagnoses were definitely leading to increased cases. ${ }^{80}$ 
The increased awareness of more diagnoses only encouraged further epidemiological studies in the UK and abroad. In 1997, the British National Autistic Society founded the journal Autism, to 'encourage free dialogue between practitioners and researchers working throughout the world in autism..${ }^{81}$ In the late 1990s, Uta Frith's student, Simon BaronCohen, along with Gillian Baird and others from both the Newcomen Centre at Guy's Hospital, London, and Cambridge University, used new testing methods to argue that there were, in fact, 57.9 per 10,000 children with 'autistic spectrum disorders', a term used increasingly to refer to almost all 'pervasive developmental disorders. ${ }^{82}$ After this figure was published, a flood of international studies confirmed that the rate for all 'autistic spectrums' was also very high. A study from the same year in New Jersey, USA, came up with a figure of 67.4 per 10,000 , a Danish study with 30 per 10,000 in 2002, a Cambridge study with 58.3 per 10,000 in 2002, and an Atlanta study with 34 per 10,000 in 2003. After the UK Department of Health admitted they were puzzled and concerned by the increase, being reported. Gillian Baird and others then looked back at the South Thames population in the UK and came up with an even higher figure of 116.1 per 10,000, also translatable as over 1 per cent of the total child population or 1 in every 64 children. Two US studies across states then came up with 66 per 10,000 and 67 per 10,000 respectively, with Denmark then coming in at 53.3 and Canada at 64.9 in 2006. The Australians and the Chinese were a little more cautious but came up with figures in the thirties and forties per 10,000 in the mid-2000s, but the British and North Americans continued to publish studies with around 60 per 10,000. In 2008, a Japanese study then went out on a limb with a rate of 181.1 per 10,000 , verging on 2 per cent. ${ }^{83}$

Autism has since been reported to have grown in such proportions that it has become common in popular literature to talk of an autism 'epidemic. ${ }^{84}$ This is somewhat ironic because Wing's autism, the second autism, is hugely dependent on the science of epidemiology to delimit and demarcate its boundaries. The initial reaction to these increased diagnoses was cautious, but it did not take long before multiple theories and explanations were put forward to explain this phenomenon and discussions of the autism epidemic took place on an international platform. Wing's expansion of the category, and the theory of the 'autistic spectrum', became an international phenomenon through 
DSM-III-R and ICD 10 which followed her definitions. This led eventually to reports of increases internationally. Wing's definition of 'autism', what one may term the 'total population definition of autism', was carried out in the interests of establishing comprehensive, inclusive epidemiological studies of child development. However, it then unleashed a spread of interpretations, analyses, qualifications, explanations and rationalisations internationally.

The first decade of the new millennium saw increased global reflection and consideration over whether or not this epidemic was 'real'. For example, Ashley Wazana and others from Columbia University in 2007 asked whether 'the autism epidemic' was a 'fact or artifact'. Helen Leonard and others from the University of Western Australia spent much of the 2000s 'unpacking the complex nature of the autism epidemic'. Jørn Isaksen and other Norwegian researchers simply asked: 'Autism Spectrum Disorders: Are They Really Epidemic?' 85 They were aware that there had been changes in diagnostic criteria and diagnostic practices, that the promise of additional school help encouraged parents to get a diagnosis for their child. They also knew that there had been an increase in the number of professionals able to identify autism, as well as their ability to reach younger age groups. However, none of this explained why the world had become so focused on 'autism' and ASDs in particular, as opposed to any other disorder, and why health and education institutions were so keen on working with, and thinking about, this particular 'triad of impairments'.

This seemed to be a puzzle for many who oversaw the increase. As Gil Eyal and Eric Fombonne have argued, these higher rates were in large part a reflection of the fact that children with both higher intelligence and lower intelligence, or retardation, were also included in the studies. ${ }^{86}$ Simon Baron-Cohen's development of the Checklist for Autism in Toddlers (CHAT) has also encouraged earlier diagnosis, serving a pre-emptive purpose. The ADOS has improved the techniques used to measure autism accurately, which is in many ways self-fulfilling. The more the ADOS is used in studies and confirms findings, the more it is recognised as an accurate measure of autism, and the more it is used in future studies. As described throughout this book, changes in the institutionalisation, schooling and treatment of children who show atypical development have also helped to increase the observation of autism. Similar changes have occurred in the USA and many other countries. 
Since the increased attention focused on the autism 'epidemic', other countries across the world have begun to wonder about rates of autism and whether these have changed. Needless to say, researchers from these countries look straight to the DSM, the ICD and to testing instruments such as the ADI and the ADOS, rather than to Bleuler, Piaget or others who described autistic thought before the onset of epidemiologically defined autism.

Controversies surrounding the autism 'epidemic' have built up an awareness of autism and provided fertile ground for further research. News and reports of an autism epidemic have definitely placed autism firmly on the international health research agenda. This has forced other countries to rethink their theories of intelligence and child development and has challenged them to embrace autism as a charity cause and to do more research into the issue of autism and social impairment. All of this activity supports the spread of the second autism within a wider theory of psychology, creating a solid body of research activity built on this model. There is now a global tendency to think of child development in terms of autism and the autistic spectrum and so epidemiological studies for this purpose flourish all over the globe. And although many people have asked questions about the increase, no one has asked why this particular model is so attractive to child psychologists and others. The answer, however, is more obvious than it seems. Wing, Gould and other Maudsley-trained psychiatrists developed a way to calculate 'social impairment' across entire societies. They devised a way to measure the limitations of this entity called 'society' via the study of some of its most vulnerable members. The 'triad of impairments' was a powerful organising concept that came to replace intelligence as a way to measure the limits and potential of advanced social organisation. A 'society' is only as good as its ability to detect and assist all its members who are 'socially impaired'.

\section{Hope is not a dream}

As increasing numbers of epidemiological studies were conducted, developing countries sought to emulate European and American research into autism as it was regarded as a reflection of improved children's rights and disability rights. This was accompanied by a growing 
number of international conferences. In the early 1990s, international conferences on autism focused almost exclusively on successful treatment methods. In contrast with the overall despondent and hopeless attitude to the first autism, the attitude towards the cure of the second autism was hugely optimistic and encouraging. In 1996, the Autism Europe Conference was held in Barcelona with the title: 'Hope Is Not a Dream'. A 1993 International Conference on Autism held in Ontario had only twelve papers on biomedical research out of a total of seventy, with the majority focusing on approaches to develop language and communication skills. ${ }^{87}$ The year 1994 saw a variety of new, sometimes controversial, treatments for autism publicised. A 1994 international conference organised by the National Autistic Society, bringing together researchers from twenty-three countries, showcased 'facilitated communication', which involved physical support and touch to encourage communication by Richard Brooks at the Chinnor Resource Centre in Oxford, UK; 'The use of video techniques' to develop language skills by Fahri Zinhi in the UK; 'Auditory integration training' by Aditi Silverstein from Innovative Therapies, Roanoke, USA; the Storm House Positive Approach by Kit Howe and Geoff Evans from the Storm House School in Rotherham, UK; the gluten- and casein-free diet by researchers at the University of Oslo, Norway; and the use of computers in teaching people with autism by Stuart Powell from the University of Hertfordshire, UK. ${ }^{88}$

There was a huge amount of optimism concerning the treatment of autism in the 1990s amongst some biomedical and educational professionals. This is another cause of the skyrocketing of diagnoses. Even more importantly, the assurance of welfare rights to all those diagnosed ensured that the diagnosis was extremely popular. The European parliament adopted an abridged version of Autism Europe's charter of rights as a written declaration on 9 May 1996. The European Commission's Communication on Equality of Opportunity for People with Disabilities (1996) argued for a 'renewed impetus towards the rights-based equal opportunities approach to disability'. The Council Resolution on Equality of Opportunity for People with Disabilities (1996) reaffirmed that people with disabilities should have 'equal opportunities for productive employment in the labour market. ${ }^{89}$ In 1997, Rita Jordan from the University of Birmingham, UK, wrote a guide on the 'Education of Children and Young People with Autism' as the tenth in a series of 
UNESCO 'Guides for Special Needs Education' This all ensured that Wing's triad of impairments was recognised in changing education and employment legislation across Europe.

In 1998, Pat Matthews, director of the Irish Autistic Society, then established the WOA in collaboration with Autism Europe, with the aim of 'the protection and enhancement of the lives of children and adults worldwide.' They quickly arranged meetings with the WHO and UNESCO and established a bank account in Brussels to receive funds, in collaboration with Autism Europe.

In the same year that the WOA was established, Autism Europe published a Code of Good Practice on Prevention of Violence against Persons with Autism. ${ }^{90}$ This featured reports by several European specialists working with autistic people as doctors and carers. It reinforced the idea that autistic people had human rights that were similar to, but distinct from, those of the rest of the population. Donatta Vivanti, president of the Associazione Nazionale Genitori Soggetti Autistic in Italy, pointed out that 'parents may sometimes impose excessive social promiscuity' on a child with autism without realising that their inability to understand 'the complex rules that are implicit in our relationships' left them susceptible to suffering and humiliation and in some situations even violence and abuse. André Foubert, Director of Maison Spécialisé d'Accueil in France, warned against physical violence, negligence and lack of care in institutions, linking this with a wider movement to prevent violence against all people with mental disabilities. Bill Meldrum from the Scottish Society for Autistic Children argued that all 'organisations and public agencies working in the field of autism should have a code of good practice which takes account of the particular difficulties associated with autism. Christopher Williams from the Institute of Education, London, pointed out that omission, neglect and negligence could also lead to harm against autistic people. The Code of Good Practice also encompassed a scathing critique of psychoanalytic treatment for people with autism by Swedish self-advocate, Gunilla Gerland, which argued that the 'theory of object relations' and the use of transference and counter-transference models were useless in the treatment of autism because of 'the profoundly different way in which autistic clients interact'. She urged others to recognise that autism was a disability, that autistic people needed a 'positive disability identity' and that therapy could only ever treat the 'secondary symptoms' of autism 
rather than autism itself. ${ }^{91}$ They recommended to national legislators that 'Autism should be recognised in the legislation as a specific disability with specific needs and appropriate and sufficient services should be implemented to meet the needs of all people with autism including early diagnosis programmes. ${ }^{92}$ Thereafter, all national legislators should ensure that procedures were put in place specifically to prevent violence and abusive behaviour towards these individuals. At a European level, they argued that a Europe-wide constituency should be arranged regarding the guardianship, legal capacity and criminal responsibility of autistic people and that the European Commission should extend anti-discrimination and racial harassment laws to those with disabilities including autism.

Although the classification and diagnosis of autism was becoming more standardised by the late 1990s, there was still no clearly definable object called autism, and thus legal changes aimed at 'autistic' people had the potential also to define the rights of individuals who were as yet to obtain this label. The mid- to late 1990s also saw increasing reports that the diagnosis of autism could be applied to wider groups of children and adults as part of a spectrum, and led to questions being raised about the 'autism epidemic'. There is, of course, an irony to this situation because just as national and international law began to isolate and clarify the rights of people with autism, the number of people with autism began to increase. Laws concerning autism as a kind of social disability therefore applied to increasing numbers of people and affirmed their international rights to be non-social or non-interactive beings if they so chose.

Without any clear-cut biochemical basis for the category of autism, what essentially occurred from the 1980s in the UK, and from the 1990s across Europe, was that autism rights activists demanded that social institutions adapted their approach to social care and education based on Wing's model of the triad of impairments. Educational and social work institutions were urged, and later required by legislation, to alter their established practices of social betterment and social organisation based on the fact that there were some people who were impaired in their ability to act typically according to the demands of others. Instead of excluding those individuals according to ideal blueprints of social interaction, the post-1980s and post-1990s models of societal health and welfare ostensibly urged the inclusion of 'autistic' 
beings by marking out and legislating for their supposed social impairments. Such a model has been successful to a large degree, although its limitations obviously rest on the conceptual margins of the diagnosis and the fact that social institutions do not always easily alter their ideological assumptions about child development and socialisation.

The autism rights movement has increasingly demanded that all institutions, even including employers who previously had no approach to autism, alter their behaviour. In 1992, Autism Europe published a book 'describing autism', which was specifically to be used not for the purposes of researchers, in the vein of DSM and ICD, but rather as a way to work on a definition 'to establish the lifelong needs and requirements of people with autism'. It highlighted parental rights to be involved in treatment, but in its description it drew, again, almost wholesale from Wing. This distinction is important as it shows that Wing's definition of autism entered several different arenas. Within the global expansion taking place in relation to disability rights, Wing's autism was used to argue that individual rights and social, welfare and education services should be aimed specifically at protecting the 'dignity, individuality and capability of the person with autism' by providing opportunities for 'education, vocational training, and job opportunities.93 This is why it was so important.

The 1997 Amsterdam Treaty on Fundamental Rights and Nondiscrimination contained an article providing for action to 'combat discrimination' based on disabilities and also included a declaration to take into account people with disabilities in relation to single market harmonisation. This was a perfect opportunity for campaigners to articulate and clarify the condition of autism and the unique needs of autistic individuals and their families. For example, a message from Autism Europe addressed to European Commissioner Pádraig Flynn in 1997 urged that the employability of mothers of children with autism and others be enhanced by the creation of European policies encouraging flexible working hours within companies, so that these mothers are able also to care for their children in places where adequate education and support are lacking. Whilst supporting more freedom of movement in employment throughout Europe, they pointed out that parents, particularly mothers, of children with autism had a very limited level of mobility and thus whilst it was 'advisable to favour the free circulation of workers', this 'should not be done at the expense of the 
social values that are the basis of European society, i.e. the family'. They thus encouraged greater employment support for the families of disabled people and the integration of children with autism into European mainstream schools. ${ }^{94}$ Such an approach had clear political objectives to ensure that autistic people actually had a place in the new European and international model of the free market, rather than merely being placated without there being any real political will to enable those with 'social impairments' to integrate. In practice, in 1998, the Governmental Committee of the European Social Charter of the Council of Europe included Autism Europe in a list of international NGOs who were entitled to make collective complaints for violation of the European Social Charter, which is how autism began to be acknowledged in international law.

In the late 1990s and early 2000s, Autism Europe became increasingly globally focused. As part of the efforts of Autism Europe, Dr Joaquin Fuentes from the Child and Adolescent Psychiatry Unit, Policlinica Gipuzkoa, and Scientific Advisor of GAUTENA Autism Society, Spain, gave seminars to parents and professionals in New Delhi, India. Dr Hans Wulffsberg from the Danish Disability Council, and father of a son with autism, commented at an Autism Europe meeting that his work in Africa and Asia had led him to believe that 'the situation of people with autism in developing countries is dreadful as in most of these countries autism is not recognised'. He thus was keen to support a 2000 congress on 'Autism: Developing Programmes in Countries Where Services are Less Developed. ${ }^{95}$ This was part of a growing movement championing the rights of people with disabilities, supported by organisations such as the European Disability Forum (founded in 1996) to defend the interests of people with disabilities. Such changes have encouraged the developmental condition of autism to be conceptualised as a disability in order to encourage international action.

In 1999, members of Autism South Africa managed to get an article published in the Reader's Digest on the 'enigma' of autism that is 'incurable, but treatable'. In the same year, Isabel Bayonas, vice president of World Autism Organisation (WAO), organised a seminar on autism for Latin American countries in Columbia with parents and professionals attending from Brazil, Costa Rica, Cuba, Chile, Ecuador, Honduras, the Dominican Republic and Uruguay. Bayonas also helped to establish the Latin American Autism Federation in 1999, 
with Rosa Corzo from the Mexican Parent Organisation SOMAC as president. In the late 1990s, Autism Europe also made connections with the International Association of Child and Adolescent Psychiatry and Allied Professions (IACAPAP) in order to encourage further co-operation in autism research. ${ }^{96}$ Autistic societies across the world were also particularly savvy in using new Internet technologies, with the UK society founding an Internet-based conference in the late 1990 s and the WAO setting up their own website in the same year. In 2000, a workshop was organised for UNESCO in Glasgow, Scotland, which focused almost entirely on Wing's description of autism in its conceptual presentations. ${ }^{97}$ The fact that this has now become a global mission has helped to establish an Anglocentric approach to atypical child development in children generally through the spread of Wing's autistic spectrum.

Increased international debate also encouraged the exchange of ideas concerning the education and treatment of autistic children. In 1991 and 1995, the British National Autistic Society organised visits to the Boston Higashi School, a branch of Japanese treatment centres for autism established in 1987 that was very popular amongst parents. Judith Gould and members of the National Autistic Society wrote reports on the teaching methods used there. ${ }^{98}$ The school became known for employing the principle of 'Daily Life Therapy' aimed at encouraging children to dress, feed and clothe themselves and live independently, whilst also engaging in extensive physical exercise and using many techniques to stimulate each child's intellect. The aim was to prepare each child for mainstream education within 2-3 years at the school. The NAS 1991 report drew attention to the emphasis placed on physical education at the school, arguing that British schools could perhaps learn from this. The 1995 report also discussed the ways in which play therapy was employed in the school with a focus on 'the reduction of stereotypes and encouraging children to engage in what would be described as socially acceptable play', such as 'the bathing of the baby in the bath' or 'the running a car around a track'. Unlike the British technique of play therapy, these activities were not aimed at stimulating 'the imaginative development of the child' but rather on 'structure, predictability, routine and a clear and consistent rhythm to life. ${ }^{99}$ 
These techniques appeared to provide a means of encouraging a form of 'play' in autistic children, without the baggage of European models of play therapy that had become so closely associated with psychoanalysis, hence the popularity of these models amongst Western parents of children diagnosed with autism. In 1990, several parents in Britain appealed to have their children sent to the Higashi School in Boston at the expense of the local authority, though these appeals were unsuccessful. ${ }^{100}$ In 1990, the International Autistic Research Organisation was founded, reporting on international ventures and collaborations. This enabled the international promotion of various treatment programmes, such as the TEACCH programme that had been developed by Eric Schopler at the University of North Carolina in the 1960s after a general disillusionment with psychoanalytic models of therapy for autistic children. ${ }^{101}$ It claimed to iron out inconsistencies in applying professional approaches from separate disciplines such as speech therapy, occupational therapy, etc. and creating a unified model. The concept of autism had enabled a huge variety of innovative teaching methods, together with a flood of acronyms to describe them. These acronyms and fixed methods also helped to encourage international dialogue and were presented as products that could be assessed and purchased in an international marketplace. In the UK, the NAS Earlybird project promoted the SPELL approach that encouraged Structure, Positive (approaches and expectations), Empathy, Low arousal and Links. Other methods included the Son Rise programme developed in the USA by Barry and Samahria Kaufman in 1983 and Framework for Communication, developed by Phil Christie and Elizabeth Newson in the UK. ${ }^{102}$ These enabled parents and any other health care, social work or educational assistants and professionals to develop clear methods and practices in the treatment of children, many of which could even be applied to preschool children. For example, in the mid-1990s, the London Early Autism project was established to encourage the enactment of social play at a young age. ${ }^{103}$ All of these approaches enabled new networks to form, many of which were supported by ever-increasing Internet technologies.

As Silverman has pointed out, parent organisations, such as Autism Speaks, have empowered parents to set their own research agendas by affirming their ownership of genetic data and other data that researchers are dependent on. The databases Autism Genetic Research Exchange (AGRE), Autism Tissue Program (ATP) and Autism Clinical Trials 
Network (ACTN) were founded by Autism Speaks to enable scientific research based on parent agendas. US parental organisations have since become driving forces in increasing global autism awareness. In particular, Autism Speaks helped to found World Autism Awareness Day on 2 April every year. World Autism Awareness Day was ratified by the United Nations in 2007 in order to raise international awareness that:

autism is a lifelong developmental disability that manifests itself during the first three years of life and results from a neurological disorder that affects the functioning of the brain, mostly affecting children in many countries irrespective of gender, race or socioeconomic status, and characterised by impairments in social interaction, problems with verbal and non-verbal communication and restricted, repetitive behaviour, interests and activities. ${ }^{104}$

This classification was drawn almost verbatim from Lorna Wing's triad, enhanced by the statement that the condition knew no national boundaries.

In 2008, the United Nations World Focus on Autism forum was held, bringing together members of the United Nations Diplomatic Corps, autism researchers, advocates and political representatives including Sarah Brown, wife of the then British prime minister, Gordon Brown, and Ban Soon-taek, wife of United Nations Secretary General Ban Ki-moon, who chaired the discussions. Suzanne Wright, co-founder of the charity Autism Speaks, stated that, 'Autism is a global health crisis that knows no borders', adding that 'it does not discriminate based on nationality, ethnicity or social status. ${ }^{105}$ Other speakers drew attention to the importance of identifying and treating autism internationally. Autism Speaks has since initiated its 'Light It up Blue' campaign, which has published pictures of major architectural monuments, such as the Sydney Opera House in Australia, Nelson Mandela Bridge in South Africa, Christ the Redeemer statue in Brazil, the leaning tower of Pisa in Italy and the Macau Tower in China, bathed in blue light on World Autism Day in order to raise global awareness of autism. Epidemiological figures are often used to support the need for global recognition. There would clearly be less global recognition, and medical research funding, if figures were still at 4.5 per 10,000 in England. In 2015, Autism Speaks put the figure at seventy million people with autism across the globe. ${ }^{106}$ 


\section{Autism epidemiology as a symbol of child rights and disability rights}

Low rates for autism have now become synonymous with a lack of education about disability rights. This is why many non-Western researchers have sought to emulate epidemiological rates of autism produced in Western countries. For example, epidemiological studies of autism in China only began in the mid-1990s with a study in Fujian using DSMIII-R criteria, together with the Chinese Classification of Mental Disorders 2 (CCMD-2), finding a rate of 2.8 per 10,000. Studies in China throughout the 2000s found rates ranging from 2.9 to 13.9 per 10,000. The CCMD-3 was published in 2001 using similar criteria to DSM-IV (1994), featuring 'autism' and 'Asperger's' as two of the six pervasive developmental disorders in order to classify cases. This influenced new perspectives on the condition, as did growing international public awareness of autism. In 2011, Ning Li and colleagues from the Institute of Population Research at Peking University, China, found a rate of 2.38 per 10,000 , still well out of kilter with most other international reports of that time. They based their figures only on information that had been collected from the Second China National Survey Sample on Disability (2006), in which a sample population of 616,940 children with disabilities were identified. The type of their disability was assessed using classifications based on ISD 10. The authors put the low rate down to the fact that it was based only on children already thought to be 'disabled' and that the minutiae of detail needed to identify a case 'may not be fully captured by the ICD-10', and appealed for better distribution and availability of Rutter and Lord's ADOS to help improve awareness and to obtain a more accurate rate. ${ }^{107}$

Similar appeals have issued from other countries. In 2011, Muideen O. Bakare from the Child and Adolescent Unit, Federal Neuro-Psychiatric Hospital, Enugu State, Nigeria, and one of the most prolific writers on autism in Africa, pointed out that no one had studied autism epidemiology since Lotter in the late 1970s and appealed: 'There is a need for epidemiological studies in Africa to define the magnitude of the problem of ASD and the characteristics of children affected by ASD in this region. ${ }^{108}$ In 2012 he conducted his own study investigating autism within a sample of children with intellectual disability, arguing that a 
higher percentage of intellectually disabled children appeared to have autism compared to the 1970s. Bakare found that 11.4 per cent of children with intellectual disability also had autism in his Nigerian sample, whereas Lotter found that only 0.7 per cent of children with intellectual disability in his total African sample had 'autism. This only encouraged further investigation and again repeated the 'need for large scale epidemiological studies of autism spectrum disorders among sub-Saharan African children. ${ }^{109}$ A recent study across the Arab world employed the CHAT to test for autistic spectrum disorders. The reasons given for this are very interesting. As Eldin et al. put it:

With the apparent rise in the prevalence of ASD and the growing need to screen large populations of children, the members of the Eastern Mediterranean Association of Child and Adolescent Psychiatry and Allied Professions (EMACAPAP) developed a study using the M-CHAT to screen children for autism in the Arab world. ${ }^{110}$

The 'apparent rise in the prevalence of ASD' was an encouragement to developing countries to develop measures for ASD and to find out how they fared on the international map of autism.

The use of internationally ratified diagnostic tools makes sense when making such comparisons, but it is important that all these international researchers are then employing classifications devised by Wing, Rutter, Frith and others in the unique cultural moment described in this book. This is the legacy of the psychology of autism spectrum-making. Researchers are no longer interested in intelligence and intelligence alone, they want to know how much 'autism' their nations encompass because it has become a symbol of advanced nations, of ethical altruistic approaches to all children. It is also a symbol of a new version of humanitarian commitment. Developing nations state that they will no longer hide their autistic populations, and medical research companies support this approach because it promises to bring new neuroscientific breakthroughs. This represents a new version of psychology in a postcolonial context. This replaces human relations theory and more stagnant versions of evolutionary theory, society and psychology that were prominent in earlier work, such as that of Cyril Burt. This new psychology of autism enables atypical children to have their own autonomy but only via this particular set of psychological schemes, systems and concepts framed around the idea of the autistic spectrum. 
China presents an example case where growing media attention and growing international consensus have encouraged and enabled the uptake of epidemiological methods developed in Britain. In 1993, Tian Huiping founded Beijing Stars and Rain, a non-governmental rehabilitation centre for children with autism in China, after her son was diagnosed with autism at the age of two. In 2007, an English-language documentary about the school, Children of the Stars, became a global success and was nominated for several awards. ${ }^{111}$ It led to increased media focus on the school and, of course, increased awareness of autism in China. The film presents autism as a major humanitarian crisis that requires the best international medical and educational efforts. It shows the approaches to autism taken when no resources or understanding are available, including the tragic depiction of one mother's daily ritual of tying her autistic son to a chair. Many mothers travel across China to seek help at the rehabilitation centre. The growing awareness that the film generated fueled more epidemiological studies. In 2013, Simon Baron-Cohen and colleagues reviewed all previous Chinese epidemiological studies of autism to find a rate of 11.8 per 10,000 individuals with autism and 26.6 per 10,000 with Autistic Spectrum Conditions (ASC). They argued there was 'a potential under-diagnosis and underdetection of ASC in mainland China, Hong Kong and Taiwan, and a need to adopt more advanced methods for research of ASC in these areas. ${ }^{\prime 12}$ In 2012, Chinese versions of the ADI-R and the ADOS were approved by the publisher, Western Psychological Services, thus providing the ideal instrument for such an analysis. These instruments provide support for the development of the concept of autistic spectrum disorders across the globe. This model of psychology is often presented as the basis for humanitarian approaches to psychological conditions in children.

In Brazil, similar developments have taken place. Between 2002 and 2009, Brazilian researchers published 93 articles and 140 theses and dissertations on the topic of autistic spectrum disorders. In 2007, the Brazilian Ministry of Health established a working group responsible for the care of people with autism, as part of the Brazilian Unified Health System, also signalling the importance attached to this disorder in the field of public health. The working group has since highlighted its commitment to scientific research to improve care. ${ }^{113}$ Researchers at the Institute of Biosciences, Universidade Estadual Paulista, Campus 
de São José do Rio Preto, and the Department of Genetics at the Federal University of Rio Grande do Sul have since contributed to neuroscientific theories of autism. ${ }^{114}$ In April 2010, the first national Brazilian Meeting for Autism Research was held, bringing together representatives from government departments and research centres. Writing on science and society, several of the participants concluded that 'ASD cannot be considered a rare disorder anymore and over a million Brazilians are likely to be affected.' ${ }^{115}$ They argued it was therefore a major public health problem. Researchers have also drawn attention to the problems that arise when there is not an effective infrastructure to support interventions to help people with the diagnosis of 'autistic spectrum disorders'. Writing in 2014, Paulyane Gomes and colleagues from the Department of Clinical Medicine at the Universidade José do Rosário Vellano argued that 'difficulties in access to health care services and adequate social support contribute to increased levels of stress for caregivers of children diagnosed with ASD'. ${ }^{16}$ Gomes encouraged the formation of educational establishments, health care networks and related institutions to provide social support for families of children who have autism. This approach involves the adoption of measures for autism of which the ADI and ADOS are becoming global standards.

A few autism epidemiological studies have been conducted in South Asia, for example in Sri Lanka. Even fewer have been conducted in India, using largely indigenous instruments. However, new work now seeks to translate English-language autism screening and diagnostic tools into Bengali and Hindi so that global models of autism epidemiology can become a reality there. ${ }^{117}$

In India, many researchers now talk of the 'unmet needs' of children with autism. In 2012, a team of researchers from Sangath Centre for Child Development in Goa argued that there was a need to develop 'packages of care' for autistic spectrum disorders and other developmental conditions that could be 'delivered through a collaboration between trained community health workers and parents. ${ }^{118}$ Others frequently argue for better education for parents, health workers and teachers about autism in children and ways to manage this. The fact that new approaches to child disability rights come in one particular package is because it was this package that was exported via the DSM, ICD and the ADOS.

In Africa, Bakare's work has encouraged deeper reflection on all child rights. This has drawn attention to the discourse of children's rights as 
defined in the 1990 United Nations Convention on the Rights of the Child and the 1991 African Charter. The African Charter on the Rights and Welfare of the Child (2001) helped to ensure that children have a right to health, education and special care. In 2003, Nigeria adopted the Child Right Act and Bakare used this law to appeal for more training for health care workers and the mobilisation of child psychiatrists, pedagogues, speech and language pathologists and special educators. Bakare also pointed out the "unmet needs of children with childhood autism and other developmental disorders in the present healthcare delivery system. Such unmet needs are, of course, made apparent via epidemiological studies of autism that present a population figure for children who demand these services under the auspices of their rights as a child. ${ }^{119}$

The model of these sciences that is being spread internationally is not that of 'human relations' psychology but that of the autistic spectrum and the model of social development and social impairment that was developed in Britain in the 1980s and early 1990s as a challenge to the Tavistock hegemony. This psychological approach is now influencing theories of child development, education and socialisation across the globe. This is part of a wider international movement to adopt DSMstyle psychiatry. Although such as model is often criticised by those who think that it is part of a global conspiracy by drugs companies to make more money by peddling unnecessary drugs for psychological disorders, this is a simplification of the facts. ${ }^{120}$ In the particular case of autism, it is less easy to take such an ironic view of the condition and its diagnosis at an international level, because it is so intimately tied up with humanitarian approaches to education and improvement in social attitudes to disability. The growth of global autism research was paralleled with growing rights for children with autism in the UK. These built even further on those established before the 1980s.

In the 1990s, there was a growth of legal cases in which the rights of autistic children were challenged and tested. In 2000, the House of Lords established that LEAs could be held liable if they did not meet their duty of care to provide education to children with special educational needs. ${ }^{121}$ This coincided with a landmark High Court ruling in Ireland concerning the handling of provision for an autistic child where a family was awarded $£ 255,000$ in damages because the child's needs were not met by the LEA. ${ }^{122}$ In the same year, a Department of 
Health report co-authored by Simon Baron-Cohen argued that 'greater emphasis should be placed on the autistic spectrum disorders generally in relevant undergraduate and postgraduate programmes', and this has indeed happened with the study of autism being at the heart of many psychology programmes in Britain. ${ }^{123}$ Furthermore, the report placed great emphasis on ensuring that local authorities spot cases of autistic spectrum disorders early to prevent the development of problems later in life, such as psychiatric disorder, 'social exclusion' or contact with the criminal justice system.

In 2001, a report funded by the Local Government Association argued that any professional staff who were 'likely to come into contact with children with ASD' should be 'adequately trained and updated. and that 'provision for younger children should be available' and that LEAs should put in place the means to track children's progress through various educational and health provisions. ${ }^{124}$

The legal recognition of autism has come as a result of work by Institute of Psychiatry psychologists and the Society for Autistic Children, ensuring that the rights and needs of people with this diagnosis were respected. It was the changes in the 1990s that helped to push through landmark legal changes in the UK, namely the Autism Act 2009. In 2012, children diagnosed with autism became the largest subgroup of children registered with a statement of special educational need. ${ }^{125}$ From a political perspective, it is obviously a challenge for politicians and policy-makers to devise coherent policy to integrate those with 'social impairments' into society. The creation of legislation specific to autism has been the first real attempt to do so, and to ensure that the psychology of autism spectrum-making finds its place on the political map.

The promotion of new international attitudes to child rights and disability has generated a new internationally accepted model of intervention into atypical child development. For example, in 2013, Brian Reichow from the Yale Child Study Center argued that low-level health care workers should be trained in developing countries to provide 'psychosocial' interventions for 'low functioning' autistic children. Unlike the kind of psychological help that was provided by child guidance clinics in England from the 1930s to the 1970s, which provided support by adapting family circumstances and intervening to support a human relations model of psychology, Reichow and others argue for 
'the development of daily skills. Cognitive rehabilitation, training, and support (interventions that facilitates the relearning of lost or altered cognitive skills)' and 'parental training interventions (which teach parents how to provide therapy services for their child) had strong effects on developmental, behavioral, and family outcomes'. Such an approach has had support from Bakare in Nigeria and in other locations where professionals face many economic challenges in establishing effective networks of care and education for children with an autism diagnosis. ${ }^{126}$ The approach is also supported by the WHO's Mental Health Gap Action Programme, which provides guidance to developing countries on how to deal with autism and other developmental disorders. This has shifted international attention away from the first autism within general theories of child development, and towards the second autism. If children meet the criteria for 'autism' or 'pervasive developmental disorders' then the intervention recommendations are markedly different from those suggested if they do not. Focus is placed on implementing social interventions such as parental skills training and the notification of educational institutions, etc. rather than direct intervention into the management of human relations. ${ }^{127}$ The degree to which the model of the 'autistic spectrum' outweighs human relations psychology depends on the number of children considered to be autistic, or how much the category is applied to high-functioning cases.

Wing's model of 'the autistic spectrum' has brought new visions of society, social organisation and social care into developing countries. The fact that epidemiological studies find increased rates of autism, whilst genetic studies find increasing complexity to the disorder and pathogens are still little understood, only compound and support the idea of the autistic spectrum, and encourage further anxieties around what it is all about. The spirit of international collaboration is now called upon in order to clarify both epidemiological rates of autism and also the international rights of autistic individuals. For example, in 2012, a large team of researchers from countries across the world, namely Canada, the UK, India, South Korea, USA, South Africa, Mexico City, Venezuela, Brazil and China, came up with a prevalence rate of 62 per 10,000 for autism and other 'pervasive developmental disorders' internationally. They pooled data from various locations across the Americas and the Caribbean, Western Pacific, Europe, Eastern Mediterranean and Southeast Asia. By providing a global estimate, 
these researchers did what Lotter had done for the UK in 1966: they drew attention to the lack of services for children and adults who could be classed with this condition. They argued that 'The need for services especially in low and middle-income countries is felt more than before. It is imperative to engage community resources and more peripheral extensions of health systems as well. ${ }^{128}$ Whilst developing countries had focused on infant mortality and basic diseases of childhood until the early 2000s, the growing focus on autism as a global health crisis has encouraged international organisations to shift their attention to child mental health too, an initiative supported by the WHO.

Whilst some researchers have drawn attention to the difficulties of such an approach in countries where resources are scarce, this does not detract from the ultimate message of autism evangelism, which is to start people thinking about atypical child development in terms of autism and about how these models can be harvested to construct a new model of children's rights and disability rights. ${ }^{129}$ It should therefore not be surprising that by the early twenty-first century, researchers from around the world were all in agreement in their description of the autistic spectrum drawing directly from Lorna Wing and DSMIV. Researchers from Egypt, Saudi Arabia, Oman, Kuwait, Syria, Tunisia, India, Nigeria, China and Brazil, to name just a few, all know autism, a central concept of child development, according to its new reincarnation. ${ }^{130}$

\section{Global anxiety and explanations for the increase}

Although descriptions of child psychological development and autism have become less focused on the imagination since the 1980s, the public imagination about the meaning and causes of autism has grown substantially. Britain has always been at the forefront of autism epidemiology but it has also always been incredibly reserved about making interpretations over reported increases. The one notorious exception to this reserved attitude is the work of Andrew Wakefield, who originated the vaccine hypothesis to explain increased rates of autism. Wakefield's work was particularly controversial because it threatened so many beliefs and assumptions about mental development and created a cultural crisis. Remarkably, Wakefield's theory then became the 
most widely circulated theory concerning environmental causes for the increase in autism cases.

In 1998, Wakefield, a gastroenterologist by training, published a study on twelve children aged three to ten years who were referred to a paediatric gastroenterology unit at the Royal Free Hospital in London. The children were described as having a 'history of normal development followed by a loss of acquired skills, including language, together with diarrhoea and abdominal pain.' ${ }^{131}$ Most were given a diagnosis of 'autism' and were given various tests including ileocolonoscopy, biopsy sampling, lumbar puncture, magnetic resonance imaging, electroencephalography, barium follow-through radiography, as well as the collection of biochemical, haematological and immunological profiles a level of testing for which he was later widely criticised. Wakefield claimed that he had 'identified a chronic enterocolitis in children that may be related to neuropsychiatric dysfunction' and that in most of the cases 'the onset of symptoms was after measles, mumps and rubella vaccination. ${ }^{\text {' }}{ }^{132} \mathrm{He}$ also raised the possibility that the introduction of the vaccine in the UK in 1988 may be responsible for a reported increase in cases.

A press conference was swiftly held at the Royal Free Hospital where Wakefield made a case for splitting the vaccine into its component parts. After the press conference, several British papers published the story as front-page news. ${ }^{133}$ Wakefield's research was immediately controversial, leading to growing discussions and debates globally. This, along with Wakefield's persistent claims of a link, not least in a paper to the US Congress in 2000, 'triggered a collapse of confidence in the UK's MMR vaccination programme', as the chief editor of the Lancet, Richard Horton, described it, leading to a partial retraction of the article in 2004. ${ }^{134}$ The Wakefield article presented a medical explanation for the 'autism epidemic' that no other study had done, hence its immediate notoriety and the global attention that it attracted. In 2000, the MRC established a committee that agreed that there was no evidence of a link between MMR and autism and that the MMR vaccination campaign in Britain should persist, hoping to quell public anxiety. However, the vaccine remained controversial, with Wakefield continuing to publish claims of a link, for example in Adverse Drug Reactions and Toxicological Reviews (2000) and the Journal of Molecular Psychiatry (2002). ${ }^{135}$ In 2001, press reports that the then British prime minister, Tony Blair, 
refused to say whether or not his baby son, Leo, had received the MMR vaccine fanned the flames of the controversy. ${ }^{136}$ Public anxiety was further fuelled in the UK by televised dramas such as Channel 5's Hear the Silence (2003) followed by a televised debate, MMR: The Debate, where the actors and producers debated alongside Andrew Wakefield himself. ${ }^{137}$

In response to this ever-increasing controversy, the General Medical Council conducted an investigation into the conduct of the research and the way it was reported, and in 2010 the Lancet article was retracted and Wakefield was also removed from the British Medical Register. The story might have ended there, but Wakefield then moved to Texas where he continues to defend his research and his claims of a causal link between autism and the MMR vaccine. In 2013, he issued a statement that defended his claims about the MMR vaccine, making reference to several legal rulings where parents had been awarded compensation following the administration of the MMR vaccine to their children in Italy and the USA. ${ }^{138} \mathrm{He}$ has now become associated with a wider antivaccination movement in the USA and internationally that investigates not only the MMR vaccine but also the use of mercury in vaccines, and, indeed, wider research in the impact of environmental factors to the causation of autism. ${ }^{139}$

Nevertheless, epidemiological evidence to support Wakefield's claim was never forthcoming, which is important given the links made in both scientific literature and the popular press about vaccines being the cause of the autism 'epidemic'. The misrepresentation of the autism 'epidemic' by high-profile international researchers, journalists, politicians, parents and celebrities has not helped to quell controversy or to clarify the multiple factors at work in producing 'autistic' children. Prominent Internet resources such as US journalist Dan Olmsted's Age of Autism: Daily Newspaper of the Autism Epidemic and books such as David Kirby's Evidence of Harm: Mercury in Vaccines and the Autism Epidemic (2005) present increased reported prevalence of autism at face value, and not as part of wider historical shifts in diagnosis and in the presentation of children's rights. ${ }^{140}$

Epidemiological and statistical 'styles of reasoning' have been employed countless times in order to test Wakefield's hypothesis and each time they fail to prove it. Most epidemiological studies show that rates of autism have been rising, despite stable MMR inoculations. 
A 1999 study of children in North East Thames, London, found that clinical cases of autistic spectrum disorder had been rising since 1979, but there had been no sharp increase after the introduction of the MMR jab in $1988 .{ }^{141}$ A 2001 study in the British Medical Journal used the UK General Practice Research Database (GPRD) to conduct a time-trend analysis to measure rates of children with clinical diagnoses of autism in relation to uptake of MMR. Whereas rates of autism in 2-5-year-olds increased from 8 per 10,000 to 29 per 10,000 from 1988 to 1993, the uptake of the MMR vaccine had been stable in the same birth cohorts. ${ }^{142}$ Another 2001 study in the Journal of the American Medical Association found a 373 per cent relative increase in rates of autism from 1980 to 1994 in California, but only a 14 per cent relative increase in the uptake of the MMR jab. ${ }^{143}$ A 2005 study by Rutter and Hideo Honda found an increased rate of autistic spectrum disorder in a district of Yokohama city, Japan, even after the MMR vaccine was no longer given to children. ${ }^{144}$ Fombonne pointed out that although autistic spectrum disorder had increased over his eleven-year study of the child population of Montreal, the administration of MMR vaccines had actually decreased. ${ }^{145}$ Similar epidemiological studies came up with similar results in relation to mercury and vaccines, claiming that no causal link could be made from epidemiological data. ${ }^{146}$

However, the fact that there was no other reported or known reason for the 'epidemic' did not exactly help matters. Whatever their overall validity, vaccine hypotheses did plug a gaping hole in scientific knowledge about this condition that everyone thought had been measured so precisely and accurately with a wealth of new measurement tools and scales. How could it be that no one actually knew why autism was increasing? In 2008, Lynn Waterhouse from the Global Studies Programs at the College of New Jersey argued that there was a 'lack of explanation for the sharply increasing prevalence of autism'. Epidemiological studies giving increased rates stimulated, indeed demanded, explanations. As Waterhouse put it, 'Whatever its causes, the increasing prevalence of autism/ASD has put pressure on the field of autism research to generate productive and predictive theories.' Indeed, this was the case. However, she also pointed out that new theories of autism being generated did not seem to be 'additive and progressive' but instead rather ad hoc. ${ }^{147}$ Given all the time and effort that had been put into standardising and understanding the category of autism, it seemed incongruous 
that no one could convincingly explain the 'epidemic'. Wakefield's work was so popular because it promised so much. It promised to fully explain the autism epidemic, thus it was particularly ironic that epidemiological sciences never supported his claims.

It is no wonder that the general public thought that they were being manipulated as they were told that there was an epidemic, yet it had no known cause. What the controversy surrounding the MMR vaccine did highlight was the fact that parents, advocates and others no longer trusted that epidemiological data should be the sole domain of scientific researchers. There was growing concern that the public was being lied to, particularly in the USA. In 2003, a group of largely parent-led organisations, including the Cure Autism Now Foundation and the Autism Society of America, issued a statement urging easier access to a large database on vaccine safety, the Vaccine Safety Datalink, managed by the US Centers for Disease Control to enable the voluntary reporting of health variables in different populations that can be correlated with the application of vaccines in those areas. They hoped to further democratise mass data on vaccinations and epidemiological interpretations. ${ }^{148}$ In 2002, Sandra and Max Desorgher, directors of the World Community Autism Program in South Africa, communicated with Melanie Landman at the British National Autistic Society about 'The Vaccine Issue, Humanity and Autism, a Common Causal Factor', combining personal experience with evidence taken from various scientific studies, arguing that no hypothesis should be silenced. ${ }^{149}$

In the scientific literature, other genetic and environmental explanations were later proposed to explain the increase, although they never achieved the notoriety of Wakefield's claims. These explanations ranged from some that were very specific and emanated from case studies, to those that were extremely unspecific and could have enlisted any variable in an attempt to explain causation. For example, from the specific domain of biochemical research came the claim that children classified with autistic spectrum disorder had a significantly higher chance of having mutant forms of a gene for a folate-related enzyme, 5-methylenetetrahydrofolate reductase, and that the increase could therefore be linked to an increase in pregnant women taking folate supplements and improved survival rates for infants with a genetic polymorphism. ${ }^{150}$ At the other end of the scale came the claim from a team linked to Michael Waldman that autism prevalence was associated with precipitation or, 
scientifically speaking, 'there is an environmental trigger for autism among genetically vulnerable children that is correlated with bad weather', possibly because bad weather encourages more time indoors watching television. ${ }^{151}$ Increased rates of autism are now explored in relation to things as diverse as children's proximity to motorways; maternal metabolic conditions; maternal infections; the effects of prenatal vitamins; and lack of oxygen at birth to name but a few. ${ }^{152}$ Increased rates of autism have thus become part of a wider project to think about atypicalities in child development and their prevalence more generally.

To claim that the 'autism epidemic' is a historical by-product is not to claim that there are no environmental factors that may be affecting the development of autistic spectrum disorders as they are currently defined. However, it does take the edge off any sensationalism and ensures that researchers remain aware that their approach represents only one style of thinking when it comes to the formation of human identity and its differences. Gil Eyal's work has been fundamental in exposing the ways in which diagnostic change has affected the phenomenon of the autism 'epidemic'. However, it is not just diagnostic change across time that matters, but also wider historical changes that have affected the very thing that researchers are purporting to look for. As Paul Shattuck has pointed out, in the USA, diagnoses of 'mental retardation' and 'learning disability' declined as diagnoses of both 'autism' and 'developmental delay' increased. ${ }^{153}$ However, no one has been interested in why there was an increase in 'developmental delay', whilst there was almost mass hysteria over the 'autism epidemic.' This is because the second autism has become emblematic of children's rights to a 'typical', or rather a statistically 'typical', development. That has become a fundamental right for reasons that are beyond the auspices of current scientific enquiry.

Parent groups have attempted to acquire the rights to autism epidemiology, and to ensure that research is conducted according to their interests, because they know that so much is invested in this research. The production of knowledge about autism is part of a new global project to understand child development. This new project also has the potential to reframe wider claims about cause and effect in the development of social abilities in children. In fact, one could argue that there have been so many controversies about the autism 'epidemic' precisely because it was a category that built itself on the idea that child psychology could be completely known through epidemiological research. 
The second autism is intimately tied up with the epidemiological method itself. It is important to appreciate this fact in order to prevent researchers chasing too far up blind alleys. In fact, if Susan Isaacs, Melanie Klein and other psychologists who espoused the first autism could be criticised for their focus on the impact of instincts on thought processes in infants, one could equally criticise researchers who have latched on to epidemiological figures without looking at the multiple factors involved in their production, assuming that the numbers speak for themselves and that there is no need to challenge their validity when searching for causal hypotheses. This is largely because the core components of autism have shifted from the study of internal hallucinations to the study of epidemiology itself. As this book has argued, there was a dramatic shift in the 'styles of reasoning' used to understand autism and this dramatic shift has affected the kinds of arguments about causation that could be made about it. Epidemiological sciences have come to replace 'reasoning in cases', or thinking about individual lives, and this has had a major impact on how autism, and child development generally, is understood across multiple fields of enquiry. There is nothing particularly remarkable about this; it relates to changes in the way we think about child development. Nevertheless, the incongruity of Wakefield's claims to explain an epidemic with no supporting epidemiological data should not be forgotten, as it typifies the way epidemiological 'styles of reasoning' can be distorted way beyond their limits of enquiry.

Finding the biochemical correlates of the second autism

Although biochemical approaches to autism, such as Wakefield's, are often framed in relation to epidemiological data, there has also been a tradition of biochemical research unrelated to epidemiology. Allan Horwitz, Professor of Sociology at Rutgers University, USA, as well as other historians, sociologists, social commentators and others, have argued that psychological conditions are unlike other health conditions in that they have been primarily defined by symptomatology rather than biochemical correlates. ${ }^{154}$ However, this has not stopped researchers from delving into the possible genetic, biochemical and neurological differences between humans that may push them towards a diagnosis, and this has particularly been the case with the 
major conditions treated by drugs such as chlorpromazine, lithium, the amphetamines, etc. ${ }^{155}$ However, unlike other mental conditions, the search for biochemical correlates for autism has been a particularly complex project associated with brain development in children generally, and the ways in which children's physical development mapped onto their abilities to sense and engage with the social world. Early neuroscientific research into autism and autistic spectrum disorders was therefore never dominated by a project to tally the effects of a drug with the underlying mental condition that this drug was supposed to alleviate. Furthermore, twin studies and genetic research during the 1980s and 1990s was constantly being overshadowed by the fact that criteria for autism were rapidly changing and that investigations and fears over the autism 'epidemic' were constantly growing. This meant that early attempts to identify a specific gene abnormality for 'autism' quickly turned into more broad attempts to identify minute genetic variations that may or may not have an impact on the creation of a wider autism 'phenotype' and that, in total, were investigations into variations in child development generally.

Throughout the 1970s and 1980s, Michael Rutter had held on to the possibility that autism would be identified as a classic Mendelian genetic disorder. In the late 1970s, Rutter together with Susan Folstein, a graduate of Weill-Cornell Medical College then based at the Institute of Psychiatry, conducted a study of autism in monozygotic and dizygotic twins. Based on 'blind' diagnoses made by Rutter, they argued that autism was far more common in monozygotic than dizygotic twins, and that monozygotic twins also shared more 'cognitive abnormalities'. Although this was later often hailed as the first ever 'genetic' study of autism, it did not in fact examine genetic material in a lab. Studying the behaviour of twins was not as solid a scientific approach and, in fact, ended up only further supporting a much wider and looser category of 'autism'. As Rutter and Folstein put it, 'autism is genetically linked with a broader range of cognitive disorders. ${ }^{156}$ This category of 'autism' was much closer to that of 'intelligence', in which there was a strong genetic basis, but in fact a very variable scale in which one could present with impairments.

As with intelligence, this wider category of autism was given support via genetic studies, even though these never provided definitive proof that the category itself was genetic. Proof of the genetics of 
autism offered stark scientific evidence to what was otherwise a rather problematic psychological concept. Just as pioneers in early psychology and intelligence testing, such as Cyril Burt, had cultivated genetic approaches to this psychological concept, pioneers in the new autism psychology, such as Rutter, cultivated genetic approaches to autism in order to buttress its scientific legitimacy. Developing a theory of autism as a genetic disorder gave further support to the concept of autism as a psychological organiser. This only strengthened the flood of new tools to test, perceive and conceptualise and, above all, to measure the milestones and indicators of child development in relation to autism. However, as with intelligence, genetic proof for autism had major political implications.

The 1980s saw further work that supported the idea of a broad autism 'phenotype' characterised by impairments in social function. Reports from Britain and the USA found that siblings of children with the autism diagnosis often shared similar 'cognitive abnormalities' and suggested that there was a milder variant of autism. ${ }^{157}$ In the late 1980s, Rutter began a further family genetic study of autism together with Patrick Bolton and others from the Maudsley's Institute of Psychiatry, which employed the standardised ADI. This genetic research supported Wing's argument that 'autism' was not an isolated category, confirming a biological basis to the theory of a spectrum of autistic disorders. Comparing children classed as autistic with those diagnosed with Down's syndrome, Rutter and Bolton found 'a raised familial loading for both autism and more broadly defined pervasive developmental disorders' in those with autism, thereby encouraging a broadening out of the category. They argued that:

these data provide compelling evidence for broadening the phenotypic definition beyond the criteria usually specified for autism and other forms of pervasive developmental disorder. They also show that the broader phenotype is characterized by language-related cognitive deficits, social impairments and stereotypic behaviours, but not mental retardation, per se. ${ }^{158}$

A further twin study by Rutter and colleagues took a much wider epidemiological sample of autistic twins, and employed the ADI and ADOS for the purposes of diagnosis, finding a concordance rate for autism of 60 per cent for monozygotic twins and 0 per cent for dizygotic twins, 
with 92 per cent of monozygotic twins and 10 per cent of dizygotic twins concordant for 'a broader spectrum of related cognitive and social abnormalities', arguing that autism was a 'strongly genetic disorder. ${ }^{159}$ Genetic research initially supported broader epidemiological research and, hand in hand, the two went on to sustain the development of the 'autistic spectrum'.

The DSM-III-R encouraged research into the biochemical basis of autism, such as the work of Christopher Gillberg, then based at the Institute of Psychiatry who conducted work on the cerebral spinal fluid of children diagnosed with autism in the $1980 \mathrm{~s} .{ }^{160}$ Lorna Wing's broadening of the autistic spectrum drew support from this genetic research. The prospect of a genetic basis thus supported the autism concepts that were being formulated, even as those concepts began to expand and envelop other definitions.

The early 1990s saw a growth of family studies that supported the autism concept from across Europe and the USA. Rutter and his colleague Patrick Bolton started to conduct family studies in which they randomly selected 100 children diagnosed with autism and then followed up and tested their first-degree relatives for metabolic and chromosomal abnormalities. ${ }^{161}$

At any rate, the genetic research was buttressing the epidemiological research and the broader category of autism. These worked hand in hand to outweigh and challenge case-based thinking about autism and to develop new global research networks on autism genetics.

By the mid-1990s, biochemical research delivered some major findings in individuals diagnosed with autism. Rutter published his followup work on children with the autism diagnosis and its association with epilepsy and fragile X syndrome. ${ }^{162}$ In 1994, Gillberg recommended that doctors include tests for neurocutaneous disorders, CAT scans, investigation of chromosomal structures, EEGs, blood and urine tests, collection of cerebral/spinal fluid and tests for visual and auditory systems. ${ }^{163}$ This supported a biochemical basis to autism, even as the category was still expanding its remit. Even in the 1980s and 1990s, biochemical and particularly genetic research supported autism's hegemony, and supported a broadening out of the category to echo the epidemiologically defined autism that was expanding its global remit, challenging earlier models of child development and redefining children's rights. Genetic research thus became an important reinforcement to these new models 
of child development even though the dream of a unique gene for autism receded pretty quickly.

The mathematical, logical, scientific autism

The growth in interest in genetic studies, coupled with a growing global market for epidemiological studies, gave autism a new-found fame as well as a new authority by the late 1990s. Autism researchers quickly became authorities on child development when, in fact, their field of study had previously been very limited. One important development that occurred in relation to this was that new autism researchers quickly had to step up and clarify more clearly what they meant by 'social impairment. Previously, this had largely been formulated as a deficit model of what autism is. However, by the 1990s, more questions were being raised over what features were present in autistic children and how these could be systematically summarised, without having to resort to advanced complicated tools of assessment such as the ADOS. What had happened was that the second autism, formulated through the logic of epidemiological studies in the 1960s as an absence of fantasy, imagination and hallucination, had been expanded and globalised to such a degree that its portrayal as mere absence or 'social impairment' became increasingly difficult to justify. Into this social absence, researchers began to explain the new abilities, new capacities, new skills that autistic individuals may have. It is, for example, no coincidence that the idea that autism is characterised by marked mathematical and scientific skills arose in the 1980s in line with the expansion of the Asperger's category and the growth of a new theory of human relations. It is also not a coincidence that this model arose in the midst of mass collections of global epidemiological data on an aspect of child development that otherwise had no meaning. The growth in scales to measure autism came to define the concept itself. Unlike the expansion of any other psychiatric disorders, the problem with autism had always been associated with its role as a central organising concept in wider theories of child development. Gaps in knowledge about this central concept were increasingly filled with knowledge produced from the instruments used to measure it.

Measurement instruments for autism continue to grow. A perfect example of how autism scientists have attempted to mimic and 
outshine the intelligence test is undoubtably the creation of Simon Baron Cohen's 'Autism Spectrum Quotient', also known as the AQ. Baron Cohen developed the AQ in 2001, as an challenge to the supremacy of the Intelligence Quotient (IQ) as a means to measure the sum of human psychology and its genetic basis. This instrument could also be used on adults and all 'high-functioning' individuals, including mathematicians and scientists who Baron-Cohen has consistently argued display 'high-functioning autism' to a higher degree than the normal population. The AQ could be self-administered, thus making it an easy and convenient way to spread awareness of the triad of impairments and the significance of autism as a way to explain psychological atypicalities that affect social interaction and socialisation. ${ }^{164}$ Furthermore, Frith and her students also continued to develop theories of the wider 'cognitive style' of autism. Based on her studies of sensori-motor tests and pattern detection in autistic children, Frith had argued that 'central coherence' was a normal cognitive tendency to focus attention on extracting general meaning and gist or gestalt from information. ${ }^{165}$ Frith and Happé then argued that the autistic inability to extract general information could be called 'weak central coherence', which referred to a focus on parts, details and particulars rather than wholes. It was a way of thinking that on its own could actually be beneficial, enabling people to focus on details without worrying about the general gestalt, hence why Baron-Cohen identified engineers, mathematicians and physicists as having autistic traits. ${ }^{166}$ All these hypotheses provide alternatives to intelligence in their explanation of variances in children's thought. They also provide alternatives to human relations psychology. BaronCohen and others have thus skilfully constructed a model of 'autism' that beautifully reflects the tools that they have been using to measure it. The high end of the 'autistic spectrum' is now regarded as a condition marked by mathematical skill, scientific ability and logical thinking. This was exactly what the new autism psychologists were always looking for: logic, skill, rigour, numbers, certainty, proof. Because autism was such an illusive concept, this gave greater scope for psychologists to build a model of it supported by the instruments used to measure it.

Genetic studies have supported this epidemiological statistical autism - the second autism. There has even been increased standardisation of the category in even younger children. ${ }^{167}$ As the sociologist Gregory Hollin has pointed out, the assessment of autism in younger 
children, and the potential to identify it prenatally, has become an increased focus of much recent research in Britain. ${ }^{168}$ Internationally, younger diagnosis is also becoming more common. A later revision of the ADI in 1994 reduced the number of questions and made it applicable to younger preschool children, and a revision of the ADOS in 2012 included a toddler module. These instruments have since been adopted in many international settings.

At the same time, there have been increasing attempts to delineate the broader 'phenotype' of autism, such as in Baron-Cohen's work on the 'cognitive phenotype' of Asperger's syndrome. ${ }^{169}$ Indeed, the more children that received the diagnosis, the harder it was to challenge the category, or to deny the broader phenotype of autism. Increasing numbers of studies described different psychological profiles in family members as part of a broader 'autism phenotype'. However, the boundaries needed to be defined if researchers in molecular genetics were going to find the genes for autism. Another compelling argument for some kind of genetic cause came from the fact that all epidemiological studies consistently found a higher percentage of male cases in their samples. ${ }^{170}$ When it came to the extended wider category of autistic spectrum disorders and Asperger's syndrome, the figures were often even higher, with Wing arguing that there were fifteen times as many boys with Asperger's as there were girls. ${ }^{171}$ This led Baron-Cohen to develop his theories of autism as caused by the 'extreme male brain' in the late 1990s, later studying the effects of testosterone on brain development in foetuses and young infants to explore why male and female brains developed differently. ${ }^{172}$ One of Baron-Cohen's most formidable experiments involved the accessing of a bank of frozen amniocentesis specimens to measure foetal testosterone levels then later testing the babies in their psychological performances. They first measured frequency of eye contact with the mother as opposed to mobile and mechanical objects, then later language abilities, finding a correlation between high testosterone levels and low eye contact with the mother and restricted language skills. ${ }^{173}$ This finding supported various theories put forward since the late 1950s relating language and cognition skills to sex differences. ${ }^{174}$ It also added to a growing number of studies examining the effects of testosterone on foetal brain development in both humans and rats following the work of Geschwind and Galaburda. ${ }^{175}$ In fact, BaronCohen's work on autism and the extreme male brain uses the concept 
of autism to understand gender differences in infants and children in very similar ways to the use of the concept by earlier writers, such as Anthony and Winnicott, to understand infantile unconscious drives for human relations; however, instead of trying to theorise the sex instinct within individual child cases, Baron-Cohen theorises the wider concept of gender across child populations. Baron-Cohen's work on autism attempts to explain an issue concerning sex differences and the impact of hormones on the function of psychological drives towards particular objects. It is another perfect example of how the study of autism led to a shift in psychology from a focus on instincts, unconscious phantasy and individuality to a focus on gender, behaviour and populations. This was not due to a greater understanding of autism as an aspect of the human condition. It was an artefact of the systems used to measure it.

For the new autism psychologists, what was being hypothesised in the biological realm was not desires, drives and motivations, but cognitive tracking devices that made individuals want to be social. The new generation of autism psychologists started to tie themselves to a theory of sociality as the innate capacity to mind-read, to detect patterns, to observe cues, to understand configurations and to map the thought of others. This was the new, epidemiologically defined, autism that would become a dominant model for thinking about child thought by the 1990s, the dominant 'style of reasoning' around child development. Statistics could now show the movements and compulsions of unconscious thought driven by instinctual and hormonal forces. It could reveal the depths of human drives and explain them without having to resort to conscious thought and description. It could explain instincts as a sum of statistical measures and so longer needed to rely on the logic of phantasy and drives.

\section{Molecular genetics and the success of the 'autistic spectrum'}

At the turn of the twenty-first century, many researchers thought that the genes for autism might be quickly discovered due to major advances following the establishment of the Human Genome Project by the US government. This stimulated genetic research into various conditions and also assisted the development of sophisticated tools to analyse genetic data. It became evident early on that no single gene mutation could be linked to autism and the focus shifted to full-genome scans coupled with candidate gene studies. Research into the genetics of 
autism has since helped to buttress the idea of a broad autism spectrum with complex genetic correlates.

Genetic studies of autism have increased rapidly since the late 1990s and have enabled a new international scientific community to develop. As several sociologists of autism have pointed out, autism research has come to attract large amounts of funding due to the popular status of the diagnosis. Much of this funding has been pumped into genetic research, particularly that focusing on 'susceptibility genes', as well as brain-imaging studies, because many companies have a vested interest in finding autism susceptibility genes and in demonstrating brain atypicalities that could potentially be rectified using pharmaceutical products. ${ }^{176}$ At the same time, the fact that autism researchers sought to compete with intelligence researchers prepared the ground for this focus on genetic research to flourish.

In 1997, early molecular genetic studies of autism looked to the 'serotonin transporter' (5-HTT) to find some biological basis to the disorder, serotonin having sprung to fame in the description and treatment of depressive disorders. These studies were conducted in the USA and Germany and both employed the ADI and the ADOS to identify cases. ${ }^{177}$ The interest in 5-HTT had arisen in relation to autism as part of a broader theory of psychological atypicality, in particular reports of its association with 'anxiety-related traits. ${ }^{178}$ Such traits had been observed in family members of individuals with autism and so hypotheses began to be drawn around this new way of thinking about psychological development as part of an autistic spectrum. However, by 1999, new studies emerged that debunked the association between 5-HTT and autism, in particular one US study 'generated from an ethnically heterogeneous group of Caucasian, Hispanics, African-Americans, and Asians'. Another joint UK and US study based on data from the International Molecular Study of Autism Consortium, and employing the ADI to measure 'type 1' autism, also showed no association. A joint Italian and US study of 'two ethnically' distinct samples found the same result, based on DSM criteria but not the ADI and ADOS. However, in 2001 an Israeli study claimed there was an association, using $\mathrm{ADI}$ and $\mathrm{ADOS}$ tools translated into Hebrew. ${ }^{179} \mathrm{~A}$ joint US and French venture from the same year claimed that the association between the promoter polymorphism of the serotonin transporter and autism did exist, with the short allele being more common in children who scored highest in the severity of 
the triad of impairments as measured in the $\mathrm{ADI}$, and the longer allele more common in children who scored lower, thus demonstrating a milder or more moderate version of the triad. ${ }^{180}$ Wing's triad of impairments, in particular as measured in $\mathrm{ADI}$, was being linked to discrete fragments of the human genome through major international research programmes. This was an obvious abstraction from the social and political context in which the idea of 'social impairment' was formed. Nevertheless, the concept enabled new international communities to form, now focused simply on creating reproducible studies.

Genetic studies of autism were, at one point, used to invalidate environmental hypotheses, in particular the MMR theory. ${ }^{181}$ However, as research developed, the complexities of environment and gene interaction were realised, again, helping to expand the domain of the autistic spectrum. Some other early human molecular genetic studies of autism examined the promoter region of the dopamine $\beta$-hydroxylase gene, finding that the mothers of autistic children seemed to show abnormalities that may create a 'suboptimal uterine environment.' ${ }^{182}$ The dopamine hypothesis emerged from other biochemical studies of depression and other mental illness in adults, much as the serotonin hypothesis had done. Many other candidate genes in autistic people themselves were suggested from the late 1990s. For example, candidate genes on chromosome 15q11-13 (a region associated with Prader-Willi and Angelman syndrome) were examined at the turn of the century because it was found to be a common site for chromosomal abnormalities in autism, although early studies found little conclusive results. Nevertheless, international scholars jumped at the prospect of contributing to this work, with research on 15q11-13 issuing from Brazil, India and elsewhere. ${ }^{183}$

In 2006, Sabhrangshu Guhathakurta from the Manivokas Biomedical Research and Diagnostics Centre, Kolkata, published the results of a major autism study funded by the Council of Scientific and Industrial Research, Government of India. The research had brought together colleagues from across India to produce a study of 5-HTT in an Indian population. They argued that disagreement between reports on 5-HTT could be explained because of 'the complexity of serotoninergic neurotransmitter system where the synthesis, uptake, neurotransmission, metabolism and regulation of 5-HTT involve an array of proteins and the effect of each protein may contribute to the pathology.' ${ }^{184}$ Indeed, 
such studies highlighted the complexity of the genetic data and dissolved the idea that a single gene for autism would be discovered. Yet, as with all genetic studies, the belief still held that genetic research, based on the autistic spectrum, would yield results in time. As Guhathakurta put it, 'A systematic investigation taking into account the varying spectra of impairments in interaction, communication, and behavior might prove to be more appropriate to clarify the present confusing results. ${ }^{185}$ However, the more research that was conducted, the more complex the results became. A 2007 study by Guhathakurta and other Indian researchers found no association between autism and glutamate receptor 6 gene, GluR6 or GRIK2, polymorphisms, despite the fact that findings from the Paris Autism Research International Sibpair (PARIS) Study and a major study in China had found that there was an association. ${ }^{186}$ All of these studies used DSM-IV or ICD 10 in the diagnosis of cases, and thus Wing's essential triad. Although they had different findings, Guhathakurta and others argued this was all the more reason to conduct even more studies to see if an association could be drawn from even larger population samples from the genetic profiles of autistic people across the globe.

Neuroscientific research on humans has been paralleled by new explorations into 'autism' and 'social impairment' in other animals, such as mice, in order to assist large-scale testing of genetic atypicalities and enabling genetic research to thrive. The conceptual problems of identifying autism in a mouse were usually sidelined by wider claims that genetic correlates had been discovered. ${ }^{187}$ Although there is currently no version of the $\mathrm{ADI}$ or $\mathrm{ADOS}$ for mouse or rat populations, international researchers have tried to categorise behaviours associated with the triad of impairments as these exist in rodents. In 2013, Marcus Wöhr from the Philipps-University of Marburg, and Maria Luisa Scattoni from the Instituto Superiore di Sanità in Italy, argued that if tested in an open field or observation box, rodents with 'autism' would demonstrate the social deficits of the triad through restricted 'social interaction' and 'social play'. They would demonstrate the communication deficits of the triad through lack of scent marking, lack of female-induced and interactioninduced ultrasonic vocalisations. Finally, 'motor stereotypes', 'repetitive self-grooming', repetitive marble-burying and 'restricted exploration' demonstrated the stereotypic and repetitive behaviours of Wing's triad of impairments. This was an attempt to synthesise approaches to 
mouse behaviour that had been focused on measuring abnormal social interaction, by creating a model that encompassed the whole triad. ${ }^{188}$ A collaborative German and French project also developed an 'autism severity score' to measure the degree of autism in mice by measuring the degree of their abilities in nest-making and other activities and the degree of any atypical behaviours such as excessive marble-burying. ${ }^{189}$ These standardised approaches helped cement the idea that rodents can suffer from autism. The problems of anthropomorphism and of delimiting the nature of the imagination in humans are glossed over in these attempts to bring the autistic spectrum to the animal world and thus to rethink early animal development.

In the USA, autism genetic research in human and animal forms is particularly thriving, largely due to the efforts of parental organisations, as Chloe Silverman has pointed out, in particular the National Alliance for Autism Research (NAAR), founded in 1994, and the Cure Autism Now (CAN) foundation, founded in 1995. CAN established the Autism Genetic Research Exchange (AGRE), a gene repository for families with two or more members with an autism diagnosis. The repository attracted many parents who sought to speed up genetic research. ${ }^{190}$ In 2003, the NAAR launched the Autism Genome Project (AGP) consortium that brought together North American and European researchers in an effort to improve genetic research into autism. In 2005, NAAR merged with a new organisation, Autism Speaks, and in 2006, CAN also merged with them. Autism Speaks is now the dominant autism science and advocacy organisation internationally, serving to facilitate and fund research and awareness. ${ }^{191}$ Although the AGP did not match its initial hopes of finding a single gene mutation, it has since served as an exemplar model to encourage scientific exchange of data and has also encouraged the growth of new theories surrounding the role that genes may play in the development of all psychological conditions in childhood. It has also encouraged a greater understanding of the complexity of gene and environment interactions in the formation of all developmental disorders. More recently, genetic studies have taken into account a wider, and comprehensive range of childhood developmental conditions. This merely confirms that autism is a central concept of child development and is associated with many different conditions, and debunks the idea that it is a unique disorder. For example, a 2012, a study by D. Moreno-De-Luca, Emory State 
University, and colleagues from across the USA analysed data from 35,516 cases using two large datasets, namely Signature Genomics and the International Standards for Cytogenomic Arrays Consortium, the latter of which includes data from the Autism Genetic Resource Exchange, the Autism Genome Project and the Simons Simplex Collection. Moreno-De-Luca reported that if children with a range of developmental delays, intellectual disability, ASD or related problems from this dataset were included, then around 1 in every 553 showed deleterious recurrent deletions in 15q11-13. Further analysis of the datasets exploring ASDs specifically found deleterious recurrent deletions in only ten regions that showed statistical significance, the most significant being 16p11.2, although even this showed a frequency, in total autistic spectrum conditions, of 1 in $304 .{ }^{192}$ This only confirmed that wider samples relating to numerous conditions in childhood were the best way to take genetic research, thus ultimately pulling it further from the initial attempts to find genes for 'autism. In early 2015, a team of researchers from Canada, USA, China and Sweden concluded that substantial genetic and clinical heterogeneity exists in ASD and that much larger surveys will need to be completed to completely understand the genetic architecture of ASD'. ${ }^{193}$ It would be hard to find a clearer advertisement for the idea of neurodiversity. In fact, genetic research has, in many ways, undermined the concept of the second autism that it was developed to support.

Even as early as 2007, Daniel Geschwind, from the neurogenetics programme at the University of California, and Pat Levitt, from the Vanderbilt Kennedy Center for Research on Human Development, argued that autism was 'analogous to broad syndromes such as mental retardation', had multiple causes and was best considered as a 'heterogeneous, neurodevelopmental syndrome'. It was therefore better to think in terms of 'the autisms' rather than 'autism. ${ }^{194}$ In 2012, Christopher Gillberg, the enthusiastic supporter of the epidemiological method for autism and Asperger's research, famously published The Autisms to highlight varied aetiology and the multiple ways in which the triad of impairments can manifest itself across the entire gamut of autistic spectrum disorders. This tendency to think broadly around the category has been supported by genetic research that is also problematising the idea that there is a simple medical problem called 'autism' or even 'autistic spectrum disorder.' 195 
Although this study and others do not claim that there is unique genetic disorder called 'autism', finding instead multiple variations and differences in the data, they have generally stopped short of completely abandoning the concept of the second autism. Of course, it would be virtually impossible to do so given its extensive presence in the fields of politics and social justice. Autism thus continues to garner political and scientific support, even as its fundamental diagnostic criteria are challenged. However, this project to identify the genetic substructure to autism is likely to represent the pinnacle, and perhaps even the end, of the second autism, as challenges to this definition continue to grow.

The reason why the phenotypical model for autism has been so zealously sought is because it is the only model that measures social interaction and its atypicalities through genetic phenotypes. It is also the replacement for 'human relations' psychology and so researchers desperately seek the complex architecture of the human genome to support it. If any new researchers want to think about what is abnormal or unusual in the development of human relationships, they no longer look to anthropology or psychoanalysis, which are often regarded as obsolete human sciences. Instead they think about autism and its development in humans, as mapped in the human genome, as quantified in epidemiological studies all over the world, as discussed on global health platforms. These new models used to investigate and explore the second autism as the kernel of theories of child identity and social development are based on statistical, epidemiological and biomedical sciences that are vastly different from those used to investigate the first autism. The approach to children as cases, and the approach to 'data' produced by those children, has changed so dramatically that earlier sciences and approaches to human development and human relationships have been almost entirely forgotten. New epidemiological definitions of autism have redefined the way we think about child development and human relations. Yet these approaches have historical roots and historical origins. The fact that this particular model of children's developmental atypicalities was formulated via British epidemiological sciences from the 1960 s to the late 1970 s is actually relevant to genetic researchers who are now busy searching with common diagnostic tools. 


\section{The Global Autism}

Many international autism researchers have thought about infant and child cognitive development, along with its 'deficits' and 'impairments', using cognitive models derived from British psychological models from the 1960 s to the 1980 s that used epidemiological methods to measure autism and the autistic spectrum. Although much genetic and environmental research has reinforced the claim that there is no such thing as 'autism' and no genetic components that correlate with 'the autistic spectrum', so much has been invested in studying the autistic spectrum, and the idea of the spectrum been so convincing and powerful in eradicating earlier psychological models of child development, that it is now virtually impossible to view any differences or atypicalities in children's social development through any other lens. We have reached a point where genetic research, and other neuroscientific research in autism, promises to provide answers to all problems and questions raised about different kinds of social engagement. So many studies have been conducted, so much data collected, there is no way that neuroscientists and psychologists could really turn their back on this idea. Not only research programmes, but also NGOs, and national and international laws all now support the idea of the 'autistic spectrum'.

Nevertheless, by examining the historical assumptions that the theory of the autistic spectrum psychology rests upon, and the conceptual frameworks that have provided its base, it is possible to see a more multifaceted historical model that has produced this concept. Unique 'styles of reasoning' that focused on autism as an epidemiological object have shaped our current understanding of autism. Not only have these models had an impact on autism research, they have also had a major impact on children's rights and on education, health and welfare policy. Autism is a defining concept that has structured ideas of what child development means, and how different social and legal agencies should respond to it. Changes in the meaning of autism have thus also had the capacity to transform human relations and social structures in the national and international contexts where the concept has been employed. International scientific communities, education, health, and social care systems have now been built up around this concept of autism and it is hard to imagine how they could now be dismantled. 


\section{Notes}

1 B. Jackson, 'The think-tank archipelago'.

2 Rose, Powers of Freedom; Rose, 'The death of the social?'.

3 Cockburn, Rethinking Children's Citizenship.

4 Hendrick, Child welfare and Social Policy.

5 Detrick et al., The United Nations Convention on the Rights of the Child.

6 KCL/BCGC: Brixton CGU Annual Reports 1980s: Brixton CGU Annual Report, 1984, p. 7.

7 Rutter et al., 'Children of West Indian immigrants'.

8 Littlewood, 'From categories to contexts'; Kleinman, 'Depression, somatization and the "new cross-cultural psychiatry".

9 Lotter, 'Childhood autism in Africa'.

10 Lotter, 'Childhood autism in Africa', 232.

11 Lotter, 'Childhood autism in Africa', 239.

12 Lotter, 'Cross cultural perspectives on childhood autism'.

13 E.g. Fanon, The Wretched of the Earth.

14 Lotter, 'Childhood autism in Africa', 231.

15 Brask, 'A prevalence investigation of childhood psychosis'; Brask, quoted in L. Wing et al., 'The prevalence of early childhood autism'; L. Wing et al., 'The prevalence of early childhood autism'; Treffert, 'Epidemiology of infantile autism'; L. Wing, 'The definition and prevalence of autism'.

16 Volkmar et al., 'Age of recognition of pervasive developmental disorder'; Fisher et al., 'A treatable language disorder'; Anderson, 'Monoamines in autism'.

17 Stengal, 'A comparative study of psychiatric classifications'; Miller, 'The problem of classification in child psychiatry'.

18 Rutter et al., Multi-Axial Classification of Child Psychiatric Disorders.

19 Klerman et al., 'A debate on DSM-III'; Spitzer, 'Values and assumptions in the development of DSM-III and DSM-III-R', 356; Shaffer, 'Classification and categorisation revisited'.

20 Mayes and Horwitz, 'DSM-III and the revolution in the classification of mental illness', 249, 263.

21 E.g. Wilson, 'DSM-III and the transformation of American psychiatry'; Shorter, A History of Psychiatry, p. 302.

22 Rutter, 'Diagnosis and definition of childhood autism', 156.

23 American Psychiatric Association [APA], Diagnostic and Statistical Manual of Mental Disorders: DSM-III; Lindsay, Screening for Children with Special 
Needs, pp. 88-89; Volkmar, Handbook of Autism and Pervasive Developmental Disorders, p. 15.

24 Porter, London, p. 354.

25 Waterhouse et al. 'Pervasive developmental disorders and schizophrenia occurring in childhood'.

26 Waterhouse et al., 'Pervasive developmental disorders: From DSM-III to DSM-III-R'

27 E.g. Becker and Thoman, 'Rapid eye movement storms in infants'; Calame et al., 'Psychological and neurodevelopmental outcome of high risk newborn infants'; Astbury et al., 'Neonatal and neurodevelopmental significance'.

28 Rutter, 'Autistic children: Infancy to adulthood', quoted in Denckla, 'New diagnostic criteria for autism and related behavioral disorders', 221.

29 Mayes and Horwitz, 'DSM-III and the revolution in the classification of mental illness'.

30 Denckla, 'New diagnostic criteria for autism and related behavioral disorders'.

31 American Psychiatric Association, Diagnostic and Statistical Manual of Mental Disorders: DSM-III-R.

32 Waterhouse et al., 'Pervasive developmental disorders and schizophrenia occurring in childhood'.

33 Sanua, 'Is infantile autism a universal phenomenon?', 167, 172, 173.

34 Other collaborators were Sarnoff Mednick from the University of Southern California and Fini Schlusinger, director of the Psykologisk Institut at Kommunehospitalet, Copenhagen.

35 Raine et al., 'Cohort profile: The Mauritius child health project'.

36 E.g. The Danish State Department for Technical Collaboration with Developing Countries, the British Medical Research Council, the Danish International Aid Organisation, the Wellcome Trust, the Leverhulme Trust, the Mental Health Foundation, the Ford Foundation, the Scottish Rite, the National Institute of Mental Health (US), and the National Institute of Child Health and Development (US).

37 National Autistic Society (NAS) Archives NAS archives: Box 4. File: Autism Europe Publications/Charters/Leaflets. Autism Europe IAAE leaflet 1984.

38 NAS archives: Box 4. File: Autism Europe Publications/Charters/Leaflets. Link Autism Europe Magazine Special 20th Anniversary August 2003.

39 NAS archives: Box 2: Autism Europe. 3rd European Congress 6-8 May 1988. 
40 Baron-Cohen and Bolton, Autism: The Facts, Appendix.

41 Baron-Cohen and Bolton, Autism: The Facts, appendix; Daley, 'The need for cross-cultural research'.

42 Gillberg et al., 'Psychiatric disorders in mildly and severely mentally retarded urban children and adolescents.

43 Bryson et al., 'First report of a Canadian epidemiological study of autistic syndromes', 443.

44 Chamak, 'Autism and social movements'.

45 Cialdella and Mamelle, 'An epidemiological study of infantile autism in a French department (Rhône)', 172.

46 Sugiyama and Abe, 'The prevalence of autism in Nagoya, Japan'.

47 Steffenburg and Gillberg, 'Autism and autistic-like conditions in Swedish rural and urban areas'.

48 Gillberg et al., 'Infantile autism in children of immigrant parents'; Gillberg et al., 'Is autism more common now than ten years ago?'; Gillberg, 'Maternal age and infantile autism'.

49 Hayward, 'Medicine and the mind'.

50 Kramer, Listening to Prozac; Hacking, Rewriting the Soul; Olfman, Bipolar Children.

51 Kramer, Listening to Prozac.

52 Le Couteur et al., 'Autism diagnostic interview', 363.

53 Rutter and Schopler, 'Autism and pervasive developmental disorders', 163.

54 Schopler et al., The Childhood Autism Rating Scale (CARS); Freeman et al., 'The behavior observation scale for autism'; Freeman et al., 'Behaviour assessment of the syndrome of autism'; Krug et al., 'Behaviour checklist'; Volkmar et al., 'An evaluation of the autism behavior checklist'; Ruttenberg et al., Behavioral Rating Instrument for Autistic and Other Atypical Children.

55 MHCP/A. Completed ADI form, 1987: Social Development First Five Years. Affection p. 29.

$56 \mathrm{MHCP} / \mathrm{A}$. Completed ADI form, 1987.

57 Lord et al., 'Autism diagnostic observation schedule', 187.

$58 \mathrm{MHCP} / \mathrm{A}$. Material on ADI and ADOS. Commentary on ADI (R) training tapes, 1991, 'Social Development and Play'. Example 3.

59 Interview with Uta Frith. Conducted by Bonnie Evans. 17 December 2014.

60 Murray, Representing Autism.

61 Morton, 'The origins of autism', 44, 47.

62 Frith, 'Autism', 114. 
63 Uta Frith Archive. BPS Media Release: Asperger's Syndrome: Eccentricity or Disability 30 August 1991.

64 O'Sullivan, 'Train spotters "may suffer from autism”".

65 Sellin, In Dark Hours I Find My Way; Williams, Nobody Nowhere.

66 Sacks, An Anthropologist on Mars.

67 Newnham, 'News from nowhere?'.

68 Baron-Cohen and Bolton, Autism: The Facts, p. 10.

69 Happe, Autism, pp. 5-6.

70 L. Wing, 'Autistic spectrum disorders', 312.

71 L. Wing, 'Autistic spectrum disorders'.

72 Ehlers and Gillberg, 'The epidemiology of Asperger syndrome'.

73 APA, Diagnostic and Statistical Manual of Mental Disorders: DSM-IV, p. 77.

74 Waterhouse et al., 'Pervasive developmental disorders: From DSM-III to DSM-III-R', 530. Baird et al., 'Autism is not necessarily a pervasive developmental disorder', 363.

75 E.g. Gillberg, 'Neurodevelopmental processes and psychological functioning in autism'; Trevarthen, 'Autism as a neurodevelopmental disorder'.

76 E.g. Whitmore et al., A Neurodevelopmental Approach to Specific Learning Disorders.

77 E.g. Leslie and Thaiss, 'Domain specificity in conceptual development'.

78 E.g. Losh and Piven, 'Social-cognition and the broad autism phenotype'; Campbell et al., 'Association of MET with social and communication phenotypes.

79 Wignyosumarto et al., 'Epidemiological and clinical study of autistic children in Yogyakarta, Indonesia'; Honda et al., 'Cumulative incidence and prevalence of childhood autism in children in Japan', 234.

80 Magnusson and Sæmundsen, 'Prevalence of autism in Iceland'.

81 NAS archives: Box 4. File: Autism Europe Publications/Charters/Leaflets. 'Building a Brighter Future' pamphlet, 10/9/97, p. 17.

82 Baird et al., 'A screening instrument for autism at 18 months of age'.

83 Centers for Disease Control and Prevention (CDC), Prevalence of Autism in Brick Township, New Jersey, 1998; Department of Health, 'Medical research council to re-examine autism'; Baird et al., 'A screening instrument for autism at 18 months of age'; Madsen et al., 'A population-based study of measles, mumps, and rubella vaccination and autism'; Scott et al., 'Brief report: Prevalence of autism spectrum conditions'; Yeargin-Allsopp et al., 'Prevalence of autism in a US metropolitan area'; Baird et al., 'Prevalence of disorders of the autism spectrum'; Kawamura et al., 'Reevaluating 
the incidence of pervasive developmental disorders'; Fombonne, 'Epidemiology of pervasive developmental disorders'.

84 Eyal et al., The Autism Matrix.

85 Wazana et al., 'The autism epidemic'; Leonard et al., 'Unpacking the complex nature of the autism epidemic'; Isaksen et al., 'Autism spectrum disorders'.

86 Fombonne, 'Epidemiology of pervasive developmental disorders'; Eyal et al., The Autism Matrix.

87 NAS archives: Box 2: File 'Autism on the Agenda'. 1993 International Conference on Autism agenda.

88 NAS archives: Box 2: File 'Autism on the Agenda': Autism on the Agenda, Leeds University, 8-10 April 1994.

89 NAS archives: Box 4. File: Autism Europe Publications/Charters/Leaflets. Statement to the European Council on the eve of the Luxembourg Jobs Summit. 18 November 1997.

90 NAS archives: Box 4. File: Autism Europe Publications/Charters/Leaflets. Code of Good Practice on Prevention of Violence against Persons with Autism, December 1998.

91 NAS archives: Box 4. File: Autism Europe Publications/Charters/Leaflets. Code of Good Practice on Prevention of Violence against Persons with Autism, December 1998, pp. 27-30, 55, 33.

92 NAS archives: Box 4. File: Autism Europe Publications/Charters/Leaflets. Code of Good Practice on Prevention of Violence against Persons with Autism, December 1998, p. 89.

93 NAS archives: Box 4. File: Autism Europe Publications/Charters/Leaflets: 'Describing Autism', booklet May 1992.

94 NAS archives: Box 4. File: Autism Europe Publications/Charters/Leaflets: Fax message from Anne Sophie (Parent) regarded European Summit on Employment. Message from Autism Europe to Commissioner Flynn 20/11/97.

95 NAS archives: Box 4. File: Autism Europe Publications/Charters/Leaflets. Notes on Autism Europe meeting 1998.

96 NAS archives: Box 2: File 'NAS Board and Council Minutes': WAO newsletter December 1999.

97 NAS archives: Box 2: File 'NAS Board and Council Minutes': Agenda of two-day autism conference for UNESCO, 17-18 May 2000.

98 NAS archives: Chief Executive Higashi File and Boston Visit File. The Higashi Experience, 1991; Report on a Visit by NAS to the Boston Higashi School, 5-9 November 1995. 
99 Wallace, 'Hope for shadow children'. NAS archives: Chief Executive Higashi File and Boston Visit File. Report on a Visit by NAS to the Boston Higashi School, 5-9 November 1995, p. 12.

100 NAS archives: Chief Executive Higashi File and Boston Visit File. Mooney, F 'Parents go Bust as "Rain Man” Children Suffer', cutting from Daily Express, 27 June 1990.

101 NAS archives: Chief Executive Higashi File and Boston Visit File: The International Autistic Research Organisation newsletter 1990, p. 8.

102 NAS archives: Research Papers and Info/Autism Europe Congress 2000. Summary of Early Intervention Conference 12 June 2001.

103 NAS archives: Research Papers and Info/Autism Europe Congress 2000. London Early Autism Project report, p. 1.

104 United Nations, Resolution 62/139 World Autism Day.

105 Autism Speaks, 'Autism Speaks launches unprecedented global autism public health initiative'. Author italics

106 Autism Speaks, 'Autism Speaks launches global action committee'.

107 Li et al., 'Prevalence of autism-caused disability among Chinese children'.

108 Bakare and Munir, 'Autism spectrum disorders (ASD) in Africa'.

109 Bakare et al., 'Prevalence of autism spectrum disorder among Nigerian children with intellectual disability', 517.

110 Eldin et al., 'Use of m-chat for a multinational screening', 282.

111 Children of the Stars [documentary].

112 Sun et al., 'Prevalence of autism in mainland China, Hong Kong and Taiwan', 7.

113 Teixeira et al., 'Brazilian scientific output on autism spectrum disorders'.

114 Estecio et al., 'Molecular and cytogenetic analyses on Brazilian youths with pervasive developmental disorders'; dos Santos et al., 'Mthfr c677t is not a risk factor for autism spectrum disorders in South Brazil'.

115 Paula et al., 'Autism in Brazil: Perspectives', 5.

116 Gomes et al., 'Autism in Brazil: A systematic review'.

117 Rudra et al., 'Translation and usability of autism screening and diagnostic tools'

118 Divan et al., 'Challenges, coping strategies, and unmet needs'.

119 Igwe et al., 'Factors influencing knowledge about childhood autism', 44.

120 Kutchins and Kirk, Making Us Crazy.

121 NAS Archives: Research Papers and Info/Autism Europe Congress 2000: 'Landmark Ruling by the House of Lords', 27 July 2000. 
122 NAS Archives: Research Papers and Info/Autism Europe Congress 2000: press cutting, 'The Sincott Case', The Irish Times, 7 October 2000.

123 NAS Archives: Research Papers and Info/Autism Europe Congress 2000: Tony Holland et al., Report Commissioned by the Department of Health, 2000, p. 26.

124 J. Evans et al., Making a Difference.

125 Department for Education, Statistics (2012).

126 Reichow et al., 'Non-specialist psychosocial interventions'. BelloMojeed and Bakare, 'Improving treatment of children with autism spectrum disorder'.

$127 \mathrm{WHO}$, MhGAP Intervention Guide for Mental, Neurological and Substance Use Disorders.

128 Elsabbagh et al., 'Global prevalence of autism and other pervasive developmental disorders', 176.

129 Omigbodun, 'Developing child mental health services in resource-poor countries'.

130 Eldin et al., 'Use of m-chat for a multinational screening', 281; Igwe et al., 'Assessment of knowledge about childhood autism', 1; Li et al., 'Prevalence of autism-caused disability among chinese children'; Gomes et al., 'Autism in Brazil: A systematic review'; Balasubramanian et al., 'Genetic studies in children with intellectual disability'.

131 Wakefield et al., 'Retracted: Ileal-lymphoid-nodular hyperplasia', 637.

132 Wakefield et al., 'Retracted: Ileal-lymphoid-nodular hyperplasia', 641.

133 Murray, Autism, p. 81.

134 Horton, 'The lessons of MMR', 747.

135 Wakefield and Montgomery, 'Measles, mumps, rubella vaccine'; Wakefield, 'Enterocolitis, autism and measles virus'.

136 BBC, 'Blair stays mum on Leo and MMR'.

137 Murray, Representing Autism.

138 Wakefield, 'Statement from Dr Andrew Wakefield'.

139 Silverman, Understanding Autism.

140 Olmsted and Blaxill, Age of Autism; Kirby, Evidence of Harm.

141 B. Taylor et al., 'Autism and measles, mumps, and rubella vaccine'.

142 Kaye et al., 'Mumps, measles, and rubella vaccine and the incidence of autism? 
143 Dales et al., 'Time trends in autism and in MMR immunization coverage in California'.

144 Honda et al., 'No effect of MMR withdrawal on the incidence of autism'.

145 Fombonne et al., 'Pervasive developmental disorders in Montreal, Quebec, Canada'.

146 Heron et al., 'Thimerosal exposure in infants and developmental disorders', 583; Fombonne et al., 'Pervasive developmental disorders in Montreal, Quebec, Canada'; Madsen et al., 'Thimerosal and the occurrence of autism'; L. E. Taylor et al., 'Vaccines are not associated with autism'.

147 Waterhouse, 'Autism overflows', 273.

148 Silverman, Understanding Autism.

149 NAS Archive. Box 1. MMR. Sandra and Max Desorgher email to Malanie Landman, 'The Vaccine Issue, Humanity and Autism, a Common Causal Factor' 25 June 2002.

150 Rogers, 'Has enhanced folate status during pregnancy altered natural selection and possibly autism prevalence?'

151 Waldman et al., 'Autism prevalence and precipitation rates', 1027.

152 E.g. Volk et al., 'Residential proximity to freeways and autism in the charge study'; Schmidt et al., 'Prenatal vitamins, one-carbon metabolism gene variants, and risk for autism'; Brown et al., 'Maternal thyroid autoantibody and elevated risk of autism'; Gardener et al., 'Perinatal and neonatal risk factors for autism.

153 Shattuck, 'Diagnostic substitution and changing autism prevalence.'

154 Horwitz, Creating Mental Illness; Kutchins and Kirk, Making Us Crazy.

155 Healy, The Creation of Psychopharmacology.

156 Rutter and Folstein, 'A twin study of individuals with infantile autism', p. 234.

157 E.g. August et al., 'The incidence of cognitive disabilities in the siblings of autistic children'; Minton et al., 'Cognitive assessment of siblings of autistic children'.

158 Bolton et al., 'A case-control family history study of autism', 895.

159 Bailey et al., 'Autism as a strongly genetic disorder'.

160 Gillberg and Svennerholm, 'Csf monoamines in autistic syndromes'.

161 Rutter, Bailey et al., 'Autism: Syndrome of definition'; Bolton et al., 'Genetic findings and heterogeneity in autism'.

162 M. Rutter et al., 'Autism and known medical conditions: Myth and substance', J Child Psychol Psychiatry 35, no. 2 (1994): 311-322. 
163 NAS archives: Box 2: File 'Autism on the Agenda': Autism on the Agenda, Leeds University, 8-10 April 1994. 'Medical Aspects of Autism' Dr Christopher Gillberg. Baron-Cohen et al., 'The autismspectrum quotient (AQ)'. Rutter, Bailey et al., 'Autism and known medical conditions'.

164 Baron-Cohen et al., 'The autism-spectrum quotient (AQ)'.

165 Frith, Autism: Explaining the Enigma.

166 Happe et al., 'Exploring the cognitive phenotype of autism'.

167 Baird et al., 'A screening instrument for autism at 18 months of age', 695.

168 Hollin and Pilnick, 'Infancy, autism, and the emergence of a socially disordered body'.

169 Baron-Cohen and Hammer, 'Parents of children with Asperger syndrome'; Gillberg, 'Clinical and neurobiological aspects of Asperger's syndrome'.

170 Rutter et al., 'A five to fifteen year follow up study of infantile psychosis'; Rutter, 'Diagnosis and definition'.

171 L. Wing, 'Asperger's syndrome: A clinical account'.

172 Baron-Cohen and Hammer, 'Is autism an extreme form of the male brain?'; Baron-Cohen et al., Prenatal Testosterone in Mind.

173 Baron-Cohen et al., Prenatal Testosterone in Mind.

174 For example: Goodenough, 'Interest in persons as an aspect of sex differences in the early years'; McGuinness and Pribram, 'The origins of sensory bias.

175 Geschwind and Galaburda, Cerebral Lateralization. See Baron-Cohen, 'The extreme male brain theory of autism'.

176 E.g. Nadesan, 'Autism and genetics'.

177 Cook et al., 'Evidence of linkage between the serotonin transporter and autistic disorder'; Klauck et al., 'Serotonin transporter (5-HTT) gene variants associated with autism?'.

178 Lesch et al., 'Association of anxiety-related traits'.

179 Zhong et al., '5-HTTLPR variants not associated with autistic spectrum disorders', 130; E. Maestrini et al., 'Serotonin transporter (5-HTT) and gamma-aminobutyric acid receptor subunit beta 3 (GABRB3) gene polymorphisms'; Persico et al., 'Lack of association between serotonin transporter gene promoter variants and autistic disorder'; Yirmiya et al., 'Evidence for an association'. 
180 Tordjman et al., 'Role of the serotonin transporter gene'.

181 Folstein and Rosen-Sheidley, 'Genetics of autism.

182 Robinson et al., 'Genetically determined low maternal serum dopamine beta-hydroxylase levels'.

183 Silva et al., 'Tetrasomy 15q11-q13 identified by fluorescence in situ hybridization'; Cook et al., 'Linkage-disequilibrium mapping of autistic disorder'; Moreno-De-Luca et al., 'Using large clinical data sets to infer pathogenicity'.

184 Guhathakurta et al., 'Serotonin transporter promoter variants', 32.

185 Guhathakurta et al., 'Serotonin transporter promoter variants', 32.

186 Shuang et al., 'Family-based association study'; Jamain et al., 'Linkage and association of the glutamate receptor 6 gene with autism. Dutta et al., 'Glutamate receptor 6 gene (GLuR6 or GRIK2) polymorphisms in the Indian population'.

187 Lee et al., 'Impairment of social behavior and communication'.

188 Wöhr and Scattoni, 'Behavioural methods used in rodent models of autism spectrum disorders'.

189 El-Kordi et al., 'Development of an autism severity score for mice'.

190 Silverman, Understanding Autism, p. 156.

191 Silverman, Understanding Autism, pp. 158-159.

192 Moreno-De-Luca et al., 'Using large clinical data sets to infer pathogenicity'.

193 Yuen et al., 'Whole-genome sequencing of quartet families with autism spectrum disorder', 185-186.

194 Geschwind and Levitt, 'Autism spectrum disorders', 103.

195 Coleman and Gillberg, The Autisms; Powell and Monteggia, The Autisms. 


\section{Conclusion}

Is the tide turning?

In 2014, the UK government implemented the Children and Families Act, a major piece of legislation aimed at reforming child rights. With regard to children on the autistic spectrum, the most important change effected by the Act was that it linked up domains of state intervention that had previously been separate. The 2014 Act eradicated the system of 'statements' that were so crucial to the expansion of the autism diagnosis from the 1980s to the 2000s, and replaced them with 'Education, Health and Care Plans' that cover not only educational provision but also health and social care support. This expansion of autism rights across multiple domains has since led to an increase in parental appeals against local authority services, as well as demands that autistic children receive greater support from the entire social support system. There has also been a growth in the number of children with 'autistic spectrum disorder' who have Education and Health Care Plans. In England, in 2012, there were 44,000 children with autistic spectrum disorder with a statement of special educational need. In 2015, there were 54,000 children with autistic spectrum disorder with a statement or an Education, Health and Care Plan. In 2016, there were 57,211. ${ }^{1}$

As this book has argued, the metamorphosis of the autism concept occurred following radical changes in the construction of child rights in the late 1950s. The integration and education of large groups of children who had previously been excluded from the education system, and from society at large, led to the creation of numerous laws for autism and a reversal in the meaning of the term. Although this latest change 
in the construction of child rights is not as dramatic as that which was instigated in 1959, the Children and Families Act 2014 nevertheless has led to significant alterations to the ways in which autism is managed.

Since 1959, parents and the new autism psychologists had been adamant that children with autism should be primarily diagnosed, administered and treated within the education system and that the health or social welfare systems should merely support this process. Education authorities and the government Education Department retained overall responsibility for autistic children as a population group. This arrangement originated in the context of repressive legislation in the 1950s. The new autism psychologists wanted to define 'social impairment' and demand educational rights, and they did not want to be dictated to by medical agencies, or social service agencies who were constructing their own understandings of social deprivation and policy intervention. Since the 1960s, policy towards childhood autism in Britain has been almost wholly managed via the education system, with other professionals acting only as agents to support this. It is only recently that this has begun to change. The Autism Act 2009 began this transition with the legal and political acknowledgement that autistic children become autistic adults, ensuring that autism was listed specifically in policy documents relating to social care for autistic people when they left the education system. The Children and Families Act 2014 further expanded the significance of the category within wider health and welfare management in the UK, ensuring that multiple agencies acknowledge that they have an obligation to provide services to those on the autistic spectrum.

It is highly likely that this expansion of the domains in which the administration and authority of autism is discussed, debated and enacted upon will lead to further and significant alterations in the meaning of the term and new 'styles of reasoning' about it. Such changes will also have an impact on neuroscientific, genetic and epidemiological studies, even though all of these approaches often claim to bypass historical, social and political factors. We are in the midst of these changes and any predictions would be hasty, but this change could easily lead to the end of the epidemiologically defined population-based autism that had been driven by the desire to prove educational rights. This could be replaced with the formation of a concept that is demarcated via the law concerning wider social welfare provisions. To add to these changes, DSM-V (2013) has now dropped the category of Asperger's and 
fused the 'social' and 'communication' aspects of Lorna Wing's 'triad of impairments', putting 'autism' all on one wide spectrum. Whilst this in many ways expands the category, it has also destabilised it. Perhaps this could lead to another kind of metamorphosis? It does appear that our current concept of autism is approaching its zenith as 'the fastest growing neurodevelopmental disorder in childhood', as it is often touted. ${ }^{2}$ It is questionable whether there is anywhere else for it to go from this peak.

Recently, several new challenges have been levelled at autism researchers. Ever since Jim Sinclair's radical criticism of models of autism in the early 1990s, 'Don't Mourn for Us', the autism rights movement has been growing exponentially and generating new ways to consider what it means to be autistic. Adherents of the 'neurodiversity' movement argue that autism is not an illness, a disorder, nor even always a disability, but merely a different kind of thinking. In fact, if one looks back at the history, this argument can be seen as simply an extension of fact that 'autism' came to define an increasingly diverse field of symptoms. As the boundaries of autism expanded to define a model of child development that, by its own definition, was merely non-typical, or not statistically significant, it is no wonder that individuals seek to challenge the idea that merely being developmentally not-typical necessarily makes them sick or ill. Whilst many biomedical researchers are still flummoxed by the 'neurodiversity' movement, some now openly talk of 'neurodiversity' themselves and refer to those without a diagnosis as merely 'neurotypical'. ${ }^{3}$ The neurodiversity movement has led to a shift in approach as researchers concede to a growing and increasingly powerful distinctive discourse of autism rights, social justice and reflection on the creative aspects of autism and early infantile development.

Recent years have seen the autism rights movement take new turns in critical reflection. New initiatives have sprung up in Britain that attempt to relocate autism within a new psychoanalytic model, such as the Critical Autism Forum in Nottingham, which reclaims psychoanalysis as a critical analytic tool in relation to autism under the auspices of the neurodiversity and autism rights movement. ${ }^{4}$ Similarly, the Critical Autism Network, a global collaborative project based in Britain and funded by the Leverhulme Trust, aims to 'develop a challenge to dominant understandings of autism as a neurological deficit, instead focusing on autism as an identity that is discursively produced within specific sociocultural 
contexts. Again, it does this within the autism rights and neurodiversity movement. ${ }^{5}$ Elsewhere new research in the Lancet is arguing that parenting skills can lead to long-term amelioration of symptoms in children with autism. All This would have been unthinkable in the 1990s or even 2000s. Other initiatives, such as Nicola Shaughnessy's major Arts and Humanities Research Council project 'Imagining Autism', seek to challenge the circumscribed models of autism put forward in the epidemiological, statistical, mathematical model of autism using new ways of engaging with the theory of child development and childhood imagination and creativity. ${ }^{6}$ These changing 'styles of reasoning' about autism are being driven by legal, political and social change as much as scientific developments. They are generating new perspectives on autism, sometimes highlighting research that had subsided whilst Wing's research was dominating the field.

At the same time, several researchers have started to re-examine the relationship between schizophrenia and autism, opening up the difficult territory that distinguishes diagnoses that explore both social reality and reality. In 2009, Judith Rappoport and colleagues at the US National Institute of Health 'revisited' the link that had previously been drawn between autism and childhood schizophrenia, arguing that schizophrenia and autism are sometimes seen in the same patients and that autism and other developmental disorders may be a risk-factor for schizophrenia. ${ }^{7}$ Other similar studies have followed. ${ }^{8}$ This re-association between these disorders represents a sea change and perhaps another reframing of the problem, perhaps simply because the DSMIII and later publications have led to so much co-morbidity, particularly in childhood disorders, that these connections can no longer be ignored. If the categories of autism and schizophrenia are linked in the future through scientific models of neurodevelopment and epigenetic studies, there may be another radical shift in the description of infantile thought on the horizon. This shift to rethink autism in relation to childhood schizophrenia and hallucination has been contemporaneous with an increased acceptance that there may be multiple 'autisms.' It is also concurrent with new approaches to the rights of autistic individuals. At any rate, tides are definitely turning, approaches are definitely shifting and we may well see more former models of autism being resurrected.

'It is important to be aware, in the process of this resurrection, that the second autism served a phenomenally important role in assuring 
independent rights for individuals so classified. Changes in the law in the 1980s and 1990s required fixed models of autism to assure children's rights. Returning to earlier models, and advocating neurodiversity, are important projects, but these projects must be embarked upon with an informed awareness of the importance of the second autism to ensuring child rights. In other words, it is imperative that child rights are supported in the throws of this massive conceptual change and that the neurodiversity movement doesn't unwittingly lead to an erosion of such rights.

Some of the central questions raised in the controversies over the first autism in the 1940s have resurfaced in new forms. These are most evident in Michael Rutter's well-known studies on Romanian orphans who had been seriously deprived during the early stages of their development. ${ }^{10}$ In 2007, Rutter argued that around one in ten of these severely deprived children showed 'quasi-autism' that was very similar, though not identical, to 'ordinary autism'. All the children with 'quasiautism' showed 'theory of mind' deficits, a finding that confirms the universality of that concept to cover general relational and social difficulties. ${ }^{11}$ Furthermore, deprived orphans adopted after six months were likely to show 'theory of mind' deficits even if they did not show fullblown 'quasi-autism. ${ }^{12}$ Interestingly, Rutter and colleagues have argued that infants who are severely deprived during the first six months of life do not develop 'quasi-autism', whereas those who were deprived for longer periods do have a tendency to do so. This finding essentially revisits the controversial discussions between Melanie Klein and Anna Freud about the nature of thought during the first six months of life and whether infants during this phase were dominated by 'primary narcissism', as Anna Freud had argued. In essence, Rutter now argues that environmental circumstances can affect the development of 'quasiautism', a finding that is less contentious when phrased in new language. Legal, political and social developments and new models of children's rights and disability rights are influencing these changes. ${ }^{13}$ Elsewhere, psychologists such as Vasu Reddy are re-interrogating the formation of the self in early infancy in relation to parental, and other social and cultural factors.

Rutter clearly has an appreciation of the impact of the law and society on psychological categories and argued in 2011 that there should be two versions of classifications used in the DSM: one aimed at all 
professionals working in front-line, caregiving and administrative capacities, and one aimed at researchers who seek to explore neuroscience, epigenetics and environmental factors in the causation of mental states. He references the case of autism as an example of how categorisation practices could be better. ${ }^{14}$ Because the epidemiological model of autism became fused with the child rights and disability rights model of autism by the late 2000s, it makes sense that new taxonomies and new styles of thinking about autism are now on the horizon. It is likely that these will break down and problematise the 'autisms' and their relation to social, educational and welfare rights. It is likely that another metamorphosis of autism, prompted by the 'neurodiversity' movement, is now on the horizon.

\section{Rethinking social development}

This book has described the origins and foundations of autism as a concept and the role of British researchers in appropriating the concept, making it their own via epidemiological exploration, and then promoting it to the rest of the world. This was an important project that enabled a complete transformation of models for thinking about child development. Nikolas Rose's work on the spread of 'human relations' psychology as important to the development of social models and modes of governmentality has been critical in explaining how the psychological sciences have enabled complex models of self-governance in Britain. Yet, from the 1960s, such models have been placed under an increasing amount of pressure as radically new models of identity development in children began to come to the fore. In these new models, children could be regarded as social subjects with social rights regardless of their actual engagement in an idealised model of 'the social' and 'society'. The new autism was a critical concept for rethinking psychology and social development in the 1960s and it became increasingly important over the ensuing decades. Theories of the second autism have since been used to promote a model of global children's rights centred on the idea that all children have the right to be considered as social subjects, even if they are not fully 'social' in the sense promoted by social scientists and human relations theorists of the previous generation.

In Rose's later work, he has argued that 'the social', as tied to a single national model of government, has been reconstructed within a new 
global neoliberal model of governance in which new kinds of communities are advised, managed and governed by expert authorities. ${ }^{15}$ The growth of neuroscientific approaches to social engagement are regarded merely as extensions of 'technologies of the self' in which subjects are beholden to expert opinions offered by 'psy' experts and other authorities. These are simply veiled in new neoliberal ideologies. ${ }^{16}$ The argument in this book is that new models of autism and social engagement are not just an extension of previous models of governance as characterised by the growth of 'human relations' psychology. In fact, the rise of autism and new models of social engagement have radically reformulated ideas about social engagement. The metamorphosis of the concept of autism is a reflection of this fact. The rise of the second autism has been associated with the development of important new models of self-identity that do not slot easily into a model of growing 'technologies of the self' within a wider framework of governmentality. These new models of social engagement are direct reactions to the Tavistock model of human relations and have increasingly demonstrated that individuals do not need to succumb to pressures to become social beings. The Autism Act 2009 was a critical piece of legislation that upheld such models and demanded that the law acts to support the welfare and care of autistic individuals without forcing them into a wider framework of self-governance. The concept of autism has redefined how we think about individual rights and child rights. If there is another metamorphosis of autism on the horizon, it will be shaped in a very different political and legal climate to that which supported the first autism.

The Mental Deficiency Act 1913 and the growth of psychological services for children in the early twentieth century led psychologists to develop a new language with which to conceptualise the problem of severe mental pathology in infants and children drawing from the study of psychopathology in adults. Up until the 1950s, the concepts of childhood schizophrenia and autism were used to reframe central issues in child development based on the idea of infantile hallucination. However, this foundational work for the autism concept was conducted in a unique historical climate in Britain where a population of children were hidden from the gaze of important early child psychology researchers. Psychologists such as Melanie Klein, Susan Isaacs and 
John Bowlby were influencing government policy towards children as recipients of welfare and education but their approach was blinkered. 'Mentally defective' children were neglected as subjects of sustained psychological research and 'styles of reasoning' around autism were limited by the fact that a major section of the population was not included in the studies.

The Mental Health Act 1959 saw the hidden population of children begin to reappear in families, schools, hospitals and clinics. Most importantly, they were finally acknowledged as individuals with rights in the eyes of the law. It was this moment of rediscovery that encouraged the first epidemiological study of the 'autistic' and that simultaneously shifted the focus of child psychology away from the kernels of desire for relationships and human interactions, and towards the limitations on their thoughts about social interactions. The expansion of the epidemiological method in child psychiatry and developmental psychology led to new standardised measures of sensory-motor function and language ability. A child's behavioural and linguistic 'stereotypies' could be correlated with similar 'stereotypies' in other children through cohort studies. These studies gave rise to new scientific facts about infantile psychology. Victor Lotter's behavioural items for autism were developed to enable reproducible studies that would not be affected by the subjective judgements of individual researchers. It was in response to these changes that statistical researchers such as Lotter, Lorna Wing and Rutter transformed the meaning of autism from 'a withdrawal into fantasy', as in the Piagetian description of the concept, to an inability to fantasise that could be calculated through a sum of cognitive measures. It was through the work of Lorna Wing that the theory of 'social impairment' reached its pinnacle and from which models of 'theory of mind' and 'executive function' impairments sprang. It is important to note that these were not merely 'cognitive models' of autism but that they were premised on a very significant claim to knowledge within a total model of psychiatric epidemiology. Furthermore, they were developed in order to ensure all children's rights to live within society as social beings.

The claim that statistical inference should be used as the basis of scientific knowledge is not an invention of autism researchers in the 1960s. Such a claim can be traced back to the work of Karl Pearson, Francis Galton and Cyril Burt. However, historical contingencies 
impacted on the way in which children were organised and administrated within the school system, the juvenile justice system and the maternity and child welfare system in the early twentieth century that affected the model of psychology that was developed before the 1959 Mental Health Act was passed. The work of Burt, Isaacs, Winnicott and Bowlby had some very specific agendas, and some very specific omissions, that characterised it. For example, although Burt was obsessed with norms, means, averages and generalities, he was not concerned with children who lay beyond those norms and left them to deficiency institutions. Furthermore, he thought of instinct theory in terms of its impact on individuals and so his reasoning about psychological development drew just as much from the individual case as it did from the statistical sample. The problem was that this individual case was always a child with 'normal' intelligence. In the post-war period, researchers such as Bowlby were interested in encouraging policy-makers to think about the flaws of institutional care. The fact that they worked in child guidance clinics and everyday community institutions, far removed from the tragic drudgery of institutional care for mental defectives in the 1950s, meant that they were not able to see beyond the cultural vacuum, and the ethical nightmare, that mental deficiency law had created. However, when mental deficiency law came to be seriously challenged in the mid-1950s, the application of Bowlby's views at policy level seemed increasingly inconsistent. Why was mother love deemed so important for 'normal' children but so unimportant for 'defective' children who remained in institutional care? The contradiction in government policy towards 'defective' children in the immediate post-war period no doubt fuelled the need for quantitative accuracy regarding the problems and needs of this borderline population.

The meaning of 'autism', as both a defining state in the development of individuality and an aspect of schizophrenic thinking, has always been dependent upon the broader gestalt of psychological theory and the institutional structures that have supported it. It is for this reason that the closure of mental deficiency institutions had such a profound effect on the theoretical structures of child psychology. Statistical child psychology as it developed in the 1960s used epidemiological studies in order to answer questions about 
the development of all infantile thought in a new social context. Researchers such as Rutter, Lotter and Wing used epidemiology to understand social development in children. They thereby transformed psychological questions about children's individual unconscious desire for relationships into statistical questions about how a total population of children behave in relation to others. In doing so, they developed a 'style of reasoning' about child development that relied extensively on epidemiological studies.

When epidemiologists employed statistical methods to understand the development of the infantile mind, they appropriated the concept of autism because the explanation of it was imbued with so much potential. The potential of the concept has since been fulfilled, in the sense that it has been readily applied to increasing numbers of children. However, its meaning remains problematic within general psychiatry due to its complex history and dissociation from the key concept of descriptive psychopathology - hallucination. Whereas the Piagetian, Isaacian and Kleinian theories of autism that had dominated until the 1950s had constructed autism and primary narcissism as the 'pre-social' stages of development that later re-emerged in pathological psychosis, the psychology of 'autistic spectrum disorders' would regard these early stages of thought in infancy as a defect, deficiency or shortcoming that could only be surmounted via a full-blown interaction with the social world. As it blossomed in the 1980s and 1990s, Wing's autistic spectrum psychology organised theories of mental development around the contention that infants and children could be 'deficient' or 'impaired' in their ability to engage in the social world. More importantly, however, the social world was no longer thought to be constructed from phantasy and hallucination concerning the body and bodily functions. Now the social world was created in the very material of statistical and epidemiological studies, in the logic of collecting and collating. Detailed observations of infants shifting their eyes, reaching for toys and moving objects around were no longer just of interest to psychologists studying intellectual development or psychoanalysts studying human desire. These now featured in a new discourse of collective social impairment. When the theory of instincts lost its discursive power, after child psychologists had to succumb to the reality of a 'mentally defective' population, mothers no longer held the descriptive power that they had previously held as the harbingers 
of social reality. Child psychologists now came to construct 'the social' in a domain entirely separate from family life. Although psychoanalytic theory was influential within government policy in the 1960s and 1970s, it was simultaneously being stripped of its descriptive terminology and the language that supported all of its major contentions concerning childhood psychopathology. The science of 'mental defect' posed a challenge to these psychoanalytically influenced alltoo-perfect constructions of children's social and emotional development, and it was a challenge that was virtually impossible to overcome. New 'styles of reasoning' around autism took account of multiple and varied forms of child development, but they did so in a way that was restricted by the scientific models used to formulate them. Epidemiological sciences became the quintessential element of autism research, so much so that it was hard to see beyond the figures.

Whereas pre-epidemiological definitions of autism were criticised for relying too heavily on the description of subjective mental states, in particular the attribution of hallucinatory and delusional experiences, post-epidemiological descriptions of autism relied just as heavily on the description of social norms, assuming a shared understanding of what constituted 'society'. These were arguably just as abstract as definitions of mental states, although epidemiological researchers did not view it this way. In descriptions of the early stages of socialisation in the first two to three years of life, one could argue that 'the social' could be measured quite successfully through behavioural criteria such as reaching to be carried, seeking eye contact and engaging in conversation with others - and similar behaviours explored in instruments such as the $\mathrm{ADOS}$. However, as children got older, their engagement with 'the social' became increasingly difficult to define and increasingly difficult to measure. In many studies, the term 'social' then came to be bandied about in way that was not particularly useful for epidemiological study. It was because of this that Simon Baron-Cohen, Alan Leslie and Uta Frith's work in the late 1980s was so important. It promised to provide a deeper theory to explain social abnormalities.

Just as psychoanalytic models of autism had influenced wider theories of child psychology since the 1920s, and just as 'Bowlbyism' had dominated policy approaches to nursery provision in the postwar period, the new epidemiologically defined 'autistic spectrum' would have a huge influence on wider theories of child development 
and children's right, particularly from the 1980s onwards. After the 1960s, models of 'social development' in children could no longer employ progressive evolutionary descriptions of increasing mental functions as they tallied with increasing social complexity as in the models of McDougall and Burt. Radical critique of these sociological approaches increasingly gained ground. The Seebohm reforms and ensuing reflections on the complexity of 'the social' as managed through administrative systems also had a huge impact. The Education Act 1981 (1983) further supported such reflections, as did Margaret Thatcher's denigration of 'society' and the increase in neoliberal approaches to active social citizenship. By the 1980s, it was not just ideas about autism, 'social' impairment and atypical development that had changed, but also ideas about 'normal' social development in children.

In fact, research on theory of mind, and the ways in which one individual projects intentions onto another, was a pretty low-key topic for a long time. No one was very interested in Frith, Leslie and BaronCohen's first article on 'theory of mind' in the 1980s, leaving Frith exasperated at the lack of engagement. ${ }^{17}$ In the early 1990s, in line with growing epidemiological studies of autism, the first research on 'mirror neurons' emerged via studies on monkeys, generating greater interest in the brain mechanisms by which humans were able to empathise or share mental states with others. ${ }^{18}$ Baron-Cohen has been the central scholar to latch on to this work and to associate it to autism research. However, as Allan Young has argued, there is still much controversy around the way that mirror neurons work in empathising processes and all of the findings must be viewed in relation to what he calls the 'neoDarwinian back story' of the social brain, tracing back to the $1960 \mathrm{~s}^{19}$ As Young points out, since the 1980s, neuroscientists have also been describing what they refer to as 'the cognitive unconscious' or 'the new unconscious', using computer models and metaphors to describe the way that 'preattentive perceptual processes' and 'memory traces' support higher mental processes in humans. This 'unconscious' is one of self-regulation and is thus often contrasted with 'the conflict and drama of the psychoanalytic unconscious. ${ }^{20}$ Nevertheless, even within cognitive psychology, claims are clearly made about the way that the unconscious 'social brain' directs behaviour. Because autism has always been such a crucial concept in the development of theories of the origins of 
the unconscious mind, and in the description of social engagement in infants and children, it is no wonder that interest in empathy, mirror neurons and the social brain has heightened in an international context. The 1990s thus witnessed both a boom in autism diagnoses and a burgeoning of research into mirror neurons and the social brain.

At the same time, new theories of social development emerged in child development studies. Social development was no longer an achievement; it was more of an engagement with multiple agencies. For example, in 1986, Martin Richards, who established the Medical Psychology Unit at the University of Cambridge, together with Paul Light from the University of Southampton, published Children of Social Worlds, a text that examined the impacts on the process of psychological development made by institutions of family life, the status of children within the legal system, the work roles of parents, schooling and education, gender difference and the ability to acquire communication skills. In 1991, Paul Light drew attention to major 'changing perspectives on cognitive development during the past decade'. As summarised in the preface:

Piaget's theory has informed the popular image of the child as a solitary thinker struggling to construct a personal understanding of the mathematical and logical properties of the physical world. But this image is now giving way to a view of the child being initiated into shared cultural understandings through close relationships with parents and teachers, as well as siblings and peers. ${ }^{21}$

Any child who was a solitary thinker who struggled to understand the mathematical and logical properties of the world was now on 'the autistic spectrum', an anomaly within a new model of the development of relationships that shunned psychoanalytic models and argued that social engagement occurred through other kinds of 'social' engagement that, ironically, were actually being described at a more abstract level. Instead of drawing from the psychoanalytic theory of human relationships, these texts increasingly drew from cognitive models in order to describe how children became social subjects. Now that the new model of autism was accepted as the absence of social development, 'social development' in children also came to be redefined.

These changes were contemporaneous with changes in the meaning of autism. These were new descriptions of the society that housed 
psychological development, born of the work of the Institute of Psychiatry-trained epidemiologists and psychologists. This model was particularly receptive to the psychology of the 'autistic spectrum' because this psychology provided new agency to the child himself or herself. Gone were the days of adults imposing their views of evolutionary development on the blank canvas of the infant brain; now that infant had autonomy and the democratic potential to alter the perception of himself through statistical patterning. If more children glanced away from the psychologist's gaze, looked blankly at their questions and played with their toys as if they were scientific instruments, these actions would be collected, recorded and analysed as part of the psychology of the social. This voice, this agency was the psychology of the autistic spectrum writ large because the individuals it represented were the most disadvantaged. It is for this reason that a 'social impairment' became simultaneously a deficiency and a benefit.

By the mid-1990s, psychology textbooks began to address the 'personal, social and emotional' development of children, drawing distinctions between these different areas to ensure that 'social development' was distinguished from general emotional and personal growth. ${ }^{22}$ These were also spurred by legal changes concerning the organisation of childcare and education. In 1996, Desirable Outcomes for Children's Learning on Entering Compulsory Education introduced national guidelines for the education of preschool children and promoted the idea that children should achieve a number of 'personal' and 'social' skills before they entered into compulsory education at age five. ${ }^{23}$ In 2000, these goals were revised under Blair's Labour government as the Early Learning Goals of the statutory Curriculum Guidance for the Foundation Stage for children aged 3-5 years. Birth to Three Matters was also published as non-statutory guidance for children under the age of three. ${ }^{24}$ These guidelines and goals focused on the need for children to develop early social skills. New practical guides were then written to promote 'social' learning in children and these treated the development of relationships as a cognitive and educational issue. ${ }^{25}$

The theory of the 'social brain' now thrives in neuroscientific studies, given further support from research in 'mirroring' and 'mirror neurons', first reported in the late 1990s. ${ }^{26}$ The neuroscientist Chris Frith, husband of Uta Frith, argued that emotions are mirrored in others, 
developing the idea that humans' capacity to empathise is related to a social part of the brain that enables one to understand the thoughts and feelings of others. ${ }^{27}$ Together the Friths also argued for the idea of a 'social brain. ${ }^{28}$ Baron-Cohen developed these ideas particularly in relation to empathy. ${ }^{29}$ The fact that these theories of the social brain have arisen from the study of individuals who apparently lack social capacities, is somewhat ironic. However, this irony is easier to appreciate when one realises that these new theories of the 'social brain' developed from a unique historical context in Britain when children who were previously considered extraneous to psychology were integrated into psychological studies. The consequences of this change spread far wider than the study of just autism. They have entered into all descriptions and studies of infants and children who display mental atypicalities and have influenced international theories of psychological development. 'Autism' is a defining concept that has altered our perception of how infants and children think.

\section{How models of social development affect society}

The epidemiological approach to autism has enabled researchers, parents and others to think about gene/environment interactions in psychological development in more detail than early-twentieth-century developmental psychologists would ever have thought possible. The globalisation of Wing's 'triad of impairments' enabled the epidemiological model of autism spectrum psychology to be applied in countries across the world where the collection of vast amounts of genetic data, and mouse models of 'social impairment', encouraged researchers to look at how multiple genetic abnormalities can manifest themselves as 'autism. These studies now seek to analyse the entire autism spectrum, the possible genes involved and the potential environmental factors that could trigger the development of this spectrum condition. There is nothing particularly clear-cut about this approach. It does not approach autism as disease entity but rather as a psychological presentation that has some bearing in biological facts. This conceptualisation of autism has some similarities to the instinct model of autism and social development that originated in the 1920s and 1930s, which regarded autistic thought as a critical point of reflection on a wider model of biological 
drives in infants and children. What distinguishes the current genetic model is its basis in epidemiological studies of total populations rather than an individual child's troubled relationships.

Such opposing claims of biochemical difference in children had a different meaning depending on the historical and legal context. Biological descriptions of childhood schizophrenia before the 1960s were framed within a legal model that supported medical interventions and exclusion. A diagnosis of childhood schizophrenia by Kenneth Cameron in the early 1950s, for example, could lead to a regime of forced insulin-shock treatment followed by a lifetime of institutional commitment and exclusion from the rest of 'society'. A diagnosis from Lauretta Bender in the USA could be even more detrimental to a child's later ability to function as a social being. However, legal changes that ensued from the late 1950s to the early 1990s turned the diagnosis of autism from a one-way ticket to lifetime institutional commitment into a positive description of children's individuality. The fact that autism advocates now campaign so loudly that they are proud of their diagnosis and do not wish for it to be seen as a disorder or a problem, but rather as a positive affirmation of their being, is confirmation of the success of these legal and conceptual transformations. After legal changes ensured that the autism diagnosis was accompanied by legal rights to education and social acceptance, in particular after the law affirmed the rights of child expression more generally, then biochemically different beings were no longer regarded as threats to the social order and recipients of social care, but rather as actors who had a right to their individual thoughts and expressions. Post-1989, biological psychiatry changed - it was no longer the repressive state-protected diagnosis of a psychiatrist, because children's autonomy was now protected in law. Autism thus became a statement of the authenticity of children's individuality.

The category 'autism' has been used to label increasing numbers of children in Britain, particularly since the 1990s, and these increases were largely driven by changes in the administration of institutional care and education for children. This increase in diagnoses of autism has been associated with the accession of a new model of children's rights. The 1981 Education Act (1983) and the Children's Act 1989, spurred further by the rise of Thatcherism and neoliberal approaches to social welfare in which individual rights were championed, were the drivers for 
these changes. This supported the growth of autism as a category and supported further laws that put this model of autistic children's rights into practice. By the 1990s, the new epidemiologically defined version of autism had already taken on a life of its own. Researchers, parents and others were debating its possible increase, children were being diagnosed with the problem internationally, schools were developing new ways to teach children with autism and to manage them in classrooms and education systems, adults were also acknowledging their condition, some self-diagnosing, and developing a new discourse for understanding what autism was. It was this model of autism that held such a wide international appeal and which has since prevailed across the globe.

Through the application of more and more tests for impairments in social engagement, communication and imagination, the new autism psychologists sought to discover the meaning of early infantile thought. The psychology of intelligence testing became a mainstay of government policy and intervention from the 1910s to the 1960s in the UK, and presented a scientific model that could also be used as a powerful administrative tool by the government. Likewise, theories of autism have adopted a similar role since the 1980s. Tests for autism have become part of everyday life; they have shaped understandings of child development for everyone from government officials and policy advisers to educational psychologists and teachers to parents and, not least, to children themselves. A lot of information has been collected but, similarly to intelligence tests, these tests have reached a limit in their applicability as the basis for wholesale genetic theories, as well as arguments for social policy engagement to support their logic. Just as Steven J. Gould radically debunked the scientific theory of intelligence in the early $1980 \mathrm{~s},{ }^{30}$ today autism advocates are presenting a critical challenge to the idea of the 'autistic spectrum' as a useful scientific instrument to think about genetic abnormality, pointing out that it embraces individuals who have been excluded due to society's own limitations, and should now be embraced and appreciated for the skills and abilities that they can offer. This has led to a championing of the idea of autism as biochemical 'difference' rather than illness. If one looks at the history of autism as a central concept of child development, it is clear that the affirmation of autistic individuals' rights to be autistic and their claims to de-medicalise the entire concept of autism are just a natural 
progression from the recognition that autism needed to be released from state control in deficiency institutions, into the hands of schools and parents, and eventually children and adults with the diagnosis. At its core, this is a debate about rights. It is part of the democratisation of the topic of autism, which was, in its previous incarnation, limited to medical, psychological and government officials.

The first generation of statistical psychologists, including Burt, had been interested in using psychological techniques in order to measure IQ and delinquency levels and to make comments about meritocracies and the way that society should be organised in order to ensure economic prosperity. The new autism psychologists did not do this. Tizard, in particular, strongly believed that 'mentally handicapped' children could be educated and integrated into society. Rutter believed that social scientific work could help to break 'cycles of disadvantage' by exposing social organisation for what it really was. Unlike a model of 'governmentality' in which all individuals are induced to govern themselves, the new autism psychologists integrated new ideas about dependency and self-awareness that bypassed the idea of social dependence. The second autism encouraged the recognition of individuals with atypical forms of 'social development' and ultimately did not seek to enable their compliance as social subjects. This is why the rise in autism, the rise in recognition of children's rights and the rise of neoliberalism go hand in hand. All these phenomena have presented new ways for conceptualising the individual within a social context. The growth in the application and the study of autism as a 'social impairment' has paralleled legal changes that have championed the rights of children no matter what their mental impairments may be. This new model of social welfare and human relationships has become increasingly desirable in an international context. Nevertheless, we are beginning to see seismic shifts again, not only in the meaning of autism as the neurodiversity movement takes on the 'impairment' model, but also in social policy, as the 2014 Children and Families Act redefines the way that social care, provision and support is provided to all children.

The entire basis for autism, in its second metamorphosis, rested on the possibility that statistical, epidemiological and genetic studies would, in the future, be able to define the concept itself. Dominant descriptions of autism, such as Baron-Cohen's, state that the potential of 'autistic' thought lies in its capacity to think mathematically, 
scientifically and logically. This is not a coincidence but a reflection of the way that epidemiological models have been developed to measure the concept and make claims as to its scientific accuracy. In many ways, the second definition of autism was merely a reflection of the instruments that have been used to measure, contain, control and identify aspects of the infantile mind that are just unknowable. In fact, the way that this impenetrable part of the infantile psyche has been conveyed has a lot more to say about the society that has fabricated it than about the infantile mind itself. If the tide turns again, and if autism experiences another metamorphosis, this will also be accompanied by new 'styles of reasoning' about society, individuality and the right to have individual children's needs recognised. The potential of autism to reshape these diverse domains of human knowledge should not be underestimated.

\section{Notes}

1 Department for Education, Statistics (2016), online: www.gov.uk/government/statistics/special-educational-needs-in-england-january-2016. Statistics (2015), online: www.gov.uk/government/statistics/specialeducational-needs-in-england-january-2015; Statistics (2012), online: www.gov.uk/government/statistics/special-educational-needs-inengland-january-2012.

2 E.g. Hidalgo et al., 'Sociodemographic differences in parental satisfaction'.

3 Interview with Uta Frith, Bonnie Evans, 17 December 2014. Frith stated that the neurodiversity movement presented a challenge to her work. Others such as Francesca Happé readily use the language of the neurodiversity movement, e.g. Happé, 'Autism and the concept of psychological normality'.

4 Critical Autism Forum, Nottingham: http://blogs.nottingham.ac.uk/criticalmoment/2015/01/05/critical-autism-forum-launch-weekend-report (accessed 25 October, 2016).

5 Critical Autism Network: www.open.ac.uk/health-and-social-care/ research/critical-autism-network/ (accessed 26 October 2016).

6 www.imaginingautism.org (accessed 29 October 2016).

7 Rapoport et al., 'Autism spectrum disorders and childhood-onset schizophrenia. 
8 E.g. Meyer et al., 'Schizophrenia and autism'; Waltereit et al., 'Interaction of neurodevelopmental pathways and synaptic plasticity'; Devanna and Vernes, 'A direct molecular link'.

9 Coleman and Gillberg, The Autisms.

10 E.g. Rutter et al., 'Specificity and heterogeneity in children's responses to profound institutional privation'; Rutter, 'Developmental catch-up, and deficit, following adoption'.

11 Rutter, Kreppner et al., 'Early adolescent outcomes of institutionally deprived and non-deprived adoptees'. This built on an earlier study of a smaller group of children: Rutter, Anderson-Wood et al., 'Quasi-autistic patterns following severe early global privation.

12 Colvert et al., 'Do theory of mind and executive function deficits underlie the adverse outcomes'.

13 E.g. Reddy, \& Rossmanith, 'Structure and Openess in the Development of Self in Infancy. Journal of Consciousness Studies, Volume 23, Numbers 1-2, 2016, pp. 237-257(21).

14 Rutter, 'Research review: Child psychiatric diagnosis and classification'.

15 Rose, 'The death of the social?'.

16 Rose and Abi-Rached, Neuro; Rose, Powers of Freedom.

17 Interview with Uta Frith, Bonnie Evans, 17 December 2014.

18 Di Pellegrino et al., 'Understanding motor events'.

19 Young, 'The social brain and the myth of empathy'.

20 Hassin et al., The New Unconscious.

21 Light et al., Child Development in Social Context, vol. II: Learning to Think, p.x.

22 Barnes, Personal, Social and Emotional Development of Children; Dowling, Young Children's Personal, Social and Emotional Development.

23 School Curriculum Assessment Authority, Nursery Education.

24 Qualifications and Curriculum Authority, Curriculum Guidance for the Foundation Stage.

25 Evans, Personal, Social and Emotional Development; Leach, Personal, Social and Emotional Development.

26 Rose and Abi-Rached, Neuro, p. 145.

27 C. D. Frith, 'The social brain?'.

28 Frith and Frith, 'The social brain'.

29 Baron-Cohen, Zero Degrees of Empathy.

30 Gould, The Mismeasure of Man. 


\title{
Abbreviations for Archives and Government Acts
}

\author{
Archives
}

Bethlem Museum of the Mind Archives. BMM.S11.CFM: Microfilmed Database of Patient Case Notes from the Maudsley Hospital, 1923-38 (restricted access).

Hansard. The Official Report of Parliamentary Debates, UK Parliament and House of Lords Transcripts.

King's College London Archives. KCL/BCGC: Brixton Child Guidance Clinic Administrative Archive, 1951-88.

Maudsley Hospital Archives. MHCP/A: Maudsley Hospital Childhood Psychosis/Autism Archive, 1950-90 (restricted access, anonymised reference numbers).

National Archives. NA/ED50/994: Records from Board of Education and Medical Branch concerning 'Psychotic Autistic Children', 1961-65.

—. NA/ED50/944: Transfer of Responsibility for Junior Training Centres for Children Unsuitable for Education at School from the Ministry of Health to the Local Education Authorities, 1969-70. . NA/ED50/969: Society for Autistic Children, 1964-68.

. NA/BD 18/1438: Appointments of Consultants in Child Psychiatry, 1965.

- NA/M.603(1)/61 (ED 50/789-792): Correspondence with Local Authorities on Special Educational Treatment, 1958-63.

NA/FD9/901 MRC Developmental Psychology Unit: Physiological Study with Autistic Children.

National Autistic Society Archives. NAS: National Autistic Society Historical Records, 1963-2014 (boxes 1-8 - uncatalogued).

Royal Society Archives. UFPA: Uta Frith Personal Notes and Collected Material. 
Wellcome Trust Archives. WT/PSY/BPS: British Psychological Society Archives, 1891-2005.

. WT/PP/ADD/5: Inter-Clinic Conference and Child Guidance Trust Papers, 1958-80. .WT/PSY/KEN/4/1: Lucy G. Fildes Archive.

\section{Abbreviations}

CA1989(1991)

CLAAPS1968

CSDPA1970(1971)

MHA1959

WARNOCK1978
Children Act 1989 (1991)

Report of the Committee on Local Authority and Allied Personal Social Services (1968)

Chronically Sick and Disabled Persons Act 1970 (1971)

Mental Health Act 1959

Special Educational Needs: Report of the Committee of Enquiry into the Education of Handicapped Children and Young People (1978) 


\section{Bibliography}

Abram, J. and H. Karnac. The Language of Winnicott: A Dictionary of Winnicott's Use of Words, 2nd edn. London: Karnac, 2007.

Abramson, H. A. 'The use of LSD (d-lysergic acid diethylamide) in the therapy of children (a brief review)'. Journal of Asthma Research 5, no. 2 (1967): 139-143.

Ackerman, N. W. 'Psychiatric disorders in children: Diagnosis and etiology in our time.' In Current Problems in Psychiatric Diagnosis, edited by P. H. Hoch and J. Zubin. New York: Grune \& Stratton, 1953.

Ainsworth, M. D., R. G. Andry, R. G. Harlow, S. Lebovici, M. Mead, D. G. Prugh and B. Wooton. Deprivation of Maternal Care: A Reassessment of Its Effects, Public Health Papers no. 14. Geneva: World Health Organization, 1962.

Allison, H. G. 'Perspectives on a puzzle piece'. Communication 22, no. 1 (1988): 6-9.

Alpert, A. The Solving of Problem-Situations by Preschool Children: An Analysis. New York: Teachers College, Columbia University, 1928.

American Psychiatric Association [APA]. Diagnostic and Statistical Manual: Mental Disorders. Washington, DC: American Psychiatric Association Mental Hospital Service, 1952.

- Diagnostic and Statistical Manual of Mental Disorders: DSM-III, 3rd edn. Washington, DC: American Psychiatric Association, 1980.

- Diagnostic and Statistical Manual of Mental Disorders: DSM-III-R, 3rd rev. edn. Washington, DC: American Psychiatric Association, 1987.

. Diagnostic and Statistical Manual of Mental Disorders: DSM-IV, 4th edn. Washington, DC: American Psychiatric Association, 1994.

American Psychoanalytic Association. 'Annual meetings of the APA 1960'. Bulletin of the American Psychoanalytic Association 16 (1960): 724-741. 
Anderson, A. and B. Zahm. 'Obituary: Helen Margulies Mehr (1916-1992)'. American Psychologist 50, no. 10 (1995): 878.

Anderson, G. M. 'Monoamines in autism: An update of neurochemical research on a pervasive developmental disorder'. Med Biol 65, no. 2-3 (1987): 67-74.

Anon. 'Advertisement: Journal of Autism and Childhood Schizophrenia'. Schizophrenia Bulletin 12 (1975): 17.

Anon. 'Beatrice Edgell, 1871-1948'. British Journal of Psychology, General Section 39, no. 3 (1949): 121-122.

Anon. 'Kenneth Cameron: Obituary'. The Lancet (1963): 782-783.

Anon. 'Obituary: C. J. C. Earl'. British Medical Journal 2, no. 5163 (1959): 1407-1408.

Anthony, E. J. 'An aetiological approach to the diagnosis of psychosis in childhood'. Acta Paedopsychiatrica 25 (1958): 89-96.

- Clinical Aspects of Childhood Psychosis. Film shown at the 2nd International Congress in Psychiatry, Zurich, 1957.

- An experimental approach to the psychopathology of childhood: Autism. British Journal of Medical Psychology 30 (1957): 211-227.

- 'An experimental approach to the psychopathology of childhood: Encopresis'. British Journal of Medical Psychology 30 (1957): 146-175. . 'Group therapeutic techniques for residential units'. Case Conference 4, no. 6 (1957): 186-193.

'Other people's children'. Case Conference 5, no. 2 (1958): 63-66.

. 'The significance of Jean Piaget for child psychiatry'. British Journal of Medical Psychology 29 (1956): 20-34.

- 'The system makers: Piaget and Freud'. British Journal of Medical Psychology 30 (1957): 255-269.

Appignanesi, L. and J. Forrester. Freud's Women, rev. edn. London: Phoenix, 2005.

Astbury, J., A. A. Orgill, B. Bajuk and V. Y. Yu. 'Neonatal and neurodevelopmental significance of behaviour in very low birthweight children'. Early Hum Dev 11, no. 2 (1985): 113-121.

Auden, G. A. 'The maladjusted child'. British Journal of Educational Psychology 1, no. 3 (1931): 266-278.

August, G. J., M. A. Stewart and L. Tsai. 'The incidence of cognitive disabilities in the siblings of autistic children'. British Journal of Psychiatry 138 (1981): 416-422.

Autism Speaks. 'Autism Speaks launches global action committee', 2015. www.autismspeaks.org/about-us/press-releases/autism-speaks-launchesglobal-action-committee [accessed 13 January 2015].

- 'Autism Speaks launches unprecedented global autism public health initiative'. Press release. New York, 26 September 2008. 
Bailey, A., A. Lecouteur, I. Gottesman, P. Bolton, E. Simonoff, E. Yuzda and M. Rutter. 'Autism as a strongly genetic disorder: Evidence from a British twin study'. Psychological Medicine 25, no. 1 (1995): 63-77.

Baird, G., S. Baron-Cohen, M. Bohman, M. Coleman, U. Frith, C. Gillberg, C. Gillberg, P. Howlin, G. Mesibov and T. Peeters. 'Autism is not necessarily a pervasive developmental disorder'. Developmental Medicine and Child Neurology 33, no. 4 (1991): 363-364.

Baird, G., T. Charman, S. Baron-Cohen, A. Cox, J. Swettenham, S. Wheelwright and A. Drew. 'A screening instrument for autism at 18 months of age: A 6-year follow-up study'. J Am Acad Child Adolesc Psychiatry 39, no. 6 (2000): 694-702.

Baird, G., E. Simonoff, A. Pickles, S. Chandler, T. Loucas, D. Meldrum and T. Charman. 'Prevalence of disorders of the autism spectrum in a population cohort of children in South Thames: The Special Needs and Autism Project'. The Lancet 368, no. 9531 (2006): 210-215.

Bakare, M. O., P. O. Ebigbo and V. N. Ubochi. 'Prevalence of autism spectrum disorder among Nigerian children with intellectual disability: A stopgap assessment'. J Health Care Poor Underserved 23, no. 2 (2012): 513-518.

Bakare, M. O. and K. M. Munir. 'Autism spectrum disorders (ASD) in Africa: A perspective'. Afr J Psychiatry (Johannesbg) 14, no. 3 (2011): 208-210.

Bakwin, H. 'Early infantile autism'. Journal of Paediatrics 45 (1954): 492-497.

- 'Etiology of behavior disorders'. Postgraduate Medical Journal 9 (1951): 260-265.

Balasubramanian, B., C. V. Bhatt and N. A. Goyel. 'Genetic studies in children with intellectual disability and autistic spectrum of disorders'. Indian J Hum Genet 15, no. 3 (2009): 103-107.

Baldwin, B. T. and L. I. Stecher. The Psychology of the Preschool Child. London: D. Appleton \& Co., 1924.

Barnes, P. Personal, Social and Emotional Development of Children. Milton Keynes: Blackwell Publishers in association with the Open University, 1995.

Baron-Cohen, S. 'The extreme male brain theory of autism'. In Neurodevelopmental Disorders, edited by H. Tager-Flusberg. Cambridge, MA: MIT Press, 1999.

- Zero Degrees of Empathy: A New Theory of Human Cruelty. London: Allen Lane, 2011.

Baron-Cohen, S. and P. Bolton. Autism: The Facts. Oxford: Oxford University Press, 2004.

Baron-Cohen, S. and J. Hammer. 'Is autism an extreme form of the male brain?' Advances in Infancy Research 11 (1997): 193-217.

. 'Parents of children with Asperger syndrome: What is the cognitive phenotype?' J Cogn Neurosci 9, no. 4 (1997): 548-554. 
Baron-Cohen, S., A. M. Leslie and U. Frith. 'Does the autistic child have a "theory of mind”?' Cognition 21, no. 1 (1985): 37-46.

Baron-Cohen, S., S. Lutchmaya and R. Knickmeyer. Prenatal Testosterone in Mind: Amniotic Fluid Studies. Cambridge, MA: MIT Press, 2004.

Baron-Cohen, S., F. J. Scott, C. Allison, J. Williams, P. Bolton, F. E. Matthews and C. Brayne. 'Prevalence of autism-spectrum conditions: UK schoolbased population study'. British Journal of Psychiatry 194, no. 6 (2009): 500509.

Baron-Cohen, S., S. Wheelwright, R. Skinner, J. Martin and E. Clubley. 'The autism-spectrum quotient (AQ): Evidence from Asperger syndrome/ high-functioning autism, males and females, scientists and mathematicians'. J Autism Dev Disord 31, no. 1 (2001): 5-17.

Bartak, L. and M. Rutter. 'Special educational treatment of autistic children: A comparative study - I: Design of study and characteristics of units'. Journal of Child Psychology and Psychiatry 14, no. 3 (1973): 161-179.

Bartak, L., M. Rutter and A. Cox. 'A comparative study of infantile autism and specific developmental receptive language disorders: III - Discriminant function analysis'. Journal of Autism and Developmental Disorders 7, no. 4 (1977): 383-396.

Bartolucci, G., S. Pierce, D. Streiner and P. T. Eppel. 'Phonological investigation of verbal autistic and mentally retarded subjects. J Autism Child Schizophr 6, no. 4 (1976): 303-316.

Bax, M. and K. Whitmore. 'Neurodevelopmental screening in the schoolentrant medical examination'. The Lancet 2, no. 7825 (1973): 368-370.

BBC. 'Blair stays mum on Leo and MMR'. BBC News Online, 19 December 2001. http://news.bbc.co.uk/1/hi/uk_politics/1719666.stm.

Becker, P. T. and E. B. Thoman. 'Rapid eye movement storms in infants: Rate of occurrence at 6 months predicts mental development at 1 year'. Science 212, no. 4501 (1981): 1415-1416.

Bell, N. W. and J. P. Spiegel. 'Social psychiatry: Vagaries of a term'. Archives of General Psychiatry 14, no. 4 (1966): 337-345.

Bello-Mojeed, M. A. and M. O. Bakare. 'Improving treatment of children with autism spectrum disorder in low- and middle-income countries: The role of non-specialist care providers'. PloS Med 10, no. 12 (2013): e1001573.

Benda, C. E. Developmental Disorders of Mentation and Cerebral Palsies. New York: Grune \& Stratton, 1952.

Benda, C. E., M. J. Farrell and C. E. Chipman. 'The inadequacy of present-day concepts in mental deficiency and mental illness in child psychiatry' American Journal of Psychiatry 107 (1951): 721-729.

Bender, L. 'The anal component in persecutory delusions'. Psychoanalytic Review 21 (1938): 75-85. 
'Autism in children with mental deficiency'. American Journal of Mental Deficiency 64, no. 1 (1959): 81-86.

—. 'Childhood schizophrenia'. Nervous Child 1 (1941): 138-140. 663-681.

. 'Clinical study of one hundred schizophrenic children'. American Journal of Orthopsychiatry 17 (1947): 40-56.

- 'Genesis of hostility in children'. American Journal of Psychiatry 105 (1948): 241-245.

- 'One hundred cases of childhood schizophrenia treated with electric shock'. Transactions of the American Neurological Association 72 (1947): 165-169.

- A Visual Motor Gestalt Test and Its Clinical Use. New York: American Orthopsychiatric Association, 1938.

Bender, L., G. Faretra, L. Cobrinik and D. V. Sankar. 'The treatment of childhood schizophrenia with LSD and UML'. In Biological Treatment of Mental Illness, edited by M. Rinkel. New York: L. C. Page \& Co., 1966.

Bender, L., A. M. Freedman, A. E. Gruggett and W. Helme. 'Schizophrenia in childhood: A confirmation of the diagnosis'. Transactions of the American Neurological Association 56 (1952): 67-73.

Bender, L., L. Goldschmidt and D. V. Sankar. 'Treatment of autistic schizophrenic children with LSD-25 and UML-491'. Recent Adv Biol Psychiatry 4 (1962): 170-179.

Berger, M., W. Yule and M. Rutter. 'Attainment and adjustment in two geographical areas: II - The prevalence of specific reading retardation'. British Journal of Psychiatry 126 (1975): 510-519.

Bergman, M., W. Heinz and J. Marchand. 'Schizophrenic reactions during childhood in mental defectives'. Psychiatric Quarterly 25 (1951): 294-333.

Berlucchi, G. and H. A. Buchtel. 'Neuronal plasticity: Historical roots and evolution of meaning'. Experimental Brain Research 192, no. 3 (2009): 307-319.

Berrios, G. E. 'Historical aspects of psychoses: 19th century issues'. British Medical Bulletin 43, no. 3 (1987): 484-498.

- The History of Mental Symptoms: Descriptive Psychopathology since the Nineteenth Century. Cambridge: Cambridge University Press, 1996.

' 'Retard mental et psychiatrie: Une histoire conceptuelle'. Revue Européenne du Handicap Mentale 25 (2003): 5-21.

Betz, B. J. 'A study of tactics for resolving the autistic barrier in psychotherapy of the schizophrenic personality'. American Journal of Psychiatry 104 (1947): 267-273. 
Bishop, D. V. M. and L. B. Leonard. Speech and Language Impairments in Children: Causes, Characteristics, Intervention and Outcome. Hove: Psychology Press, 2000.

Bleuler, E. Dementia Praecox oder Gruppe der Schizophrenien. Leipzig: Franz Deuticke, 1911.

- Dementia Praecox or the Group of Schizophrenias, translated by Joseph Zinkin. New York: International Universities, 1950.

Blum, D. Love at Goon Park: Harry Harlow and the Science of Affection. Chichester: Wiley, 2003.

Bolton, P., H. Macdonald, M. Murphy, S. Scott, M. Rutter et al. 'Genetic findings and heterogeneity in autism'. Psychiatric Genetics 2 (1991): 277-300.

Bolton, P., H. Macdonald, A. Pickles, P. Rios, S. Goode, M. Crowson, A. Bailey and M. Rutter. 'A case-control family history study of autism. J Child Psychol Psychiatry 35, no. 5 (1994): 877-900.

Bond, T. and A. Tryphon. 'Piaget and method'. In The Cambridge Companion to Piaget, edited by U. Muller, J. I. M. Carpendale and L. Smith. Cambridge: Cambridge University Press, 2009.

Borsay, A. 'Disability and education in historical perspective'. In Education, Disability and Social Policy, edited by S. Haines and D. Ruebain. Bristol: Policy, 2011.

Bowlby, J. Maternal Care and Mental Health. Geneva: World Health Organization, 1951.

Bowtell, O. 'The historical background'. In The Mentally Subnormal: Social Work Approaches, edited by M. Adams and H. Lovejoy. London: Heinemann Medical, 1972.

Bradley, C. Schizophrenia in Childhood. New York: Macmillan, 1941.

Brain, W. R. 'Speech and handedness'. The Lancet 246, no. 6383 (1945): 837-842.

Brask, B. H. 'A prevalence investigation of childhood psychosis'. Paper presented at the 16th Scandinavian Congress of Psychiatry, 1970.

Brearley, C. P. Admission to Residential Care. London: Tavistock, 1980.

Bridges, K. M. B. The Social and Emotional Development of the Pre-school Child. London: Kegan Paul Trench Trubner and Co., 1931.

Brodbeck, A. J. and O. C. Irwin. 'The speech behaviour of infants without families'. Child Development 17, no. 3 (1946): 145-156.

Brothers, L. 'The social brain: A project for integrating primate behaviour and neurophysiology in a new domain'. Concepts in Neuroscience 1 (1990): 27-61.

Brown, A. S., H. M. Surcel, S. Hinkka-Yli-Salomaki, K. Cheslack-Postava, Y. Bao and A. Sourander. 'Maternal thyroid autoantibody and elevated risk of autism in a national birth cohort'. Prog Neuropsychopharmacol Biol Psychiatry 57 (2015): 86-92. 
Brown, G. W. and M. Rutter. 'The measurement of family activities and relationships: A methodological study'. Human Relations 19 (1966): 241-263.

Brugha, T. S., L. Wing, J. Cooper and N. Sartorius. 'Contribution and legacy of John Wing, 1923-2010'. British Journal of Psychiatry 198, no. 3 (2011): 176-178.

Bryson, S. E., B. S. Clark and I. M. Smith. 'First report of a Canadian epidemiological study of autistic syndromes'. J Child Psychol Psychiatry 29, no. 4 (1988): 433-445.

Bühler, C. 'The social behaviour of children'. In A Handbook of Child Psychology, edited by C. Murchison. Worcester, MA: Clark University Press, 1931.

Burt, C. The Backward Child. London: University of London Press, 1937.

- Distribution and Relations of Educational Abilities. London: London County Council, 1917.

. 'The evidence for the concept of intelligence.' British Journal of Educational Psychology 25 (1955): 158-177.

- 'Is the doctrine of instincts dead? A symposium: I - The case for human instincts'. British Journal of Educational Psychology 11, no. 3 (1941): $155-172$.

. 'Is the doctrine of instincts dead? A symposium: VII - Conclusion'. British Journal of Educational Psychology 13, no. 1 (1943): 1-15.

- 'The measurement of intelligence by the Binet tests'. Eugenics Review 6 (1914).

- Mental and Scholastic Tests. London: P. S. King and Staples, 1921.

'Symposium on psychologists and psychiatrists in the child guidance service: VII - Conclusion'. British Journal of Educational Psychology 23, no. 1 (1953): 8-28.

Calame, A., I. Reymond-Goni, M. Maherzi, M. Roulet, C. Marchand and L. S. Prod'hom. 'Psychological and neurodevelopmental outcome of high risk newborn infants'. Helv Paediatr Acta 31, no. 4-5 (1976): 287-297.

Cameron, K. 'Diagnostic categories in child psychiatry'. British Journal of Medical Psychology 28 (1955): 67-71.

- 'Past and present trends in child psychiatry'. Journal of Mental Science 102 (1956): 599-603.

-. 'A psychiatric inpatient department for children'. Journal of Mental Science 95 (1949): 560-566.

- 'Psychoses in infancy and early childhood'. The Medical Press (1955): 280-283.

- 'Symptom classification in child psychiatry'. Acta Paedopsychiatrica 25, no. 6 (1958): 241-245. 
Campbell, D. B., D. Warren, J. S. Sutcliffe, E. B. Lee and P. Levitt. 'Association of MET with social and communication phenotypes in individuals with autism spectrum disorder. Am J Med Genet B Neuropsychiatr Genet 153B, no. 2 (2010): 438-446.

Carothers, J. C. The African Mind in Health and Disease: A Study in Ethnopsychiatry. Geneva: World Health Organization, 1953.

Casper, S. The Neurologists: A History of a Medical Speciality in Modern Britain c.1789-2000. Manchester: Manchester University Press, 2014.

Centers for Disease Control and Prevention [CDC]. Prevalence of Autism in Brick Township, New Jersey, 1998. Atlanta, GA: CDC, 2000.

Central Advisory Council for Education (England). Children and Their Primary Schools: A Report of the Central Advisory Council for Education, England. London: HMSO, 1967.

Chamak, B. 'Autism and social movements: French parents' associations and international autistic individuals' organisations'. Sociol Health Illn 30, no. 1 (2008): 76-96.

Chapman, M. Constructive Evolution: Origins and Development of Piaget's Thought. Cambridge: Cambridge University Press, 1988.

Chomsky, N. 'A review of B. F. Skinner's Verbal Behaviour [1958]'. In Structure of Language: Readings in the Philosophy of Language, edited by J. A. Fodor and J. T. Katz. Englewood Cliffs, NJ: Prentice-Hall, 1964.

'A transformational approach to syntax [1958]'. In Structure of Language: Readings in the Philosophy of Language, edited by J. A. Fodor and J. T. Katz. Englewood Cliffs, NJ: Prentice-Hall, 1964.

Cialdella, P. and N. Mamelle. 'An epidemiological study of infantile autism in a French department (Rhône): A research note'. Journal of Child Psychology and Psychiatry 30 (1989): 165-176.

Clardy, E. R. 'A study of the development and course of schizophrenia in children'. Psychiatric Quarterly 25, no. 1-4 (1951): 81-90.

Clardy, E. R. and E. M. Rumpf. 'The effect of electric shock treatment on children having schizophrenic manifestations'. Psychiatric Quarterly 28 (1954): 616-623.

Clark, E. A. History, Theory, Text: Historians and the Linguistic Turn. Cambridge, MA: Harvard University Press, 2004.

Clarke, A. D. B. and B. F. Hermelin. 'Adult imbeciles: Their abilities and trainability'. The Lancet 266, no. 6885 (1955): 337-339.

Clarke, E. and L. S. Jacyna. Nineteenth-Century Origins of Neuroscientific Concepts. Berkeley: University of California Press, 1987.

Claude, H., A. Borel and G. Robin. 'Démence précoce, schizopmanie at schizophrénie'. L'Encéphale 19, no. 3 (1924): 147-148. 
Cockburn, T. Rethinking Children's Citizenship. Houndmills: Palgrave Macmillan, 2013.

Cole, R., F. C. Shrubsall, E. Bramwell, A. Hall, A. S. MacNalty, P. C. P. Cloake, C. Worster-Drought, D. N. Hardcastle, E. Mapother, G. Forbes, H. Crichton Miller and A. Hutchinson. 'Discussion on the mental sequelae of encephalitis lethargica'. Proceedings of the Royal Society of Medicine 18, January (1925): 17-39.

Cole, T. Apart or a Part?: Integration and the Growth of British Special Education. Milton Keynes: Open University Press, 1989.

Coleman, M. and C. Gillberg. The Autisms, 4th edn. Oxford: Oxford University Press, 2012.

Collins, A. 'England'. In The Oxford Handbook of the History of Psychology: Global Perspectives, edited by D. B. Baker. Oxford: Oxford University Press, 2012.

Colvert, E., M. Rutter, J. Kreppner, C. Beckett, J. Castle, C. Groothues, A. Hawkins, S. Stevens and E. J. Sonuga-Barke. 'Do theory of mind and executive function deficits underlie the adverse outcomes associated with profound early deprivation?: Findings from the English and Romanian adoptees study'. J Abnorm Child Psychol 36, no. 7 (2008): 1057-1068.

Condon, W. S. and L. W. Sander. 'Neonate movement is synchronized with adult speech: Interactional participation and language acquisition'. Science 183, no. 4120 (1974): 99-101.

. 'Synchrony demonstrated between movements of neonate and adult speech. Child Dev 45, no. 2 (1974): 456-462.

Cook, E. H., R. Y. Courchesne, N. J. Cox, C. Lord, D. Gonen, S. J. Guter, A. Lincoln, K. Nix, R. Haas, B. L. Leventhal and E. Courchesne. 'Linkagedisequilibrium mapping of autistic disorder, with 15q11-13 markers'. Am J Hum Genet 62, no. 5 (1998): 1077-1083.

Cook, E. H., R. Courchesne, C. Lord, N. J. Cox, S. Yan, A. Lincoln, R. Haas, E. Courchesne and B. L. Leventhal. 'Evidence of linkage between the serotonin transporter and autistic disorder'. Mol Psychiatry 2, no. 3 (1997): $247-250$.

Cook, J. ‘Obituary: Lauretta Bender'. New York Times, 17 January 1987.

Cottington, F. 'The treatment of childhood schizophrenia by metrazol shock modified by b-erythroidin'. American Journal of Psychiatry 98, no. 3 (1941):397-400.

Crane, J. 'Painful times: The emergence and campaigning of parents against injustice in 1980s Britain'. 20 Century Br Hist 26, no. 3 (2015): 450-476.

Creak, M. 'Psychoses in childhood'. British Journal of Psychiatry 97, no. 408 (1951): 545-554. 
. 'Psychoses in children'. Proceedings of the Royal Society of Medicine 31 (1937): 519-528.

- 'Schizophrenic syndrome in childhood'. British Medical Journal (1961): 889-890.

Crichton Miller, H. The New Psychology and the Parent. London: Jarrolds, 1922.

Dales, L., S. J. Hammer and N. J. Smith. 'Time trends in autism and in MMR immunization coverage in California'. JAMA 285, no. 9 (2001): $1183-1185$.

Daley, T. C. 'The need for cross-cultural research on the pervasive developmental disorders'. Transcultural Psychiatry 39, no. 4 (2002): 531-550.

Danforth, S. The Incomplete Child: An Intellectual History of Learning Disabilities. Oxford: Peter Lang, 2009.

Dawson, W. S. Aids to Psychiatry. London: Bailliere, Tindall \& Cox, 1924.

De Jong, $\mathrm{H}$. and H. Baruk. La catatonie expérimentale par la bulbocapnine. Paris: Masson et Cie, 1930.

Denckla, M. B. 'New diagnostic criteria for autism and related behavioral disorders: Guidelines for research protocols'. J Am Acad Child Psychiatry 25, no. 2 (1986): 221-224.

Department of Education and Science (UK) and A. Summerfield. Psychologists in Education Services. London: HMSO, 1968.

Department of Health (UK). 'Medical Research Council to re-examine autism', 2001.

Derksen, M. 'Science in the clinic: Clinical psychology at the Maudsley'. In Psychology in Britain: Historical Essays and Personal Reflections, edited by G. D. Bunn, A. D. Lovie and G. D. Richards, pp. 267-289. Leicester: BPS Books, 2001.

Detrick, S., J. Doek and N. Cantwell. The United Nations Convention on the Rights of the Child: A Guide to the 'Travaux Préparatoires'. Dordrecht: Martinus Nijhoff, 1992.

Devanna, P. and S. C. Vernes. 'A direct molecular link between the autism candidate gene rora and the schizophrenia candidate mir137'. Sci Rep 4 (2014): 3994.

Dicks, H. V. 50 Years of the Tavistock Clinic. London: Routledge \& Kegan Paul, 1970.

Dickson, J. T. The Science and Practice of Medicine in Relation to Mind, the Pathology of Nerve Centres, and the Jurisprudence of Insanity: Being a Course of Lectures Delivered in Guy's Hospital. London: Lewis, 1874.

di Pellegrino, G., L. Fadiga, L. Fogassi, V. Gallese and G. Rizzolatti. 'Understanding motor events: A neurophysiological study'. Experimental Brain Research 91, no. 1 (1992): 176-180. 
Divan, G., V. Vajaratkar, M. U. Desai, L. Strik-Lievers and V. Patel. 'Challenges, coping strategies, and unmet needs of families with a child with autism spectrum disorder in Goa, India'. Autism Res 5, no. 3 (2012): 190-200.

Doll, E. A. Mental Deficiency Due to Birth Injuries. New York: Macmillan, 1932. dos Santos, P. A., D. Longo, A. P. Brandalize and L. Schuler-Faccini. 'Mthfr c677t is not a risk factor for autism spectrum disorders in South Brazil'. Psychiatr Genet 20, no. 4 (2010): 187-189.

Dowling, M. Young Children's Personal, Social and Emotional Development. London: Paul Chapman, 2000.

Dreosti, I. E. and R. M. Smith. Neurobiology of the Trace Elements, Vol. I. Clifton, NJ: Humana Press, 1983.

Drever, J. 'Is the doctrine of instincts dead? A symposium: IV - Instinct as impulse'. British Journal of Educational Psychology 12, no. 2 (1942): 88-96.

Drillien, C. M. and M. B. Drummond. Neurodevelopmental Problems in Early Childhood: Assessment and Management. Oxford: Blackwell Scientific, 1977.

Dror, O. E. 'Techniques of the brain and the paradox of emotions, 1880-1930'. Science in Context 14, no. 4 (2001): 643-660.

Duché, D.-J. Histoire de la psychiatrie de l'enfant. Paris: Presses Universitaires de France, 1990.

Dunae, P. 'Gender, generations and social class: The Fairbridge Society and British child migration to Canada, 1930-1960'. In Child Welfare and Social Action in the Nineteenth and Twentieth Centuries: International Perspectives, edited by J. Lawrence and P. Starkey, pp. 256-276. Liverpool: Liverpool University Press, 2001.

Durbin, E. F. M. and J. Bowlby. Personal Aggressiveness and War. London: Routledge \& Kegan Paul, 1939.

Dutta, S., S. Das, S. Guhathakurta, B. Sen, S. Sinha, A. Chatterjee, S. Ghosh, S. Ahmed, S. Ghosh and R. Usha. 'Glutamate receptor 6 gene (GLuR6 or GRIK2) polymorphisms in the Indian population: A genetic association study on autism spectrum disorder.' Cell Mol Neurobiol 27, no. 8 (2007): 1035-1047.

Dwork, D. War Is Good for Babies and Other Young Children: A History of the Infant and Child Welfare Movement in England 1898-1918. London: Tavistock, 1987.

Earl, C. J. C. 'The primitive catatonic psychosis of idiocy'. British Journal of Medical Psychology 14, no. 3 (1934): 230-253.

Egdell, H. G. and I. Kolvin. 'Childhood hallucinations'. Journal of Child Psychology and Psychiatry and Allied Disciplines 13, no. 4 (1972): 279-287.

Ehlers, S. and C. Gillberg. 'The epidemiology of Asperger syndrome: A total population study'. J Child Psychol Psychiatry 34, no. 8 (1993): 1327-1350. 
Eickhoff, L. F. W. 'The aetiology of schizophrenia in childhood'. British Journal of Psychiatry 98, no. 411 (1952): 229-234.

- 'Treatment of childhood schizophrenia'. British Journal of Psychiatry 101 (1955): 399-403.

Eldin, A. S., D. Habib, A. Noufal, S. Farrag, K. Bazaid, M. Al-Sharbati, H. Badr, S. Moussa, A. Essali and N. Gaddour. 'Use of m-chat for a multinational screening of young children with autism in the Arab countries'. Int Rev Psychiatry 20, no. 3 (2008): 281-289.

El-Kordi, A., D. Winkler, K. Hammerschmidt, A. Kastner, D. Krueger, A. Ronnenberg, C. Ritter, J. Jatho, K. Radyushkin, T. Bourgeron, J. Fischer, $\mathrm{N}$. Brose and $\mathrm{H}$. Ehrenreich. 'Development of an autism severity score for mice using nlgn4 null mutants as a construct-valid model of heritable monogenic autism. Behavioural Brain Research 251 (2013): 41-49.

Ellenberger, H. F. The Discovery of the Unconscious: The History and Evolution of Dynamic Psychiatry. London: Allen Lane, the Penguin Press, 1970.

Elsabbagh, M., G. Divan, Y. J. Koh, Y. S. Kim, S. Kauchali, C. Marcin, C. Montiel-Nava, V. Patel, C. S. Paula, C. Wang, M. T. Yasamy and E. Fombonne. 'Global prevalence of autism and other pervasive developmental disorders'. Autism Res 5, no. 3 (2012): 160-179.

Engstrom, E. 'Organising psychiatric research in Munich'. In International Relations in Psychiatry: Britain, Germany, and the United States to World War II, edited by V. Roelcke, P. Weindling and L. Westwood. Rochester, NY: University of Rochester Press, 2010.

Estecio, M., A. C. Fett-Conte, M. Varella-Garcia, C. Fridman and A. E. Silva. 'Molecular and cytogenetic analyses on Brazilian youths with pervasive developmental disorders'. J Autism Dev Disord 32, no. 1 (2002): 35-41.

Evans, B. and E. Jones. 'Organ extracts and the development of psychiatry: Hormonal treatments at the Maudsley Hospital 1923-1938. Journal of the History of the Behavioral Sciences 48, no. 3 (2012): 251-276.

Evans, B., S. Rahman and E. Jones. 'Managing the "unmanageable": Interwar child psychiatry at the Maudsley Hospital, London'. History of Psychiatry 19, no. 4 (2008): 454-475.

Evans, J. Personal, Social and Emotional Development: Seasonal Activities. Leamington Spa: Scholastic, 2001.

Evans, J., F. Castle and S. Barraclough. Making a Difference: Early Interventions for Children with Autistic Spectrum Disorders. London: National Foundation for Educational Research, 2001.

Ewing, A. W. G. Aphasia in Children. London: Oxford University Press, 1930.

Ewing, I. R. The Handicap of Deafness. London: Longmans, Green and Co., 1938. 
Eyal, G. 'For a sociology of expertise: The social origins of the autism epidemic'. American Journal of Sociology 118, no. 4 (2013): 863-907.

Eyal, G., B. Hart, E. Onculer, N. Oren and N. Rossi. The Autism Matrix. Cambridge: Polity, 2010.

Eysenck, H. J. Dimensions of Personality. London: Routledge \& Kegan Paul, 1947.

- Rebel with a Cause: The Autobiography of H. J. Eysenck. London: W. H. Allen, 1990.

Fairbairn, W. D. 'The repression and the return of bad objects'. British Journal of Medical Psychology 19, no. 3-4 (1943): 327-341.

Fanon, F. The Wretched of the Earth. Harmondsworth: Penguin Books, 1963.

Feinstein, A. A History of Autism: Conversations with the Pioneers. Oxford: Wiley-Blackwell, 2010.

Fenton, J. C. A Practical Psychology of Babyhood: The Mental Development and Mental Hygiene of the First Two Years of Life. New York: Houghton Mifflin, 1925.

Ferster, C. B. and M. K. DeMyer. 'The development of performances in autistic children in an automatically controlled environment'. Journal of Chronic Diseases April, no. 13 (1961): 312-345.

Fiddy, R. In Place of Work: Policy and Provision for the Young Unemployed. Lewes: Falmer, 1983.

Fildes, L. G. 'Some memory experiments with high-grade defectives'. British Journal of Psychology, General Section 14, no. 1 (1923): 39-56.

Fink, J. 'Inside a hall of mirrors: Residential care and the shifting constructions of childhood in mid-twentieth-century Britain'. Paedagogica Historica 44, no. 3 (2008): 287-307.

Fisher, J. and R. E. Harris, eds. Reinforcement Theory in Psychological Treatment: A Symposium. Sacramento, CA: Dept of Mental Hygiene, 1966.

Fisher, W., J. Kerbeshian and L. Burd. 'A treatable language disorder: Pharmacological treatment of pervasive developmental disorder'. J Dev Behav Pediatr 7, no. 2 (1986): 73-76.

Flapan, D. 'The ongoing journey of an extraordinary man in the field of group psychotherapy (an interview with Dr E. James Anthony)'. Group 6, no. 3 (1982): 49-59.

Folstein, S. E. and B. Rosen-Sheidley. 'Genetics of autism: Complex aetiology for a heterogeneous disorder'. Nature Reviews Genetics 2, no. 12 (2001): 943-955.

Fombonne, E. 'Epidemiology of pervasive developmental disorders'. Pediatr Res 65, no. 6 (2009): 591-598.

Fombonne, E., R. Zakarian, A. Bennett, L. Meng and D. McLeanHeywood. 'Pervasive developmental disorders in Montreal, Quebec, 
Canada:Prevalenceandlinkswithimmunizations'Pediatrics118,no.1(2006): e139-150.

Ford, J., D. Mongon and M. Whelan. Special Education and Social Control: Invisible Disasters. London: Routledge \& Kegan Paul, 1982.

Forrester, J. 'If $\mathrm{p}$, then what? Thinking in cases. History of the Human Sciences 9, no. 3 (1996): 1-25.

—_. '1919: Psychology and psychoanalysis, Cambridge and LondonMyers, Jones and Maccurdy'. Psychoanalysis and History 10, no. 1 (2008).

Fortes, M. 'Perceptual tests of general intelligence for inter-racial use'. Transactions of the Royal Society of South Africa 20, no. 3 (1932): 281-299.

Foucault, M. Folie et déraison: Histoire de la folie à l'âge classique. Paris: Plon, 1961.

Franklin, A. W. Children with Communication Problems: Proceedings of a Conference Called by the Invalid Children's Aid Association. London: Pitman, 1965.

Freedman, A. M. 'Childhood schizophrenia: Round table, 1953 - Maturation and its relation to the dynamics of childhood schizophrenia'. American Journal of Orthopsychiatry 24, no. 3 (1954): 487-491.

Freedman, A. M., E. V. Ebin and E. A. Wilson. 'Autistic schizophrenic children: An experiment in the use of d-lysergic acid diethylamide (LSD-25)'. Arch Gen Psychiatry 6 (1962): 203-213.

Freeman, B. J., E. R. Ritvo, D. Guthrie, P. Schroth and J. Ball. 'The behavior observation scale for autism: Initial methodology, data analysis, and preliminary findings on 89 children'. J Am Acad Child Psychiatry 17, no. 4 (1978): 576-588.

Freeman, B. J., E. R. Ritvo and P. C. Schroth. 'Behaviour assessment of the syndrome of autism: Behaviour observation system. Journal of American Academy of Child Psychiatry 23 (1984): 588-594.

Freeman, W. and J. W. Watts. 'Schizophrenia in childhood: Its modification by prefrontal lobotomy'. Digest of Neurology and Psychiatry (1947).

Freud, A. The Ego and the Mechanisms of Defence, translated by Cecil Baines. London: Hogarth, 1937.

Freud, S. The Freud-Jung Letters: The Correspondence between Sigmund Freud and C. G. Jung. London: Hogarth Press, 1974.

. The Standard Edition of the Complete Psychological Works of Sigmund Freud, 24 vols, Vol. VII. London: Vintage, 2001.

- The Standard Edition of the Complete Psychological Works of Sigmund Freud, 24 vols, Vol. XIV. London: Vintage, 2001.

- The Standard Edition of the Complete Psychological Works of Sigmund Freud, 24 vols, Vol. XXI. London: Vintage, 2001. 
Freud, S., G. Fichtner and L. Binswanger. The Sigmund Freud-Ludwig Binswanger Correspondence, 1908-1938. London: Open Gate Press, 2003 [originally published 1924].

Frith, C. D. 'The social brain?' Philos Trans R Soc Lond B Biol Sci 362, no. 1480 (2007): 671-678.

Frith, U. 'Autism'. Scientific American 268, no. 6 (1993): 108-114.

- Autism: Explaining the Enigma. Oxford: Basil Blackwell, 1989.

Autism: Explaining the Enigma, 2nd edn. New York: Blackwell, 2003.

'Autistic-children: New hope for cure - Tinbergen, N., Tinbergen, E.A.' [review]. Psychological Medicine 14, no. 2 (1984): 461-463.

- 'Cognitive mechanisms in autism: Experiments with color and tone sequence production'. Journal of Autism and Childhood Schizophrenia 2, no. 2 (1972): 160-173.

Frith, U. and C. Frith. 'The social brain: Allowing humans to boldly go where no other species has been'. Philos Trans R Soc Lond B Biol Sci 365, no. 1537 (2010): 165-176.

Frith, U. and B. Hermelin. 'The role of visual and motor cues for normal, subnormal and autistic children'. J Child Psychol Psychiatry 10, no. 3 (1969): 153-163.

Galison, P. 'Image of self'. In Things That Talk: Object Lessons from Art and Science, edited by L. Daston, pp. 257-298. New York: Zone, 2004.

Gardener, H., D. Spiegelman and S. L. Buka. 'Perinatal and neonatal risk factors for autism: A comprehensive meta-analysis'. Pediatrics 128, no. 2 (2011): 344-355.

Gardner, G. E. 'Childhood schizophrenia: Round table, 1953'. American Journal of Orthopsychiatry 24, no. 3 (1954): 517-521.

- 'The pseudo-psychotic nucleus in the behavior disorders'. American Journal of Orthopsychiatry 18, no. 2 (1948): 309-313.

Gardner, H. The Mind's New Science. New York: Basic, 1987.

Gerson, G. 'Individuality, deliberation and welfare in Donald Winnicott'. History of the Human Sciences 18, no. 1 (2005): 107-126.

Geschwind, D. H. and P. Levitt. 'Autism spectrum disorders: Developmental disconnection syndromes'. Current Opinion in Neurobiology 17, no. 1 (2007): 103-111.

Geschwind, N. and A. M. Galaburda. Cerebral Lateralization: Biological Mechanisms, Associations and Pathology. Cambridge, MA: MIT Press, 1987.

Gesell, A. The Mental Growth of the Pre-school Child. New York: Macmillan, 1925.

Gesell, A. and C. Amatruda. Developmental Diagnosis: Normal and Abnormal Child Development, Clinical Methods and Pediatric Applications, 2nd edn. New York: Hoeber, 1947.

. The Embryology of Behavior: The Beginnings of the Human Mind. New York: Harper, 1945. 
Gillberg, C. 'Clinical and neurobiological aspects of Asperger's syndrome in six family studies'. In Autism and Asperger Syndrome, edited by U. Frith. Cambridge: Cambridge University Press, 1991.

- 'Maternal age and infantile autism'. J Autism Dev Disord 10, no. 3 (1980): 293-297.

- 'Neurodevelopmental processes and psychological functioning in autism'. Dev Psychopathol 11, no. 3 (1999): 567-587.

Gillberg, C., E. Persson, M. Grufman and U. Themner. 'Psychiatric disorders in mildly and severely mentally retarded urban children and adolescents: Epidemiological aspects'. British Journal of Psychiatry 149 (1986): 68-74.

Gillberg, C., S. Steffenburg, B. Borjesson and L. Andersson. 'Infantile autism in children of immigrant parents: A population-based study from Goteborg, Sweden'. British Journal of Psychiatry 150 (1987): 856-858.

Gillberg, C., S. Steffenburg and H. Schaumann. 'Is autism more common now than ten years ago?' British Journal of Psychiatry 158 (1991): 403-409.

Gillberg, C. and L. Svennerholm. 'Csf monoamines in autistic syndromes and other pervasive developmental disorders of early childhood'. British Journal of Psychiatry 151 (1987): 89-94.

Gillies, S. M. 'Some abilities of psychotic children and subnormal controls'. Journal of Mental Deficiency Research 9 (1965).

Gindl, I., H. Hertzer and M. Sturm. 'Inadequacy of institutions as life space of infants. Z. angew Psychol 52 (1937): 310.

Glover, E. The Diagnosis and Treatment of Delinquency: Being a Clinical Report on the Work of the Institute during the Five Years 1937 to 1941. London: Institute for the Scientific Treatment of Delinquency, 1944.

- Psycho-analysis and Child Psychiatry. London: Imago Publishing Co., 1953.

- 'A psycho-analytic approach to the classification of mental disorders'. British Journal of Psychiatry 78, no. 323 (1932): 819-842.

Goldfarb, W. 'Effects of psychological deprivation in infancy and subsequent stimulation'. American Journal of Psychiatry 102 (1945): 18-33.

- 'Receptor preferences in schizophrenic children'. AMA Arch Neurol Psychiatry 76, no. 6 (1956): 643-652.

Golldberg, B. and H. A. Soper. 'Childhood psychosis or mental retardation: A diagnostic dilemma'. Canadian Medical Association Journal 89 (1963).

Gomes, P. T., L. H. Lima, M. K. Bueno, L. A. Araujo and N. M. Souza. 'Autism in Brazil: A systematic review of family challenges and coping strategies'. J Pediatr (Rio J) (2014). 
Goodenough, E. 'Interest in persons as an aspect of sex differences in the early years'. Genetic Psychology Monographs 55 (1957): 287-323.

Goodenough, F. L. Measurement of Intelligence by Drawings. Yonkers-onHudson: World Book Company, 1926.

Goodey, C. F. A History of Intelligence and 'Intellectual Disability': The Shaping of Psychology in Early Modern Europe. Farnham: Ashgate, 2011.

Gopnik, A. and A. Meltzoff. 'Imitation, cultural learning and the origins of theory of mind'. Behavioral and Brain Sciences 16, no. 3 (1993): 521-523.

Gould, S. J. The Mismeasure of Man. New York: Norton, 1996.

Graham, P. 'Creak, (Eleanor) Mildred (1898-1993)'. In Oxford Dictionary of National Biography (2004), online: www.oxforddnb.com/view/article/ 51812.

- Susan Isaacs: A Life Freeing the Minds of Children. London: Karnac, 2009.

Grob, G. N. From Asylum to Community: Mental Health Policy in Modern America. Princeton, NJ: Princeton University Press, 1991.

Guhathakurta, S., S. Ghosh, S. Sinha, A. Chatterjee, S. Ahmed, S. R. Chowdhury, P. K. Gangopadhyay, S. Ghosh, M. Singh and R. Usha. 'Serotonin transporter promoter variants: Analysis in Indian autistic and control population'. Brain Res 1092 (2006): 28-35.

Gulliford, R. Special Educational Needs. London: Routledge \& Kegan Paul, 1971.

Gurevitz, S. 'The total point of view in psychotherapy of schizophrenic children'. Psychoanalysis 1 (1952): 62-73.

Habermas, J. 'Towards a theory of communicative competence'. Inquiry: An Interdisciplinary Journal of Philosophy 13, no. 4 (1970): 360-375.

Hacking, I. 'Autism fiction: A mirror of an internet decade?' University of Toronto Quarterly 79, no. 2 (2010): 632-655.

- 'Autistic autobiography'. Philosophical Transactions of the Royal Society B: Biological Sciences 364, no. 1522 (2009): 1467-1473.

- 'How we have been learning to talk about autism: A role for stories'. Metaphilosophy 40, no. 3-4 (2009): 499-516.

- 'Humans, aliens \& autism'. Daedalus 138, no. 3 (2009): 44-59.

- Rewriting the Soul: Multiple Personality and the Sciences of Memory. Princeton, NJ: Princeton University Press, 1995.

. The Social Construction of What? Cambridge, MA: Harvard University Press, 1999.

- The Taming of Chance. Cambridge: Cambridge University Press, 1990.

Haddon, M. The Curious Incident of the Dog in the Night-time. Rothley: W. F. Howes Ltd, 2003. 
Happé, F. 'Autism and the concept of psychological normality', King's College London, 31 January 2013.

- Autism: An Introduction to Psychological Theory. London: UCL Press, 1994.

Happé, F., J. Briskman and U. Frith. 'Exploring the cognitive phenotype of autism: Weak "central coherence" in parents and siblings of children with autism: I - Experimental tests.' J Child Psychol Psychiatry 42, no. 3 (2001): 299-307.

Harms, E. 'Essential problems regarding our present knowledge of childhood schizophrenia'. Nervous Child 10 (1952): 7-8.

Harrington, A. Medicine, Mind and the Double Brain: A Study in NineteenthCentury Thought. Princeton, NJ: Princeton University Press, 1987.

Harris, B. The Health of the Schoolchild: A History of the School Medical Service in England and Wales. Buckingham: Open University Press, 1995.

Harris, J. C. Developmental Neuropsychiatry. Oxford: Oxford University Press, 1998.

Harris, M. and E. Bick. The Tavistock Model: Papers on Child Development and Psychoanalytic Training, rev. edn. London: Published for the Harris Meltzer Trust by Karnac, 2011.

Harris, P. 'Piaget in Paris: From "autism” to logic'. Human Development 40 (1997): 109-123.

Harris, R. 'The life and death of the care order (criminal)'. British Journal of Social Work 21, no. 1 (1991): 1-17.

Hassin, R. R., J. S. Uleman and J. A. Bargh. The New Unconscious. Oxford: Oxford University Press, 2005.

Hayes, C. The Ape in Our House. New York: Harper, 1951.

Hayward, R. 'Germany and the "making” of English psychiatry: The Maudsley Hospital 1908-1939'. In International Relations in Psychiatry: Britain, Germany, and the United States to World War II, edited by V. Roelcke, P. Weindling and L. Westwood. Rochester, NY: University of Rochester Press, 2010.

- 'Medicine and the mind'. In The Oxford Handbook of the History of Medicine, edited by M. Jackson. Oxford: Oxford University Press, 2011.

- 'Sadness in Camberwell: Imagining stress and constructing history'. In Stress, Shock, and Adaptation in the Twentieth Century, edited by D. Cantor and E. Ramsden. Rochester, NY: University of Rochester Press, 2014.

- 'The tortoise and the love-machine: Grey Walter and the politics of electroencephalography'. Science in Context 14, no. 4 (2001): 615-641.

. The Transformation of the Psyche in British Primary Care, 1870-1970, London: Bloomsbury, 2014. 
Hazlitt, V. 'Modern trends in infant psychology'. British Journal of Educational Psychology 1, no. 2 (1931): 119-129.

Head, H. Aphasia and Kindred Disorders of Speech. Cambridge: Cambridge University Press, 1926.

- Studies in Neurology, Vol. II. Oxford: Oxford Medical Publications, 1920.

Healy, D. The Anti-depressant Era. London: Harvard University Press, 1997.

. The Creation of Psychopharmacology. Cambridge, MA: Harvard University Press, 2002.

Hearnshaw, L. S. The Shaping of Modern Psychology. London: Routledge, 1987. . A Short History of British Psychology 1840-1940. London: Methuen \& Co., 1964.

Heimann, P. 'Some aspects of the role of introjection and projection in early development: 1943'. In The Freud-Klein Controversies, 1941-45, edited by P. King and R. Steiner, pp. 501-530. London: Tavistock/Routledge, 1991.

Held, R. 'Plasticity in sensory-motor systems'. Scientific American 213, no. 5 (1965): 84-94.

Henderson, D. and W. Gillespie. A Text-Book of Psychiatry for Students and Practitioners. London: Humphrey Milford, 1927.

Hendrick, H. 'Child labour: Medical capital and the School Medical Service, c.1890-1918'. In In the Name of the Child: Health and Welfare, 1880-1940, edited by R. Cooter. London: Routledge, 1992.

- Child Welfare: England 1872-1989. London: Routledge, 1994.

Child Welfare and Social Policy: An Essential Reader. Bristol: Policy Press, 2005.

. 'Optimism and hope versus anxiety and narcissism: Some thoughts on children's welfare yesterday and today'. History of Education 36, no. 6 (2007): 747-768.

Herd, H. The Diagnosis of Mental Deficiency.London: Hodder \& Stoughton, 1930.

Hermelin, B. 'Coding and immediate recall in autistic children'. Proceedings of the Royal Society of Medicine 60 (1967): 563-564.

- Concept Learning and Verbalisation in Imbeciles. $\mathrm{PhD}$ thesis, University of London Institute of Psychiatry, 1958.

. 'Images and language'. In Autism: A Reappraisal of Concepts and Treatment, edited by M. Rutter and E. Schopler. London: Plenum Press, 1978.

Hermelin, B. and U. Frith. 'Psychological studies of childhood autism: Can autistic children make sense of what they see and hear'. Journal of Special Education 5, no. 2 (1971): 107-117.

Hermelin, B. and N. O'Connor. 'Crossmodal transfer in normal, subnormal and autistic children'. Neuropsychologica 2 (1964). 
. 'Effects of sensory input and sensory dominance on severely disturbed autistic children and on subnormal controls'. British Journal of Psychology 55, no. 2 (1964).

. 'Measures of distance and motility in psychotic children and severely subnormal controls'. British Journal of Social and Clinical Psychology 3 (1963): 29-33. 1970.

- 'Remembering of words by psychotic and subnormal children'. British Journal of Psychology 58, no. 3-4 (1967).

- 'The response and self-generated behaviour of severely disturbed children and severely subnormal controls'. British Journal of Social and Clinical Psychology 2 (1963).

- 'The selective visual attention of psychotic children'. Journal of Child Psychology and Psychiatry 8 (1967): 167-179.

Heron, J., J. Golding and Alspac Study Team. 'Thimerosal exposure in infants and developmental disorders: A prospective cohort study in the United Kingdom does not support a causal association. Pediatrics 114, no. 3 (2004): 577-583.

Hersov, L. 'Child psychiatry in Britain: The last thirty years'. Journal of Child Psychology and Psychiatry 27, no. 6 (1986): 781-801.

Hewett, J. M. 'Teaching speech to an autistic child through operant conditioning. American Journal of Orthopsychiatry 35 (1965): 927-936.

Hidalgo, N. J., L. L. McIntyre and E. H. McWhirter. 'Sociodemographic differences in parental satisfaction with an autism spectrum disorder diagnosis'. J Intellect Dev Disabil 40, no. 2 (2015): 147-155.

Hilliard, L. T. '(b) mental deficiency aspects'. Journal of the Royal Society for the Promotion of Health 78, no. 4 (1958): 377-392.

Hilliard, L. T. and B. H. Kirman. Mental Deficiency. London: Churchill, 1957.

Hirschberg, J. C. 'The role of education in the treatment of emotionally disturbed children through planned ego development.' American Journal of Orthopsychiatry 23, no. 4 (1953): 684-690.

HM Government. Children Act 1989. London: HMSO, 1989, chapter 41. - Report of the Committee on Maladjusted Children (The Underwood Report). London: HMSO, 1955.

Hobson, R. P. Autism and the Development of Mind. Hove: Lawrence Erlbaum, 1993.

- 'Early-childhood autism and the question of egocentrism'. Journal of Autism and Developmental Disorders 14, no. 1 (1984): 85-104. 
Hollin, G. 'Constructing a social subject: Autism and human sociality in the 1980s.' History of the Human Sciences 27, no. 4 (2014): 98-115.

Hollin, G. J. S. and A. Pilnick. 'Infancy, autism, and the emergence of a socially disordered body'. Soc Sci Med 143 (2015): 279-286.

Holloway, G. Women and Work in Britain since 1840. London: Routledge, 2005.

Holovinskyi, I. Z. Psychology in Ukraine: A Historical Perspective. Lanham, MD: University Press of America, 2008.

Holt, R. and J. Turner. Political Parties in Action: The Battle of Barons Court. London: Collier-Macmillan, 1968.

Honda, H., Y. Shimizu, K. Misumi, M. Niimi and Y. Ohashi. 'Cumulative incidence and prevalence of childhood autism in children in Japan'. British Journal of Psychiatry 169, no. 2 (1996): 228-235.

Honda, H., Y. Shimizu and M. Rutter. 'No effect of MMR withdrawal on the incidence of autism: A total population study'. J Child Psychol Psychiatry 46, no. 6 (2005): 572-579.

Horton, R. 'The lessons of MMR'. The Lancet 363, no. 9411 (2004): 747-749.

Horwitz, A. V. Creating Mental Illness. Chicago, IL: University of Chicago Press, 2002.

Howlin, P. 'The effectiveness of operant language training with autistic children'. Journal of Autism and Developmental Disorders 11, no. 1 (1981): 89-105.

Hurt, J. S. Outside the Mainstream. London: Batsford, 1988.

Husserl, E. Cartesian Meditations, translated by D. Cairns. The Hague: Martinus Nijhoff, 1977 [originally published 1931].

Igwe, M. N., A. C. Ahanotu, M. O. Bakare, J. U. Achor and C. Igwe. 'Assessment of knowledge about childhood autism among paediatric and psychiatric nurses in Ebonyi State, Nigeria. Child Adolesc Psychiatry Ment Health 5, no. 1 (2011): 1 .

Igwe, M. N., M. O. Bakare, A. O. Agomoh, G. M. Onyeama and K. O. Okonkwo. 'Factors influencing knowledge about childhood autism among final year undergraduate medical, nursing and psychology students of University of Nigeria, Enugu State, Nigeria'. Ital J Pediatr 36 (2010): 44.

Ingram, T. T. S. 'Specific developmental disorders of speech in childhood'. Brain 82, no. 3 (1959): 450-467.

Institute of Psychiatry. Annual Report, 1950-1951. London: University of London British Postgraduate Medical Federation, 1951.

Annual Report, 1951-1952. London: University of London British Postgraduate Medical Federation, 1952.

- Annual Report, 1964-1965. London: University of London British Postgraduate Medical Federation, 1965. 
Institute for Research into Mental Retardation and M. Rutter. Infantile Autism: Concepts, Characteristics and Treatment. London: Churchill Livingstone, 1971.

Ireton, $\mathrm{H}$. 'The Draw a Man test as an index of developmental disorders in a paediatric outpatient population'. Child Psychiatry and Human Development 2, no. 1 (1971): 42-49.

Isaacs, $S$. 'An acute psychotic anxiety occurring in a boy of 4 years'. International Journal of Psychoanalysis 24 (1943): 13-32.

'Anxiety in the first year of life.' Talk given at the British Psychoanalytical Society, London, 1934.

- Intellectual Growth in Young Children. London: Routledge \& Kegan Paul, 1930.

- 'The nature and function of phantasy: 1943'. In The Freud-Klein Controversies, 1941-45, edited by P. King and R. Steiner, pp. 264-321. London: Tavistock/Routledge, 1991.

- Social Development in Young Children: A Study of Beginnings. London: George Routledge \& Sons Ltd, 1933.

Isaacs, S. S., S. C. Brown and R. H. Thouless, eds. The Cambridge Evacuation Survey: A Wartime Study in Social Welfare and Education. London: Methuen \& Co., 1941.

Isaacs, W., J. Thomas and I. Goldiamond. 'Application of operant conditioning to reinstate verbal behavior in mute psychotics'. Journal of Abnormal Psychology 70 (1960): 155-164.

Isaksen, J., T. H. Diseth, S. Schjolberg and O. H. Skjeldal. 'Autism spectrum disorders: Are they really epidemic?' Eur J Paediatr Neurol 17, no. 4 (2013): 327-333.

Jackson, B. 'The think-tank archipelago: Thatcherism and neo-liberalism'. In Making Thatcher's Britain, edited by B. Jackson and R. Saunders. Cambridge: Cambridge University Press, 2012.

Jackson, L. Child Treatment and the Therapy of Play. London: Methuen \& Co., 1946.

- ' "Non-speaking” children'. British Journal of Medical Psychology 23, no. 1-2 (1950): 87-100.

Jackson, M. The Borderland of Imbecility: Medicine, Society, and the Fabrication of the Feeble Mind in Late Victorian and Edwardian England. Manchester: Manchester University Press, 2000.

Jamain, S., C. Betancur, H. Quach, A. Philippe, M. Fellous, B. Giros, C. Gillberg, M. Leboyer, T. Bourgeron and Study Paris Autism Research International Sibpair. 'Linkage and association of the glutamate receptor 6 gene with autism.' Mol Psychiatry 7, no. 3 (2002): 302-310. 
Janet, P. M. F. and F. Raymond. Les obsessions et la psychasthenie. Paris: Alcan, 1903.

Jennings, H. The Private Citizen in Public Social Work: An Account of the Voluntary Children's Care Committee System in London. London: Unwin Brothers, 1930.

Jones, G. Social Darwinism and English Thought: The Interaction between Biological and Social Theory. Brighton: Harvester, 1980.

Jones, K. A History of the Mental Health Services. London: Routledge \& Kegan Paul, 1972.

. Taming the Troublesome Child. London: Harvard University Press, 1999.

Jones, M. Social Psychiatry: A Study of Therapeutic Communities, with a foreword by Professor Aubrey Lewis. London: Tavistock Publications and Routledge \& Kegan Paul, 1952.

Joynson, R. B. The Burt Affair. London: Routledge, 1989.

Jung, C. G. Psychological Types; or, The Psychology of Individuation. London: Routledge \& Kegan Paul, 1923 [originally published 1921].

Kahn, J. H. 'The local authority child guidance clinic.' The Lancet 279, no. 7236 (1962): 959-960.

Kallman, F., S. E. Barrera, P. H. Hoch and D. M. Kelley. 'The role of mental deficiency in the incidence of schizophrenia'. American Journal of Mental Deficiency 45 (1941): 514-539.

Kanner, L. 'Autistic disturbances of affective contact'. Nervous Child 2 (1943): 217-250.

. 'Childhood psychosis: A historical overview'. Journal of Autism and Childhood Schizophrenia 1, no. 1 (1971): 14-19.

. Child Psychiatry. Baltimore: Charles C. Thomas, 1935.

. 'The conception of wholes and parts in early infantile autism'. American Journal of Psychiatry 108 (1951): 23-26.

. 'Emotional interference with intellectual functioning'. American Journal of Mental Deficiency 56, no. 4 (1952): 701-707.

- 'Infantile autism and the schizophrenias'. Behavioral Science 10, no. 4 (1965): 412-420.

Kanner, L. and L. Eisenberg. 'Early infantile autism'. American Journal of Orthopsychiatry 26 (1956): 556-566.

Kasanin, J. and M. R. Kaufmann. 'A study of the functional psychoses in childhood'. American Journal of Psychiatry 9 (1929): 307-384.

Kawamura, Y., O. Takahashi and T. Ishii. 'Reevaluating the incidence of pervasive developmental disorders: Impact of elevated rates of detection through implementation of an integrated system of screening in Toyota, Japan'. Psychiatry Clin Neurosci 62, no. 2 (2008): 152-159. 
Kaye, J. A., M. del Mar Melero-Montes and H. Jick. 'Mumps, measles, and rubella vaccine and the incidence of autism recorded by general practitioners: A time trend analysis'. British Medical Journal 322, no. 7284 (2001): 460-463.

Kellmer-Pringle, M. L. K. 11,000 Seven-Year Olds: First Report of the National Child Development Study (1958 Cohort). London: Longmans, 1966.

Kestenberg, J. S. 'The history of an autistic child: Clinical data and interpretation. J Child Psychiatry, no. 1 (1954): 5-52.

. 'Pseudo-schizophrenia in childhood and adolescence'. Nervous Child 10, no. 1 (1952): 146-162.

Kier, G. 'A history of child guidance'. British Journal of Educational Psychology 22, no. 1 (1952): 5-29.

Kihlstrom, J. F. 'The cognitive unconscious'. Science 237, no. 4821 (1987): 1445-1452.

King, P. 'Background and development of the Freud-Klein controversies on the British Psychoanalytic Society'. In The Freud-Klein Controversies, 194145, edited by P. King and R. Steiner, pp. 9-36. London: Tavistock/Routledge, 1991.

King, P. and R. Steiner, eds. The Freud-Klein Controversies, 1941-45. London: Tavistock/Routledge, 1991.

Kirby, D. Evidence of Harm: Mercury in Vaccines and the Autism Epidemic A Medical Controversy. New York: St. Martin’s Press, 2005.

Kirman, B. 'Autistic children'. British Medical Journal 3, no. 5567 (1967): 727. - Mental Handicap: A Brief Guide. London: Crosby Lockwood Staples, 1975.

- The Mentally Handicapped Child. London: Nelson, 1972.

. 'Mentally handicapped persons'. British Medical Journal 4, no. 5632 (1968): 687-690.

- Mental Retardation: Some Recent Developments in the Study of Causes and Social Effects of This Problem. London: Pergamon Press, 1968.

- Science and Psychiatry: Problems of the Scientific Approach to Mental Disorder. London: Lawrence \& Wishart, 1968.

Kirman, B. H. and C. M. B. Pare. 'Amine-oxidase inhibitors as possible treatment for phenylketonuria'. The Lancet 277, no. 7168 (1961): 117.

Klauck, S. M., F. Poustka, A. Benner, K. P. Lesch and A. Poustka. 'Serotonin transporter (5-HTT) gene variants associated with autism?' Hum Mol Genet 6, no. 13 (1997): 2233-2238.

Klein, M. 'A contribution to the psychogenesis of manic-depressive states'. International Journal of Psychoanalysis 16 (1935): 145-175.

. 'A contribution to the theory of intellectual inhibition'. International Journal of Psychoanalysis 12 (1931): 206-218. 
'Criminal tendencies in normal children' [1927]. In Love, Guilt and Reparation and Other Works 1921-1945. New York: Free Press, 1975.

. 'The emotional life and ego development of the infant with special reference to the depressive position: 1944'. In The Freud-Klein Controversies, 1941-45, edited by P. King and R. Steiner, pp. 752-797. London: Tavistock/ Routledge, 1991.

- 'The importance of symbol-formation in the development of the ego'. International Journal of Psychoanalysis 11 (1930): 24-39.

. 'Personification in the play of children'. International Journal of Psychoanalysis 10 (1929): 193-204.

- 'The psychological principles of infant analysis'. International Journal of Psychoanalysis 8 (1927): 25-38.

- 'The psychotherapy of the psychoses (IV)'. British Journal of Medical Psychology 10, no. 3 (1930): 242-244.

Klein, M., P. Heimann and R. E. Money-Kyrle, eds. New Directions in Psychoanalysis: The Significance of Infant Conflict in the Pattern of Adult Behaviour. London: Tavistock, 1955.

Kleinman, A. M. 'Depression, somatization and the "new cross-cultural psychiatry"'. Soc Sci Med 11, no. 1 (1977): 3-10.

Klerman, G. L., G. E. Vaillant, R. L. Spitzer and R. Michels. 'A debate on DSMIII. American Journal of Psychiatry 141, no. 4 (1984): 539-554.

Kolvin, I. 'Psychoses in childhood: A comparative study'. In Infantile Autism: Concepts, Characteristics and Treatment, edited by M. Rutter, pp. 7-26. London: Churchill Livingstone, 1971.

Kramer, P. D. Listening to Prozac. London: Fourth Estate, 1994.

Kramer, Y., R. Rabkin and R. L. Spitzer. 'Whirling as a clinical test in childhood schizophrenia'. Journal of Pediatrics 52, no. 3 (1958): 295-303.

Krug, D. A., J. Arick and P. Almond. 'Behaviour checklist for identifying severely handicapped individuals with high levels of autistic behaviour'. Journal of Child Psychology and Psychiatry 21 (1980): 221-229.

Kubie, L. S. 'Edward Glover: A biographical sketch'. International Journal of Psychoanalysis 54 (1973): 85-93.

Kugelmass, I. N. Management of Mental Deficiency in Children. New York: Grune \& Stratton, 1954

Kushlik, A. 'Social problems of mental subnormality'. In Foundations of Child Psychiatry, edited by E. Miller. Oxford: Pergamon Press, 1968.

Kutchins, H. and S. A. Kirk. Making Us Crazy: DSM - The Psychiatric Bible and the Creation of Mental Disorders. London: Constable, 1999.

Lay, R. A. Q. 'Schizophrenia-like psychoses in young children'. Journal of Mental Science 84 (1938): 105-133. 
Leach, B. J. Personal, Social and Emotional Development. Leamington Spa: Scholastic, 2003.

Le Couteur, A., M. Rutter, C. Lord, P. Rios, S. Robertson, M. Holdgrafer and J. McLennan. 'Autism diagnostic interview: A standardised investigatorbased instrument'. Journal of Autism and Developmental Disorders 19, no. 3 (1989): 363-387.

Lee, J. Y., M. Kwak and P. C. W. Lee. 'Impairment of social behavior and communication in mice lacking the uba6-dependent ubiquitin activation system. Behavioural Brain Research 281 (2015): 78-85.

Leonard, H., G. Dixon, A. J. O. Whitehouse, J. Bourke, K. Aiberti, N. Nassar, C. Bower and E. J. Glasson. 'Unpacking the complex nature of the autism epidemic'. Research in Autism Spectrum Disorders 4, no. 4 (2010): 548-554.

Lesch, K. P., D. Bengel, A. Heils, S. Z. Sabol, B. D. Greenberg, S. Petri, J. Benjamin, C. R. Muller, D. H. Hamer and D. L. Murphy. 'Association of anxietyrelated traits with a polymorphism in the serotonin transporter gene regulatory region'. Science 274, no. 5292 (1996): 1527-1531.

Leslie, A. M. and U. Frith. 'Autistic children's understanding of seeing, knowing and believing. British Journal of Developmental Psychology 6 (1988): $315-324$.

Leslie, A. M. and L. Thaiss. 'Domain specificity in conceptual development: Neuropsychological evidence from autism. Cognition 43, no. 3 (1992): 225-251.

Le Vann, L. J. 'A concept of schizophrenia in the lower grade mental defective'. American Journal of Mental Deficiency 54 (1950): 469-472.

Levene, A. "Family breakdown and the "welfare child" in 19th and 20th century Britain'. History of the Family 11, no. 2 (2006): 67-79.

Lewis, J. 'Anxieties about the family and the relationships between parents, children and the state in twentieth century England'. In Children of Social Worlds: Development in a Social Context, edited by M. Richards and P. Light. Cambridge, MA: Harvard University Press, 1986.

Li, N., G. Chen, X. Song, W. Du and X. Zheng. 'Prevalence of autism-caused disability among Chinese children: A national population-based survey'. Epilepsy Behav 22, no. 4 (2011): 786-789.

Lickorish, J. R. 'Psychological tests in child psychiatry'. In Modern Perspectives in Child Psychiatry, edited by J. G. Howells. Oliver \& Boyd: Edinburgh \& London, 1965.

Light, P., S. Sheldon and M. Woodhead. Child Development in Social Context, Vol. II: Learning to Think. London: Routledge, in association with the Open University, 1991.

Likierman, M. Melanie Klein: Her Work in Context. London: Continuum, 2001. 
Lindsay, G. Screening for Children with Special Needs: Multidisciplinary Approaches. London: Croom Helm, 1984.

Lipsitt, L. P. 'Learning in the first year of life'. In Advances in Child Development and Behavior, Vol. I, edited by L. P. Lipsitt and H. W. Reese. New York: Academic Press, 1963.

Littlewood, R. 'From categories to contexts: A decade of the "new cross-cultural psychiatry". British Journal of Psychiatry 156 (1990): 308-327.

Loosli-Usteri, $\mathrm{M}$. 'Le test de Rorschach appliqué à différents groupes d'enfants de 10-13 ans'. Archives of Psychology 22 (1929): 51.

Lombardo and Foschi, 'Escape from the dark forest', 48.

Lord, C., M. Rutter, S. Goode, J. Heemsbergen, H. Jordan, L. Mawhood and E. Schopler. 'Autism diagnostic observation schedule: A standardized observation of communicative and social behavior.' Journal of Autism and Developmental Disorders 19, no. 2 (1989): 185-212.

Losh, M. and J. Piven. 'Social-cognition and the broad autism phenotype: Identifying genetically meaningful phenotypes.' J Child Psychol Psychiatry 48, no. 1 (2007): 105-112.

Lotter, V. 'Childhood autism in Africa'. J Child Psychol Psychiatry 19, no. 3 (1978): 231-244.

. 'Cross cultural perspectives on childhood autism. J Trop Pediatr 26, no. 4 (1980): 131-133.

. 'Epidemiology of autistic conditions in young children'. Social Psychiatry 1, no. 3 (1966): 124-137.

Lovaas, O. I. 'A program for the establishment of speech in psychotic children'. In Early Childhood Autism: Clinical, Educational and Social Aspects, edited by J. K. Wing, pp. 3-50. London: Pergamon Press, 1966.

Lovaas, O. I.,J. P. Berberich, B. F. Perloff and B. Schaeffer. Acquisition of imitative speech by schizophrenic children'. Science 151, no. 3711 (1966): 705-707.

Lovaas, O. I., B. Shaeffer and J. Q. Simmons. 'Building social behaviour in autistic children by use of electric shock'. Journal of Experimental Research in Personality 1 (1965): 99-109.

Lowenfeld, M. F. 'A combined approach to the study and treatment of disturbed children, as carried out at the Institute of Child Psychology in London, England'. American Journal of Psychotherapy 4 (1950): 627-642.

. Play in Childhood. London: Gollancz, 1935.

Lowenfeld, M., C. Urwin and J. Hood-Williams. Child Psychotherapy, War and the Normal Child. London: Free Association Books, 1988.

Lubetsky, M. J., B. L. Handen and J. J. McGonigle. Autism Spectrum Disorder. Oxford: Oxford University Press, 2011. 
Lunbeck, E. The Psychiatric Persuasion. Princeton, NJ: Princeton University Press, 1994.

Lykken, D. T. and P. H. Venables. 'Direct measurement of skin conductance: A proposal for standardization'. Psychophysiology 8, no. 5 (1971): 656-672.

Madsen, K. M., A. Hviid, M. Vestergaard, D. Schendel, J. Wohlfahrt, P. Thorsen, J. Olsen and M. Melbye. 'A population-based study of measles, mumps, and rubella vaccination and autism. $N$ Engl J Med 347, no. 19 (2002): 1477-1482.

Madsen, K. M., M. B. Lauritsen, C. B. Pedersen, P. Thorsen, A. M. Plesner, P. H. Andersen and P. B. Mortensen. 'Thimerosal and the occurrence of autism: Negative ecological evidence from Danish population-based data' Pediatrics 112, no. 3 (2003): 604-606.

Maestrini, E., C. Lai, A. Marlow, N. Matthews, S. Wallace, A. Bailey, E. H. Cook, D. E. Weeks, A. P. Monaco and Int Molecular Genetic Study Autism Consortium. 'Serotonin transporter (5-HTT) and gammaaminobutyric acid receptor subunit beta 3 (GABRB3) gene polymorphisms are not associated with autism in the IMGSA families'. Am J Med Genet 88, no. 5 (1999): 492-496.

Magnusson, P. and E. Sæmundsen. 'Prevalence of autism in Iceland'. Journal of Autism and Developmental Disorders 31, no. 153 (2001).

Mahler, M. 'On child psychosis and schizophrenia: Autistic and symbiotic infantile psychoses'. Psychoanalytic Study of the Child 1 (1952): 286-305.

- 'Remarks on psychoanalysis with psychotic children'. Quarterly Journal of Child Behavior 1 (1949): 18-21.

Mahler, M., J. R. Ross, Jr and Z. E. Fries. 'Clinical studies in benign and malignant cases of childhood psychosis (schizophrenia-like)'. American Journal of Orthopsychiatry 19 (1949): 295-305.

Malin, N. Services for the Mentally Handicapped in Britain. London: Croom Helm, 1980.

Malster, R. St Lawrence's: The Story of a Hospital, 1870-1994. Caterham: Lifecare NHS Trust, 1994.

Marks, L. 'Medical care for pauper mothers and their infants: Poor Law provision and local demand in East London, 1870-1929'. Economic History Review 46, no. 3 (1993): 518-542.

- Sexual Chemistry: A History of the Contraceptive Pill. New Haven, CT: Yale University Press, 2010.

Martin, J. A. M. 'Sensory disorder in the autistic child and its implications for treatment'. In Infantile Autism: Concepts, Characteristics and Treatment, edited by M. Rutter. London: Churchill Livingstone, 1971. 
Mayes, R. and A. V. Horwitz. 'DSM-III and the revolution in the classification of mental illness'. Journal of the History of Behavioural Sciences 41 (2005): 249.

McCarthy, J. J. and S. A. Kirk. Illinois Test of Psycholinguistic Abilities. Urbana: University of Illinois, 1961.

McDougall, W. An Introduction to Social Psychology. London: Methuen \& Co., 1908.

- An Introduction to Social Psychology, 23rd edn. London: Methuen, 1936.

McGuinness, D. and K. Pribram. 'The origins of sensory bias in the development of gender differences in perception and cognition'. In Cognitive Growth and Development: Essays in Memory of Herbert G. Birch, edited by H. G. Birch and M. Bortner. New York: Brunner/Mazel, 1979.

Mackintosh, N. J. Cyril Burt: Fraud or Framed? Oxford: Oxford University Press, 1995.

MacMeeken, M. Ocular Dominance in Relation to Developmental Aphasia. London: University of London Press, 1939.

Mead, M. 'The primitive child'. In A Handbook of Child Psychology, edited by C. Murchison, pp. 669-687. Worcester, MA: Clark University Press, 1931.

Mehr, H. 'The application of psychological tests and methods to schizophrenia in childhood'. Nervous Child 10 (1952): 63-93.

Merleau-Ponty, M. Phénoménologie de la perception. Paris: Gallimard, 1987 [originally published 1945].

Meyer, U., J. Feldon and O. Dammann. 'Schizophrenia and autism: Both shared and disorder-specific pathogenesis via perinatal inflammation?' Pediatr Res 69, no. 5 Pt 2 (2011): 26R-33R.

Meyers, D. 'Obituary: William Goldfarb'. International Journal of Psychoanalysis 78 (1997): 391-392.

Miller, E. The Growing Child and Its Problems. London: Kegan Paul Trench Trubner \& Co. Ltd, 1937.

. 'The problem of classification in child psychiatry'. In Foundations of Child Psychiatry, edited by E. Miller, pp. 251-269. Oxford: Pergamon Press, 1968.

Miller, P. and N. S. Rose. 'The Tavistock Programme: The government of subjectivity and social life'. Sociology 22 (1988): 171-192.

Minton, J., M. Campbell, W. H. Green, S. Jennings and C. Samit. 'Cognitive assessment of siblings of autistic children'. J Am Acad Child Psychiatry 21, no. 3 (1982): 256-261.

Mittler, P. 'Obituary: Stanley Segal'. The Independent, 9 July 1994. 
'Opening remarks to discussion'. In Infantile Autism: Concepts, Characteristics and Treatment, edited by M. Rutter, pp. 137-146. London: Churchill Livingstone, 1971.

- 'Psychological assessment'. In Early Childhood Autism: Clinical, Educational and Social Aspects, edited by J. K. Wing. London: Pergamon, 1966.

Monroe, W. S. 'Discussion and reports: Social consciousness in children'. Psychological Review 15 (1898): 68-70.

Montague, J. A. 'Spontaneous drawings of the human form in childhood schizophrenia' In An Introduction to Projective Techniques, edited by H. H. Anderson and G. L. Anderson. New York: Prentice Hall, 1951.

Moore, T., C. B. Hindley and F. Falkner. 'A longitudinal research in child development and some of its problems'. British Medical Journal 2, no. 4897 (1954): 1132-1137.

Moreno, J. D. Undue Risk: Secret State Experiments on Humans. Basingstoke: W. H. Freeman, 1999.

Moreno-De-Luca, D., S. J. Sanders, A. J. Willsey, J. G. Mulle, J. K. Lowe, D. H. Geschwind, M. W. State, C. L. Martin and D. H. Ledbetter. 'Using large clinical data sets to infer pathogenicity for rare copy number variants in autism cohorts. Mol Psychiatry 18, no. 10 (2013): 1090-1095.

Morley, M. E. The Development and Disorders of Speech in Childhood. London: E. \& S. Livingstone, 1957.

Morton, J. 'The origins of autism'. New Scientist, 9 December 1989.

Moskowitz, A. 'Pierre Janet's influence on Bleuler's concept of schizophrenia'. Janetian Studies November, no. 2 (2005).

Mosse, H. 'The Duess test'. American Journal of Psychotherapy 8 (1954): 251-264.

Murray, S. Autism. New York: Routledge, 2012.

- Representing Autism: Culture, Narrative, Fascination. Liverpool: Liverpool University Press, 2008.

Myers, C. S. 'Is the doctrine of instincts dead? A symposium: 6 - Retrospect and prospect'. British Journal of Educational Psychology 12, no. 3 (1942): 148-155.

Nadesan, M. H. 'Autism and genetics: Profit, risk and bare life'. In Worlds of Autism: Across the Spectrum of Neurological Difference, edited by J. Davidson and M. Orsini. Minneapolis: Univesity of Minnesota Press, 2013.

Constructing Autism. London: Routledge, 2005.

National Development Group for the Mentally Handicapped. Improving the Quality of Services for Mentally Handicapped People. London: Department of Health and Social Security, 1980. 
Neve, M. and T. Turner. 'History of child and adolescent psychiatry'. In Rutter's Child and Adolescent Psychiatry, edited by M. Rutter. Oxford: Blackwell, 2008.

Newnham, D. 'News from nowhere?' Guardian Weekend, 25 March 1995.

Newson, E. 'Diagnosis and early problems of autistic children'. Communication 11 (1977).

Newson, J. and E. Newson. Four Years Old in an Urban Community. London: Allen \& Unwin, 1968. 1963.

Infant Care in an Urban Community. London: Allen \& Unwin,

'Intersubjectivity and the transmission of culture: On the social origins of symbolic functioning. Bulletin of the British Psychological Society 28 (1975): 437-446.

- Seven Years Old in the Home Environment. Harmondsworth: Penguin, 1978.

Nolan, P. A History of Mental Health Nursing. London: Chapman \& Hall, 1993. Norman, E. 'Affect and withdrawal in schizophrenic children'. British Journal of Medical Psychology 28, no. 1 (1955): 1-18.

'The play of a psychotic child. British Journal of Medical Psychology 21, no. 3 (1948): 155-170.

- 'Reality relationships of schizophrenic children'. British Journal of Medical Psychology 27, no. 3 (1954): 126-141.

O'Connor, N. 'Neuroticism and emotional instability in high-grade male defectives'. Journal of Neurology, Neurosurgery and Psychiatry 14, no. 3 (1951): 226-230.

' 'The origins of the Medical Research Council Social Psychiatry Unit'. In Studies in Psychiatry: A Survey of Work Carried out in the Department of Psychiatry of the Institute of Psychiatry, under the Chairmanship of Sir Aubrey Lewis, 1945-66, edited by M Shepherd and D. L. Davies. Oxford: Oxford University Press, 1968.

. 'Visual input and social response in autistic children'. Proceedings of the Royal Society of Medicine 60 (1967): 560-562.

O'Connor, N. and B. Hermelin. Speech and Thought in Severe Subnormality: An Experimental Study. Oxford: Pergamon Press, 1963.

O'Connor, N. and J. Tizard. The Social Problem of Mental Deficiency. London: Pergamon Press, 1956.

O'Gorman, G. 'Psychoses in childhood'. The Lancet 259, no. 6708 (1952): 602-603.

.'Psychosis as a cause of mental defect'. British Journal of Psychiatry 100, no. 421 (1954): 934-943. 
Olfman, S. Bipolar Children: Cutting-Edge Controversy, Insights, and Research. Westport, CT: Praeger, 2007.

Olmsted, D. and M. Blaxhill, Age of Autism: Daily Web Newspaper of the Autism Epidemic, online: www.ageofautism.com [accessed 5 February 2015].

Omigbodun, O. 'Developing child mental health services in resource-poor countries'. Int Rev Psychiatry 20, no. 3 (2008): 225-235.

Ornitz, E. M. 'Childhood autism: A disorder of sensorimotor integration'. In Infantile Autism: Concepts, Characteristics and Treatment, edited by M. Rutter. London: Churchill Livingstone, 1971.

Orton, S. Reading, Writing and Speech Problems in Children. New York: Chapman \& Hall, 1937.

O'Sullivan, J. 'Train spotters "may suffer from autism”'. The Independent, 14 September 1991.

Oxford Dictionary of National Biography. Oxford: Oxford University Press, 2004.

Parry-Jones, W. L. 'Childhood psychosis and schizophrenia: A historical review'. In Schizophrenia in Children and Adolescents, edited by H. Remschmidt. Cambridge: Cambridge University Press, 2001.

Parton, N. and C. Lyon. 'Children's rights and the Children Act 1989'. In The Handbook of Children's Rights: Comparative Policy and Practice, edited by B. Franklin. London: Routledge, 1995.

Paula, C. S., E. Fombonne, C. Gadia, R. Tuchman and M. Rosanoff. 'Autism in Brazil: Perspectives from science and society'. Rev Assoc Med Bras 57, no. 1 (2011): 2-5.

Pear, T. H. 'Is the doctrine of instincts dead? A symposium: 5 - Not dead, but obsolescent.' British Journal of Educational Psychology 12, no. 3 (1942): 139-147.

Peel, R., ed. Essays in the History of Eugenics: Proceedings of a Conference Organised by the Galton Institute, London, 1997. London: Galton Institute, 1998.

Penrose, L. S. A Clinical and Genetic Study of 1280 Cases of Mental Defect. London: HMSO, 1938.

. Mental Defect. London: Sidgwick \& Jackson, 1933.

Perera, H., K. Wijewardena and R. Aluthwelage. 'Screening of 18-24-monthold children for autism in a semi-urban community in Sri Lanka'. J Trop Pediatr 55, no. 6 (2009): 402-405.

Perner, J., U. Frith, A. M. Leslie and S. R. Leekam. 'Exploration of the autistic child's theory of mind: Knowledge, belief and communication.' Child Development 60 (1989): 689-700.

Persico, A. M., R. Militerni, C. Bravaccio, C. Schneider, R. Melmed, M. Conciatori, V. Damiani, A. Baldi and F. Keller. 'Lack of association between serotonin transporter gene promoter variants and autistic disorder in two ethnically distinct samples.' Am J Med Genet 96, no. 1 (2000): 123-127.

Phtiaka, H. Special Kids for Special Treatment? London: Falmer Press, 1997. 
Piaget, J. La causalite physique chez l'enfant, etc. Paris: Alcan, 1927.

- La formation du symbole chez l'enfant: Imitation, jeu et reve - Image et representation. Paris: Delachaux \& Niestlé, 1945.

- Judgment and Reasoning in the Child. London: Routledge \& Kegan Paul, 1928.

—. Le jugement moral chez l'enfant. Paris: Alcan, 1932.

- Le langage et la pensee chezl'enfant, etc. Paris: Delachaux et Niestlé, 1923.

—. La naissance de l'intelligence chez l'enfant. Paris: Delachaux et Niestlé, 1936.

'La pensée symbolique et la pensée de l'enfant'. Archives de psychologie 18, no. 72 (1923): 273-304.

. 'The psychogenesis of knowledge and its epistemological significance (1975)'. In Language and Learning: The Debate between Jean Piaget and Noam Chomsky, edited by M. Piattelli-Palmarini. London: Routledge \& Kegan Paul, 1983.

- La representation du monde chez l'enfant. Paris: Alcan, 1926.

Piaget, J., B. Inhelder and H. Weaver. The Psychology of the Child. London: Routledge \& Kegan Paul, 1969.

Pick, H. L., A. D. Pick and R. E. Klein. 'Perceptual integration in children'. In Advances in Child Development and Behavior, Vol. III, edited by L. P. Lipsitt and C. C. Spiker, New York: Academic Press, 1967.

Pickren, W. E., D. A. Dewsbury and M. Wertheimer. Portraits of Pioneers in Developmental Psychology. New York: Psychology Press, 2012.

Pilcher, J. and S. Wagg. 'Keeping it in the family: Thatcherism and the Children Act 1989'. In Thatcher's Children?: Politics, Childhood and Society in the 1980s and 1990s, edited by J. Pilcher and S. Wagg. London: Falmer Press, 1996.

- Thatcher's Children?: Politics, Childhood and Society in the 1980s and 1990s. London: Falmer Press, 1996.

Pines, M. 'Glover, Edward George'. In Oxford Dictionary of National Biography (2004), online: www.oxforddnb.com/view/article/51069 [accessed 21 January 2007].

Porter, R. London: A Social History. London: Penguin, 2000.

Porter, T. M. The Rise of Statistical Thinking, 1820-1900. Princeton, NJ: Princeton University Press, 1986.

Powell, C. M. and L. M. Monteggia. The Autisms: Molecules to Model Systems. New York: Oxford University Press, 2013.

Pressman, J. D. Last Resort: Psychosurgery and the Limits of Medicine. Cambridge: Cambridge University Press, 1998.

Pritchard, D. G. Education and the Handicapped, 1760-1960. London: Routledge \& Kegan Paul, 1963. 
Qualifications and Curriculum Authority. Curriculum Guidance for the Foundation Stage: Early Years Practitioners. London: Qualifications and Curriculum Authority, 2000.

Raine, A., J. Liu, P. H. Venables, S. A. Mednick and C. Dalais. 'Cohort profile: The Mauritius child health project'. Int J Epidemiol 39, no. 6 (2010): 1441-1451.

Rand, W., M. E. Sweeny and E. L. Vincent. Growth and Development of the Young Child. Philadelphia: W. B. Saunders, 1931.

Rapoport, J., A. Chavez, D. Greenstein, A. Addington and N. Gogtay. 'Autism spectrum disorders and childhood-onset schizophrenia: Clinical and biological contributions to a relation revisited'. J Am Acad Child Adolesc Psychiatry 48, no. 1 (2009): 10-18.

Raz, M. What's Wrong with the Poor?: Psychiatry, Race, and the War on Poverty. Chapel Hill: University of North Carolina Press, 2013.

Reichow, B., C. Servili, M. T. Yasamy, C. Barbui and S. Saxena. 'Non-specialist psychosocial interventions for children and adolescents with intellectual disability or lower-functioning autism spectrum disorders: A systematic review'. PloS Med 10, no. 12 (2013).

Reisman, J. M. A History of Clinical Psychology. New York: Irvington Publishers, 1980.

Renshaw, S. 'The errors of cutaneous localization and the effect of practice on the localizing movement in children and adults'. Pedagogical Seminary and Journal of Genetic Psychology 38, no. 1-4 (1930).

Rheingold, H. L., J. L. Gerwirtz and H. W. Ross. 'Social conditioning of vocalisations in the infant'. Journal of Comparative and Physiological Psychology 52 (1959): 66-73.

Richards, B. W. 'Childhood schizophrenia and mental deficiency'. British Journal of Psychiatry 97, no. 407 (1951): 290-312.

Richards, G. 'Campbell, Charles Macfie (1876-1943)'. In Oxford Dictionary of National Biography (2004), online: www.oxforddnb.com/view/article/ 61404 [accessed 15 March 2009].

-. Putting Psychology in Its Place: An Introduction from a Critical Historical Perspective. London: Routledge, 1996.

Richards, M. and P. Light. Children of Social Worlds: Development in a Social Context. Cambridge, MA: Harvard University Press, 1986.

Ricks, D. M. and L. Wing. 'Language, communication, and use of symbols in normal and autistic-children.' Journal of Autism and Childhood Schizophrenia 5, no. 3 (1975): 191-221.

Riley, D. War in the Nursery: Theories of the Child and Mother. London: Virago, 1983. 
Rimland, B. Infantile Autism: The Syndrome and Its Implications for a Neural Theory of Behavior. New York: Appleton-Century-Crofts, 1964.

Roazen, P. Oedipus in Britain: Edward Glover and the Struggle over Klein. New York: Other Press, 2000.

Robinson, P. D., C. K. Schutz, F. Macciardi, B. N. White and J. J. A. Holden. 'Genetically determined low maternal serum dopamine beta-hydroxylase levels and the etiology of autism spectrum disorders'. Am J Med Genet 100, no. 1 (2001): 30-36.

Robinson, W. 'People talk with their eyes'. Nursery World, 19 September 1985, pp. 12-13.

Robson, P. and A. Kjønstad. Poverty and the Law. Oxford: Hart, 2001.

Rogers, E. J. 'Has enhanced folate status during pregnancy altered natural selection and possibly autism prevalence? A closer look at a possible link'. Medical Hypotheses 71, no. 3 (2008): 406-410.

Rorty, R. The Linguistic Turn: Recent Essays in Philosophical Method. Chicago: Chicago University Press, 1967.

Rose, N. The Tavistock Programme: governing subjectivity and social life Sociology, 1988, 22: 171-92.

Rose, N. S. 'The death of the social? Reconfiguring the territory of government.' Economy and Society 25, no. 3 (1996): 327-356.

- Governing the Soul, 2nd edn. London: Free Association Press, 1999. . Politics of Life Itself: Biomedicine, Power and Subjectivity in the TwentyFirst Century. Princeton, NJ: Princeton University Press, 2007.

- Powers of Freedom: Reframing Political Thought. Cambridge: Cambridge University Press, 1999.

- The Psychological Complex: Psychology, Politics, and Society in England, 1869-1939. London: Routledge \& Kegan Paul, 1985.

Rose, N. S. and J. M. Abi-Rached. Neuro: The New Brain Sciences and the Management of the Mind. Princeton, NJ: Princeton University Press, 2013.

Roshier, B. and H. Teff. Law and Society in England. London: Tavistock Publications, 1980.

Roudinesco, J. and G. Appell. 'Les répercussions de la stabulation hospitalière sur le développement psychomoteur des jeunes enfants'. Semaine des hôpitaux de Paris 26 (1950): 2271-2273.

Royal College of Psychiatrists. 'Statement to the DES and DHSS'. Bulletin of the Royal College of Psychiatrists 12 (1988): 72.

Rudra, A., S. Banerjee, N. Singhal, M. Barua, S. Mukerji and B. Chakrabarti. 'Translation and usability of autism screening and diagnostic tools for autism spectrum conditions in India'. Autism Res 7, no. 5 (2014): 598-607. 
Ruesch, J. and G. Bateson. Communication: The Social Matrix of Psychiatry. New York: W. W. Norton \& Co., 1951.

Ruttenberg, B. A., B. I. Kalish, C. Wenar and E. G. Woolf. Behavioral Rating Instrument for Autistic and Other Atypical Children. Philadelphia: Developmental Centre for Autistic Children, 1977.

Rutter, M. 'Autistic children: Infancy to adulthood'. Semin Psychiatry 2, no. 4 (1970): 435-450.

- 'Behavioural and cognitive characteristics'. In Early Childhood Autism: Clinical, Educational and Social Aspects, edited by J. K. Wing, pp. 3-50. London: Pergamon Press, 1966.

- Changing Youth in a Changing Society: Patterns of Adolescent Development and Disorder. London: Nuffield Provincial Hospitals Trust, 1979.

. 'Childhood schizophrenia reconsidered'. Journal of Autism and Developmental Disorders 2, no. 3 (1972): 315-337.

. 'Classification and categorisation in child psychiatry'. Journal of Child Psychology and Psychiatry 6, no. 2 (1965): 71-83.

- 'Concepts of autism'. Journal of Child Psychology and Psychiatry 9 (1968): 1-25.

- 'Developmental catch-up, and deficit, following adoption after severe global early privation: English and Romanian Adoptees (ERA) study team'. Journal of Child Psychology and Psychiatry 39, no. 4 (1998): 465-476.

. 'Diagnosis and definition. In Autism: A Reappraisal of Concepts and Treatment, edited by M. Rutter and E. Schopler. London: Plenum Press, 1978.

- 'Diagnosis and definition of childhood autism'. J Autism Child Schizophr 8, no. 2 (1978): 139-161.

- 'The emergence of developmental psychopathology'. In Psychology in Britain: Historical Essays and Personal Reflections, edited by G. D. Bunn, A. D. Lovie and G. D. Richards, pp. 422-432. Leicester: BPS Books, 2001. . Fifteen Thousand Hours: Secondary Schools and Their Effects on Children. London: Open Books, 1979.

. 'Incidence of autism spectrum disorders: Changes over time and their meaning. Acta Paediatrica 94, no. 1 (2005): 2-15.

- 'Maternal-deprivation, 1972-1978: New findings, new concepts, new approaches.' Child Dev 50, no. 2 (1979): 283-305.

- Maternal Deprivation Reassessed. Harmondsworth: Penguin, 1972.

- 'Research review: Child psychiatric diagnosis and classification Concepts, findings, challenges and potential'. J Child Psychol Psychiatry 52, no. 6 (2011): 647-660.

_. 'Schooling and the "autistic" child'. Spec Educ 56, no. 2 (1967): 19-24. 
. 'Speech disorders in a series of autistic children'. In Children with Communication Problems: Proceedings of a Conference Called by the Invalid Children's Aid Association (1964), edited by A. W. Franklin. London: Pitman, 1965.

Rutter, M., L. Andersen-Wood, C. Beckett, D. Bredenkamp, J. Castle, C. Groothues, J. Kreppner, L. Keaveney, C. Lord and T. G. O’Connor. 'Quasi-autistic patterns following severe early global privation: English and Romanian Adoptees (ERA) study team'. J Child Psychol Psychiatry 40, no. 4 (1999): 537-549.

Rutter, M., A. Bailey, P. Bolton and A. Le Couteur. 'Autism and known medical conditions: Myth and substance.' J Child Psychol Psychiatry 35, no. 2 (1994): 311-322.

Rutter, M., A. Bailey, A. Le Couteur and P. Bolton. 'Autism: Syndrome of definition and possible genetic mechanisms'. In Nature, Nurture and Psychology, edited by R. Plomin and G. E. McLearn. Washington, DC: APA Press, 1993.

Rutter, M. and L. Bartak. 'Causes of infantile autism: Some considerations from recent research'. Journal of Autism and Developmental Disorders 1, no. 1 (1971): 20-32.

Rutter, M., L. Bartak and A. Cox. 'A comparative study of infantile autism and specific developmental receptive language disorder: I - The children'. British Journal of Psychiatry 126, no. 2 (1975): 127-145.

Rutter, M., A. Cox, C. Tupling, M. Berger and W. Yule. 'Attainment and adjustment in two geographical areas: The prevalence of psychiatric disorder'. British Journal of Psychiatry 126 (1975): 493-509.

Rutter, M. and S. Folstein. 'Infantile autism: A genetic study of 21 twin pairs'. Journal of Child Psychology and Psychiatry 18 (1977): 297-321.

'A twin study of individuals with infantile autism'. In Autism: A Reappraisal of Concepts and Treatment, edited by M. Rutter and E. Schopler. New York: Plenum, 1979.

Rutter, M. and H. Giller. Juvenile Delinquency: Trends and Perspectives. Harmondsworth: Penguin, 1983.

Rutter, M., J. Green and W. Yule. Research and Innovation on the Road to Modern Child Psychiatry. London: Gaskell, 2001.

Rutter, M. and L. A. Hersov. Child Psychiatry: Modern Approaches. Oxford: Blackwell Scientific, 1977.

Rutter, M., J. Kreppner, C. Croft, M. Murin, E. Colvert, C. Beckett, J. Castle and E. Sonuga-Barke. 'Early adolescent outcomes of institutionally deprived and non-deprived adoptees: III - Quasi-autism. J Child Psychol Psychiatry 48, no. 12 (2007): 1200-1207. 
Rutter, M., J. M. Kreppner and T. G. O'Connor. 'Specificity and heterogeneity in children's responses to profound institutional privation' British Journal of Psychiatry 179, no. 2 (2001): 97-103.

Rutter, M., L. Lockyer and D. Greenfeld. 'A five to fifteen year follow up study of infantile psychosis'. British Journal of Psychiatry 113 (1967): 1183-1199.

Rutter, M. and N. Madge. Cycles of Disadvantage: A Review of Research. London: Heinemann, 1976.

Rutter, M. and E. Schopler. 'Autism and pervasive developmental disorders: Concepts and diagnostic issues'. J Autism Dev Disord 17, no. 2 (1987): 159-186.

Rutter, M., D. Shaffer and M. Shepherd. A Multi-Axial Classification of Child Psychiatric Disorders: An Evaluation of a Proposal. Geneva: World Health Organization, 1975.

Rutter, M., J. Tizard and K. Whitmore. Education, Health and Behaviour. Harlow: Longman, 1970.

Rutter, M., W. Yule, M. Berger, B. Yule, J. Morton and C. J. Bagley. 'Children of West Indian immigrants. I. Rates of behavioural deviance and of psychiatric disorder.' Child Psychol Psychiatry 15, no. 4 (1974): 241-262.

Sacks, O. W. An Anthropologist on Mars: Seven Paradoxical Tales. London: Picador, 1995.

Sanua, V. D. 'Is infantile autism a universal phenomenon? An open question'. Int J Soc Psychiatry 30, no. 3 (1984): 163-177.

Sarason, S. B. Psychological Problems in Mental Deficiency. New York: Harper \& Bros, 1949.

Savage, M. Identities and Social Change in Britain since 1940: The Politics of Method. Oxford: Oxford University Press, 2010.

Sayers, J. 'British psychology and psychoanalysis: The case of Susan Isaacs'. In Psychology in Britain: Historical Essays and Personal Reflections, edited by G. D. Bunn, A. D. Lovie and G. D. Richards, pp. 205-222. Leicester: BPS Books, 2001.

Schaffer, H. R. and P. E. Emerson. 'The development of social attachments in infancy'. Monogr Soc Res Child Dev 29 (1964): 1-77.

Schilder, P. Introduction to a Psychoanalytic Psychiatry. New York: Nervous and Mental Disease Publishing Company, 1925.

Schmidt, R. J., R. L. Hansen, J. Hartiala, H. Allayee, L. C. Schmidt, D. J. Tancredi, F. Tassone and I. Hertz-Picciotto. 'Prenatal vitamins, one-carbon metabolism gene variants, and risk for autism'. Epidemiology 22, no. 4 (2011): 476-485.

Schofield, C. Enoch Powell and the Making of Postcolonial Britain. Cambridge: Cambridge University Press, 2013. 
Schofield, J. H. 'Morley, Muriel Elizabeth (1899-1993)'. In Oxford Dictionary of National Biography (2004), online: www.oxforddnb.com/view/article/ 52304 [accessed 25 July 2009].

School Curriculum Assessment Authority. Nursery Education: Desirable Outcomes for Children's Learning on Entering Compulsory Education. London: SCAA and DfEE, 1996.

Schopler, E., R. J. Reichler and B. R. Renner. The Childhood Autism Rating Scale (CARS): For Diagnostic Screening and Classification of Autism. New York: Irvington, 1986.

Schopler, E., M. Rutter and S. Chess. 'Editorial: Change of journal scope and title'. Journal of Autism and Developmental Disorders 9, no. 1 (1979): $1-10$.

Schulman, I. 'Concept formation in the schizophrenic child: A study of ego development'. Journal of Clinical Psychology 9, no. 1 (1953): 11-15.

Scott, F. J., S. Baron-Cohen, P. Bolton and C. Brayne. 'Brief report: Prevalence of autism spectrum conditions in children aged 5-11 years in Cambridgeshire, UK'. Autism 6, no. 3 (2002): 231-237.

Scott, W. and M. Clifford. 'Psycho-analytic concept of depression'. British Medical Journal 1, no. 4550 (1948): 538-540.

Searle, G. R. Eugenics and Politics in Britain, 1900-1914. Leyden: Noordhoff International, 1976.

. The Quest for National Efficiency: A Study in British Politics and Political Thought, 1899-1914. London: Ashfield, 1990.

Seebohm, F. Report of the Committee on Local Authority and Allied Personal Social Services. London: HMSO, 1968.

Selleck, R. J. W. English Primary Education and the Progressives, 1914-1939. London: Routledge \& Kegan Paul, 1972.

Sellin, B. In Dark Hours I Find My Way: Messages from an Autistic Mind. London: Victor Gollancz, 1995.

Shaffer, D. 'Classification and categorisation revisited'. In Research and Innovation on the Road to Modern Child Psychiatry, Vol. I: Festschrift for Professor Sir Michael Rutter, edited by M. Rutter, J. Green and W. Yule, pp. 104114. London: Gaskell \& Association for Child Psychology and Psychiatry, 2001.

Shapira, M. The War Inside: Psychoanalysis, Total War, and the Making of the Democratic Self in Postwar Britain. Cambridge: Cambridge University Press, 2013.

Shattuck, P. T. 'Diagnostic substitution and changing autism prevalence'. Pediatrics 117, no. 4 (2006): 1438-1439.

Shaw, L. A. 'ISTD Summer School, 1950'. British Journal of Delinquency 1, no. 2 (1950): 150-151. 
Shephard, B. A War of Nerves: Soldiers and Psychiatrists, 1914-1994. London: Pimlico, 2002.

Shepherd, M. Conceptual Issues in Psychological Medicine. London: Routledge, 1990.

Sherlock, E. B. The Feeble-Minded: A Guide to Study and Practice. London: Macmillan \& Co., 1911.

- Minds in Arrear: Some Practical Aspects of Mental Deficiency. London: Bailliere, Tindall and Cox, 1932.

Shorter, E. A Historical Dictionary of Psychiatry. Oxford: Oxford University Press, 2005.

- A History of Psychiatry: From the Era of the Asylum to the Age of Prozac. New York: Wiley, 1997.

Shorter, E. and D. Healy. Shock Therapy: A History of Electroconvulsive Treatment in Mental Illness. New Brunswick, NJ: Rutgers University Press, 2007.

Showalter, E. The Female Malady: Women, Madness and English Culture, 18301980. London: Virago, 1987.

Shuang, M., J. Liu, M. X. Jia, J. Z. Yang, S. P. Wu, X. H. Gong, Y. S. Ling, Y. Ruan, X. L. Yang and D. Zhang. 'Family-based association study between autism and glutamate receptor 6 gene in Chinese Han trios'. Am J Med Genet B Neuropsychiatr Genet 131B, no. 1 (2004): 48-50.

Silberman, S. Neurotribes: The Legacy of Autism and How to Think Smarter about People Who Think Differently. London: Allen \& Unwin, 2015.

Silva, A. E., S. A. Vayego-Lourenco, A. C. Fett-Conte, E. M. Goloni-Bertollo and M. Varella-Garcia. 'Tetrasomy 15q11-q13 identified by fluorescence in situ hybridization in a patient with autistic disorder'. Arq Neuropsiquiatr 60, no. 2A (2002): 290-294.

Silverman, C. Understanding Autism: Parents, Doctors, and the History of a Disorder. Princeton, NJ: Princeton University Press, 2011.

Simmons, J. Q. 3rd, S. J. Leiken, O. I. Lovaas, B. Schaeffer and B. Perloff. 'Modification of autistic behavior with LSD-25'. American Journal of Psychiatry 122, no. 11 (1966): 1201-1211.

Simon, B. Education and the Social Order: 1940-1990. London: Lawrence \& Wishart, 1999.

Singh, J. Multiple Autisms: Spectrums of Advocacy and Genomic Science. London: University of Minnesota Press, (2016).

Slater, E. 'The inheritance of manic-depressive insanity and its relation to mental defect'. British Journal of Psychiatry 82, no. 340 (1936): 626-634.

Smith, A. T. and M. Montessori. The Montessori System of Education: An Examination of Characteristic Features Set Forth in 'Il Metodo della Pedagogica Scientifica'. Washington, DC: Government Printing Office, 1912. 
Smith, D. F. Nutrition in Britain: Science, Scientists and Politics in the Twentieth Century. London: Routledge, 1997.

Smith, M. Hyperactive: The Controversial History of ADHD. London: Reaktion, 2012.

Soloway, R. A. Demography and Degeneration: Eugenics and the Declining Birthrate in Twentieth Century Britain. Chapel Hill: University of North Carolina Press, 1990.

Spencer, D. A. 'The revision of the Mental Health Act, 1959: Should the mentally handicapped be excluded?' Journal of the Royal Society for the Promotion of Health 98, no. 2 (1978): 84-87.

Spencer, H. The Principles of Psychology. London: Longman, 1855.

Spitz, R. A. 'Hospitalism: An inquiry into the genesis of psychiatric conditions in early childhood'. Psychoanalytic Study of the Child 1 (1945): 53-74.

Spitzer, R. L. 'Values and assumptions in the development of DSM-III and DSM-III-R: An insider's perspective and a belated response to Sadler, Hulgus, and Agich's "On values in recent American psychiatric classification". Journal of Nervous and Mental Disease 189, no. 6 (2001): 351359.

Spradlin, J. 'Review of Speech and Thought in Severe Subnormality by Beate Hermelin and Neil O'Connor'. Contemporary Psychology 9, no. 3: 110.

Staub, M. E. Madness Is Civilization: When the Diagnosis Was Social, 19481980. Chicago, IL: University of Chicago Press.

Steffenburg, S. and C. Gillberg. 'Autism and autistic-like conditions in Swedish rural and urban areas: A population study'. British Journal of Psychiatry 149 (1986): 81-87.

Steiner, G. 'Background to the scientific controversies'. In The Freud-Klein Controversies, 1941-45, edited by P. King and R. Steiner, pp. 227-263. London: Tavistock/Routledge, 1991.

Stengal, E. 'A comparative study of psychiatric classifications'. Proceedings of the Royal Society of Medicine 53, no. 2 (1960): 123-130.

Stern, W. Psychology of Early Childhood up to the Sixth Year of Age. New York: Henry Holt and Co., 1924.

Stewart, J. Child Guidance in Britain, 1918-1955: The Dangerous Age of Childhood. London: Pickering \& Chatto, 2013.

. 'U.S. influences on the development of child guidance and psychiatric social work in Scotland and Great Britain during the inter-war period'. In Public Health and Preventive Medicine 1800-2000: Knowledge, Cooperation and Conflict, edited by A. Andresen et al. Bergen: Stein Rokkan, 2004.

Sugiyama, T. and T. Abe. 'The prevalence of autism in Nagoya, Japan: A total population study'. J Autism Dev Disord 19, no. 1 (1989): 87-96. 
Sun, X., C. Allison, F. E. Matthews, S. J. Sharp, B. Auyeung, S. Baron-Cohen and C. Brayne. 'Prevalence of autism in mainland China, Hong Kong and Taiwan: A systematic review and meta-analysis'. Mol Autism 4, no. 1 (2013): 7.

Sutherland, G. and S. Sharp. Ability, Merit and Measurement: Mental Testing and English Education 1880-1940. Oxford: Clarendon, 1984.

Taylor, B., E. Miller, C. P. Farrington, M. C. Petropoulos, I. Favot-Mayaud, J. Li and P. A. Waight. 'Autism and measles, mumps, and rubella vaccine: No epidemiological evidence for a causal association'. Lancet 353, no. 9169 (1999): 2026-2029.

Taylor, L., R. Lacey and D. Bracken. In Whose Best Interests?: The Unjust Treatment of Children in Courts and Institutions. London: Cobden Trust: MIND, 1979.

Taylor, L. E., A. L. Swerdfeger and G. D. Eslick. 'Vaccines are not associated with autism: An evidence-based meta-analysis of case-control and cohort studies. Vaccine 32, no. 29 (2014): 3623-3629.

Teixeira, M. C., T. P. Mecca, L. Velloso Rde, R. B. Bravo, S. H. Ribeiro, M. T. Mercadante and C. S. Paula. 'Brazilian scientific output on autism spectrum disorders'. Rev Assoc Med Bras 56, no. 5 (2010): 607-614.

Thane, P. and T. Evans. Sinners? Scroungers? Saints? Unmarried Motherhood in Twentieth-Century England. Oxford: Oxford University Press, 2012.

Thom, D. 'Wishes, anxieties, play, and gestures: Child guidance in inter-war England'. In In the Name of the Child: Health and Welfare, 1880-1940, edited by R. Cooter. London: Routledge, 1992.

Thomas, A., M. Bax and D. P. L. Smyth. The Health and Social Needs of Young Adults with Physical Disabilities. London: MacKeith, 1989.

Thomson, M. Lost Freedom: The Landscape of the Child and the British Post-War Settlement. Oxford: Oxford University Press, 2014.

- The Problem of Mental Deficiency: Eugenics, Democracy, and Social Policy in Britain, c.1870-1959. Oxford: Clarendon Press, 1998.

- Psychological Subjects: Identity, Culture, and Health in TwentiethCentury Britain. Oxford: Oxford University Press, 2006.

Thorndike, E. L. 'Is the doctrine of instincts dead? A symposium: 3 - Human instincts and doctrines about them. British Journal of Educational Psychology 12, no. 2 (1942): 85-87.

Tinbergen, E. A. and N. Tinbergen. Early Childhood Autism: An Ethological Approach. Berlin: Parey, 1972.

Titmuss, R. M. Commitment to Welfare. London: Allen \& Unwin, 1968.

Tizard, J. 'Community services for the mentally subnormal'. Proceedings of the Royal Society of Medicine 58, no. 5 (1965): 373-374. 
. 'Results and summary of the Brooklands experiment'. In Child Development and Social Policy, edited by A. D. B. Clarke and B. Tizard. Leicester: BPS, 1983.

- 'Social psychiatry and mental subnormality'. In Studies in Psychiatry: A Survey of Work Carried out in the Department of Psychiatry of the Institute of Psychiatry, under the Chairmanship of Sir Aubrey Lewis, 194566, edited by M Shepherd and D. L. Davies. Oxford: Oxford University Press, 1968.

Tizard, J. and J. C. Grad. The Mentally Handicapped and Their Families: A Social Survey. London: Oxford University Press, 1961.

Tizard, J. and P. H. Venables. 'Reaction time responses by schizophrenics, mental defectives and normal adults'. American Journal of Psychiatry 112 (1956): 803-807.

Tordjman, S., L. Gutknecht, M. Carlier, E. Spitz, C. Antoine, F. Slama, V. Carsalade, D. J. Cohen, P. Ferrari, P. L. Roubertoux and G. M. Anderson. 'Role of the serotonin transporter gene in the behavioral expression of autism'. Mol Psychiatry 6, no. 4 (2001): 434-439.

Treffert, D. A. 'Epidemiology of infantile autism'. Arch Gen Psychiatry 22, no. 5 (1970): 431-438.

Trevarthen, C. 'Autism as a neurodevelopmental disorder affecting communication and learning in early childhood: Prenatal origins, post-natal course and effective educational support'. Prostaglandins Leukot Essent Fatty Acids 63, no. $1-2$ (2000): 41-46.

. 'Communication and cooperation in early infancy: A description of primary intersubjectivity'. In Before Speech: The Beginning of Interpersonal Communication, edited by M. Bullowa. Cambridge: Cambridge University Press, 1978.

Trevarthen, C. and P. Hubley. 'Secondary intersubjectivity'. In Action, Gesture, Symbol: The Emergence of Language, edited by A. Lock. London: Academic Press, 1978.

- 'Sharing a task in infancy'. New Directions for Child and Adolescent Development, no. 4 (1979): 57-80.

Trevarthen, C., P. Hubley and L. Sheeran. 'Psychological actions in early infancy'. La Recherche (1975).

Tulsky, D. S., D. H. Saklofske and J. Rivker. 'Historical overview of intelligence and memory: Factors influencing the Wechsler Scales'. In Clinical Interpretation of the WAIS-III and WMS-III, edited by D. S. Tulsky. London: Academic Press, 2003.

Turbett, C. Doing Radical Social Work. London: Palgrave Macmillan, 2014. 
Turner, F. D. and L. S. Penrose. 'An investigation into the position in family of mental defectives: Prepared for the Mental Deficiency SubCommittee of the Research and Clinical Committee of the Royal Medico-Psychological Association'. British Journal of Psychiatry 77, no. 318 (1931): 512-524.

Tustin, F. Autism and Childhood Psychosis. London: Hogarth, 1972.

United Nations. United Nations Convention on the Rights of the Child. Geneva: United Nations, 1989.

United Nations General Assembly. Resolution 62/139 World Autism Day. Geneva, 18 December 2007.

Valentine, C. W. 'Reflexes in early childhood: Their development, variability, evanescence, inhibition, and relation to instincts.' British Journal of Medical Psychology 7, no. 1 (1927): 1-35.

Valentine, E. 'Women in early twentieth century psychology'. The Psychologist 23, no. 12 (2010): 972-975.

Valier, C. 'Psychoanalysis and crime in Britain during the inter-war years'. In The British Criminology Conferences: Selected Proceedings - Vol. 1: Emerging Themes in Criminology, edited by J. Vagg and T. Newburn. Loughborough: British Society of Criminology, 1998.

Van der Horst, F. C. P. John Bowlby: From Psychoanalysis to Ethology - Unravelling the Roots of Attachment Theory. Oxford: Wiley-Blackwell, 2011.

Venables, P. 'Experimental psychological studies of chronic schizophrenia'. In Studies in Psychiatry: A Survey of Work Carried out in the Department of Psychiatry of the Institute of Psychiatry, under the Chairmanship of Sir Aubrey Lewis, 1945-66, edited by M. Shepherd and D. L. Davies. Oxford: Oxford University Press, 1968.

- 'Factors in the motor behaviour of functional psychotics'. Journal of Abnormal and Social Psychology 58 (1959): 153-156.

- 'Psychophysiology of abnormal behaviour'. Br Med Bull 37, no. 2 (1981): 199-203.

Verhoeff, B. 'Autism in flux: A history of the concept from Leo Kanner to DSM-5'. History of Psychiatry 24, no. 4 (2013): 442-458.

'What is this thing called autism? A critical analysis of the tenacious search for autism's essence'. Biosocieties 7, no. 4 (2012): 410-432.

Vicedo, M. The Nature and Nurture of Love: From Imprinting to Attachment in Cold War America. Chicago: University of Chicago Press, 2014.

Vidal, F. Piaget before Piaget. Cambridge, MA: Harvard University Press, 1994.

Volk, H. E., I. Hertz-Picciotto, L. Delwiche, F. Lurmann and R. McConnell. 'Residential proximity to freeways and autism in the Charge study'. Environ Health Perspect 119, no. 6 (2011): 873-877. 
Volkmar, F. R., D. V. Cicchetti, E. Dykens, S. S. Sparrow, J. F. Leckman and D. J. Cohen. 'An evaluation of the autism behavior checklist'. Journal of Autism and Developmental Disorders 18 (1988): 81-98.

Volkmar, F. R. and R. Paul, eds. Handbook of Autism and Pervasive Developmental Disorders, 3rd edn. Hoboken, NJ: John Wiley \& Sons, 2005.

Volkmar, F. R., D. M. Stier and D. J. Cohen. 'Age of recognition of pervasive developmental disorder'. American Journal of Psychiatry 142, no. 12 (1985): 1450-1452.

Wakefield, A. J. 'Enterocolitis, autism and measles virus'. Mol Psychiatry 7, Suppl 2 (2002): S44-46.

. 'Statement from Dr Andrew Wakefield', 2013. www.ageofautism.com/ 2013/04/transcript-statement-from-andrew-wakefield.html (accessed 5 February 2015).

Wakefield, A. J. and S. M. Montgomery. 'Measles, mumps, rubella vaccine: Through a glass, darkly'. Adverse Drug React Toxicol Rev 19, no. 4 (2000): 265-283; discussion 284-292.

Wakefield, A. J., S. H. Murch, A. Anthony, J. Linnell, D. M. Casson, M. Malik, M. Berelowitz, A. P. Dhillon, M. A. Thomson, P. Harvey, A. Valentine, S. E. Davies and J. A. Walker-Smith. 'Retracted: Ileal-lymphoid-nodular hyperplasia, non-specific colitis, and pervasive developmental disorder in children. Lancet 351, no. 9103 (1998): 637-641.

Waldman, M., S. Nicholson, N. Adilov and J. Williams. 'Autism prevalence and precipitation rates in California, Oregon, and Washington counties'. Archives of Pediatrics \& Adolescent Medicine 162, no. 11 (2008): 1026-1034.

Wallace, M. 'Hope for shadow children'. Sunday Times Magazine, 30 March 1988.

Waltereit, R., T. Banaschewski, A. Meyer-Lindenberg and L. Poustka. 'Interaction of neurodevelopmental pathways and synaptic plasticity in mental retardation, autism spectrum disorder and schizophrenia: Implications for psychiatry'. World J Biol Psychiatry 15, no. 7 (2014): 507-516.

Walters, R. H. and R. D. Parke. 'The role of distance receptors in the development of social responsiveness'. In Advances in Child Development and Behavior, Vol. II, edited by L. P. Lipsitt and H. W. Reese. New York: Academic Press, 1965.

Waltz, M. Autism: A Social and Medical History. Basingstoke: Palgrave Macmillan, 2013.

Ward, S. British Culture and the End of Empire. Manchester: Manchester University Press, 2006.

Wardle, C. J. 'Twentieth-century influences on the development in Britain of services for child and adolescent psychiatry'. British Journal of Psychiatry 159 (1991): 53-68. 
Warren, W. 'Conduct disorders in children aged five to fifteen years'. British Journal of Delinquency 1, no. 3 (1950): 164-186.

- 'You can never plan the future by the past: The development of child and adolescent psychiatry in England and Wales'. Journal of Child Psychology and Psychiatry 11 (1971): 241-257.

Waterhouse, L. 'Autism overflows: Increasing prevalence and proliferating theories'. Neuropsychology Review 18, no. 4 (2008): 273-286.

Waterhouse, L., D. Fein, J. Nath and D. Snyder. 'Pervasive developmental disorders and schizophrenia occurring in childhood: A review of critical commentary'. In Diagnosis and Classification in Psychiatry: A Critical Appraisal of DSM-III, edited by G. L. Tischler. Cambridge: Cambridge University Press, 1987.

Waterhouse, L., L. Wing, R. Spitzer and B. Siegel. 'Pervasive developmental disorders: From DSM-III to DSM-III-R'. J Autism Dev Disord 22, no. 4 (1992): 525-549.

Watkin, B. Documents on Health and Social Services, 1834 to the Present Day. London: Methuen, 1975.

Watson, J. B. 'Psychology as the behaviourist views it'. Psychological Review 20 (1913): 158-177.

Wazana, A., M. Bresnahan and J. Kline. 'The autism epidemic: Fact or artifact?' J Am Acad Child Adolesc Psychiatry 46, no. 6 (2007): 721-730.

Welshman, J. Churchill's Children: The Evacuee Experience in Wartime Britain. Oxford: Oxford University Press, 2010.

- From Transmitted Deprivation to Social Exclusion: Policy, Poverty and Parenting. Bristol: Policy Press, 2012.

Weschler, D. Weschler Intelligence Test for Children. New York: Psychological Corporation, 1949.

White, J. London in the Twentieth Century: A City and Its People. London: Viking, 2001.

Whitmore, K., H. Hart and G. Willems. A Neurodevelopmental Approach to Specific Learning Disorders. London: MacKeith, 1999.

Wiener, M. J. Reconstructing the Criminal: Culture, Law and Policy, in England, 1830-1914. Cambridge: Cambridge University Press, 1990.

Wignyosumarto, S., M. Mukhlas and S. Shirataki. 'Epidemiological and clinical study of autistic children in Yogyakarta, Indonesia'. Kobe J Med Sci 38, no. 1 (1992): 1-19.

Wilkin, D. Caring for the Mentally Handicapped Child. London: Croom Helm, 1979.

Williams, D. Nobody Nowhere. London: Doubleday, 1992.

Wilson, M. 'DSM-III and the transformation of American psychiatry: A history'. American Journal of Psychiatry 150, no. 3 (1993): 399-410. 
Wilson, M. D. Administrative and Social Aspects. Proceedings of the Conference on the Educational Needs of Psychotic Children (unpublished), Hove, 1964.

Wing, J. K. 'Diagnosis, epidemiology, aetiology'. In Early Childhood Autism: Clinical, Educational and Social Aspects, edited by J. K. Wing, pp. 3-50. London: Pergamon Press, 1966.

- Schizophrenia: Towards a New Synthesis. London: Academic Press, 1978.

. 'Social treatments of mental illness'. In Studies in Psychiatry: A Survey of Work Carried out in the Department of Psychiatry of the Institute of Psychiatry, under the Chairmanship of Sir Aubrey Lewis, 1945-66, edited by M. Shepherd and D. L. Davies. Oxford: Oxford University Press, 1968.

Wing, J. K. and A. M. Hailey. Evaluating a Community Psychiatric Service: The Camberwell Register, 1964-71. London: Oxford University Press for the Nuffield Provincial Hospitals Trust, 1972.

Wing, L. 'Asperger's syndrome: A clinical account'. Psychological Medicine 11, no. 1 (1981): 115-129.

- The Autistic Spectrum: A Guide for Parents and Professionals, new updated edn. London: Robinson, 2002.

'Autistic spectrum disorders: No evidence for or against an increase in prevalence'. British Medical Journal 312, no. 7027 (1996): 327-328.

- Children Apart: Autistic Children and Their Families. London: National Society for Autistic Children, 1974.

. 'The definition and prevalence of autism: A review'. Eur Child Adolesc Psychiatry 2, no. 1 (1993): 61-74.

- 'The diagnosis of autism'. In Diagnosis and Treatment of Autism, edited by C. Gillberg. New York: Plenum Press, 1989.

- 'The handicaps of autistic children'. Maternal and Child Care 3 (1967): 521.

- 'Perceptual and language development in autistic children: A comparative study'. In Infantile Autism: Concepts, Characteristics and Treatment, edited by M. Rutter. London: Churchill Livingstone, 1971.

.'A place in life'. Times Educational Supplement, 12 May 1972.

Wing, L. and J. Gould. 'Severe impairments of social interaction and associated abnormalities in children: Epidemiology and classification'. Journal of Autism and Developmental Disorders 9, no. 1 (1979): 11-29.

- 'Systematic recording of behaviours and skills of retarded and psychotic children'.Journal of Autism and Childhood Schizophrenia 8, no. 1 (1978): 79-97.

Wing, L., J. Gould, S. R. Yeates and L. M. Brierley. 'Symbolic play in severely mentally-retarded and in autistic-children'. Journal of Child Psychology and Psychiatry and Allied Disciplines 18, no. 2 (1977): 167-178. 
Wing, L., S. R. Yeates, L. M. Brierley and J. Gould. 'The prevalence of early childhood autism: Comparison of administrative and epidemiological studies'. Psychological Medicine 6, no. 01 (1976): 89-100.

Winnicott, D. W. The Ordinary Devoted Mother and Her Baby: Nine Broadcast Talks, Autumn, 1949. London: Pamphlet, 1950.

- 'Primitive emotional development'. International Journal of Psychoanalysis 26 (1945): 137-143.

- 'Psychoses and child care'. British Journal of Medical Psychology 26, no. 1 (1953): 68-74.

Wöhr, M. and M. L. Scattoni. 'Behavioural methods used in rodent models of autism spectrum disorders: Current standards and new developments'. Behavioural Brain Research 251 (2013): 5-17.

Wolf, M., T. Risley, M. Johnston, F. Harris and E. Allen. 'Application of operant conditioning procedures to the behavior problems of an autistic child: A follow-up and extension'. Behav Res Ther 5, no. 2 (1967): 103-111.

Wolkind, S. and M. Rutter. 'Children who have been "in care": An epidemiological study'. J Child Psychol Psychiatry 14, no. 2 (1973): 97-105.

Wooldridge, A. Measuring the Mind: Education and Psychology in England, c.1860-c.1990. Cambridge: Cambridge University Press, 1994.

World Health Organization [WHO]. MhGAP Intervention Guide for Mental, Neurological and Substance Use Disorders in Non-specialized Health Settings: Version 1.0. Geneva: World Health Organization, 2010.

. The Proceedings of the First Meeting of the World Health Organization Study Group on the Psychobiological Development of the Child, Geneva, 1953. London: Tavistock Publications, 1956.

Wright, D. Down's: The History of a Disability. Oxford: Oxford University Press, 2010.

Wright, D. and A. Digby, eds. From Idiocy to Mental Deficiency: Historical Perspectives on People with Learning Disabilities. London: Routledge, 1996.

Yeargin-Allsopp, M., C. Rice, T. Karapurkar, N. Doernberg, C. Boyle and C. Murphy. 'Prevalence of autism in a US metropolitan area.' JAMA 289, no. 1 (2003): 49-55.

Yirmiya, N., T. Pilowsky, L. Nemanov, S. Arbelle, T. Feinsilver, I. Fried and R. P. Ebstein. 'Evidence for an association with the serotonin transporter promoter region polymorphism and autism. Am J Med Genet 105, no. 4 (2001): 381-386.

Young, A. The Harmony of Illusions: Inventing Post-Traumatic Stress Disorder. Princeton, NJ: Princeton University Press, 1995. (2012). 
Young, R. M. Mind, Brain and Adaptation in the Nineteenth Century: Cerebral Localization and Its Biological Context from Gall to Ferrier. Oxford: Oxford University Press, 1990.

Yudkin, S. and A. Holme. Working Mothers and Their Children: A Study for the Council for Children's Welfare. London: M. Joseph, 1963.

Yudkin, S. and G. Yudkin. 'Poverty and child development'. Dev Med Child Neurol 10, no. 5 (1968): 569-579.

Yuen, R. K., B. Thiruvahindrapuram, D. Merico, S. Walker, K. Tammimies, N. Hoang, C. Chrysler, T. Nalpathamkalam, G. Pellecchia, Y. Liu, M. J. Gazzellone, L. D’Abate, E. Deneault, J. L. Howe, R. S. Liu, A. Thompson, M. Zarrei, M. Uddin, C. R. Marshall, R. H. Ring, L. Zwaigenbaum, P. N. Ray, R. Weksberg, M. T. Carter, B. A. Fernandez, W. Roberts, P. Szatmari and S. W. Scherer. 'Whole-genome sequencing of quartet families with autism spectrum disorder'. Nat Med 21, no. 2 (2015): 185-191.

Zhong, N., L. L. Ye, W. N. Ju, J. Tsiouris, I. Cohen and W. T. Brown. '5-HTTLPR variants not associated with autistic spectrum disorders'. Neurogenetics 2, no. 2 (1999): 129-131.

Zweiniger-Bargielowska, I. 'Building a British superman: Physical culture in interwar Britain'. Journal of Contemporary History 41, no. 4 (2006): 595-610.

\section{Websites}

Critical Autism Network: www.open.ac.uk/health-and-social-care/research/ critical-autism-network [accessed 26 March 2016].

Department for Education, UK: Statistics: Special educational needs (2012): www.gov.uk/government/statistics/special-educational-needs-in-Englandjanuary-2012 [accessed 29 March 2016].

Department for Education, UK: Statistics: Special educational needs (2015): www.gov.uk/government/statistics/special-educational-needs-inEngland-january-2015 [accessed 29 March 2016].

Imagining Autism: www.imaginingautism.org [accessed 29 March 2016]. 


\section{Index}

Abe, Tokuichiro 354

abuse 370-371

ADI see Autism Diagnostic Interview ADOS see Autism Diagnostic Observation Schedule adults with autism $314-315$, 351, 361,417

aetiology see causes of autism Africa 341-343, 377-378, 380-381 age of onset 147-148, 169-170, 236, 315,347

allowances (benefits) 251, 313

Amatruda, C. 109

amphetamine treatment 111

animal studies 117, 224, 400-401

Anthony, Elwyn James 149-151,

$155,156,168-173,178$, 220,301

anthropology 63, 124

AQ see Autism Spectrum Quotient Asperger's syndrome 302, 349, 363-364, 396, 416

attachment theory 24, 117, 224, 265-266

maternal deprivation $24,115-$ $118,137,170,178,233$ theory challenged 197,264 , 266-267, 423
Auden, George Augustus 63

auditory perception $222-223,225$, $228,230-231$

Australia 366

autism

as a diagnostic category

meaning of psychological concept $4-5,10-11,23,68,83,100$, $302,352,395,424-426,432$

1911-1960 definitions 41-45, 52, 72-74, 119

Kanner's definition 112-114 1960s and 1970s definitions 203, 209, 237-240, 259-260

reversal in meaning $2,10-11$, 189-190, 237-238

1980s and 1990s definitions 345-348, 365

21 st century definitions 402 , 418-420

term in common use 202, 372 origins of psychological concept $10,41-43$

in relation to intelligence 15,52 , $93,175,218-226,277$, 313-314, 356, 360, 392, 396,431 
advantages of $202,255,259$ autistic features 282-284 autistic spectrum disorder (ASD) 363, 365 diagnostic instruments/scales 298-299, 355-360, 367, 379, 396

DSM see Diagnostic and Statistical Manual of Mental Disorders increase in frequency of 2-6, $315,362-368,369,371$, 430-431

international consensus 344-349, 352

Lotter's criteria 214-216 nine points (Creak, 1961) 200-201

in relation to Asperger's syndrome 363-364

Wing's triad of impairments 276, 296-301, 348, 376, 417

see also autistic spectrum; childhood psychosis; childhood schizophrenia; 'mental deficiency'; pervasive developmental disorders; primary narcissism

Autism Act (2009) 1, 14, 382, 416, 421

Autism Diagnostic Interview 356-358, 359-360, 396

Autism Diagnostic Observation Schedule 358-360, 367, 396

Autism Europe 351-352, 369, $370-371,372,373$

Autism Speaks 375-376, 401 Autism Spectrum Quotient 395 autistic features 282-284, 311-312

autistic spectrum 348, 363, 402 early conceptualisation as 'continuum' 301-302

autoerotism 42, 43, 100 autonomy 15, 193, 226 and the Children's Act 1989 (1991) 323, 324, 326

Baird, Gillian 366

Bakare, Muideen O. 377-378, 381

Baron-Cohen, Simon 316, 362 diagnostic instruments devised by 367,395

on the extreme male brain 396 on prevalence $1-2,366,379$ on theory of mind 317-320, 426

barrier hypothesis 169-170

Bartak, Lawrence 254, 273

Bartolucci, Giampiero 273

Bateson, Gregory 124

Bayonas, Isabel 373-374

behaviourism 95, 149, 305

Tinbergen on 306 treatment based on 207-208

Beisler, Jean M. 291

Benda, Clemens 148, 175

Bender, Lauretta 108-109, 111, 208

benefits (allowances) 251, 313

Benner, P. 200

Bergman, M. 148

Beveridge Report (1942) 108

Bick, Esther 117

biochemistry 390-391 neurotransmitters 399 screening tests 156, 231-232, 394 testosterone 396 vaccines 3, 384-387, 388

Birch, Herbert 220

Bleuler, Eugen 10, 41-43

Bolton, Patrick 362, 392, 393 
Boston Higashi School 374-375

Bowlby, John 19, 94

Bowlbyism 24, 115-118, 137, $170,178,233$

theory challenged 197, 264, 266-267, 423

Braddock, Bessie 193

Bradley, Charles 111

Brain, Sir Russell 193, 275

Brazil 349, 379-380

Brierley, Marjorie 105-106

British Journal of Delinquency 174

British Psychoanalytical Society 50, 96-97

British Psychological Society (BPS) $37,69,204,256$

Brown, M. J. 282

Bryson, Susan 353

Burt, Cyril

on 'backward' children 18-19, 47

career 40, 46

on instinct theory 96, 97-100, 423

on intelligence $16,39,47,79$

Cameron, Kenneth 142, 145, 149, $150-151,163,200$

Canada 353, 366

care orders 250

Carr, William Compton 192-193, 209

'Case Con' 309

Cashmore, Alan 143

cause and effect 320-321

causes of autism 387-389

genetic studies of 391-395, 396

early studies $175-177$

molecular 388, 397-402, 429-430

multifactorial 170, 276

maternal deprivation 24, 115-118, $137,170,178,233$ theory criticised 197, 264, 266-267, 423

stress of modern life 306, 350

vaccines 3, 384-387, 388

central coherence 395

CHAT see Checklist for Autism in Toddlers

Chataway, Christopher 209-210

Checklist for Autism in Toddlers 367, 396

child development theories 13-15, $18-20,420-433$

19 th \& early 20th century 34-40

Freud 42, 43, 106

1920s \& 1930s 44-45, 52-55, $59-60$

1930s \& 1940s 94-108

1950s 140, 178-180

Anthony 170, 171-172

1960s \& 1970s 220, 226-227, 264-269, 286

1980s 320-321

1990 s to present day 381,395

limited research on 'mentally defective' subjects 18-19, $33,47,75-84$

see also attachment theory;

instinct theory;

psychoanalytic theory;

social development

child guidance clinics 19, 49-50, 78, 93, 141

childhood psychosis

Anthony on 168-173

Cameron on 145

Klein and the Kleinians on 54-56, 102

legal position in the 1950s 140-143

at the Maudsley 142-143, 150-168

Norman on 122

terminology 52, 55, 70, 72, 125 
childhood schizophrenia compared with 'mental deficiency' 82, 146-149, 174-175

Creak on 72-74, 126

diagnostic tests 159-160 in the DSM

DSM-I 144

DSM-III (omitted) 345

Klein and the Kleinians on 54-56,

$$
\text { 121-123 }
$$

legal position in the 1950s 140-143

treatment 111-112, 121-122, 162-165, 430

in the USA 108-114, 149, 430

child psychiatry $21,23,68-74$, $141-142,235,308,312$

Children Act (1908) 34

Children Act (1948) 116, 137, 194

Children Act 1989 (1991) 323-324, 326, 327

Children and Families Act (2014) 415, 416

Children and Young Persons Act (1969) 250

Children's Handicaps, Behaviour and Skills (HBS) schedule 298-299

children's rights $5,14-15,22$, 415-416

19th \& early 20th century 34-35 1948 Children Act 116, 137

1960s 191-192, 202-203, 218

1980s 321-328

21 st century 415,419 internationally 340 , 380-381

Children of the Stars (documentary) 379

China 366, 377, 379

Chomsky, Noam 270-271
Chronically Sick and Disabled Persons Act (1970) 251

Cialdella, P. 353

Clarke, A. D. B. 177

Claude, Henri 43

Clinkard, H. E. 198-199

Cloake, Philip 71

Code of Good Practice on Prevention of Violence against Persons with Autism 370-371

cognitive disorder of autism 220, 230-231, 395

and language $270-275$

social impairment 25,287 , 291-305, 395

conditioning 95, 207

Condon, William 287

convulsive therapy 111-112, 208

Cox, Anthony 273

Creak, Mildred 70-71, 72-74, 126, 129 n. 3, 147, 200

criminal behaviour 61-62, 174, 250, 268

Critical Autism Network 417-418

cultural diversity 341-343

Daily Life Therapy 374

De Jong, H. H. 69

dementia praecox (term applied to children) 55,70 see also childhood schizophrenia Denmark 343, 366 depression 103, 163 deprivation 262-264, 265, 267 see also maternal deprivation de Sanctis, Sante 70 Desorgher, Sandra and Max 388 developing countries 341-343, 349-350, 373-374, 377-381, 382-383 
developmental delay (as diagnostic category) 389

diagnostic bracket creep 355

in psychiatry generally $21,144,355$

Diagnostic Interview for Social and Communication Disorders 360

Diagnostic and Statistical Manual of Mental Disorders

DSM-I 144

DSM-III 275, 344-348

DSM-III-R 348

DSM-IV 364, 365

DSM-V 416-417

Dickson, John Thompson 36

disability rights $369,370-373$

see also children's rights

DISCO see Diagnostic Interview for

Social and Communication

Disorders

Doll, Edgar A. 158

dopamine 399

Down, John Langdon 35

Down's syndrome 290, 299

draw a man test 160

Drever, James 99

Drillien, Cecil M. 276

drug treatments 111, 136, 208

DSM see Diagnostic and Statistical Manual of Mental Disorders

Dwork, Deborah 11

Earl, C. J. 81-82

Edgell, Beatrice 59

Education Act (1944) 140-141, 199, 205-206

Education Act (1981) (1983) 307, 310-312

Educational Guidance Centre (Brixton, London) 258, 341 'educationally subnormal' 253, 307 educational psychologists 256-259, 310

Education (Handicapped Children) Act (1970) 16, 252

Education, Health and Care Plans 415

education policy

19th and early 20th century 34

1920s and 1930s 62

1940s and 1950s 140-141

1960s 199, 205-206, 209-210, 416

1970s 251-254, 258-259, 261

1980s 307, 310-313

1990 s to present day 415,428 progressive/permissive schools $51,165-166,254$

special schools 45-47, 165, 167, 205-206, 252, 254

EEG see electroencephalography egocentrism 52, 104, 162, 171-172, 318-319

Eickhoff, Louise 121-122, 148-149 electroconvulsive therapy 111-112, 208

electroencephalography 156,270 Elementary Education (Defective and Epileptic Children) Act (1914) 46

Ellis, Lucy 282

Emerson, Peggy 265-266 employment law 372-373 encapsulated secondary autism 234 encephalitis lethargica 71 environmental causes 306, 388-389 epidemiological data (prevalence)

1960s 212,216

1970s 310, 343

1980s 353-354

1990s 364, 365-366 
21st century $366,377,379$

Asperger's syndrome 363-364 increasing 2-6, 315, 362-368, $369,371,430$

lack of data following 1959 Act 198-200

epidemiological studies 11, 211, 255, $305,390,424$

control groups 290-291

fail to support Wakefield's claims 386-387

international 341-343, 349-350, 352-354, 365-366, $377-$ $380,383-384$

Lotter 214-218, 341-343

Rutter and Tizard 212-214, 260-262

Wing and Gould 297-301, 310 eugenics 35, 37, 38-39, 47, 75, 94 Europe 351-352, 369

see also Autism Europe; individual countries

evacuation, war-time 94, 116 evolutionary theory 36,83

Ewing, Alexander 78

extreme male brain 396-397

Eyal, Gil 2, 389

Eysenck, Hans 138-139

factor analysis 98-99

false belief tasks 317, 318-319

families

breakdown of 93-94, 267

genetic studies 391, 392-393

see also parents

family law 322-327

see also children's rights

fantasy, infantile 10-11, 42, 237-

238,280

see also phantasy, infantile

'feeble-minded' 46, 75, 194 feeding difficulties 101

Ferster, Charles 207

Festival of Youth (1937) 92-93

Feversham Report (1939) 93

fiction, autism in 1, 360

Fildes, Lucy 76-77, 78

First World War 48, 70

5-HTT (serotonin transporter) 398-399

Flavell, John 286

folate 388

Folstein, Susan 391

Forrester, John 8-9

Fortes, Meyer 79

Foubert, André 370

Fox, Evelyn 50

fragile X syndrome 394

Framework for Communication programme 375

France 69, 353

Freeman, Walter 111

Freud, Anna 97, 103, 104, 105-106, 123,178

Freud, Sigmund 42, 43, 96, 106

Friedlander, Kate 103

Frith, Chris 429

Frith, Uta 228-230, 306, 316-320, 360,395

Fuentes, Joaquin 373

Galton, Francis 38-39, 423

Gardner, Dorothy 126-127

Gardner, George 149

gender differences 396-397

Gerland, Gunilla 370

Geschwind, Daniel 402

Gesell, Arnold 19, 57, 58, 109, 118

Gillberg, Christopher 352-353, 354, 363-364, 393, 394, 402

Glover, Edward 56, 61-62, 103-104, 120-121, 174 
Goddard, Henry H. 57, 158

Goldfarb, William 170, 220

Gomes, Paulyane 380

Goodenough (draw a man) test 160 'good enough mother' 120, 128

Gould, Judith 297-301

governmentality $7-8,138$

government policy/legislation

$14-15,16,17-18,22,25$

19 th and early 20 th century 11 ,

$$
\text { 34-35, 45-48 }
$$

1920s and 1930s 12, 75-76

1940s and 1950s 108, 114-116, 137, 140-143, 167-168

1960s and 1970s 192-200, 205-206, 209-210, 218, 248-251

1980s 306-15, 321-328

1990 s to present day 381-382, 415,416

Graham, Philip 308

Grey Walter, W. 270

Guhathakurta, Sabhrangshu 399

Habermas, Jürgen 288

Hacking, Ian 8, 14, 27n.18

Hadow Committee 62

hallucinations/hallucinatory thought

Bleuler and Freud on 10, 43-44, 52

Kleinians on 53, 56-57

Rorschach on 159

theories abandoned 235-238, 279-280

Handicapped Pupils and School Health Regulations (1945) 141

Happé, Francesca 362, 395

Harlow, Harry 224

Hayes, R. A. 228
Hazlitt, Victoria 59

HBS schedule 298-299

Head, Henry 108

hearing (auditory perception) 222-223, $225,228,230-231$

Heimann, Paula 101, 106-107

Held, Richard 227-228

Hendrick, Harry 11-12

Herd, Henry 79

Hermelin, Beate 177, 219-224, 228-230, 290

Heuyer, Georges 69

Hilliard, L. T. 175, 176

Hirschberg, J. Cotter 110

Hubley, Penelope 288

human relations (Tavistock) model 20, 117, 128-129, $136-138,139,192$

critiques of 145, 234, 239, 264, 303-304, 320

see also Bowlby, John; Isaacs, Susan; Klein, Melanie; Winnicott, Donald

human rights $340,351,369$, 370-373 see also children's rights

Husserl, Edmund 288

ICD see International Classification of Diseases

Iceland 365

'idiocy'/'idiots' 35-36, 46, 75, 194

Imagining Autism project 418

'imbeciles' 46, 75, 177, 194

imperialism 92-93, 190-191

India 349-350, 373, 380, 399

industrial psychology 128, 137-138

'ineducability' 46-47, 75, 194, 210

Ingram, T. T. S. 275

Inhelder, Bärbel 286

inkblot (Rorschach) test 159 
'in need of care and protection' 114, 197,340

instinct theory 62-68, 179

contrasted to behaviourism

94-100, 149

controversial discussions (Klein and Freud) 97, 100-108, 123

social instinct $37-38,67$

Institute of Child Psychology 51

Institute of Psychiatry 13, 141-142

Occupational Psychiatry Research

Unit 146-147, 174, 212,

225-226

institutionalisation

of children generally 116

of 'mentally defective' children 12 compulsory 36 , 46-47, 75-76, 80-81, 193-194, 196

discretionary 167-168, 196197

ending of the practice 12,136 , 167, 194-196, 257

psychological problems caused by 118, 204-205, 267, 419

see also special schools

insulin coma treatment 111,163 integration into mainstream schools 311-312

intelligence tests $15,16-17,39-40$, 47, 79-80, 158, 218-219

shortcomings 220, 225-226

International Classification of Diseases

1st edition 144

6th edition 344

10th edition 348-349

internet use 3, 374, 386

intersubjectivity 286-289

In Whose Best Interests? (MIND/

Cobden Trust) 324
Ireland 381

Isaacs, Susan

on behaviourism 95

career 50, 60

on childhood schizophrenia/ psychosis 56, 102

on infantile phantasies $64,101-102$, 105

on regression 106

on social development 18 ,

$$
53,58-59,60-61,62 \text {, }
$$$$
\text { 65, } 66
$$

Isaksen, Jørn 367

Jackson, Lydia 125

Janet, Pierre 42

Japan 343, 354, 365, 366

Jordan, Rita 369

Journal of Autism and Developmental Disorders (formerly Journal of Autism and Childhood Schizophrenia) 269-270, 284-285

Jung, Carl 139

juvenile delinquency 61-62, 174, 250, 268

Kanner, Leo 41, 70, 112-114, 148, 177

Kirman, Brian 175-177, 232

Klein, Melanie 50-51, 53-56, 64, 121

controversial discussions 97, 100-108, 123, 266

Koffka, Kurt 58

Kolvin, Israel 236-238

König, Karl 165

Kraepelin, Emil 69, 147

Kramer, Peter 355

Kramer, Yale 159

Kushlik, Albert 193, 255 
Laing, R. D. 136-137

language

disorders in children 161-162,

222-223, 229-230,

272-275, 277-278, 283

measurement of ability 273, 291

speech therapy 207, 259, 278, 369

theories of development of 270-272, 287-288

Latin America 349, 373-374,

$$
\text { 379-380 }
$$

Lay, R. A. Q. 74

'learning difficulties' 307

learning theory 95, 207

Le Couteur, Ann 356

legal situation see government policy/legislation

Leonard, Helen 367

Leslie, Alan 316, 317-321

Levitt, Pat 402

Lewis, Aubrey 138, 174

Li, Ning 377

liberalism 190-191, 226, 295, 363

Light, Paul 427

lobotomy 111

Local Authority Social Service

Act (1970) 249-250,

255-256

Local Government Act (1929) 49, 71

Lord, Catherine 356

Lotter, Victor 211, 214-218, 235,

$$
\text { 341-343 }
$$

Lovaas, I. O. 208

Lowenfeld, Margaret 50-51, 64-65, $66,124,159-160$

LSD treatment 208

magical thought 44

Mahler, Margaret 110

'maladjustment' 93, 141, 144-145, 192,253 males 396

Mamelle, M. 353

Marks, Lara 11

Martin, J. A. M. 230, 278

maternal deprivation 24, 115-118, $137,170,178,233$

theory challenged 197, 264, 266-267, 423

mathematical skill 395

Maudsley Hospital

1920s and 1930s 49, 68-69, 70-73, 111

1950s (Child Psychotic Clinic)

138-139, 142-143,

150-168

1960s 207, 211-218, 231-233

1970s 277-282

1980s 303-304

discharge procedures $165-168$

observational studies 150-155, 278-279

psychology of industrial relations 138

referrals to $49,71-72,143,277$

testing regimes 138-139, 156-162, 231-232, 277

treatment regimes 111, 162-165, 207 see also Institute of Psychiatry

McDougall, William 37-38, 39, 96

Mead, Margaret 63, 124

measurement systems see tests

media coverage $118,119,218,231$, 360-362, 379

vaccine controversy 386

Meldrum, Bill 370

'mental deficiency' 12

definitions 33, 35-36, 46 term abandoned 194

distinct from mental illness 36, 49-50, 82, 146-149, 174-175 
genetic and/or congenital causes

$$
\text { 175-177 }
$$

institutionalisation 46-47,

$$
\begin{aligned}
& 75-76,80-81,167-168, \\
& 193-194
\end{aligned}
$$

legislation 14, 45-47, 75, 116, 141, 167-168, 194

research 174

absence of 18-19, 75-84, 107-108, 128-129, 173

Mental Deficiency Act (1913) 14, 45-47, 167-168

Mental Health Act (1959) 190, 191, 194-196, 422

Merleau-Ponty, Maurice 288

metabolic disorders 232

methodology used in this book 6-9

Middle East 350, 378

mirror neurons 426-428

Mittler, Peter 225

MMR vaccine 3, 384-387

Moncrieff, Alan 126-127

Montessori, Maria 226

Moreno-De-Luca, D. 401

Morgan, Conwy Lloyd 95

Morgenstern, Sophie 69

Morton, John 316, 360

mothers

'good enough' 120, 128

Klein's views 55

maternal deprivation 24, 115-118, 137, 170, 178, 233

theory challenged 197, 264, 266-267, 423

'place is in the home' 115-116, 137 working 265, 372-373

Mott, Frederick 69

mouse model of autism 400-401

MRC Developmental Psychology Unit (later Cognitive Development Unit) 228, 316, 320
MRC Epidemiology of Mental

Disorders Committee 213

MRC Unit for Research in Occu-

pational Adaptation

(later Social Psychiatry

Research Unit) 146-147, $174,212,225-226$

Murray, Stuart 3, 360

Nadesan, Madjia 3

NAS see Society for Autistic Children

National Health Service, establishment 108, 115

National Insurance Acts (1970 and 1971) 251

neoliberalism 325, 339-340, 432

neurodevelopmental disorders 275-276, 347, 365

neurodiversity movement 417-418, $419,432,433 n .3$

neurotransmitters 399

Newson, John and Elizabeth 268-269, 286-287, 289, 304, 309, $313-314,314-315$

Nigeria 342, 377-378, 381

Norman, Elizabeth 122-123

nurses in the Maudsley clinic

$$
\text { 151-154 }
$$

object relations theory $117,120,128$

Occupational Psychiatry Research

Unit (later Social

Psychiatry Research

Unit) 146-147, 174, 212, 225-226

occupational therapy 164-165

O’Connor, Neil 174, 214, 219-224, 228, 290

Oedipus complex 53

Oftedal, Dagny 164

O’Gorman, Gerald 147 
operant conditioning 207

Ornitz, Edward 231

parents

advocacy

on causes of autism 388

for research 375-376, 389, 401

see also Society for Autistic

Children

and care decisions

challenging 166-167, 199, 202, $314,324,325$

responsible for 167-168, 196-197, 202

employment rights 372-373

see also mothers

Pasamanick, Ben 212

Pavitt, Lawrence 252

Pearson, Karl 38

Penrose, Lionel 79, 175-176

Percy Report (1957) 193, 194

personality tests 138-139, 175, 211

pervasive developmental disorders

345-346, 347-348,

364-365

phantasy, infantile

Glover on 120-121

Kleinians on 53-56, 64-67, 101-102, 130n.23

Rorschach test 159

theories abandoned 233-238, 278-279

phenotypical model of autism 392, 396-397, 403

Piaget, Jean 19, 41, 44-45, 53, 59-60, $156,180,286$

on egocentricity 52, 162, 319

on language development 271-272 Pick, Herbert 227

play

Kleinians on 54, 65-66, 102, 105 symbolic 280, 289-290

play therapy 374-375

Plowden Report (1967) 271

poverty 262-264, 265, 267

Power, Michael 262-263

preschool children

learning goals 428

screening 307-308, 367, 396

prevalence see epidemiological data (prevalence)

Price, G. P. 314

primary narcissism 43, 54, 100, 171, 419

progressive/permissive schools 51 , 165-166, 254

propfschizophrenia 147

psychiatry (child psychiatry) 21, 23, 68-74, 141-142, 235, 308,312

psychoanalytic theory 5, 61-62, 119-129, 417, 425

psycho-dynamics 99

psychological tests see tests 'psychopathic disorder' 194 psychosis see childhood psychosis psychotherapy 106, 163-164, 206, 370

Quirk Report (1972) 259

Rain Man (film) 360

Rappoport, Judith 418

refusal of treatment 324

regression 106

Reichow, Brian 382-383

Renshaw, Samuel 227

research

importance of British research in history of autism 4, 9-13, 19-20, 22-23,

26,349 
not done using 'mentally deficient' children 18-19, 75-84, 107-108, 128-129, 173

parent advocacy 375-376, 389, 401 see also epidemiological studies

residential care see institutionalisation Richards, B. W. 147-148

Richards, Martin 427

Rickman, John 150

Rimland, Bernard 202, 305

Romanian orphans 419

Romberg test 159

Rorschach (inkblot) test 159

Rose, Nikolas 7, 20, 36, 61, 128, 138, $339,420-421$

Royal College of Psychiatrists 312

Rudolph Steiner schools 165-166, 254

Rutter, Michael

on autism and adult schizophrenia 23

on autistic adults 314

on deficiency of fantasy 237-238, 280

on deprivation 262,267

on diagnosis 281-283, 355-356

in the DSM 344, 345, 347,

419-420

on education methods 254

epidemiological studies 213-214, 260-261

on genetics 391, 392-393, 393-394

as a journal editor 269-270, 284-285

on language and cognitive defects 270, 272-273, 278

at the Maudsley Hospital 212, 277 on quasi-autism in Romanian orphans 419

on social development 266-268, 432
SAC see Society for Autistic Children

Sally-Anne test 318-319

Sander, Louis 287

sand trays 160

Sanua, Victor 349-350

Scattoni, Maria Luisa 400

Schaffer, Rudolf 265-266

Schilder, Paul 108-109

schizophrenia, adult 69, 124

Bleuler on 10, 42

at the Maudsley 146-147, 297

relationship with autism 235, 302, 345,418

treatment 136

see also childhood schizophrenia

Schopler, Eric 284, 356, 375

Scotland 46, 196, 249

Scott, Clifford 163

Searle, Nina 66

Second World War 92-94, 108, 111, 116

Seebohm Report (1968) 249-250, 308

Segal, Stanley 206

sense perception

in child development 226-228

defective in autism 228-231, 233

Fildes on 77-78

Hermelin and Frith on 228-230

Hermelin and O'Connor on

$$
\text { 219-224 }
$$

Tustin on 234

Wing, J. on 225

Wing, L. on 291-293

serotonin (5-HT) transporter 398

'severely subnormal' 194, 252

sex differences 396-397

Shattuck, Paul 2, 389

Sherlock, Edward Birchall 80

Shrubsall, F. C. 71 
sight (visual perception) 220, 222, 225, 227, 229

Simmons, Vivienne 310

social brain 426, 429

social deprivation 262-264, 265, 267

social development 420-433

1900 to $196037-40,48,51-68$, 83-84

1960s and 1970s 265-269

Frith et al. on 319-320

impaired 25, 287, 291-305, 395

measurement scales 57-59,

158-159, 298-299,

304-305, 355-360

Newsons on 286-287

Lorna Wing on 293-294

social empathy 304

social exclusion see institutionalisation social instinct $37-38,67,96$

see also instinct theory

Social Psychiatry Research Unit (formerly Occupational Psychiatry Research Unit) 146-147, 174, 212, 225-226

Social Security Act (1975) 251

social workers, psychiatric 117-118, 137,249

social work services $25,248-250$, 308-309, 314, 322

Society for Autistic Children

201-202, 205-207, 208-209, 255

National Autistic Society 252, 309, 366, 374

sociology

in the 1970s 264-269

hierarchical views of society 37 , $75,94,135-136$

liberalism 190-191, 226, 295, 363

neoliberalism 325, 339-340, 432
Son Rise programme 375

South Africa 373

South America 349, 373-374, 379-380

Soviet Union 220

special schools

1900-1930 45-47

1950s 165,167

1960s/1970s 205-206, 252, 254

see also progressive/permissive schools

speech see language

SPELL programme 375

statementing 310-311, 382, 415

statistical analysis 8-9, 126-127, 211

Burt's factorial analysis 98-100

of delinquency 173-174

in eugenics 38-39

see also epidemiological studies

styles of reasoning 6, 8-9, 17

'subnormal' 194, 196, 253

Sugiyama, Toshiro 354

Summerfield Report (1968) 256-257

Sweden 352-353, 354

symbolic thought

lacking in autism 10-11, 272, 280, 290

Piaget on 44, 286

symbolic play $280,289-290$

tactile perception 222, 226-227

Tavistock Clinic 49, 117-118, 127, 136, 139

Tavistock model of human relations

$$
\text { 20, 117, 128-129, }
$$
$136-138,139,192$

critiques of $145,234,239,264$, 303-304, 320

see also Bowlby, John; Isaacs,

Susan; Klein, Melanie;

Winnicott, Donald 
TEACCH programme 375

testosterone 396

tests 431

$\mathrm{ADI}$ and $\mathrm{ADOS} 355-360,367$,

$$
379,396
$$

AQ 395

biochemical/physiological 156,

$$
\text { 221, 231-232, } 394
$$

\section{CHAT 367}

HBS schedule 298-299

$$
\text { intelligence } 15,16-17,39-40,47 \text {, }
$$$$
\text { 79-80, 158, 218-219 }
$$

shortcomings 220, 225-226

language ability 273, 291

at the Maudsley hospital

$$
\begin{aligned}
& 138-139,156-162, \\
& 231-232,277
\end{aligned}
$$

personality tests $138-139,175,211$

sense perception 220-223

social development scales 57-59,

$$
\text { 158-159, 298-299, }
$$$$
\text { 304-305 }
$$

theory of mind 318-319

Thatcher, Margaret 261, 325, 339

theory of mind 162, 317-320, 365, 419, 426

Thorndike, E. L. 95, 99

three mountains test 162,318

Tinbergen, Nikolas 306, 350

Titmuss, Richard 249

Tizard, Barbara 267

Tizard, Jack 174, 178, 196-197, 204-205, 210, 432

epidemiological studies 212 , 213-214

touch perception $222,226-227$

training 382

child psychiatrists $70,308,341$

educational psychologists

256-257

psychiatric social workers $117-118$ social workers 249, 309

teachers 206-207, 218

trainspotters 361

transference 105

treatment

behaviourist methods 207-208

convulsive therapy 111-112, 208

in developing countries 382-383

drug treatments 111, 136, 208

educational methods

1960s and 1970s 206-207, 254-255, 308

1990s to present day 369-370, 374-375, 382-383

insulin coma/shock 111, 163

lobotomy 111

LSD 208

occupational therapy 164-165

for older individuals 315

physiotherapy 121-122

of preschool children 308

psychotherapy 163-164, 206, 370

Tredgold, Alfred Frank 176-177

Trevarthen, Colwyn 287-288

triad of impairments

Anthony on 168-169

in mice 400

Rutter on 281-283

Lorna Wing's version 276,

$$
\text { 296-301, 348, 376, } 417
$$

Tsai, Luke Y. 291

Tustin, Frances 233-234

twin studies 391, 393

unconscious mind 5, 427 see also instinct theory

Underwood Report (1955) 145, 213

United Nations (UN)

on autism awareness 376

on human rights 340,351 
USA

behaviourism 95, 149

childhood schizophrenia 108-114, 149,430

'developmental disorders' 275

'mental deficiency' and schizophrenia 148-149, 175

parental advocacy 202, 375-376 prevalence of autism 343, 366 social development tests (1920s/1930s) 57-58, 158-159

treatment methods 111-112, 207-208, 374-375

vaccines 3, 384-387, 388

Valentine, C. W. 63

Venables, Peter 146-147, 221, 350

Vernon, Phillip 99

video use 287-288, 359

Vineland Social Maturity Test 57, 158-159

visual perception $220,222,225,227$, 229

Vivanti, Donatta 370

Wakefield, Andrew 384-386

WAO see World Autism Organization Warnock Report (1978) 261, 307, 310

Warren, Wilfred 235

Waterhouse, Lynn 387

Watson, John Broadus 95

Wazana, Ashley 367

Wechsler Intelligence Scale for Children 158

whirling test 109, 159

Whitmore, Kingsley 199, 213, 275

WHO see World Health Organization Williams, Christopher 370

Wilson, Mary 263-264

Wiltshire, Stephen 361
Wing, John 202-204, 206, 211, 225, 263, 297

Wing, Lorna 202

on Asperger's syndrome 302

and DSM-III definition of autism $346-347,348$

on education 202-204, 206, 210

on prevalence 3, 297-301, 310, 363

public engagement 231

on social impairment 291-304, 360

on symbolic play 289-290

on triad of impairments 276, 296-301, 348

Winnicott, Donald 50, 118, 119-120, 123, 137, 145, 233

WISC see Wechsler Intelligence Scale for Children

Wöhr, Marcus 400

Wolkind, Steven 267

women

increased rights in 1960s 191, 196 'place is in the home' 115-116, 137 as professional psychologists 51 , 59,67

see also mothers

Wood Report (1929) 75, 82

Woolf, Peter H. 287

World Autism Awareness Day 376

World Autism Organisation 370, 373-374

World Health Organization 136, 264, 350

World War I 48, 70

World War II 92-94, 108, 111, 116

Wright, Suzanne 376

Wulffsberg, Hans 373

Yerkes, Robert 95

Young, Sir George 309

Yudkin, Simon 265

Zaporozhets, A. V. 220, 227 